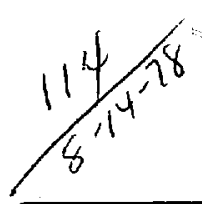

\title{
MEASUREMENT OF ENERGY DEPOSITED BY CHARGED PARTICLE BEAMS IN COMPOSITE TARGETS
}

\author{
K. Crase, W. E. Farley, H. Kruger, D. Selway and G. S. Sidhu
}

November 3, 1977

\section{MMSTER}

Work performed under the auspices of the U.S. Department of

Energy by the UCLLL under contract number W-7405-ENG-48.

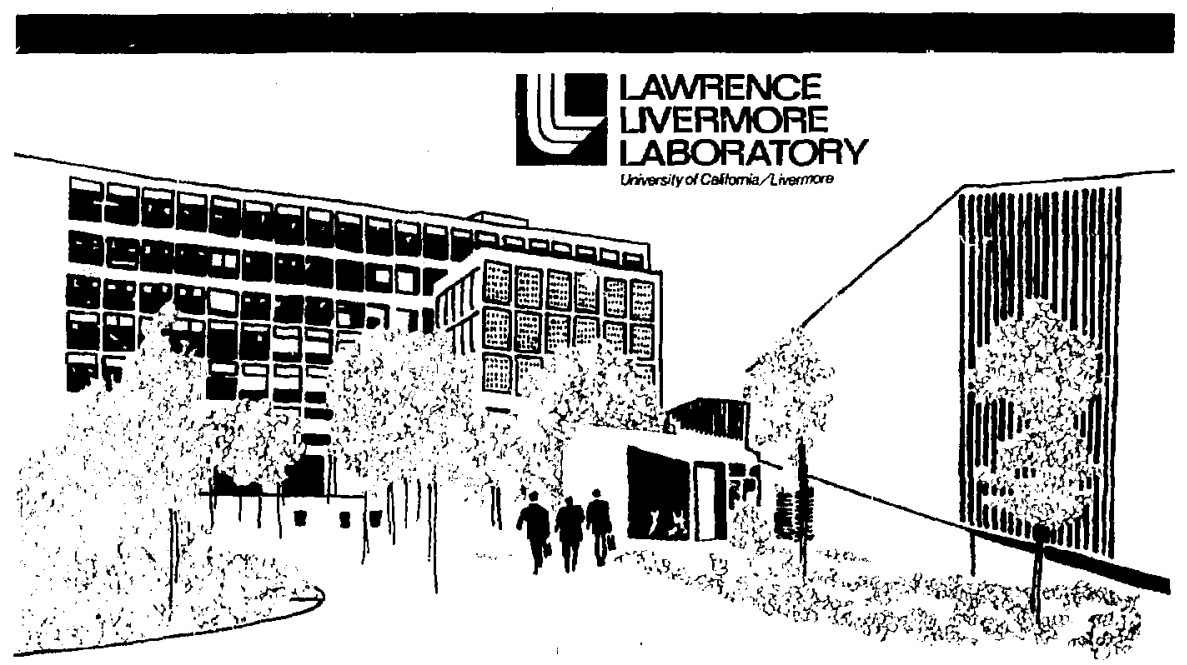




\section{近 \\ LAVMENCE LIVERMORE LABORATORY}

University of Cattornia/Livermoro, Calitornia/ 94550

\section{MEASUREMENT OF ENERGY DEPOSITED BY CHARGED PARTICLE BEAMS IN COMPOSITE TARGETS}

K. Crase, W. E. Farley, H. Kruger, D. Selway and G. S. Sidhu

MS. date: November 3, 1977

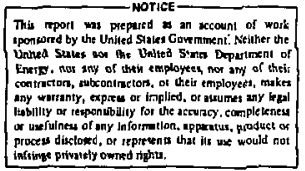




\section{CONTENTS}

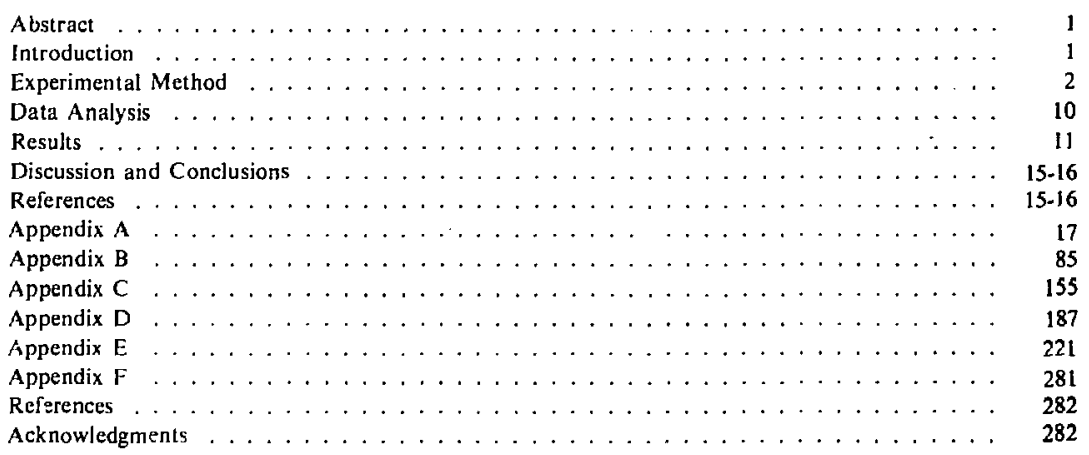




\title{
MEASUREMENT OF ENERGY DEPOSITED BY CHARGED PARTICLE BEAMS IN COMPOSITE TARGETS
}

\begin{abstract}
We have measured the energies deposited in composite targets by proton beams from 0.8 to $28.5 \mathrm{GeV}$ energy and by an electron beam at $0.5 \mathrm{GeV}$ energy. The targets consisted of various thicknesses of ${ }^{238} \mathrm{U}$ shower plates backed by a composite detector plate consisting of a $5-\mathrm{cm}$ thick $\mathrm{CH}_{2}$ moderator and a $0.635-\mathrm{cm}^{238} \mathrm{U}$ plate. The spacing between the shower and detector plates was varied to allow different spreading of the shower between plates. We used passive detectors (thermoluminescence dosimeters, Lexan fission track recorders, photographic emulsions, and removable ${ }^{238} \mathrm{U}$ pieces) to measure the fission-fragment dose and the nonfission dose at various depths and radial positions in the targets. Plots and numerical values of the measured doses are presented for comparison with computer code calculations. To provide a basis for comparison of the affects of different particle beam energies, we present data along the beam axes as specific dose (cal/g per incident integrated $\mathbf{k J} / \mathrm{cm}^{2}$ ). In general, the higher the incident proton energy, the larger is the dose in the back of the target relative to that in the front.
\end{abstract}

\section{INTRODUCTION}

Beams of high-energy charged particles can penetrate thick target materials and deposit their energy directly: the many types of secondary particles generated by means of complex nuclear interactions also behave this way. Studies of the energy deposited in targets provide information that can be useful for shielding problems or when verifying assumptions about production of particle showers and their subsequent transport. One can use charged-particle transport codes such as the nucleon-meson codes NMTC $^{1}$ and HETC ${ }^{2}$ or the coupled electron-photon code SANDYL ${ }^{3}$ to calculate the energy deposited by such charged particles. However, the incomplete knowledge of the interactions, approximations, and compromises made in the codes can make theit results unreliable. Direct measurements of the energies deposited at various depths in a simple target are necessary for comparison with code calculations. Once the performance and reliability of a code are established, it can then be used for calculating energy transport in other targets of interest.

We have measured the energy deposited and fissions induced at various depths and radial posi- tions in selected targets from incident beams of high-energy protons and electrons. Preliminary results of some measurenients made with incident protons of kinetic energy $0.8,2.1$, and $4.88 \mathrm{GeV}$ from the University of California Bevatron in Berkeley, California, were described in a previous repon. ${ }^{4}$ In this report, we have included the proton data at these energies, the results of similar measurements with 11.4-GeV-energy protons from the Zero Gradient Synchrotron (ZGS) accelerator at the Argonne National Laboratory (ANL) in Argonne, llinois, and those with 28.5-GeV-energy protons from the Alternating Gradient Synchrotron (AGS) accelerator at the Brookhaven National Laboratory (BNL) in Upton, New York. To compare the transport of protons with electrons, we exposed our targets to 500-MeV electrons from the Stanford Mk. III accelertor at Stanford, California. In the future, we intend to extend the proton measurement down to $370 \mathrm{MeV}$ or lower. At the Lawrence Livermore Laboratory (LLL), work is in progress with the codes to calculate the energies deposited from charged particle beams to compare them with the measurements. 


\section{EXPERIMENTAL METHOD}

One target plate arrangement during an irradiation is shown in Fig. 1. The assembly consists of 7-in. $(17.8-\mathrm{cm})$ square variable-thickness shower plates of $238 \mathrm{U}^{*}$ located in front of and separated from a 2-in.-thick polycthylene block and a thin ${ }^{238} \mathrm{U}$ plate, with variable spacing between the two portions. The purpose of the spacing is to radially spread the shower generated in the uranium plates to increase the radial resolution of the detectors adjacent to the polyethylene $b] \cdot k$. The polycthylene moderates the shower neutrons, which are then detected in a thin

-Actual composition in atom $\%: 99.774 \%{ }^{213} \mathrm{U} ; 0.201 \%$ 235

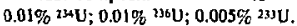

2380 plate and a 10 -mil-thick $235 \mathrm{U}^{\dagger}$ foil. The ${ }^{235} \mathrm{U}$ foil is shielded with a thin $\left(\sim 0.1 \mathrm{~g} / \mathrm{cm}^{2}\right)$ layer of ${ }^{10} \mathrm{~B}$ to protect it from the highly thermalized neutrons present as a part of the shower or accelerator background, which would otherwise dominate the fission density detected in the foil. Tecause the ${ }^{238} \mathrm{U}$ detector is sensitive to neut rons with energy in excess of about $1 \mathrm{MeV}$, and the ${ }^{10} \mathrm{~B}$-shielded ${ }^{235} \mathrm{U}$ detector to neutron energies above a few $\mathrm{eV}$, a measure of the neutron spectrum is attained by using this combination of neutron detectors.

tActual composition in atom $\%: 93$ atom $\%$ $25 \mathrm{U} ; 0.2 \%$ cach ${ }^{3} \mathrm{U}$, ${ }^{234} \mathrm{U}$, ${ }^{216} \mathrm{U}$; remainder ${ }^{238} \mathrm{U}$.

1/4-in. Lucite (TLD holder and cover plate)$$
0.003 \text {-in. Lexant }
$$

1/4-in. Lucite (TLD holder and cover plate)

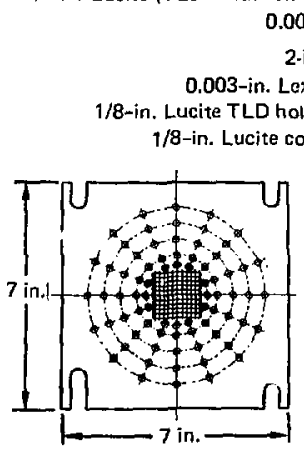

0.003 -in.

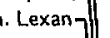

2-in. ${ }^{238} u$

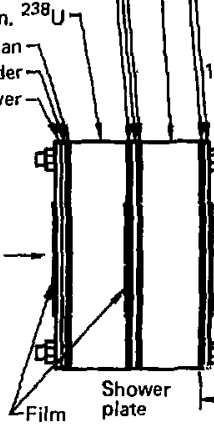

1/4-in. Lucite (TLD holder and cover platel

2-in. $\mathrm{CH}_{2}$ (polyethylene 0.003-in. Lexan

$1 / 8$-in. ${ }^{238}$ 0.003 -in. L

1/8-in. Lucite cover 7

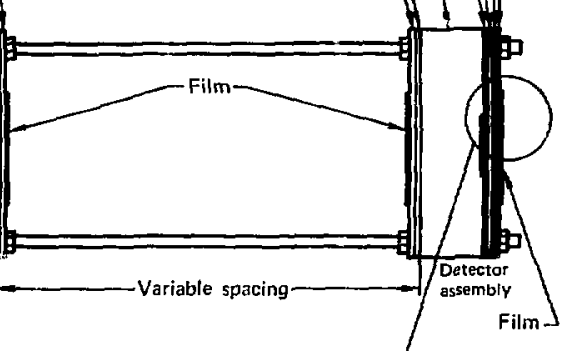

0.010 in

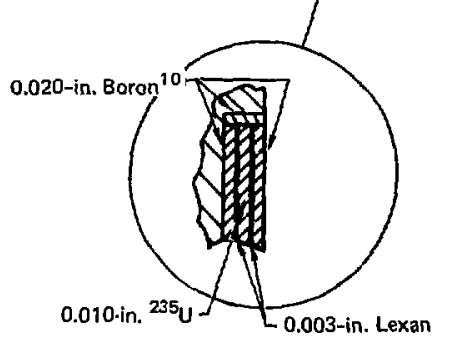

Fig. 1. Stundard showir plate and detector assembly. 
For some of the measurements, the showcr plates were removed and the back portion of the target irradiated directly by the incident beam. The target arrangements for various runs at cach particle energy are illustrated in Figs. 1 through 5. The planar dimensions of materials and detectors, e.g., lucite detector holder (Lu), photographic film (F), plastic (Lexan) foil (Lx), etc., were nearly the same as those of the ${ }^{23} \mathrm{U}$ plates (D).
For a typical run, passive energy-dose integrating detectors in the flat plate target assembly were located at different positions in the assembly. At selected depths along the beam transport path, we were therefore able to measure the radial djstribution of dose deposited by the proton team and by secondary light nuclei and by beta, gamma, and $x$ rays using thermo-luminescence dosimeters (TLD's). The TLD's were nominally $3-\mathrm{mm}$ square, and $1-\mathrm{mm}$

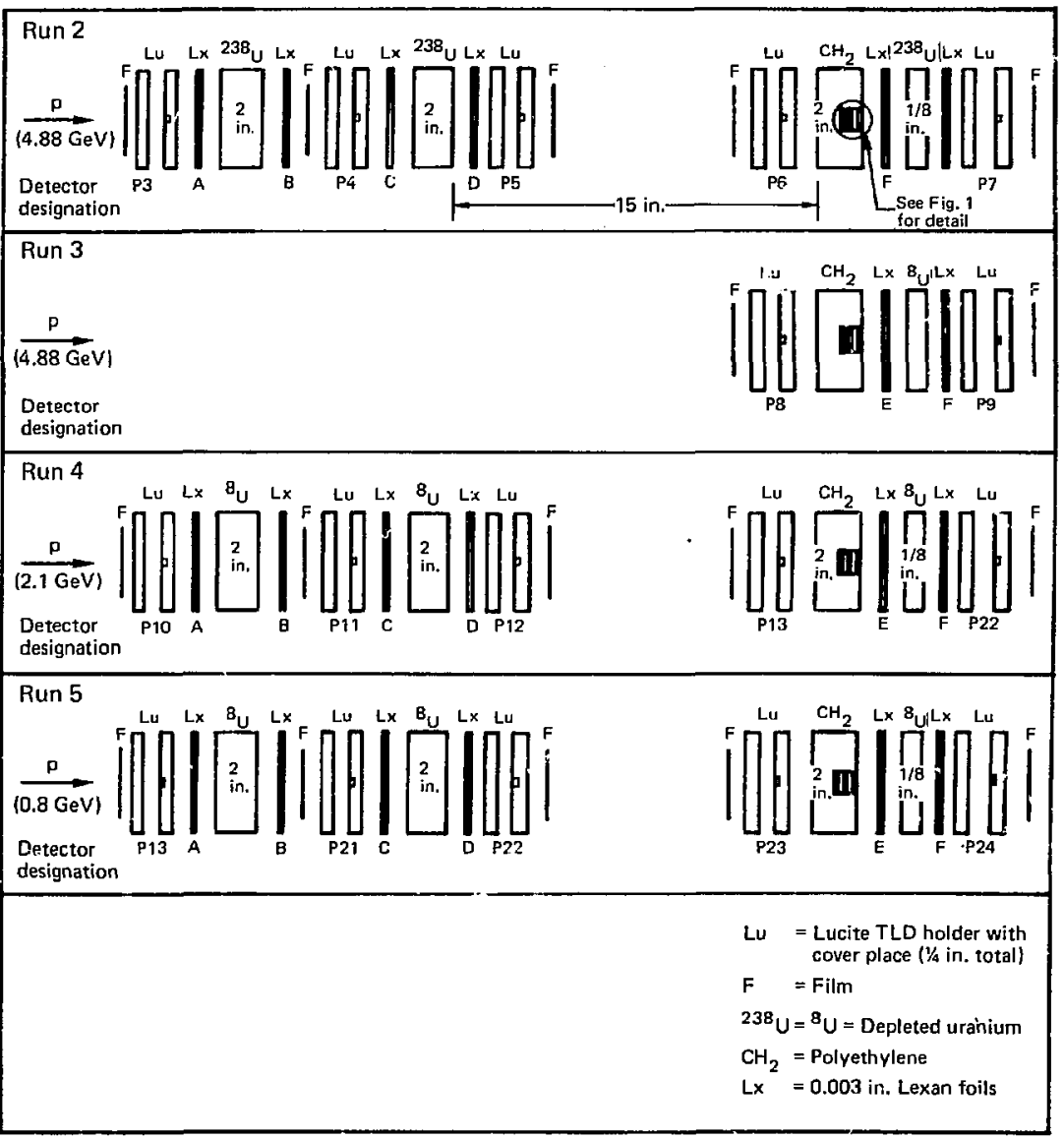

Fig. 2. Tarzet setup for Berkeley Bevatron at 0.8, 2.1, and 4.88 GeV runs (2 through 5). 


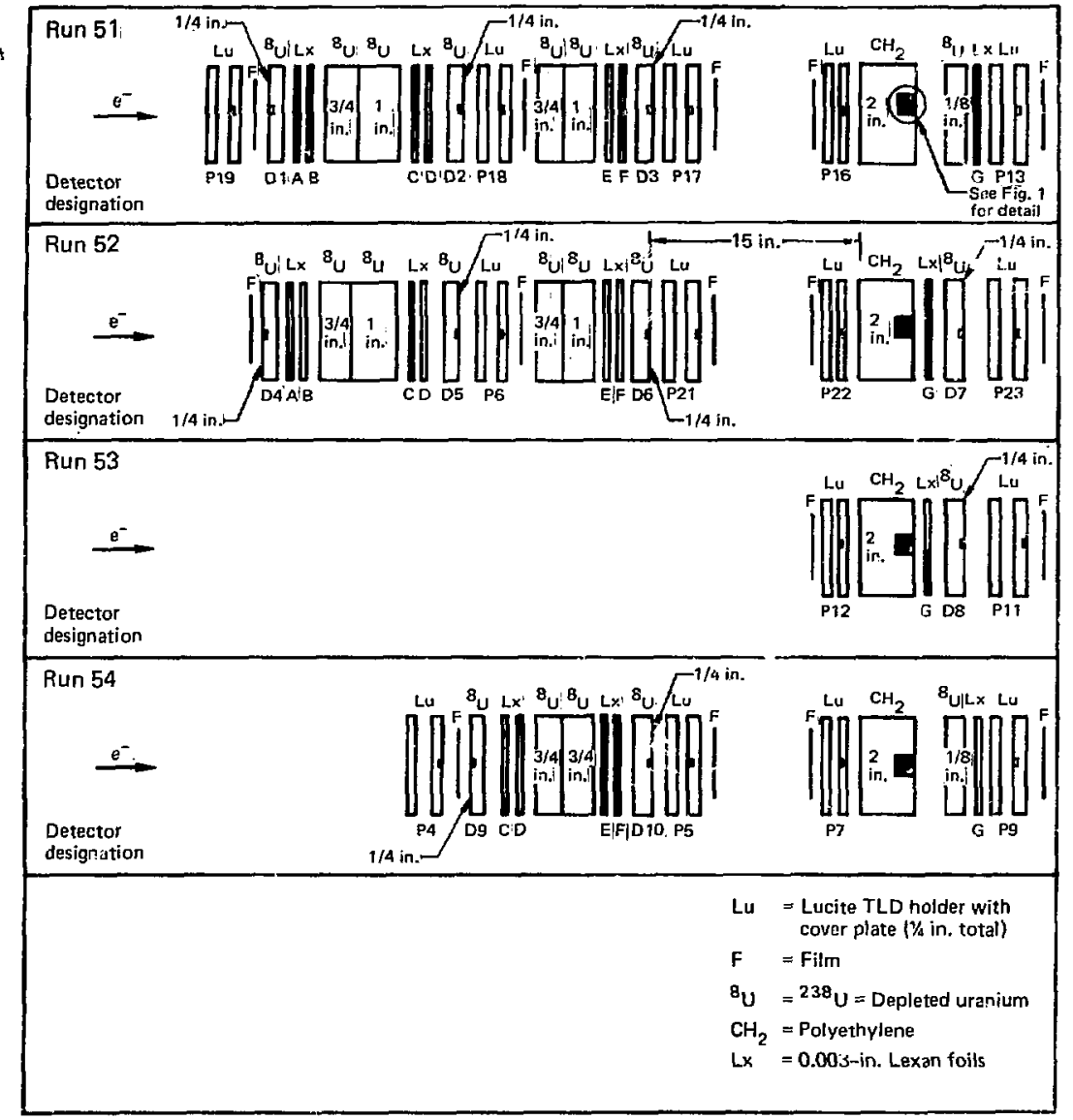

Fiz. 3, 500-MeV electron Irradiatinn targets, Stantord Mk. III acceterator. 


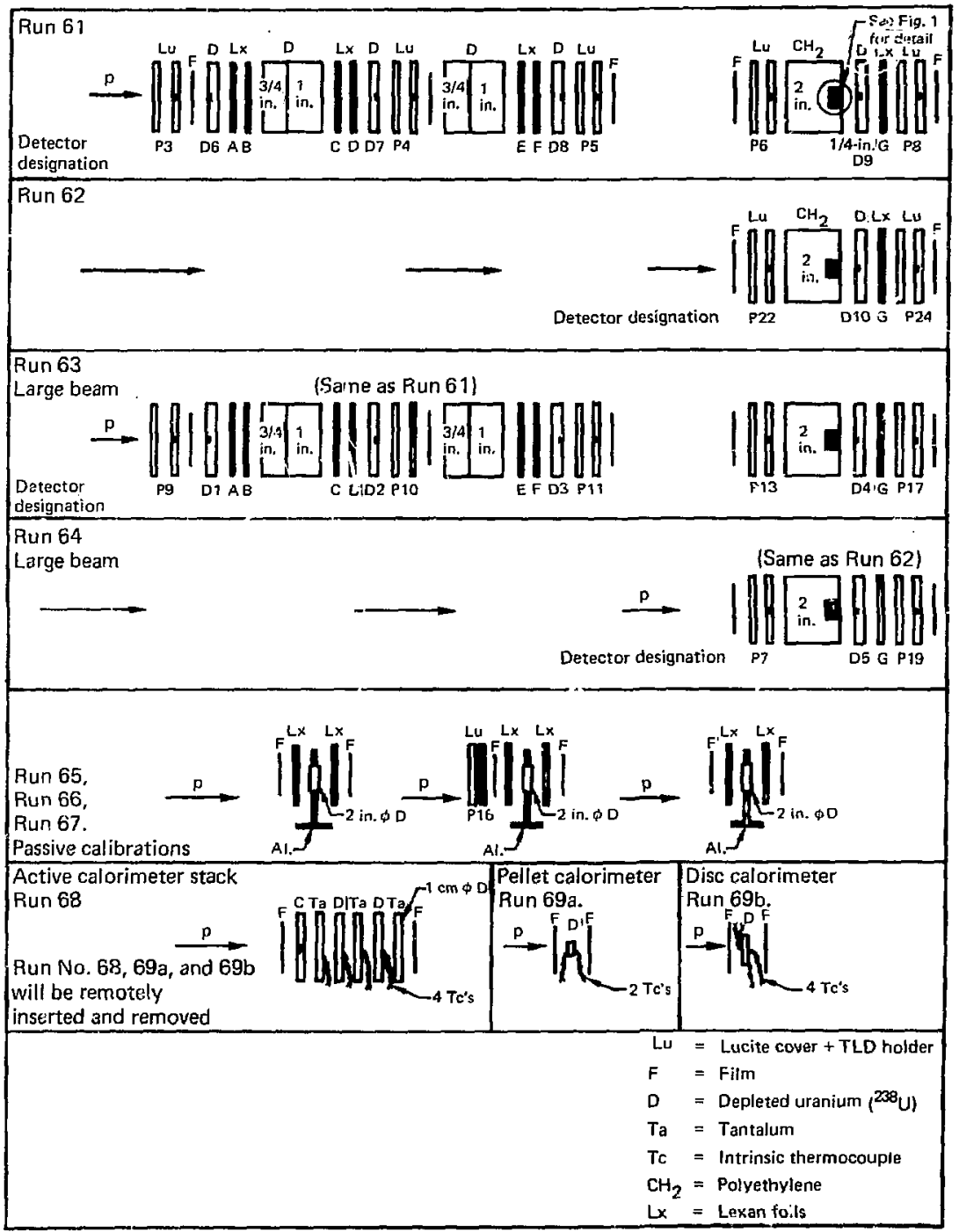

Fig. 4. Target configurations for Drookhaven runs with 28.5-GeV potons. 


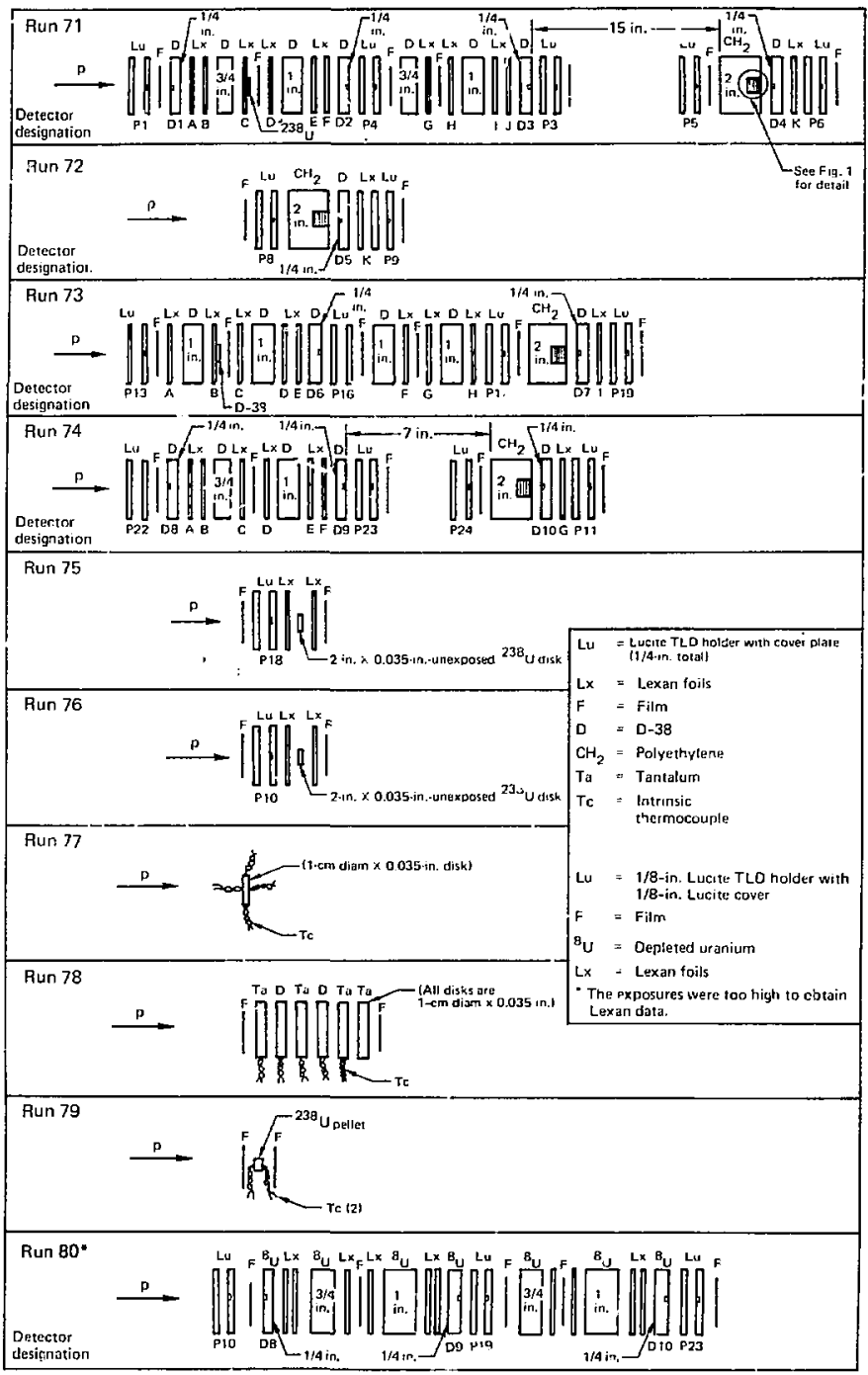

Fig. 5. Turget configura ions for Argonne runs with 11.4-GeV protons. 
thick; they were packaged in lucite holders in : pattern shown in Fig. 6 and the packages were positioned adjacent to ${ }^{238} \mathrm{U}$ plate suifaces. In later runs, additional TLD's were embedded in cylindrical holes in the ${ }^{338} \mathrm{U}$ plates and the remainder of each hole was covered with a cylinarical plug. A barrier was always prowided to prevent fission fragnents from entering the TLD's. The patrem of TLD's embedded in this manner is shown in Fig. 7. The cylindrical plags were made from the same material as the ${ }^{23} \mathrm{U}$ plates but, in some locations, we used ${ }^{235} \mathrm{U}$ plugs to measure the fissions expected in ${ }^{235} \mathrm{U}$. Photographic emulsion films were also used to measure dose. except the dose from fission fragments. This technique provides spatially continuous data and a gross visual check $c$ the energy-deposition pattern. The film dosimeters ind the T'LD's had been calitrated with a known-intensity gamma source.

The contribution of fission fragments to energy deposition was measured by 3-mil Lexan foils. The fission-fragment track-recorder foils were placed in contact with uranium surfaces .0 measure the fissinn density at the corresponding positions in the target assembly. The calibration constant, relating the fission/g in uranium to the number of tracks per unit area (track density) in the Lexan foil in contact with the surface of a thick uranium plate, bad been measured in a separate run with a $14-\mathrm{MeV}$ neutron source of known intensity. The result was $2 \times 10^{4}$ fissions/g per track $/ \mathrm{mm}^{2}$. When the fission density in a surface is large, the fission fragment tracks begin to overlap until the fissions measured by this method are no longer reliable. Further, this constant appears to vary with the surface condition of ihe uranium used in the calibration. The results of the experiment can be compromised unless the surface condition is identical with that used in the calibration. Therefore, in later runs, we adopted the inethod of counting total, resid'ral, fission gamma rays and the gamma rays from selected fission $p$ oducts ( used these gamma-ray counts to estimate the fission levels extr. polated back to the irradiation times. The removable cylindrical plugs in the ${ }^{236} \mathrm{U}$ plates were of convenient size for use in fission gamma counting.

In a typical run, the appropriate beam intensity and dimensions were first obtained on a blank target. At low intensities, a polaroid picture of the beam was taken but usually, because of the high intensities. a radio-chromic film or the auto-radiograph of an irradiatej plastic sheet on polaroid film was found more stitable. The following procedure was then taken:(1) the beam was blocked by a massive beam plug, (2) the real target was aligned with the help of the blank target, (3) the accelerator of was turned off temporarily to allow remuval of the beam plug, and (4) the rf was turned bacit on to allow the beam on the target. The appropriate number of particles per unit area of the beam was obtsined usually during a running time of one 10 several minutes in a suitable number of pulses. After the exposure, l. photrgraphic emulsions and the TLD packages were removed from the iarget assembly but the TLD's emb Ided in the uranium plates were disassembled nor mally three or four days after each irradiation.

During each run, the integrated particle-beam intensity was monitored by a secondary emission chamber based on electrons emitted from Al foils in the beam, or by the current in an ion chatiber in the beam. To obtain the absolute number of "rotons, the chambers at Berkeley and Brookhiven were calibrated by the amount of : $\mathrm{C}(20-\mathrm{min}$ half-life) produced by the ${ }^{12} \mathrm{C}(\mathrm{p}, \mathrm{pg}){ }^{11} \mathrm{C}$ reaction in a thin polystyrene sheet placed in the beam. The Argonne ion chamber was calibrated by the amount of ${ }^{119} \mathrm{~Tb}$ (alpha emitter) produced in oold foil placed in the beam. The chamber vs Faratay-cup calibration available for the 500-MeV elect-o: bcam at the Stanford Mk.III accelerator was $a$ :sumed correct.

In avxiliary runs (runs 65, 66, 75, and 76). we tried to caibrate fission-track density in $L$, xan against ${ }^{140} \mathrm{Ba}$-gamma activity produced in the 2 -in.-diam ${ }^{238} U$ foils. The results from the two techniques are generally in the same range, but the accuracy of the measurements is not good enough for the results to be a calibration standard.

In another auxiliary experiment, we directly mea . sured the heat produced in two similar targets, ${ }^{238} \mathrm{U}$ and Ta placed in the proton beams (see t: i get geometry in runs 68, Fig. 5, and 78, Fig. 6). Because the two thin (0.035-in.) targets have known masses, densities, and specific heats, the temperature rise could be used to measure the amounts of heat generated and therefore the total energy deposited by the incident proton team. The excess heat produced in the ${ }^{23} \mathrm{U}$, relative to that pror' ced in the $\mathrm{Ta}$ is a direct measure of the fission contribution because the fission cross section of ${ }^{23} \mathrm{U}$ at these energies is at least $20 \mathrm{X}$ larger than that of $\mathrm{Ta}$. From the measured excess hear, an estimate can be made of the energy deposited per fission if one knows the proton flux or measures the number of fission events.

We measured the temperature rise of several disks in a stack with thermcsouples. Each beam pulse induced a small temperature rise. The thermosoupies with their associated equipment and strip-chart recorders were calibrated prior to the experiments. To insure that the system was working properly, we made preliminary runs: $69 \mathrm{a}$ and $69 \mathrm{~b}$ at BNL; 77 ard $79 \mathrm{ai}$ ANL. A sample of thr raw data from a typical 


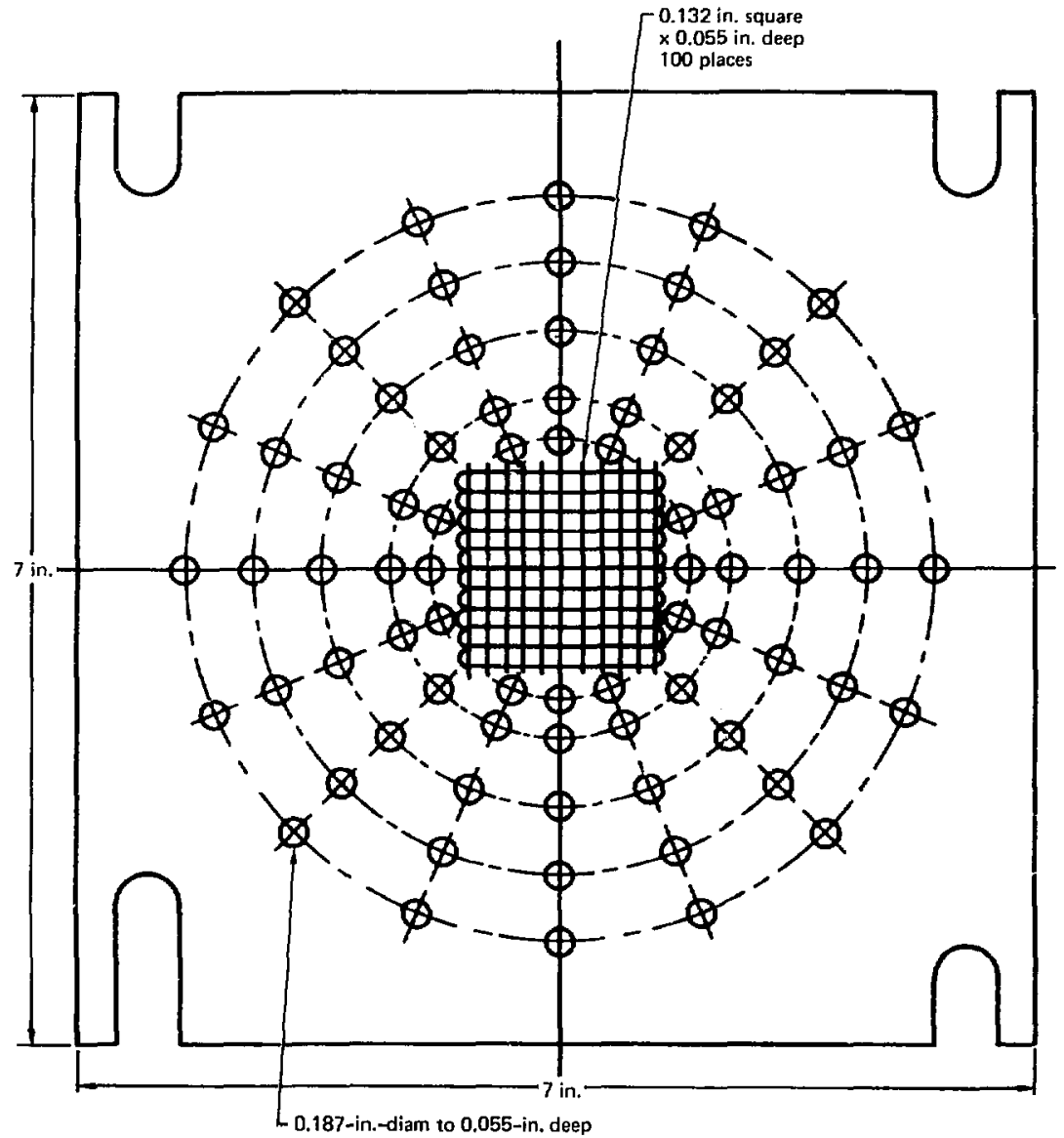

16 places equally spaced on: 16 plafes equally spaced on: 16 places equally spaced on: 16 places equally spaced on: 5.500-in.-diam bolt circle 4.500-in.-diam bolt circle 3.500-in.-diam bolt circle 2.500-in.-diam bolt cilcle 12 places as shown on a 1.925-jn. .diam bolt circle Total: 76 places

Fig. 6. Pattern of TLDs packnged in a Lucite holder for measurement of radial dose distribution in plates at specified depths in the tarzet awembly. 


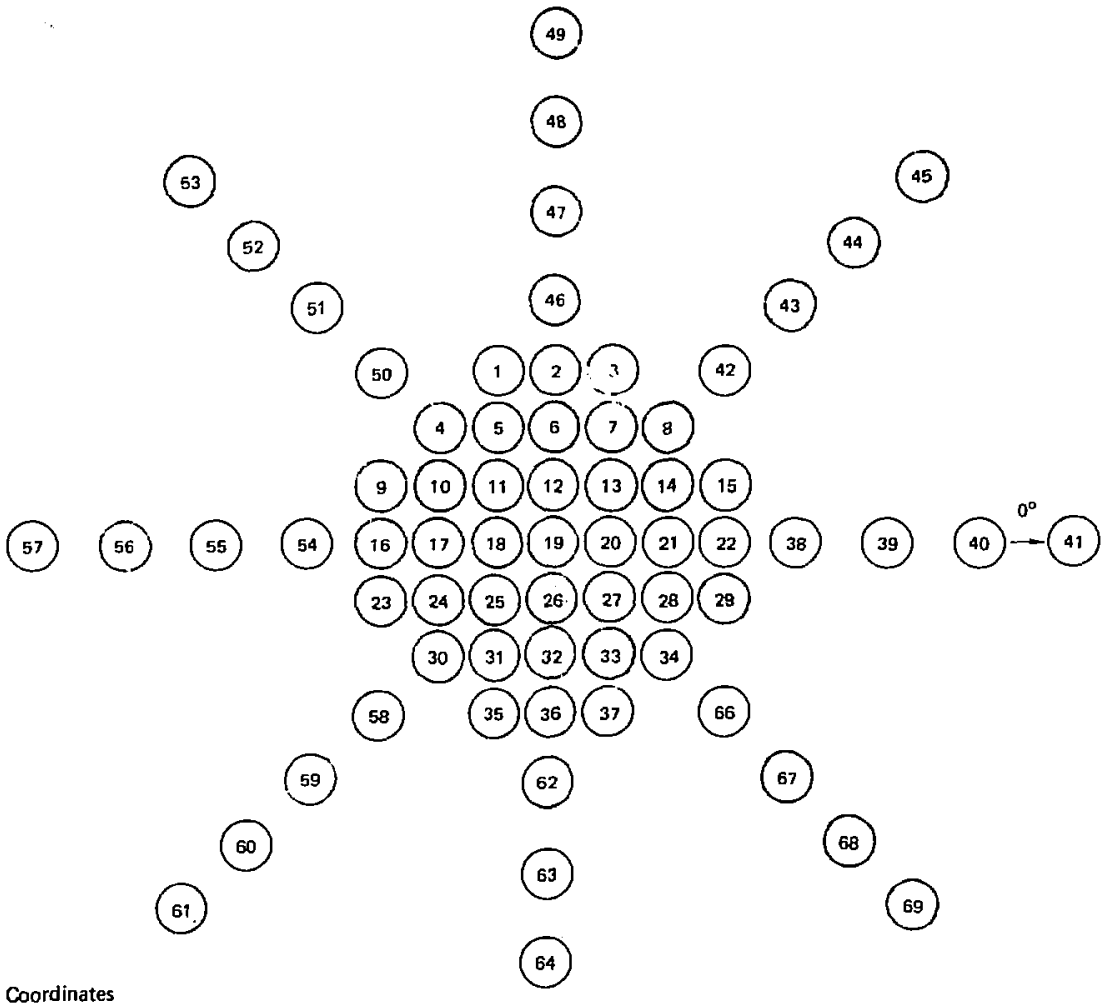

$\mathrm{A}=$ Padius in $\mathrm{cm}$

$T=$ Angle in degres

65

$R(19)=0.0 \quad T(19)=0.0$ $R(20)=0.70 \quad T(20)=0.0$ $R(22)=2.10 \quad T(22)=0.0$ $R(23)=2,214 T(23)=198.43$
$R(24)=1,565 T(24)=206.57$ $R(25)=0.990 \mathrm{~T}(25)=225.0$ $R(26)=0.70 \quad T(26)=270: 8$ $R(27)=0.99 \quad T(27)=315$. $R(2 \theta)=1.565 T(20)=333.43$ $R(20)=2,214 T(2 \%)=341,57$ $R(30)=1$. $R(31)=1.55$ T(3) $=243$ $R(32)=1.40 \quad T(32)=270 \cdot 0$ $R(32)=1.40 \quad T(32)=270.0$ $R(33)=1.565 T(33)=296.0$ $R(35)=2.214 T(35)=251.57$

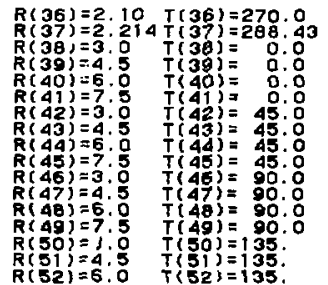

$R(36)=2.10 \quad T(36)=270.0$
$R(37)=2.214 T(37)=288.43$ $R(38)=3.0 \quad T(39)=0.0$ $R(40)=6$ : $T(39)=0$ $R(a)=7.5$ $R(42)=3$. $R(43)=4$. $R(44)=5.0$ R(45) =3. $R(4)=4$. $R(A B)=6$. $R(50)=1$. $R\left(S_{1}\right)=4$, $T\langle 52\}=135$
$R(53)=7.5 T(53)=135$. $R(54)=3.0 T(54)=180$. $R(55)=4.5 T(55)=100$. $R(56)=6.0 T(56)=100$. $R(57)=7.5 T(57)=100$. $R(58)=3$, $O T(53)=225$. $R(59)=4.5 T(50)=225$. $R(S 0)=5: 0 \mathrm{~T}(60)=22$. $R(61)=7: 5 T(61)=223$ : $R(62)=3.0 T(62)=270$. $R(63)=4.5 T(63)=270$ : $R(64)=6$. $T(E 4)=270$ $R(65)=7.5 T(65)=270$. $R(55)=7.5 T(6)=270$. $R(67)=4.5 T(67)=315$. $R(68)=6.0 T(68) \times 315$.

Fig. 1. Patiem of TLDs embedded in the surfaces of 2WU plates. 
stack ru: are shown in Fig. 8 . The temperature increased over time during irradiation, with some small heat losses between beam pulses. In our two attempts at temperature measurements, we obtained excellent thermocouple data, even though very high doses were recyuired. The main sources of uncertainty in the temperature measurements were in the act ual proton flux hitting the disks and in the yield of ${ }^{140} \mathrm{Ba}$ used to measure the number of fission events. (See Appen$\operatorname{dix} F$ for details of this experiment.)

After each irradiation run, the passive detectors were removed from the target assembly and the data from each type of detector extracted according to the procedures described below.

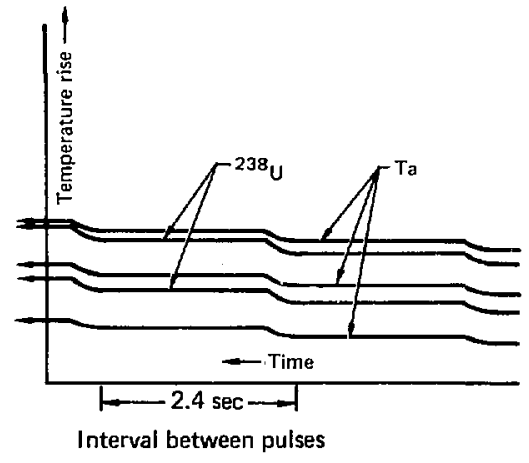

Fig. 8. Hecord of thermocouple temperature (uncalibrated) vs time with Ta and ${ }^{330} \mathrm{U}$ targets. Steep rise in temperuture occurs as beam pulse hits target. the magnitude depending on the deposited enerky and specific heats.

\section{DATA ANALYSIS}

The exposed photographic films were developed in the same way as the calibration films, which corresponded to the dose level expected. The films were then scanned by a densitometer to measure the radiation-produced opacily. The opacity vs dose calibration necessary to calculate the energy deposited at various locations in the target had been obtained earlier from the calibration films. Contour dose plots in a plane at each depth in the targets have not yet beeil completed. When completed, such measurements could provide a dose measurement similar to that obtained by TLD's.

The approximately $1000 \mathrm{TLD}$ 's irradiated during each run were removed from the lucite holders and ${ }^{218 U}$ surfaces, and their light output was measured at the LLL dosimetry facility. With the irradiationdose vs light-output calibration curve, the TLD output was converted to energy deposited at the corresponding locations in the target assembly. Finally, the fission fragment tracks in Lexan foils were developed by etching them for $75 \mathrm{~min}$ in an $\mathrm{NaOH}$ solution $\left(240 \mathrm{~g}\right.$ of $\mathrm{NaOH} / 1 \mathrm{H}_{2} \mathrm{O}$ at $\left.60^{\circ} \mathrm{C}\right)$. The etching process enlarges the damage pits produced by the fragments, rendering them visible through an optical microscope. The track density (tracks/ $\mathrm{mm}^{2}$ of foil area) was then measured by a Quantimet-pattern-recognition computer that operates together with a microscope and a television camera. By use of the calibration constant $\left(2 \times 10^{4}\right.$ fissions/g per track/ $\mathrm{mm}^{2}$ for ${ }^{238 \mathrm{U}}$ ) the tracks $/ \mathrm{mm}^{2}$ were converted to fissions/g at the corresponding locations in ${ }^{238} \mathrm{U}$ in contact with the Lexan foils. The fissions/g for the ${ }^{10} \mathrm{~B}$-shielded ${ }^{235} \mathrm{U}$ detector foils were similarly calculated.

The residual fission fragment activity was measured in gamma-ray counting equipment by the LLL Radiochemistry facility. One method of measurement we used was an NaI detector to count all gamma rays between the pulse-height biases of $600 \mathrm{keV}$ and $3 \mathrm{MeV}$ for selected ${ }^{238} \mathrm{U}$ cylindrical plugs. Tie second method we used was a germanium detector to count the number of gamma-rays in peaks identified with specific fission fragments such as ${ }^{140} \mathrm{Ba}$. In the first method, we obtained fissions/g with the curves defining the relationships between fissions/g at irradiation time and total gamma counts. In the second 
method, gamma peak activity of the selected fission fragment at counting time gives us an estimate of the a mount of that isotope immediately after irradiation. With existing data on the fraction of fissions yielding the jsotope under consideration, we obtained fissions/g. Fur comparison with the TLD data, we have assumed a deposited energy of $180 \mathrm{MeV} /$ fission and converted the fission data to rad.

\section{RESULTS}

In Appendices A-E we present detailed data, the most rcliable and complete of which are from the dose measurements by TLD's. In Afpendix A, the dose contours are shown on each page, indicating the energy deposited, in rad, in the plane, perpendicular to the beam. at the depth indicated by location number; these contour plots refer only to the detectore placed in lucite hulders. For each plane, we have also plotted the dase along lines at $0^{\circ}$, $45^{\circ}, 90^{\circ}$. and $135^{\circ}$ to the horizonta! axis of each plane. Figures I through 5 identify the locations of these detectors. All data are arranged chronologically. The ${ }^{238} \mathrm{U}$ shower plates were removed for some of the runs. As is apparent from the plots, the particle beam in most of the experiments was not centered in the target centcr, a result of uncontrollable accelerator variations. The numerical data corresponding to these conte ir plots are itcluded in Appendix B, which may be used for quantitative comparison with computer calculations. The data from runs 2 through 5 are written in a configuration sirr:"ar to the detcctor pattern, while the dose for the remainder of the runs is listed with the corresponding position coordinates or TLD position number.

The data in Appendices A and B represent only those TLD's packaged in lucite. Data from TLD's embedded in ${ }^{238} \mathrm{U}$ plates are plotted to represent the dose along vertical $\left(90^{\circ}\right)$ lines in all the plates except for run 80 , which had full TLD loadings. In Appendix $\mathrm{C}$ are shown such plots for the 28.5- and $11.4-\mathrm{GeV}$ proton runs as well as for the electron runs. The comparison of doses in Appendix A with the corresponding planes in Appendix $C$ indicates that the dose in embedded TLD's is consistently higher by a factor of approximately two. The numerical values corresponding to the plots in Appendix $C$ are presented in Appendix $D$ for comparison with code calculations. The available fission doses derived from integral gamma-ray counting are also shown in Appendix $\mathrm{D}$ to compare the relative magnitude of fission duse with the TLD dose. Those holes which contained ${ }^{23} \mathrm{U}$ plugs are marked by heavy lines.

For most of the runs, fission was measured with Lexan-track recorders. The Lexan was usually scanned along the vertical and the horizontal direc- tions. In Appendix E, we present the piots of fission dose in rad vs position along the axe: through the center for different runs. The labels "surface A, B, $C^{\prime \prime}$, etc., refer to the Lexan location as the beam sees then while passing through the target. The graphs are labeled to indicate the run number or particle energy, and position of each fission surface. The few Lexans that were in contact with $235 \mathrm{U}$ rather than ${ }^{238} \mathrm{U}$ show higher fission density, usually two- to threefold. The gamma counting results show similar differences. The embedded Lexan track reeorders indicate higher fission densities than the Lexan recorders on the outside surfaces just as the TLD's surrounded by ${ }^{238} \mathrm{U}$ read higher than those inside Lucite.

To save space, we plotied the fission data for more than onc surface on a single page, wherever practical. The solid lines, drawn for one surface in each case, are merely to guide the eye and are not more reliable than the remainder of the data. Because of the Lexan scanning procedure, 2.5 or $5 \mathrm{~mm}$ was sometimes arbitrarily added at or near the center of a plot to aid in its analysis; such plots are labeled accordingly. Wherever available, we also plotted the fission dose from radiochemistry gamma-count data together with the Lexan measurements. Although the results from the two methods generally agree, discrepancies of twofold or more are not uncommon. Usually, we found it necessary to multiply the $235 \mathrm{U}$ fission data by a factor of $\sim 1 / 2$ to plot it on the same scale as the ${ }^{2.8} \mathrm{U}$ data. The ${ }^{140} \mathrm{Ba}$ measurements taken on the 2-in. disk were inade with the whole disk in the counter. The results, therefore, represent an integrated average over the entire disk.

Room and natural- $U$ background doses given to the detectors were generally small compared with peak doses. No background corrections have been made to our data.

A result frequently useful to compare the effectiveness of energy transport by particles of various energy, is what we call the "specific dose." This is defined as the energy deposited (cal/g) divided by the total incident particle ene rgy per unit area $\left(\mathrm{kJ} / \mathrm{cm}^{2}\right)$. We have computed the maximum (on axis) specific dose for the various runs; the results are presented in Table 1. The maximum specific dose is usually 
Table 1. Measured doses along beam axes at different depths in nat plate target assemblies

\begin{tabular}{|c|c|c|c|c|c|c|}
\hline \multirow[b]{2}{*}{ Kun Nis. } & \multirow{2}{*}{$\begin{array}{l}\text { Particle encrgy } \\
\text { Total number of } \\
\text { particles } \\
\text { Beam area, FWIAM }\end{array}$} & \multirow{2}{*}{$\begin{array}{l}\text { Detector } \\
\text { designation }\end{array}$} & \multirow{2}{*}{$\begin{array}{l}\text { TLD dose, } \\
\text { rad }\end{array}$} & \multirow{2}{*}{$\begin{array}{l}\text { Fission dose, } \\
\text { rad }\end{array}$} & \multicolumn{2}{|c|}{$\begin{array}{l}\text { Specific dose, } \\
\text { al/g per kl/cm" }\end{array}$} \\
\hline & & & & & TLD & Fission \\
\hline 2 & $\begin{array}{l}4.88 \mathrm{GeV} \\
3.5 \times 10^{1} \text { a protons } \\
7 \mathrm{~cm}^{2} \text { area }\end{array}$ & $\begin{array}{l}\text { P3 } \\
\text { P4 } \\
\text { P5 } \\
\text { P6 } \\
\text { P7 }\end{array}$ & $\begin{array}{r}182 \\
378 \\
236 \\
40 \\
60\end{array}$ & $\begin{array}{l}160 \\
250 \\
110 \\
- \\
25(40)\end{array}$ & $\begin{array}{l}0.132 \\
0.232 \\
0.145 \\
0.025 \\
0.040\end{array}$ & $\begin{array}{c}0.098 \\
0.153 \\
0.067 \\
- \\
0.015(0.025)\end{array}$ \\
\hline 3 & $\begin{array}{l}4.8 B \mathrm{GeV} \\
2.2 \times 10^{10} \text { protons } \\
5 \mathrm{~cm}^{2} \text { area }\end{array}$ & $\begin{array}{l}\text { P8 } \\
\text { P9 }\end{array}$ & $\begin{array}{l}156 \\
302\end{array}$ & $52(104)$ & $\begin{array}{l}0.117 \\
0.23\end{array}$ & $0.039(0.0 ? 7)$ \\
\hline 4 & $\begin{array}{l}2.1 \mathrm{C}+\mathrm{EV} \\
0.97 \times: 0^{10} \text { protons } \\
2 \mathrm{rm}^{2} \mathrm{xts}\end{array}$ & $\begin{array}{l}\text { P10 } \\
\text { P11 } \\
\text { P12 } \\
\text { P13 } \\
\text { P22 }\end{array}$ & $\begin{array}{c}94 \\
105 \\
53 \\
4.8 \\
5.8\end{array}$ & $\begin{array}{l}76 \\
70 \\
46 \\
- \\
2(8)\end{array}$ & $\begin{array}{l}0.173 \\
0.193 \\
0.10 \\
0.009 \\
0.01\end{array}$ & $\begin{array}{c}0.14 \\
0.13 \\
0.07 \\
- \\
0.004(0.02)\end{array}$ \\
\hline$j$ & $\begin{array}{l}0.8 \mathrm{GeV} \\
1.1 \times 10^{11} \text { protons } \\
9 \mathrm{cin}^{2} \text { area }\end{array}$ & $\begin{array}{l}\text { P13 } \\
P 21 \\
P 22 \\
P 2 ? \\
P 24\end{array}$ & $\begin{array}{r}434 \\
394 \\
200 \\
21 \\
20\end{array}$ & $\begin{array}{l}150 \\
224 \\
164 \\
- \\
7(30)\end{array}$ & \begin{tabular}{l|l|}
0.58 \\
0.53 \\
0.27 \\
0.029 \\
0.026
\end{tabular} & $\begin{array}{l}9.20 \\
0.30 \\
0.22 \\
- \\
0.01(0.04)\end{array}$ \\
\hline 51 & $\begin{array}{l}0.5 \mathrm{GeV} \\
5.7 \times 10^{\prime \prime} \text { elcetrons } \\
0.13 \mathrm{~cm}^{2} \text { area }\end{array}$ & $\begin{array}{l}\text { P19 } \\
\text { D1 } \\
\text { D2 } \\
\text { P18 } \\
\text { D3 } \\
\text { P17 } \\
\text { P16 } \\
\text { P13 }\end{array}$ & $\begin{array}{r}40 \times 10^{3} \\
88 \times 10^{3} \\
1.3 \times 10^{3} \\
320 \\
40 \\
1 \\
0.2 \\
0.2\end{array}$ & $\begin{array}{c}- \\
10,000 \\
80 \\
- \\
- \\
- \\
- \\
-\end{array}$ & $\begin{array}{l}0.27 \\
0.60 \\
0.0089 \\
0.0022 \\
0.00027 \\
6.8 \times 10^{-6} \\
1.4 \times 10^{-6} \\
1.4 \times 10^{-7}\end{array}$ & $\begin{array}{c}- \\
0.068 \\
0.00055 \\
- \\
- \\
- \\
- \\
-\end{array}$ \\
\hline 52 & $\begin{array}{l}0.5 \mathrm{GeV} \\
3.1 \times 10^{19} \text { electrons } \\
0.13 \mathrm{~cm}^{2} \text { ares }\end{array}$ & $\begin{array}{l}\text { D4 } \\
\text { D5 } \\
\text { P6 } \\
\text { D6 } \\
\text { P21 } \\
\text { P22 } \\
\text { D7 } \\
\text { P23 }\end{array}$ & $\begin{array}{r}1.5 \times 10^{6} \\
85 \times 10^{3} \\
18 \times 10^{3} \\
230 \\
65 \\
3 \\
40 \\
2\end{array}$ & $\begin{array}{r}\left(1.7 \times 10^{5}\right) \\
\left(6 \times 10^{3}\right) \\
(460) \\
(80)\end{array}$ & $\begin{array}{l}0.19 \\
0.011 \\
0.0023 \\
0.000029 \\
8.2 \times 10^{-1} \\
3.8 \times 10^{-7} \\
5.0 \times 10^{-6} \\
2.5 \times 10^{-7}\end{array}$ & $\begin{array}{l}(0.022) \\
(0.0008) \\
\left(5.8 \times 10^{-5}\right) \\
\left(1.0 \times 10^{-5}\right)\end{array}$ \\
\hline 53 & $\begin{array}{l}0.5 \mathrm{GeV} \\
6.6 \times 10^{12} \text { ulectrons } \\
0.1 \mathrm{~cm}^{2} \text { arca }\end{array}$ & $\begin{array}{l}\text { P12 } \\
\text { D8 } \\
\text { P11 }\end{array}$ & $\begin{array}{r}-50 \times 10^{3} \\
75 \times 10^{3} \\
80 \times 10^{3}\end{array}$ & $\begin{array}{c}- \\
(7.300) \\
-\end{array}$ & $\begin{array}{l}0.23 \\
0.34 \\
0.36\end{array}$ & $\begin{array}{c}- \\
(0.033) \\
-\end{array}$ \\
\hline 54 & $\begin{array}{l}0.5 \mathrm{GeV} \\
7.8 \times 10^{11} \text { clectrons } \\
0.2 \mathrm{~cm}^{2} \text { area }\end{array}$ & $\begin{array}{l}\text { P4 } \\
\text { D9 } \\
\text { D10 } \\
\text { P5 } \\
\text { P7 } \\
\text { P9 }\end{array}$ & $\begin{array}{c}40 \times 10^{3} \\
90 \times 10^{3} \\
4000 \\
900 \\
10 \\
17\end{array}$ & $\begin{array}{c}- \\
5,000 \\
200 \\
- \\
- \\
(5)\end{array}$ & $\begin{array}{l}0.31 \\
0.70 \\
0.03 \\
0.007 \\
0.00008 \\
0.0001\end{array}$ & $\begin{array}{c}0 . \\
0.04 \\
0.02 \\
- \\
- \\
(0.00004)\end{array}$ \\
\hline 61 & $\begin{array}{l}28.5 \mathrm{GeV} \\
1.94 \times 10^{11} \text { protons } \\
2 \mathrm{~cm}^{2} \text { area }\end{array}$ & $\begin{array}{l}\text { P3 } \\
\text { D6 } \\
\text { D7 } \\
\text { P4 } \\
\text { D8 } \\
\text { P5 } \\
\text { P6 } \\
\text { D9 } \\
\text { P8 }\end{array}$ & $\begin{array}{r}3,500 \\
8,700 \\
29,000 \\
16,000 \\
20,000 \\
10,000 \\
1,200 \\
4,000 \\
3,100\end{array}$ & $\begin{array}{c}- \\
(7,500) \\
(17,000) \\
- \\
(11,000) \\
- \\
- \\
(1,500) \\
-\end{array}$ & $\begin{array}{l}0.019 \\
0.047 \\
0.160 \\
0.087 \\
0.11 \\
0.054 \\
0.0065 \\
0.022 \\
0.017\end{array}$ & $\begin{array}{r}(0 . \overline{04}) \\
(0.09) \\
- \\
(0.06) \\
- \\
- \\
(0.009) \\
-\end{array}$ \\
\hline 62 & $\begin{array}{l}28.5 \mathrm{GeV} \\
1.95 \times 10^{14} \text { protons } \\
1 \mathrm{~cm}^{2} \text { aren }\end{array}$ & $\begin{array}{l}\text { P22 } \\
\text { D10 } \\
\text { P24 }\end{array}$ & $\begin{array}{l}2,800 \\
9,700 \\
7,200\end{array}$ & $\begin{array}{c}- \\
(3,500) \\
-\end{array}$ & $\begin{array}{l}0.0075 \\
0.026 \\
0.019\end{array}$ & $\frac{-}{(0.009)}$ \\
\hline
\end{tabular}


Table 1. Continued.

\begin{tabular}{|c|c|c|c|c|c|c|}
\hline \multirow[b]{2}{*}{ Ruก No. } & \multirow{2}{*}{$\begin{array}{l}\text { Particle encrgy } \\
\text { Total number of } \\
\text { particles } \\
\text { Beam area, FWHM }\end{array}$} & \multirow{2}{*}{$\begin{array}{c}\text { Detector } \\
\text { designation }\end{array}$} & \multirow{2}{*}{$\begin{array}{c}\text { TLD dose, } \\
\text { rad }\end{array}$} & \multirow{2}{*}{$\begin{array}{c}\text { Fission dose, } \\
\text { tad }\end{array}$} & \multicolumn{2}{|c|}{$\begin{array}{l}\text { Specific dose, } \\
\text { al/g per } \mathrm{kJ} / \mathrm{cm}^{3}\end{array}$} \\
\hline & & & & & TLD & Fission \\
\hline 63 & $\begin{array}{l}28.5 \mathrm{GeV} \\
9.1 \times 10^{14} \text { protons } \\
3.8 \mathrm{~cm}^{2} \text { arca }\end{array}$ & $\begin{array}{l}\text { P9 } \\
\text { D1 } \\
\text { D2 } \\
\text { P10 } \\
\text { DA } \\
\text { P11 } \\
\text { P13 } \\
\text { D4 } \\
\text { P17 }\end{array}$ & $\begin{array}{r}7,400 \\
18,000 \\
51,000 \\
38,000 \\
47,000 \\
25,000 \\
2,500 \\
8,000 \\
6,500\end{array}$ & $\begin{array}{c}\sim \\
(22,500) \\
(56,000) \\
- \\
(34,000) \\
- \\
- \\
(1,100) \\
-\end{array}$ & $\begin{array}{l}0.016 \\
0.039 \\
0.11 \\
0.083 \\
0.10 \\
0.055 \\
0.0055 \\
0.017 \\
0.014\end{array}$ & $\begin{array}{c}- \\
(0.049) \\
- \\
(0.52) \\
(0.074) \\
- \\
- \\
(0.009) \\
-\end{array}$ \\
\hline 64 & $\begin{array}{l}28.5 \mathrm{GeV} \\
1.21 \times 10^{13} \text { protons } \\
2.8 \mathrm{~cm}^{2} \text { area }\end{array}$ & $\begin{array}{l}\text { P7 } \\
\text { DS } \\
\text { PI9 }\end{array}$ & $\begin{array}{r}8,100 \\
23,000 \\
23,000\end{array}$ & $\begin{array}{c}- \\
(11,300) \\
-\end{array}$ & $\begin{array}{l}0.0098 \\
0.028 \\
0.028\end{array}$ & $\begin{array}{r}-\overline{1} \\
-\end{array}$ \\
\hline 66 & $\begin{array}{l}28.5 \mathrm{GeV} \\
2 \times 10^{13} \text { protons } \\
3.5 \mathrm{~cm}^{2} \text { arca }\end{array}$ & $\begin{array}{l}P 16 \\
D\end{array}$ & $\begin{array}{c}11,000 \\
-\end{array}$ & 20,000 & $\begin{array}{c}0.010 \\
-\end{array}$ & 0.018 \\
\hline 71 & $\begin{array}{l}11.4 \mathrm{GeV} \\
3.5 \times 1 \mathrm{C}^{13} \\
3.8 \mathrm{~cm}^{2}\end{array}$ & $\begin{array}{l}\text { P1 } \\
\text { D1 } \\
\text { D2 } \\
\text { P4 } \\
\text { D3 } \\
\text { P3 } \\
\text { P5 } \\
\text { D4 } \\
\text { P6 }\end{array}$ & $\begin{array}{r}1,700 \\
4,500 \\
7,900 \\
4,300 \\
5,000 \\
3,200 \\
670 \\
1,400 \\
1,100\end{array}$ & $\begin{array}{c}- \\
1,400(4,000) \\
2,400(8.000) \\
- \\
2.500(4,400) \\
- \\
- \\
600(800) \\
-\end{array}$ & $\begin{array}{l}0.024 \\
0.063 \\
0.113 \\
0.061 \\
0.071 \\
0.045 \\
0.0095 \\
0.0198 \\
0.016\end{array}$ & $\begin{array}{c}- \\
0.020(0.057) \\
0.034(0.114) \\
- \\
0.036(0.063) \\
- \\
0.009(0.011) \\
-\end{array}$ \\
\hline 72 & $\begin{array}{l}1 \mathrm{I.4 \textrm {GeV }} \\
3.4 \times 10^{21} \\
3.6 \mathrm{~cm}^{2} \text { area }\end{array}$ & $\begin{array}{l}\text { P8 } \\
\text { D5 } \\
\text { P9 }\end{array}$ & $\begin{array}{l}1,500 \\
3,800 \\
3,200\end{array}$ & $\begin{array}{c}- \\
1,100(1,800) \\
-\end{array}$ & $\begin{array}{l}0.021 \\
0.053 \\
0.045\end{array}$ & $0.0 \overline{15}(0.025)$ \\
\hline 73 & $\begin{array}{l}11.4 \mathrm{GeV} \\
4.1 \times 10^{\mathrm{si}} \\
4.9 \mathrm{~cm}^{2} \text { area }\end{array}$ & $\begin{array}{l}\text { P13 } \\
\text { D6 } \\
\text { P16 } \\
\text { P17 } \\
\text { D7 } \\
\text { P19 }\end{array}$ & $\begin{array}{l}2,000 \\
9,500 \\
5,700 \\
5,000 \\
3,000 \\
2,000\end{array}$ & $\begin{array}{c}- \\
2,600(11,000) \\
- \\
2,000 \\
700(2,600) \\
-\end{array}$ & $\begin{array}{l}0.031 \\
0.149 \\
0.089 \\
0.078 \\
0.047 \\
0.031\end{array}$ & $\begin{array}{l}0.025 \\
0.041(0.172) \\
\quad- \\
0.031 \\
0.011(0.041) \\
\quad-\end{array}$ \\
\hline 74 & $\begin{array}{l}11.4 \mathrm{GeV} \\
3.7 \times 10^{11} \\
4.1 \mathrm{~cm}^{2} \text { arca }\end{array}$ & $\begin{array}{l}\text { P22 } \\
\text { D8 } \\
\text { D9 } \\
\text { P23 } \\
\text { P24 } \\
\text { D10 } \\
\text { P11 }\end{array}$ & $\begin{array}{l}1,800 \\
4,500 \\
8,700 \\
4,200 \\
1,200 \\
2,900 \\
2,000\end{array}$ & $\begin{array}{c}-\overline{-} \\
1,500(3,600) \\
2,000(4,900) \\
- \\
- \\
1,000(1, \overline{400}) \\
-\end{array}$ & $\begin{array}{l}0.026 \\
0.065 \\
0.126 \\
0.061 \\
0.017 \\
0.042 \\
0.029\end{array}$ & $\begin{array}{c}- \\
0.022(0.052) \\
0.029(0.071) \\
- \\
- \\
0.015(0.020) \\
-\end{array}$ \\
\hline 80 & $\begin{array}{l}11.4 \mathrm{GeV} \\
2.7 \times 10^{12} \\
7.1 \mathrm{~cm}^{2}\end{array}$ & $\begin{array}{l}\text { P10 } \\
\text { D8 } \\
\text { P19 } \\
\text { D9 } \\
\text { P23 } \\
\text { D10 }\end{array}$ & $\begin{array}{l}12,000 \\
27,000 \\
38,000 \\
47,000 \\
22,000 \\
37,000\end{array}$ & $\begin{array}{r}- \\
13,000 \\
- \\
20,000 \\
- \\
16,000\end{array}$ & $\begin{array}{l}0.041 \\
0.093 \\
0.131 \\
0.162 \\
0.076 \\
0.128\end{array}$ & $\begin{array}{r}-\overline{-} \\
0.045 \\
- \\
0.049 \\
- \\
0.05 E\end{array}$ \\
\hline
\end{tabular}

${ }^{2}$ P designates Lucite TLD holder; D, D-38 plate.

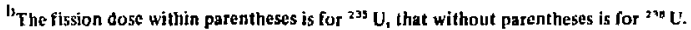

"Eror estinated for the TLD data is $\pm 15 \%$. For the fission measurements the error is $\sim 30 \%$ for the medium doses and may exceed $100 \%$ for very low and high doses. 
derived from the averabe of three highest doses at each depth, execpt when the beam sire is comparable to the dimensions of a single Tl.D or when the dose varies ritpidly from une detector location to the next. The onan area was measured al full-width, halfmaximum value of the dose contous for the first T1. D plate in each experiment.

From tice data in lable 1 , we have piolled in Fig. 9 , pirt (it) (h: Il. I) specific dose as a function of depth for one measurement at eitch energy for visual comparison. By coinparing the specific orse in the back of a targel relative to that in front, we can qualitalively assess the penctration af the incident particles and of the secondary showers they produce. The speciftc dos.: from fission are plotted sepatrallely in Fig. 9. part (b), becausc the fission detectors were not located at all the [].1) depth positions.

I he specific dose data in Jable I and Fig. 9 summarise the results for rough comparison of effects from incident piarticles ol different energy.

\section{TC Results}

An example of the data reduction process for the AN1. thermocouple insta umented stack run (No. 78) is given in Appendix $F$. Four methods outlined in Appendix Fare available to reduce the data. The preferred method yields a best estimate of 150-220 MeV ifission. Refinement of the experimental methods are needed, hut we have demonstrated the potenlial of the technigue.

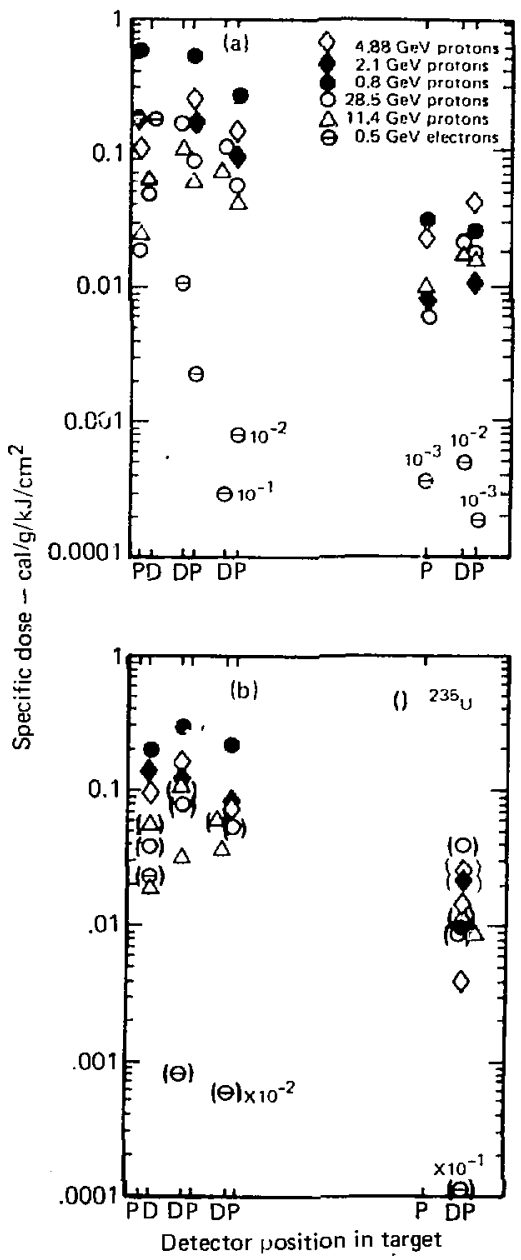

Fig. 9. Specific dose at various depths fro... particle beams for (a) TLD datz and (b) fission data. (Detectors at P locations were in L.ucito plates. Detectors at D locations were in 2MU plates.) 


\section{DISCUSSION AND CONCLUSIONS}

The data we present here were taken fron many experiments over a span of more than one year with suitable accelerator beams at different U.S. laboratorics. The data provide detailed information on dose at different locations in selected targets from a variety of incident particle beams. Not all of the information contained in the raw data has yet been extracted. Additional useful resules ean be obtained with some effort and may be availabic in the future. The uncertainty of the TLD doses is $\pm 15 \%$ in the dose range below $10^{9}$ rad, and somewhat higher for doses $>10^{5}$ ras The fission measurements either from Lexan-track counting or from residual ga mmaray counting arc generally within a twofold difference of one another, alt tholigh larger differences have sometimes been observed. These differenees are a measure of the uncertainties in the results. The following are conclusions that can be drawn from our meas urements.

1. Even if not measured in detail, there is some builjup at all incident energies, i.c., initially the energy density deposited increases as a function of target depth. The buildip is larger and the subsequent drop is siower for high-energy protons than for low-energy protons or electrons.

2. There are variations in specific dose results as a result of beam size and shape; thus, one should be cautious when comparing the results from one rin to the nexi. For cxample, beam sizes in electron and most proton runs are different enough to invalidate absolute comparisons of specific dose For a valid comparison, the beam size and shape from one incident beam to the next must be identical.
3. The 500-MeV-electron beam deposits most of its energy in the first fcw $\mathrm{cm}$ of the target. The TLD dose is reduced 25,000 -fold after 4 in. of uranium, conspared with a buildup factor of 2.5 in the 28.5-GeV proton run.

4. The fission dose is generally two-to fourfold lower than the TLD dose for protons in the front of the target. After the beam penetrates deep into the target, the measured fission dose often is comparable with the TLD dose, especially in ${ }^{235} \mathrm{U}$, where low-energy neutrons may contribute to dose.

5 . In general, the fission density observed in ${ }^{235} \mathrm{G}$ is two- or 1 hreefold higher than the density in $238 \mathrm{U}$. Considering that the high-energy fission cross sections might be comparable, this suggests a contribution from low-energy ( $<1 \mathrm{MeV}$ ) neutrons, eomparable to that of highenergy particles.

6. Onc ineasure of deep penetration by beams is the energy deposited in the back of the target relative to the energy deposited in front. By comparing the doses from Table 1 and Fig. 10, we found that shower production and smaller attenuation of the highenergy proton beam is the most effective in depositing energy in the back of the target, while $0.5-\mathrm{GeV}$ electrons are the least effective.

7. There are some problems that are not yet resolved. For example, (a) there is $\sim 3.5$ times as much ${ }^{140} \mathrm{Ba}$ produced in the proton experiments as would be calculated from fissinn events alone, (b) consistently higher doses are seen in TLD's embedded in 23*U compared with those TLD's in Lucite $\sim 1 / 4 \mathrm{in}$. away, and (c) the measured fission density is higher inside the ${ }^{238} \mathrm{U}$ plates compared with the density on the surfaces.

\section{REFERENCES}

1. RSIC Computer Code Collection, NMTC. Monte Carlo Nucleon-Meson Transport Code System. CCC-16I, Oak Ridge National Laboratory, Oak Ridge, Tenn. (1974).

2. RSIC Computer Cude Collection, HETC, Monte Carlo Nucleon-Meson Transport Code System CCC-178, Oak Ridge National Laboratory, Oak Ridge, Tenn. (I970).

3. H. M. Colbert, SANDYL, A Computer Program for Calculating Combined Photon-Electron Transport in Complex Systems, Sandia Laboratories, Rept. SLL-74-0012 (1974).

4. G. Sidhu, Measurement of Energy Transport by Charged Particle Beams. Lawrence Livermore Laboratory, Livermore, Calif., Rept. D-76-9 (1976). 


\section{APPENDIX A \\ DOSE CONTOUR PLOTS \\ TLD DETECTORS IN LUCITE PLATES}

(Lovation numbers are with respect to incident beam.) 

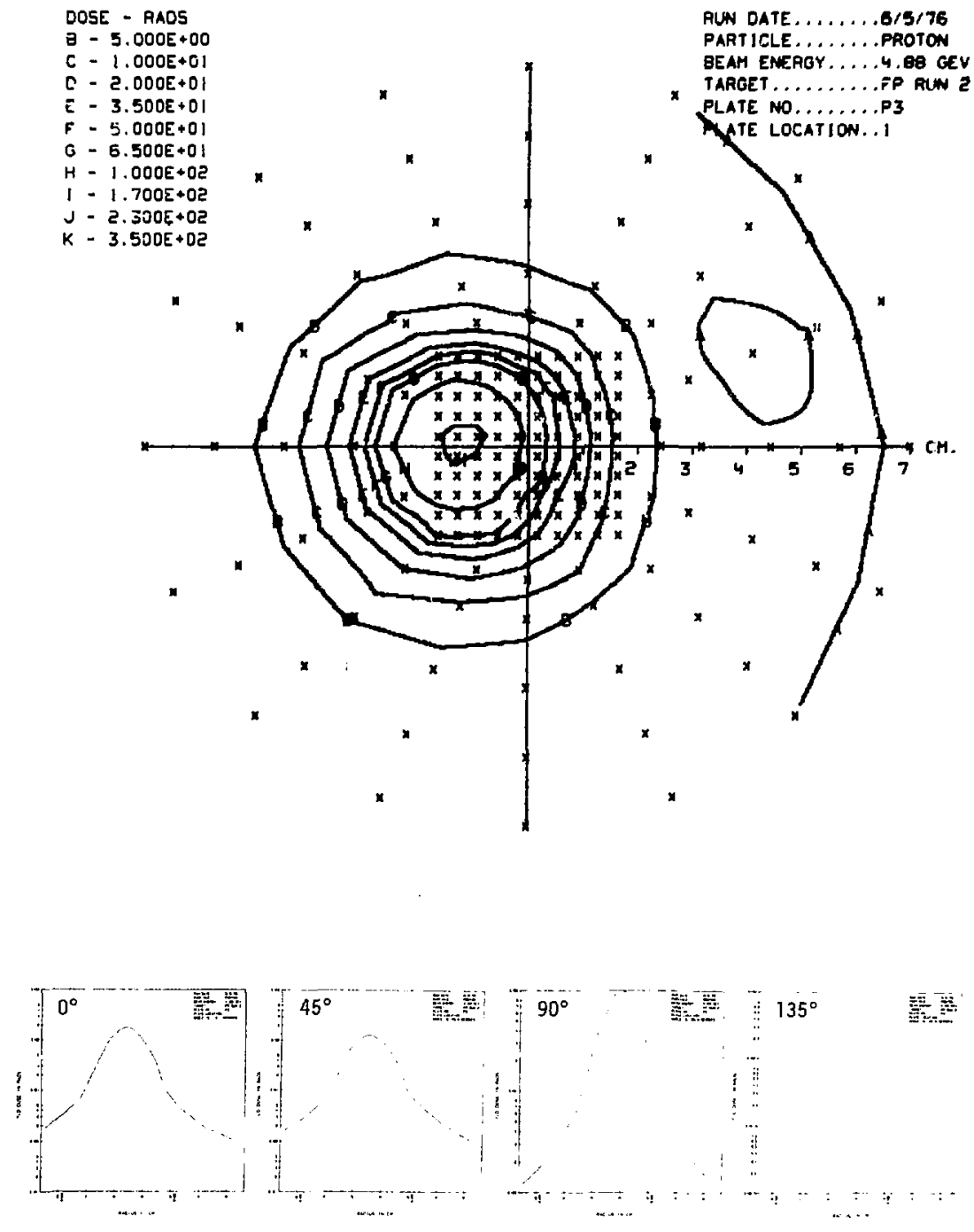

Fis. A-1. 

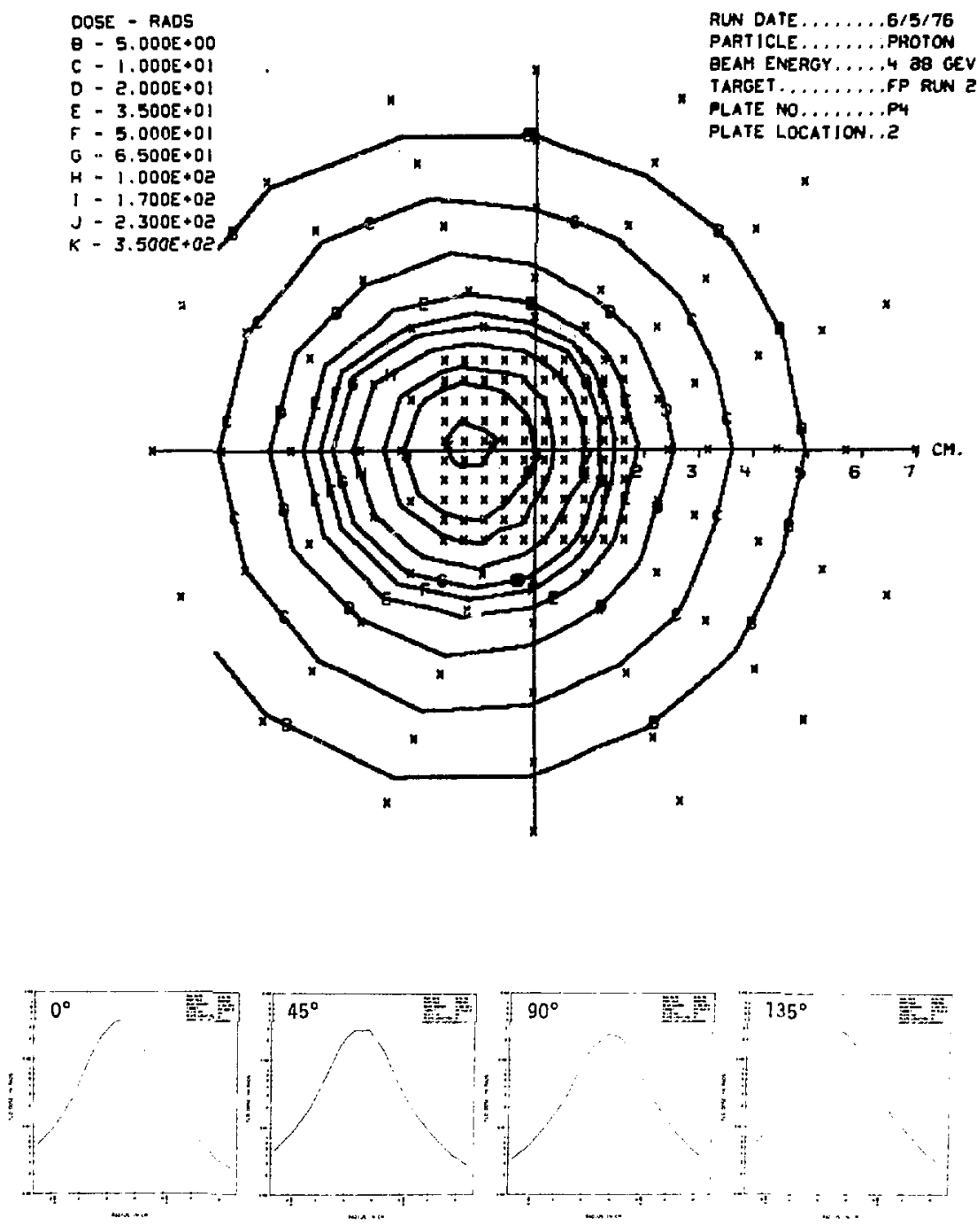

Fig. A-2. 

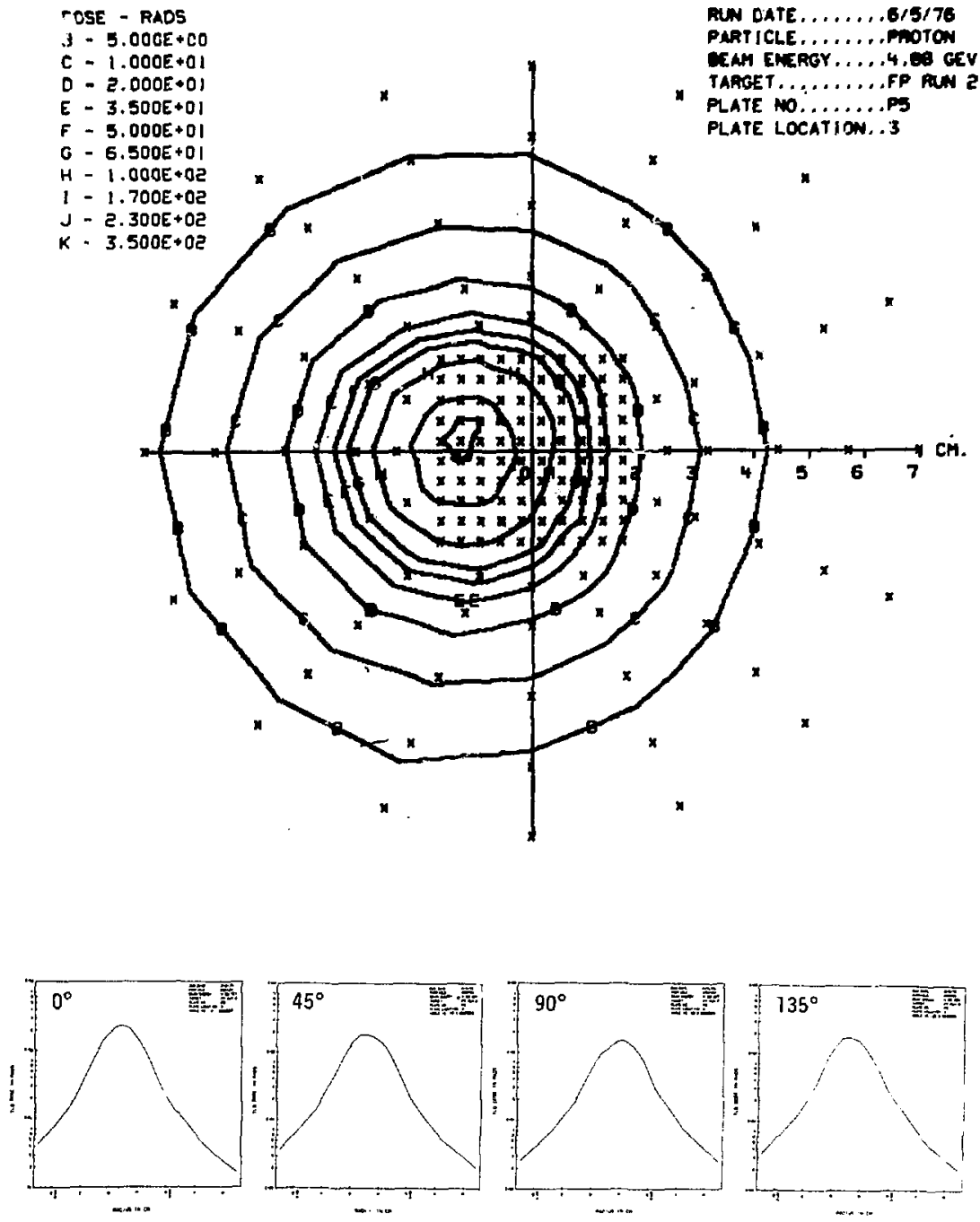

Fis. A-3. 

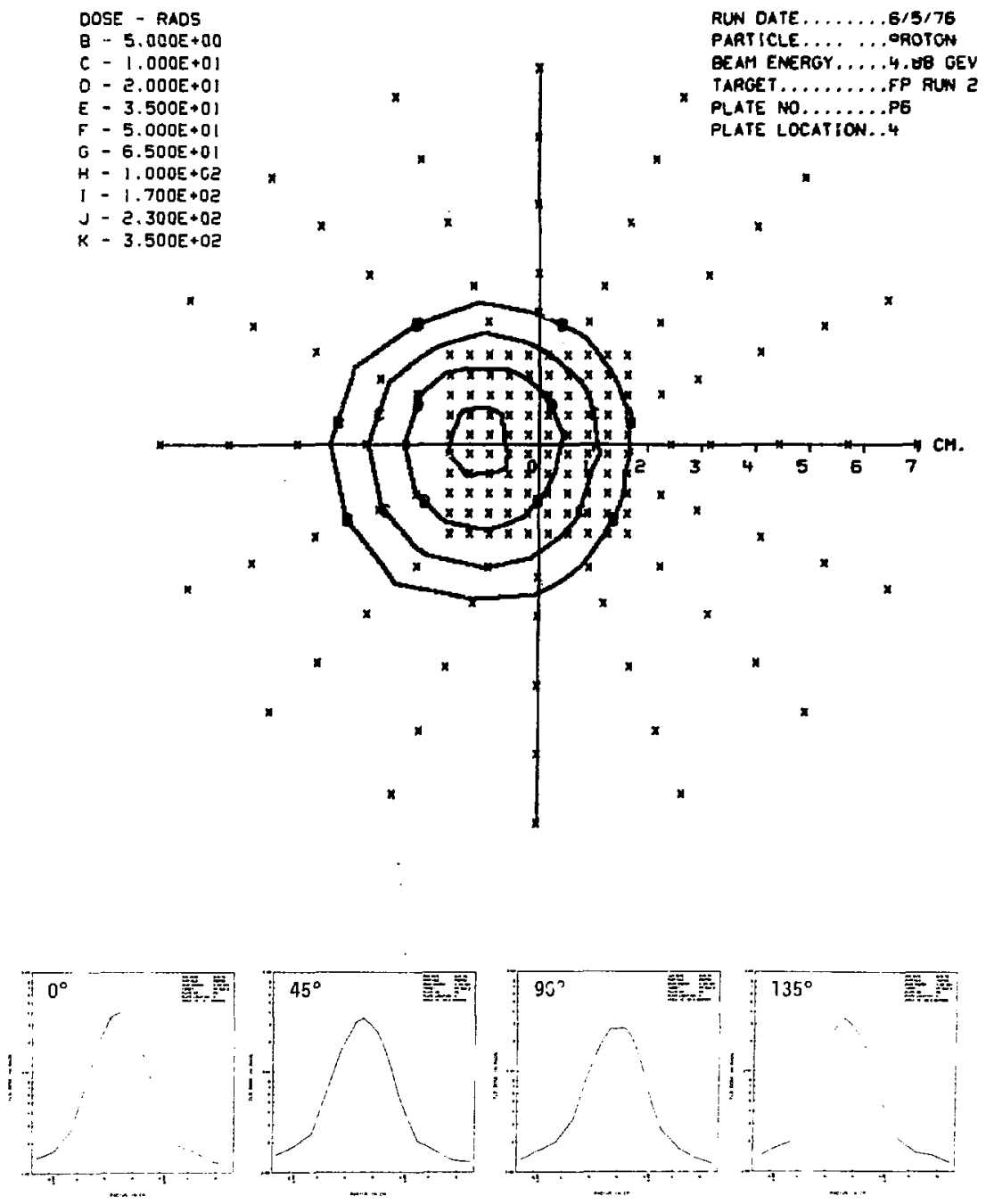

Fig. A-4. 

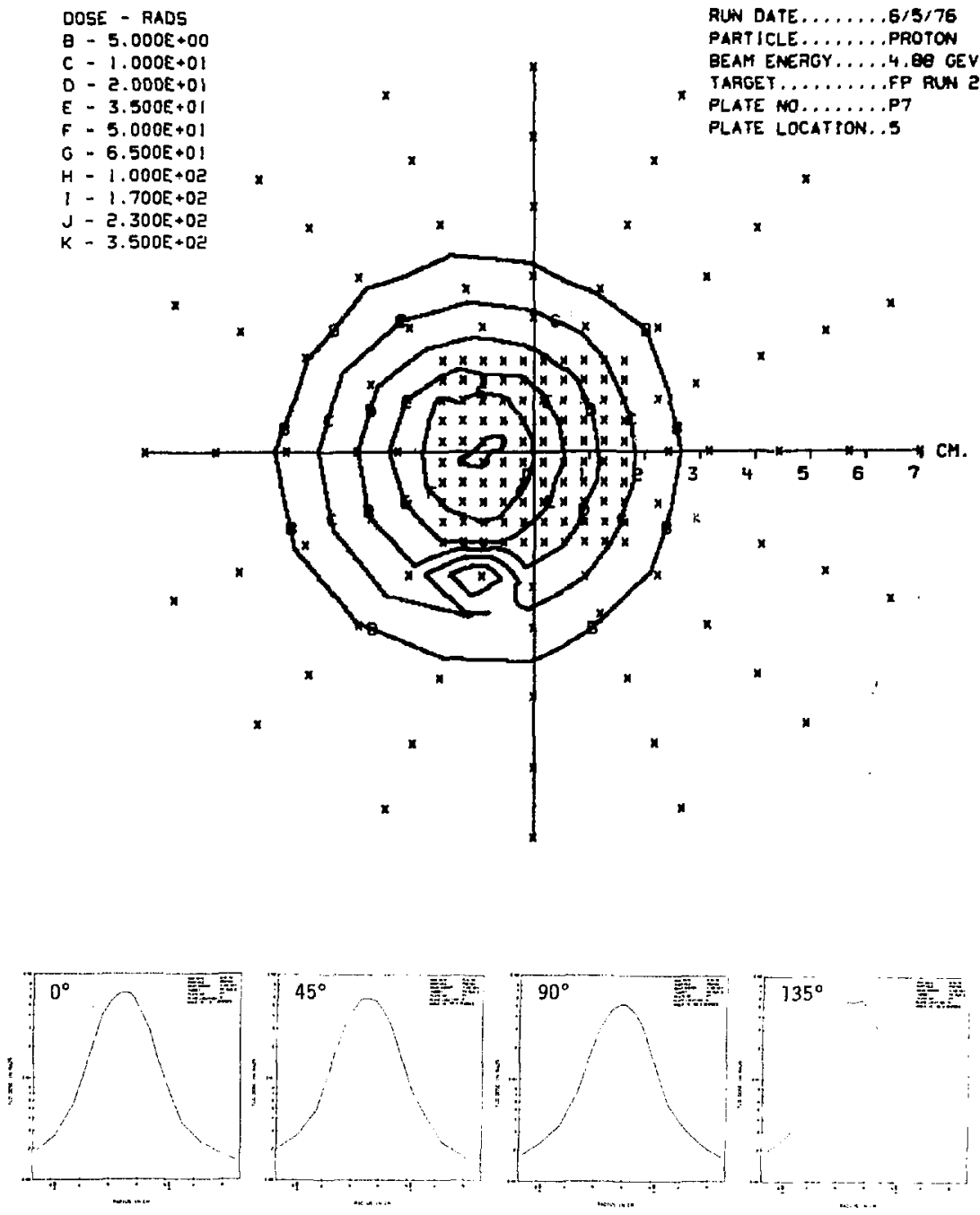

Fig. A-5. 

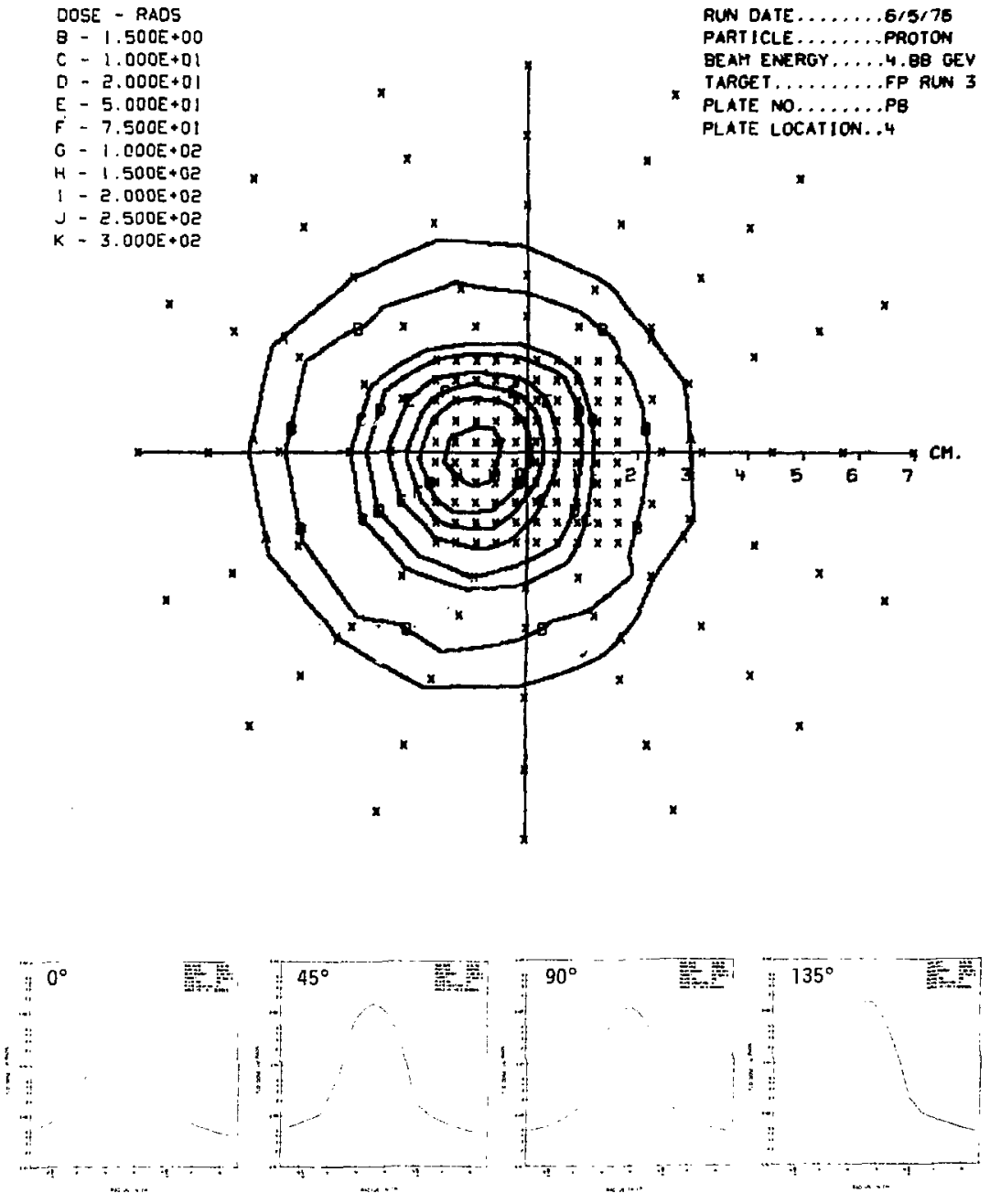

Fig. A-6. 

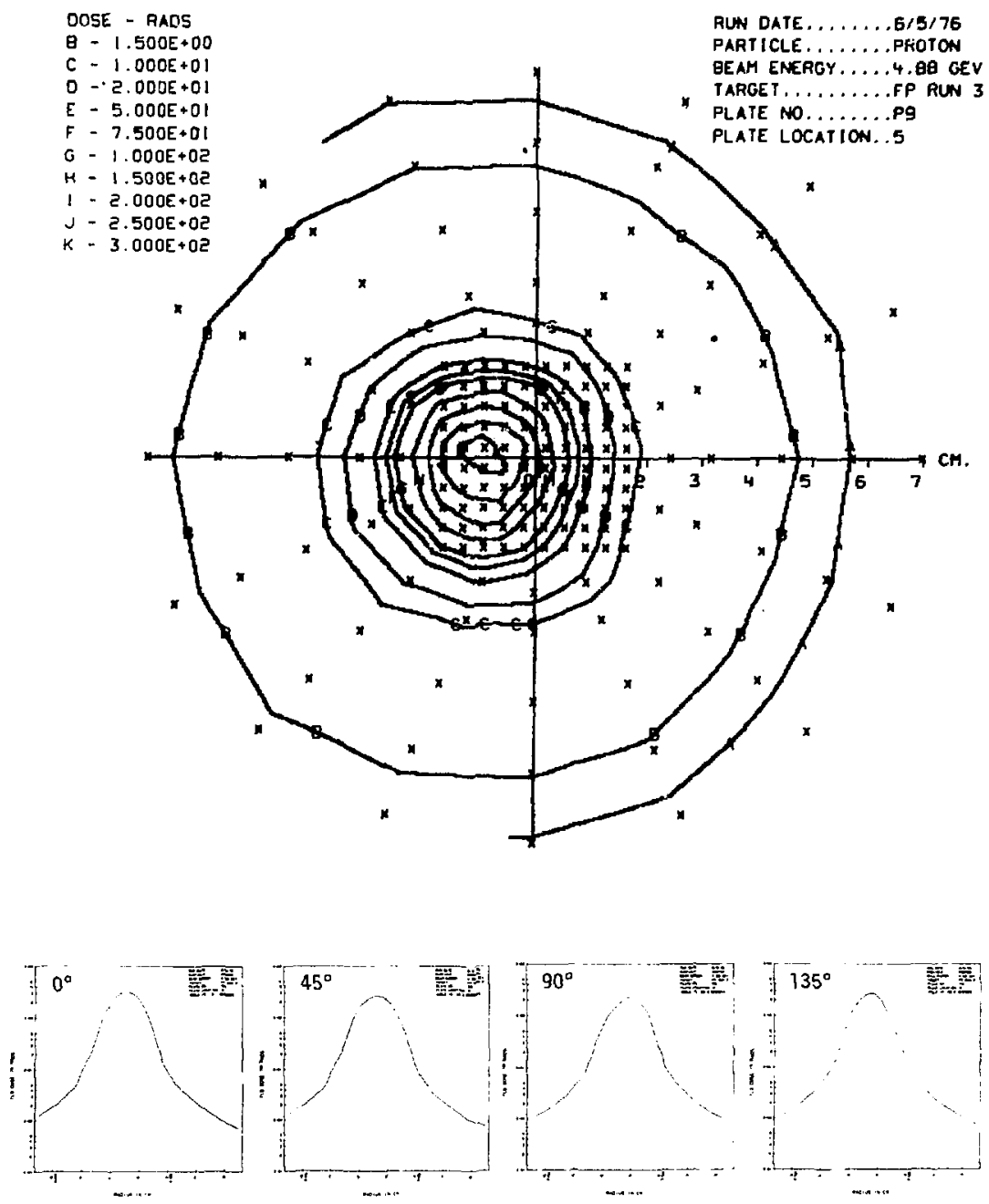

Fis. A-7. 

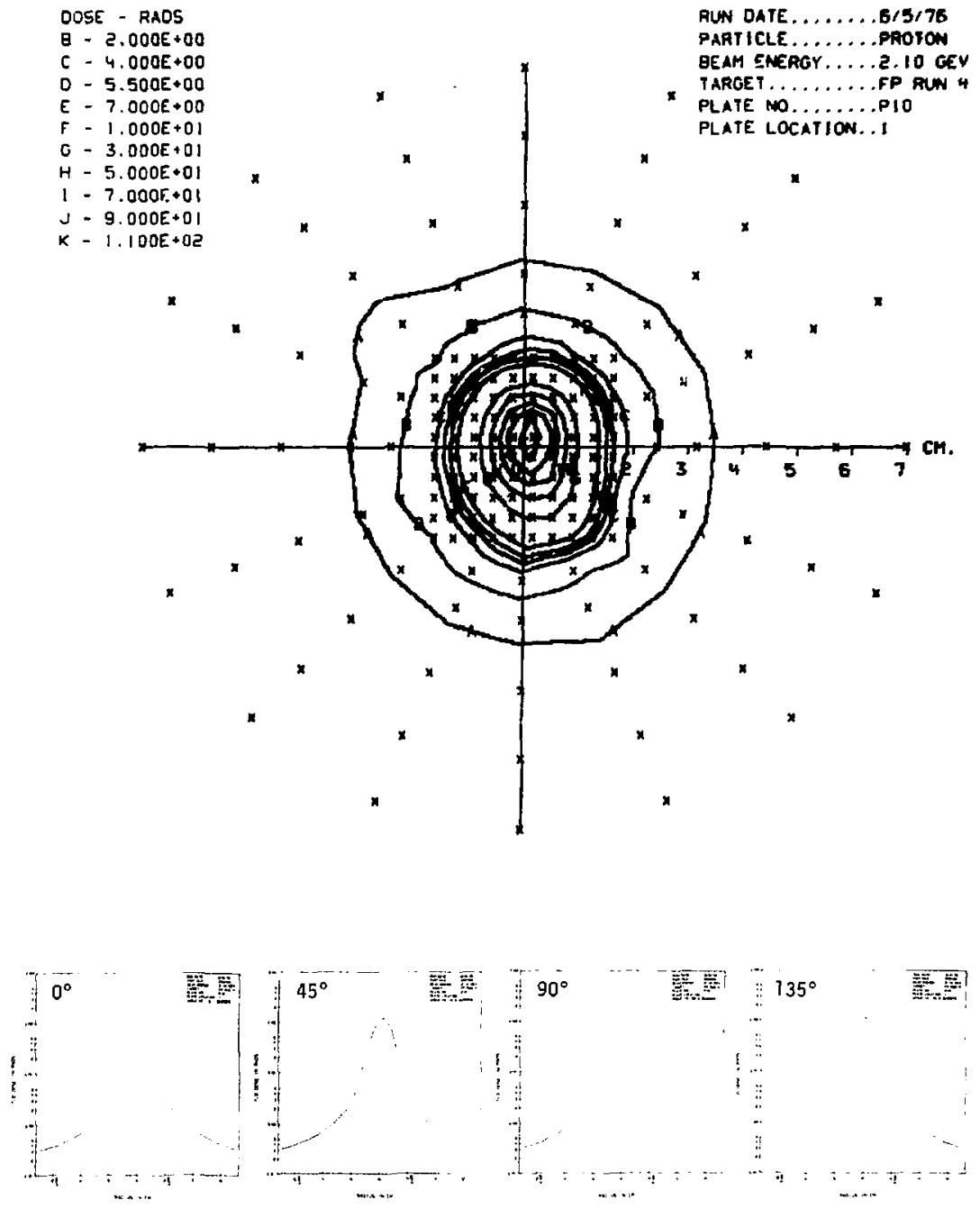

Fig. A-8. 

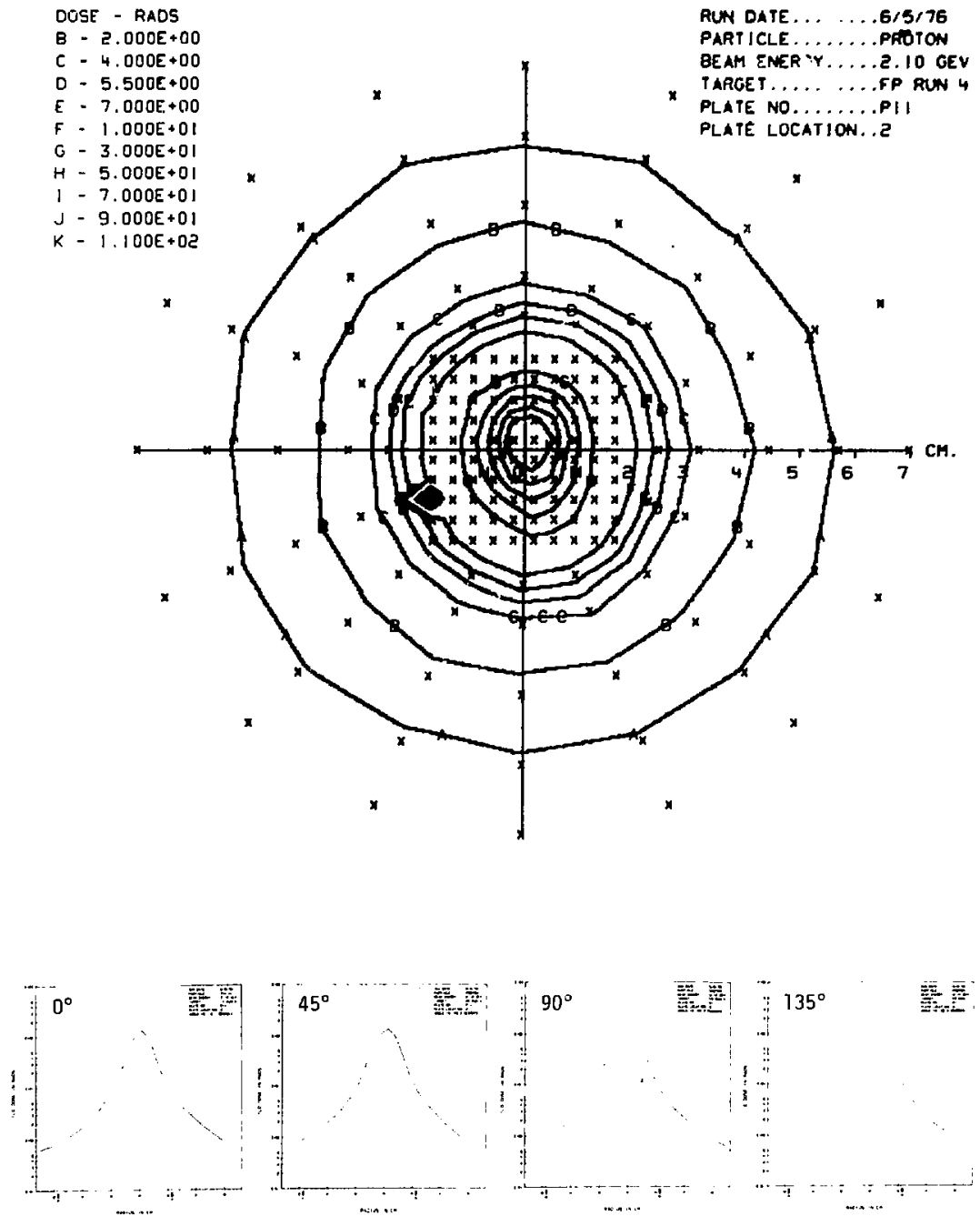

Fig. A-9. 

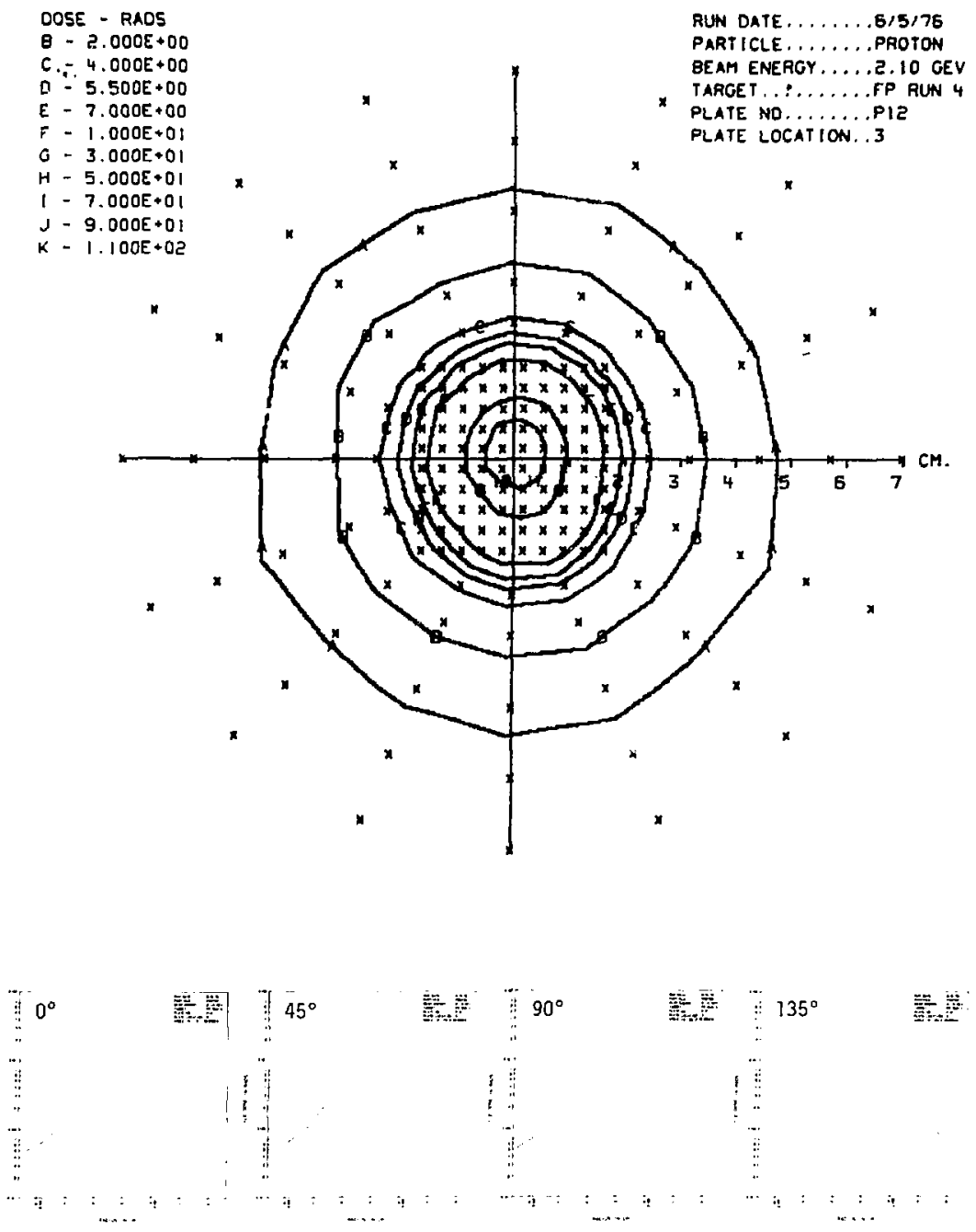

Fig. A-10. 

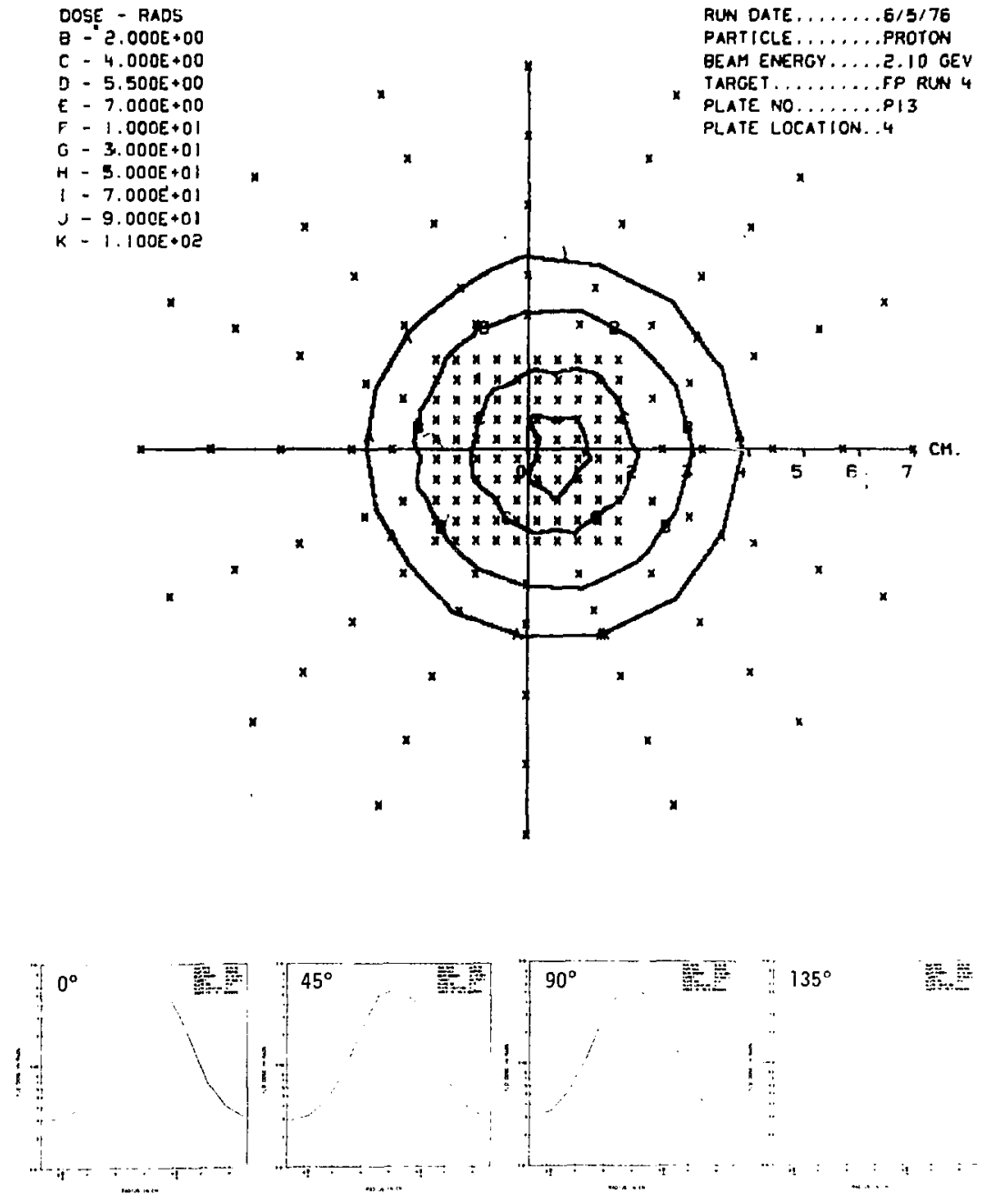

Fis. A-11. 

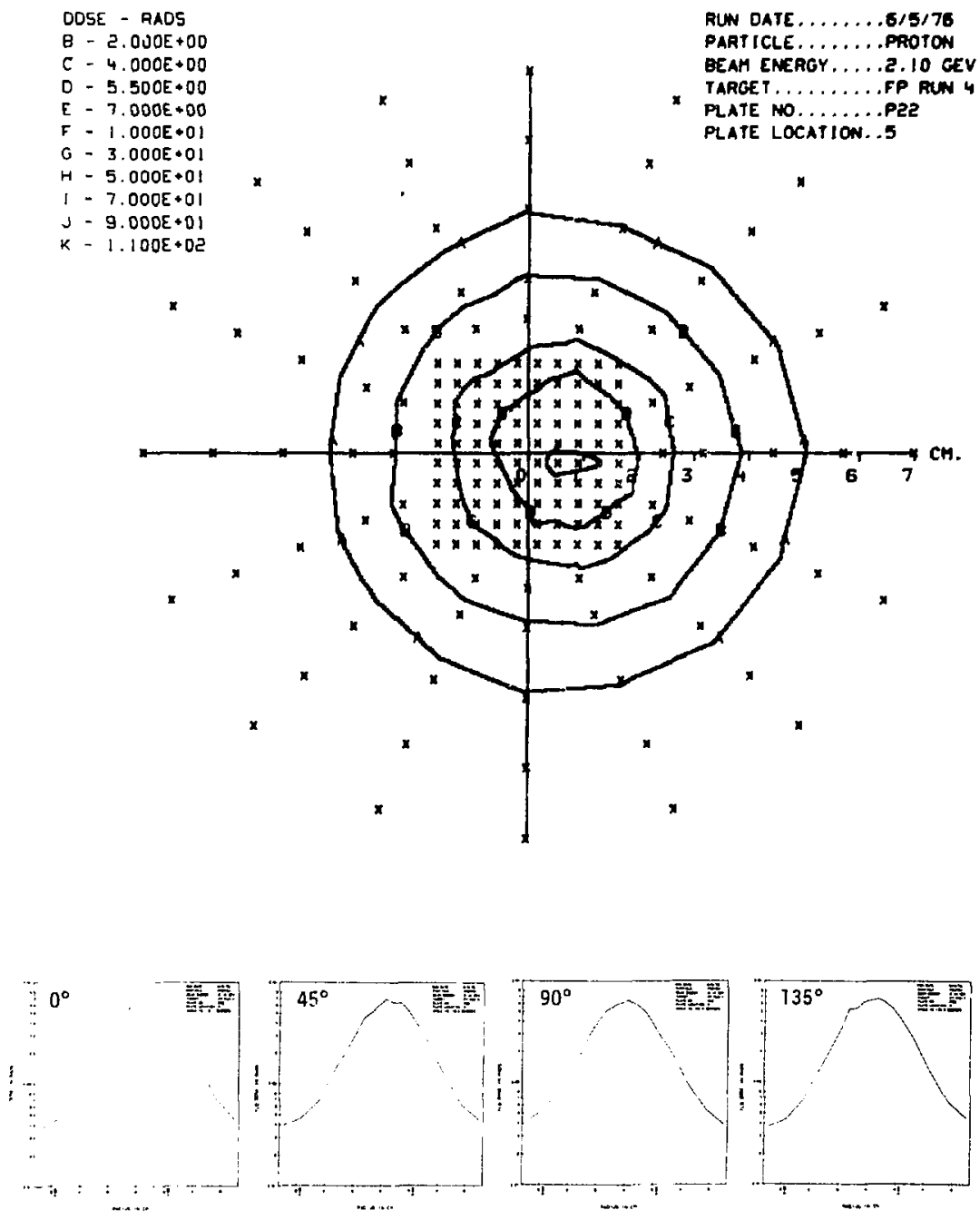

Fis. A-12. 

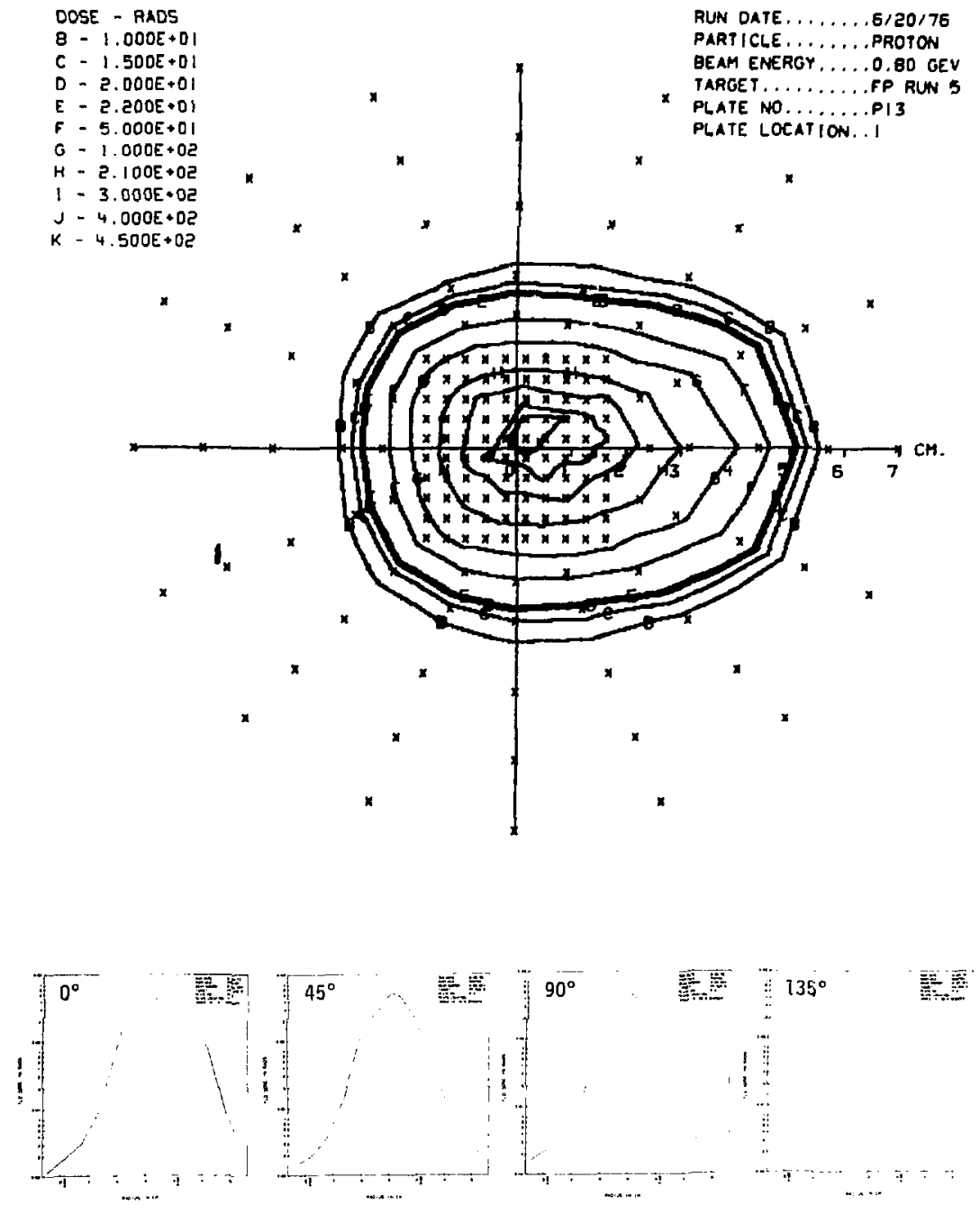

Fig. A-13. 

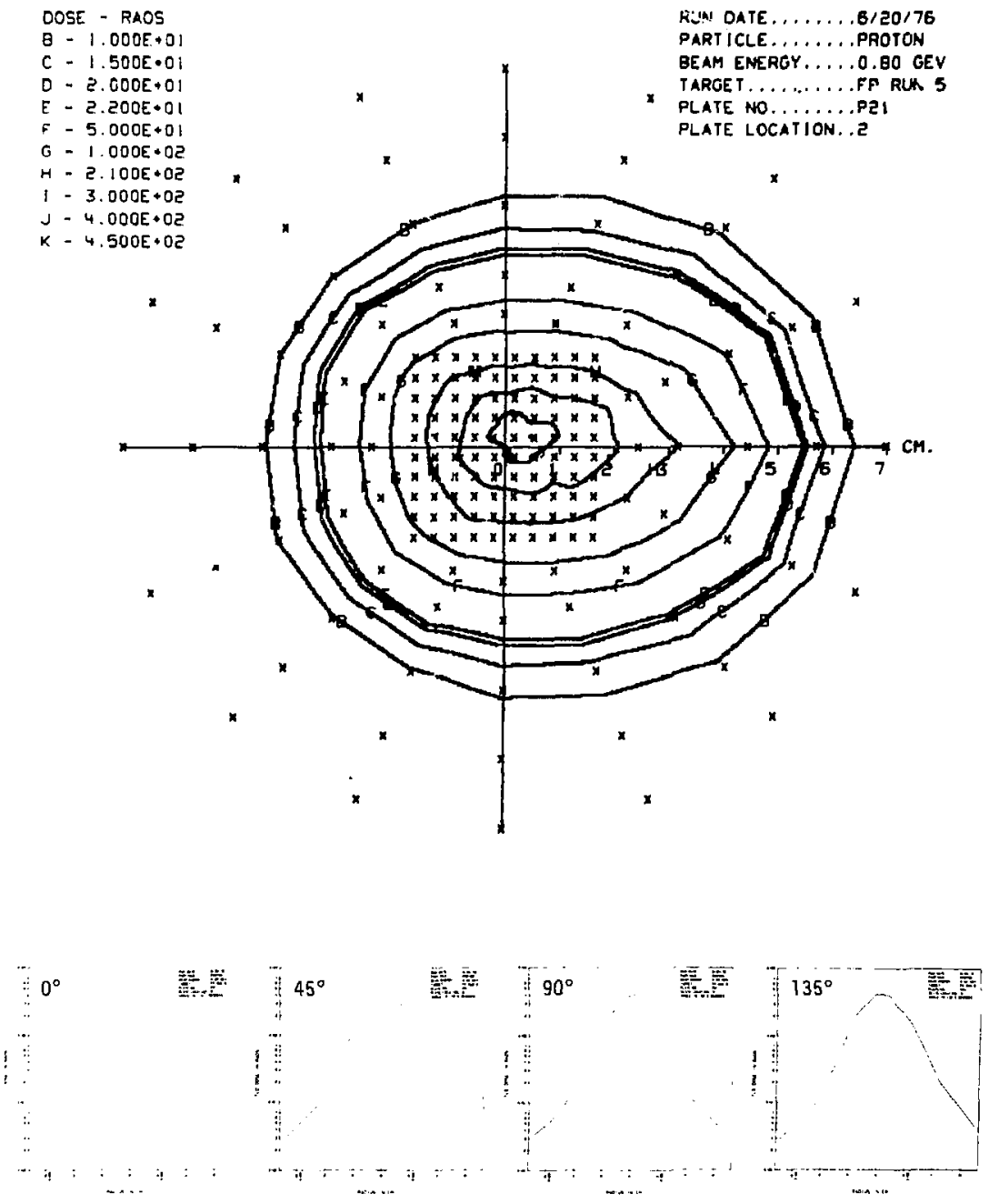

Fit. A-14. 
DOSE - RADS

o - 1.000E*01

$C \cdot 1.500 E \cdot 01$

D - $2.00 C E ; 01$

$E-2,200 E+01$

$F=5.000 E+01$

$0-1.000 E+02$

H - 2., 100E+02

$1-3.000 E+02$

$J-4.000 E+02$

K $-4.500 E+02$
RUN OATE, ...., 6/20/76

PARTICLE. ....... PROTON

BEAH ENERGY,...,0.80 GEV

TARGE $1 . . . \ldots \ldots$. . RP RUN 5

- plate no..........pez

plate location. .
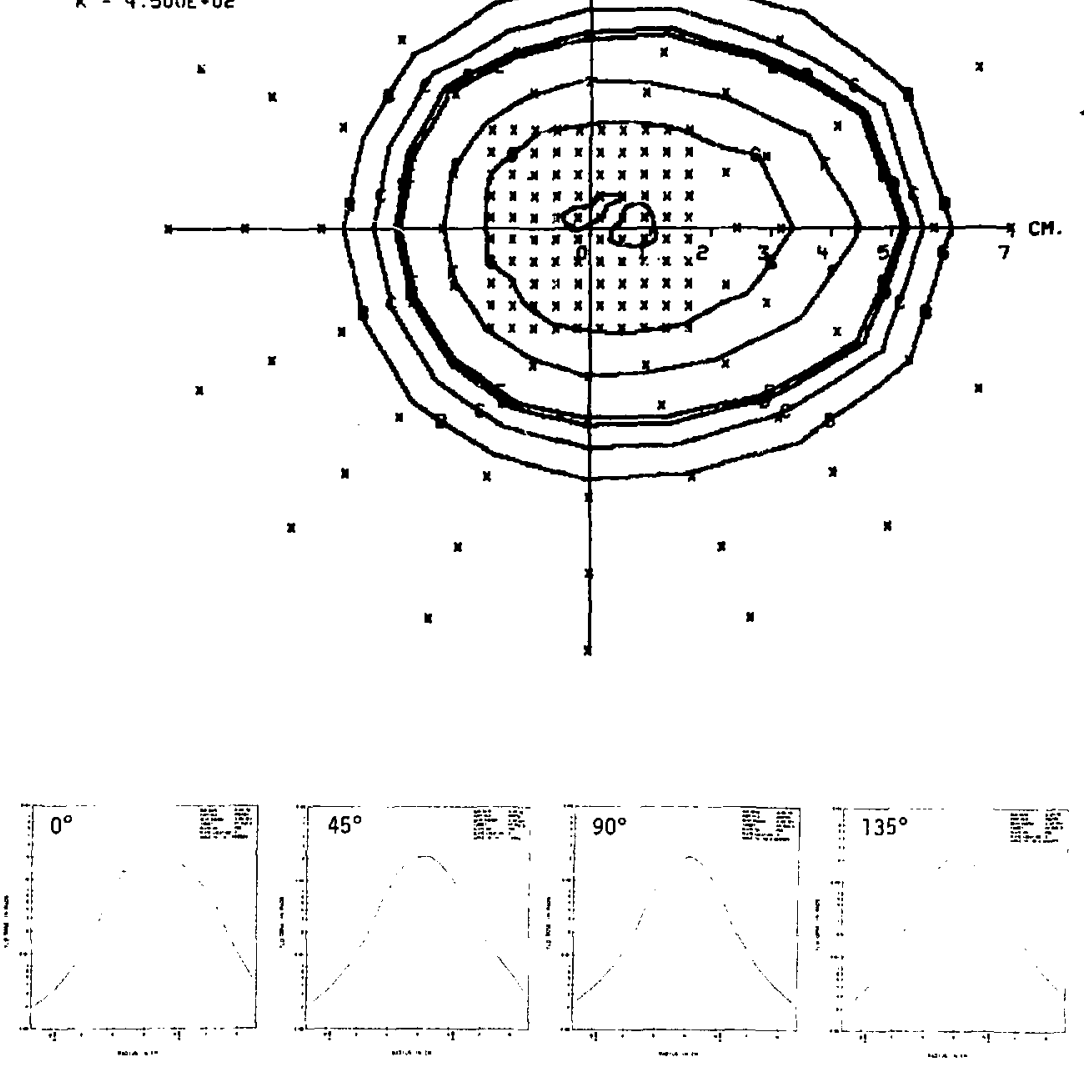

Fit. A-15. 

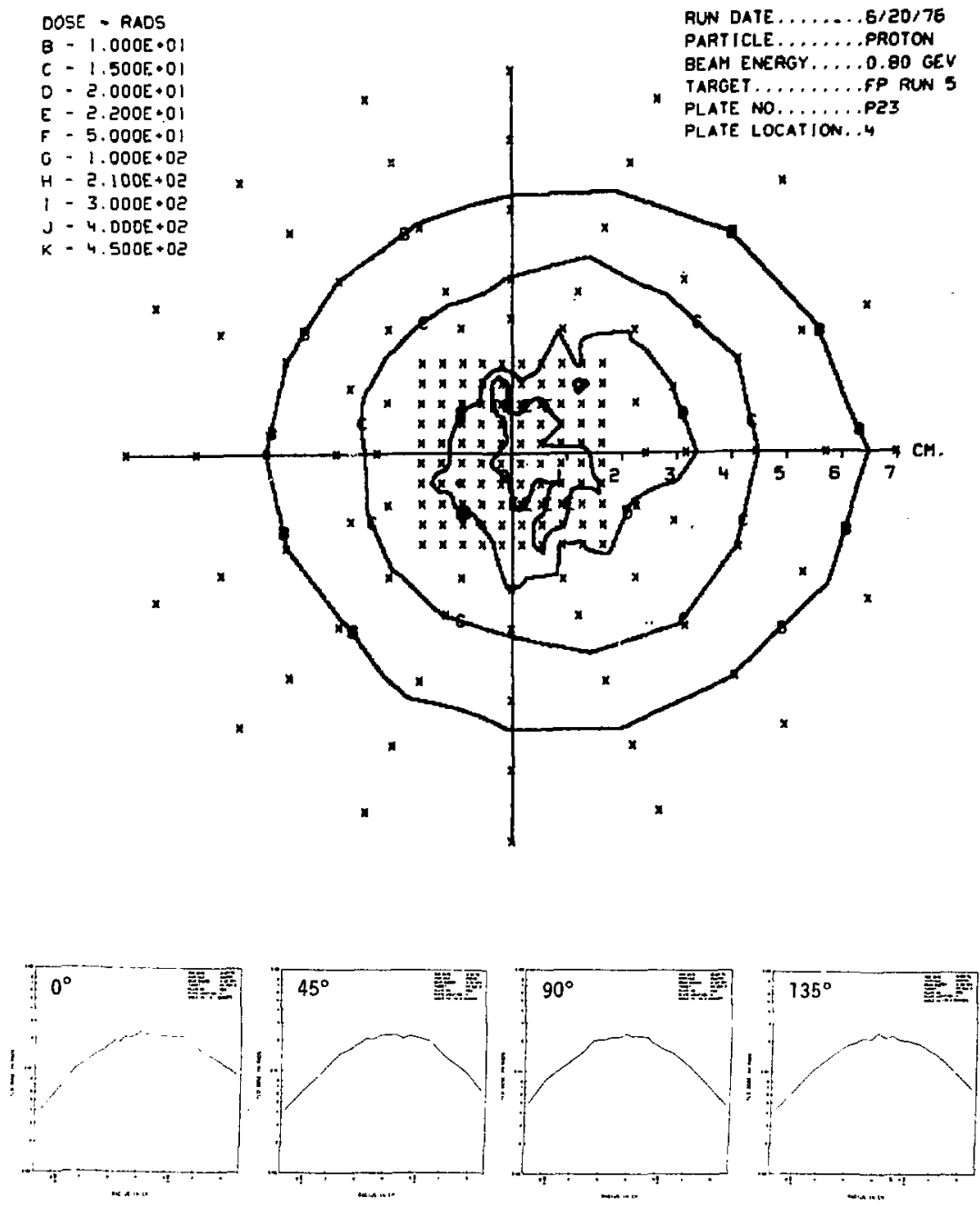

Fie. A-16. 

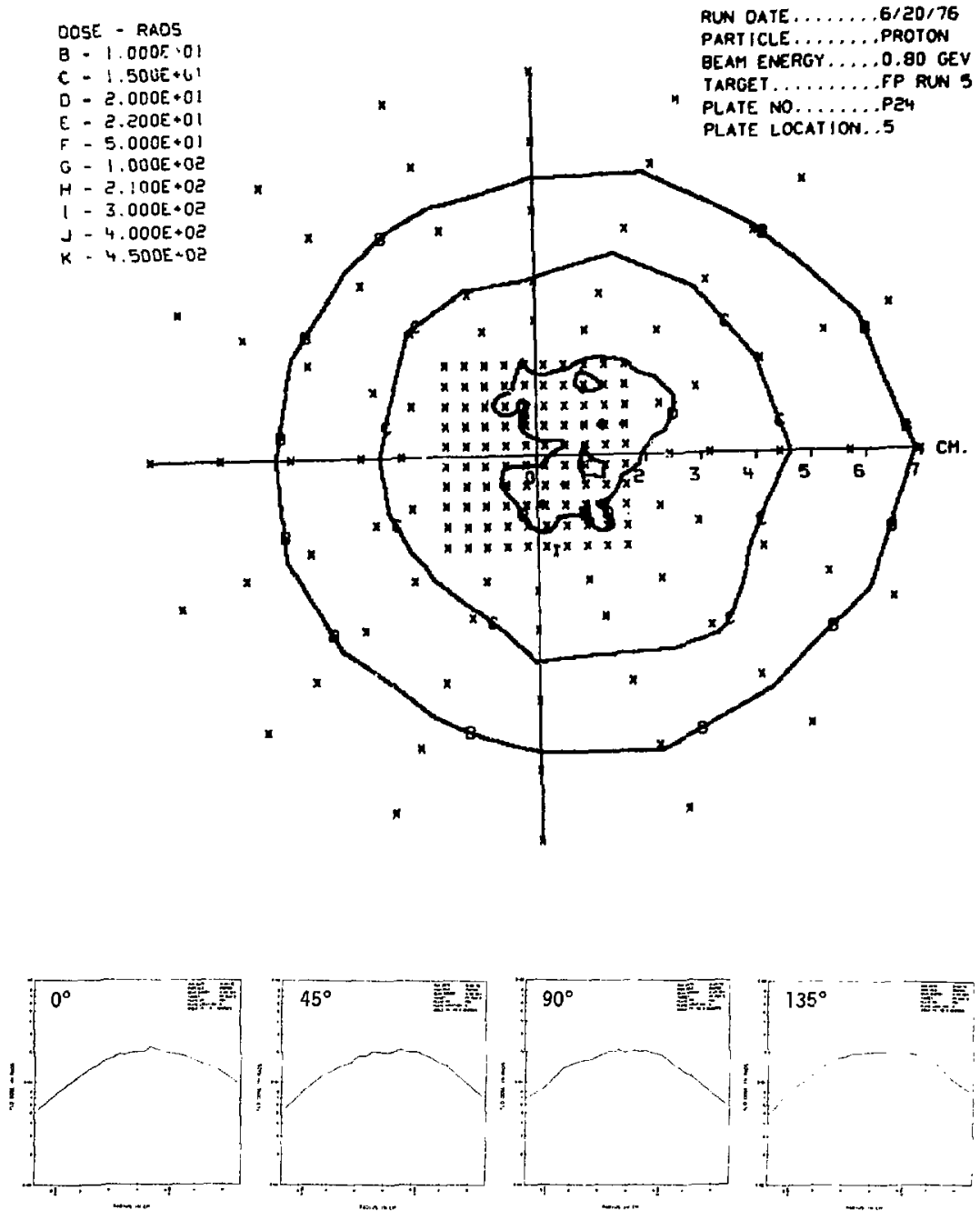

Fig. A-17. 

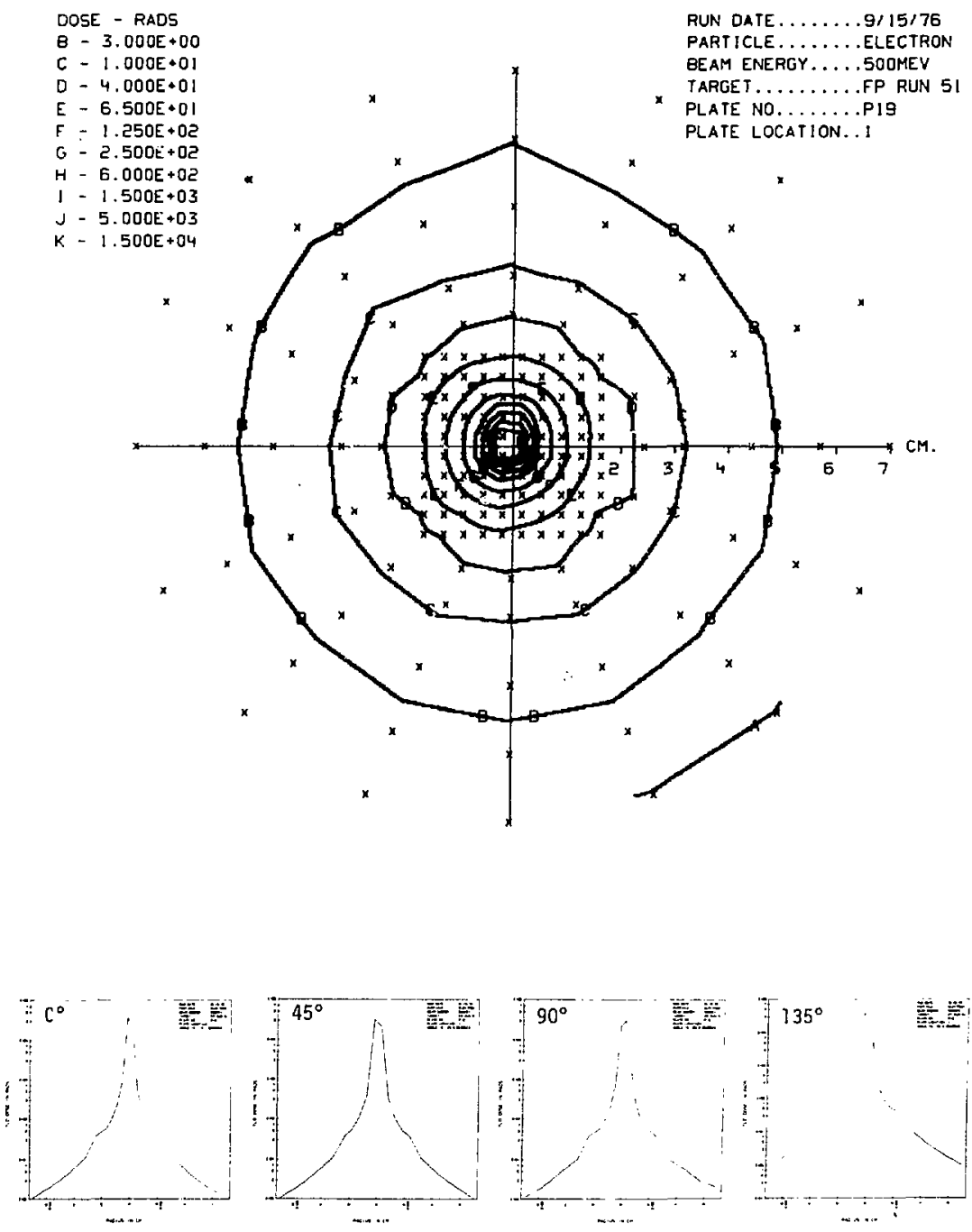

Fig. A-18. 

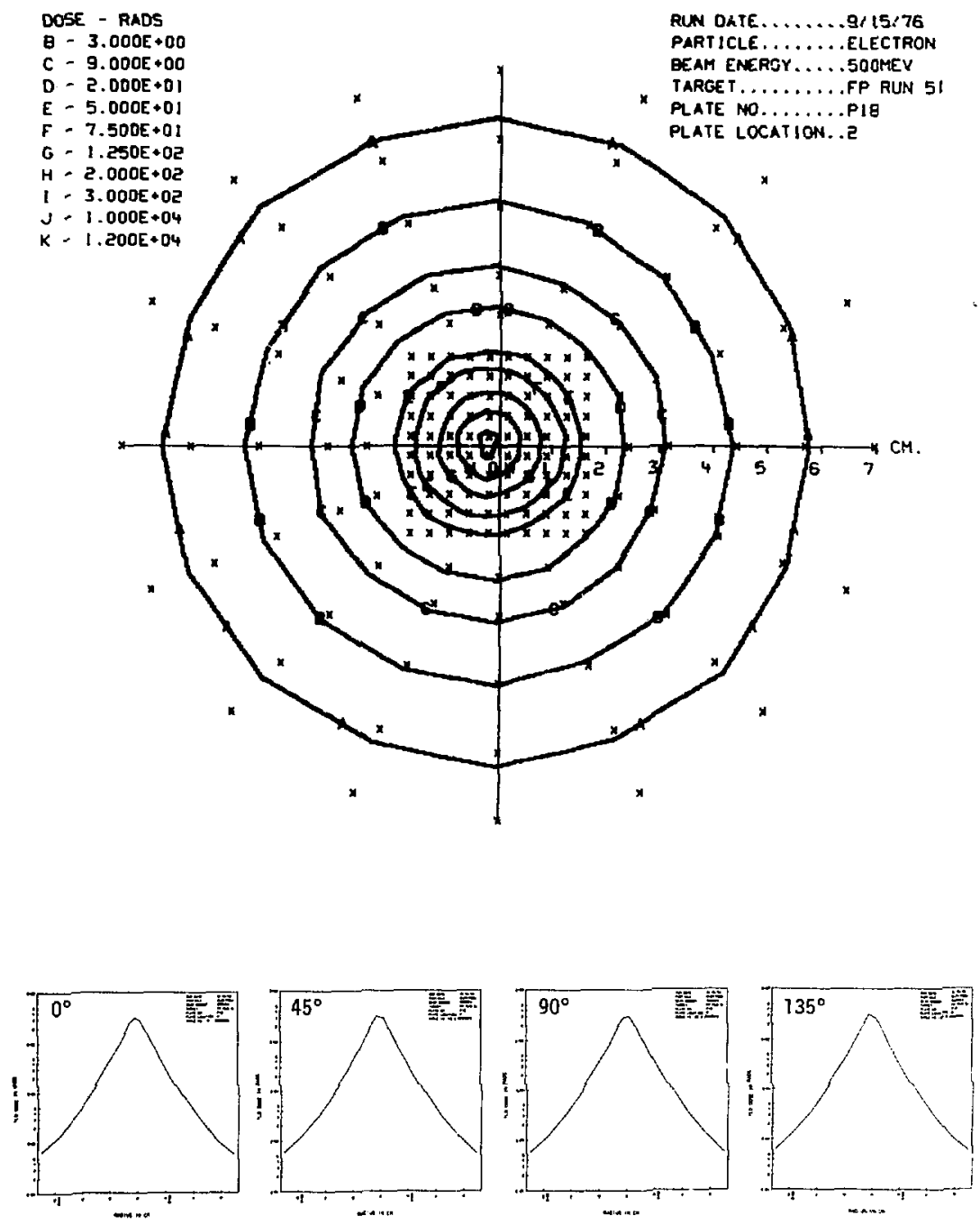

Fis. A-19. 

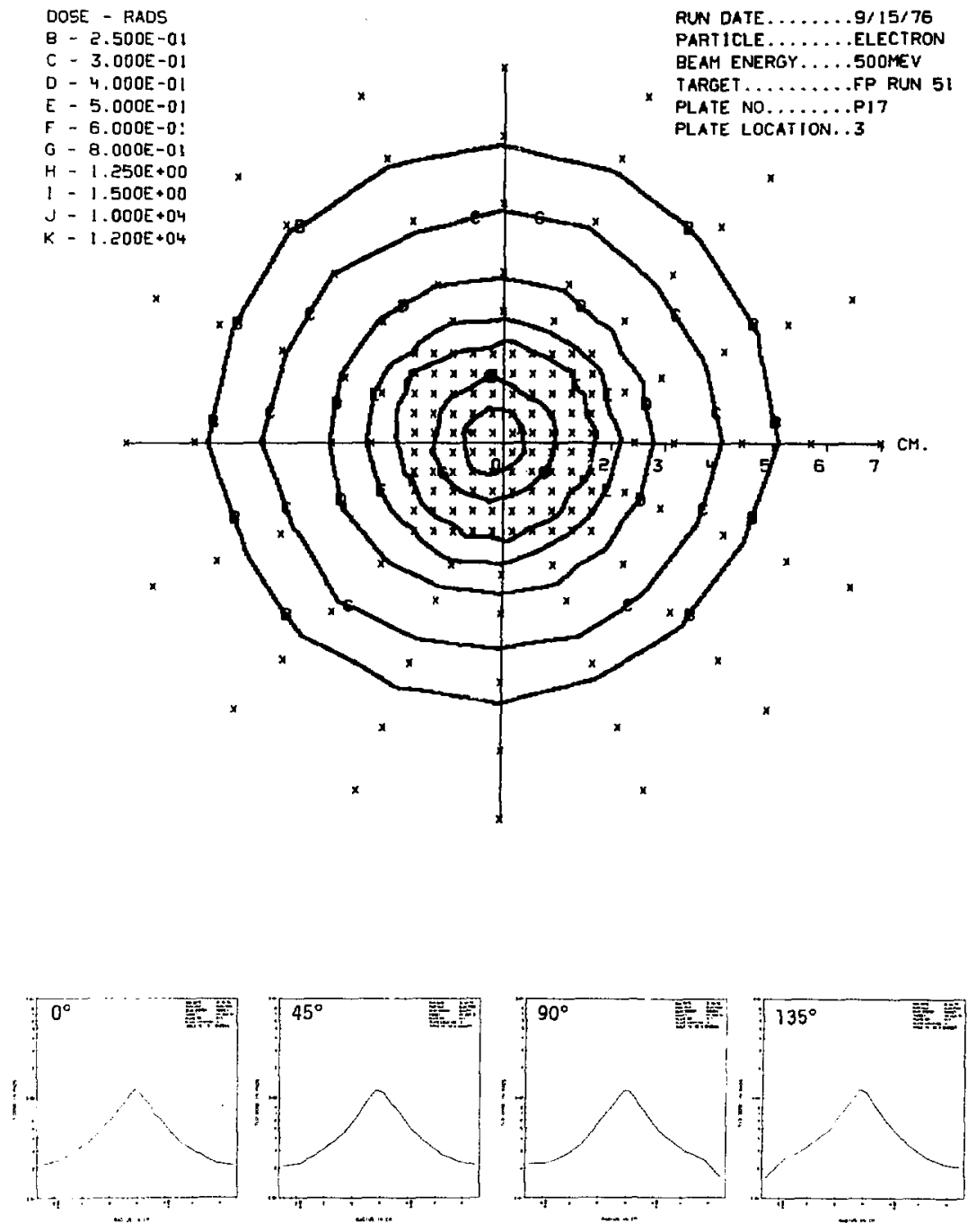

Fis. A-20. 

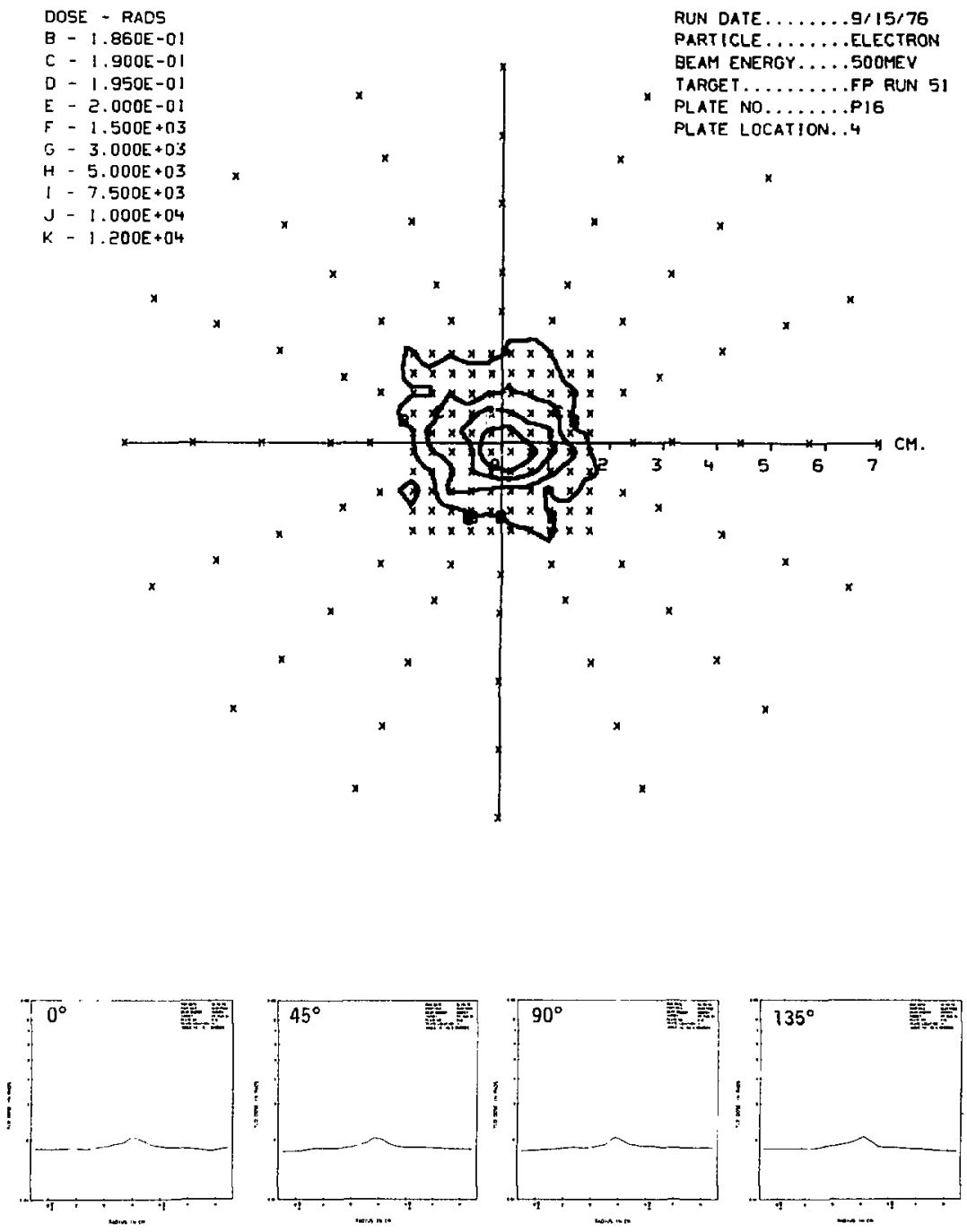

Fig. A-21. 


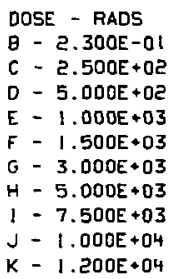

RUN DATE......9/15/7E

PARTICLE.........ELECTRON

BEAM ENERGY.... SOOMEV

FET ........FP RUN 5

PLATE NO......P13

PLATE LOCATION.. 5

x $x$

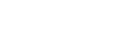

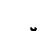

$\times \quad x \times x \times x \times x \times x \times x$

$\times$

$x \times x \times x \times x \times x$

$\mathbf{x}$

$x$

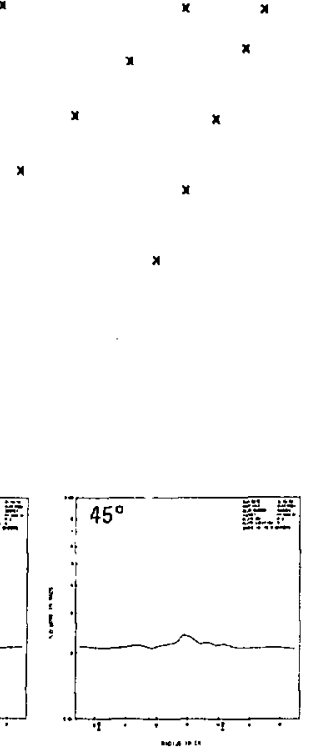

x
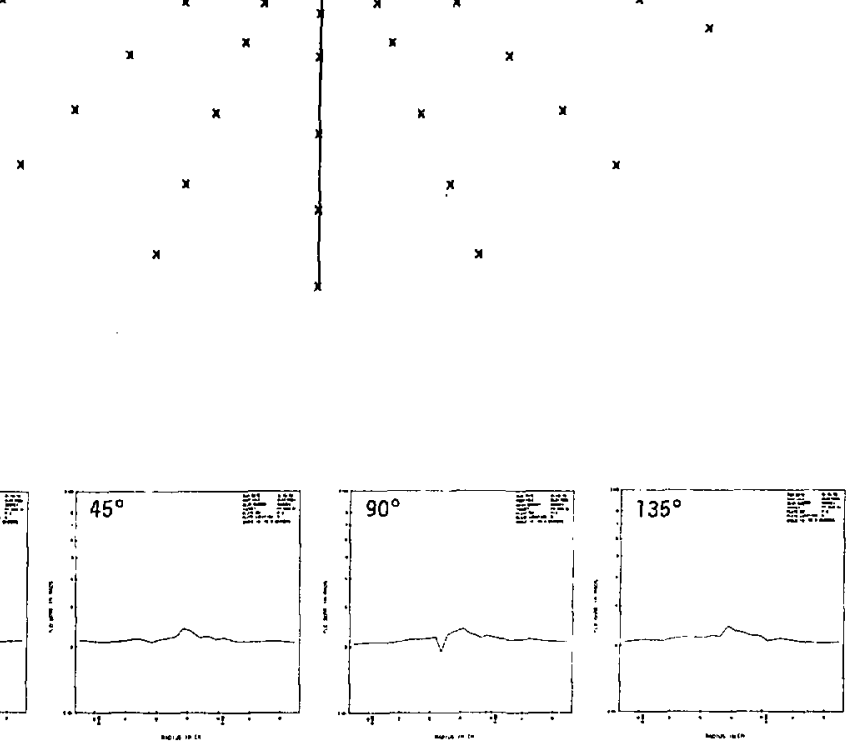

Fig. A-22. 

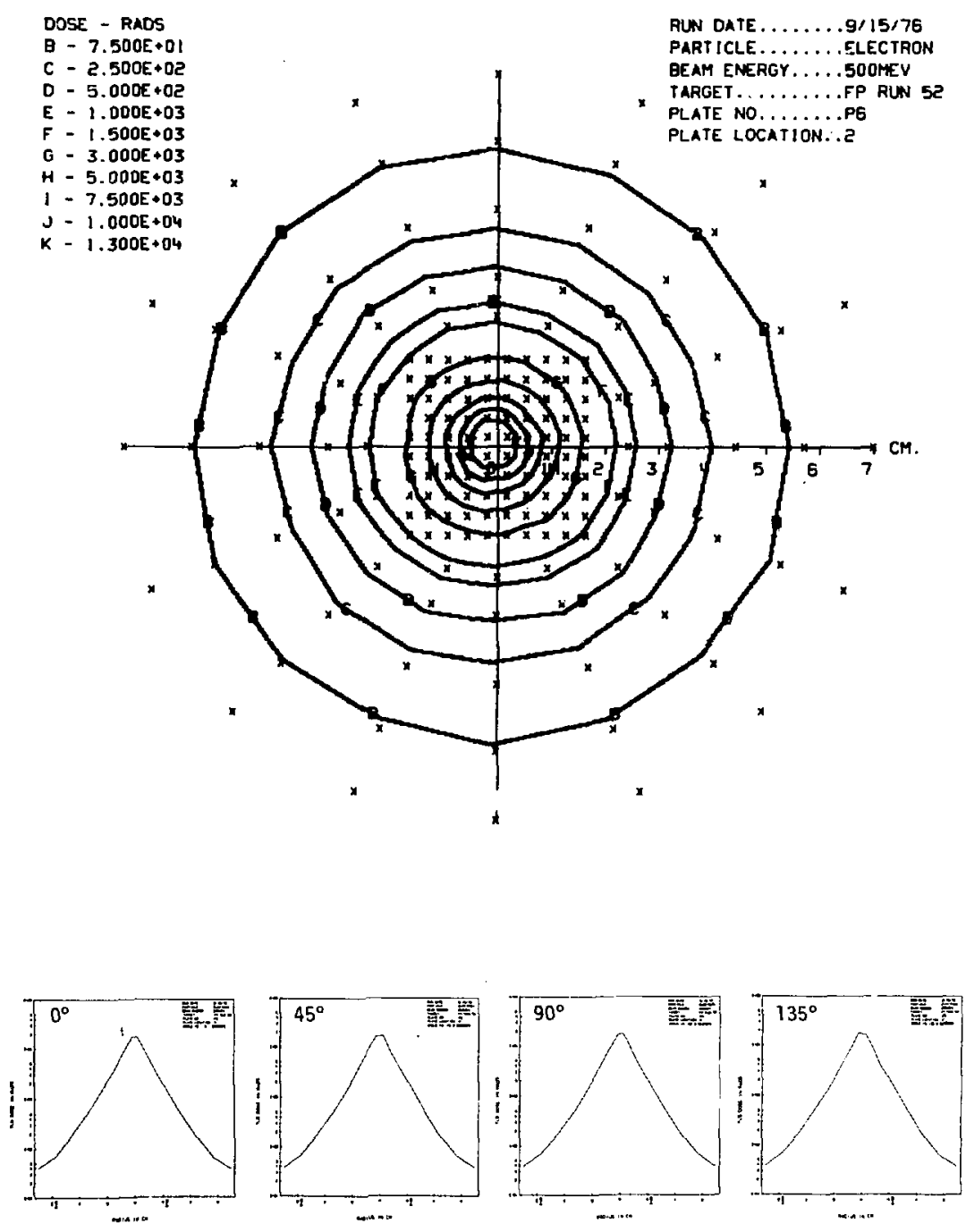

Fis, A-23. 

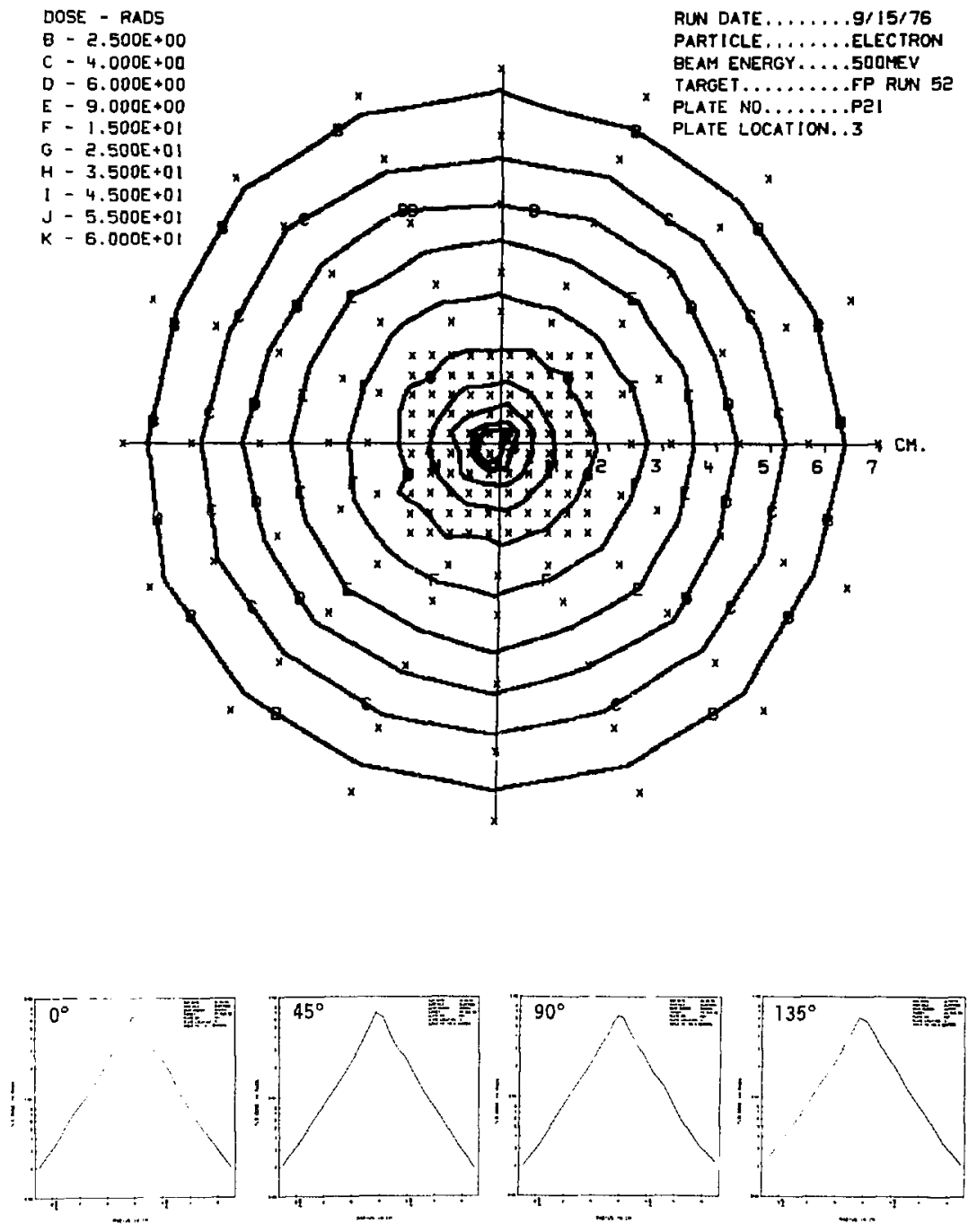

Fis. A-24. 

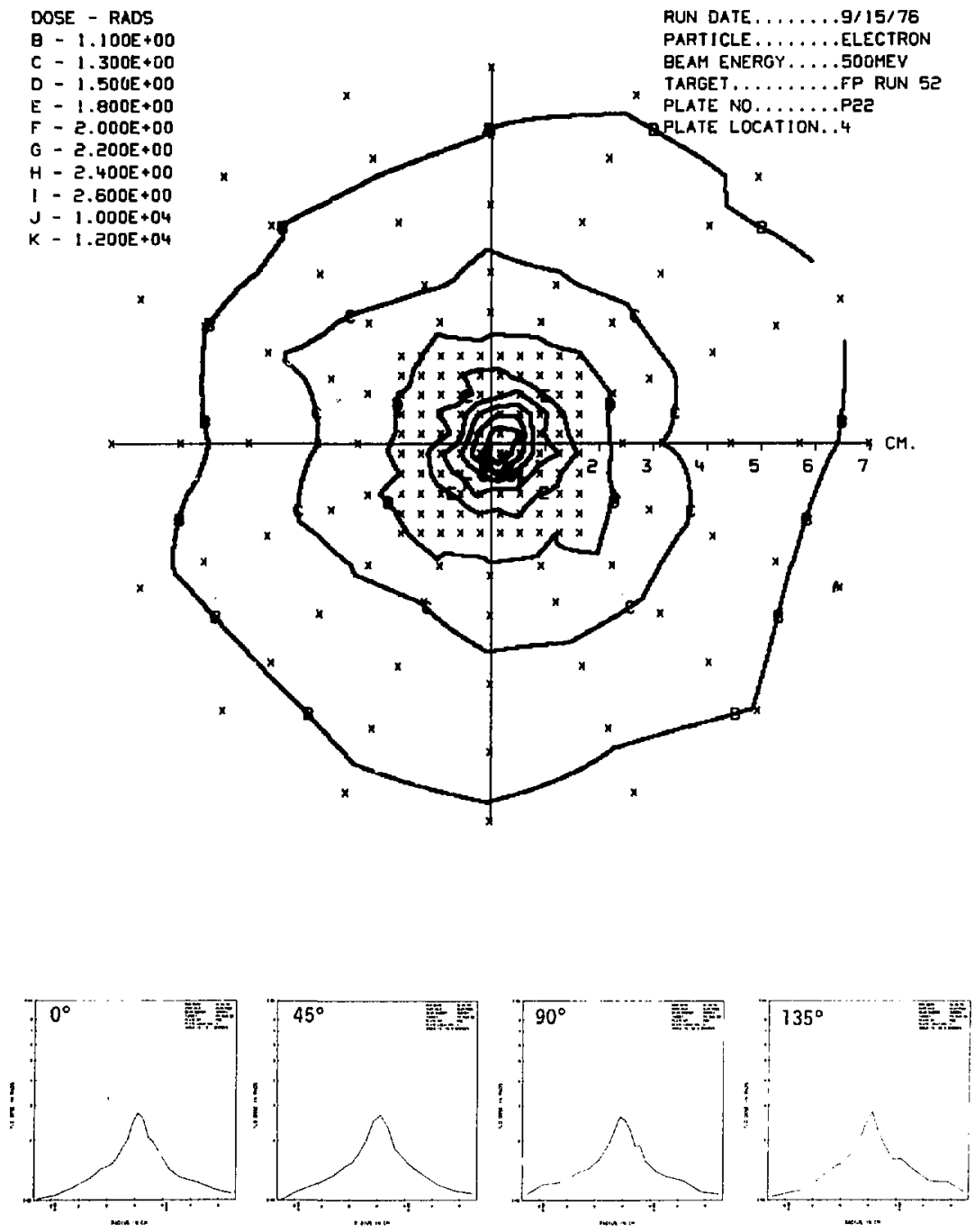

Fis. A-25. 

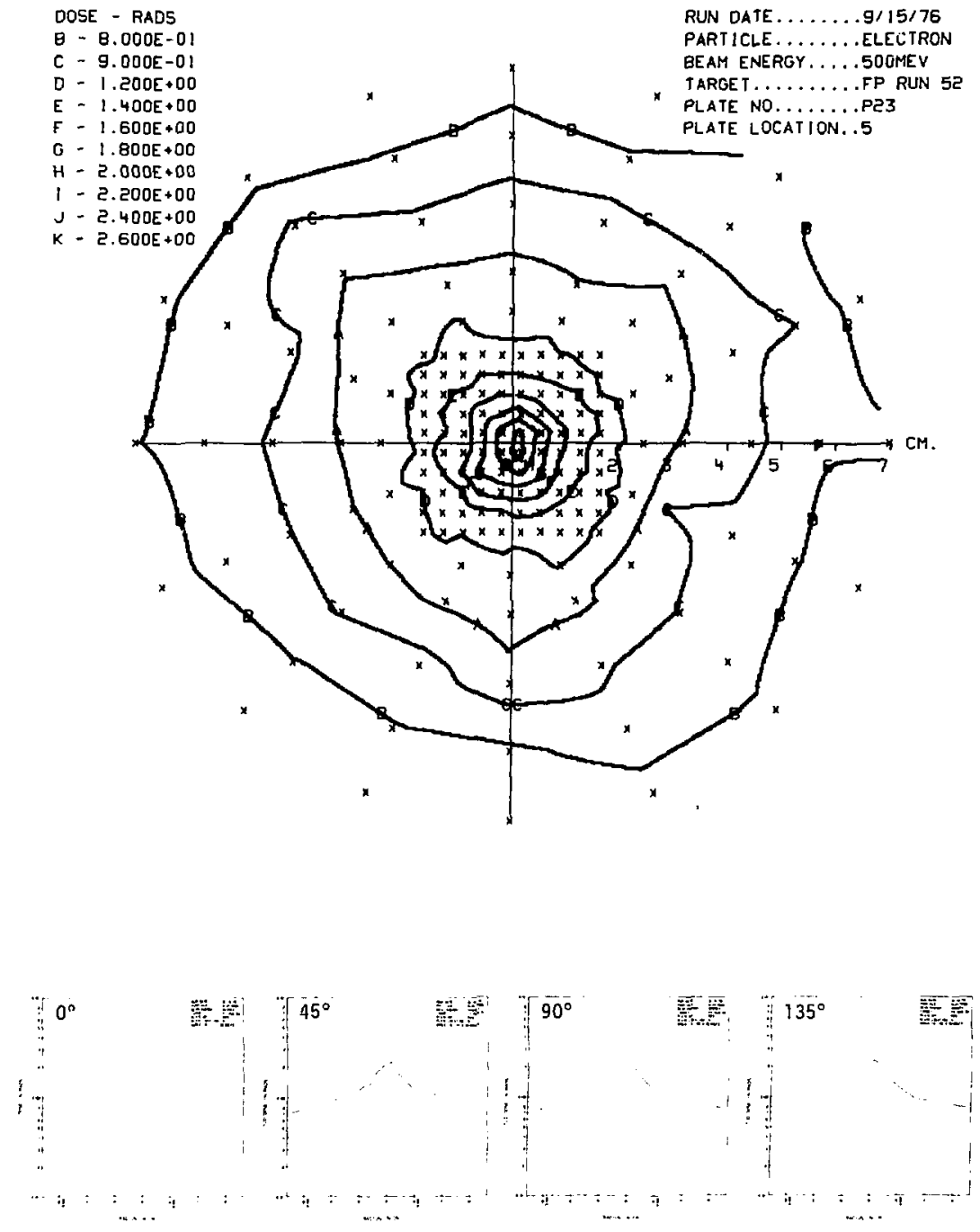

Fin, A-26. 

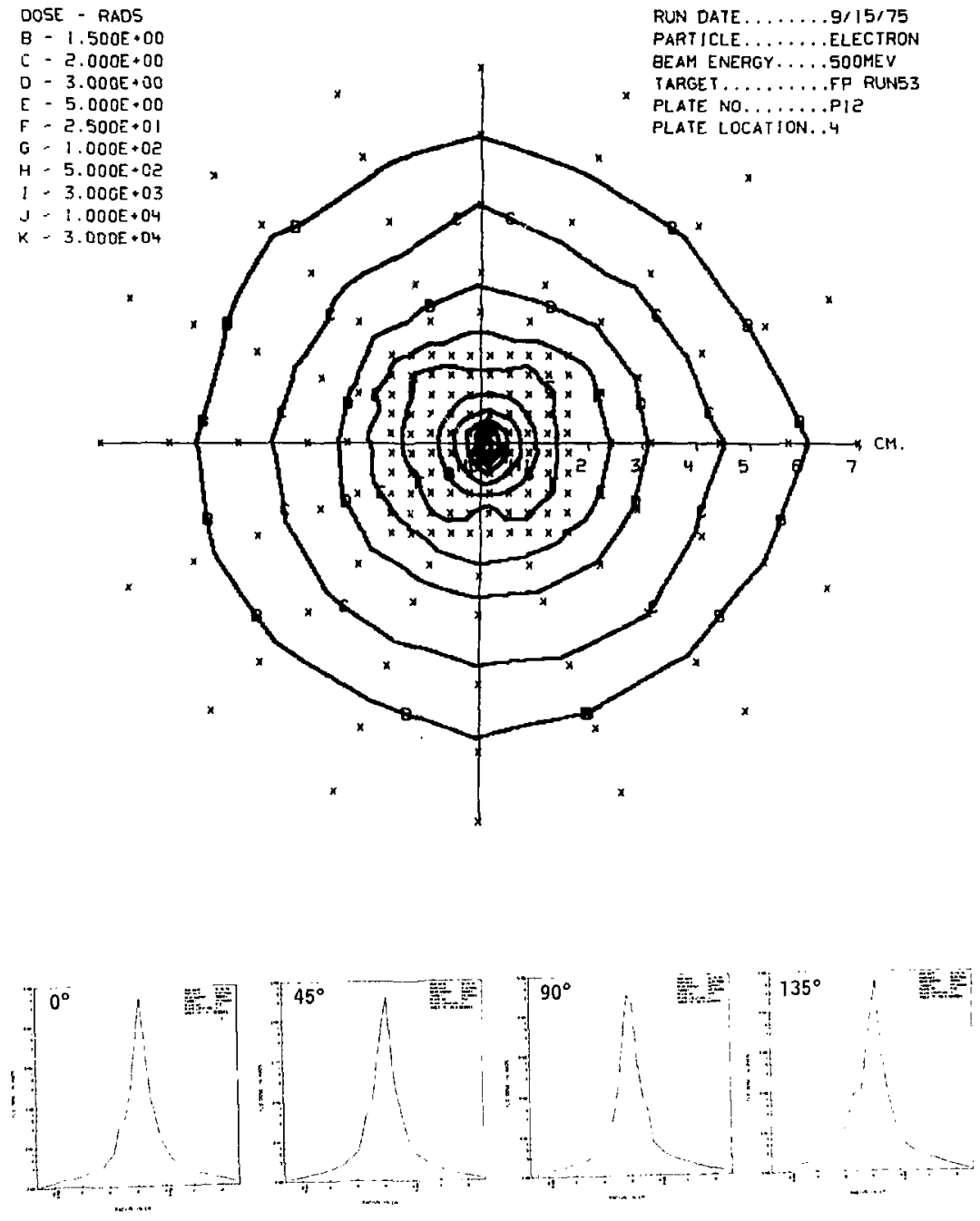

Fin. A-27, 

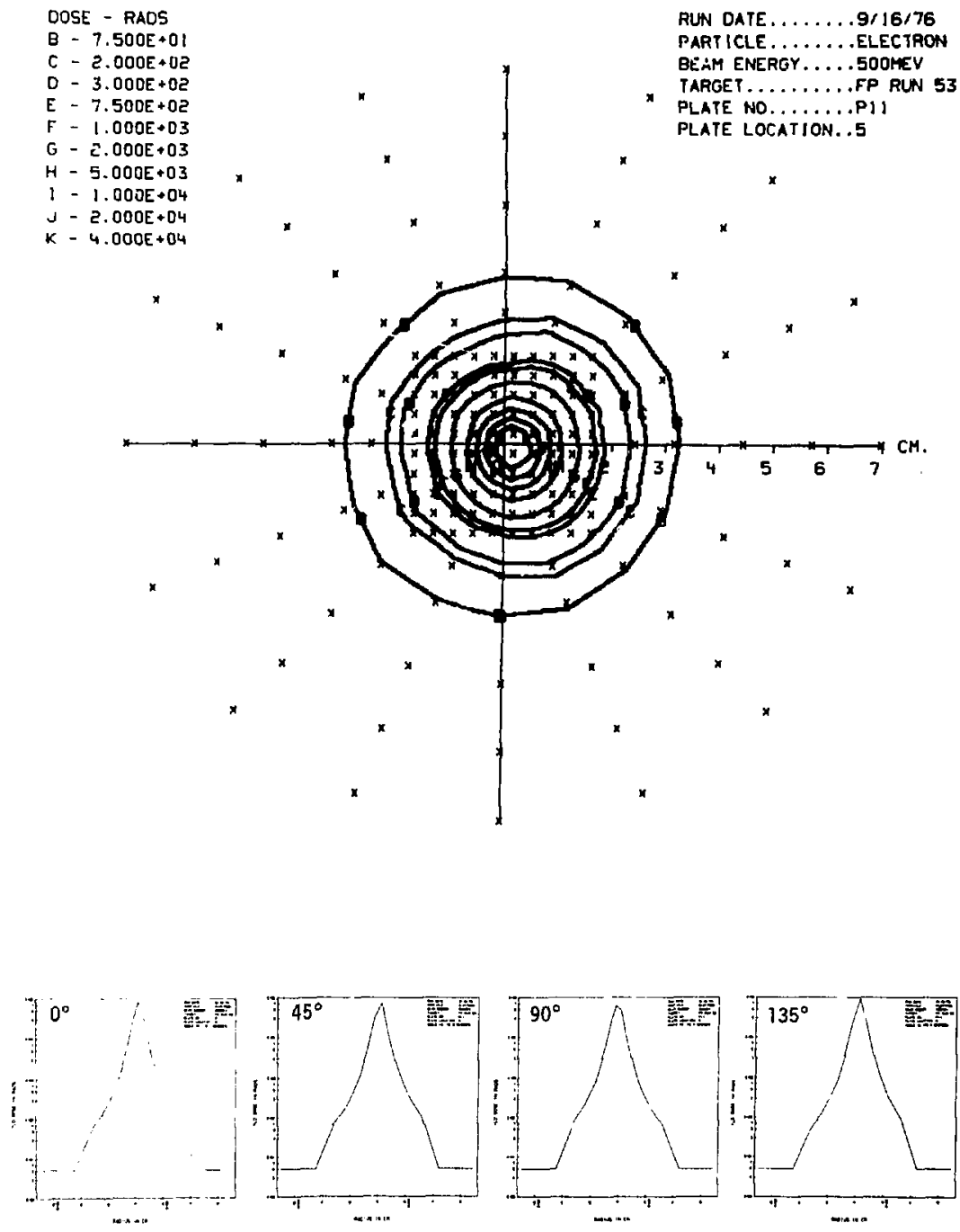

Fig, A-28. 

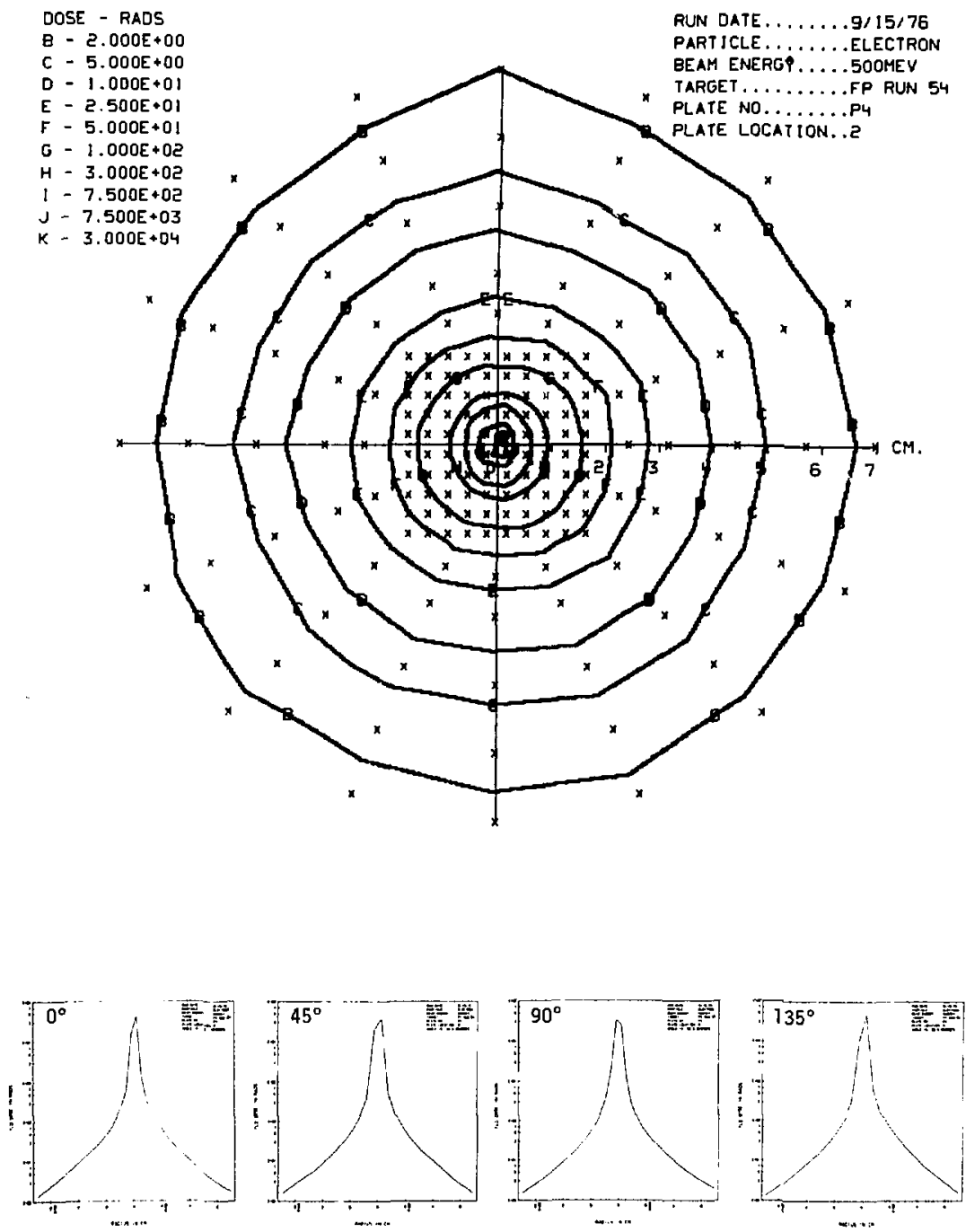

Fig. A-29. 

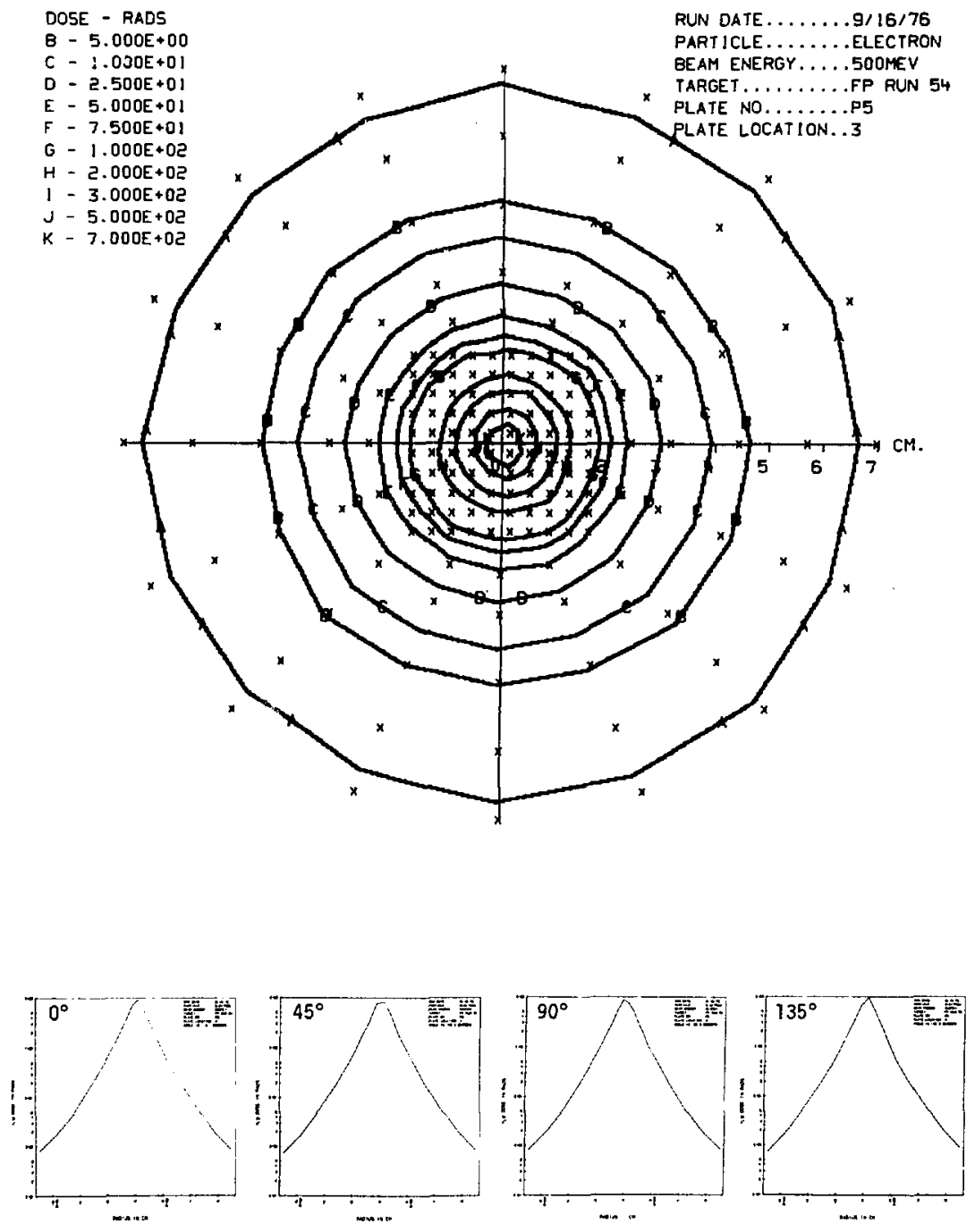

Fis. A-30, 

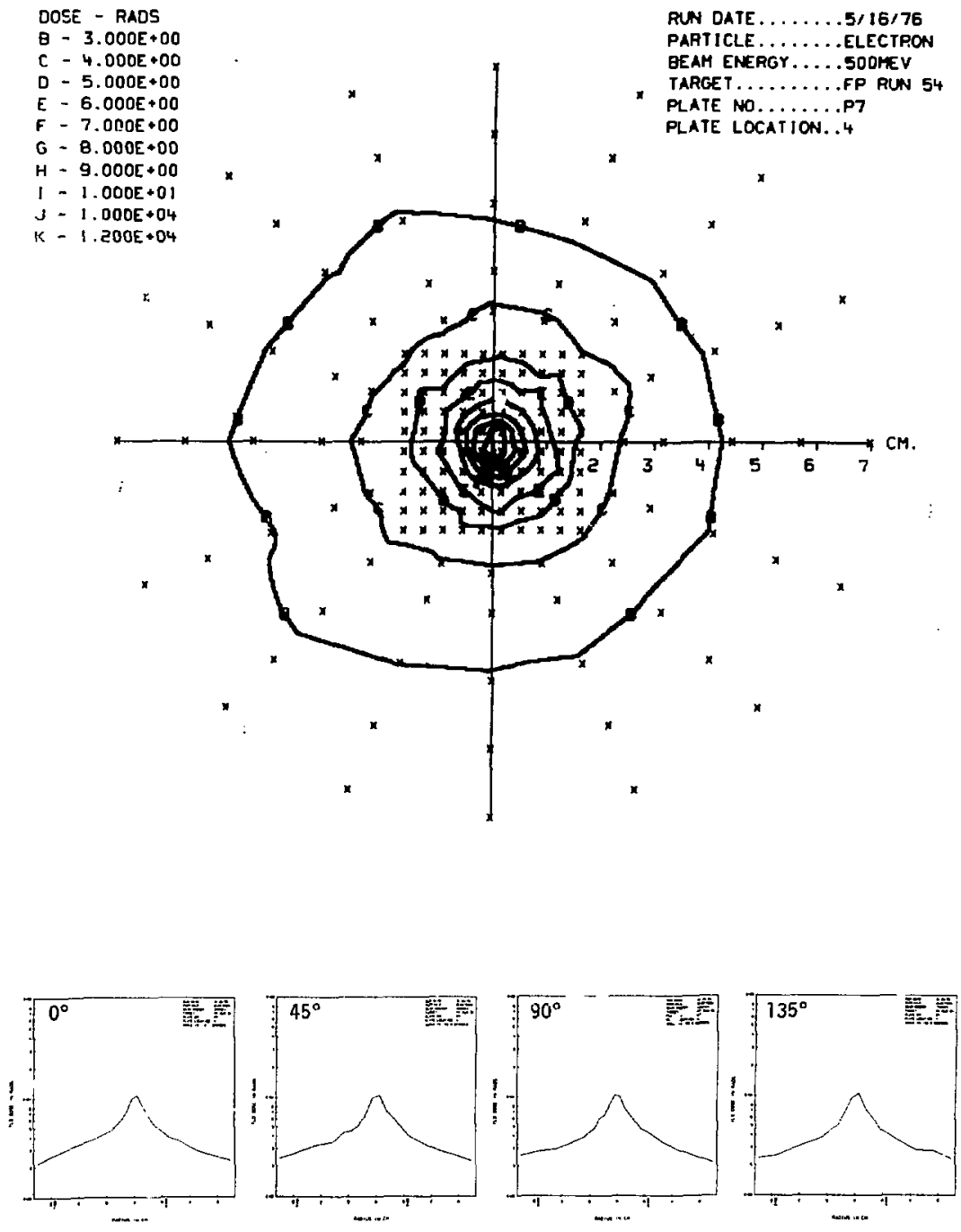

Fis. A-31, 

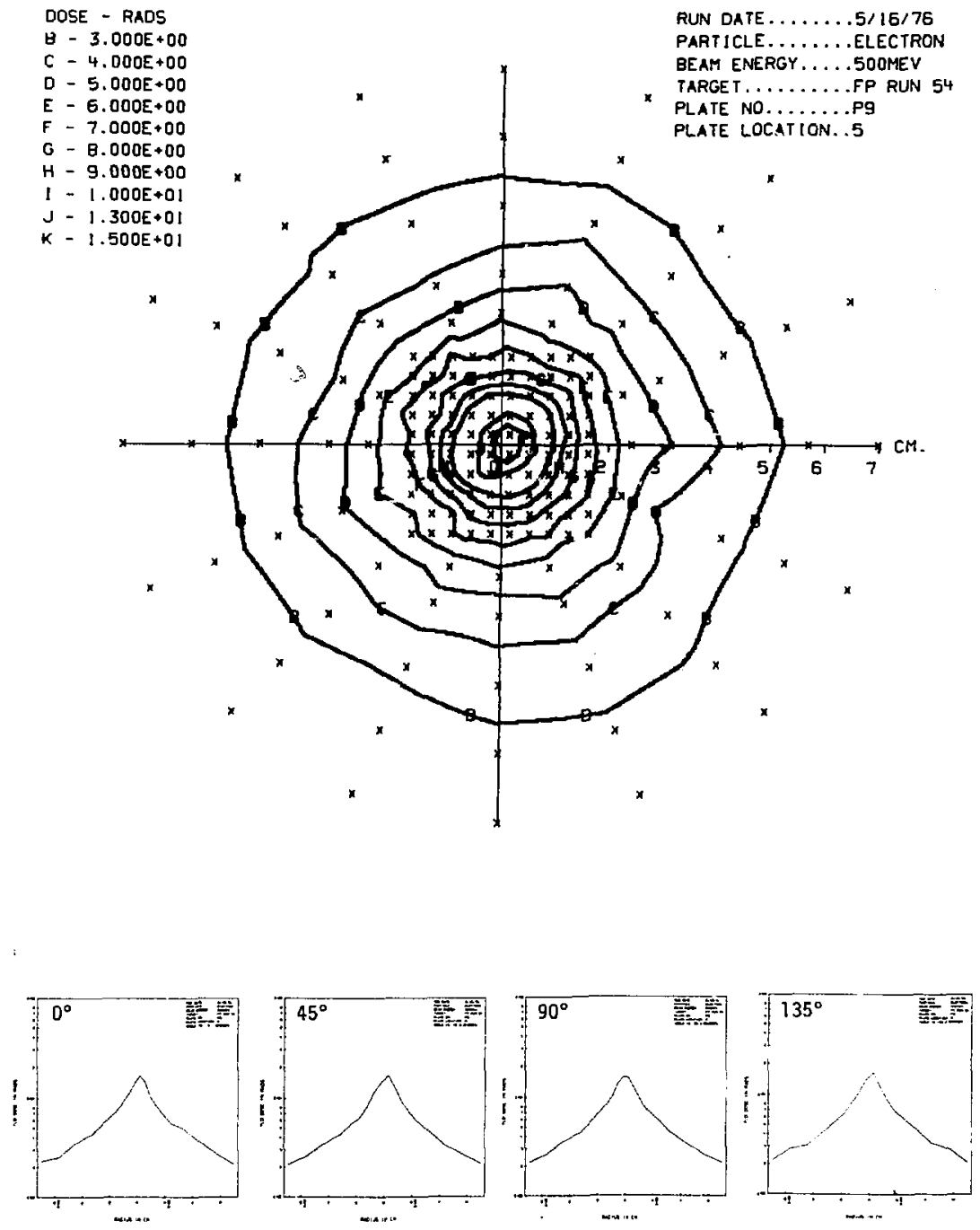

Fis. A-32. 

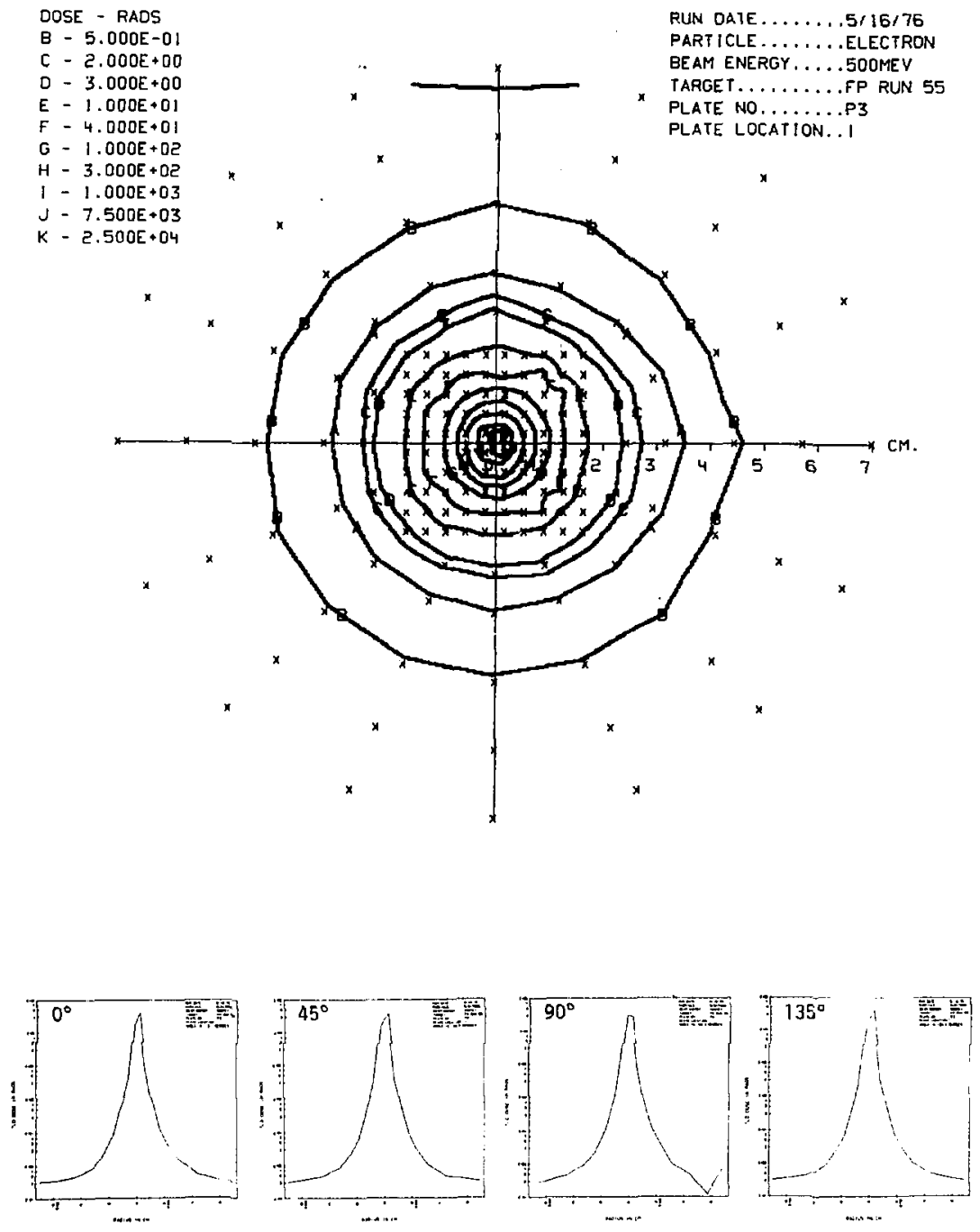

Fib. A-33. 

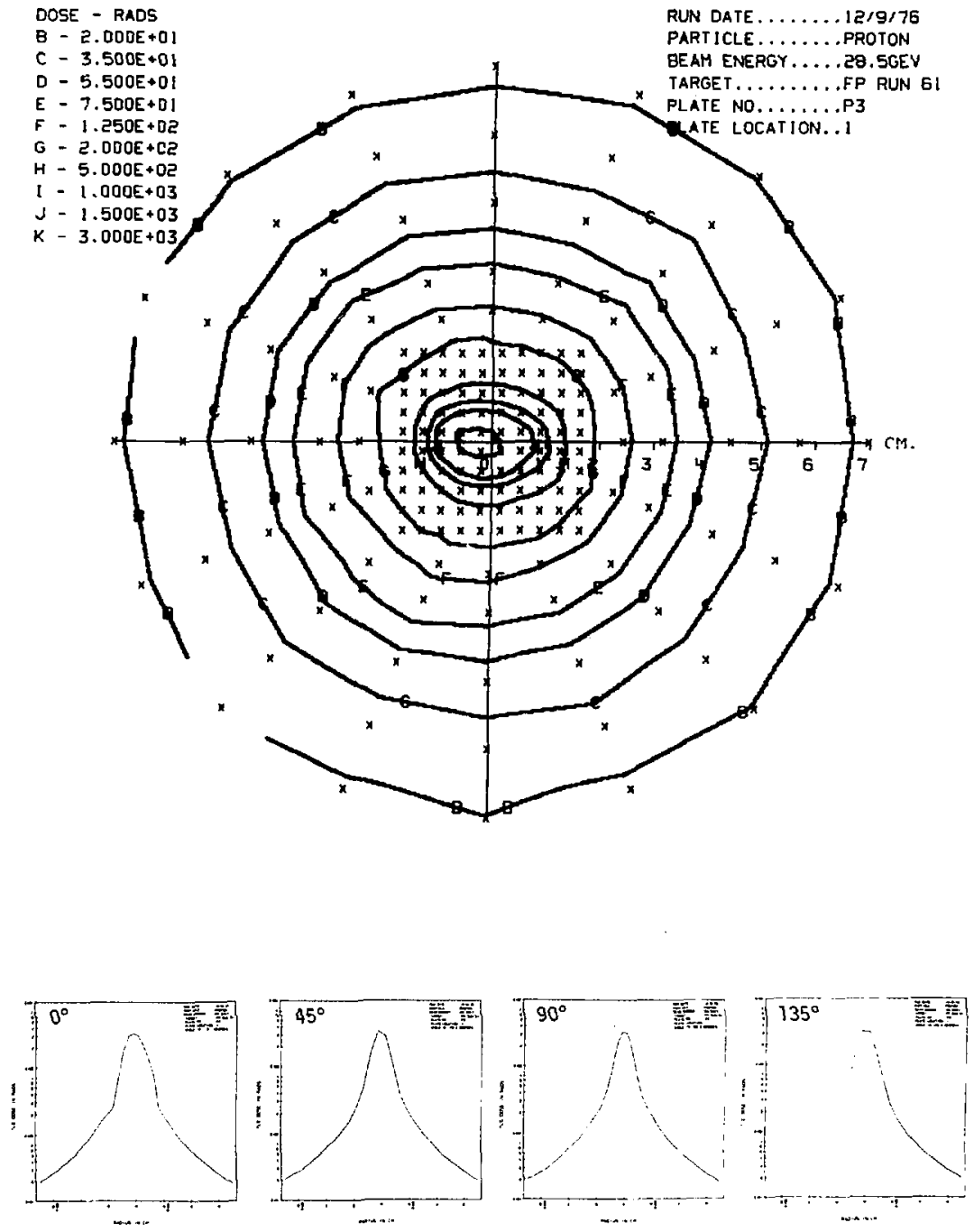

Fis, A-34. 

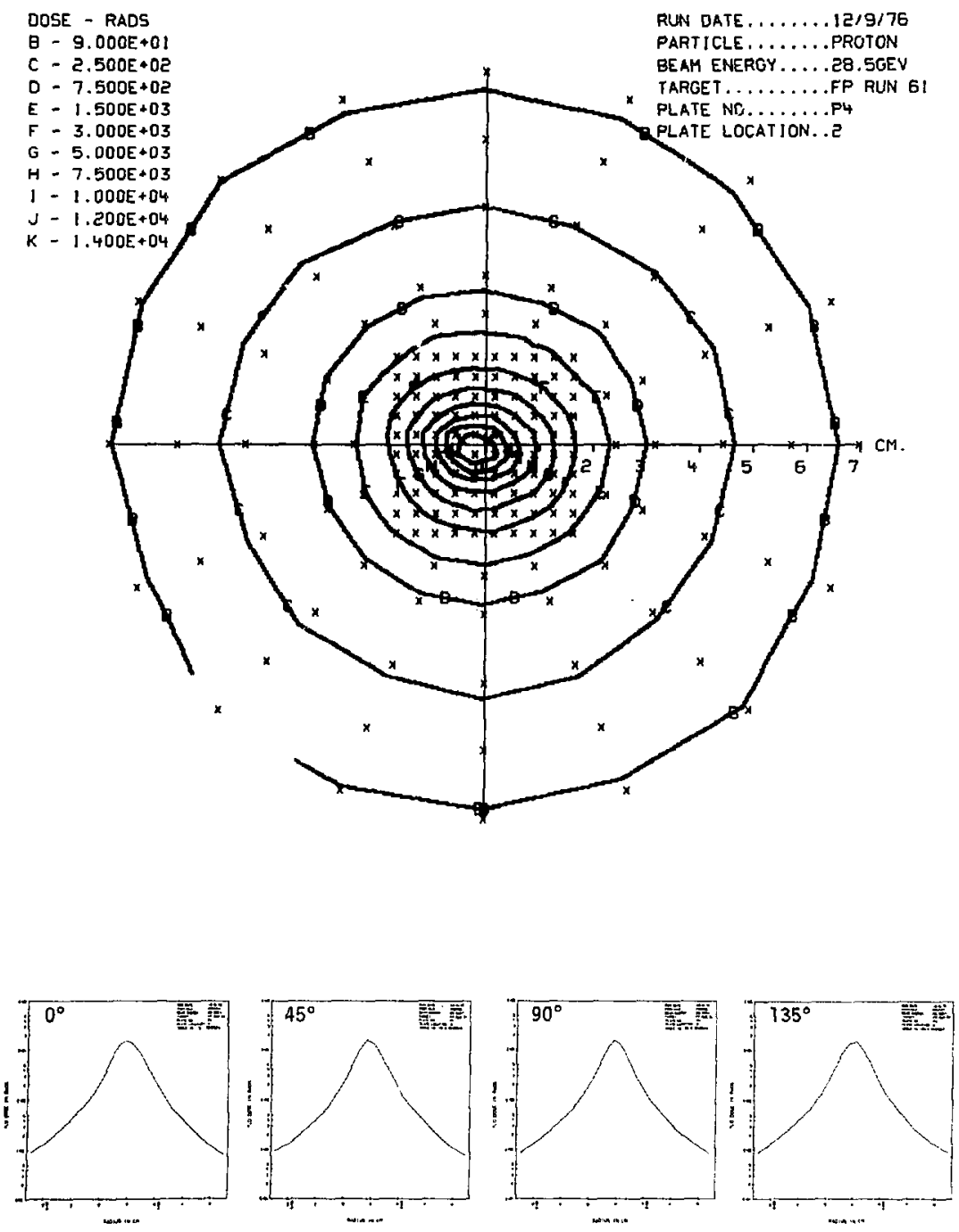

Fig. A-35. 

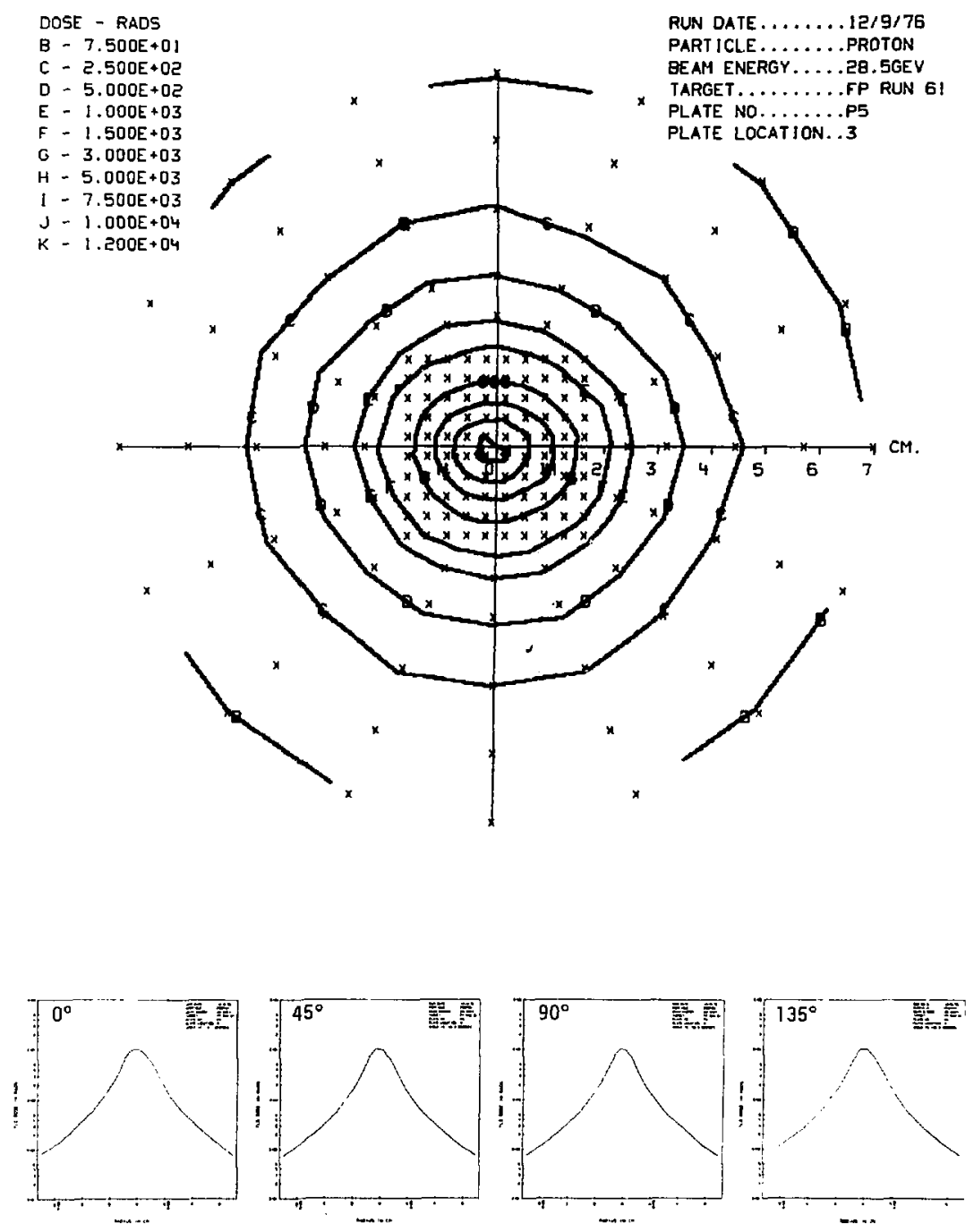

Fis. A-36. 

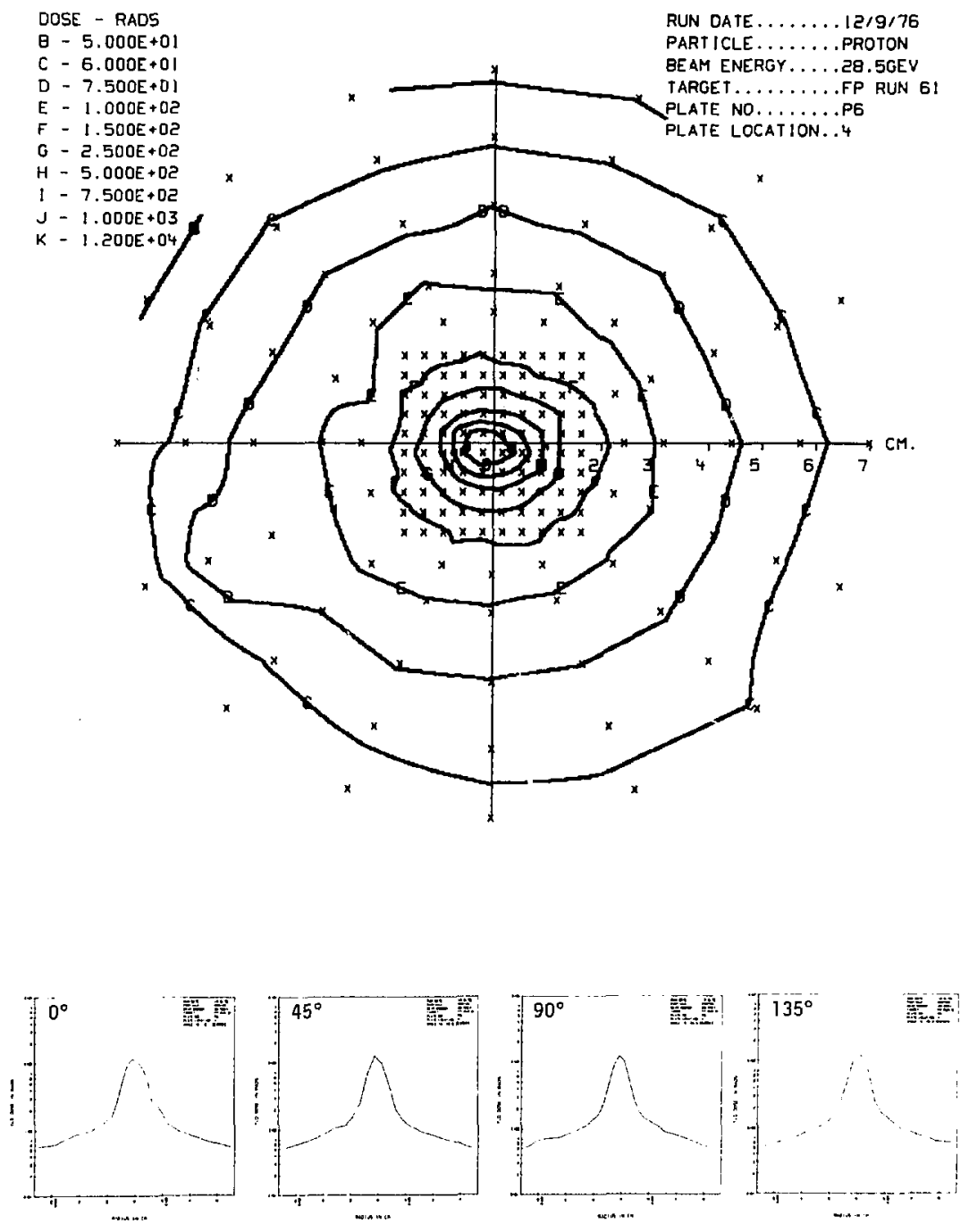

Flg- A-37. 

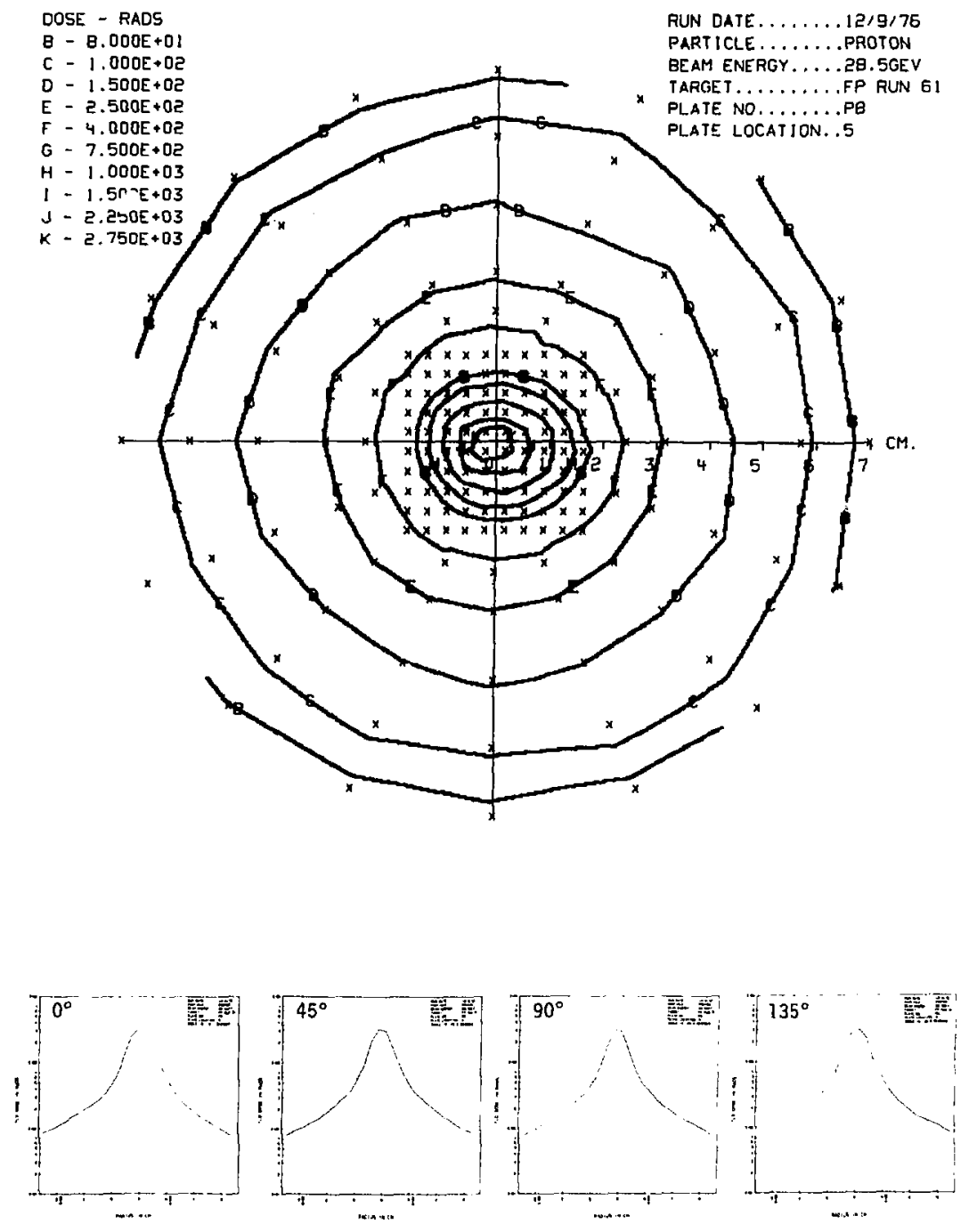

Fis. A-38. 

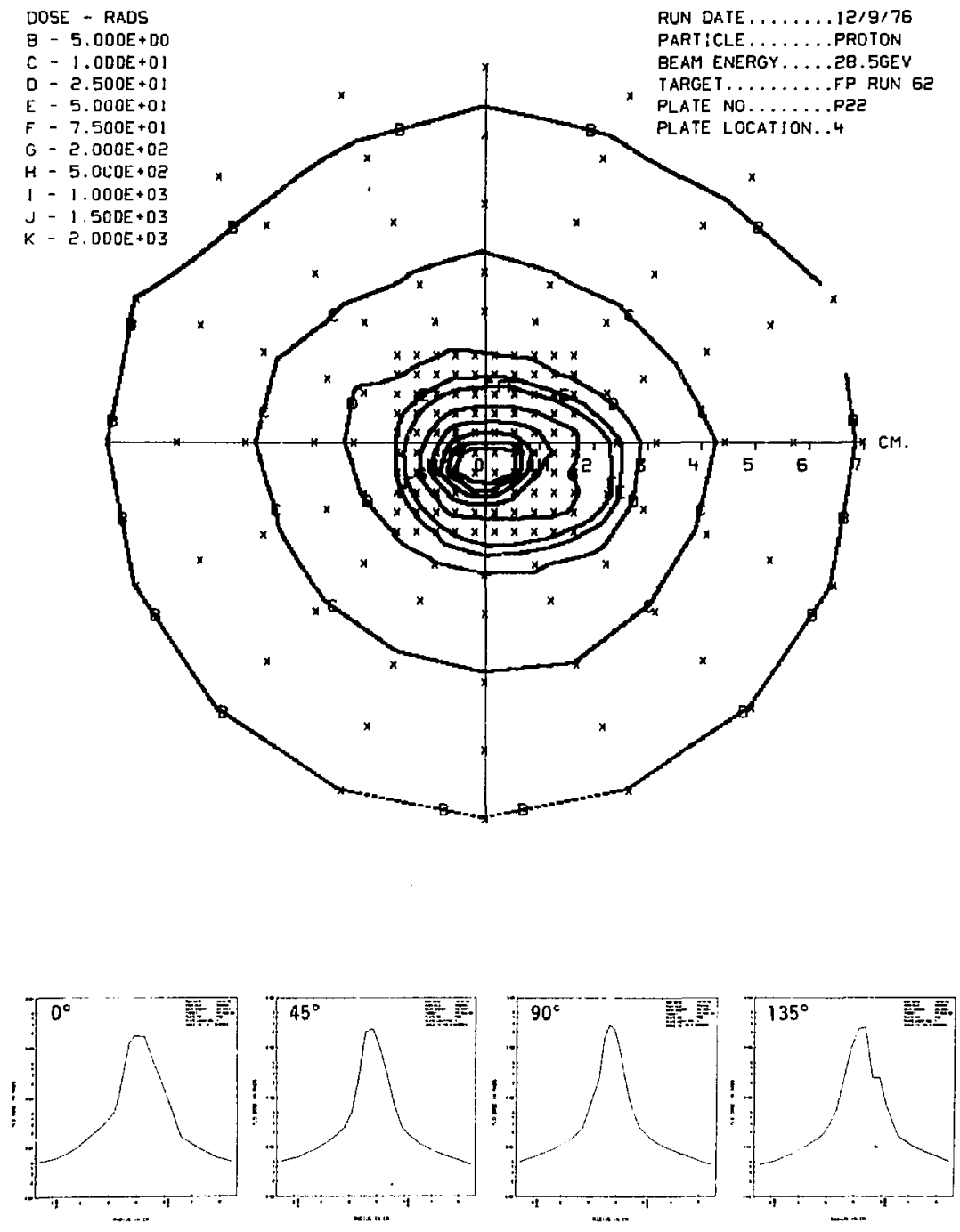

Fis. A-39. 

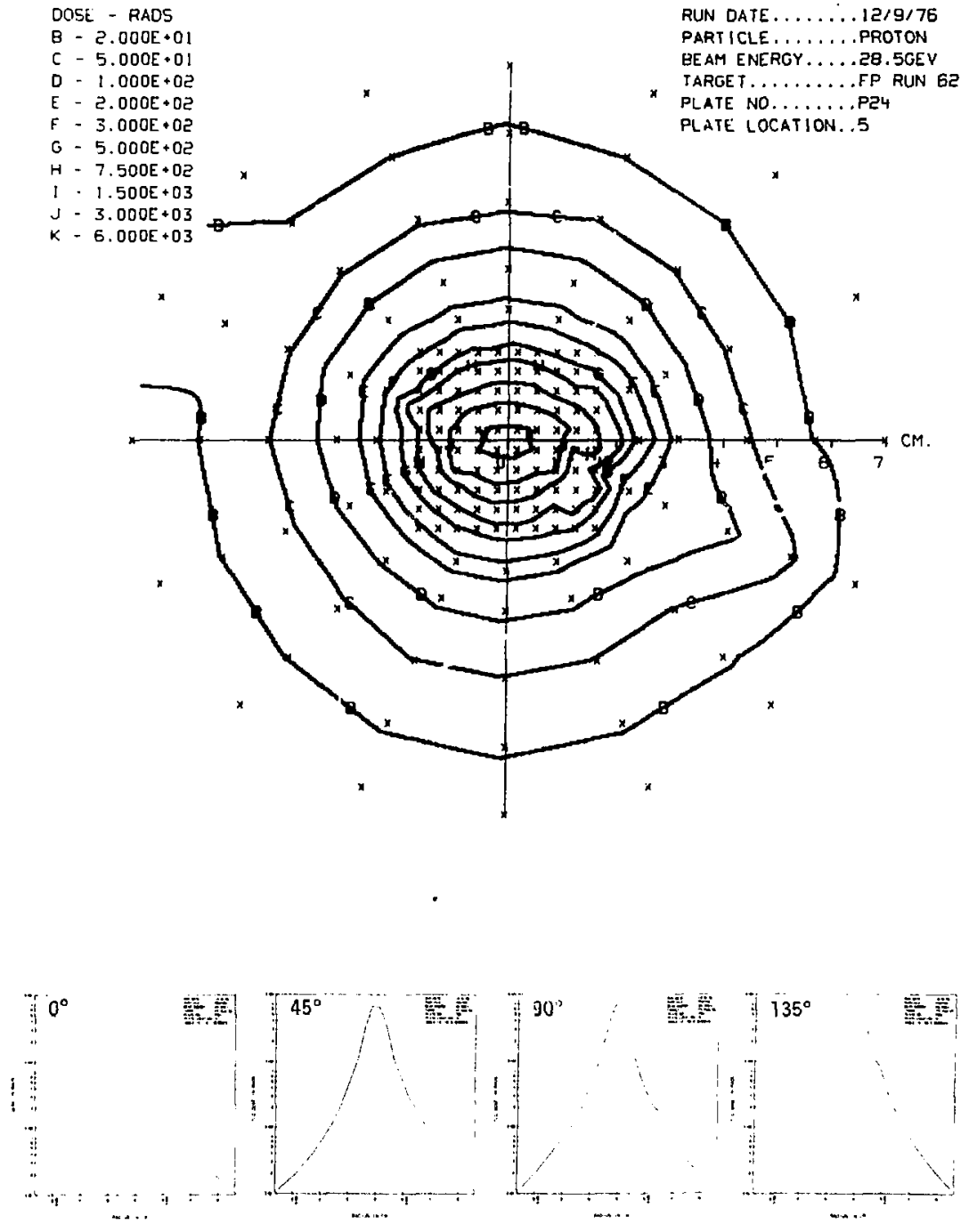

Fis. A-40. 

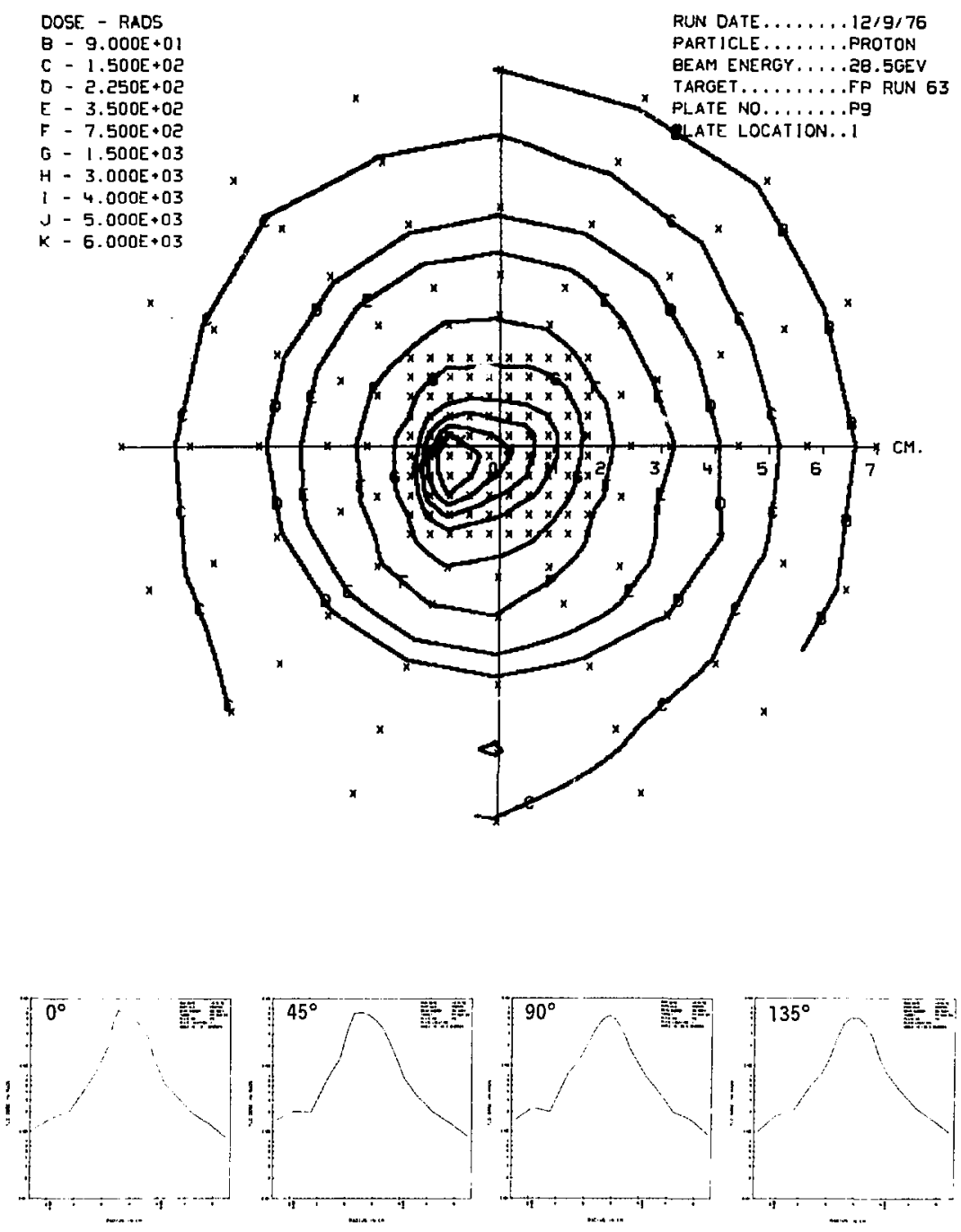

Fit. A-41. 

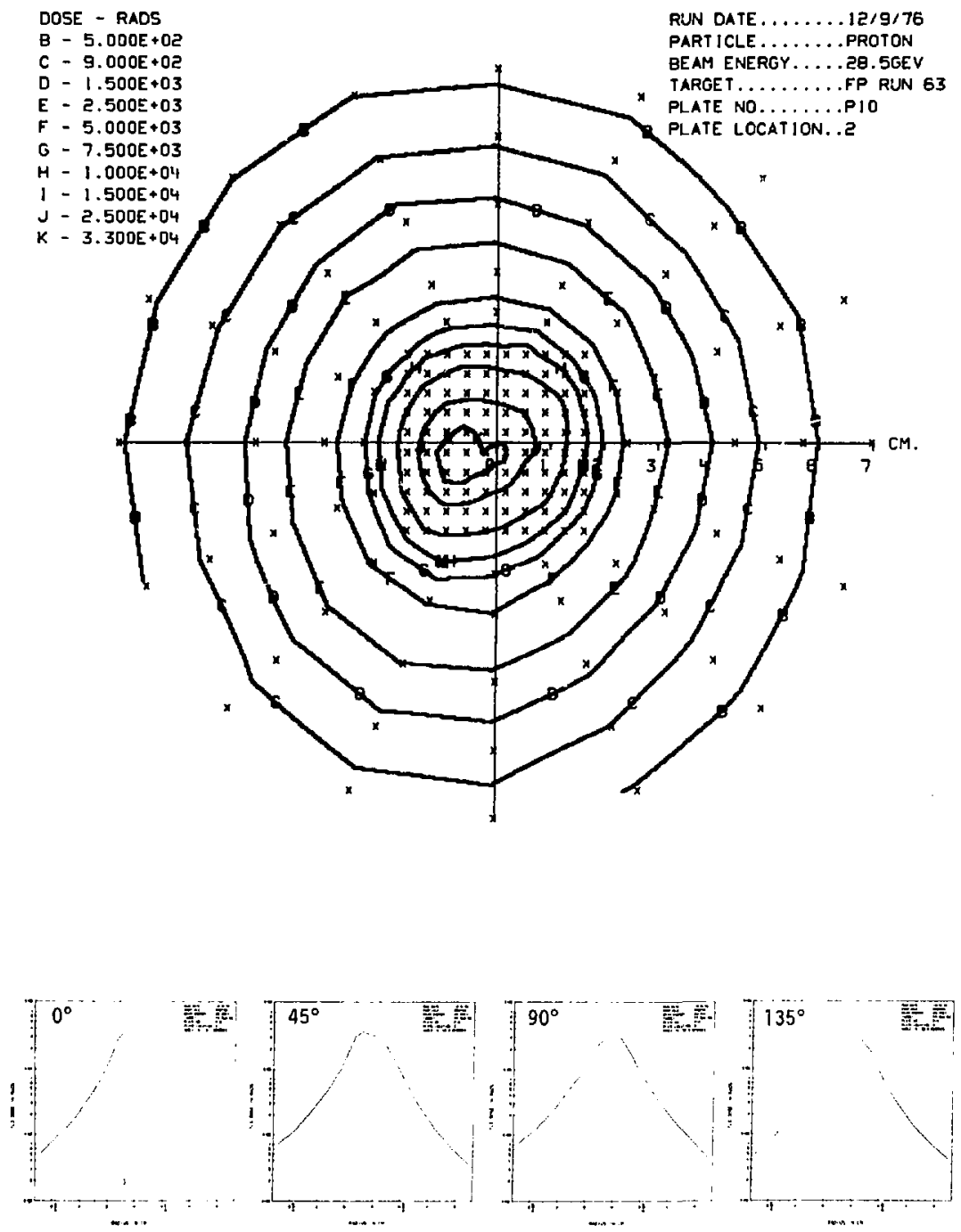

Fis. A-42. 

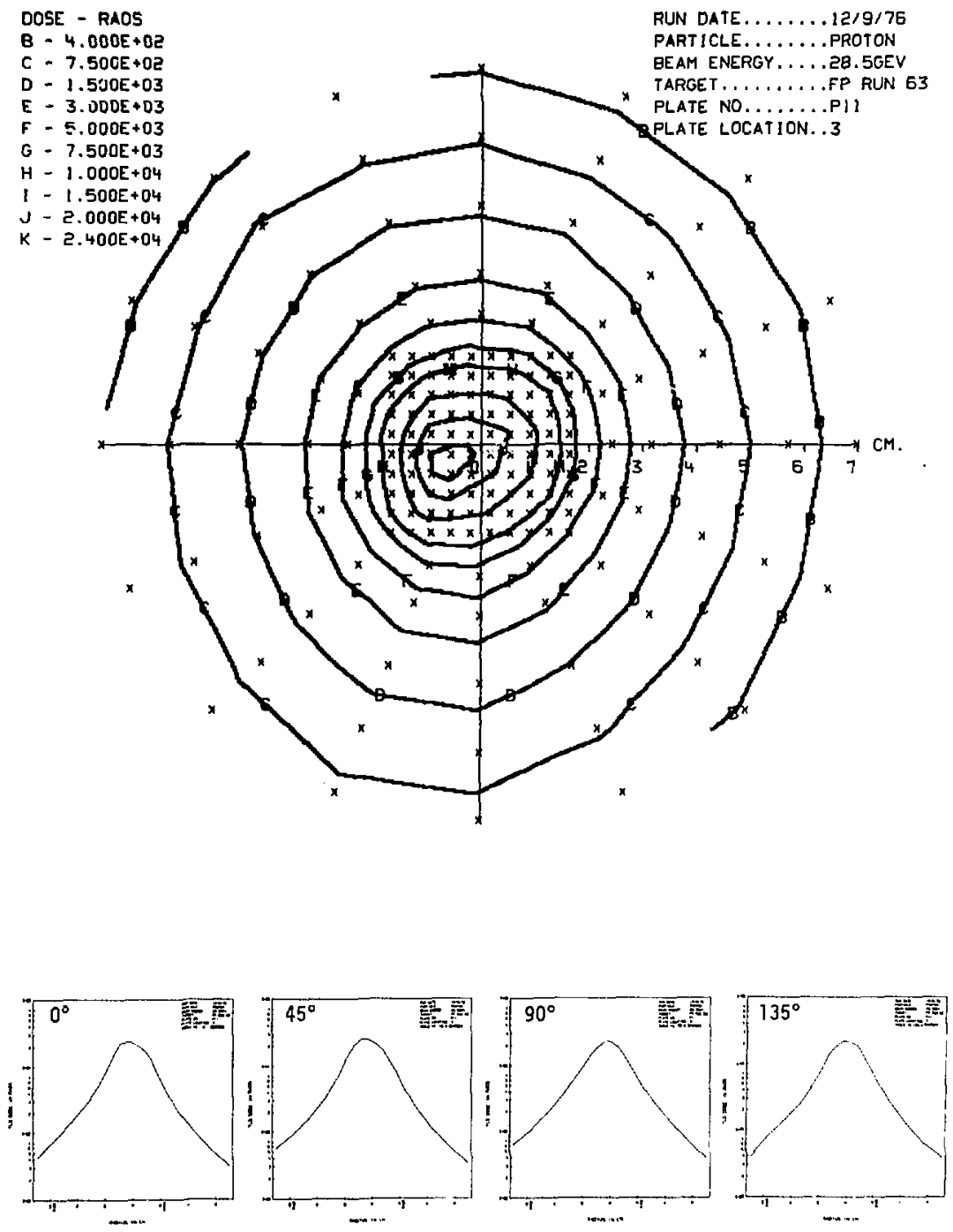

Fite. A-43. 

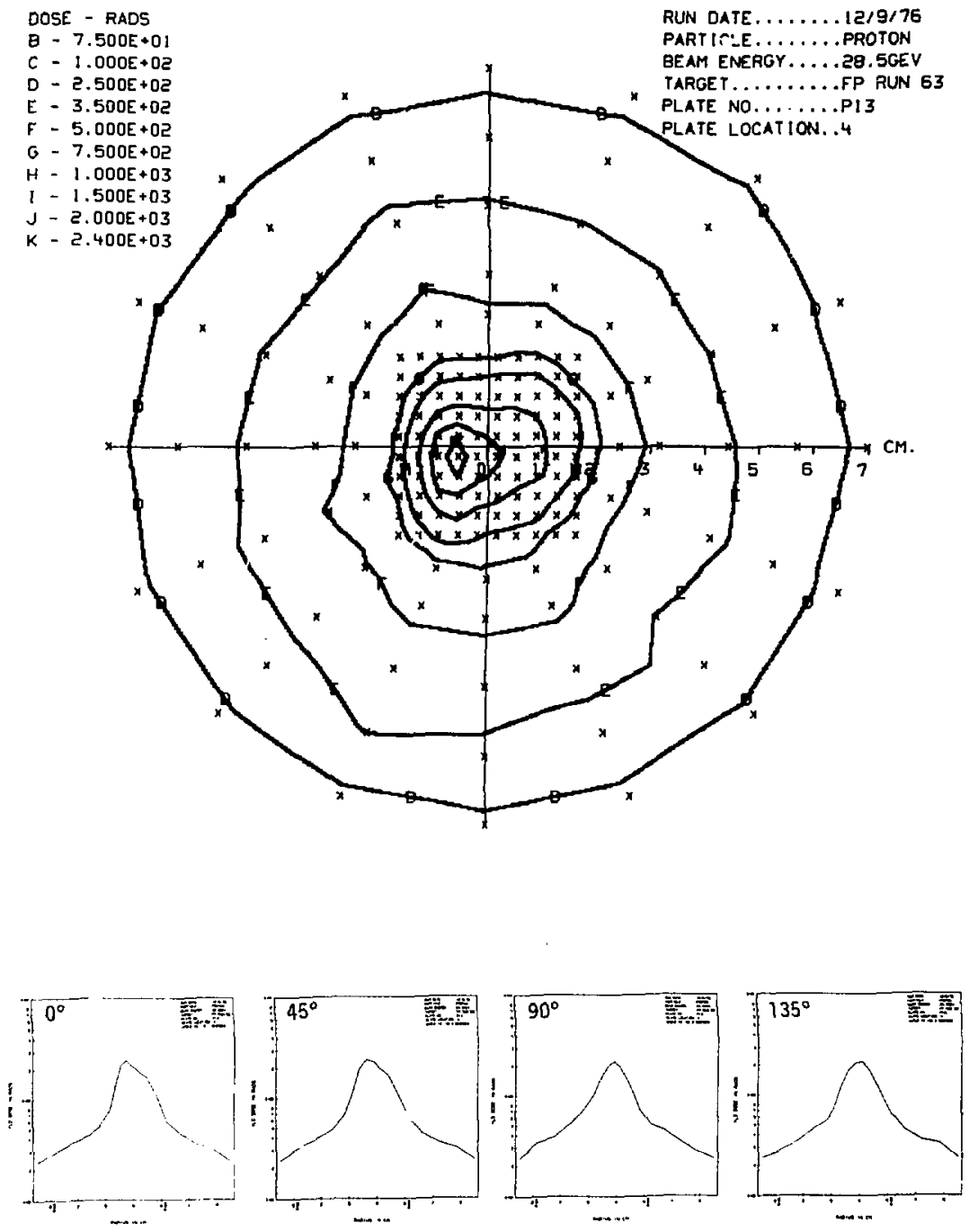

Fig. A-44. 

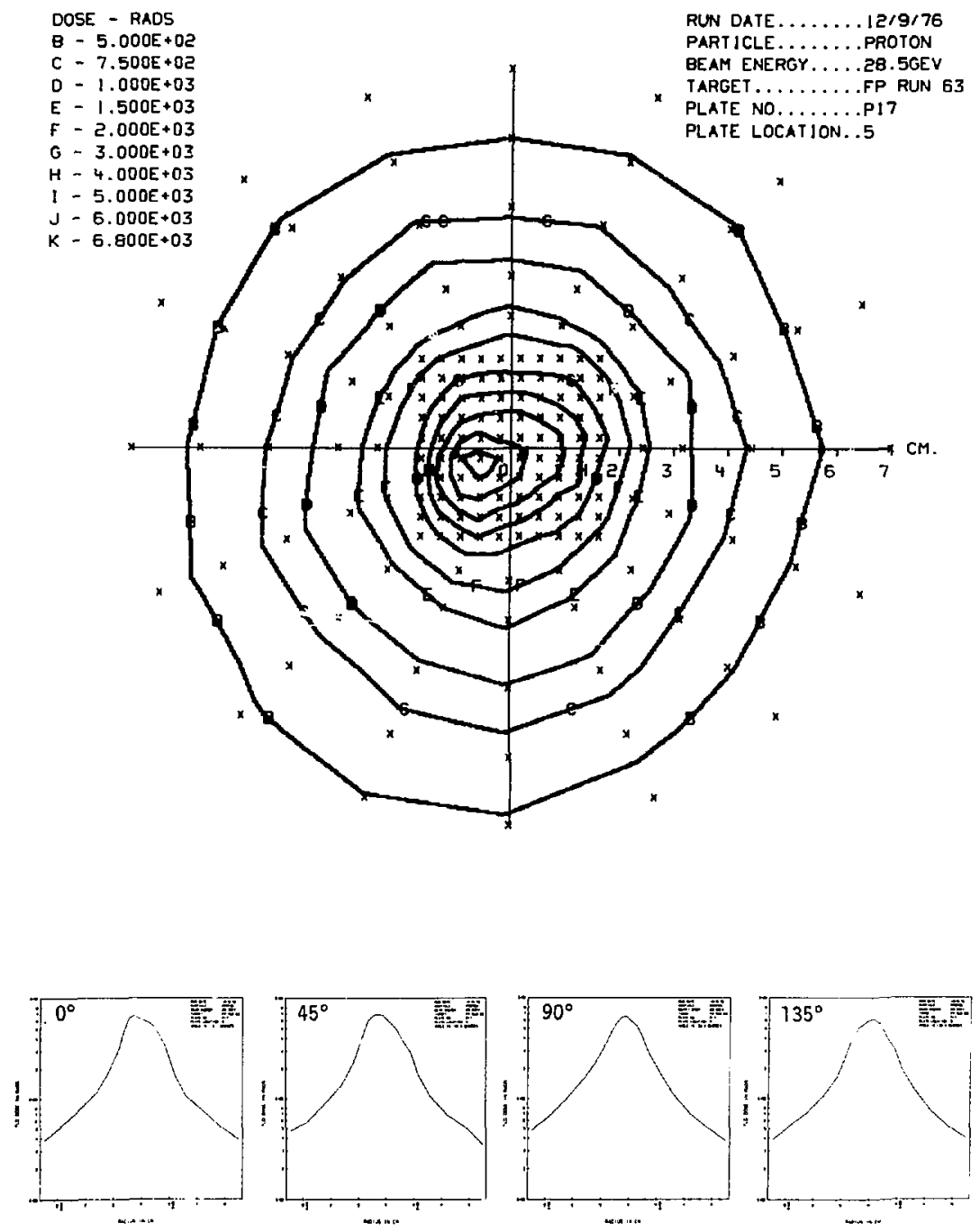

Fig, A-45. 

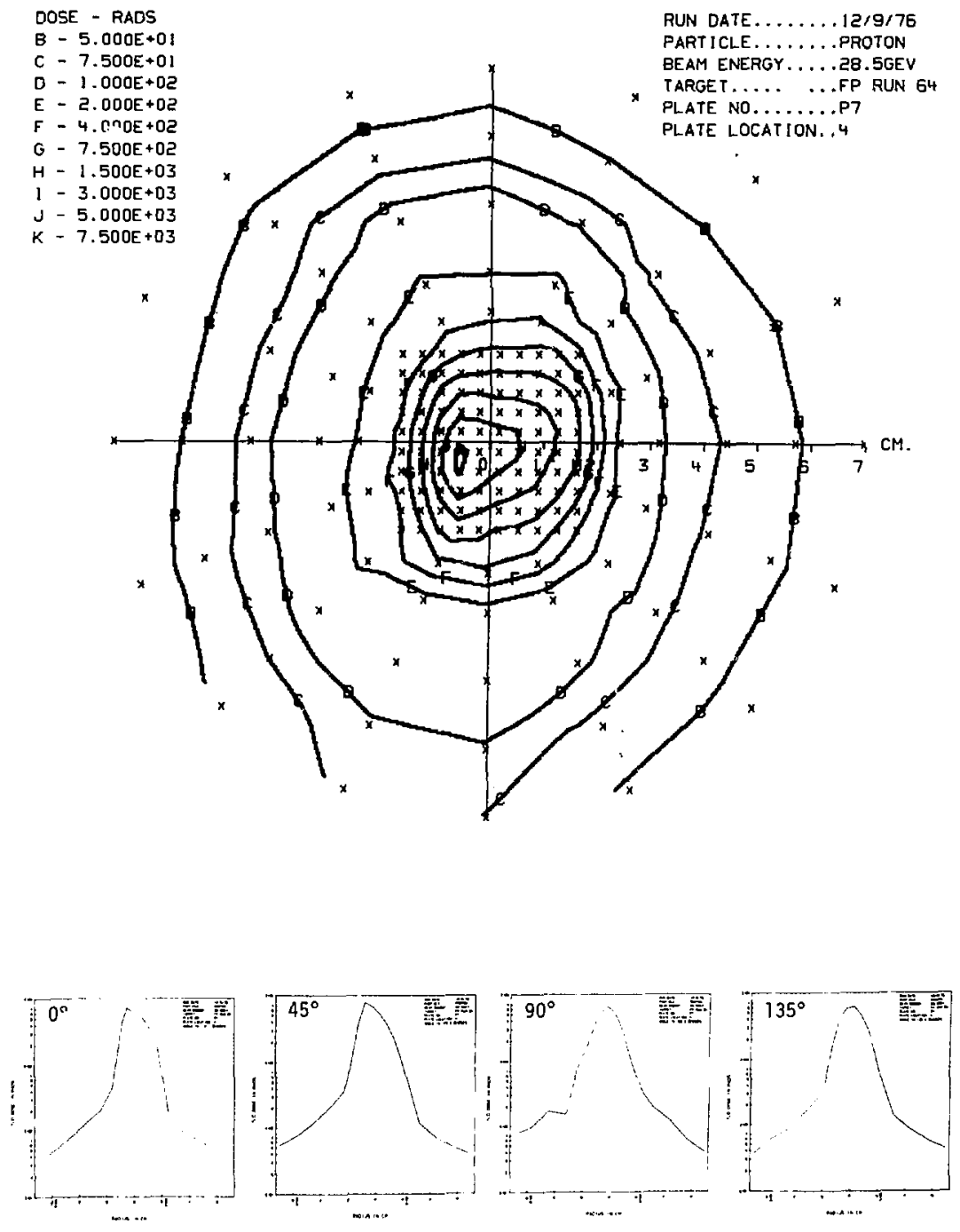

Fig. A-46. 

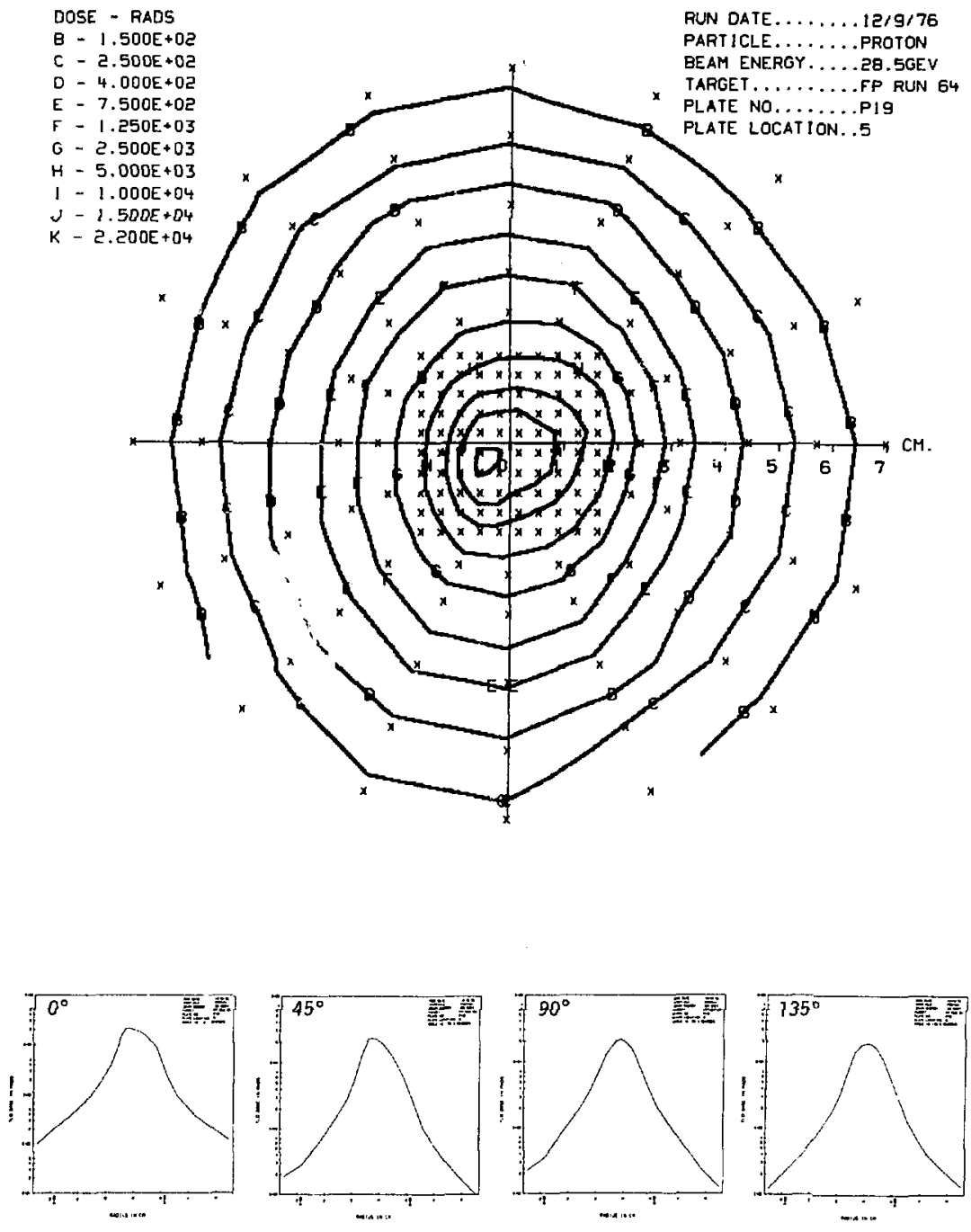

Fig. A-47. 

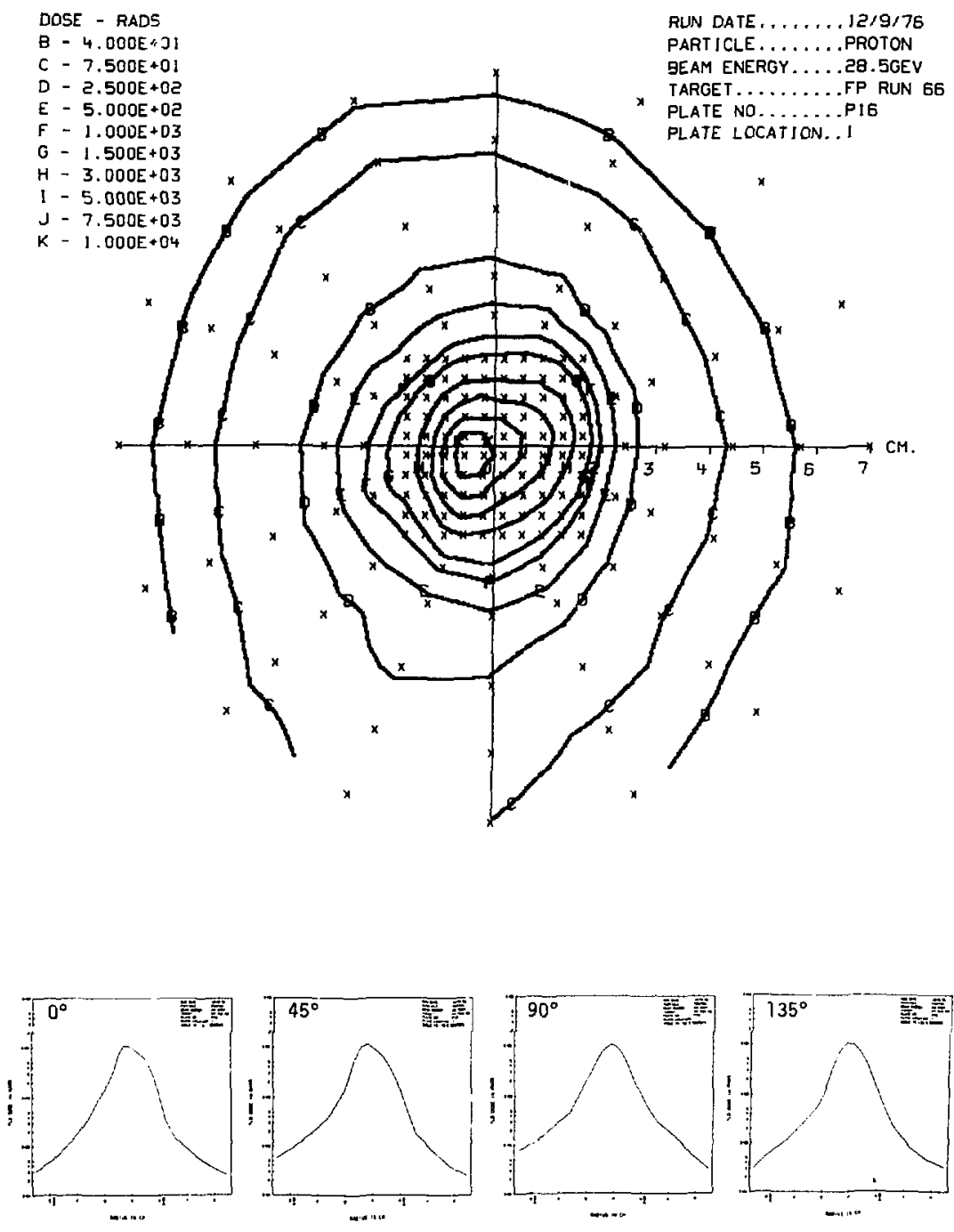

Fiz. A-48. 

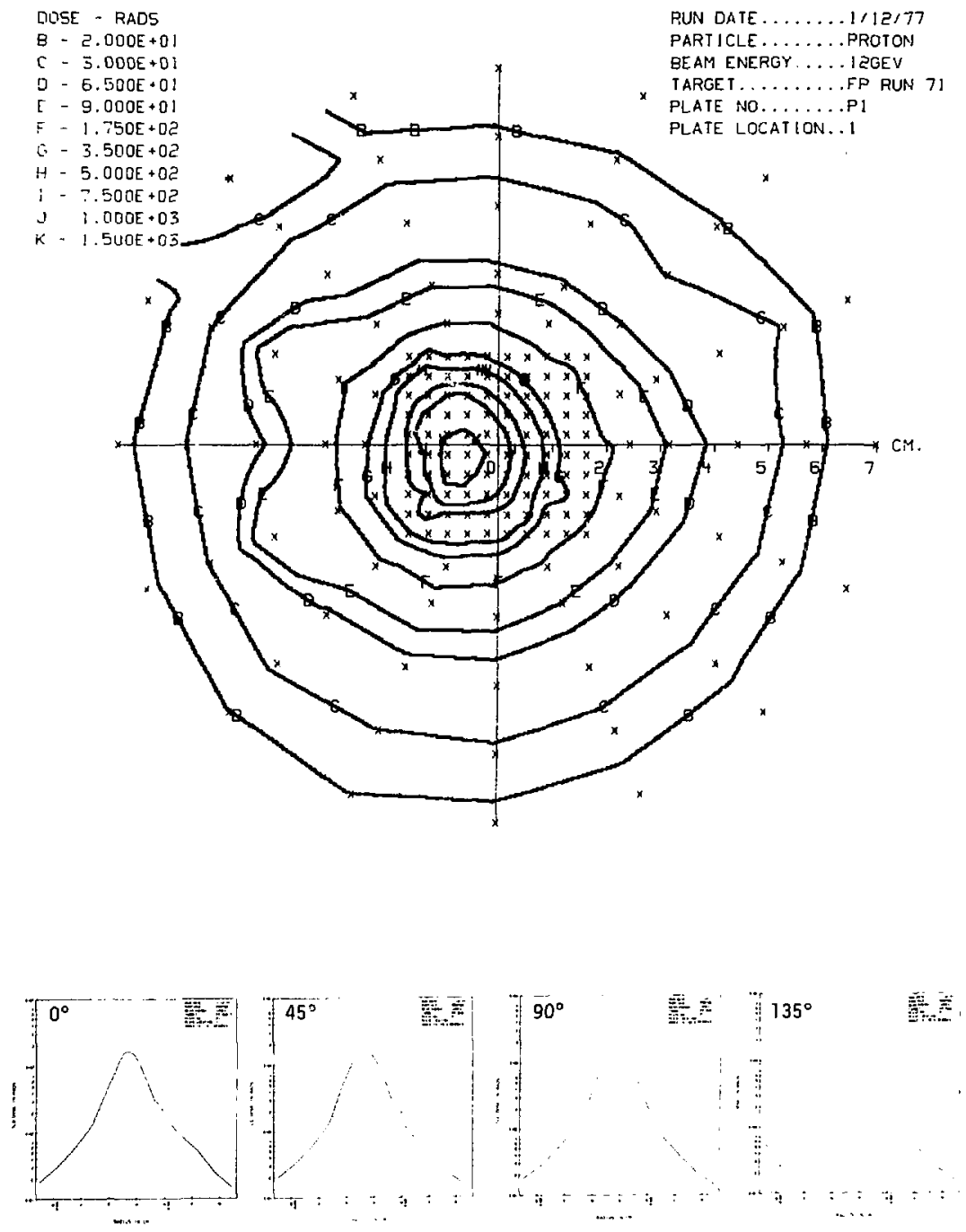

Fig. A 49 . 

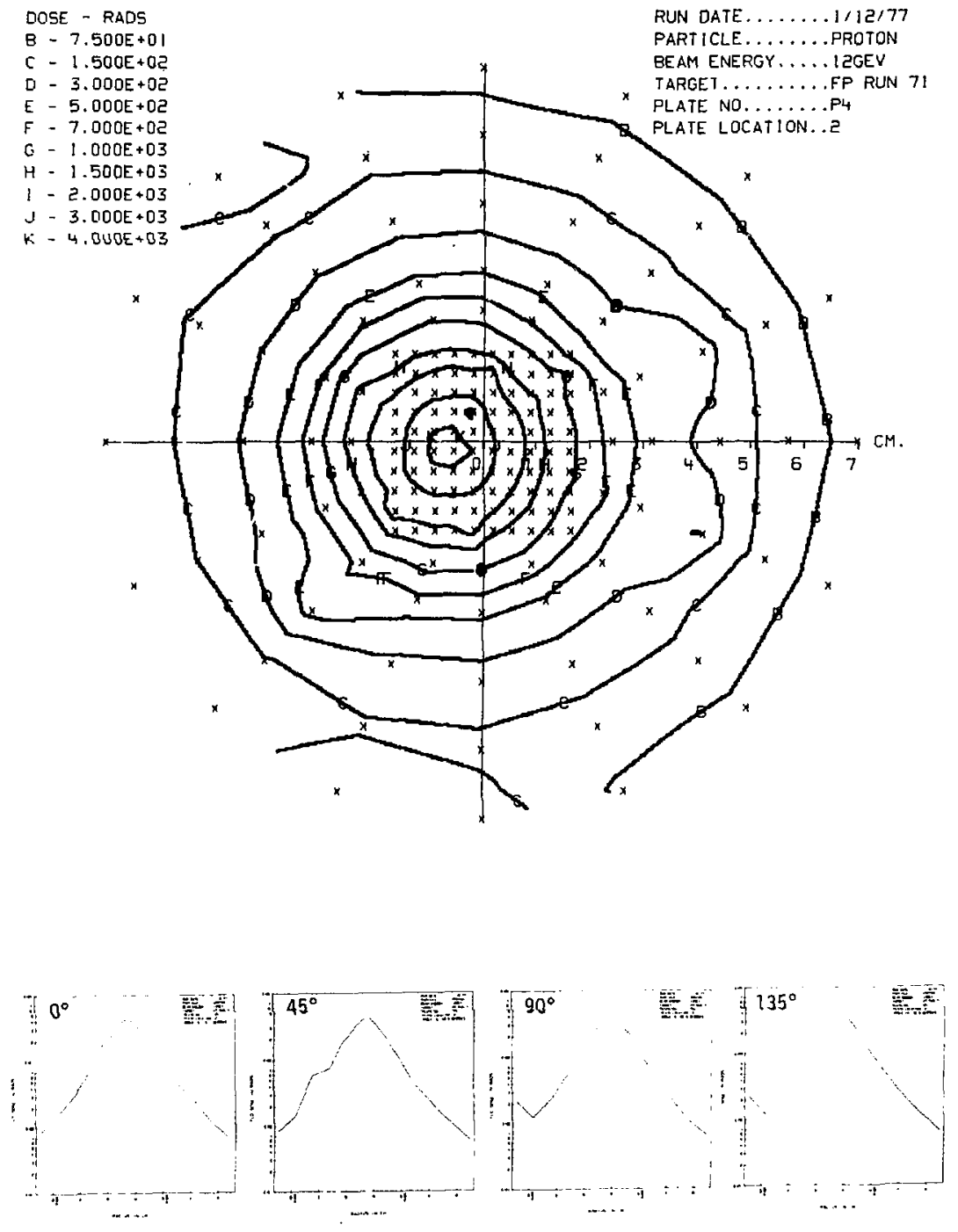

Fig. A-50). 

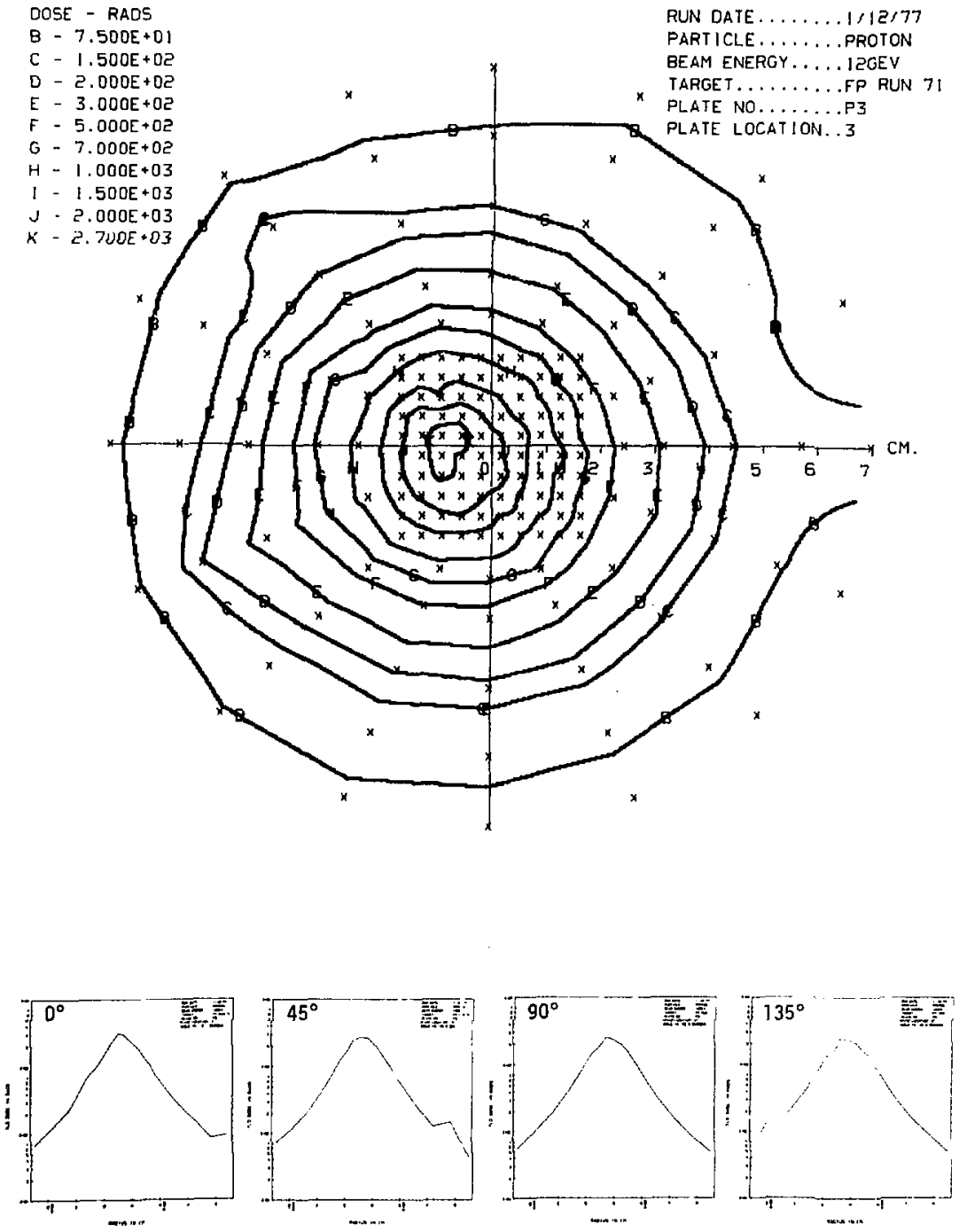

Fis, A-51, 

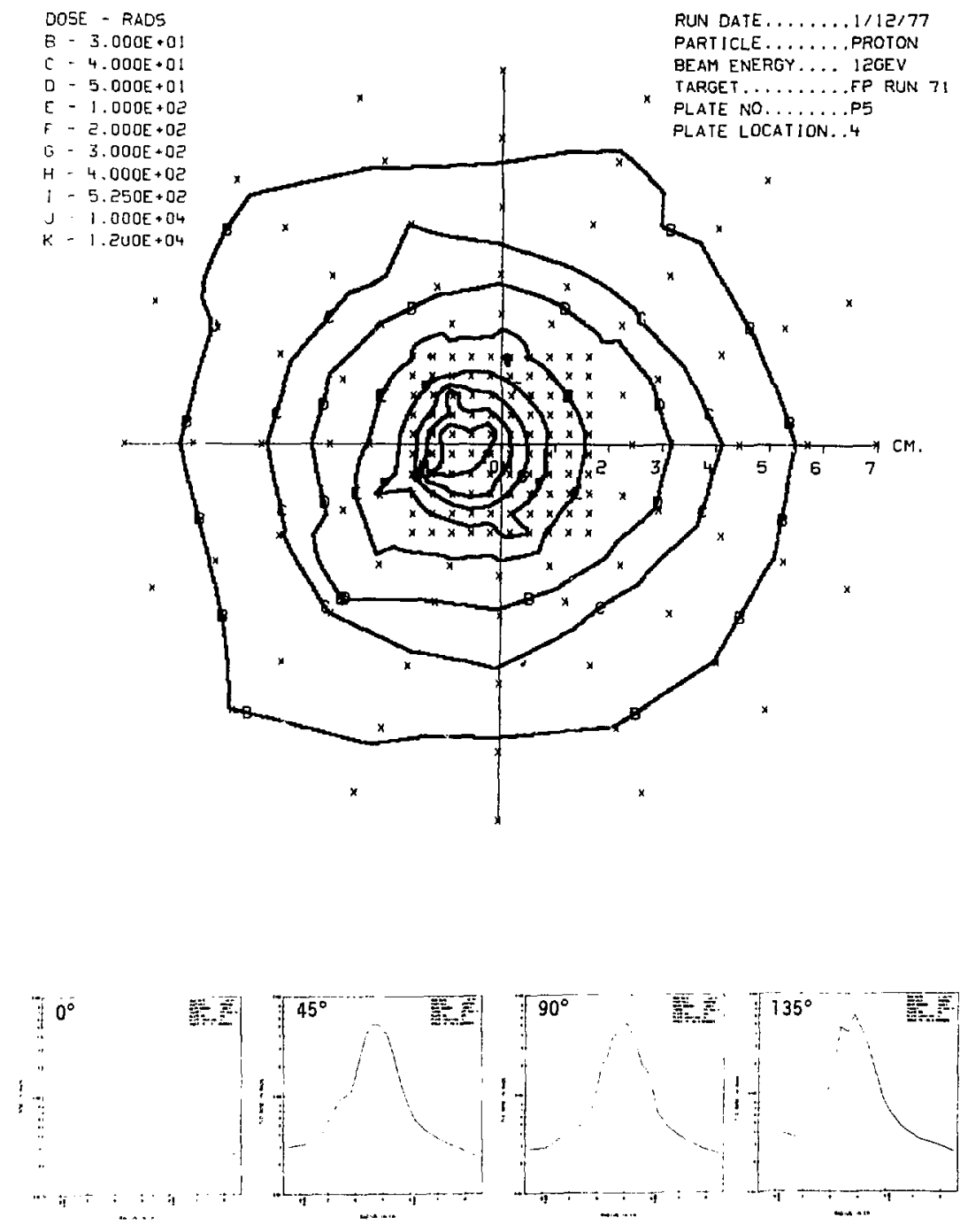

Fin. A-52. 

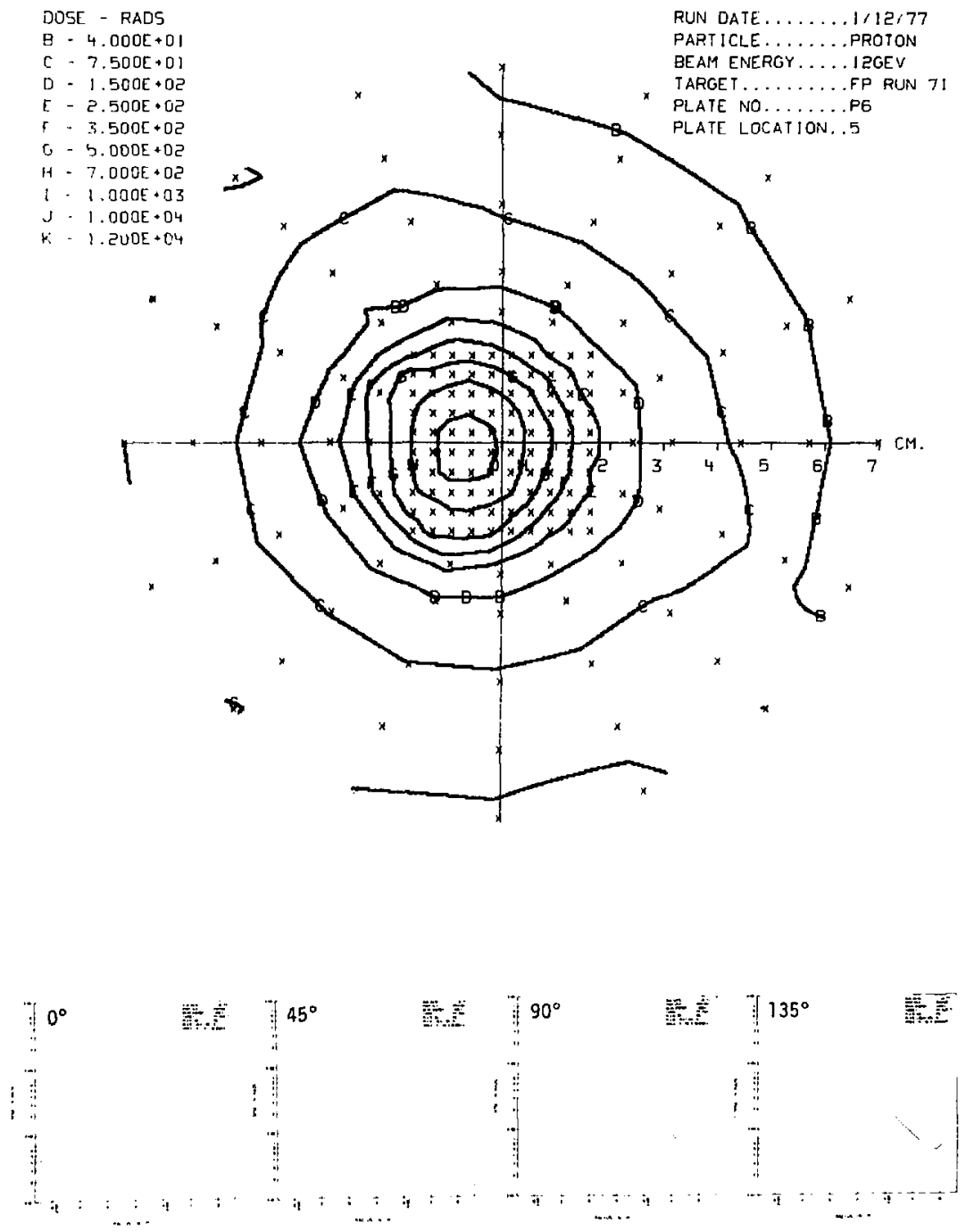

Fig. A-53. 

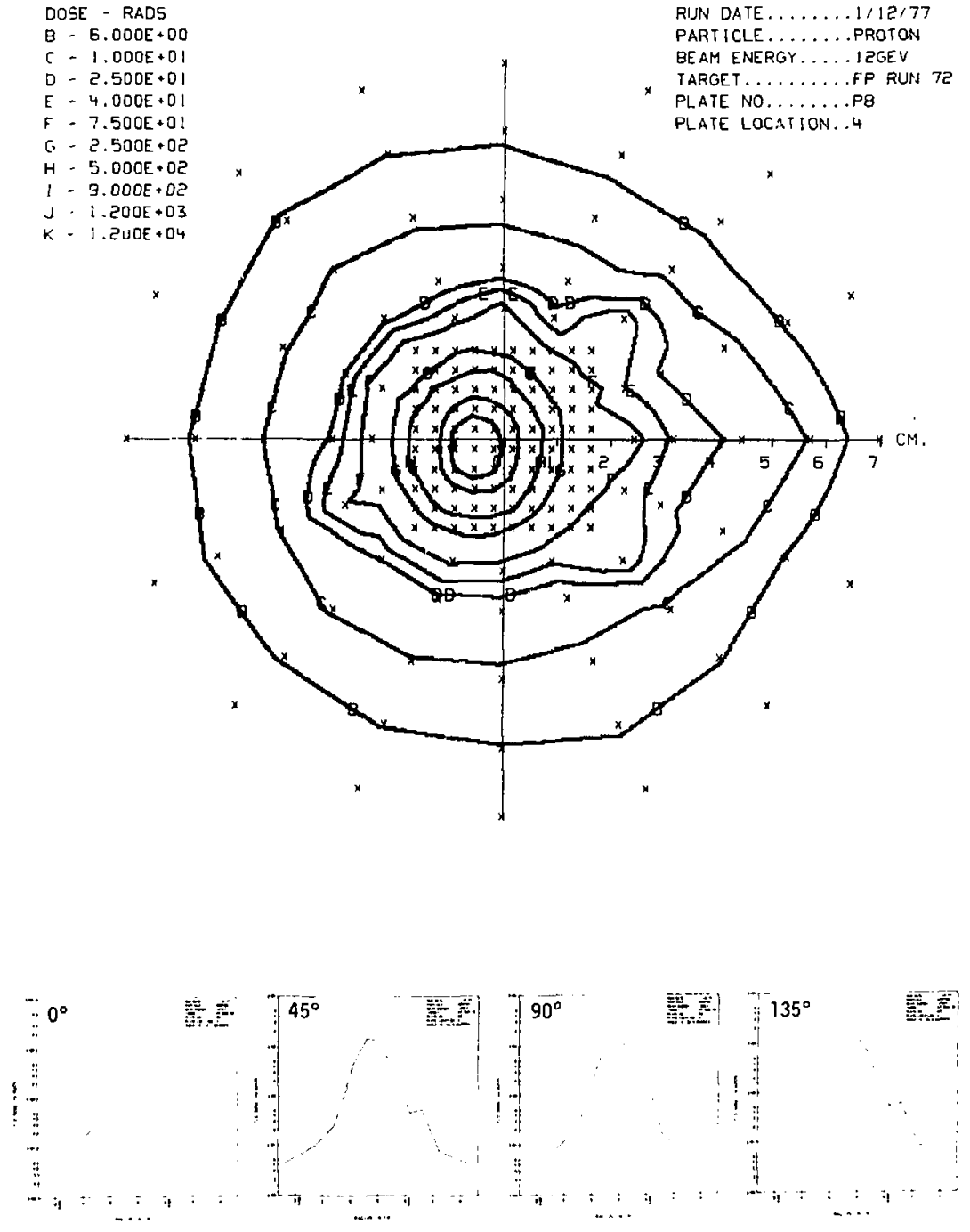

Fil. A-54. 

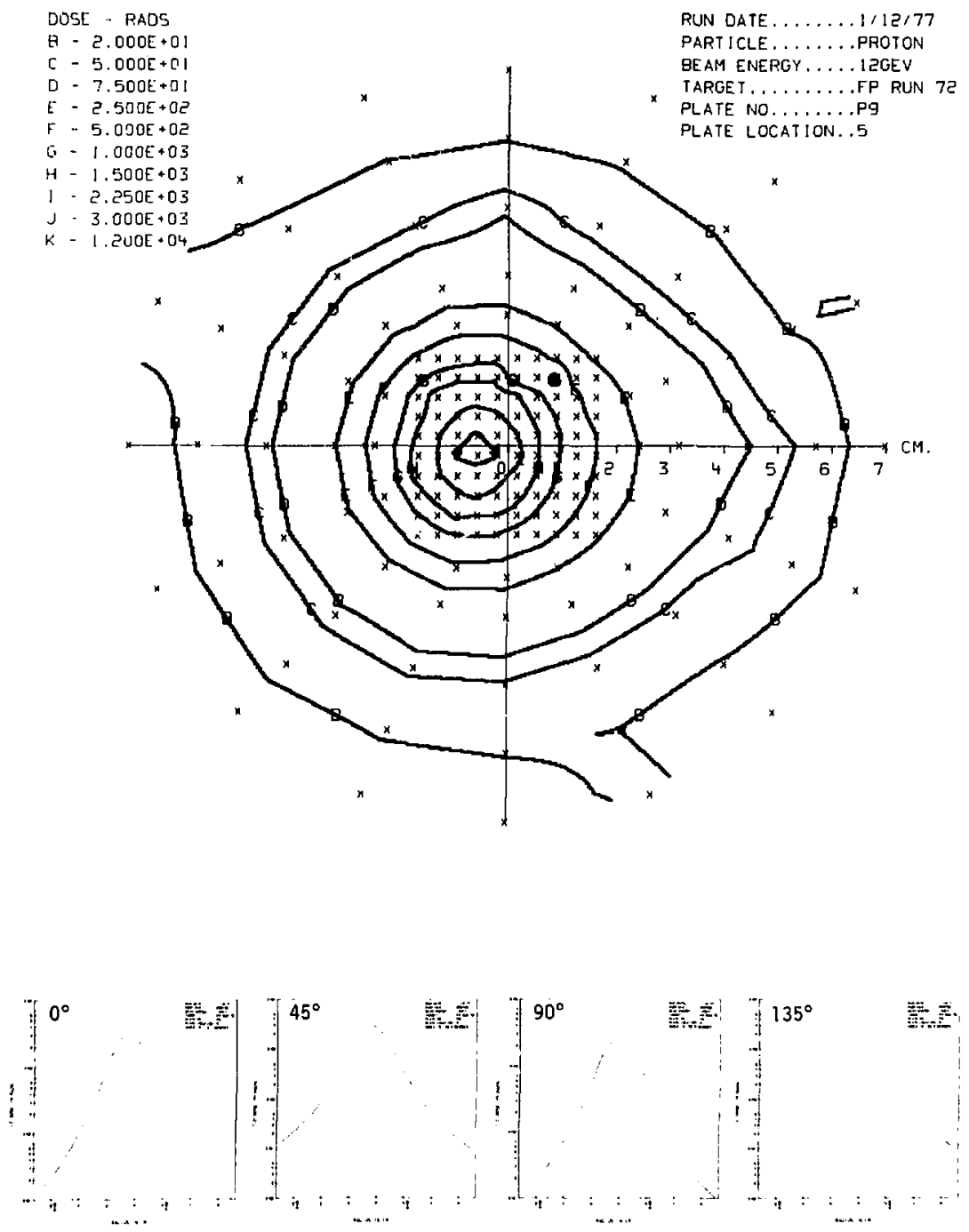

Fin. A-ss. 

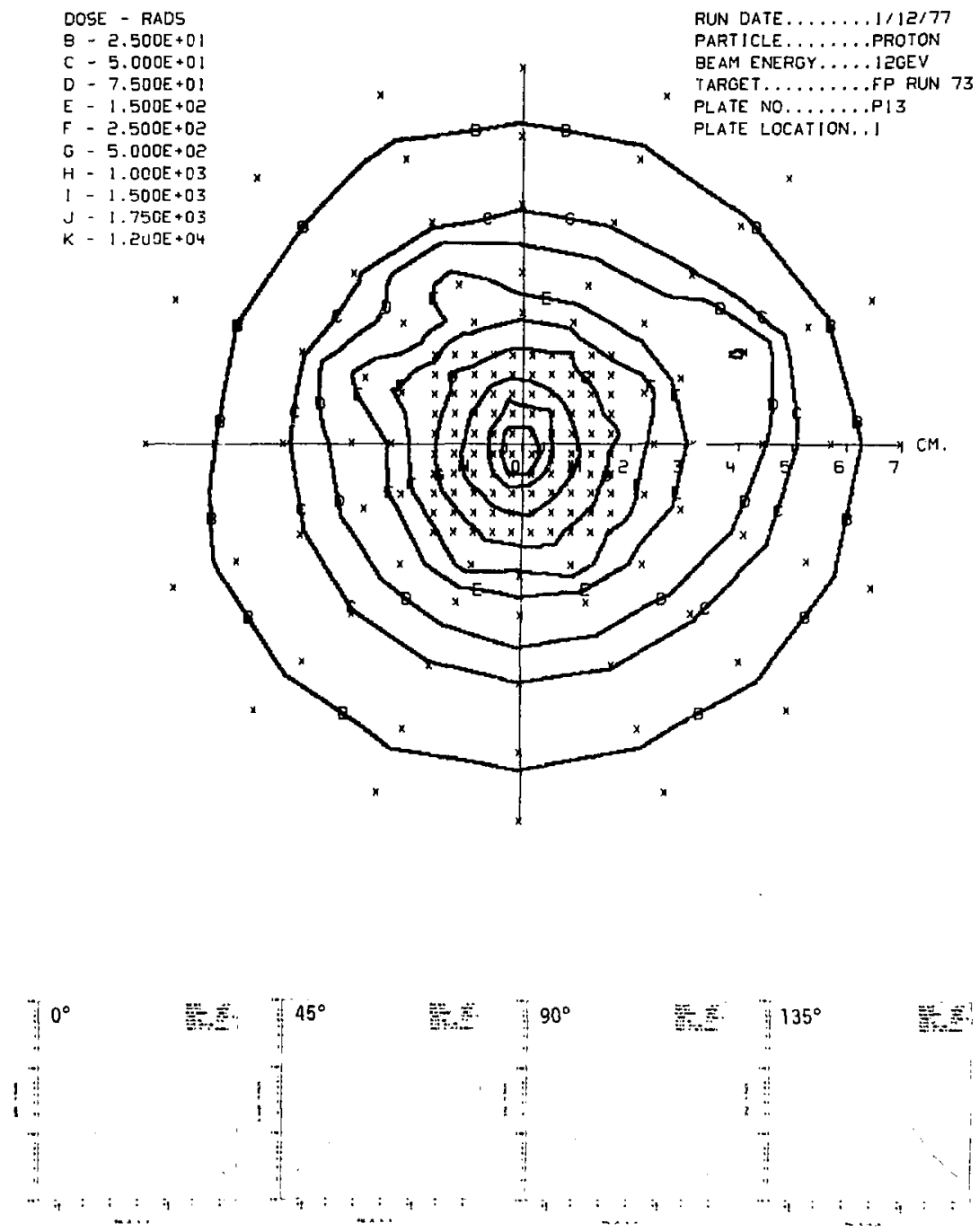

Fig. A-56, 

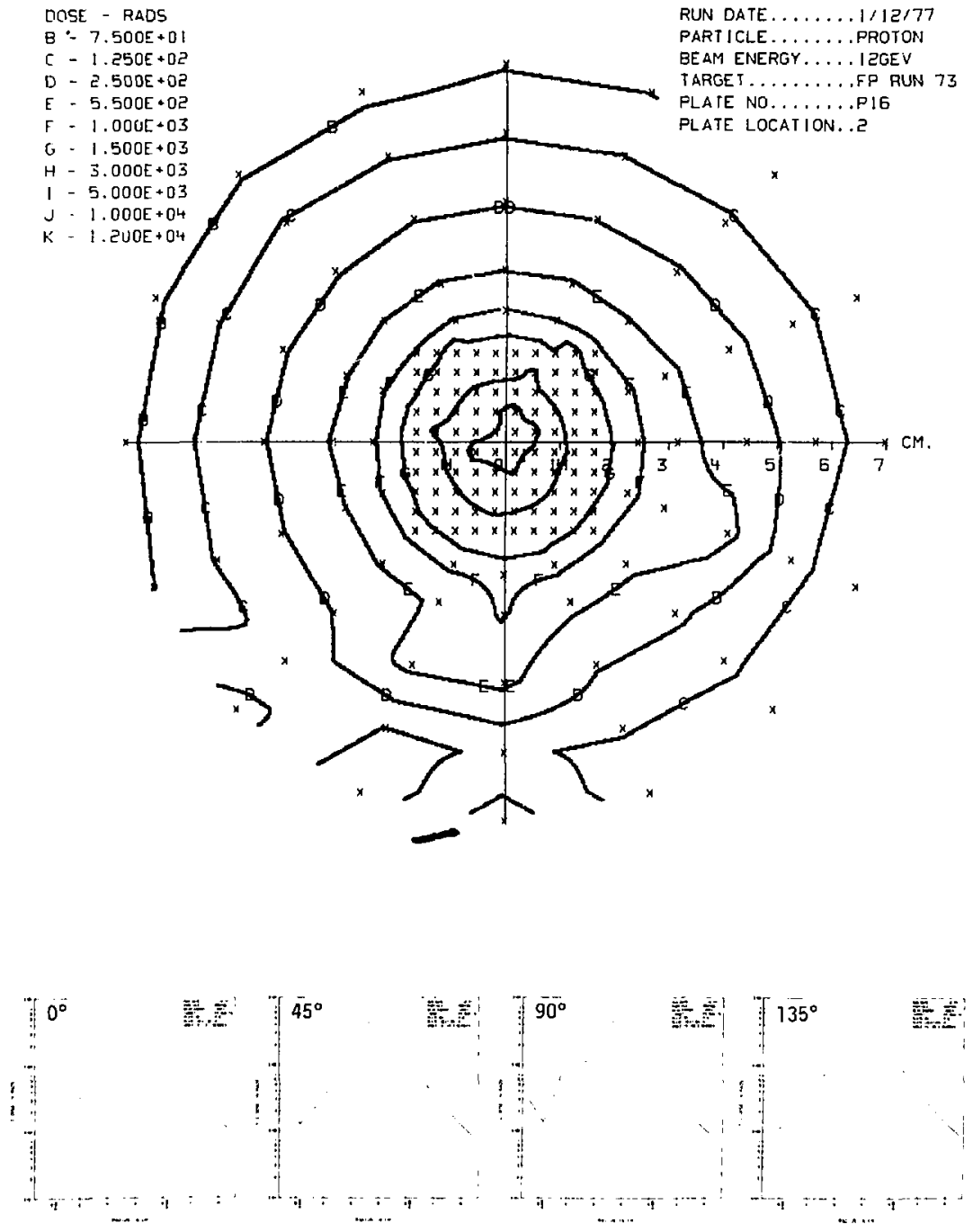

Fis. A-57. 

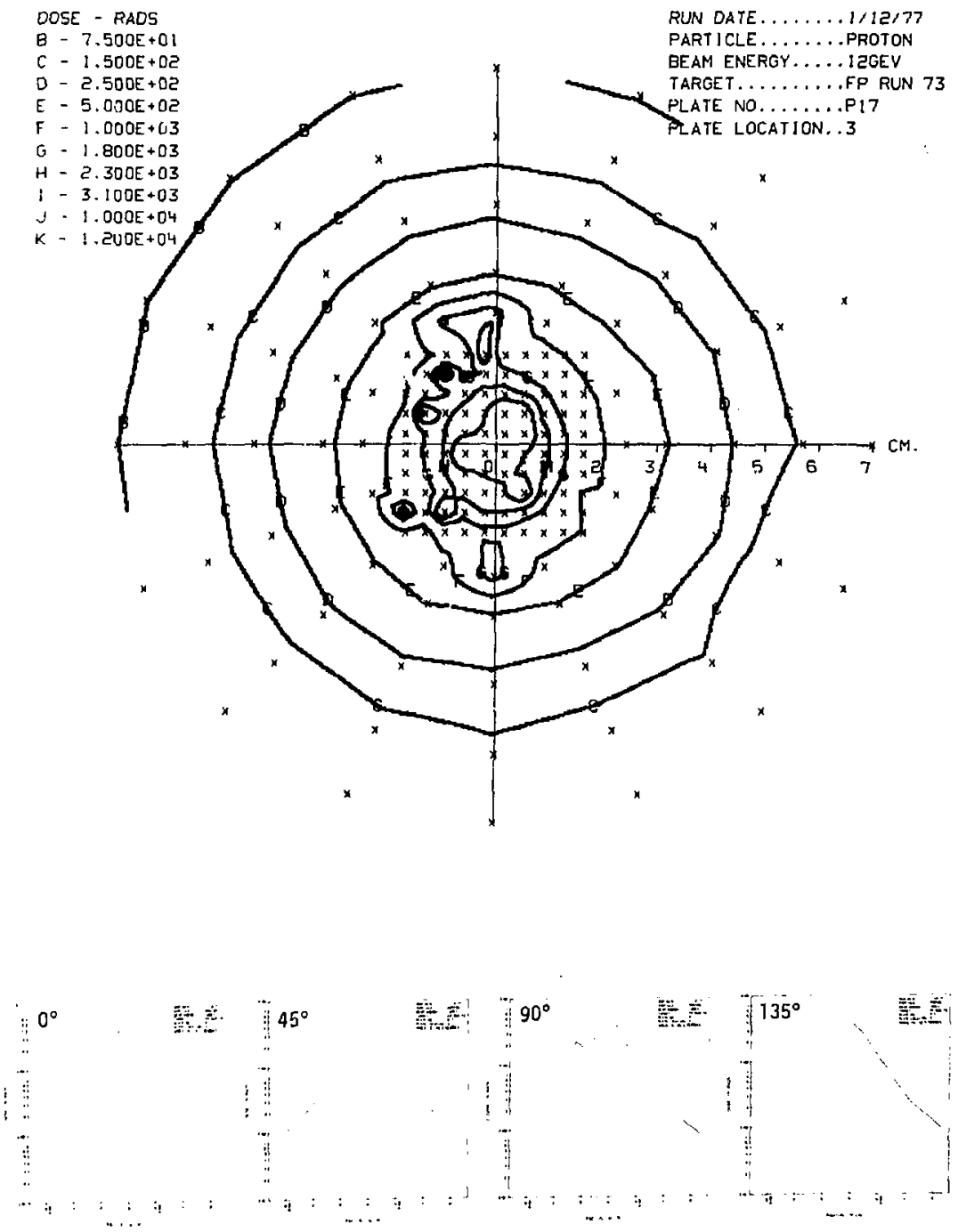

Fis. A-58. 

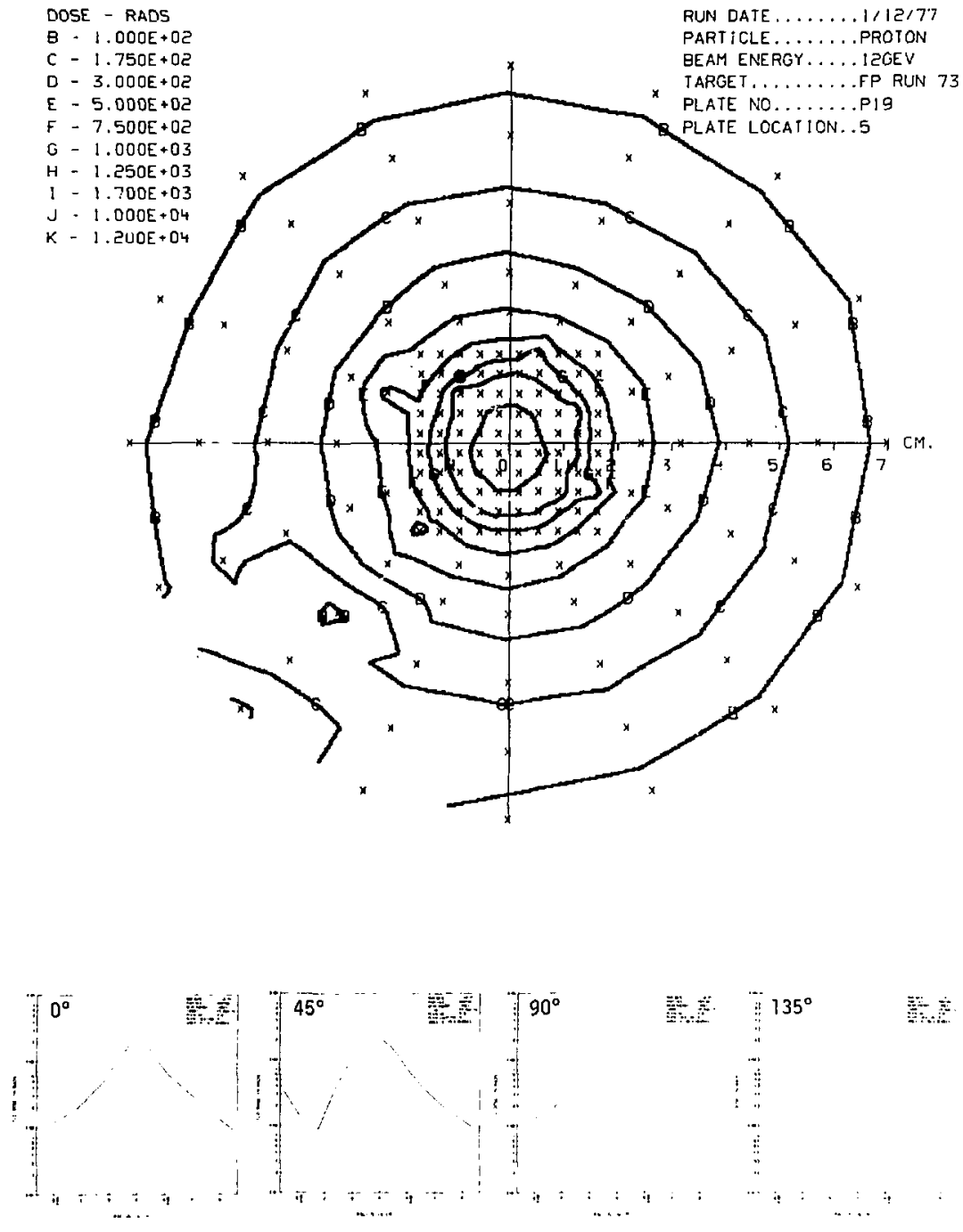

Fig. A.59. 

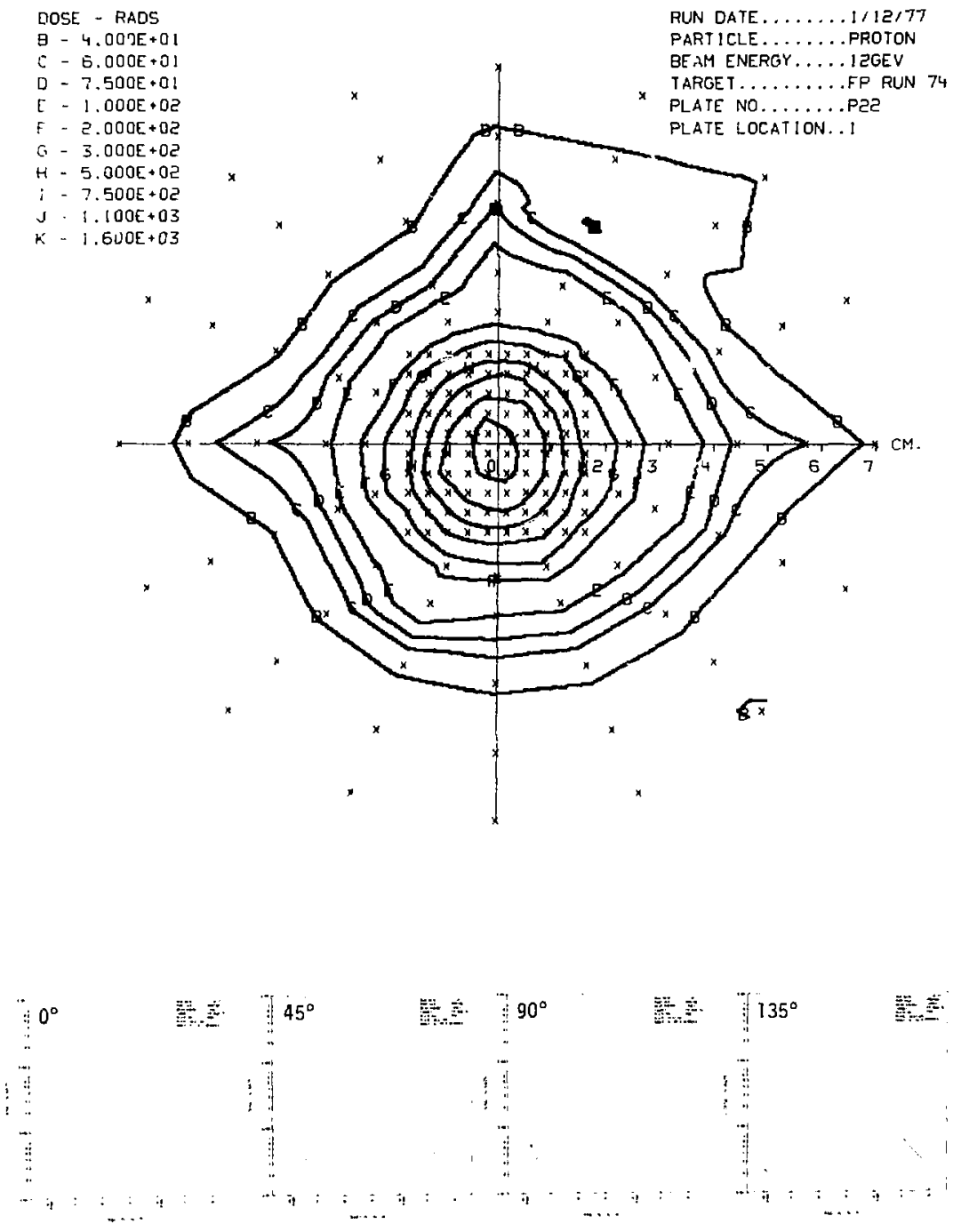

Fis. A-60, 

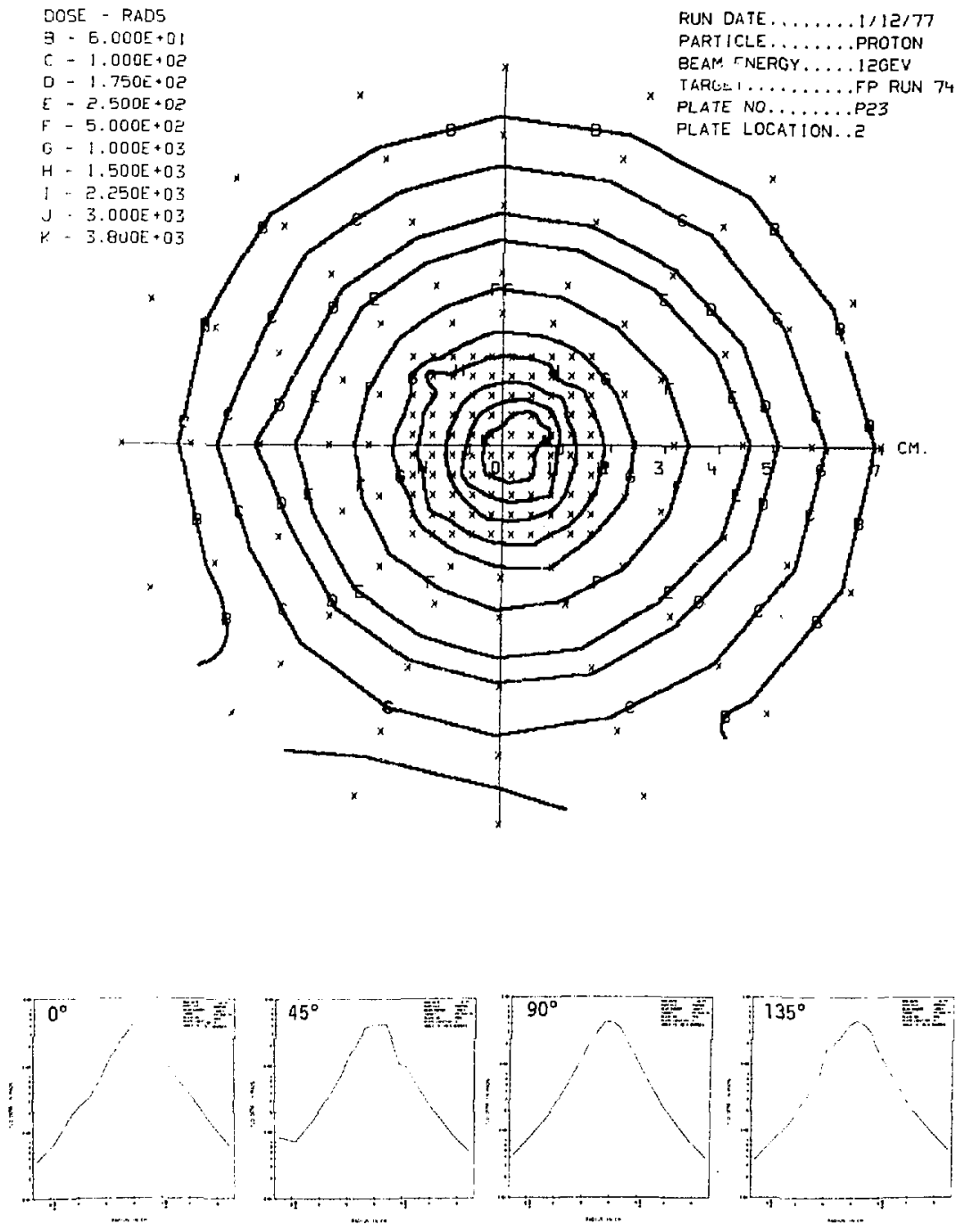

File. A-61. 

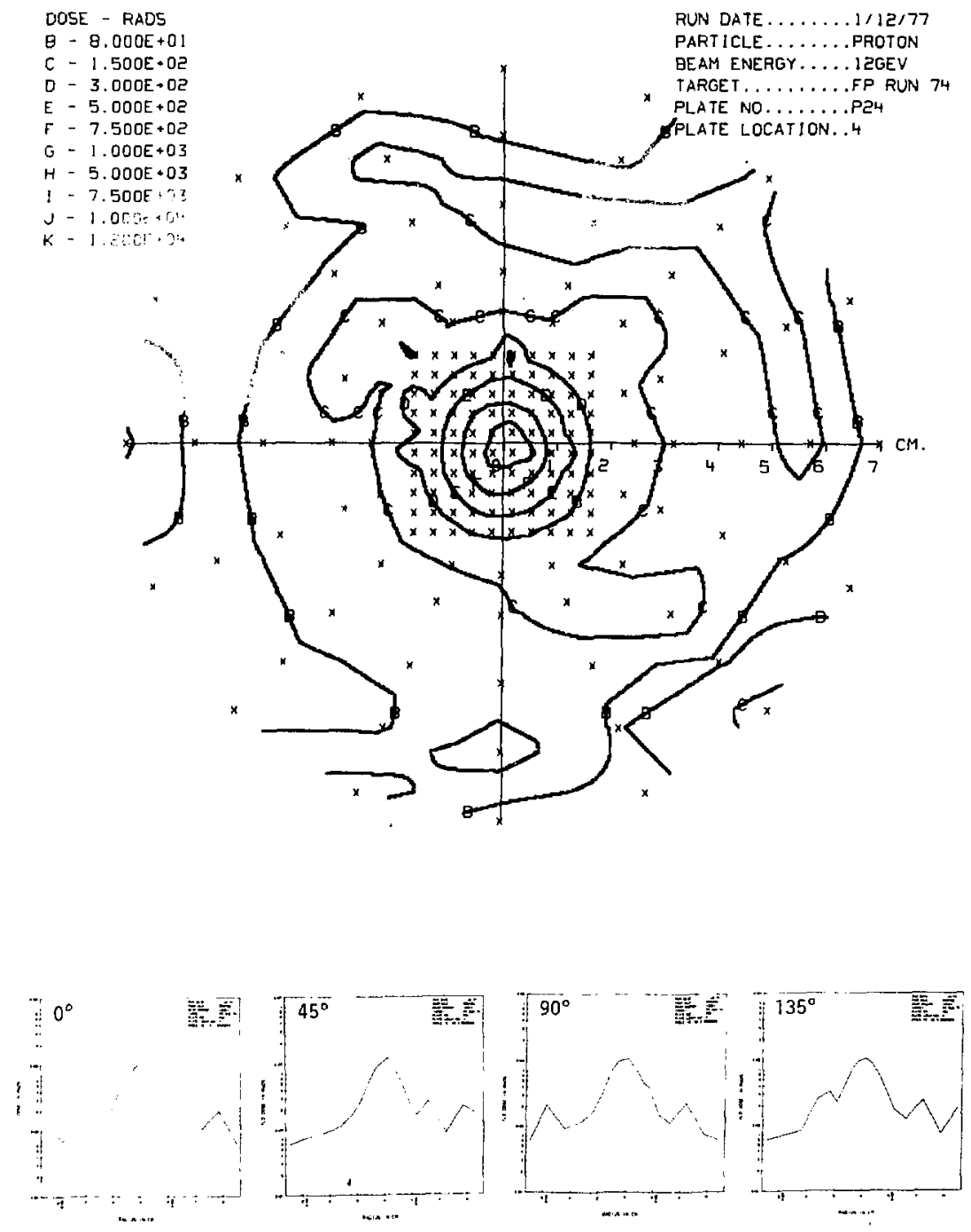

Fis. A-62. 

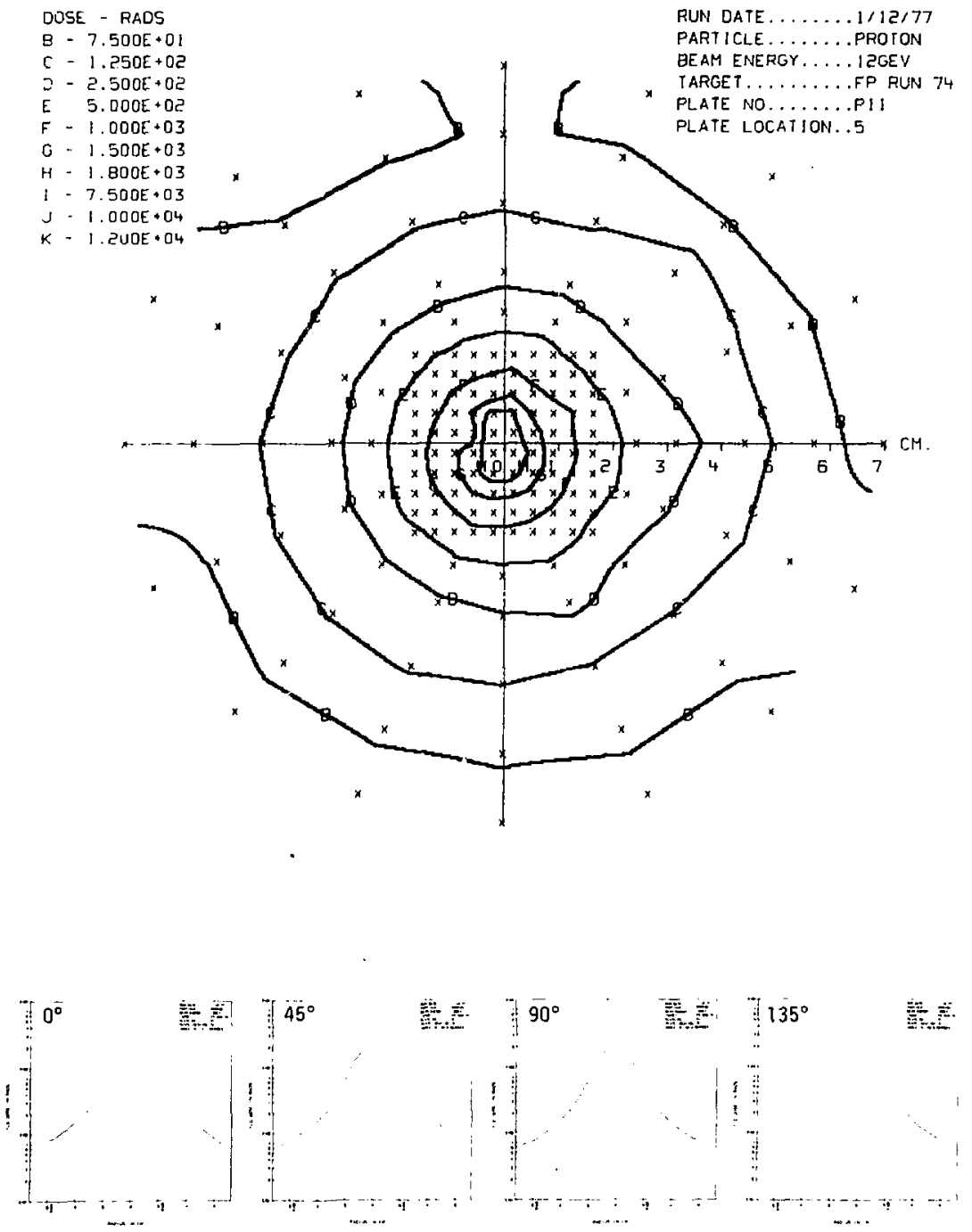

Fig. A-6.9, 

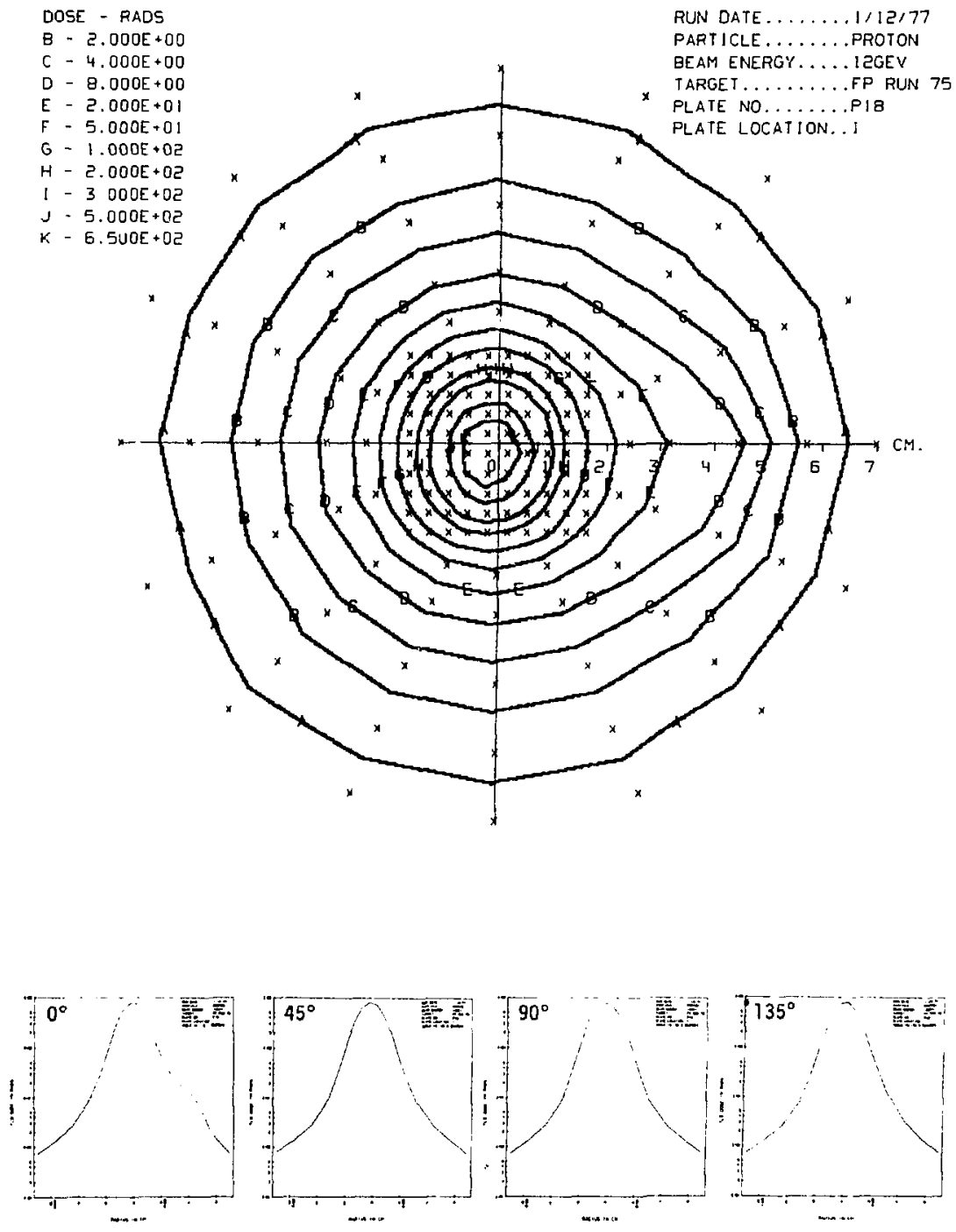

Fis. A-64. 

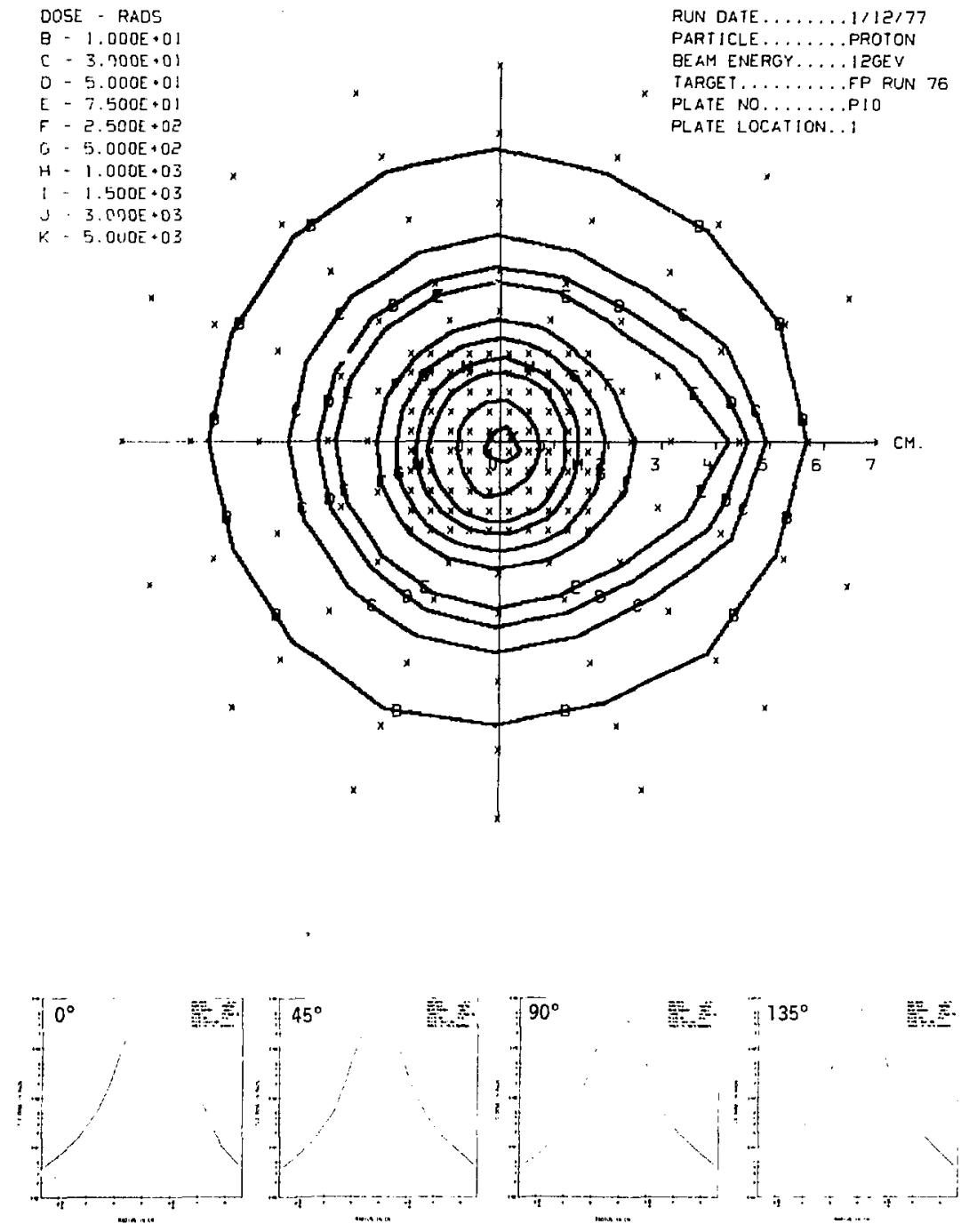

File. A-65. 


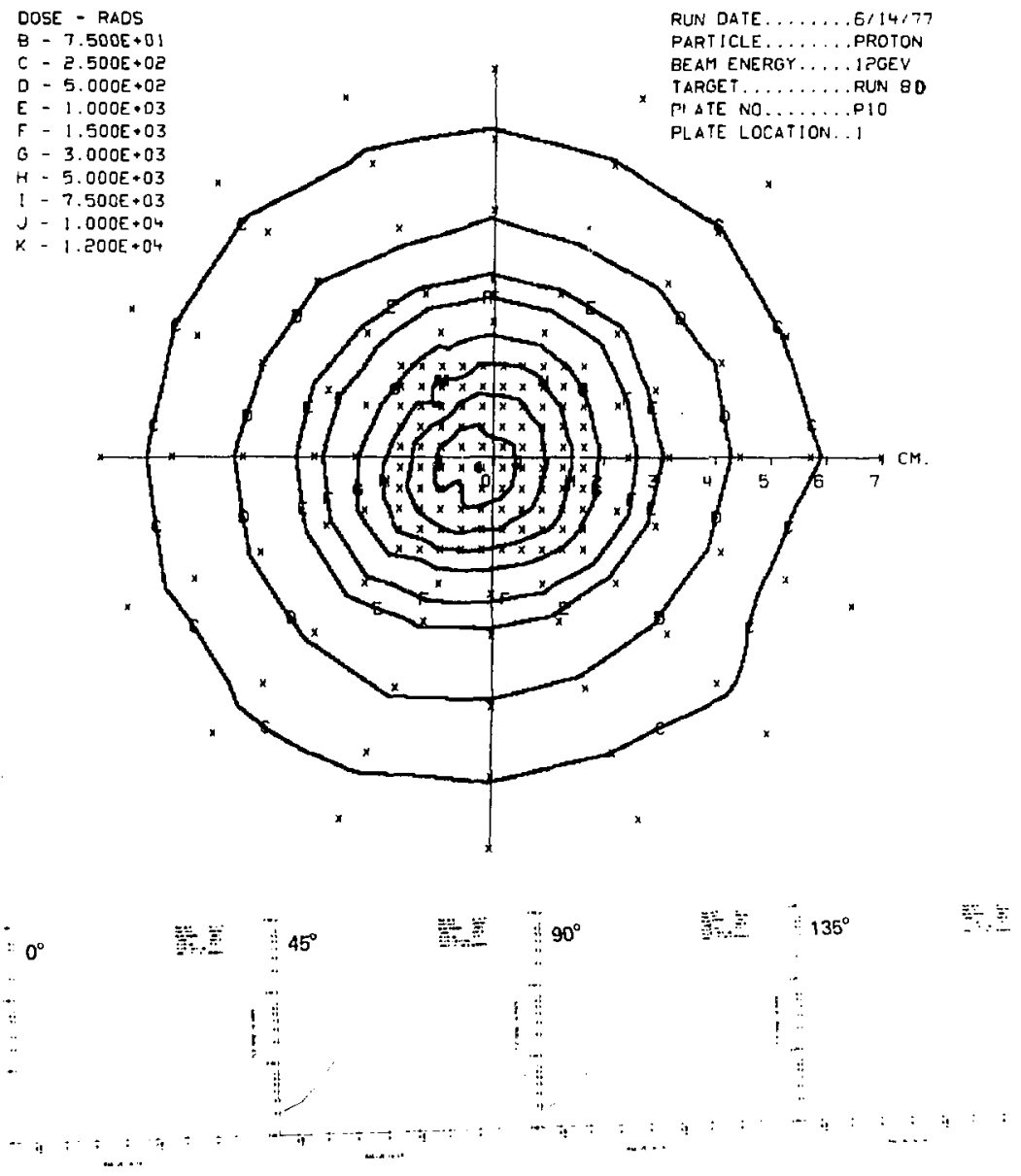

Fis. A-66. 

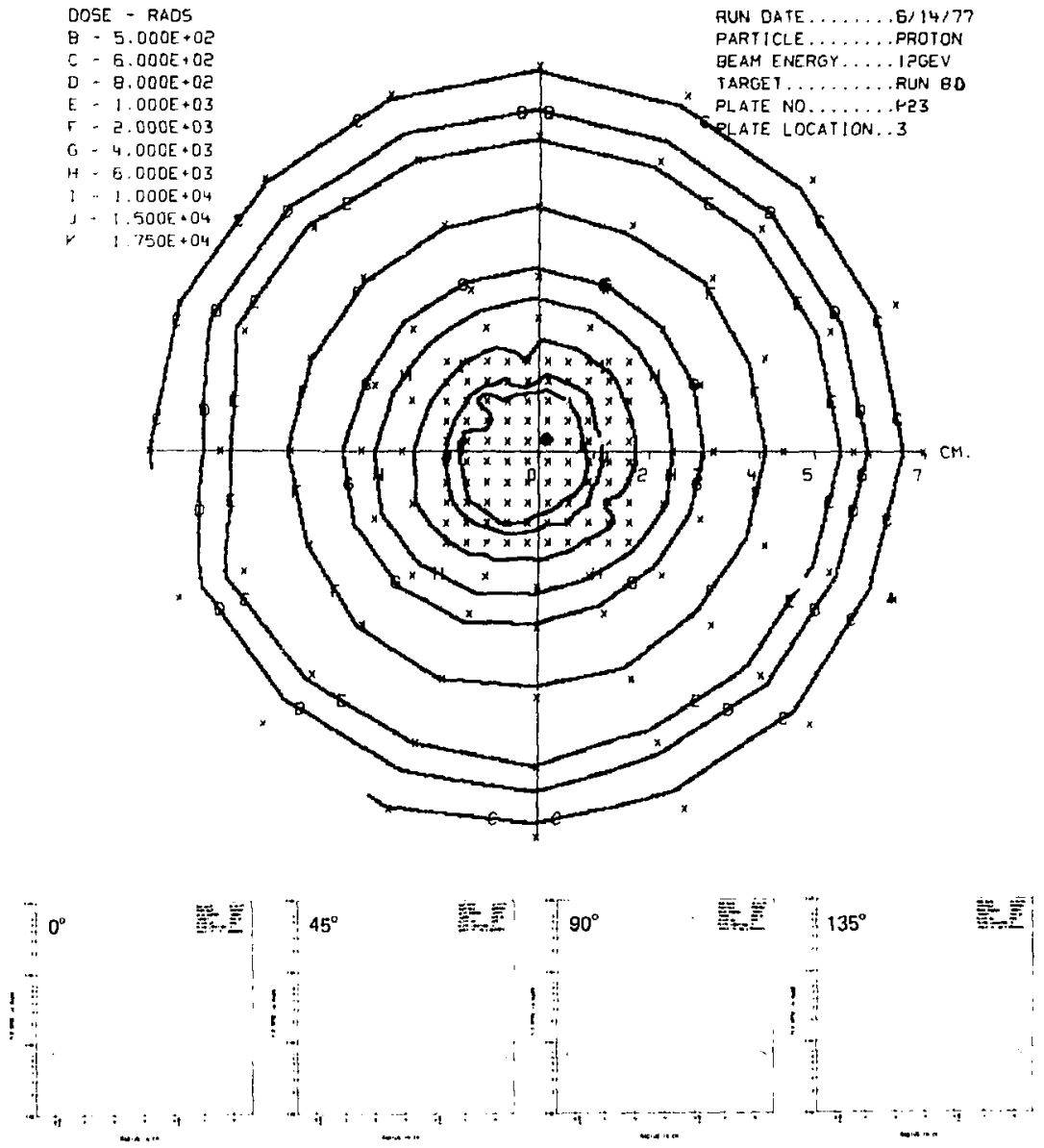

Fis. A-67. 


\section{APPENDIX B \\ DOSE CONTOUR PLOT NUMERICAL DATA}

Figure B-1 shows the numbering system for the TLD detcctors in Lucite. Figures B-2 through B-18 (runs 2 through 5) have the numerical data written into a pattern corresponding to their holder locations. The doses for the remainder of the runs are listed and the coordinates for each detector number are the same as those listed for run 5l. Radius is in $\mathrm{cm}$, dose in rad.

Plate code numbering system

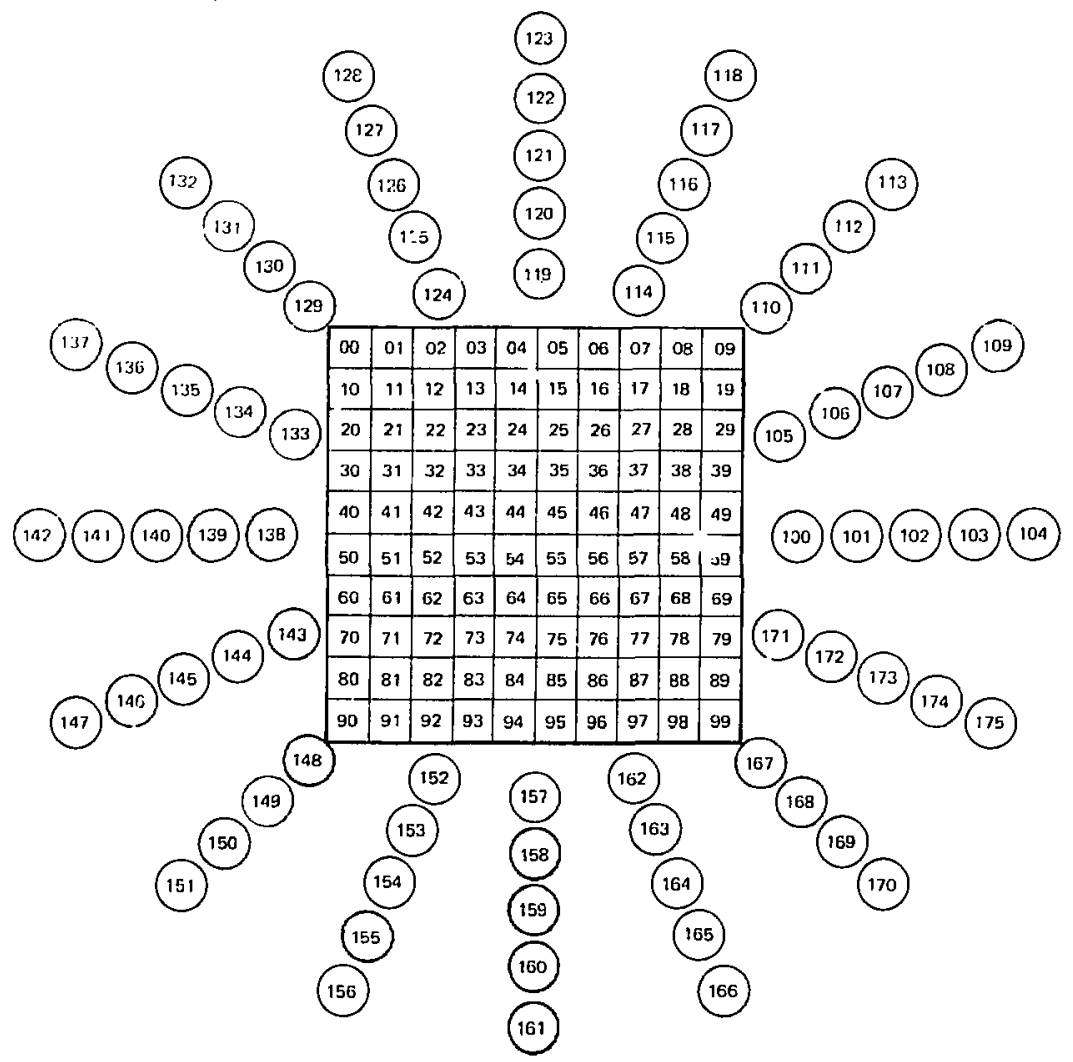

See run- 51 data for $R, 0$ coordinates

Fig. I-I. 


\begin{tabular}{|c|c|}
\hline Buam energy & 4. BB GoV \\
\hline Run date & $6 / 8 / 76$ \\
\hline Particlo & Proton \\
\hline Plate No. & P3 \\
\hline Plate locition & 1 \\
\hline
\end{tabular}

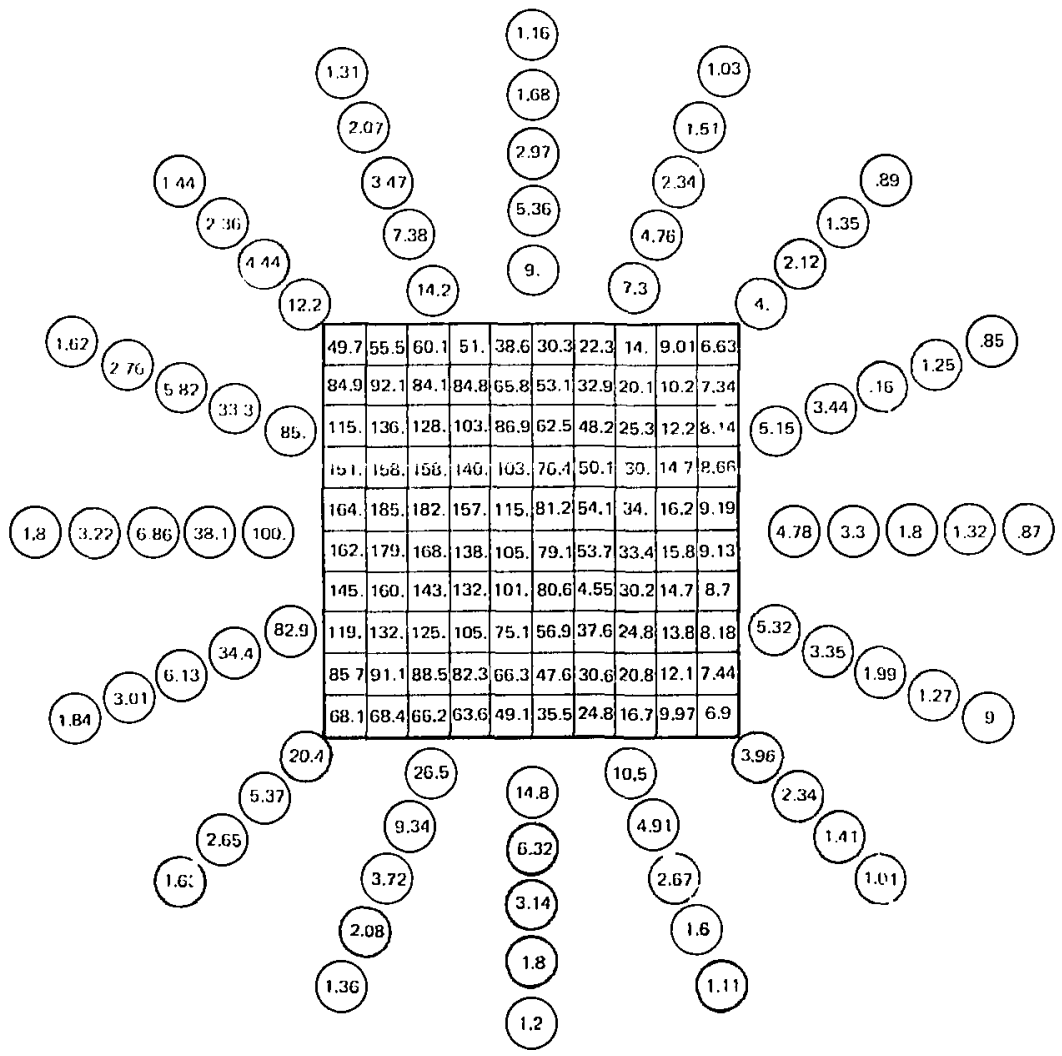

Fis. B-2. 


Beam energy $\frac{4.88 \mathrm{GeV}}{6 / 8 / 76}$
Run date $-\frac{\text { Proton }}{\text { Particle }}$
Plate No. $\frac{\mathrm{P} 4}{2}$
Piate Jocation 2

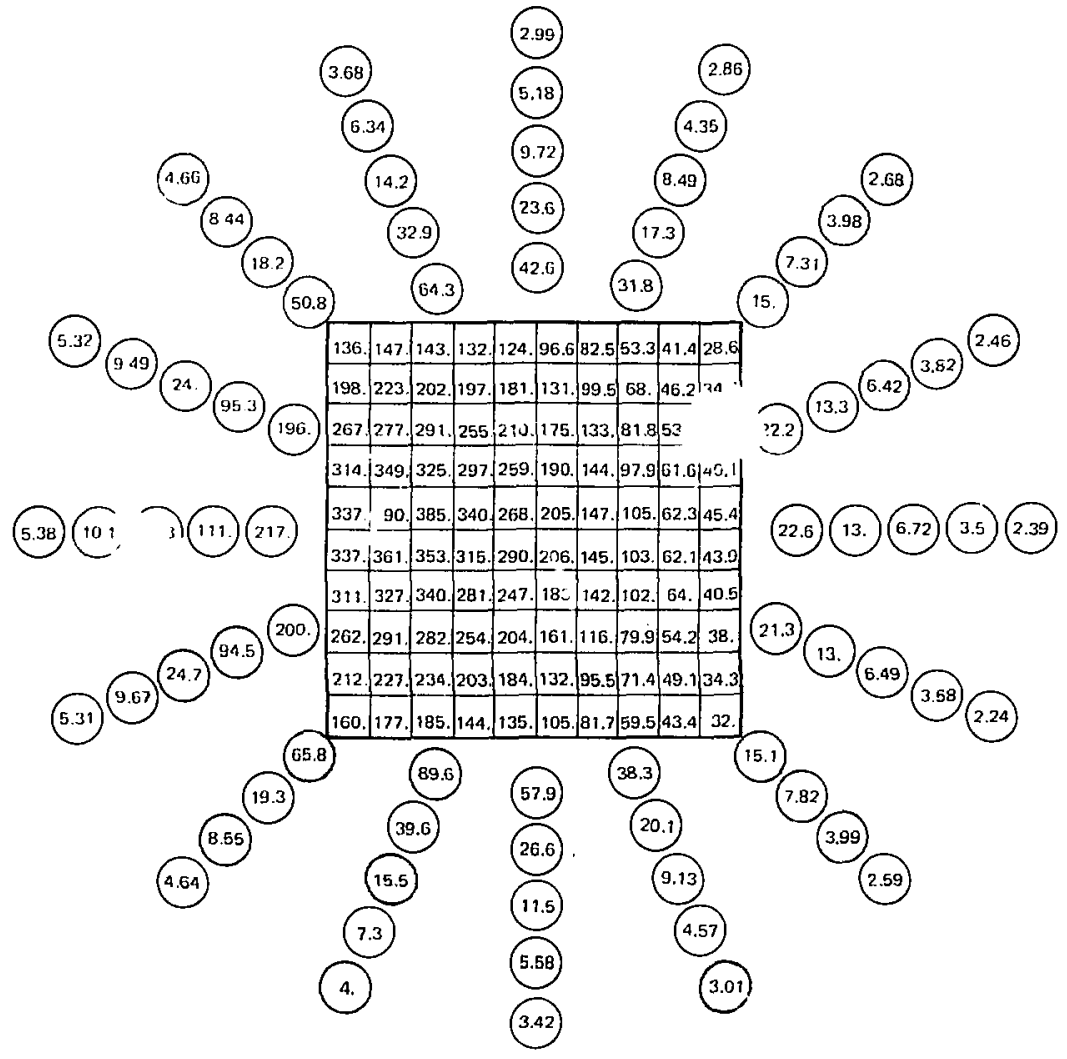

Fit. B-3. 


Beam energy $-\frac{4.88 \mathrm{GEV}}{6 / 8 / 76}$
Run date $\frac{6 / 2}{\text { Proton }}$
Particle $\frac{\mathrm{P5}}{-}$
Plate No.
Plate location 3

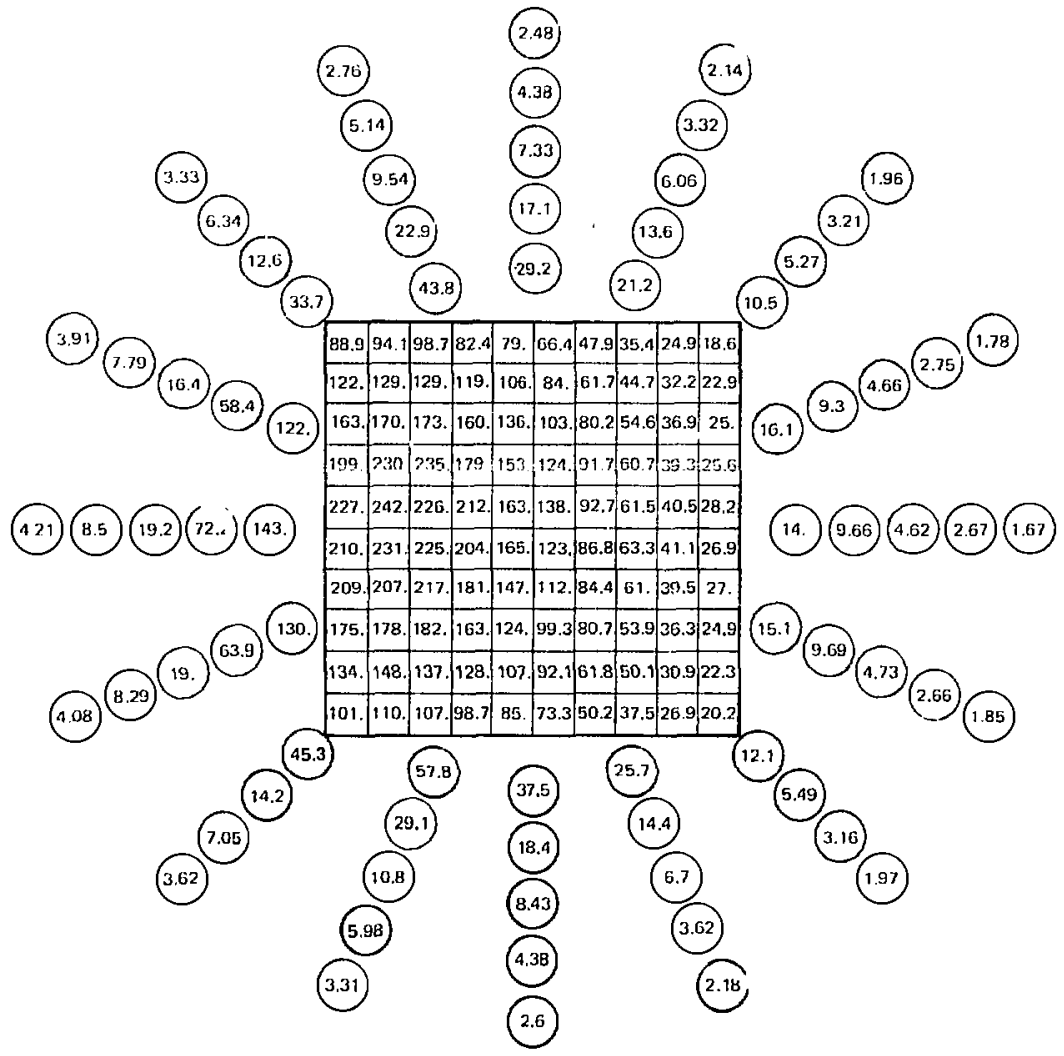

Fin. B.4. 


\begin{tabular}{ll} 
Bearn energy & $4.88 \mathrm{GeV}$ \\
Run date & $6 / 8 / 76$ \\
Particle & Proton \\
Plate No. & P6 \\
\hline Plate locotion & 4 \\
\hline
\end{tabular}

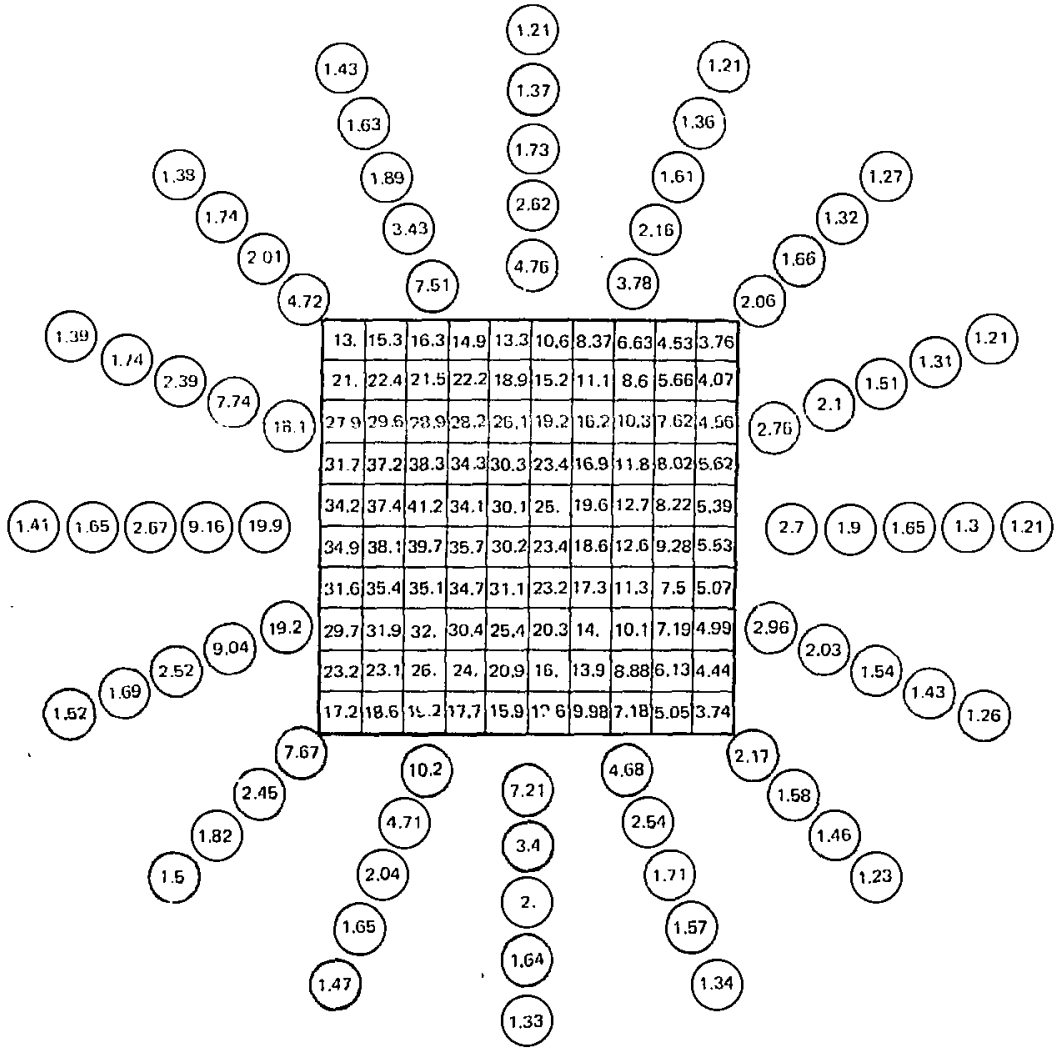

Fì. B-5. 


\begin{tabular}{ll} 
Beam energV & $4.88 \mathrm{GeV}$ \\
Ruri date & $6 / 8 / 76$ \\
Particle & Proton \\
Plate No. & P7 \\
Plite location & 5 \\
\hline
\end{tabular}

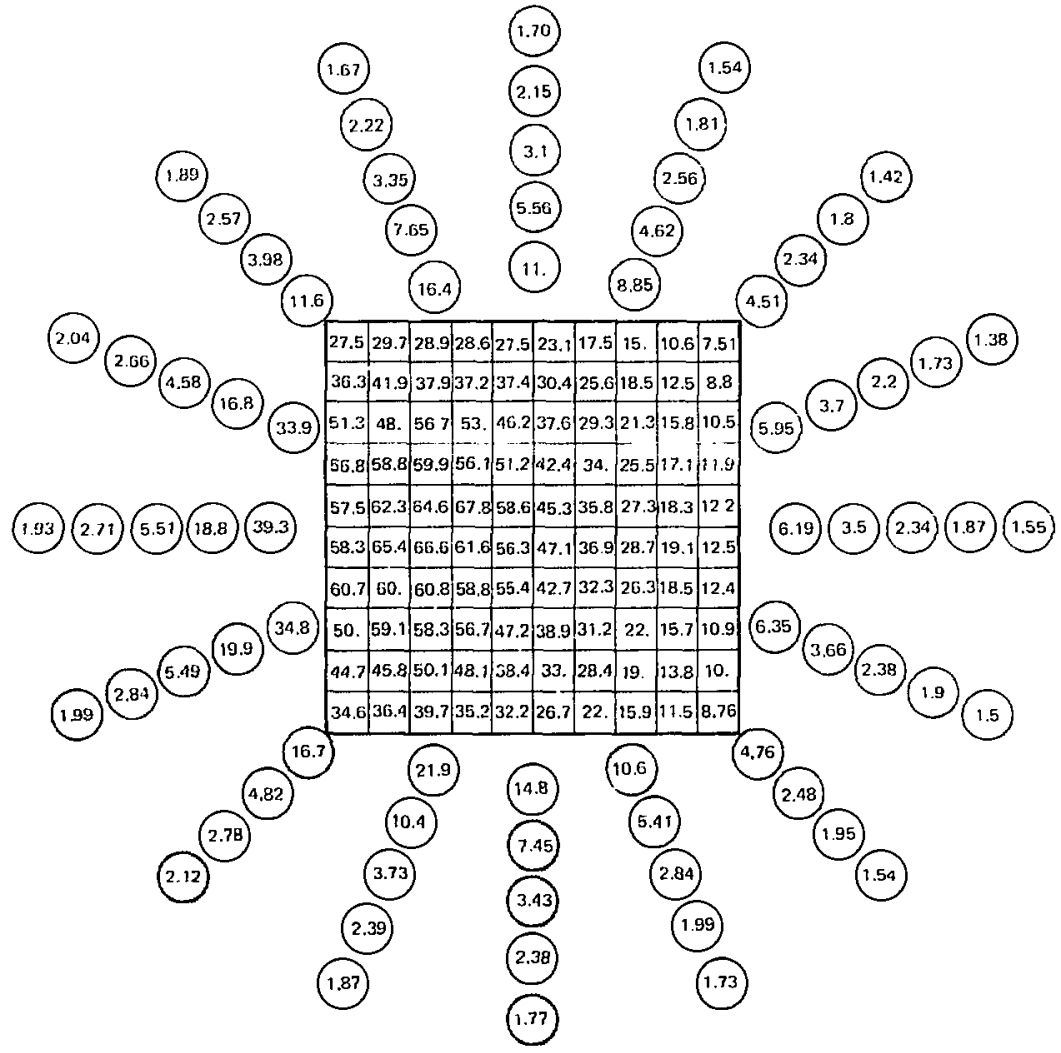

Fis. B-b. 


\begin{tabular}{l} 
Beam energy $-\frac{4.88 \mathrm{GeV}}{6 / 8 / 76}$ \\
Run date $-\frac{6 / 8}{\text { Proton }}$ \\
Particle $-\frac{P 8}{}$ \\
Plate No. \\
Plate location -4 \\
\hline
\end{tabular}

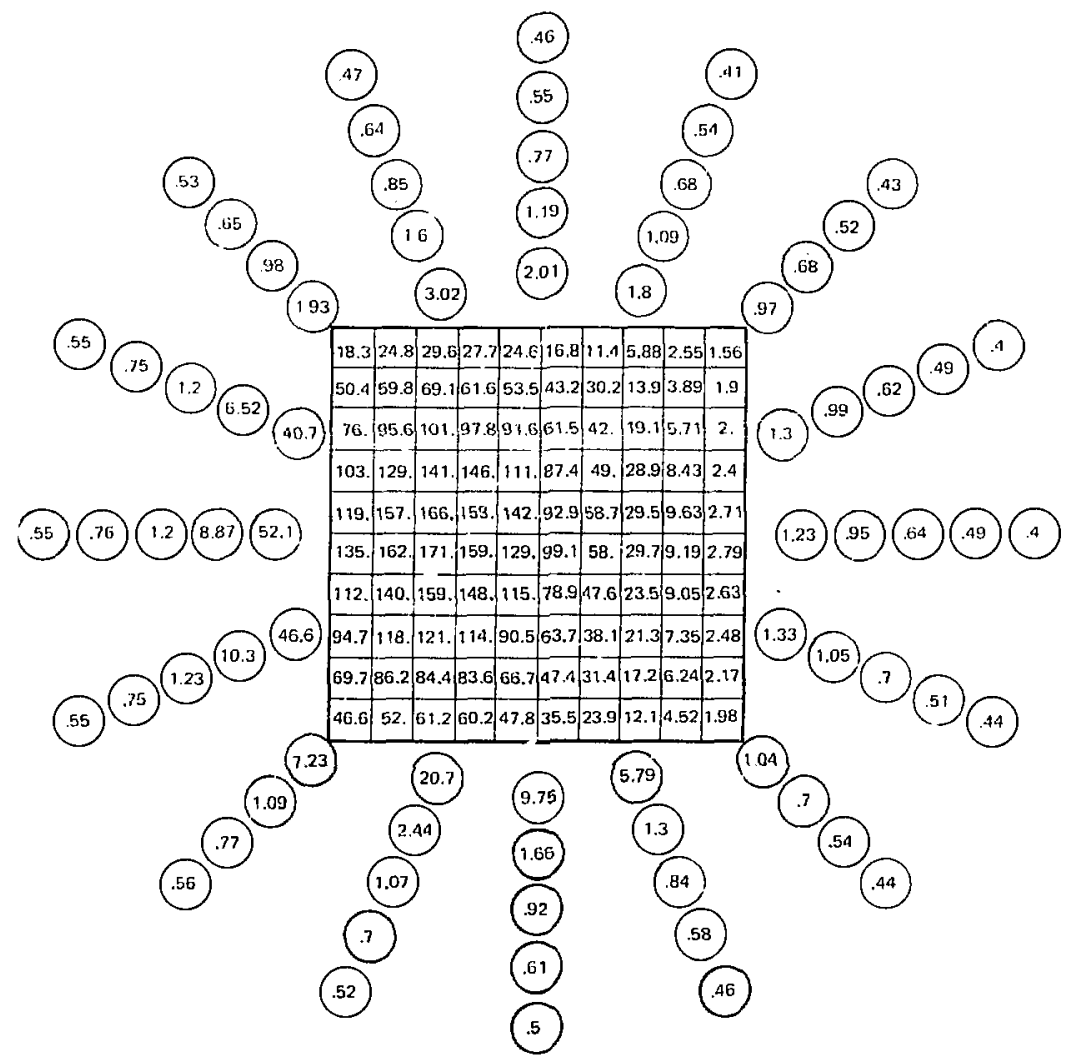

Fin. B-7. 


\begin{tabular}{ll} 
Beam energy & $4.88 \mathrm{GeV}$ \\
Run date & $6 / 8 / 76$ \\
Particle & Proton \\
Plate No. & P9 \\
Plate location & 5 \\
\hline
\end{tabular}

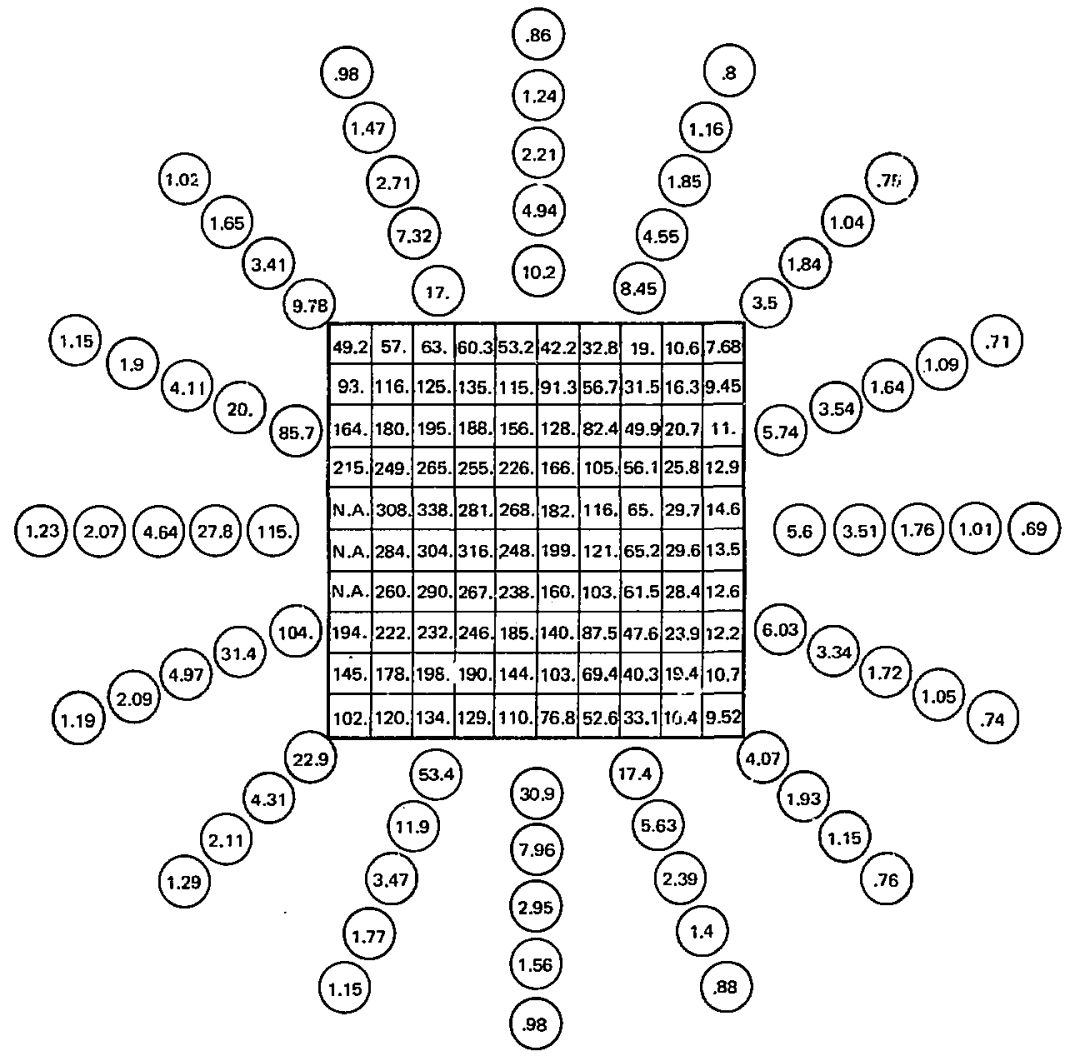

Fis. B-8. 


\begin{tabular}{ll} 
Beam energy & $2.1 \mathrm{GeV}$ \\
Run date & $6 / \mathrm{B} / 76$ \\
Particle & Proton \\
Plate No. & P10 \\
Plate location & 1 \\
\hline
\end{tabular}

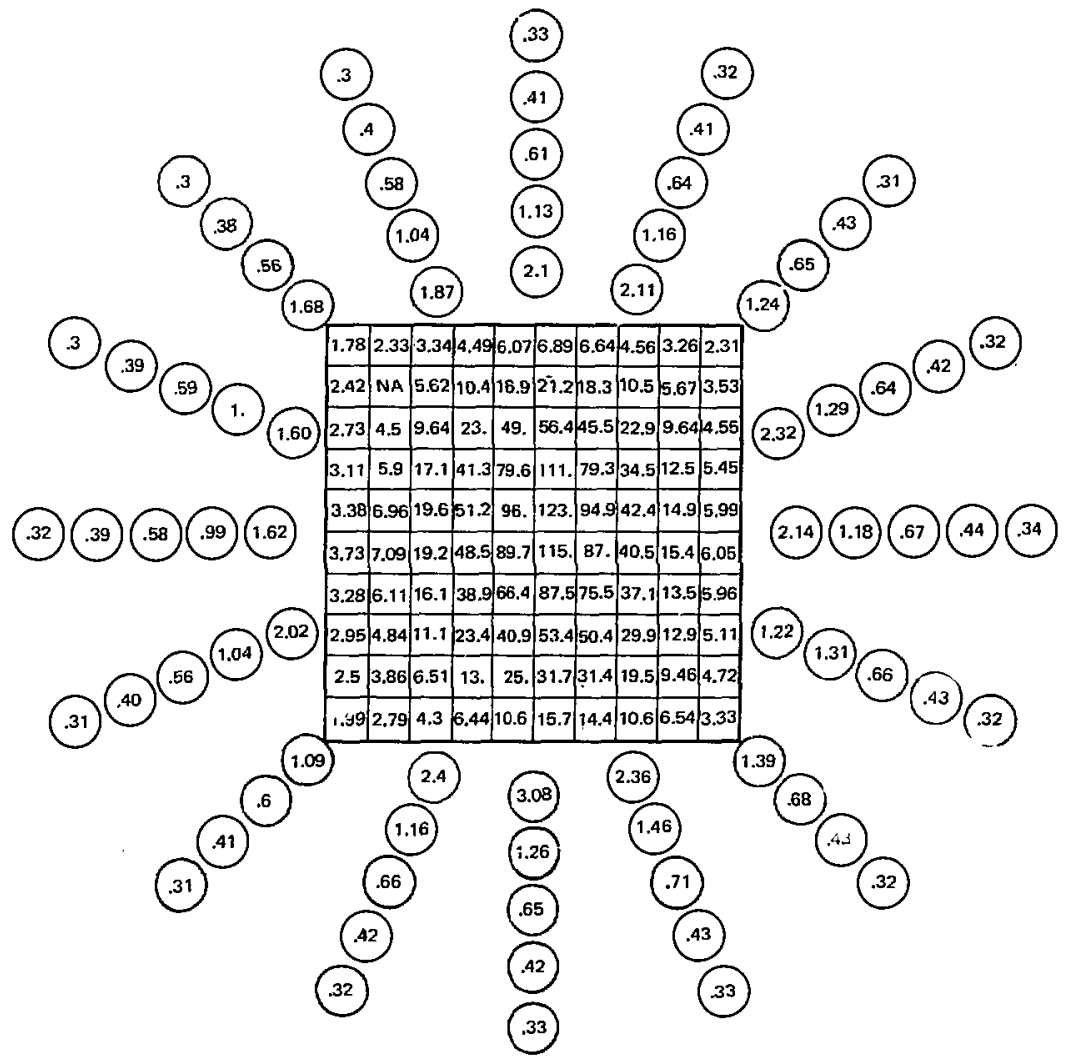

Fis, B-9. 


\begin{tabular}{ll} 
Beam energy & $2.1 \mathrm{GeV}$ \\
Run date & $6 / 8 / 76$ \\
Particle & Proton \\
Plate No. & P11 \\
Plate location & 2 \\
\hline
\end{tabular}

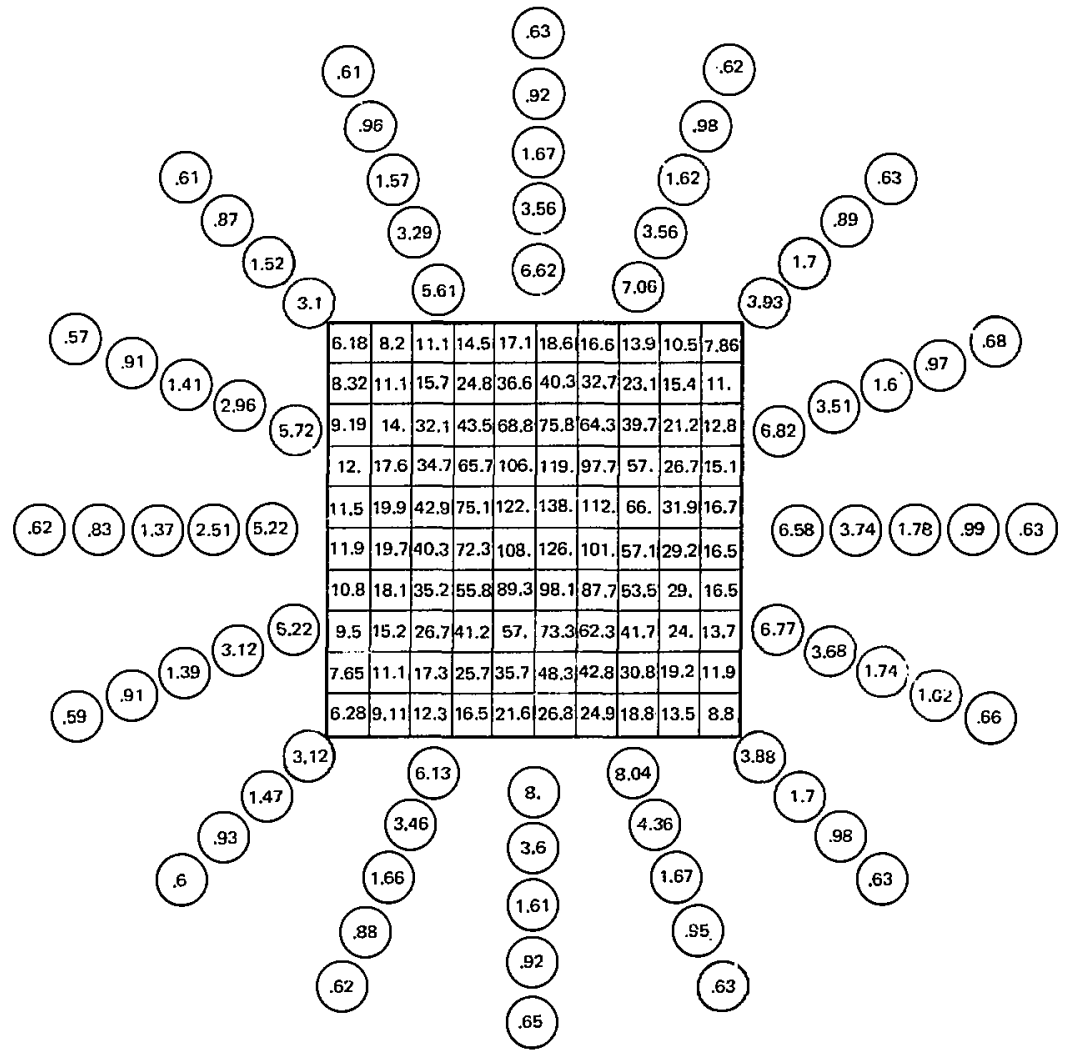

Fig. B-10. 


Beam energy $\frac{2.1 \mathrm{GeV}}{6 / 8 / 76}$
Run date $\frac{\text { Proton }}{\text { Particle }}$
Plate No. $\frac{\text { P12 }}{3}$
Plate location $\frac{3}{}$

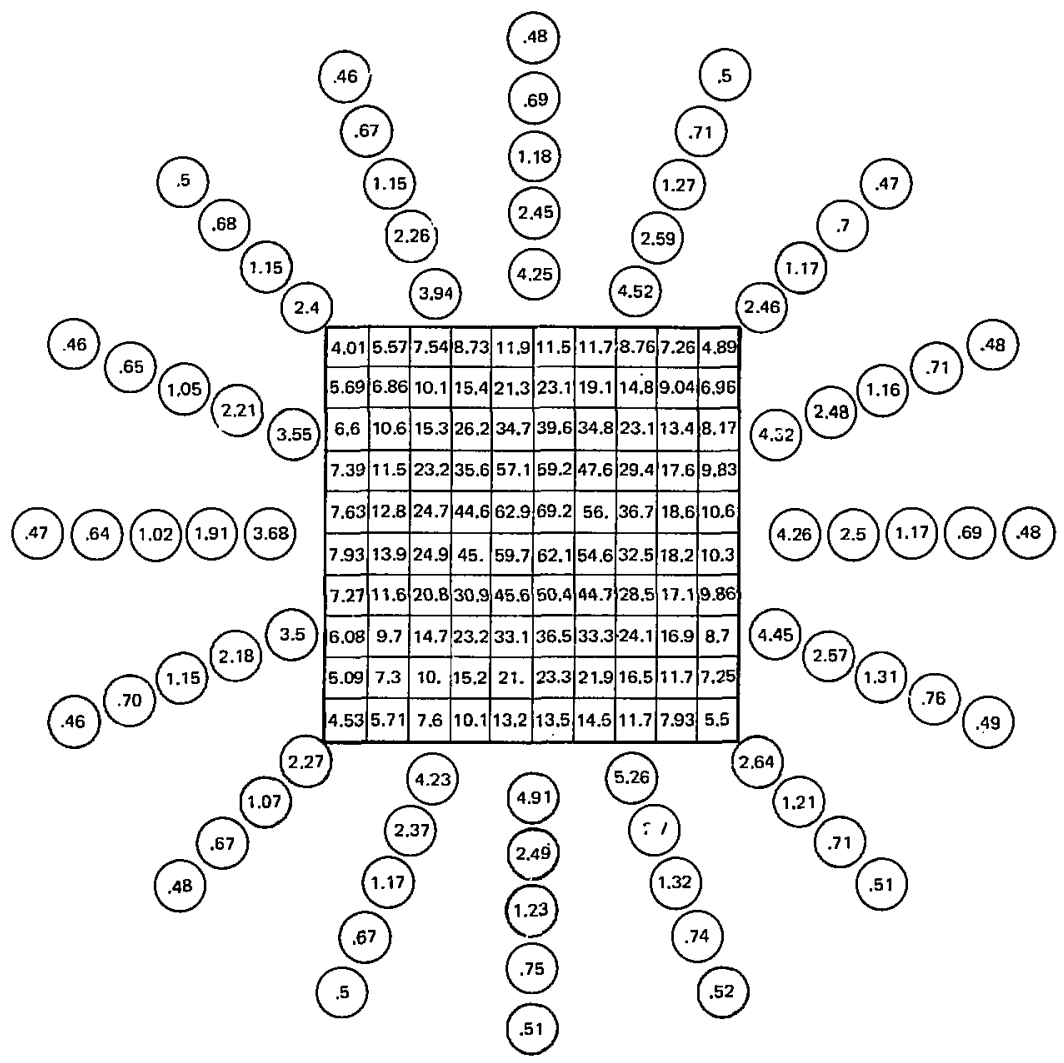

Fis. D-11. 


Beam energy $\frac{2.1 \mathrm{GeV}}{6 / 8 / 76}$
Run date $\frac{\text { Proton }}{-}$
Particle $\frac{\mathrm{P13}}{}$
Plate No. $\frac{4}{}$
Plate location $\frac{4}{}$

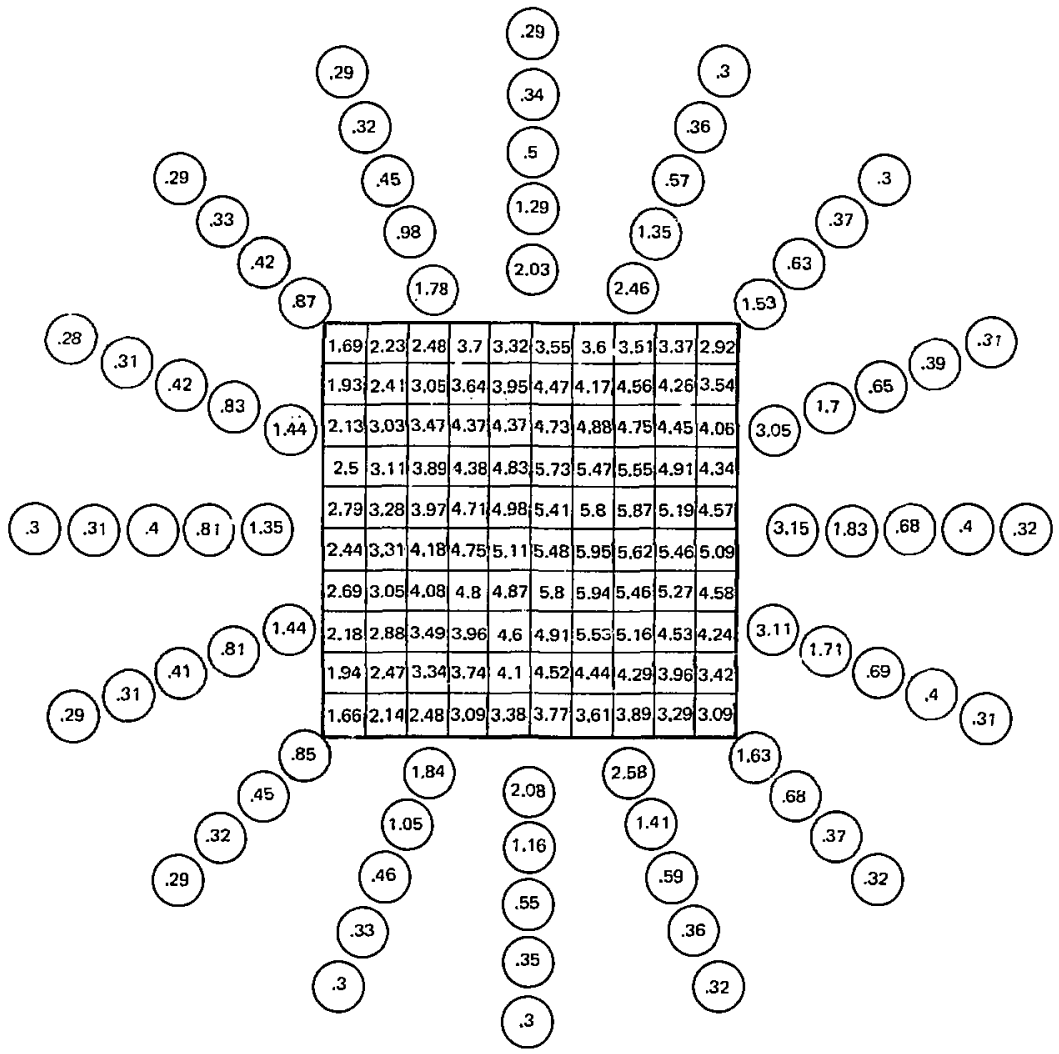

Fig. B-12. 


\begin{tabular}{|c|c|}
\hline Beam energy & $2.1 \mathrm{GeV}$ \\
\hline Run date & $6 / 8 / 76$ \\
\hline Particle & Proton \\
\hline Plate No. & P22 \\
\hline Plate location & 5 \\
\hline
\end{tabular}

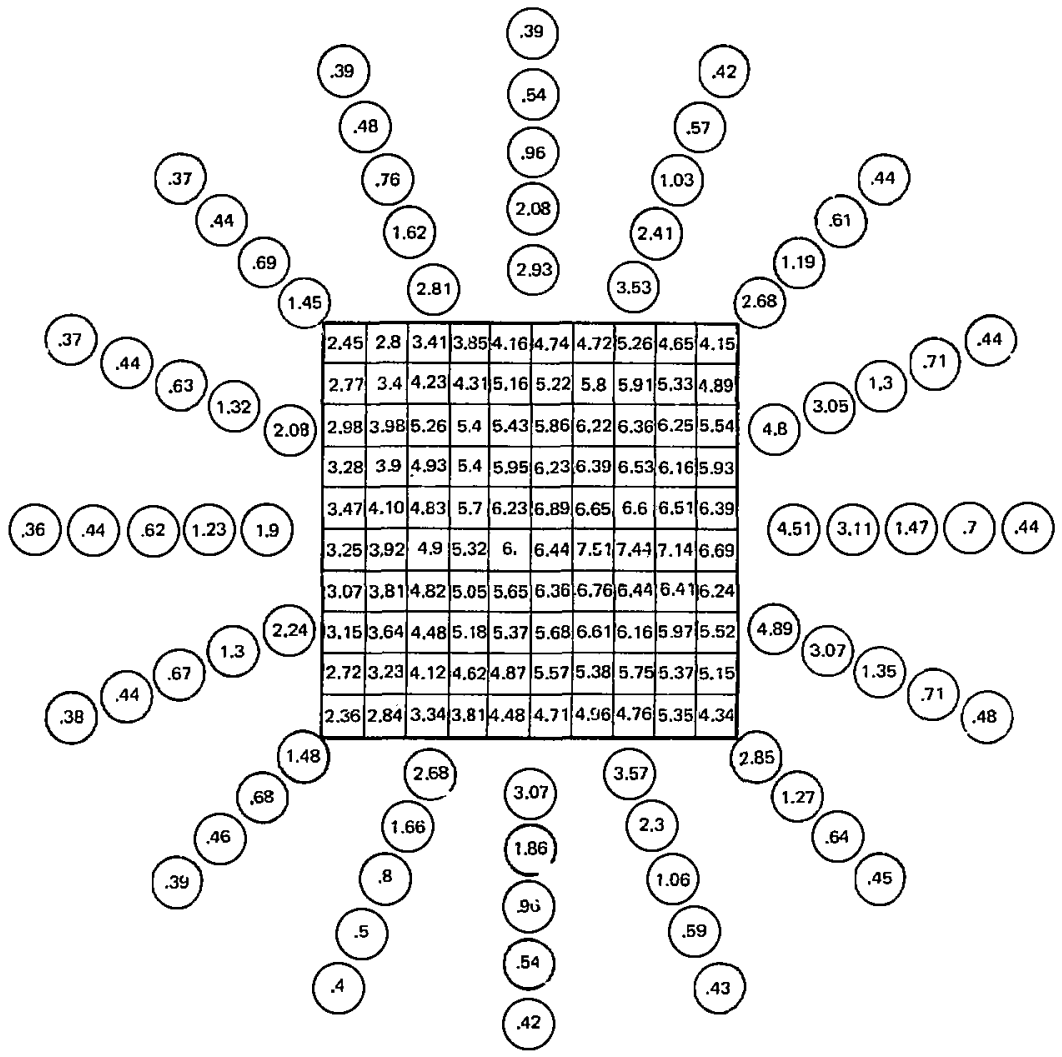

Fig. B-13. 


\begin{tabular}{ll} 
Beam energy & $0.8 \mathrm{GeV}$ \\
Run date & $6 / 20 / 76$ \\
Particle & Proten \\
Plate No. & P13 \\
\hline
\end{tabular}

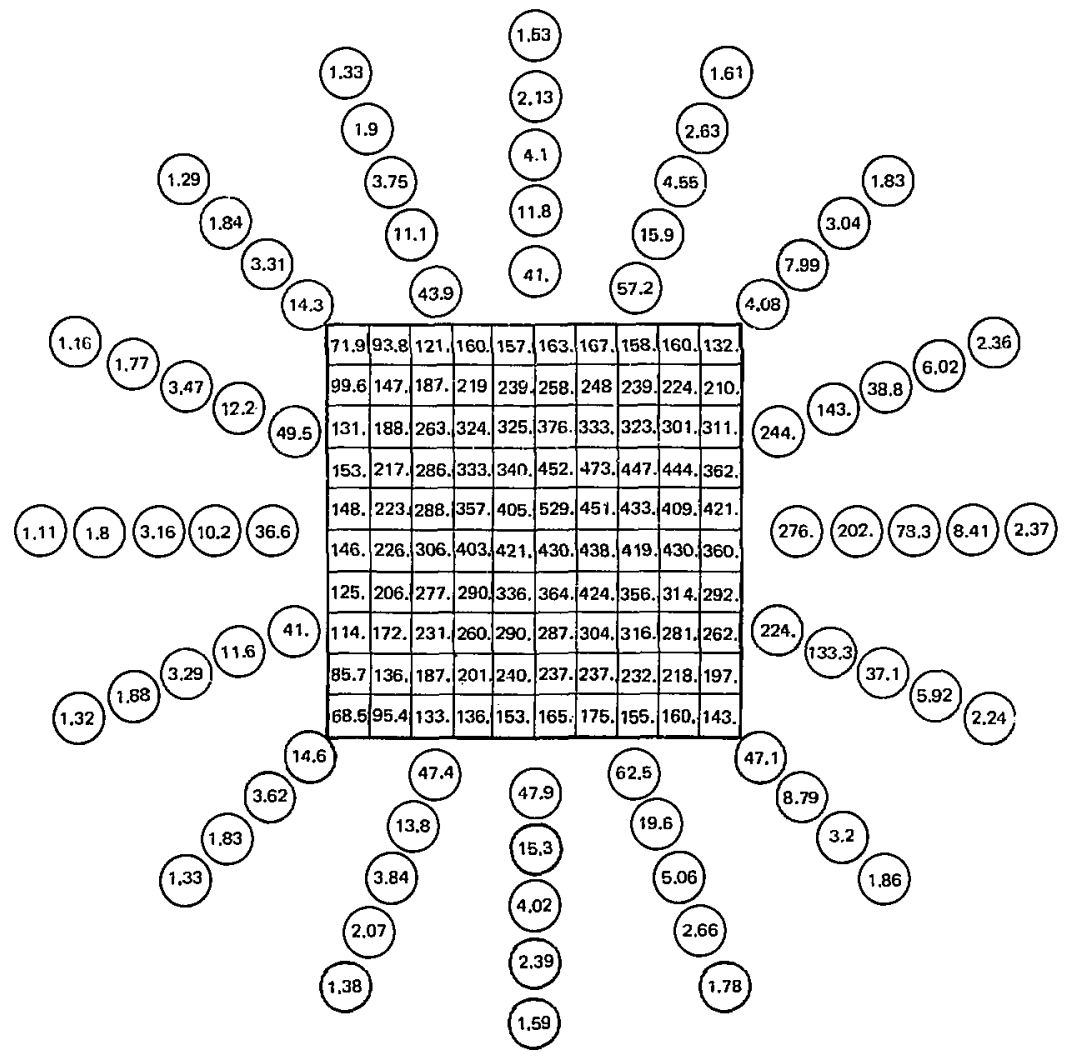

Fig. B-14. 


\begin{tabular}{ll} 
Beam energy & $0.8 \mathrm{GeV}$ \\
Run date & $6 / 20 / 76$ \\
Particle & Proton \\
Plate No. & $\mathrm{P} 21$ \\
\hline Plate location & 2 \\
\hline
\end{tabular}

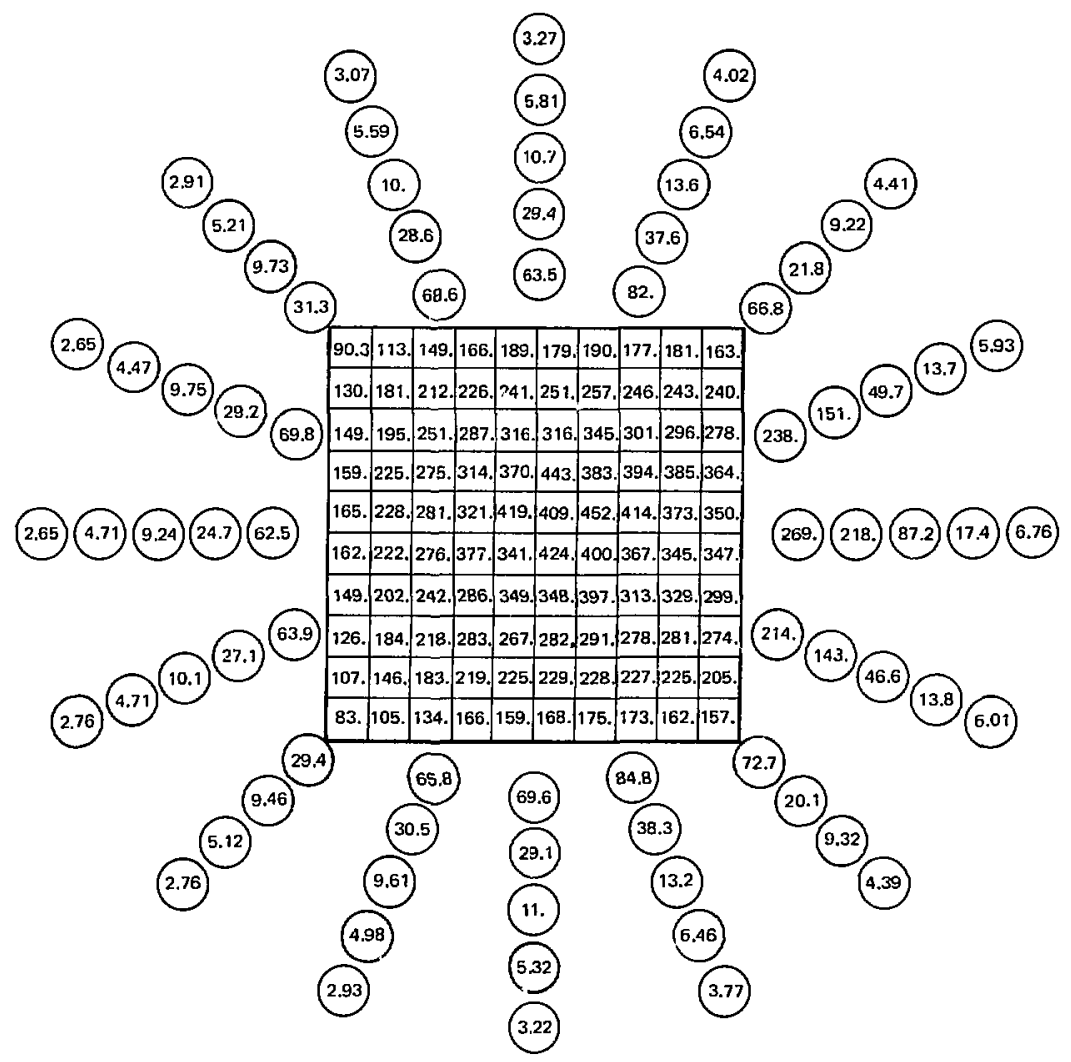

Fis. D-15. 


\begin{tabular}{|c|c|}
\hline Beam energy & $0.8 \mathrm{GeV}$ \\
\hline Run sate & $6 / 20 / 76$ \\
\hline Particle & Proton \\
\hline Plate No. & P22 \\
\hline Plate location & 3 \\
\hline
\end{tabular}

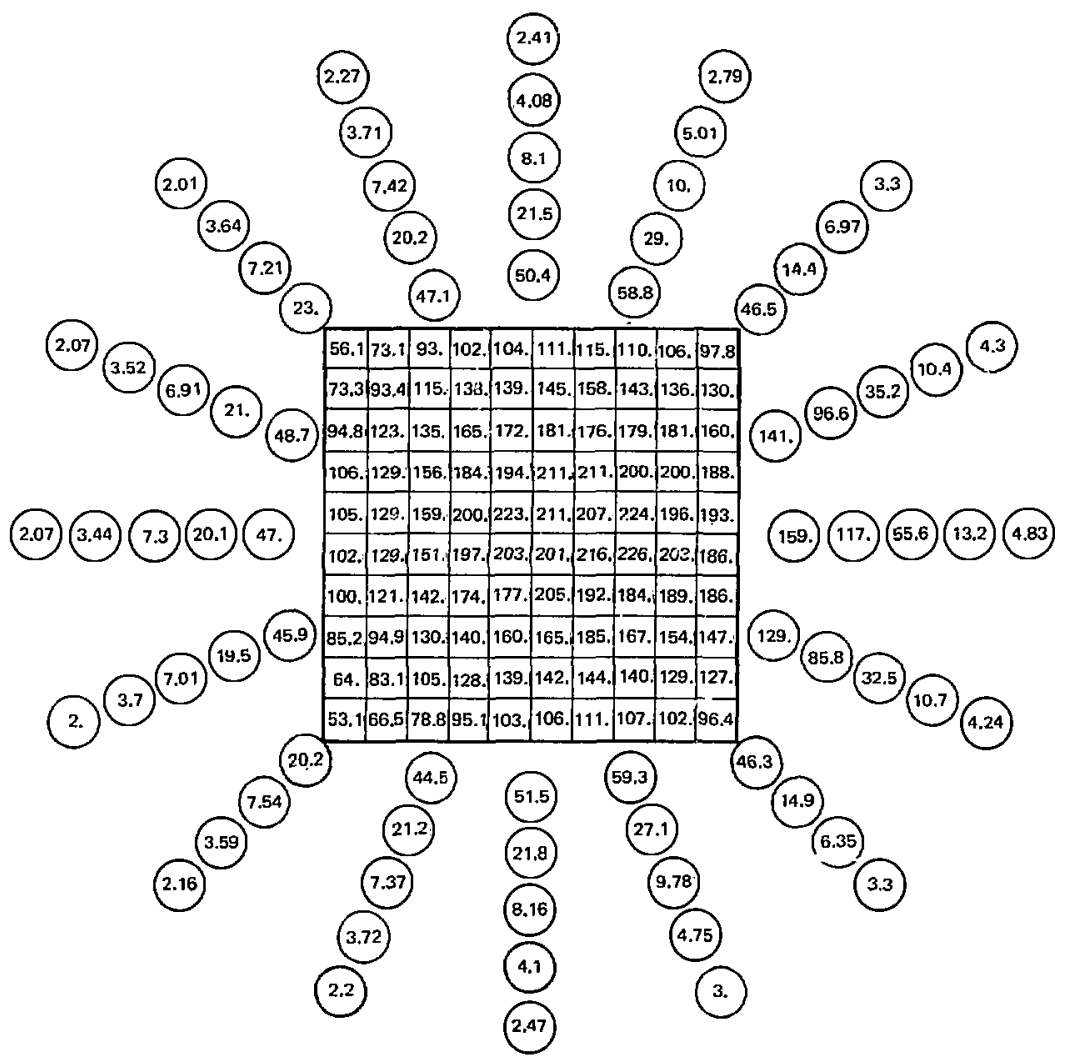




\begin{tabular}{ll} 
Beam energy & $\frac{0.8 \mathrm{GeV}}{6 / 20 / 76}$ \\
Run date & Proton \\
Particle & Prot \\
Plate No. & P.23 \\
\hline
\end{tabular}

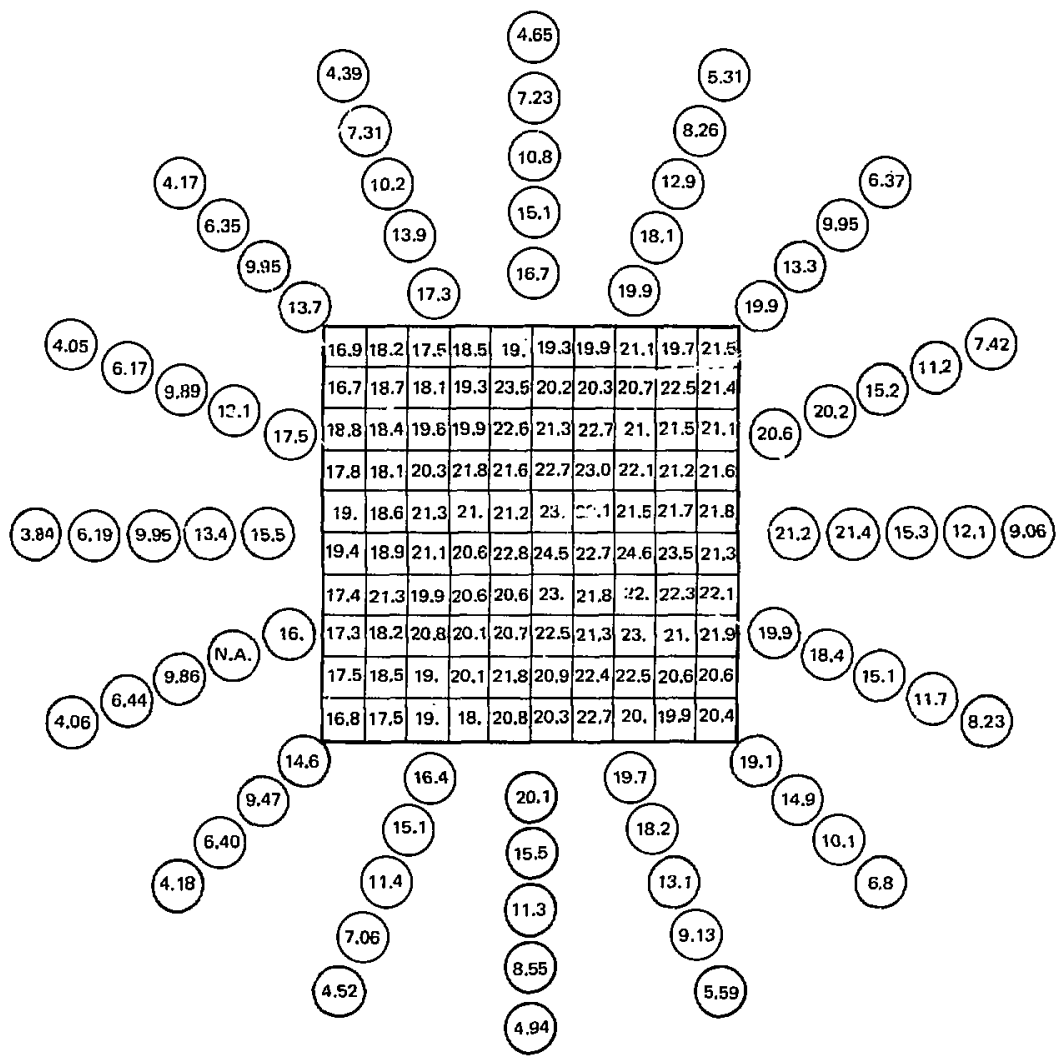

Fis. B-17. 


\begin{tabular}{ll} 
Beam energy & $0.8 \mathrm{GeV}$ \\
Run date & $6 / 20 / 76$ \\
Particle & Proton \\
\hline Plate No. & P24 \\
Plate location & 5 \\
\hline
\end{tabular}

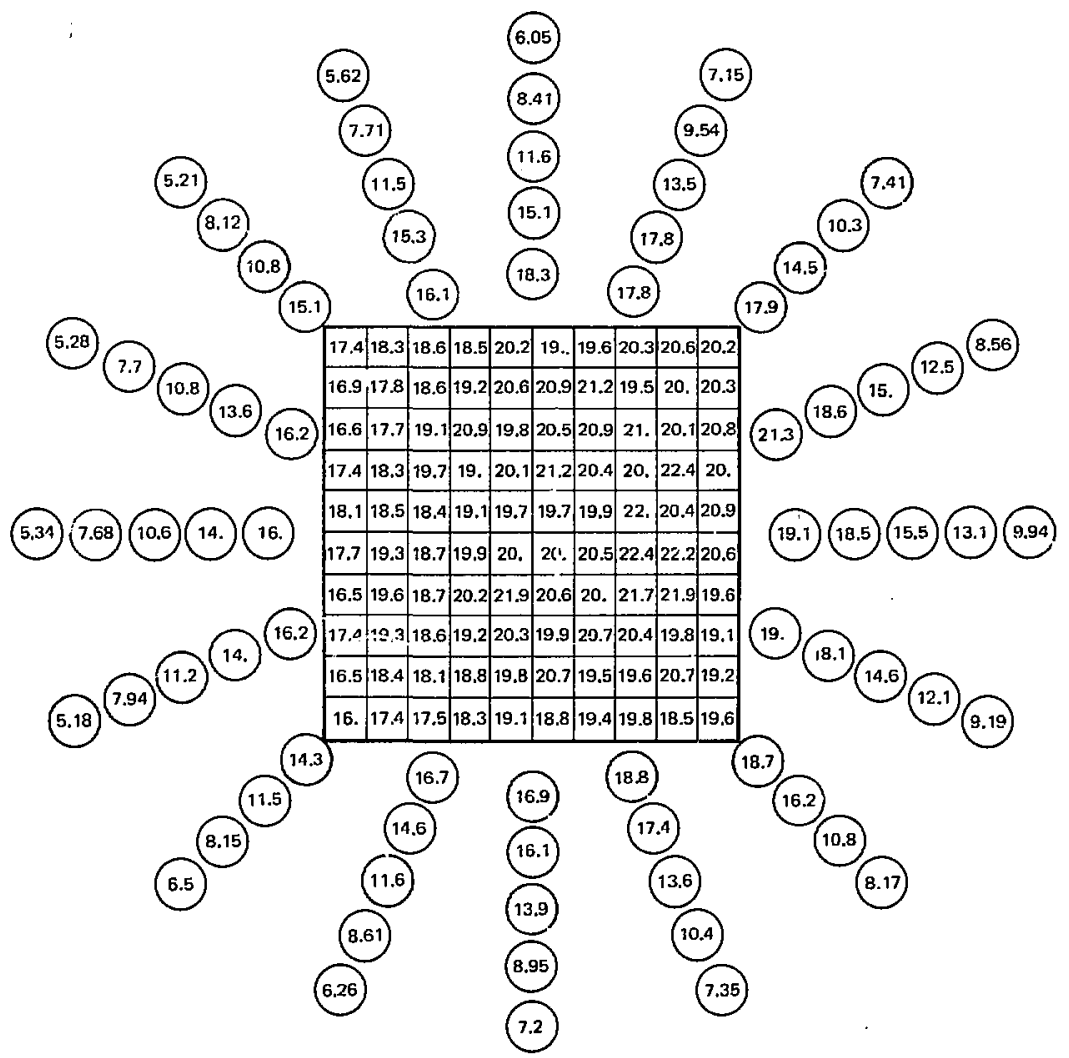

Fig. B-18. 
Table B-1.
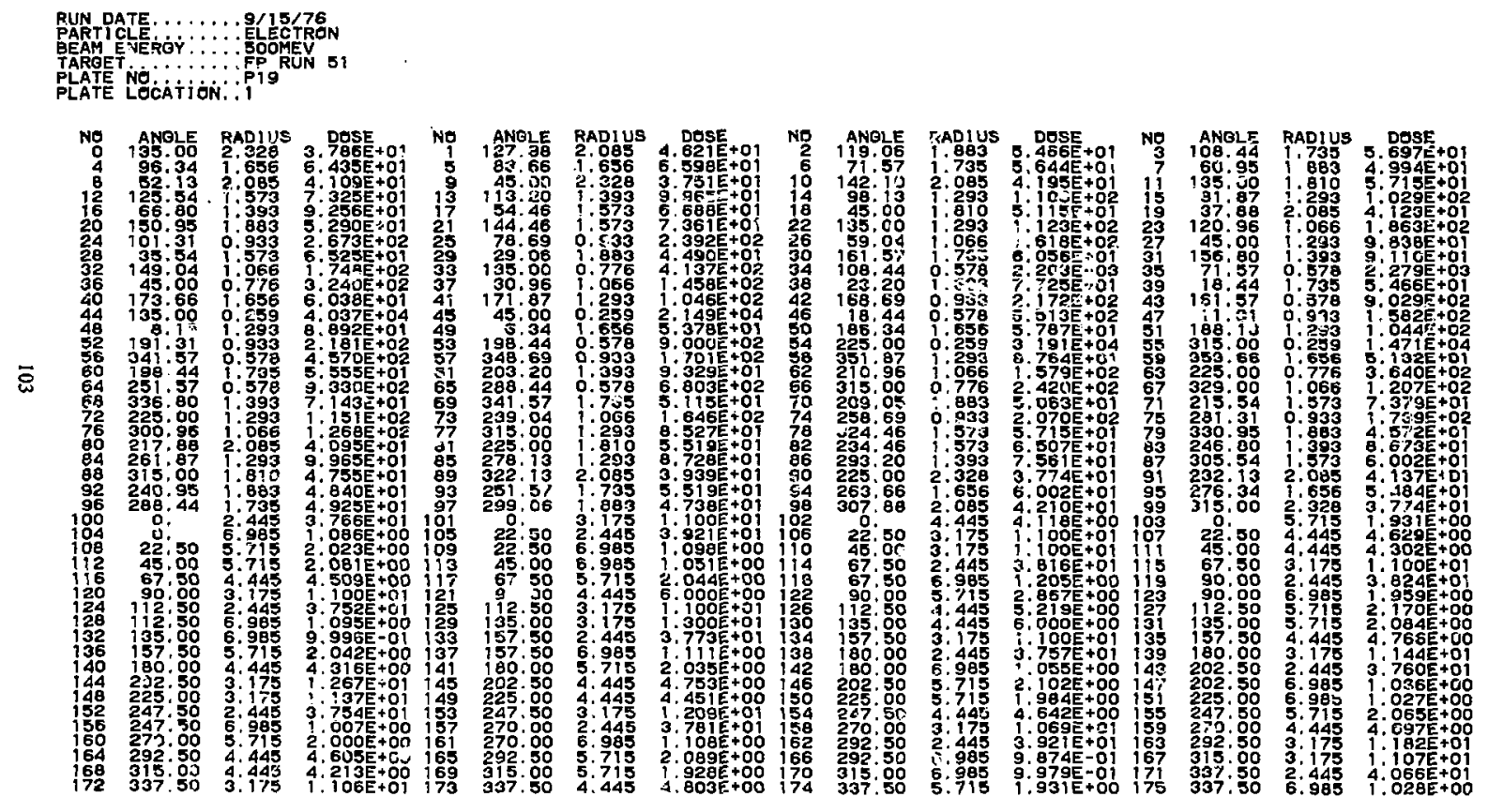
Table B-2.

RUN DATE. $\ldots \ldots \ldots$ 9/15/76

GEAM ENERGYY $\ldots .$. SOLOMEV

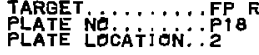
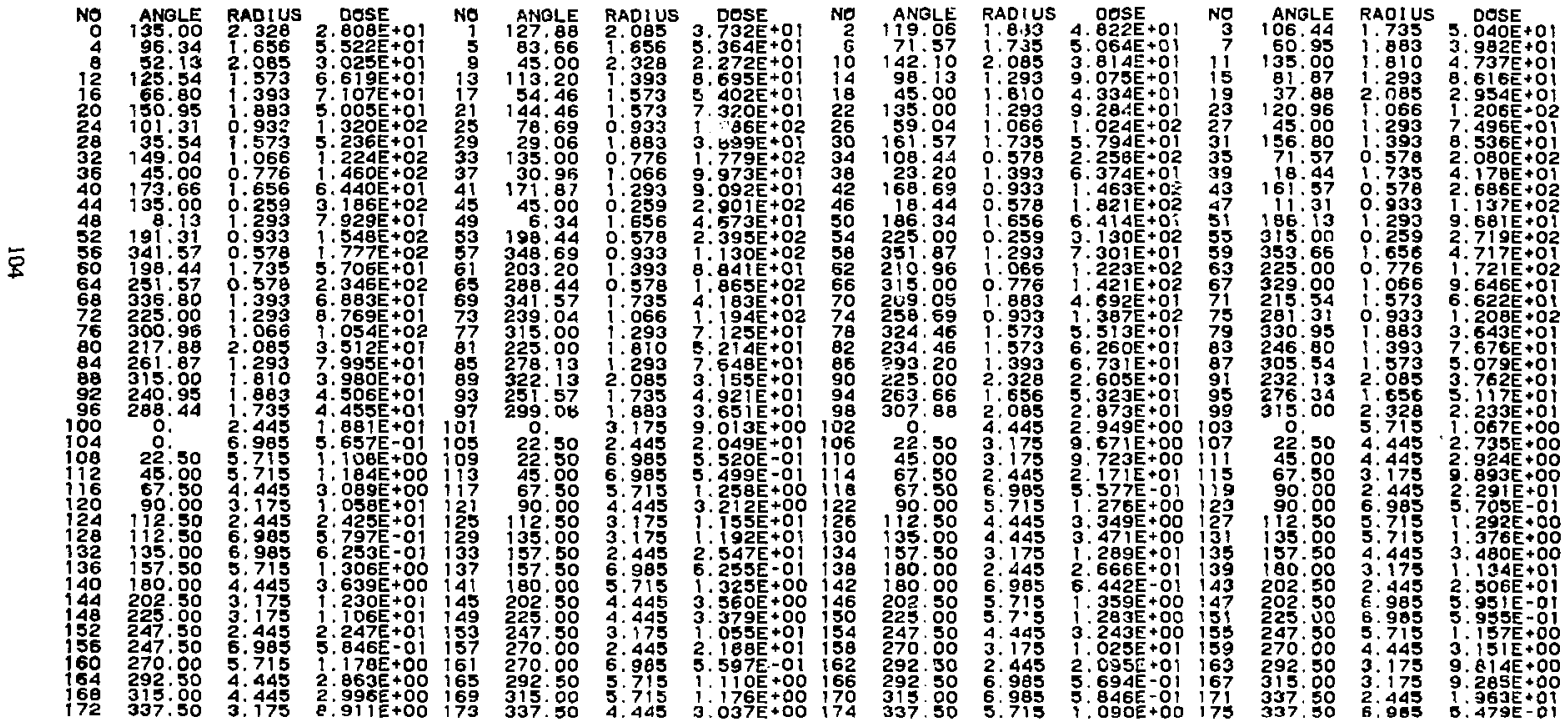

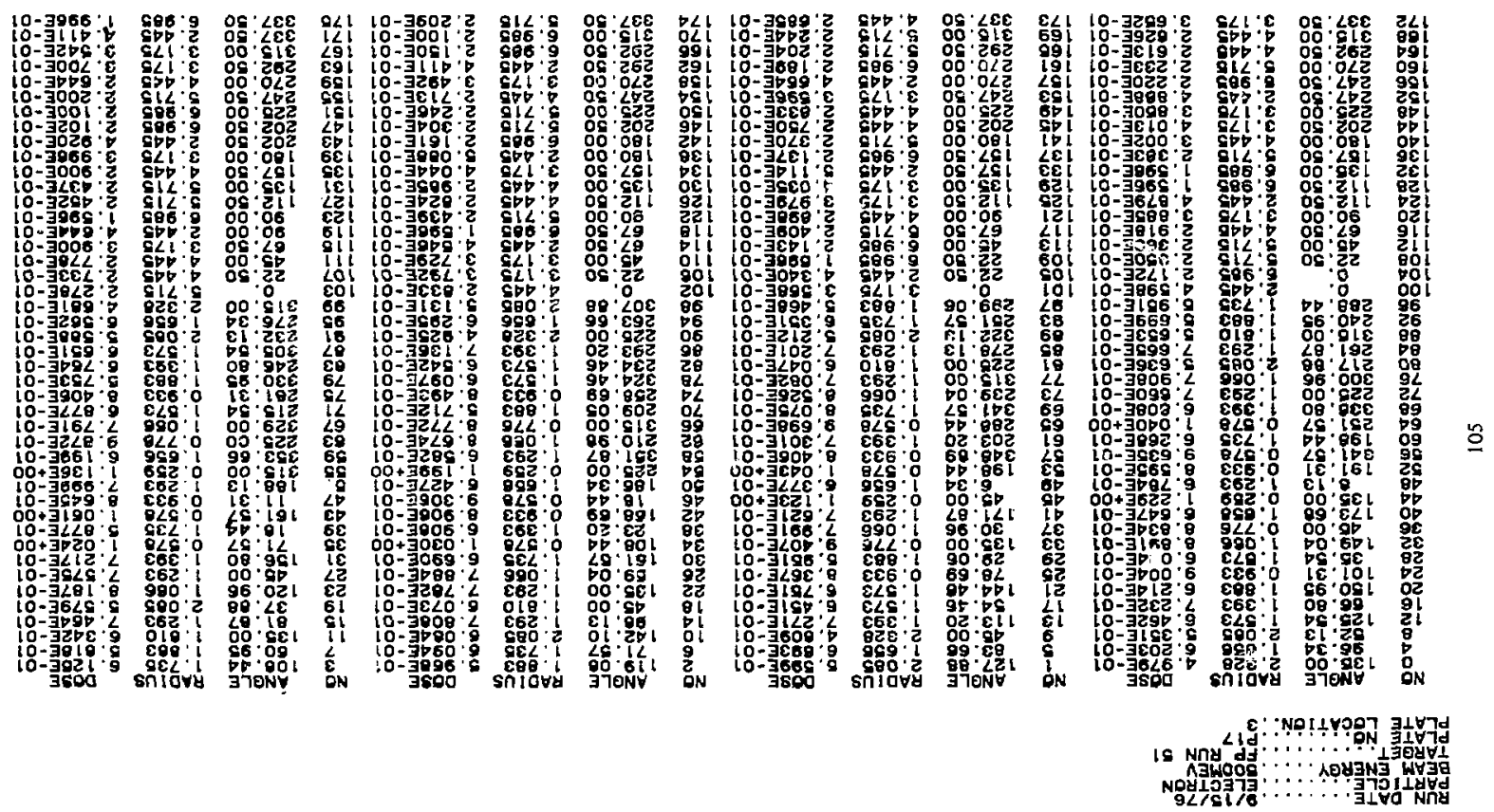
Table B-4.
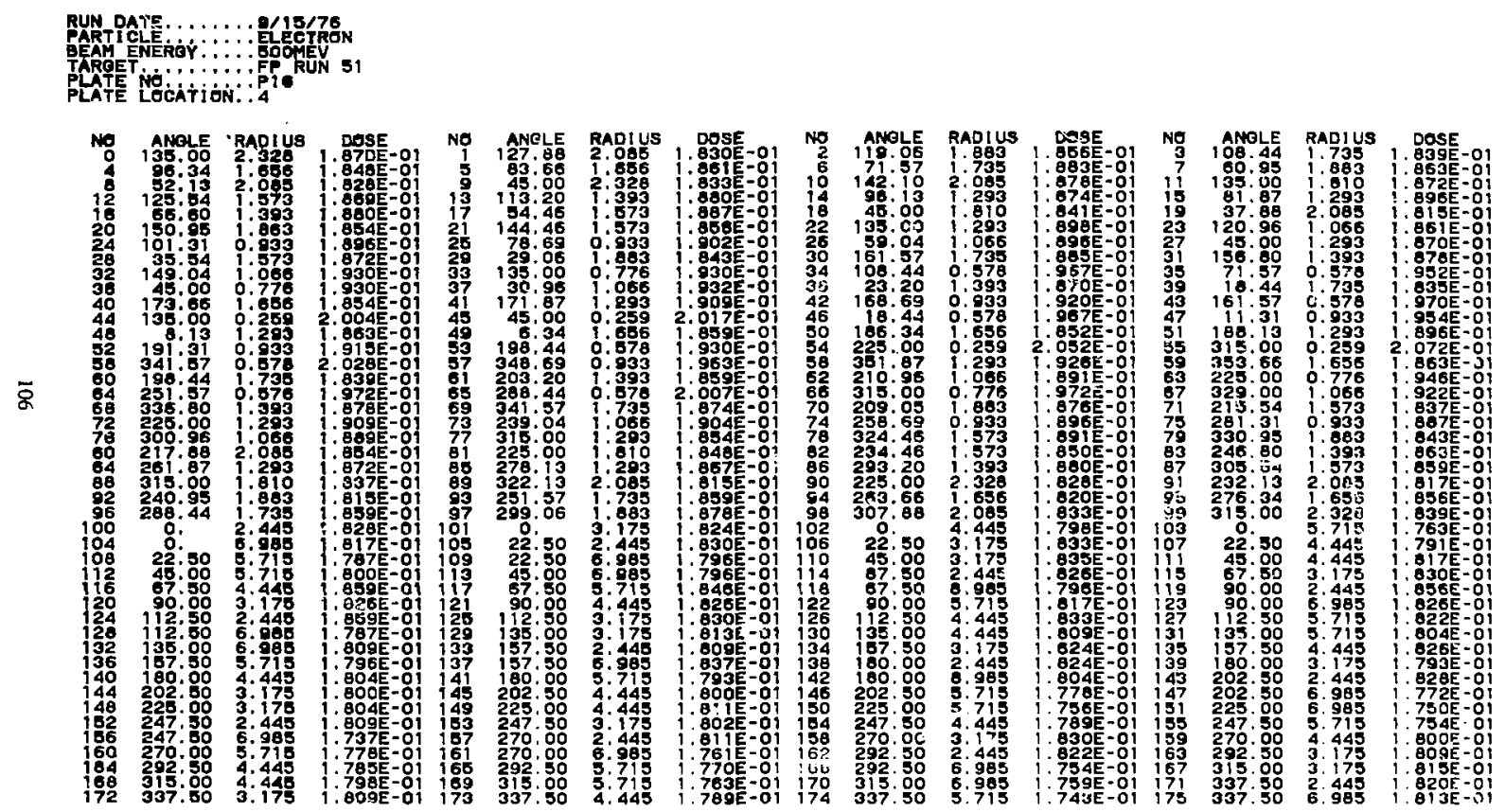

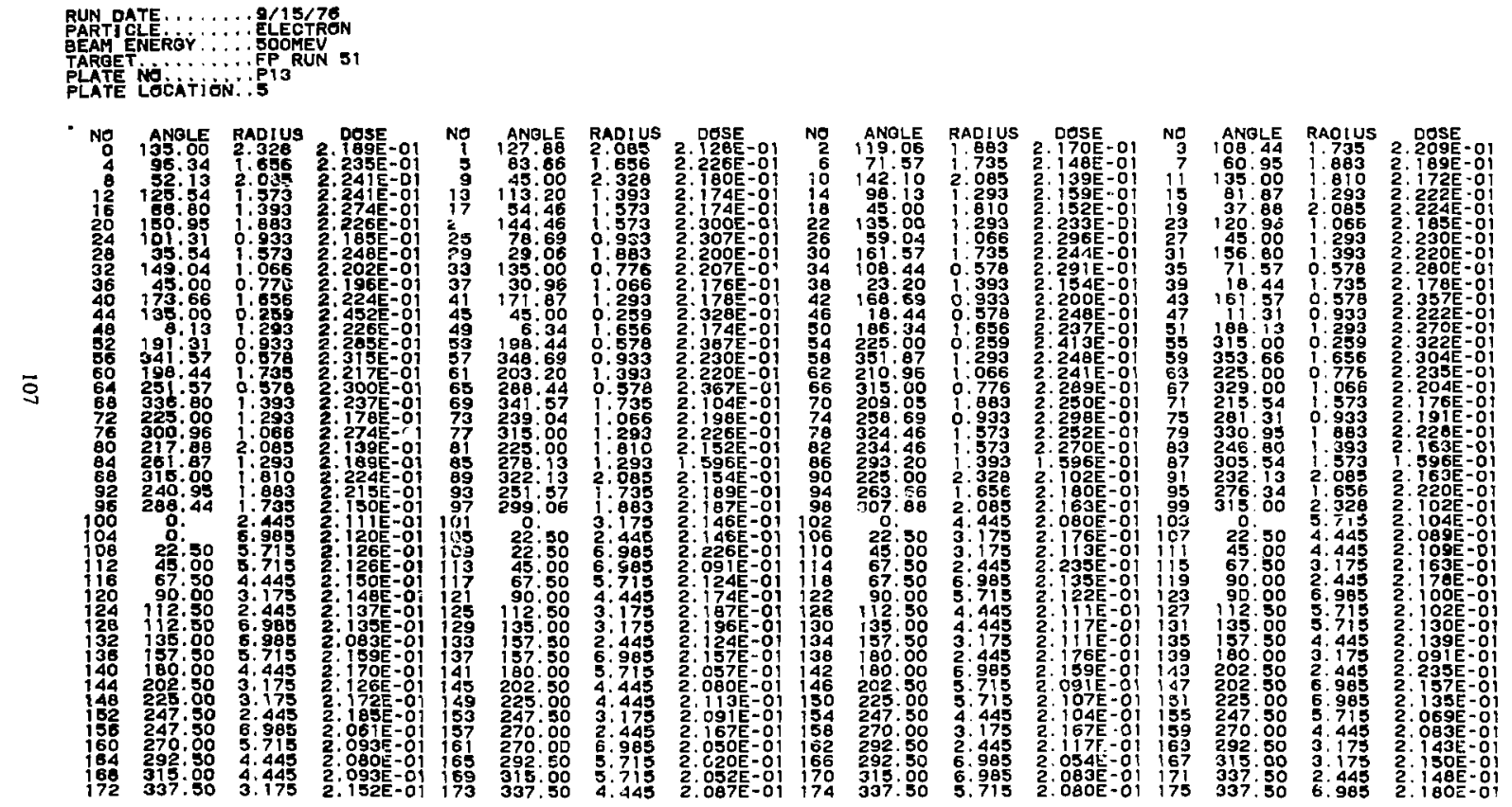

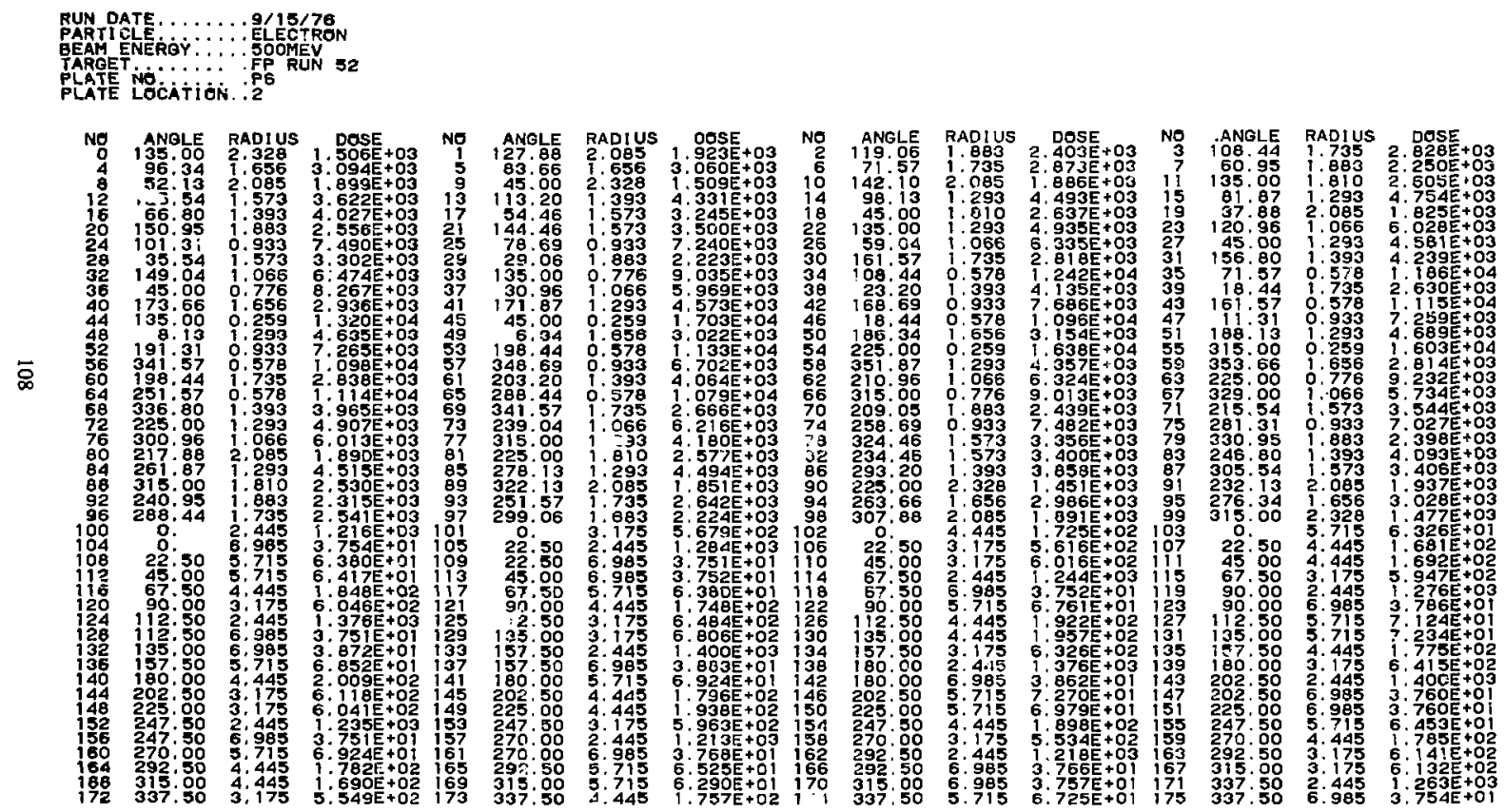


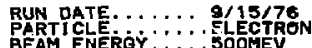

TARGET T........ : PP RUN 52

PLATE NG:AT广ONO::321

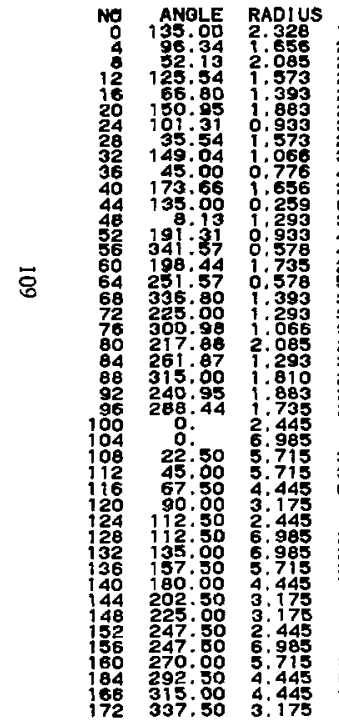
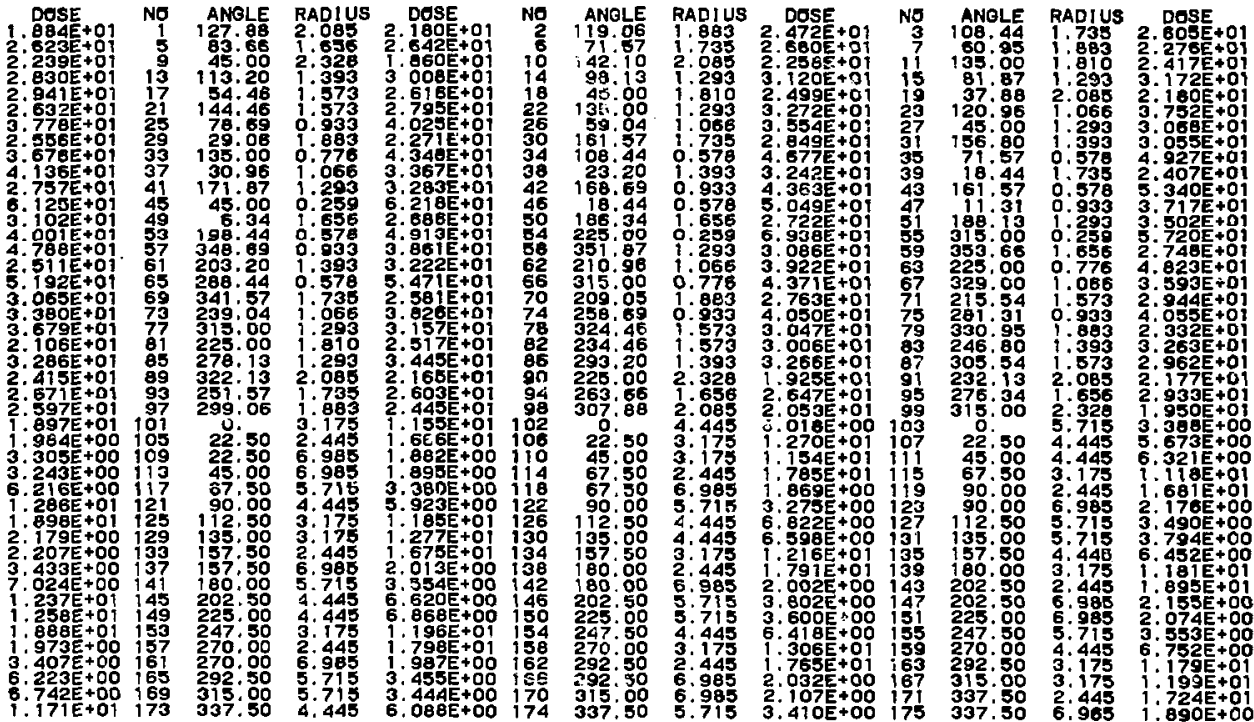
Table B-8.

RUN DATE. . . . . . 9/15/76

PARTI CLEERĠ $: \ldots:$ ELECTRON

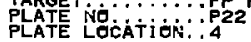

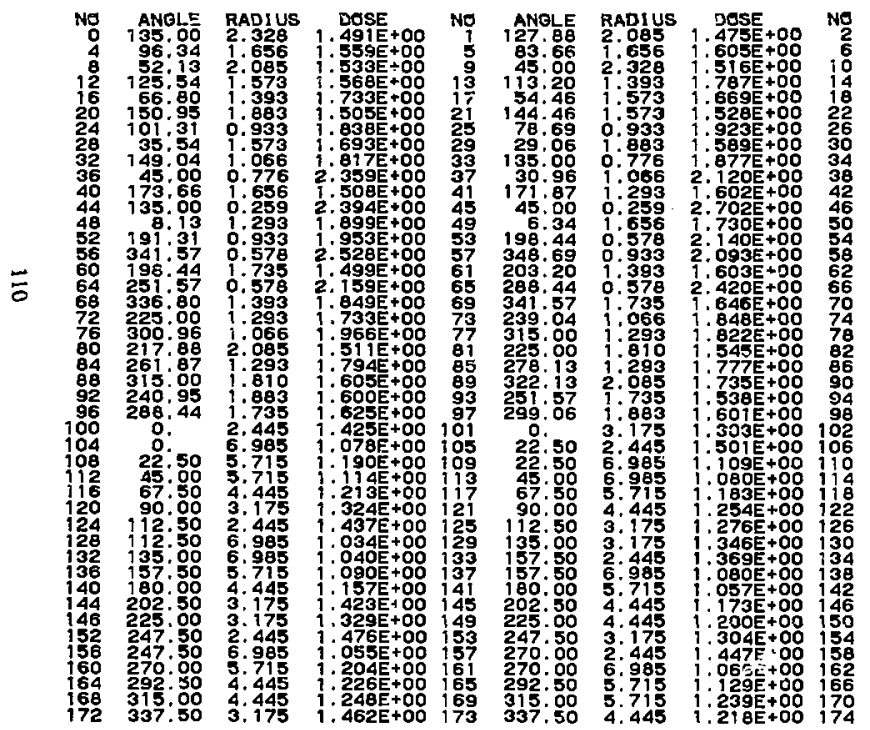

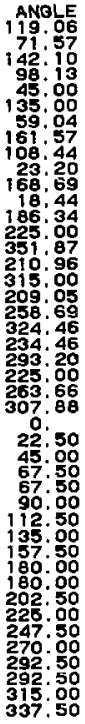

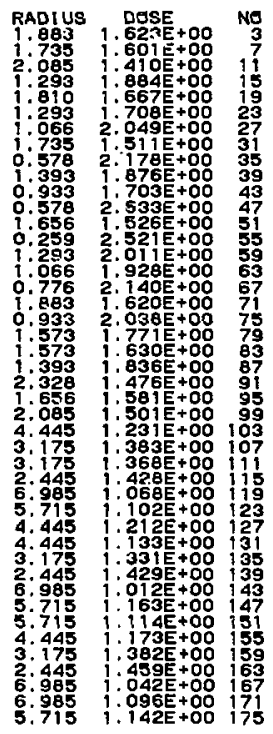

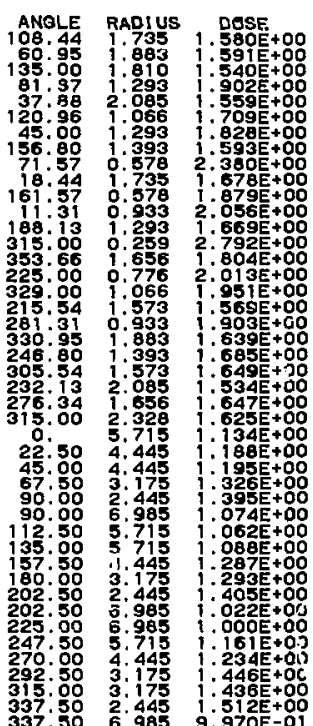


Table B-9.

RUN PEIE. . . . . 9/15/76

GEAY ENERơ $: \ldots$ : : 5 SOMEV

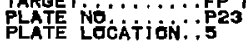
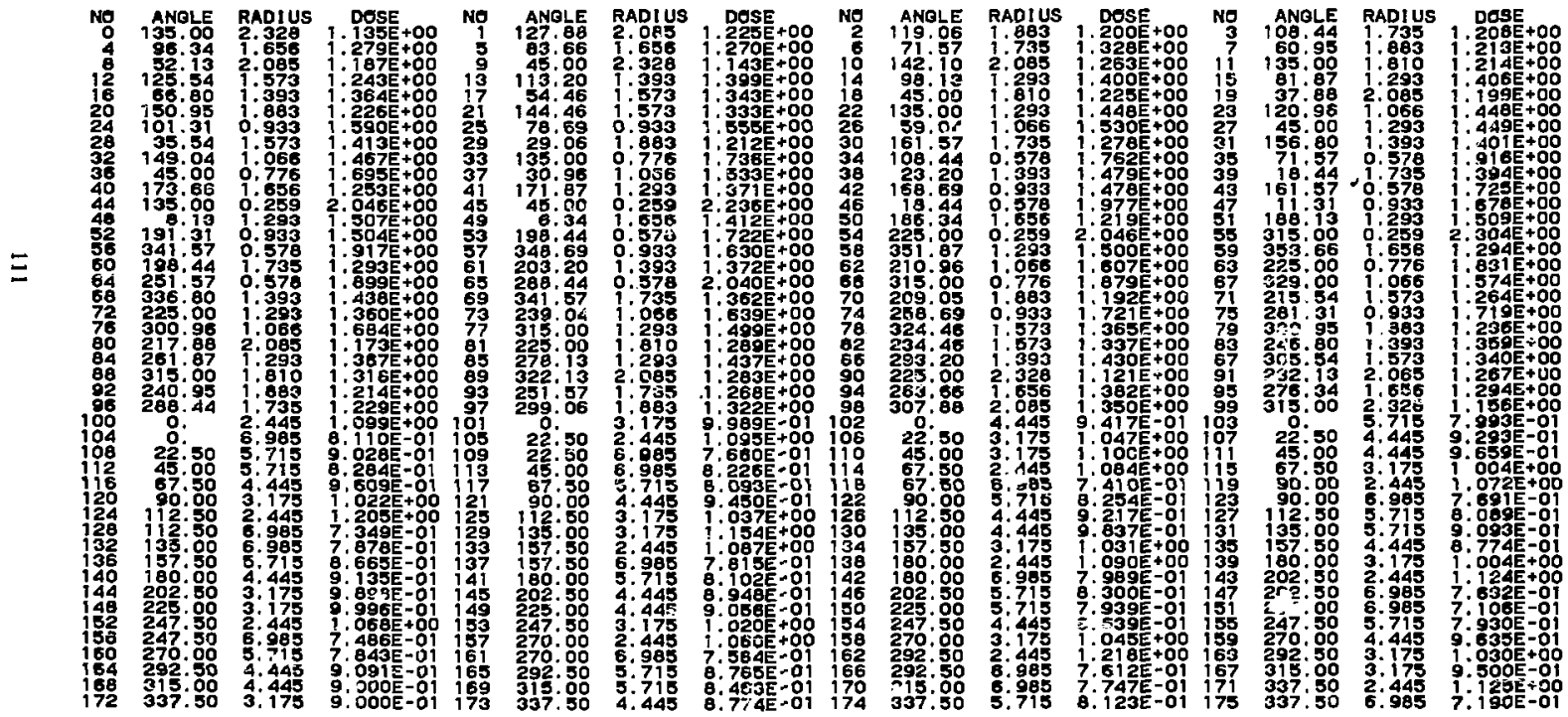
Table B-10.

RUN DATE, $\ldots \ldots \ldots$ 9/10/75

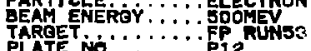

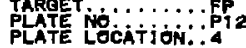

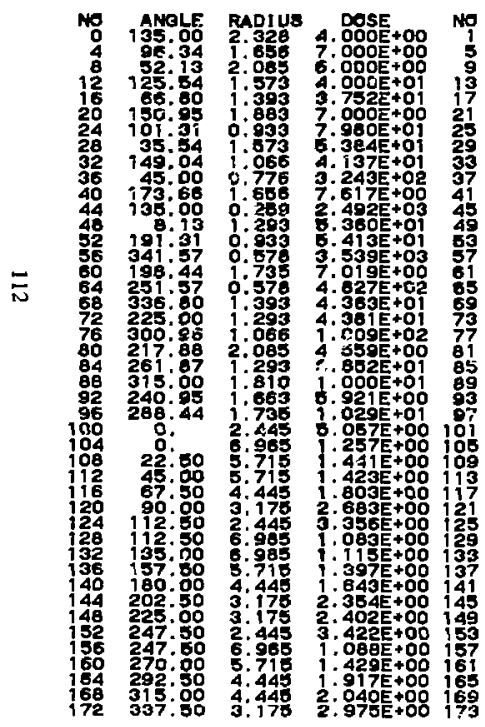

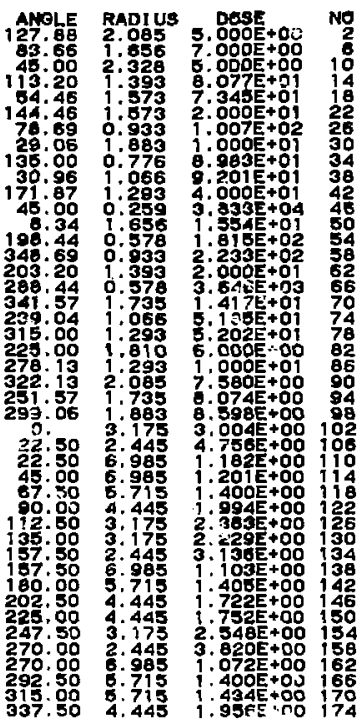

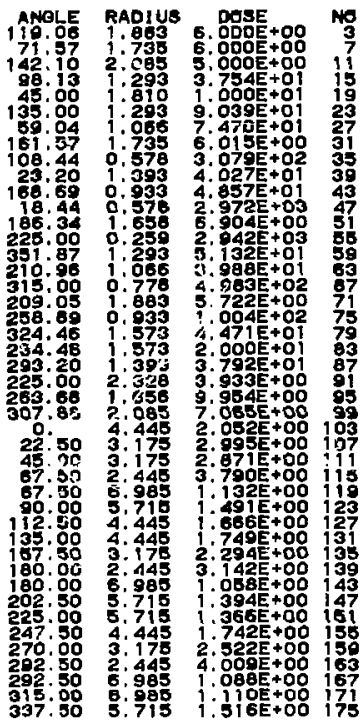

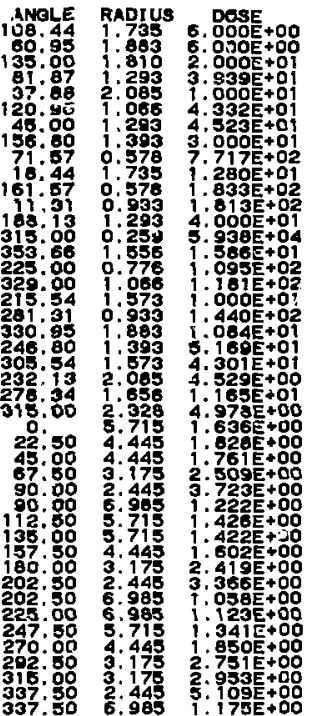


Table E-11.
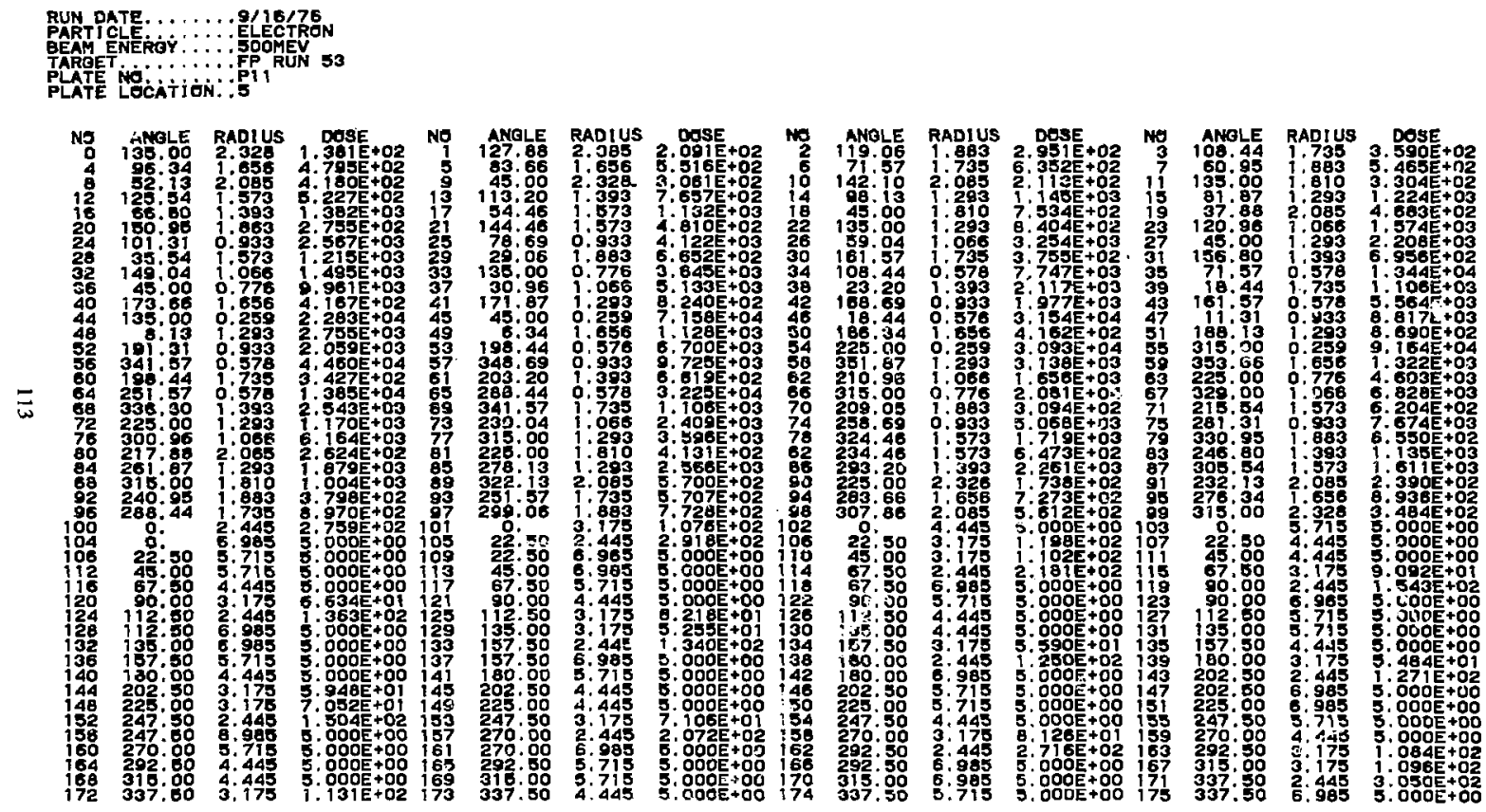

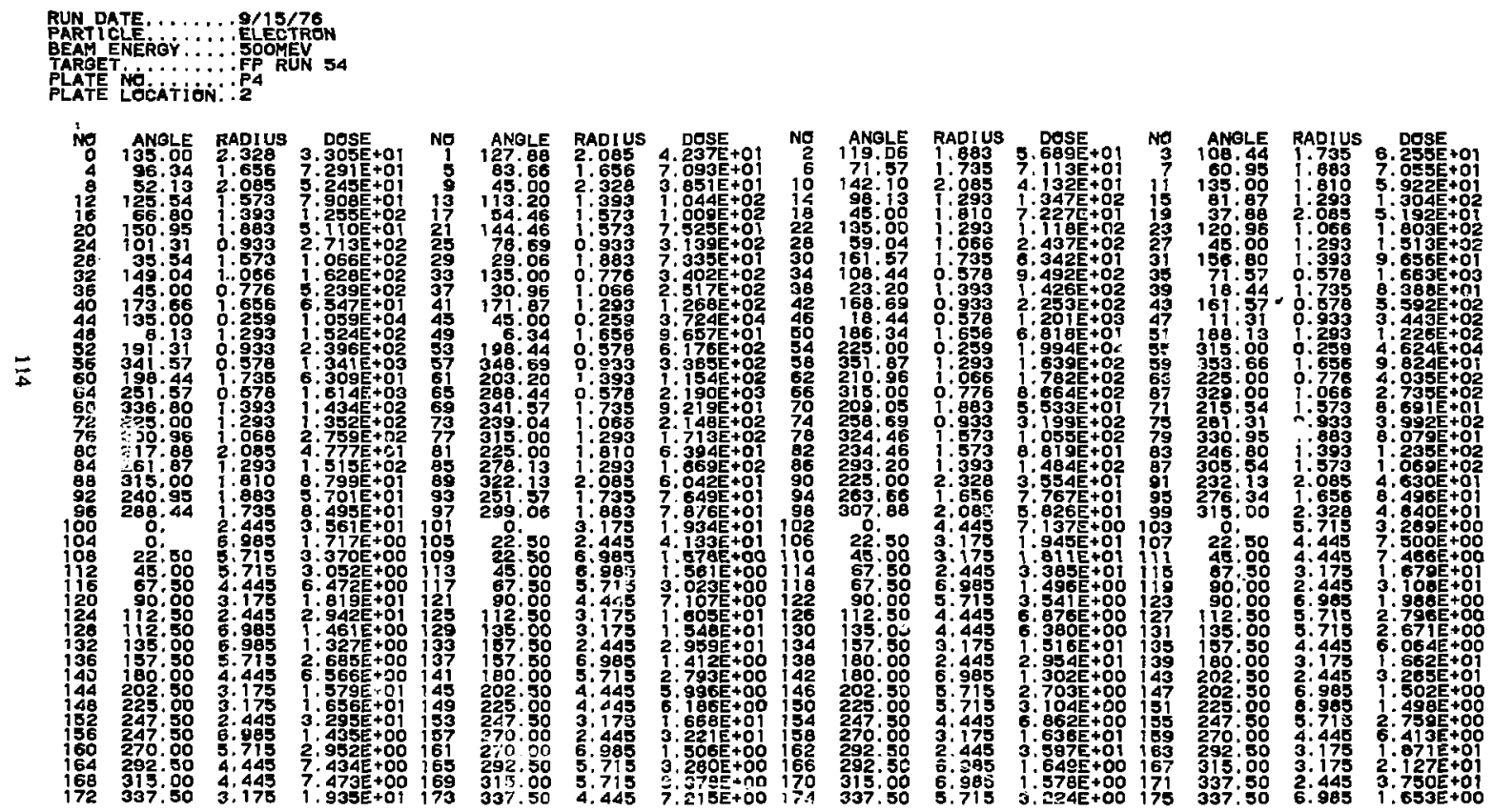
Table B-14.
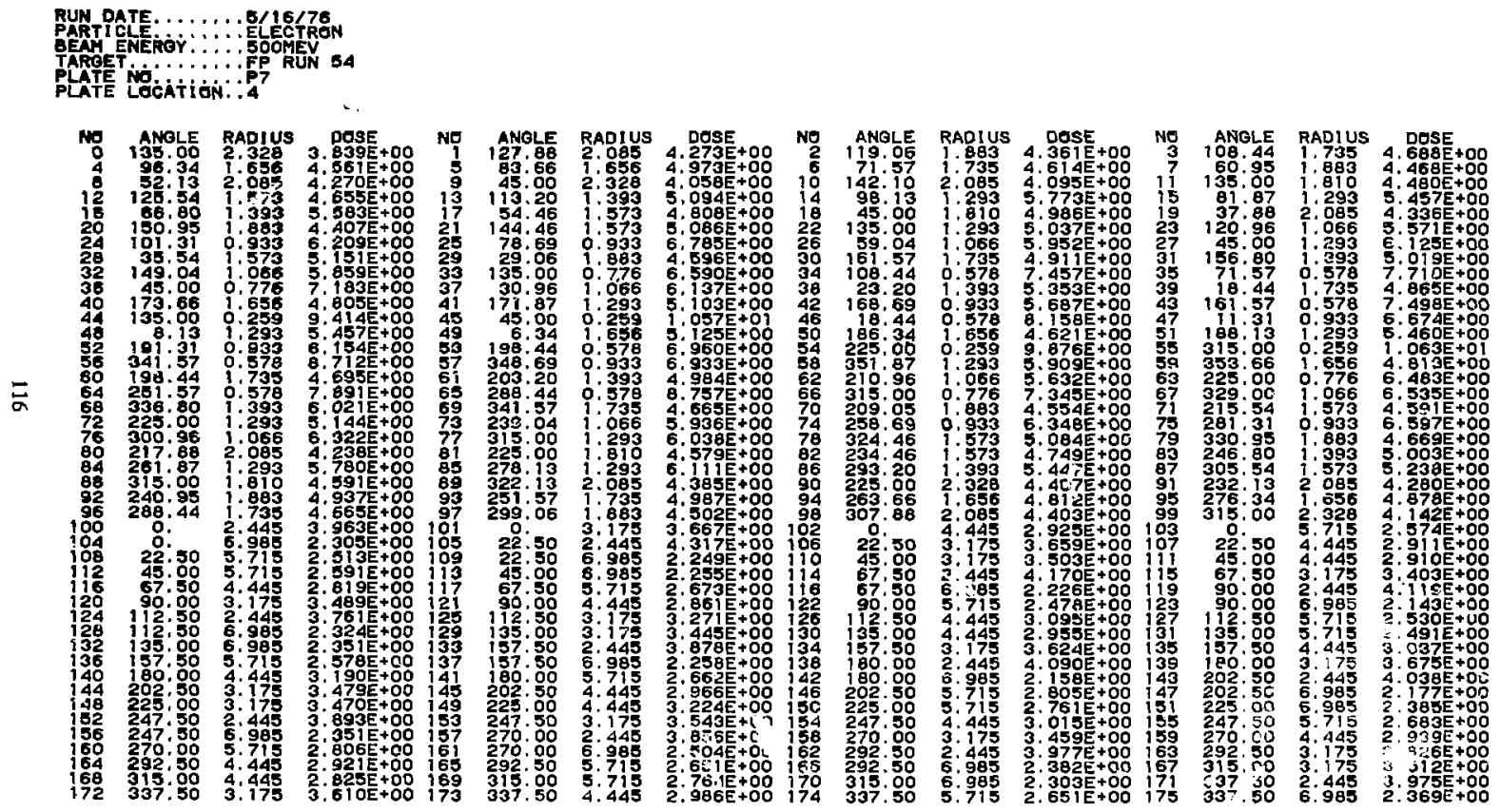
Table B-15.

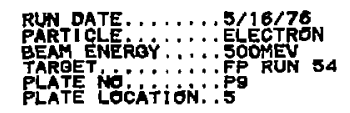

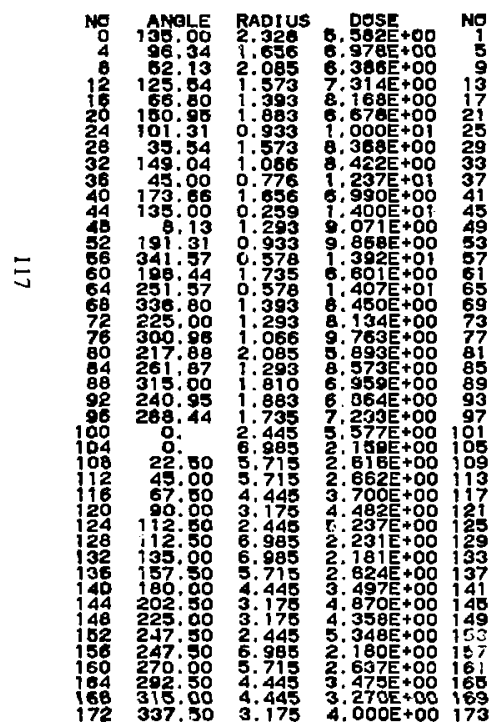
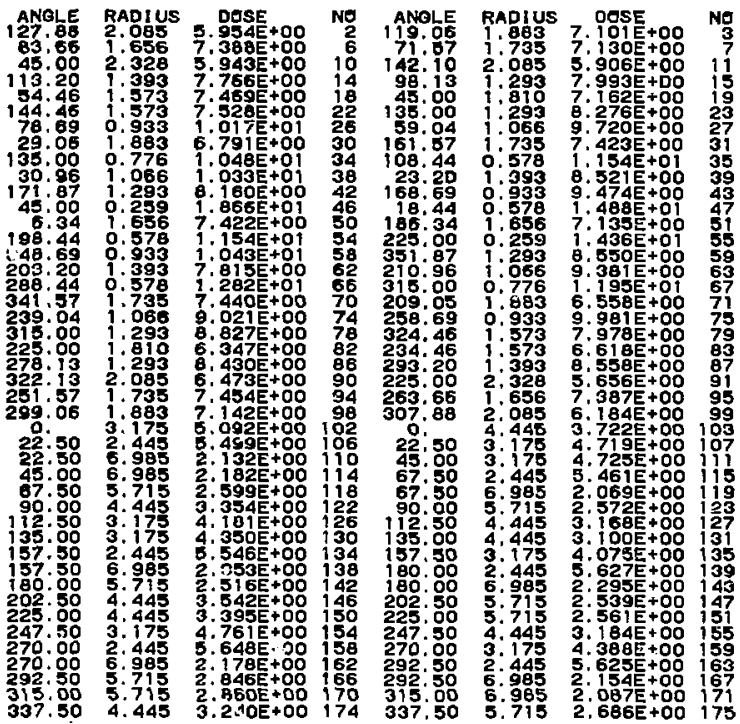

ANOLE 108
160
135 Q1.87 $120: 96$ 45.00 156.80 18.44

11131 i5: 0 353.66 $329: 00$ 215.54 281.31

330.95

246: 80 232.13 315.00 $22: 50$ $45: 00$ 67.50 90: 00 $135: 00$ 157.50 202.50 202.50

225.00

247.50

292. 50 337.50

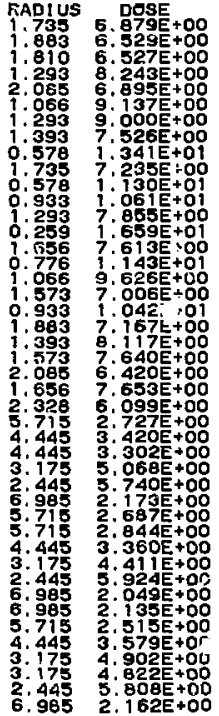


Table B-16.

RUN DATE $\ldots \ldots \ldots 5 / 16 / 76$

BEAM ENERÉY.:., : SOMOMEV $55^{*}$

PLATE LOQGATIOAN:,: :

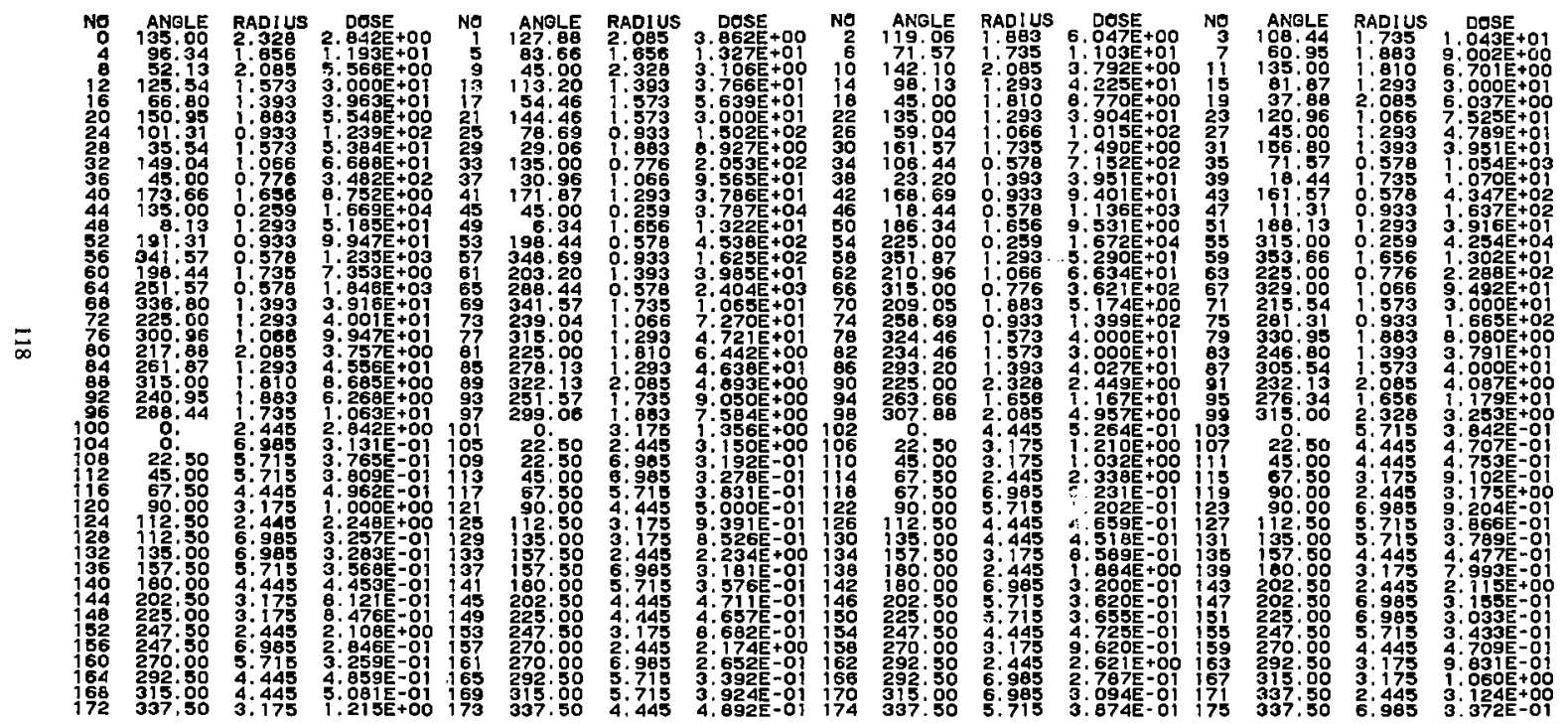

*Run 55 was an exposure of a single TLD plate. Beam parameters were the same as run $\$ 4$ 
Table B-17.

12,9/16 PROTON 2B. 5GEV FP RUN 61 P3 1

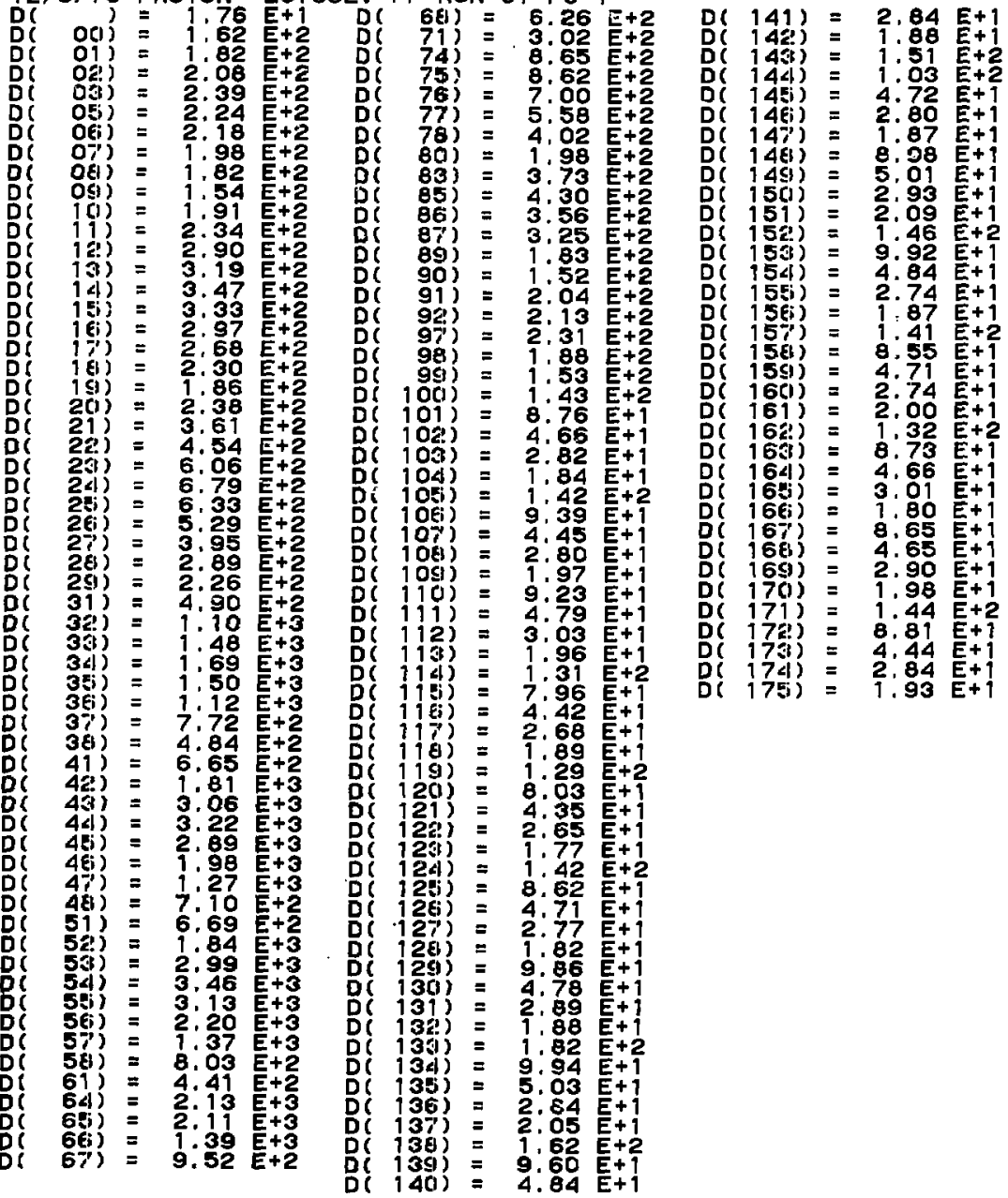


Table B-18.

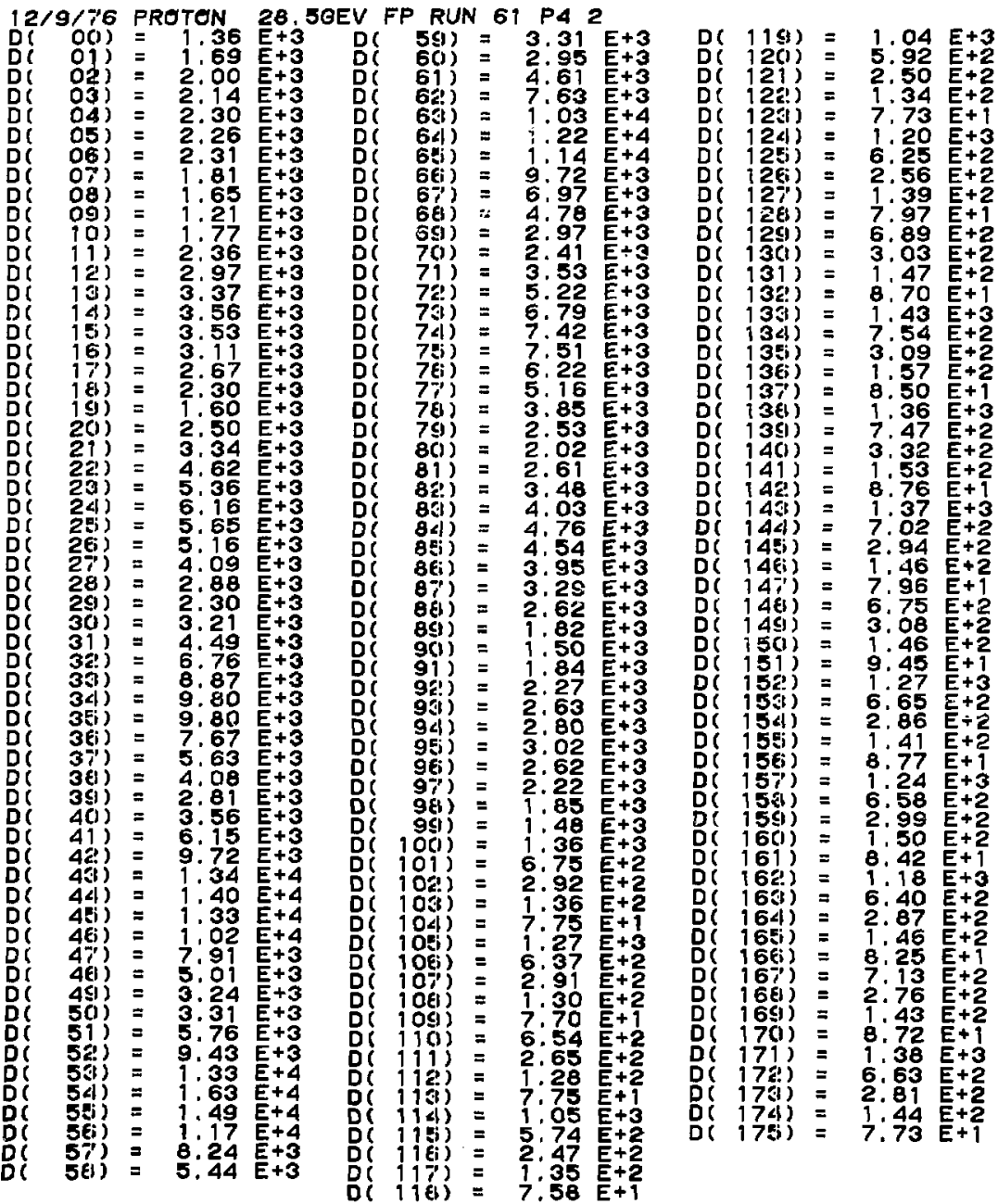


Table B-19.

12/9/7'6 PROTON 28.50EV FP RUN 61 P5 3

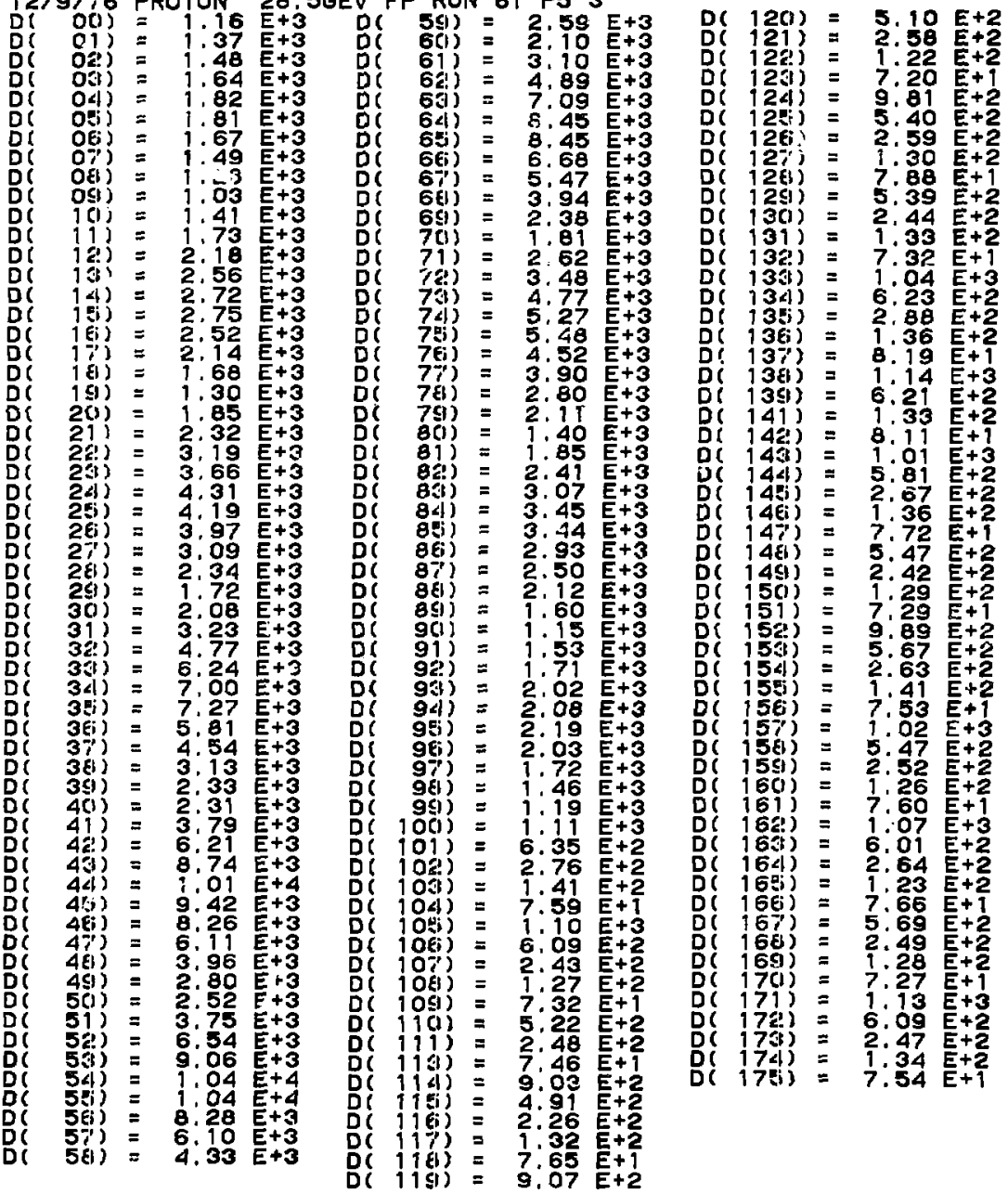


Table B-20.

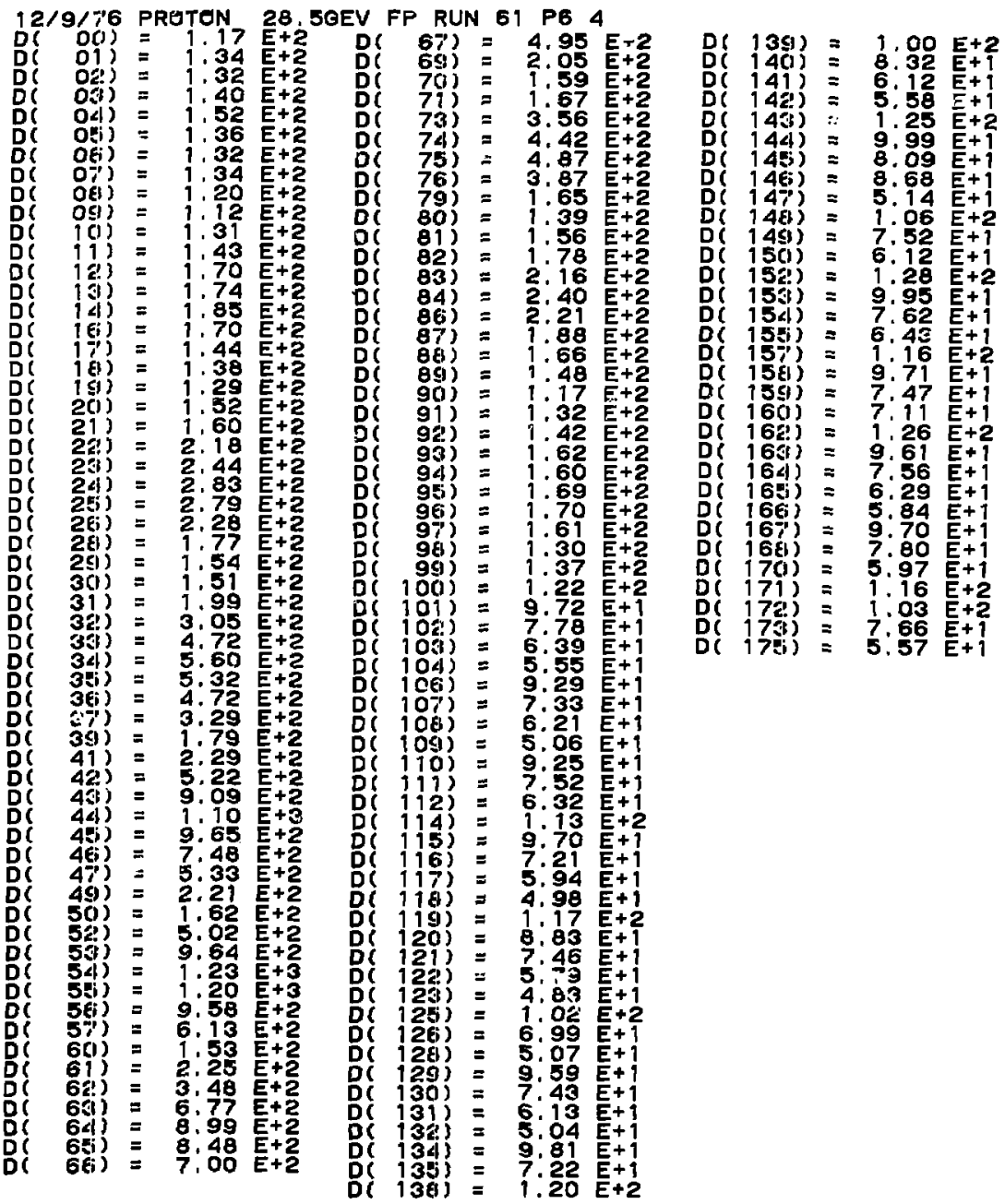


Table B-21.

\begin{tabular}{|c|c|c|c|c|c|c|c|c|c|c|}
\hline 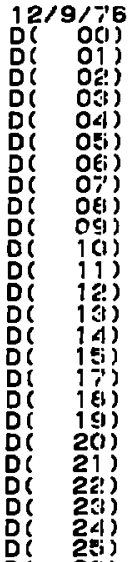 & 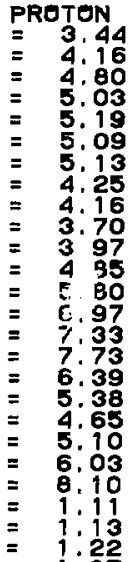 & $\begin{array}{l}E+2 \\
E+2 \\
E+2 \\
E+2 \\
E+2 \\
E+2 \\
E+2 \\
E+2 \\
E+2 \\
E+2 \\
E+2 \\
E+2 \\
E+2 \\
E+2 \\
E+2 \\
E+2 \\
E+2 \\
E+2 \\
E+2 \\
E+2 \\
E+2 \\
E+2 \\
E+3 \\
E+3 \\
E+3\end{array}$ & 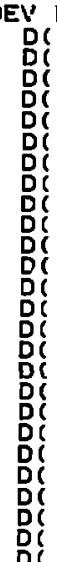 & 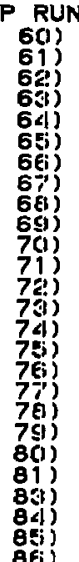 & 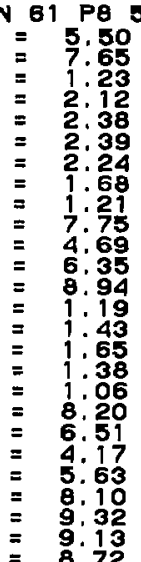 & $\begin{array}{l}E+2 \\
E+2 \\
E+3 \\
E+3 \\
E+3 \\
E+3 \\
E+3 \\
E+3 \\
E+3 \\
E+2 \\
E+2 \\
E+2 \\
E+2 \\
E+3 \\
E+3 \\
E+3 \\
E+3 \\
E+3 \\
E+2 \\
E+2 \\
E+2 \\
E+2 \\
E+2 \\
E+2 \\
E+2\end{array}$ & 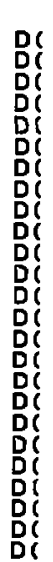 & 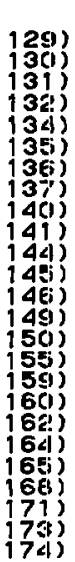 & $\begin{array}{l}= \\
= \\
= \\
= \\
= \\
= \\
= \\
= \\
= \\
= \\
= \\
= \\
= \\
= \\
= \\
= \\
=\end{array}$ & $\begin{array}{r}2.28 \\
1.48 \\
1.08 \\
7.74 \\
2.56 \\
1.56 \\
1.07 \\
7.79 \\
1.69 \\
1.13 \\
2.39 \\
1.61 \\
1.07 \\
1.49 \\
1.06 \\
1.09 \\
1.58\end{array}$ \\
\hline
\end{tabular}

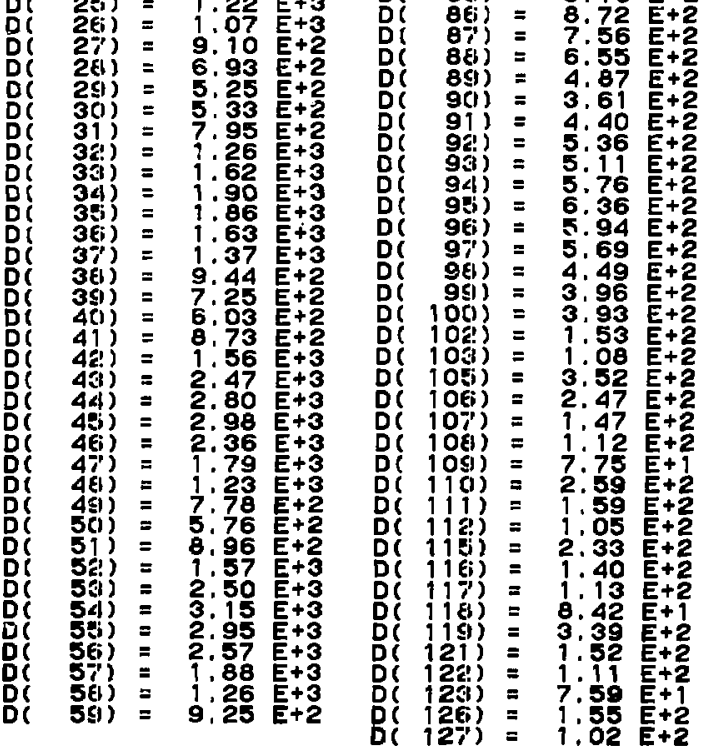


Table B-22.

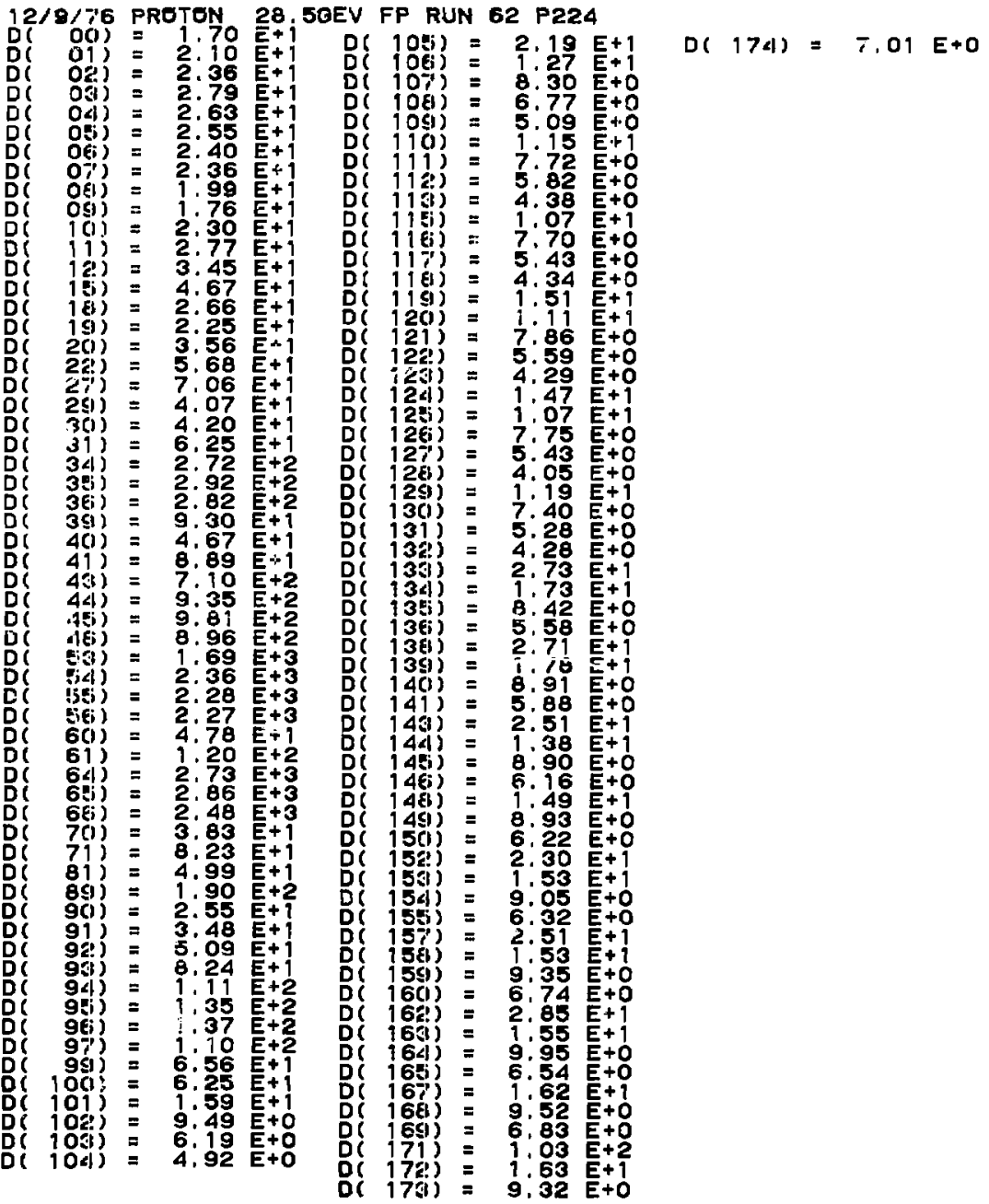




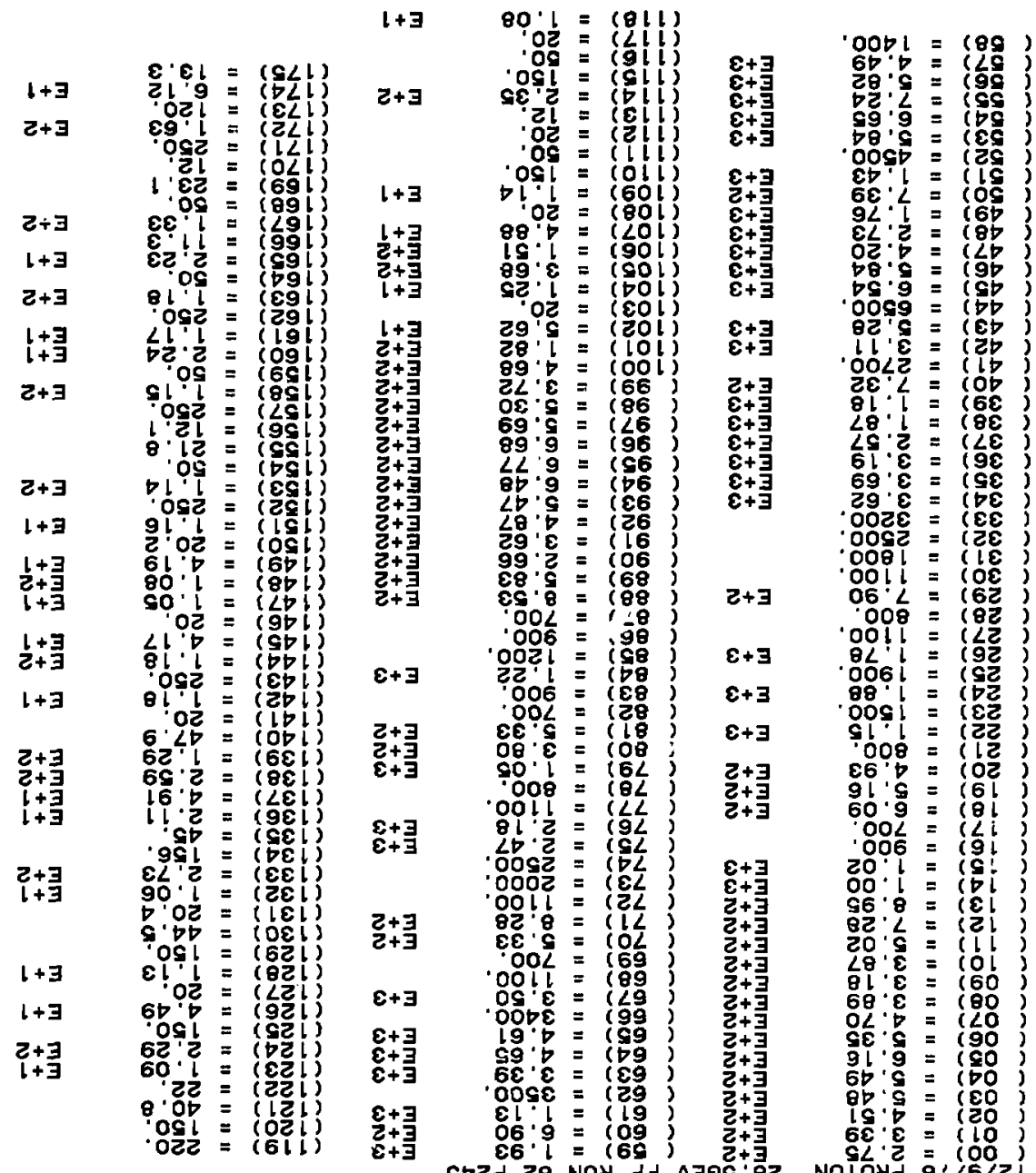

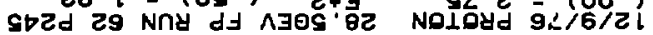


Table B-25.

12/9/76 PROTON 28,5GEV FP RUN 63 P102

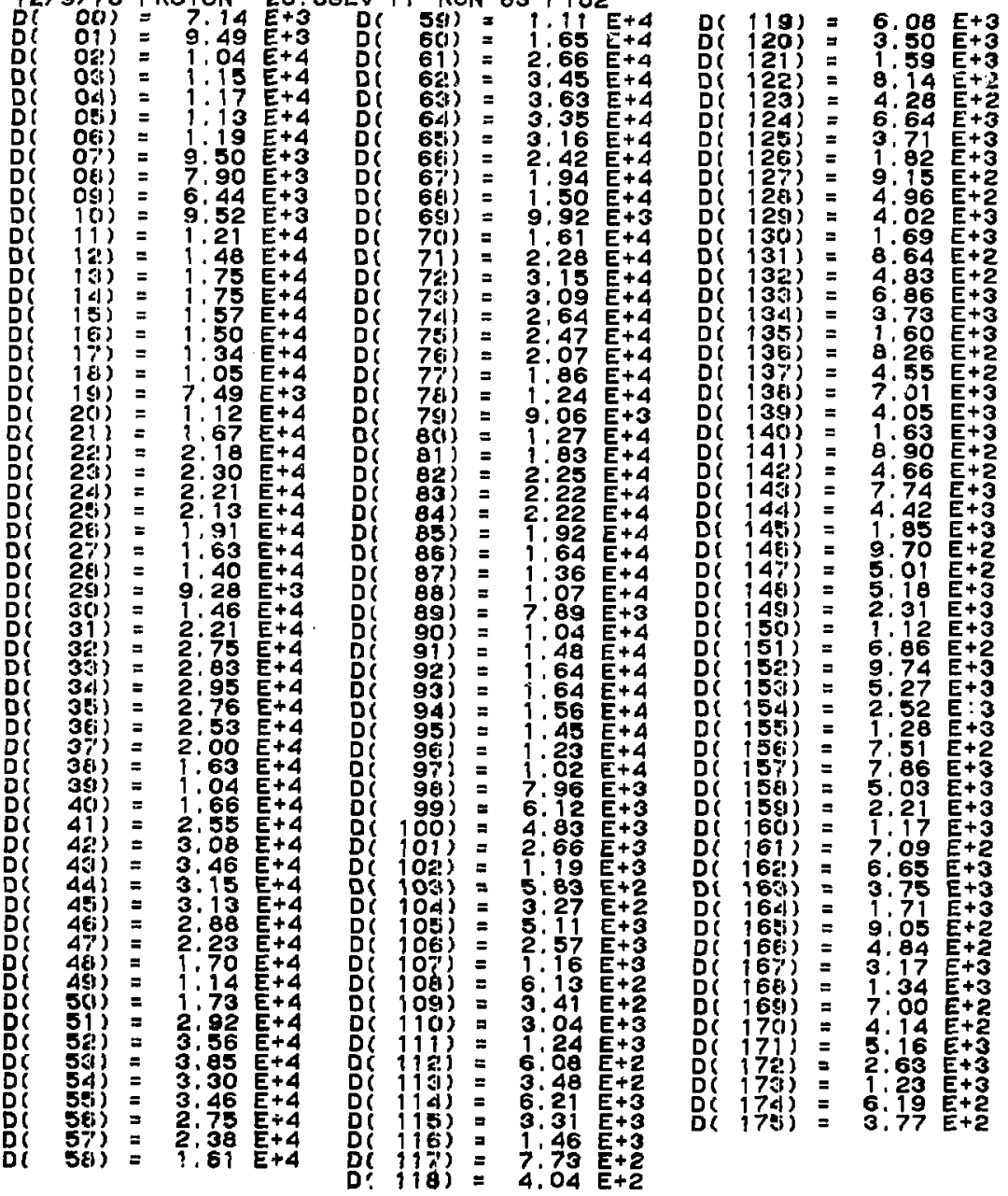


Table B-26.

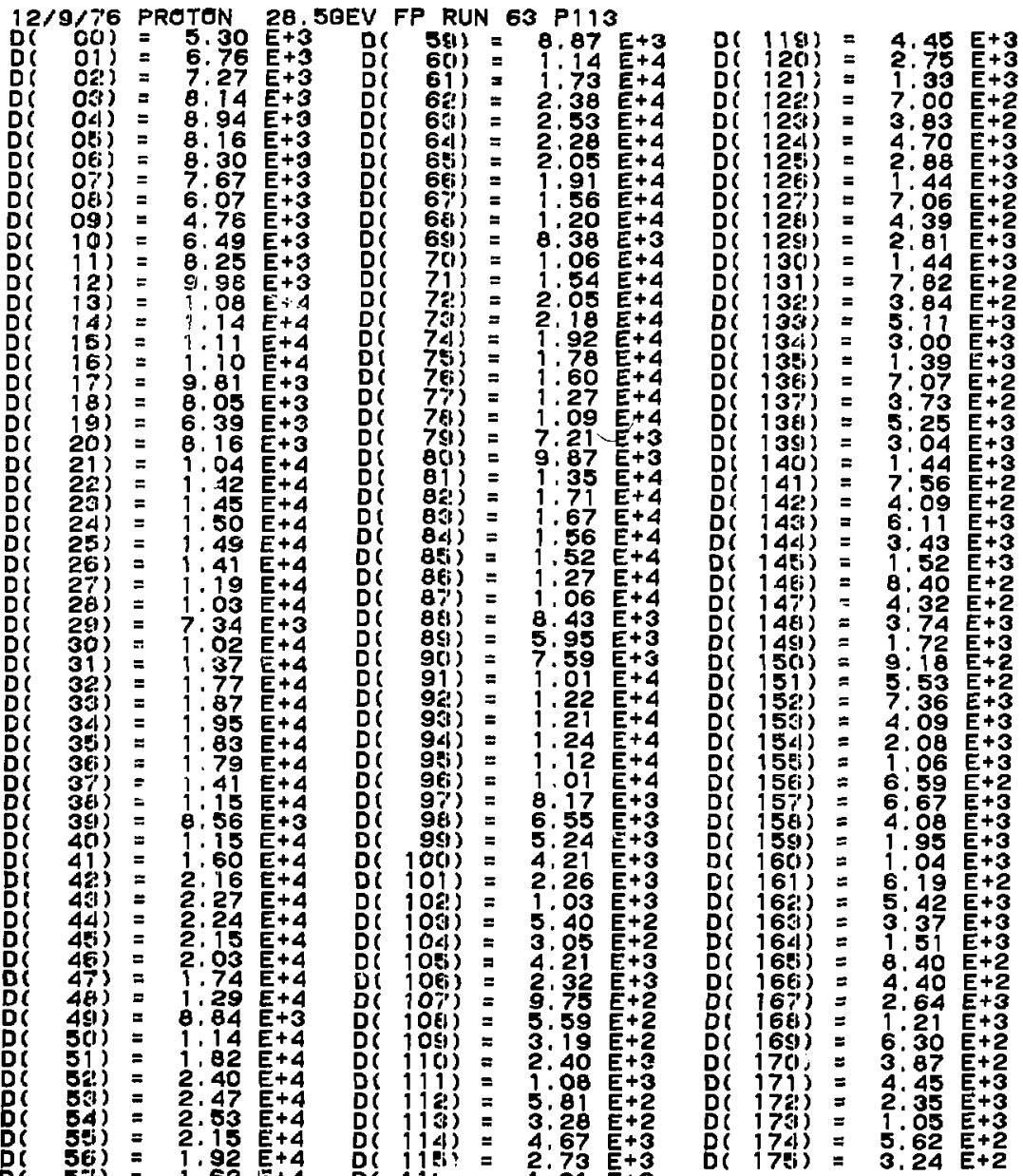


Table B-27.

$12 / 9 / 7 ' 6$ PROTON 2B.5OEV FP RUN 63 P134

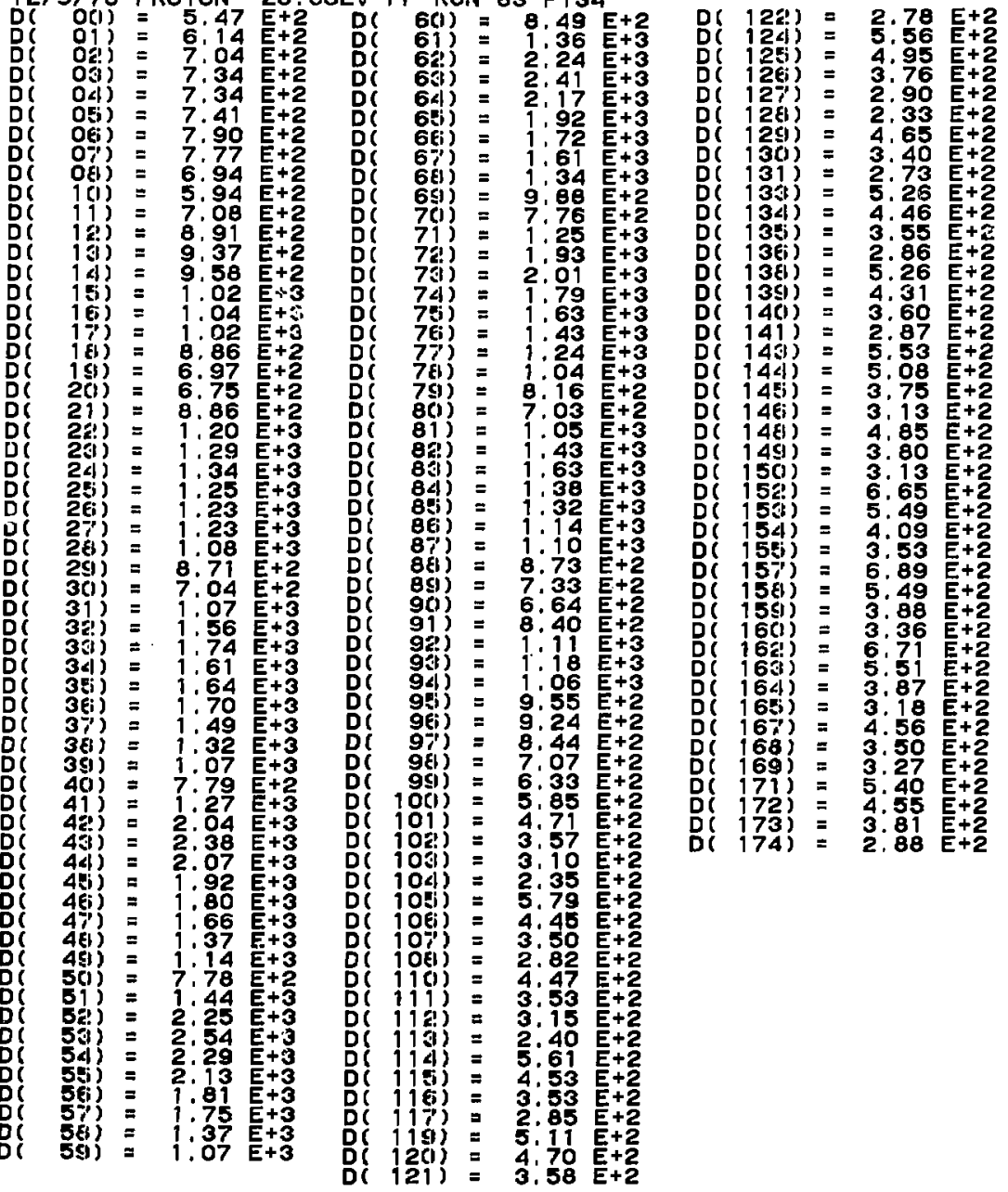


Table B-28.

$12 / 9 / 7 ' 6$ PROTON 28.5EEV FP RUN 63 P175

\begin{tabular}{|c|c|c|c|c|c|c|c|c|c|c|}
\hline & \multicolumn{3}{|c|}{ 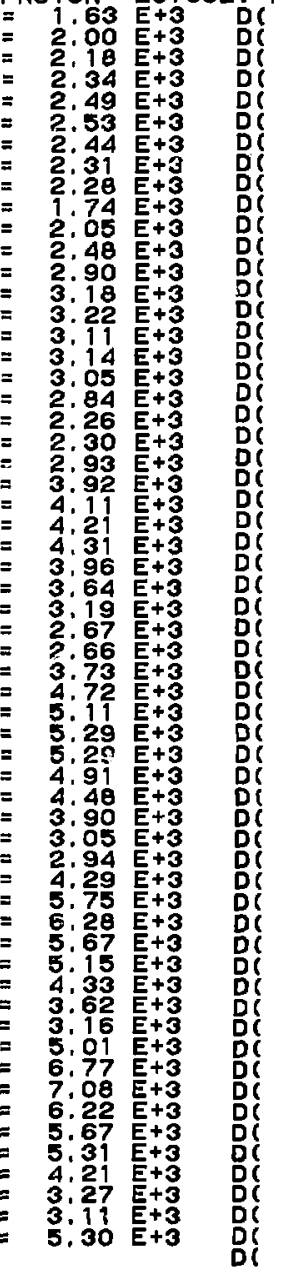 } & \multicolumn{2}{|c|}{ 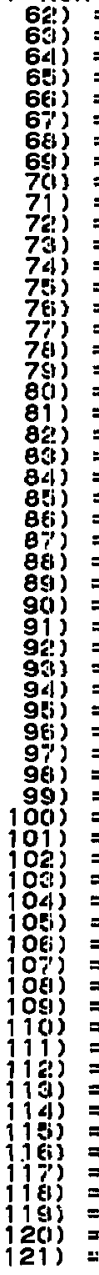 } & \multicolumn{2}{|c|}{ 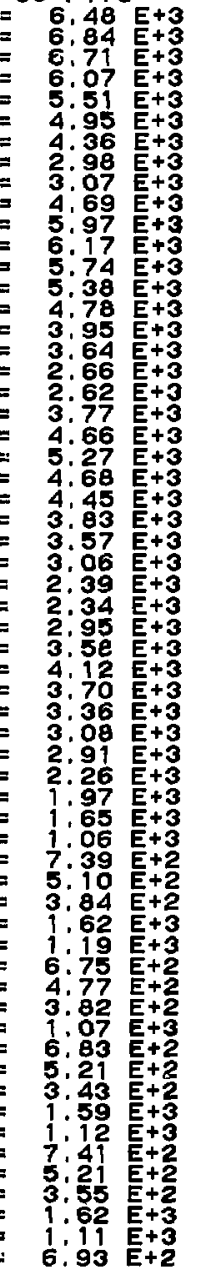 } & \multicolumn{2}{|l|}{ 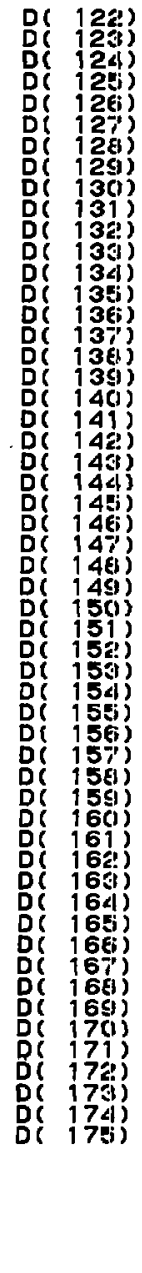 } & 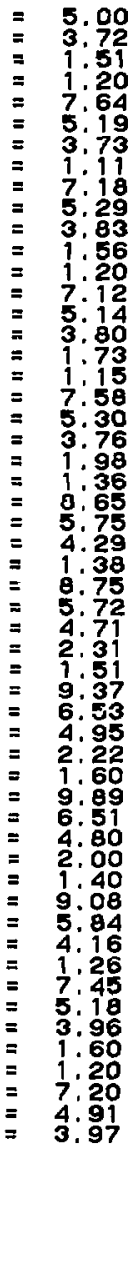 \\
\hline
\end{tabular}


Table B-29.

$12 / 9 / 16$ FROTON 28.5OEV FP RUN 64 P7 4

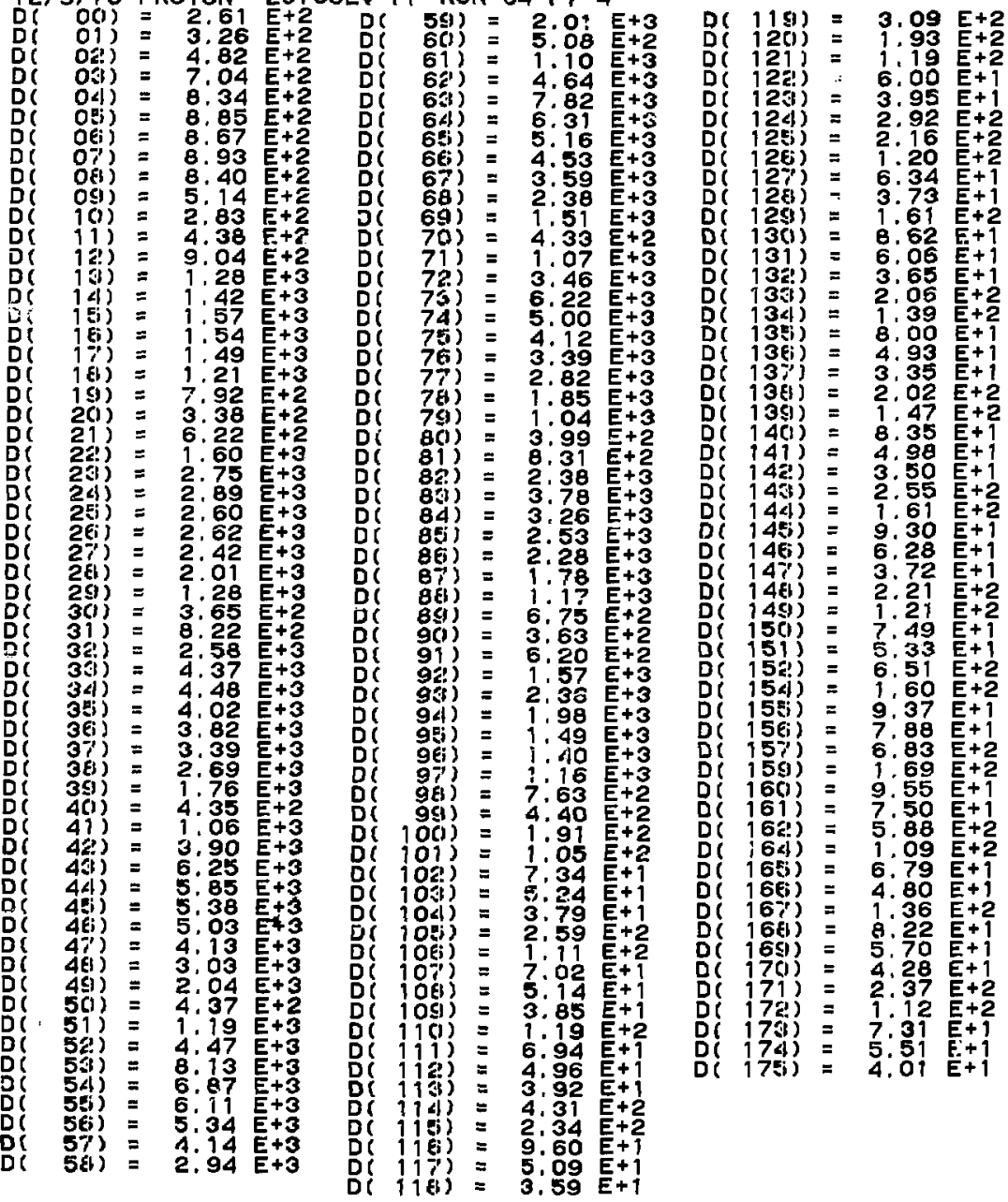


Table B-30.

12/9/7'6 PROTON 20,50EV FP RUN 64 P195

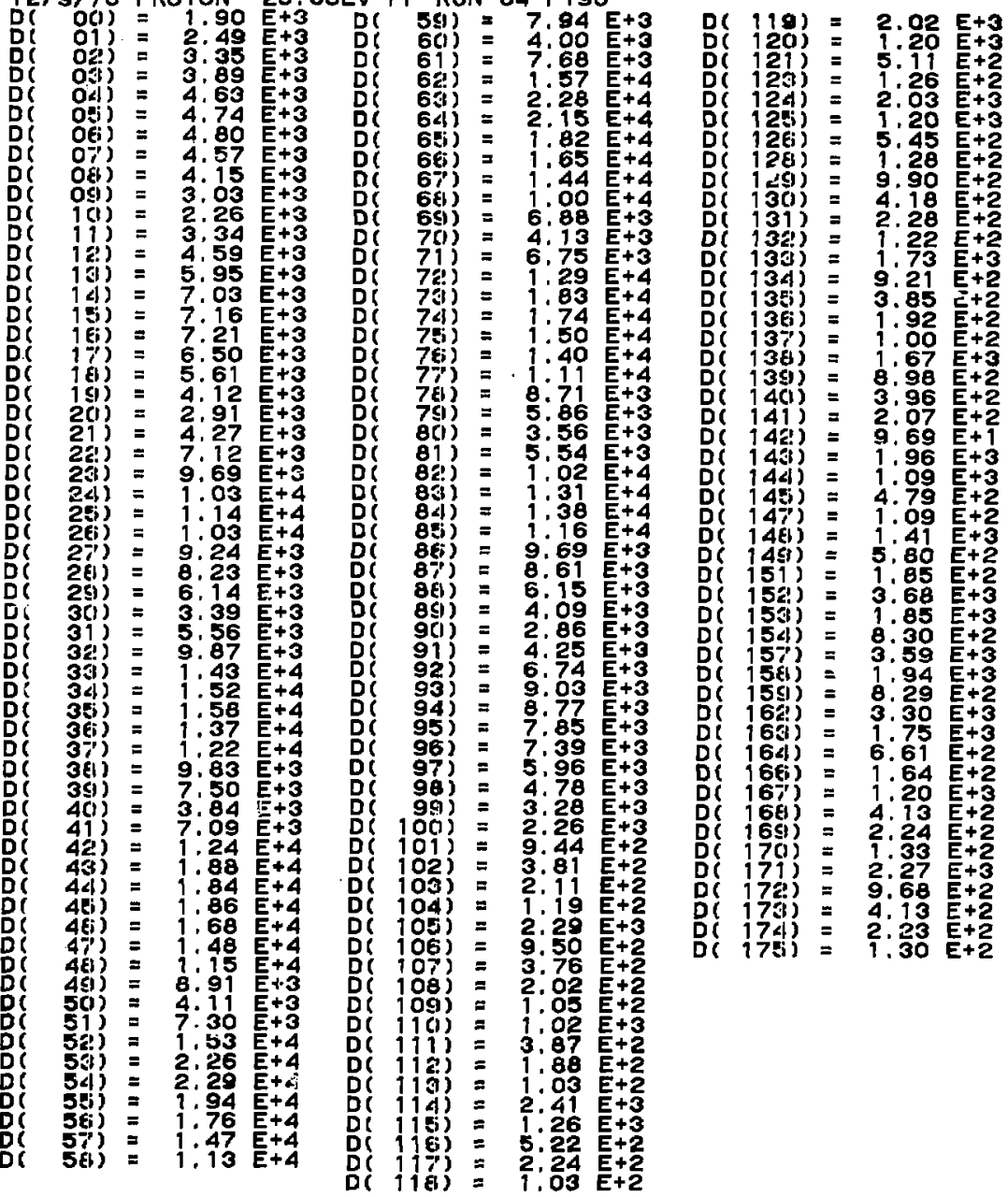


Table B-31.

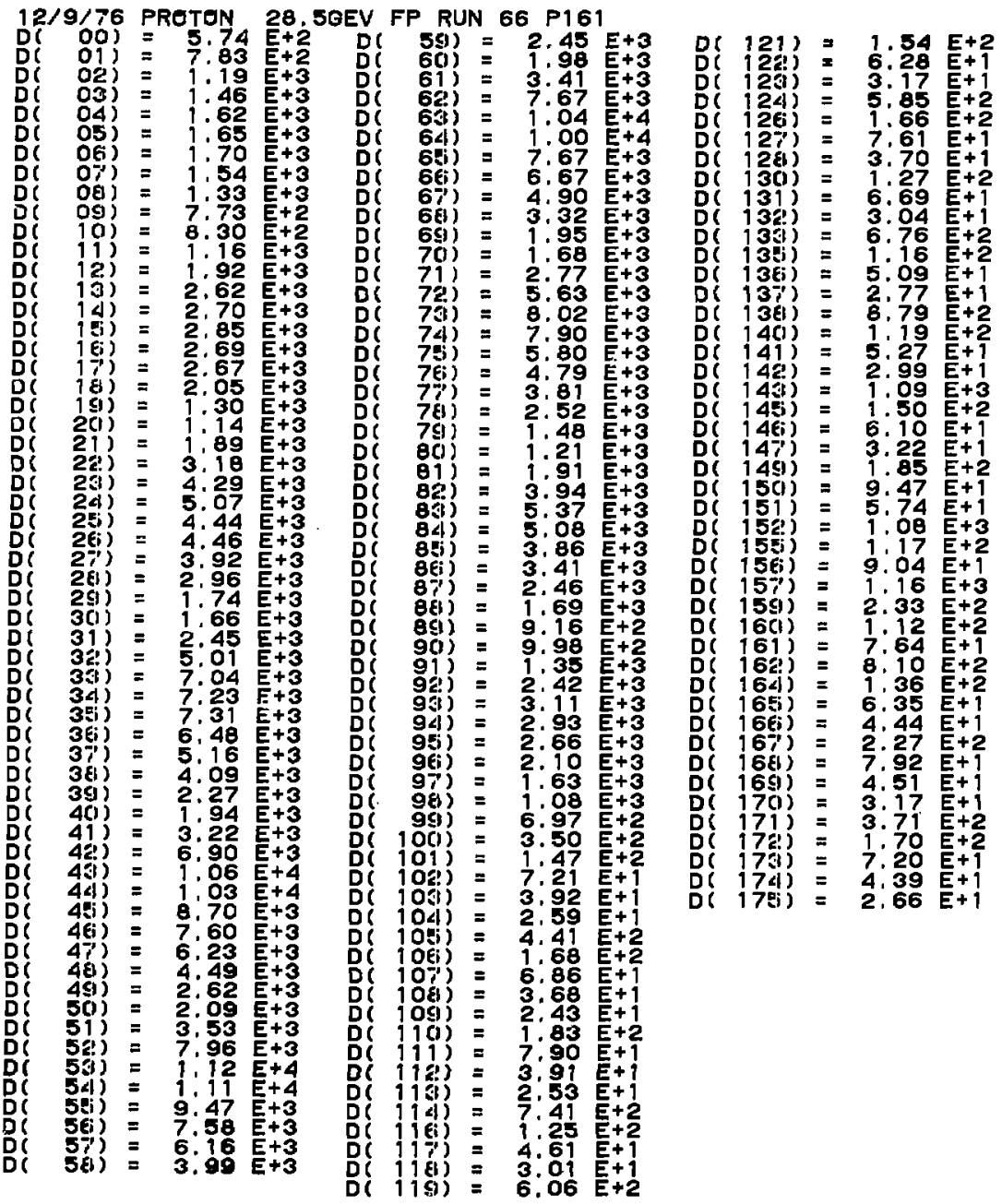


Table B-32.

RUN DATE $\ldots \ldots \ldots 1 / 12 / 77$

PARTICLE,$\ldots$. $\ldots$ PROTON

BAAM ENEROY $\ldots, \ldots, 12$ 12GEV 71

PLATE NGOAOATIOAN: ?

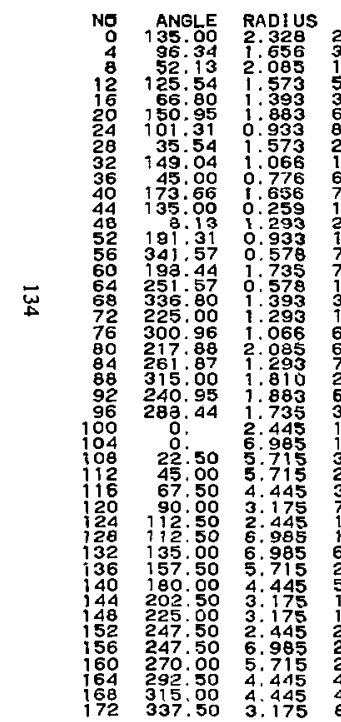

\begin{tabular}{|c|c|c|c|c|}
\hline $\begin{array}{l}\text { D SEE } \\
390 E+02 \\
520 E+02 \\
410 E+02 \\
860 E+02 \\
310 E+02 \\
410 E+02 \\
320 E+02 \\
180 E+02 \\
280 E+03 \\
150 E+02 \\
300 E+02 \\
400 E+03 \\
970 E+02 \\
680 E+03 \\
870 E+02 \\
260 E+02 \\
430 E+03 \\
030 E+02 \\
410 E+03 \\
440 E+02 \\
520 E+02 \\
430 E+02 \\
470 E+02 \\
540 E+02 \\
810 E+02 \\
350 E+02 \\
430 E+01 \\
000+01 \\
120 E+01 \\
610 E+01 \\
250 E+01 \\
720 E+02 \\
500 E+01 \\
530 E+01 \\
650 E+01 \\
710 E+01 \\
530 E+02\end{array}$ & $\begin{array}{r}N O \\
1 \\
5 \\
9 \\
13 \\
17 \\
21 \\
25 \\
29 \\
33 \\
37 \\
41 \\
45 \\
49 \\
53 \\
57 \\
61 \\
65 \\
69 \\
73 \\
77 \\
81 \\
85 \\
89 \\
93 \\
97 \\
101 \\
105 \\
109 \\
113 \\
117 \\
121 \\
125 \\
129 \\
133 \\
137 \\
141 \\
121\end{array}$ & $\begin{array}{r}\text { ANGLE } \\
127.68 \\
83.66 \\
45.00 \\
113.20 \\
54.46 \\
144.46 \\
78.69 \\
29.06 \\
135.00 \\
30.96 \\
171.07 \\
45.00 \\
198.44 \\
348.69 \\
203.20 \\
288.44 \\
341.57 \\
239.04 \\
315.00 \\
25.00 \\
278.13 \\
372.13 \\
251.57 \\
299.06 \\
20.50 \\
22.50 \\
42.50 \\
67.50 \\
90.00 \\
112.50 \\
135.00 \\
157.50 \\
157.50 \\
100.00 \\
202.50 \\
225.00 \\
247.50 \\
270.00 \\
270.00 \\
292.50 \\
315.00\end{array}$ & $\begin{array}{l}\text { RAD UUS } \\
2.085 \\
1.655 \\
2.328 \\
1.393 \\
1.573 \\
1.573 \\
0.933 \\
1.853 \\
0.776 \\
1.066 \\
1.293 \\
0.259 \\
1.655 \\
0.578 \\
0.933 \\
1.393 \\
0.578 \\
1.735 \\
1.065 \\
1.293 \\
1.810 \\
1.293 \\
2.035 \\
1.735 \\
1.883 \\
3.175 \\
2.145 \\
6.985 \\
6.985 \\
5.715 \\
4.445 \\
3.175 \\
3.175 \\
2.445 \\
6.985 \\
5.715 \\
4.445 \\
4.445 \\
3.175 \\
2.445 \\
0.985 \\
5.715 \\
5.715 \\
4.445\end{array}$ & 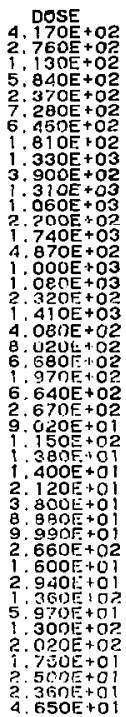 \\
\hline
\end{tabular}

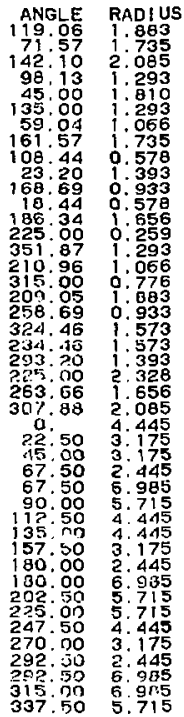

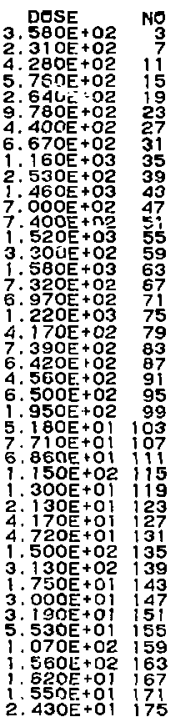

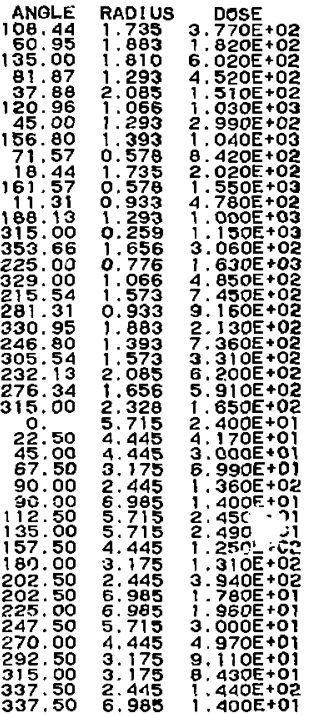


Table B-33.
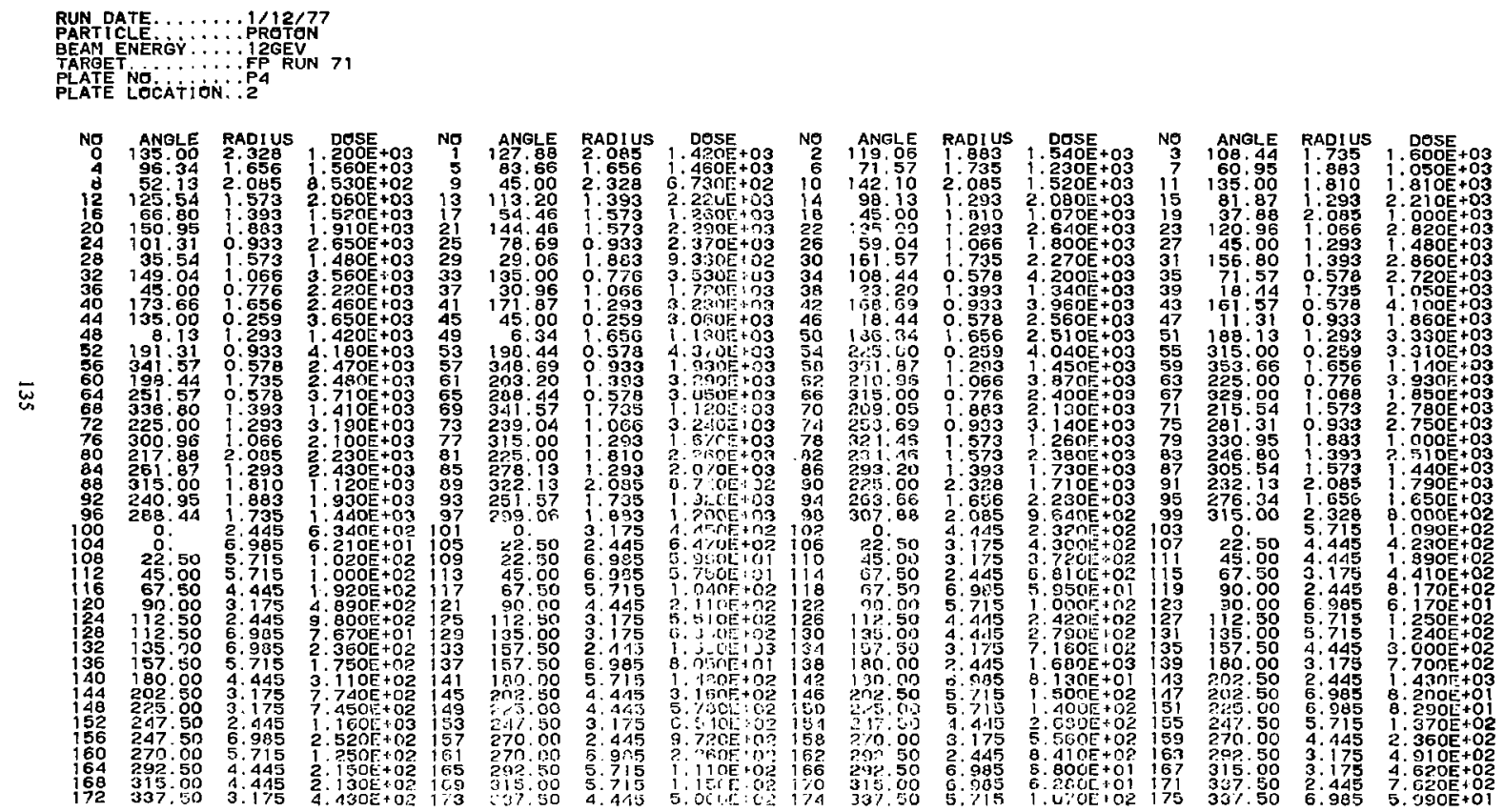
Table B-34.

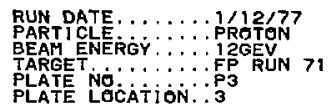

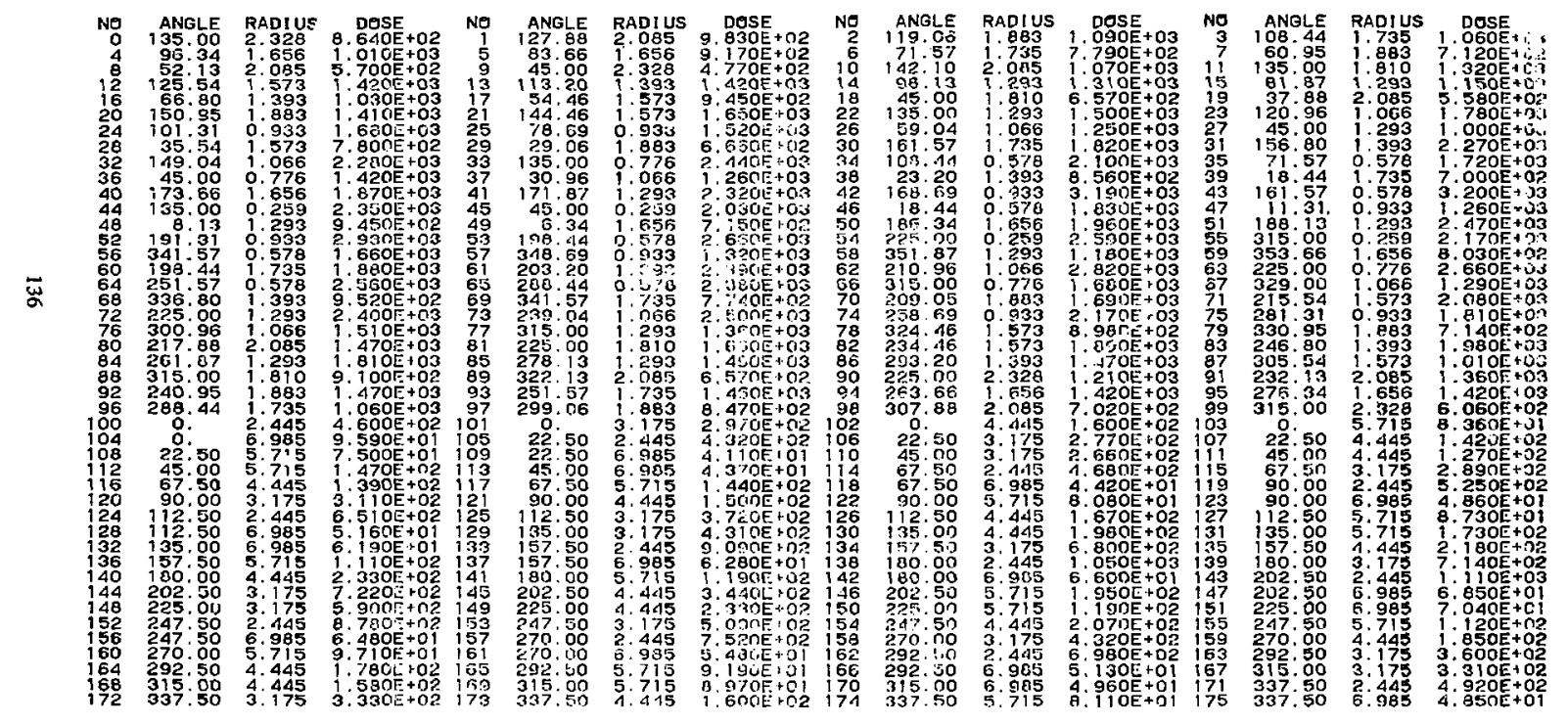


Table B-35.

RUN DATE $\ldots \ldots \cdots, 1 / 12 / 77$

PART ICLE...... PROTON

PEAM ENTERGY $\ldots \ldots$ T2GEV

PLATE HOOCAT IÓN: : 4

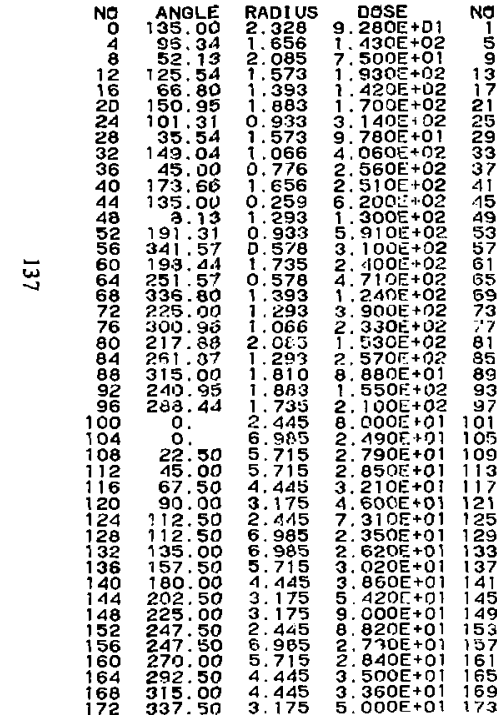

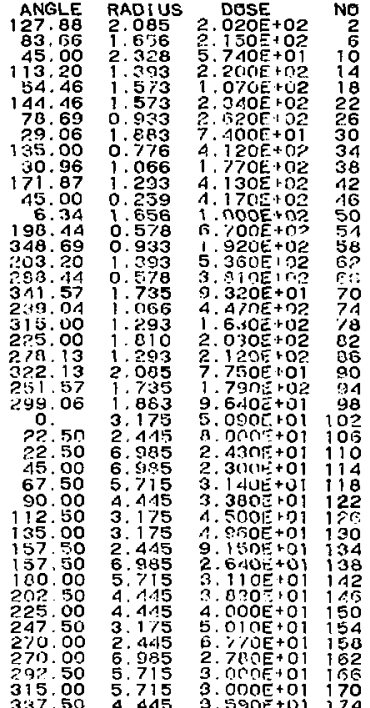

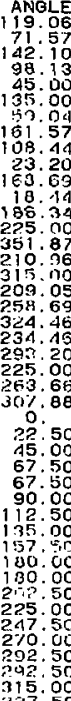

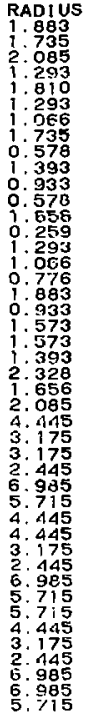

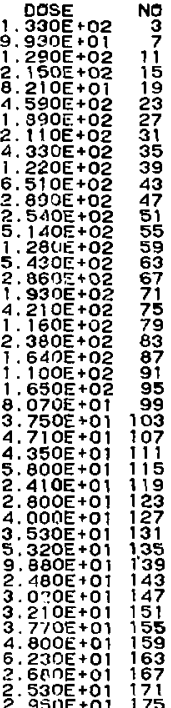

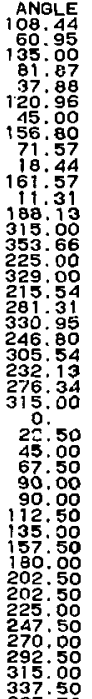

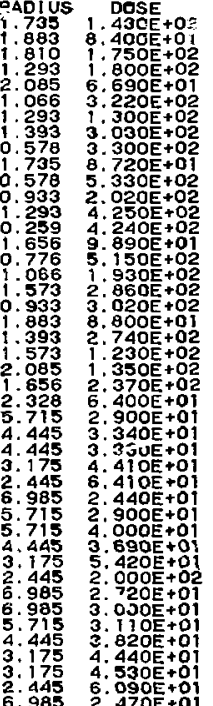


Table B-36.

RUN DATE $\ldots \ldots \ldots 1 / 12 / 77$

BEAM ENERGY ...... PRGEV

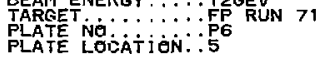

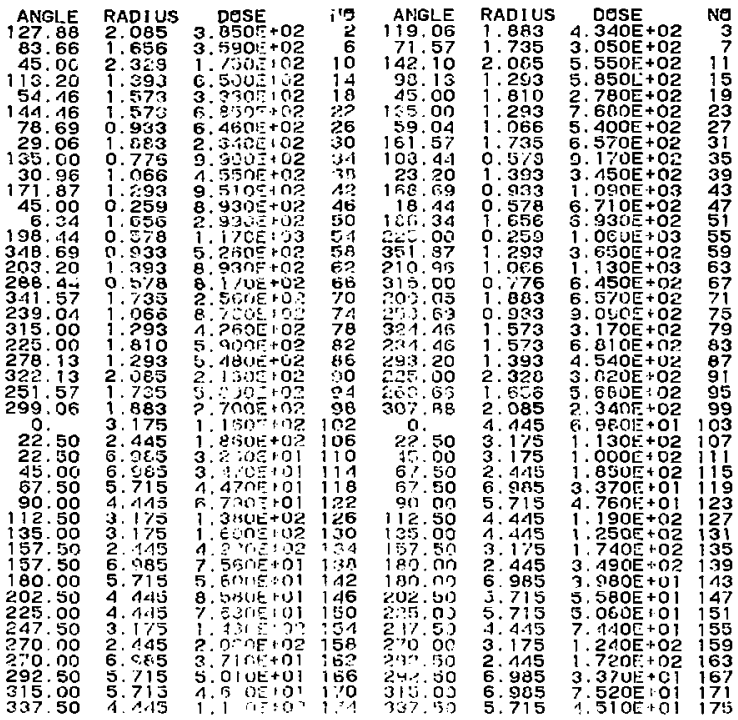

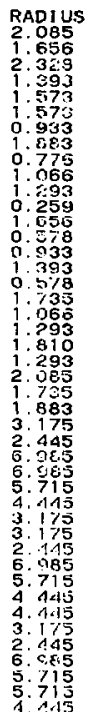

AMGLE 71.57 32.13 :5. 61.57 $23: 20$ 18. 44 $35 \mathrm{i}, \mathrm{g}$ 315.00 $32.3 \cdot 3$ 293.20 30.68 28.50 6.50 on 125.00 $190 . n$ 20040 (अ)

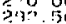
3,$0 ; 0$

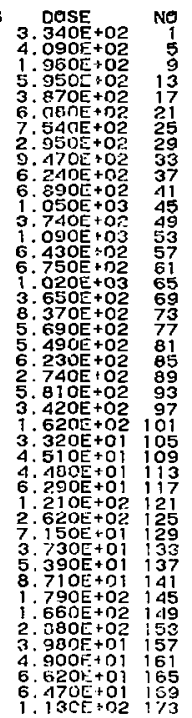

ANGLE RADIUS DOSE $60.95 \quad 1.883 \quad 2.460 E+02$ $135.00 \quad 1.810 \quad 5.300 E+02$ $81.87 \quad 1.293 \quad 4.920 \mathrm{E}+02$ $120.961 .065 \quad 8.040 E+02$ $45.00 \quad .293 \quad 3.820 \mathrm{E}+02$ $1.80 \quad 1.393 \quad 8.360 \mathrm{c}+02$ 18.440 .735 2. $161.570 .578 \quad 3.110 \mathrm{k}+03$ $11.31 \quad 0.933 \quad 5.410 \mathrm{E}+02$ 315.00 O.Z59 $9.420 \mathrm{E}+02$ $\begin{array}{lll}353.66 & 1.656 & 2.990 F+02 \\ 3 & 0.075 & 1.090 E+03\end{array}$

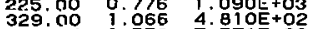
215.54 $\quad: .573 \quad 7.570 \mathrm{E}+02$ $281.31 \quad 0.933 \quad 7.530 E+02$ $330.951 .883 \quad 2.6201+02$ $246.80 \quad 1.393 \quad 6.920 E+02$ 232:13 $2.085 \quad 5.770 \mathrm{OE}+02$ $270.34 \quad 1.655 \quad 4.530 E+02$

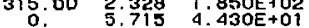
$22.50 \quad 4.4456 .800 \mathrm{E}+01$ $45.00 \quad 4.445 \quad 6.270 \mathrm{OE}+01$ $90: 00$ 2.445 2.080E+02 90.00 6.985 3.A40E+01 $112.50 \quad 5.715 \quad 4.870 E+01$ 5.50 4.445 8.3605:01 $180.00 \quad 3.175 \quad 2.190$ +02 50 . 545 . $225.006 .905 \quad 7.8201+01$ $247.50 \quad 5.715 \quad 5.190 E+01$ 270.00 4.445 6.780E+01 $292.50 \quad 3.175 \quad 1.110 E+02$ $315.00 \quad 3.175 \quad 1.150 E+02$ $\begin{array}{lll}337.50 & 2.445 & 1: 970 E+02 \\ 337.50 & 6.985 & 3.250 E\end{array}$ 
Table B-37.

RUN DATE......1/12/77

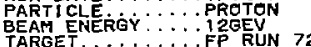

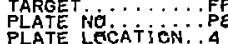

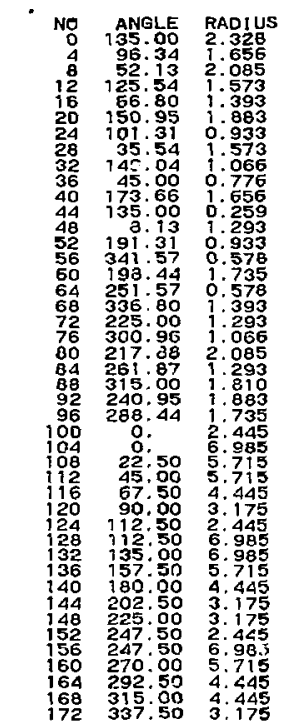

\begin{tabular}{|c|c|c|c|c|c|}
\hline 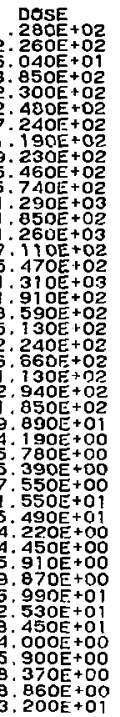 & $\begin{array}{r}\text { No } \\
1 \\
59 \\
99 \\
13 \\
17 \\
27 \\
25 \\
29 \\
33 \\
37 \\
41 \\
45 \\
49 \\
53 \\
67 \\
65 \\
69 \\
63 \\
77 \\
91 \\
85 \\
89 \\
93 \\
99 \\
101 \\
105 \\
109 \\
113 \\
117 \\
121 \\
125 \\
129 \\
133 \\
137 \\
141 \\
145 \\
149\end{array}$ & 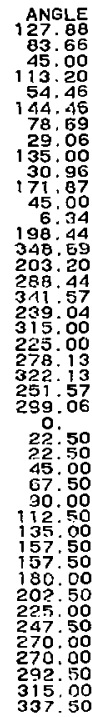 & 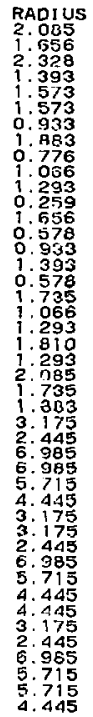 & 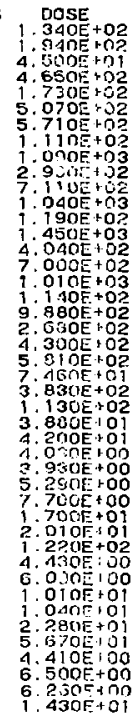 & $\begin{array}{l}10 \\
14 \\
18\end{array}$ \\
\hline
\end{tabular}

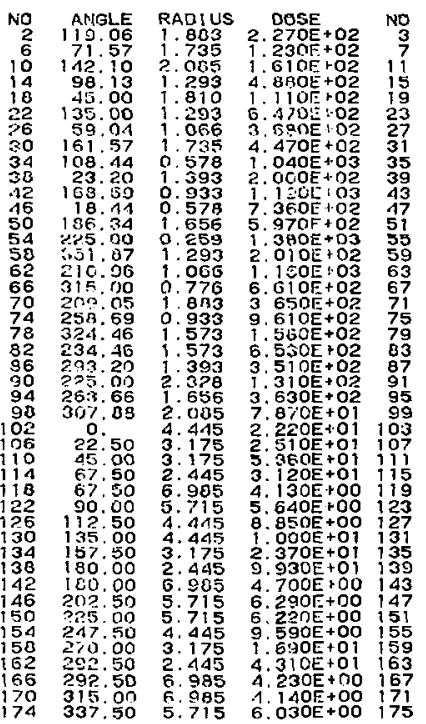

ANGLE 108.44 135.00 81.87
37.80 120.96 45.00 156.80 18.44 161.57 188.13 315.00 225.00 275.54 281.31
330.95 246.00 305.54

232. 13 315.00 22.50 45.00 90: 00 119.00

$135: 00$ 180,00 202.50 202.50 247.50 270.00 315.00 337.50
RADIUS 1.735 2. $5950 \mathrm{SEE} 1.02$ 1.810 2.510E 2. $2934.220 E+02$ 1.

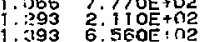
1.735 8.990E 01 0.933 4:110E 1.293 1. $1.656 \quad 1.1005+02$ $.776 \quad 1.450 E+03$ $1.0653 .720 E+02$ $0: 933 \quad 7: 960 E+02$ 1.393 6.480E $\% 02$ 2.005 - 1002 $1.6562 .680 \mathrm{0}+02$ 2.323 $5.430 \mathrm{E}+01$ 4.445 I:OOOE +oi 4.445 7. $840 E+00$ 445 8.560E+01 6.985 4.210E 100 5.715 6. $190 E+00$ $4.445 \quad 9,020 E+00$ 2.560E+01 . $1450 \mathrm{O}+02$ 9.985 4.760E+00 .715 $6.150 E+\infty 0$ 4.445
3.175
$3.630 E+01$ 3.175 6.150E+01 $\begin{array}{ll}2.445 & 5: 150 E \\ 6.985 & 4.130 E+01\end{array}$ 
Table B-39.
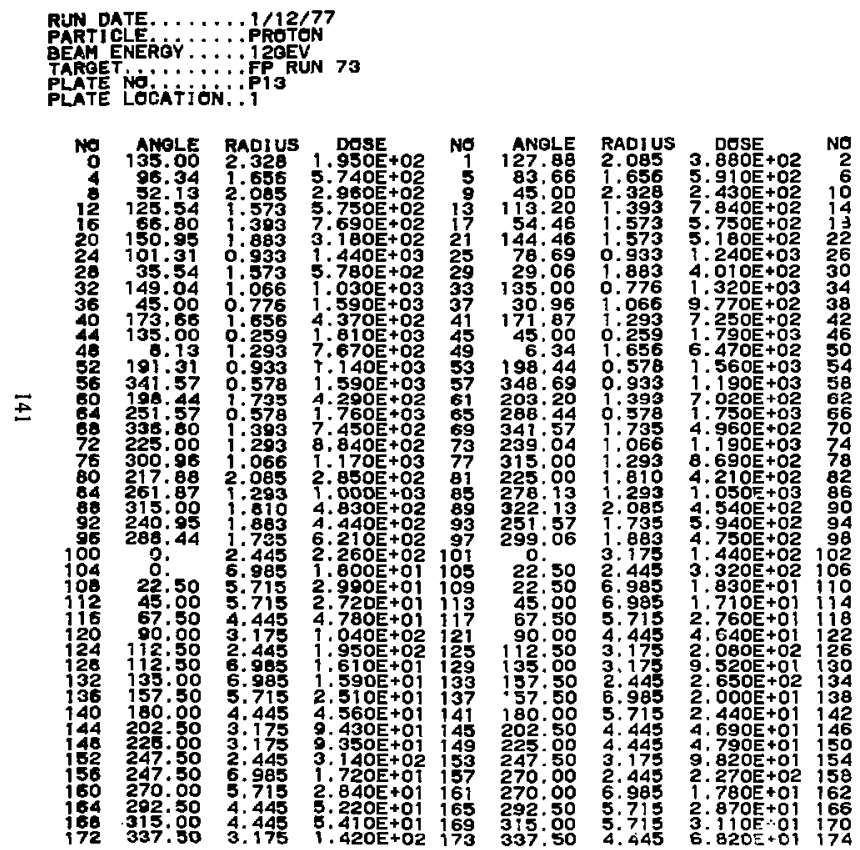

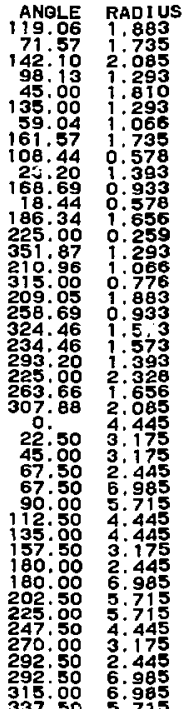
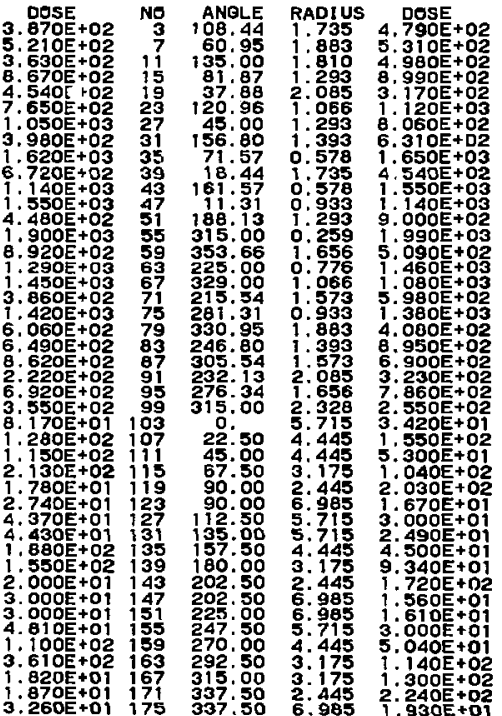
Table B-40.

RUN DATE. . . . . . 1 12/77

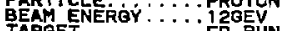

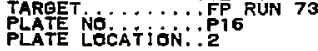

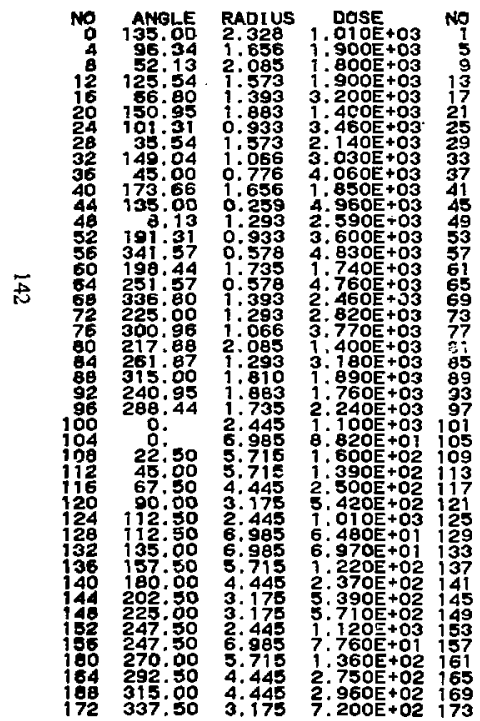

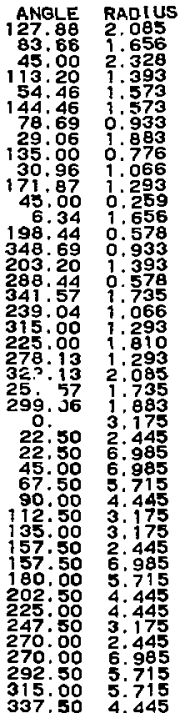
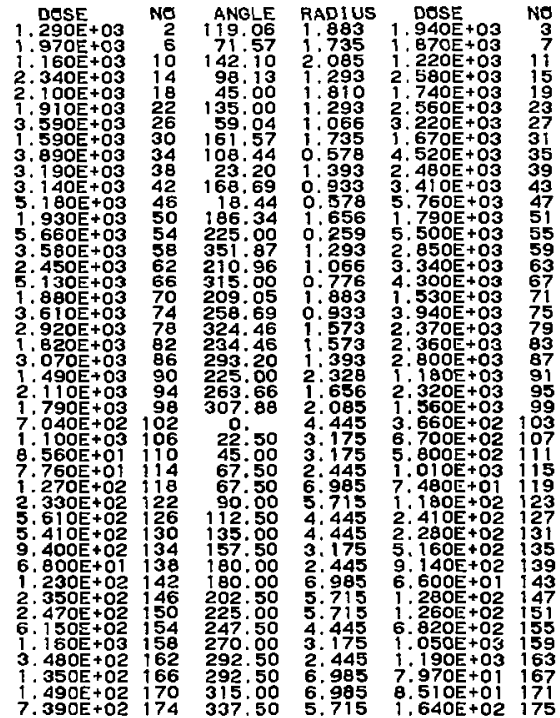

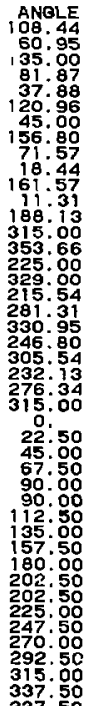

RADIUS, DOSE

$1.735 \quad 1.810 E+03$

$1.8101 .570 E+03$

$2.0852 .630 \mathrm{E}+03$

$1.0663 .140 \mathrm{E}+03$

$1.393 \quad 2: 320 \mathrm{E}+03$

$57.790 E+03$

$0.578 \quad 4.370 \mathrm{E}+03$

$0.933 \quad 3.770 \mathrm{E}+03$

$1.293 \quad 2.510 \mathrm{E}+03$

$\begin{array}{ll}0.259 & 5.420 E+03 \\ 1.656 & 1.980 E+03\end{array}$

0.776 4. $120 \mathrm{E}+03$

$1.5732 .080 \mathrm{E}+03$

$0.933 \quad 4.030 \mathrm{OE}+03$

$1.6831 .700 E+03$

$\begin{array}{ll}1.593 & 2.780 E+03 \\ 1.573 & 2.480 E+03\end{array}$

2. 085 1. $450 \mathrm{E}+03$

1.65 $2.490 E+03$

$5: 715 \quad 1: 760 \mathrm{E}+02$

$4.445 \quad 3: 100 \mathrm{E}+02$

$4.445 \quad 2.700 \mathrm{E}+02$

2.445 1. OOOKE+03

$6.985 \quad 7.1100+01$

$5.715 \quad 1.200 E+02$

$4.445 \quad 2.290 \mathrm{O}+02$

$.1755 .640 E+02$

$2.4459 .770 E+02$

6. $9853.3605+02$

$5.7151 .250 \mathrm{O}+02$

$4.4456 .780 \mathrm{E}+02$

3.175 6.790E+02

$3.175 \quad 6.720 E+02$ 337.50 5.715

337.50

8. $190 \mathrm{E}+01$ 
Table B-41.

RUN DATE. . . . . 1/12/77

GEAM ENERGY $\ldots \ldots, 12$ TEV

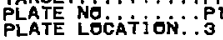

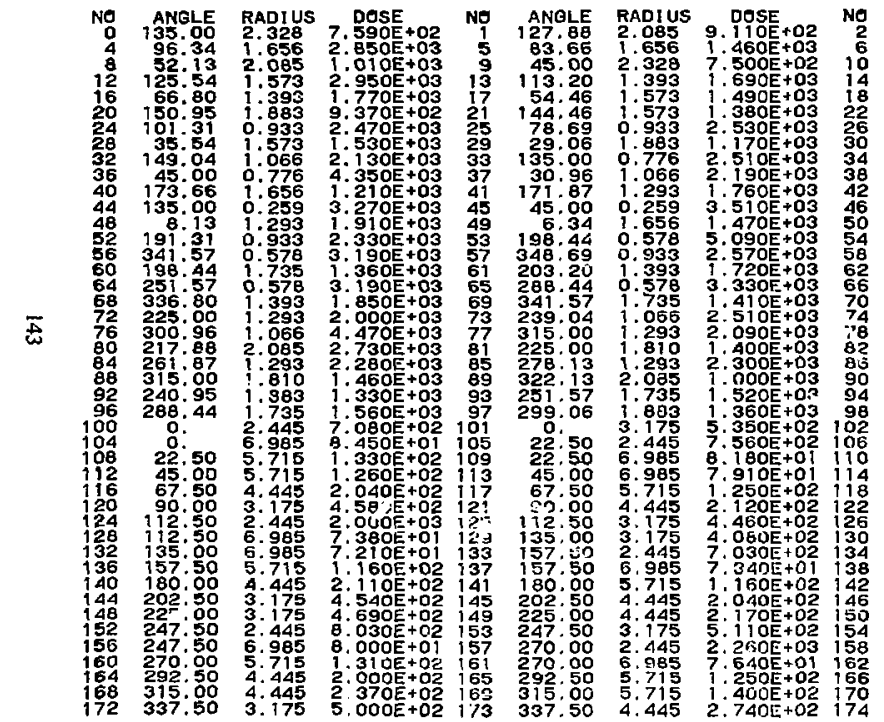

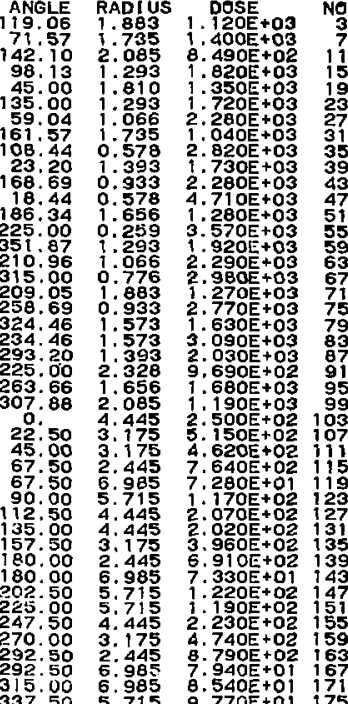

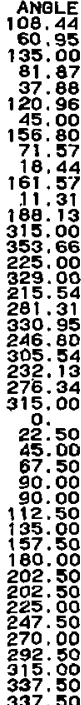

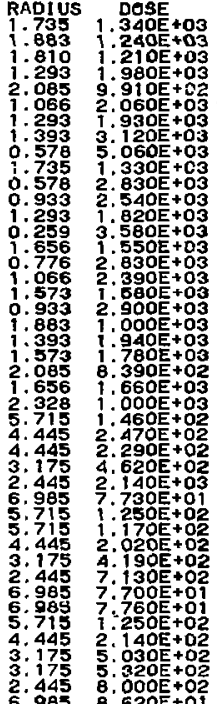

337.50 6.,985 $8.620 \mathrm{E}+01$ 
Table B-42.

RUN DATE . . . . . . 1/12/7\%7

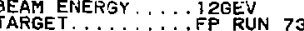

PLATE NÖ.

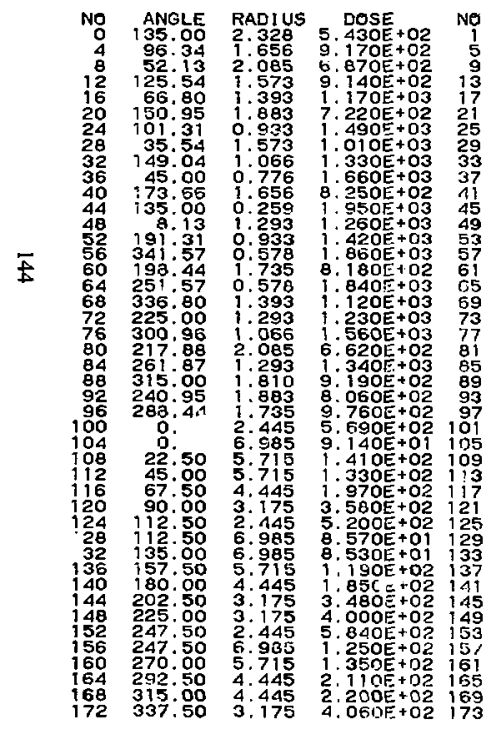

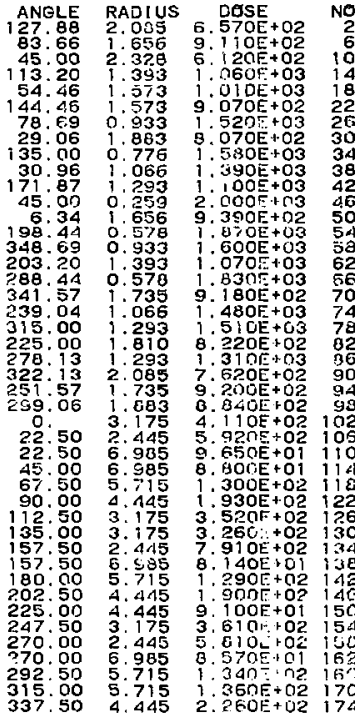

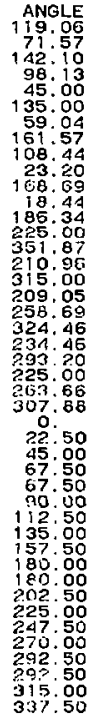

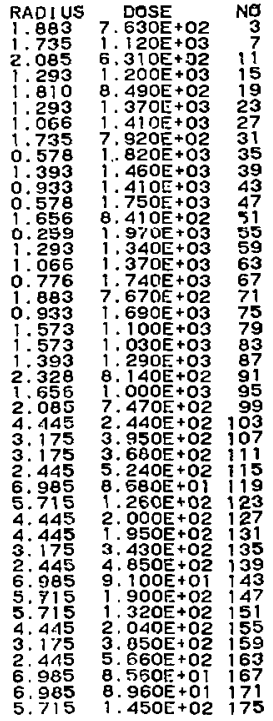

ANGLE

RADIUS DJSE 60.95

135.00

37.88 45.00

156.80

18.44

11.31

180.13

353.66

225.00

$215: 54$

31.31

246.80

332.5

$276: 34$

15.00

22.50

$\begin{array}{ll}.735 & 8.200 E+02 \\ .983 & 8: 220=+02 \\ 910 & 7.670 E+02\end{array}$

$1: 293$ $1.6705+02$
$1.260 E+03$

$\begin{array}{ll}2.085 & 7.1805+02 \\ 1.066 & 1.380 \mathrm{E}+03\end{array}$

$1.393 \quad 1.230 E+03$

$0.578 \quad 1.820 \mathrm{OE}+03$

0.578 1.690E+03

$1.2931: 130 E+03$

$0.2591 .990 E+09$

$\begin{array}{ll}1.656 & 9.020 E+02 \\ 0.776 \quad 1.720 E+03\end{array}$

$1.066 \quad 1.4605+03$

$0.933 \quad 1: 700 E+03$

$1.393 \quad 1.220 E+03$

$1: 5731: 2505+03$

2.

$600 \mathrm{O}+02$
$.820 \mathrm{E}+02$

2.328 $6.250 \mathrm{E}+\mathrm{O}$

$67.50 \quad 3.175 \quad 3.480 E+02$

$90.002 .445 \quad 5.130 E+02$

90.00 5.985 8.560E+01

$112.50 \quad 5.7151 .250 E+02$

135.00 5.711 $1.270 \mathrm{E}+02$

$180.00 \quad 3.175 \quad 3.3705+02$

202.502 .445

225.00 6.985 3.330E+02

$247.50 \quad 5.715 \quad 1,330 E+02$

$270.00 \quad 4.445 \quad 2.000 E+02$

$292.503 .1753 .850 E+02$

15.00

3. 175

$3.720 \mathrm{E}+02$

$337: 50$

9. $200 \mathrm{E}+01$ 
Table B-43.

RUN DATE. . . . . . 1/12/77

PARTICLE

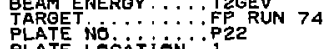

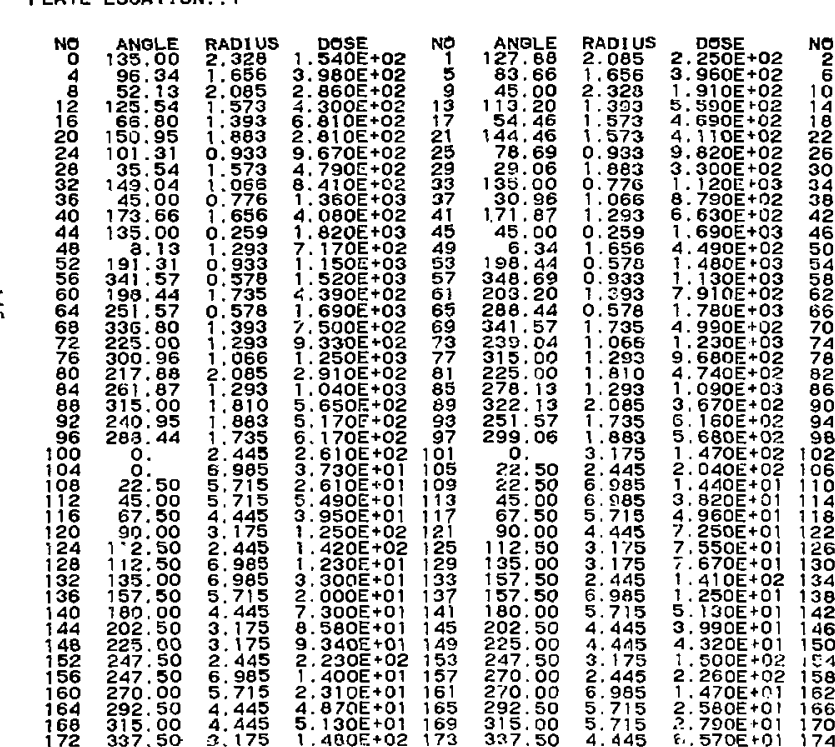

\begin{tabular}{|c|c|c|c|c|c|c|}
\hline & 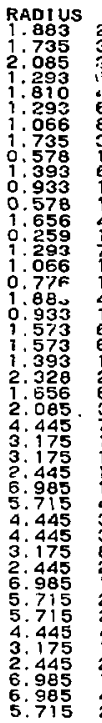 & 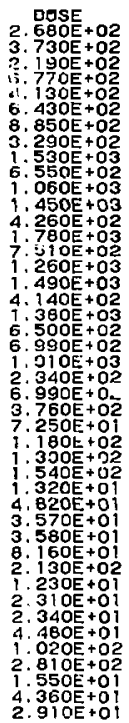 & $\begin{array}{l}11 \\
115 \\
19 \\
23 \\
27 \\
31 \\
35 \\
39 \\
43 \\
47 \\
51 \\
55 \\
59 \\
63 \\
67 \\
71 \\
75 \\
79 \\
83 \\
87 \\
91 \\
95\end{array}$ & $\begin{array}{r}\text { ANGLE } \\
108.44 \\
60.95 \\
135.00 \\
011.87 \\
37.88 \\
120.96 \\
45.00 \\
155.80 \\
71.57 \\
18.44 \\
161.57 \\
11.31 \\
186: 13 \\
315.00 \\
353.66 \\
225.00 \\
329.00 \\
215.54 \\
281.31 \\
330.95 \\
246.00 \\
305.54 \\
232.13 \\
275.34 \\
315.00 \\
0.50 \\
22.50 \\
45.00 \\
67.50 \\
90.00 \\
90.00 \\
112.50 \\
135.00 \\
157.50\end{array}$ & 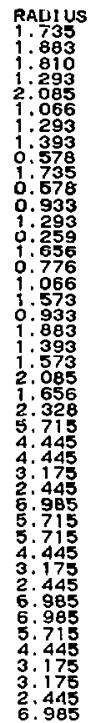 & \\
\hline
\end{tabular}


RUN DATE......1/12/77

PART I CLE $: \ldots \ldots$ PRGTON

BEAM ENERGY $\ldots \ldots 1$ 12GEV

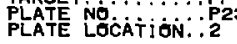

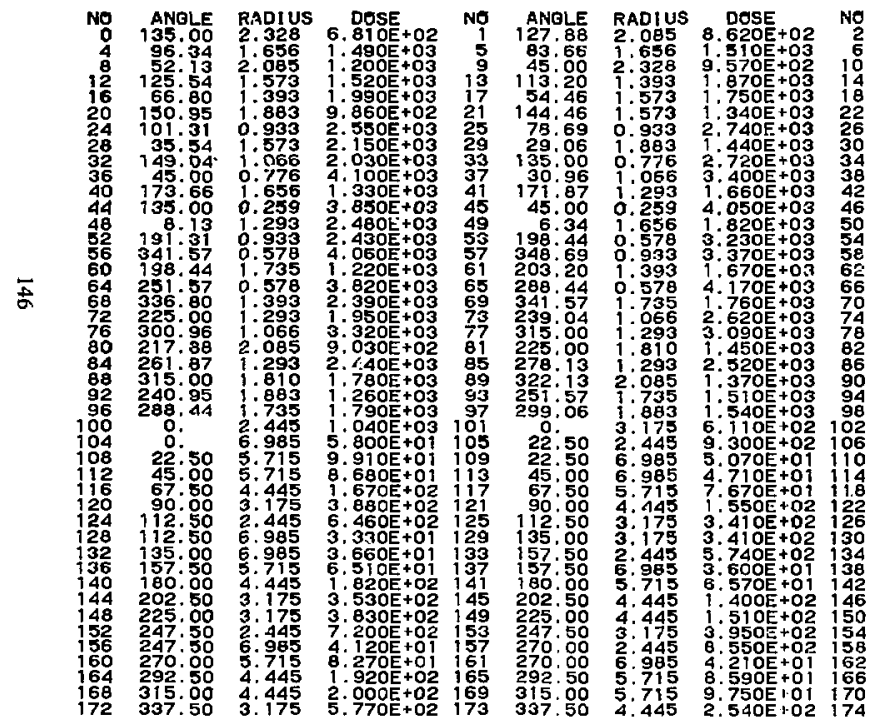

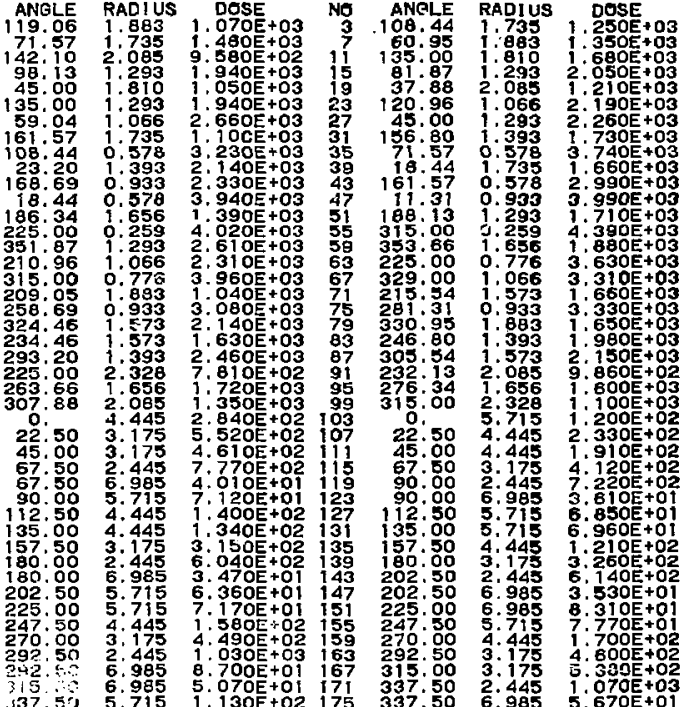


Te.ble B-45.

RUN DATE ....... 1/12/77

PART GLE

TARGET T.........FP RUN 74

PLATE LOOCATIOON :

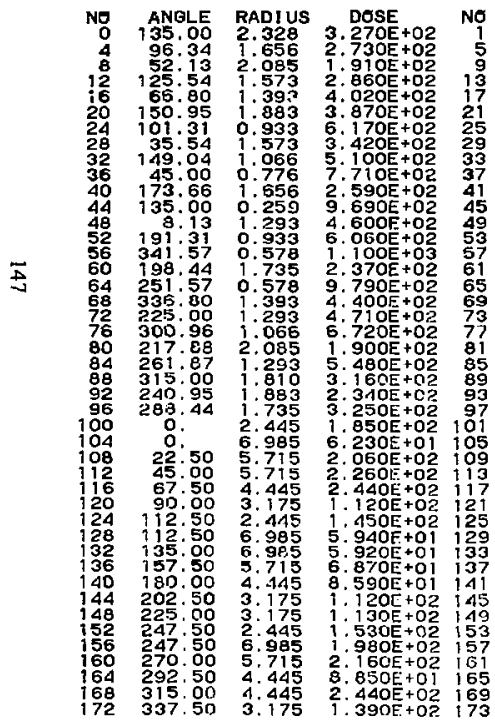

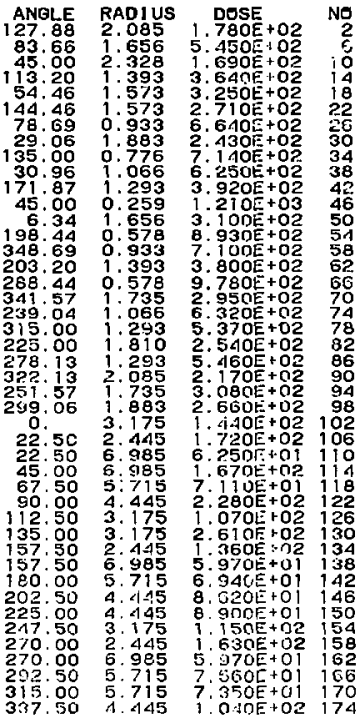

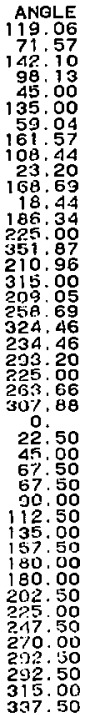

RADIUS

DOSE
2. $070 \mathrm{O}$.
230E+0

NO

ANGLE

RADIUS

DOSE

$1.2934480+0$

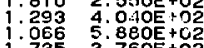

$0.578 \quad 8.590$

$0.9335 .860 E+02$

0. 578 9. $060 \mathrm{OE}+02$

o. 259

. $540 \mathrm{OE}+\mathrm{O} 2$

$1.0665 .840 E+0$

.7768 .

8. $510 \mathrm{E}+\mathrm{C2}$
2. $280 \mathrm{OLE}$

0.933

$7.710 E+O$

$1.573 \quad 3.590 E+02$

1. 393 4. $3000+0$

2. 056

$1.700 \mathrm{OE}+\mathrm{O}$

4.445

2. $210 \mathrm{O}+\mathrm{O}$

$.050 \mathrm{E}+02103$

3. 175

2. $690 \mathrm{O}+02111$

6.985

6. $190 E+02115$

$\begin{array}{lll}5.715 & 7.370 E+01 & 23 \\ 4.445 & 8.690 E+01 & 27\end{array}$ $135: 05$

1.883 $2.470 E+02$
$2.320 E+02$ 81.87

120.88 2.085 45.0011 .293 $156.80 \quad 1.393$ $18.44 \quad 1.735$ 11.31 0.933 188.131 .293 $315.00 \quad 0.25$ 225:00 0,77 329.001 .066 281.31 0.933 $390.95 \quad 1.883$ 305.5

232: 13 315: 340 22.50 45.00 4. 445 9o. oo 90.00
112.50
135.715
1350 4.445 2.445

$8.270+01131$
$2.670+02$ $\begin{array}{ll}2.670+02 & 35 \\ 1.430 E+02 & 39 \\ 1.670 E+02 & 43\end{array}$ 157.5 180. 00 $7.030 E+01147$ 50 50 6. 985 $8.570 E+01155$ 247.50 270. 응 315.00 2. 445 6. 985 $6.230=01$ i 67 $\begin{array}{ll}315.00 & 5.715 \\ 337.50 & 4.445\end{array}$ 5.715 
Table B-46.
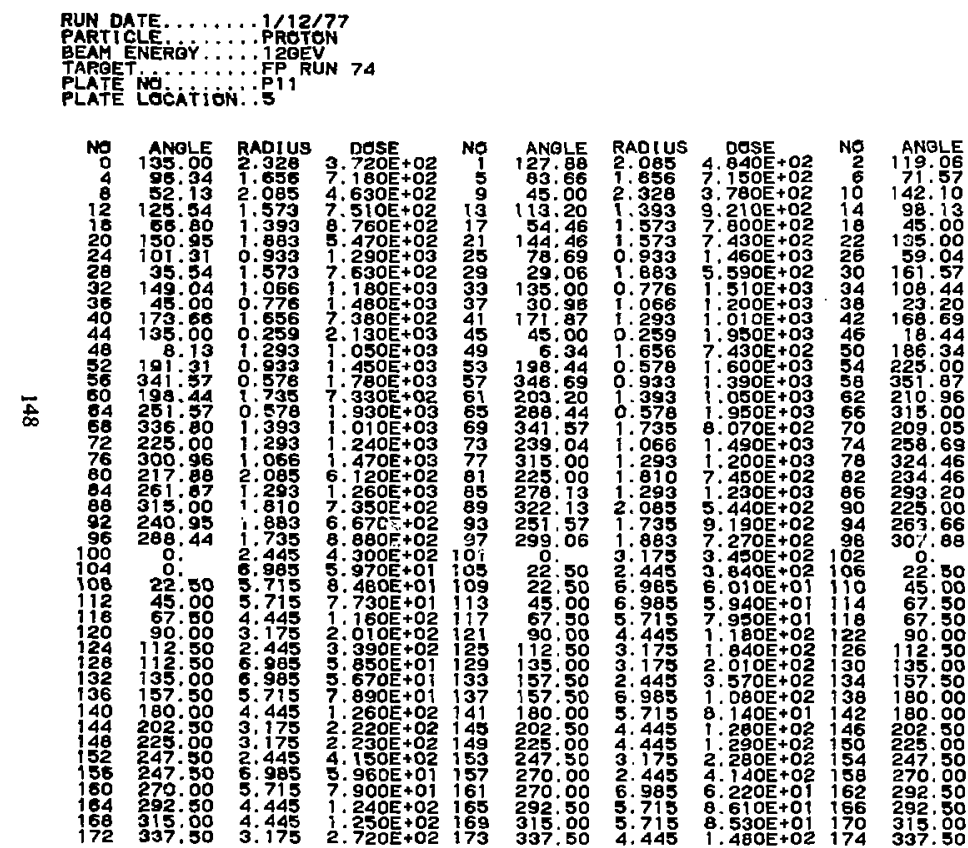

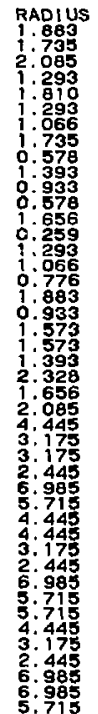
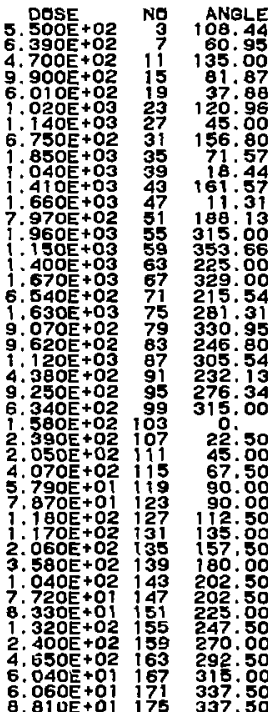

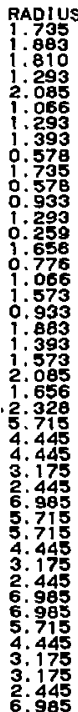

6. 只政 5. $620 \mathrm{E}+02$ 1. $110 \mathrm{E}+03$ 4: $740 E+02$ - $150 E+0$ 9.020 +02 1.860 + $1360 \mathrm{E}+03$ . $360 \mathrm{E}+03$ $1.980 E+03$ $7.620 E+02$ $1.400 E+03$ $9.090+02$ $1.600 E+03$ I. $180 \mathrm{OE}+03$ $5.540 E+02$ 9. $290 \mathrm{E}+02$ 9. $290 \mathrm{E}+01$ $1.430 E+02$ $2.070 E+02$ $1: 010 E+02$ $7.2200+0$ $1.140 E+02$ $3.820=+02$ $5.810+0$ :ijoto $1,270 \mathrm{E}+02$ 3. $060 \mathrm{0}+02$ 1. $400 \mathrm{E}+\mathrm{+} 2$ 
Table B-47.

RUN DATE.......1/12/77

PEA ENEROY $: \ldots, 12$ 12OEV

PLATE HOCATI UN:: :
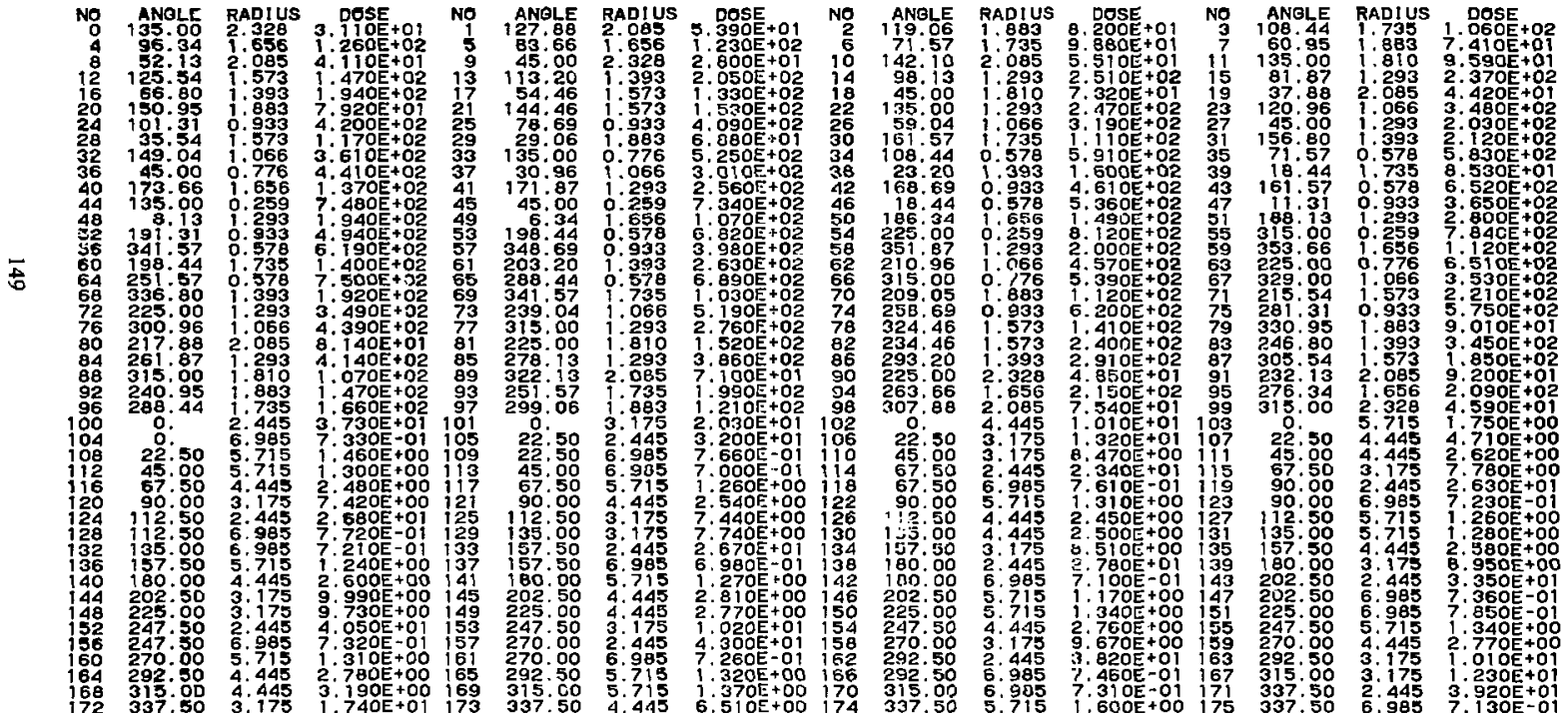
Table B-48.
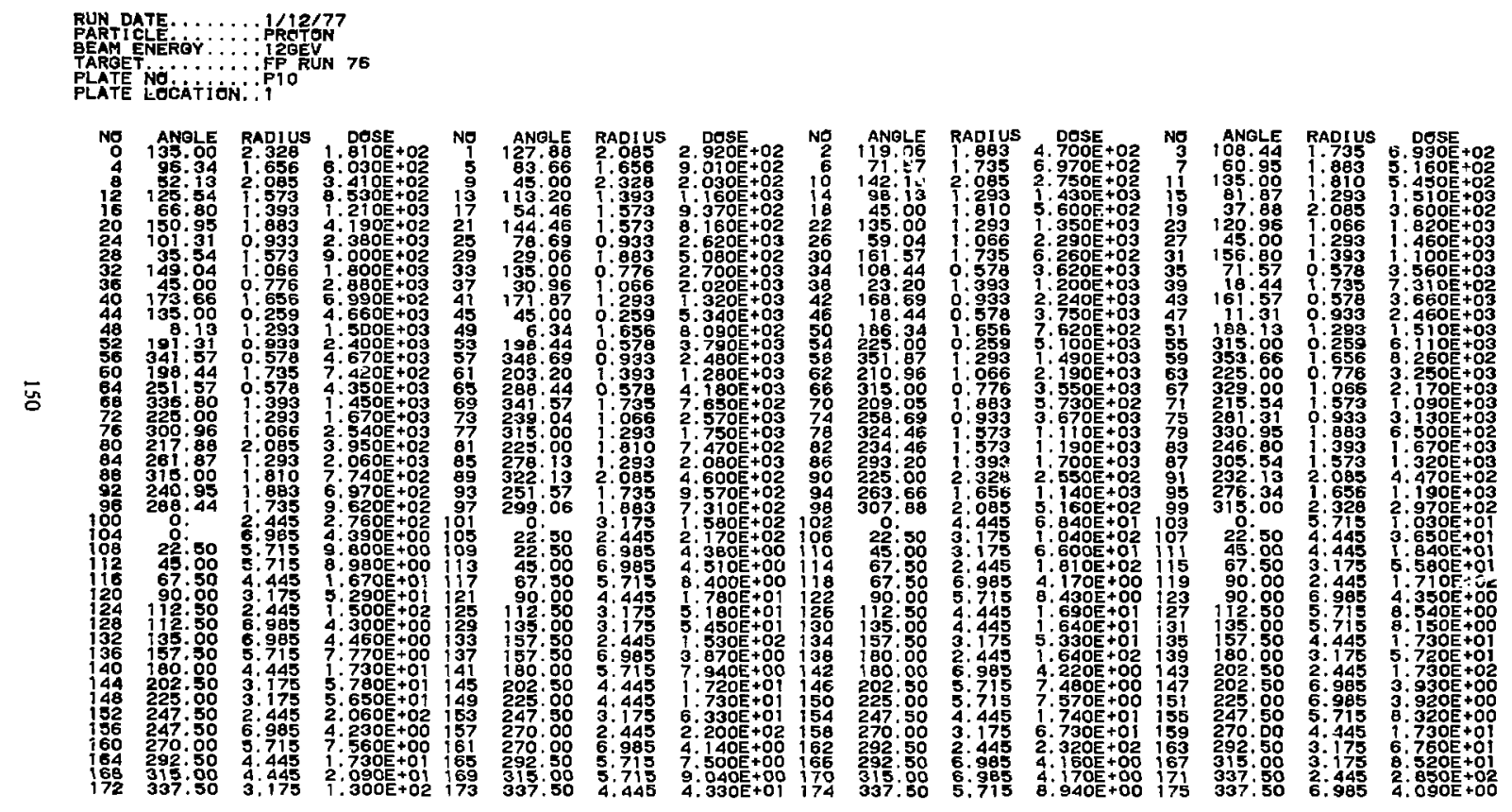
Table B-49.
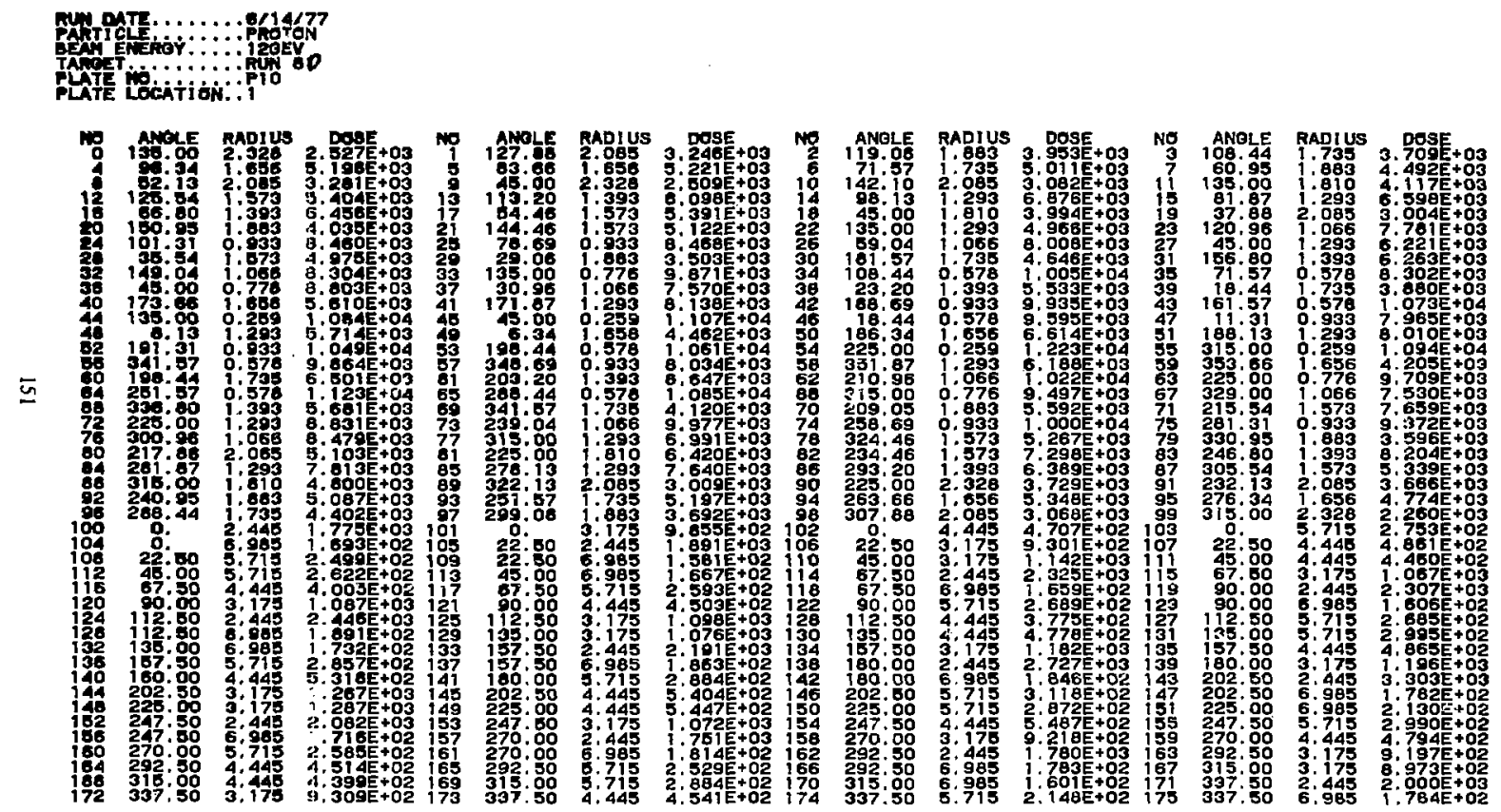
Table B-50.
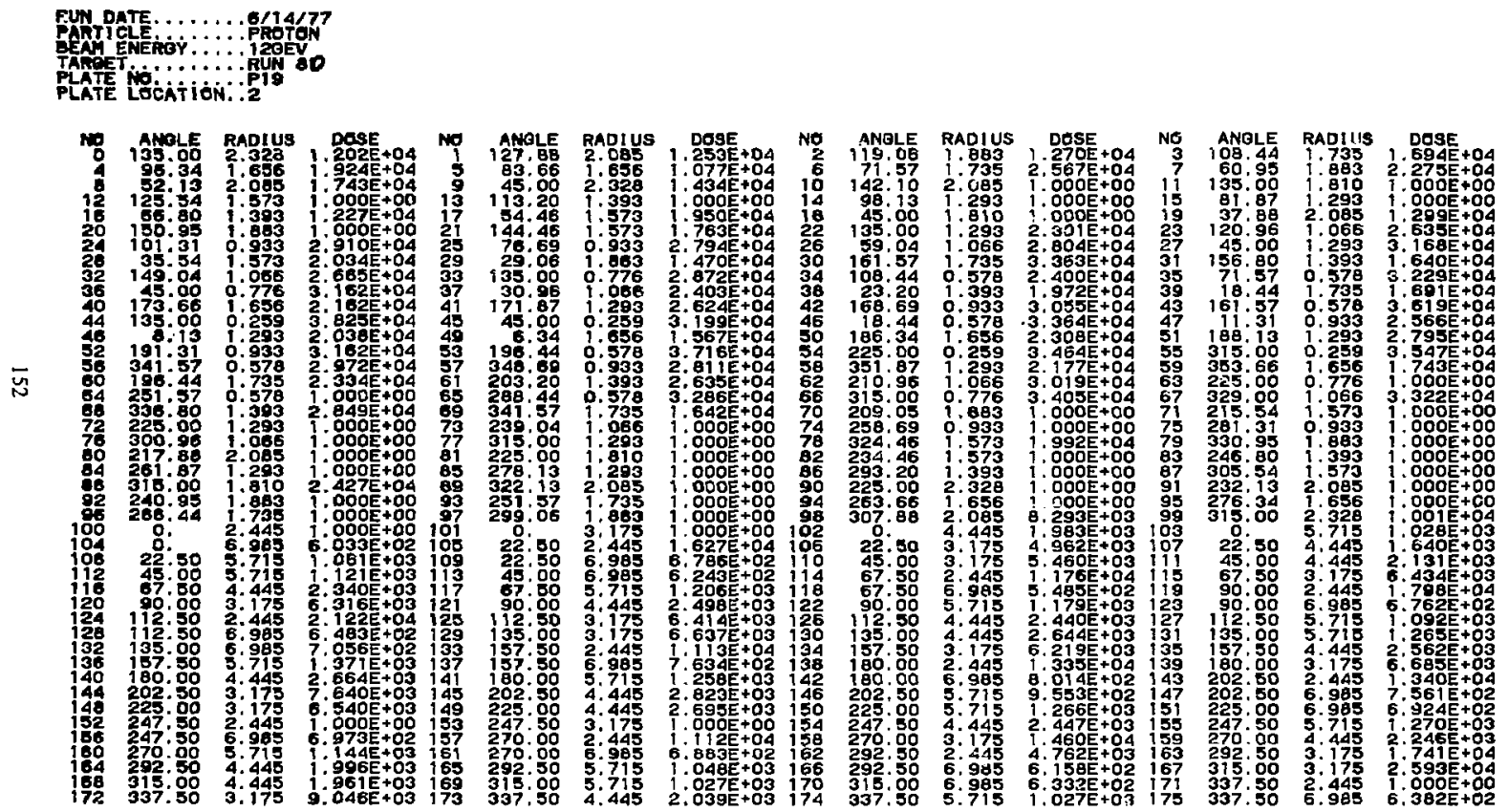
Table B-51.
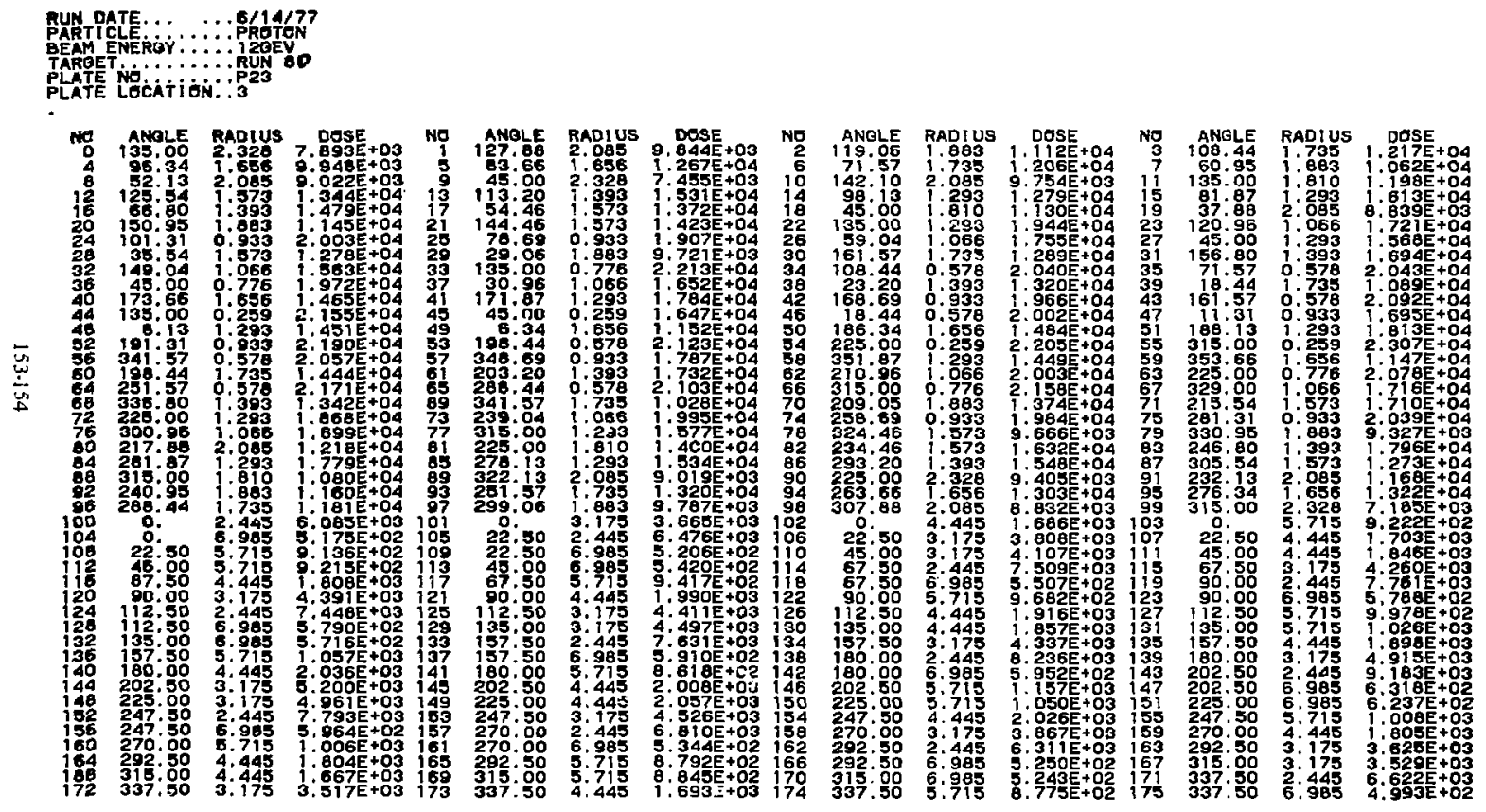


\section{APPENDIX C DOSE PLOTS FOR \\ TLD DETECTORS EMBEDDED IN 238U PLATES}

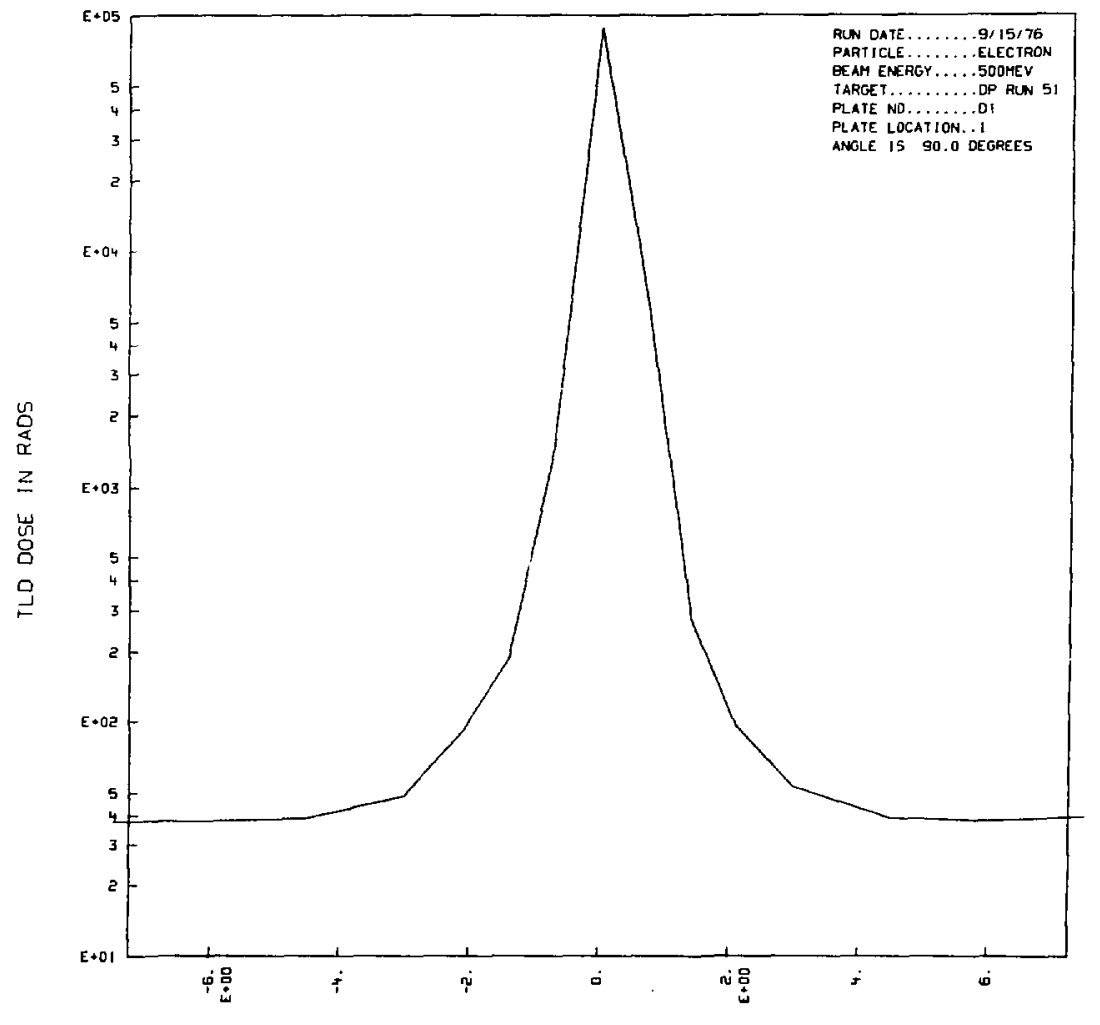

RADIUS IN CM

Fig. C-1. 


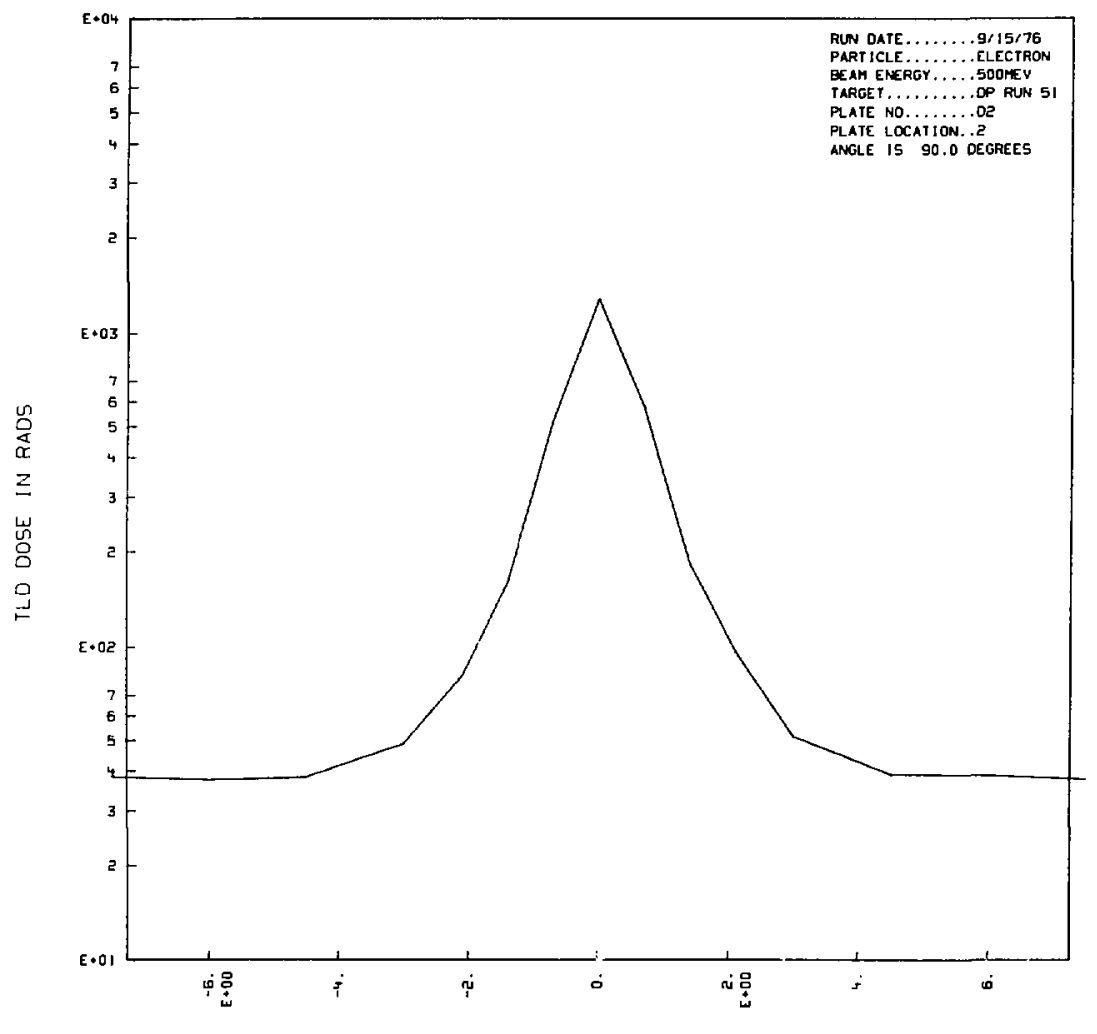

RADIUS IN CM

Fig. C-2. 


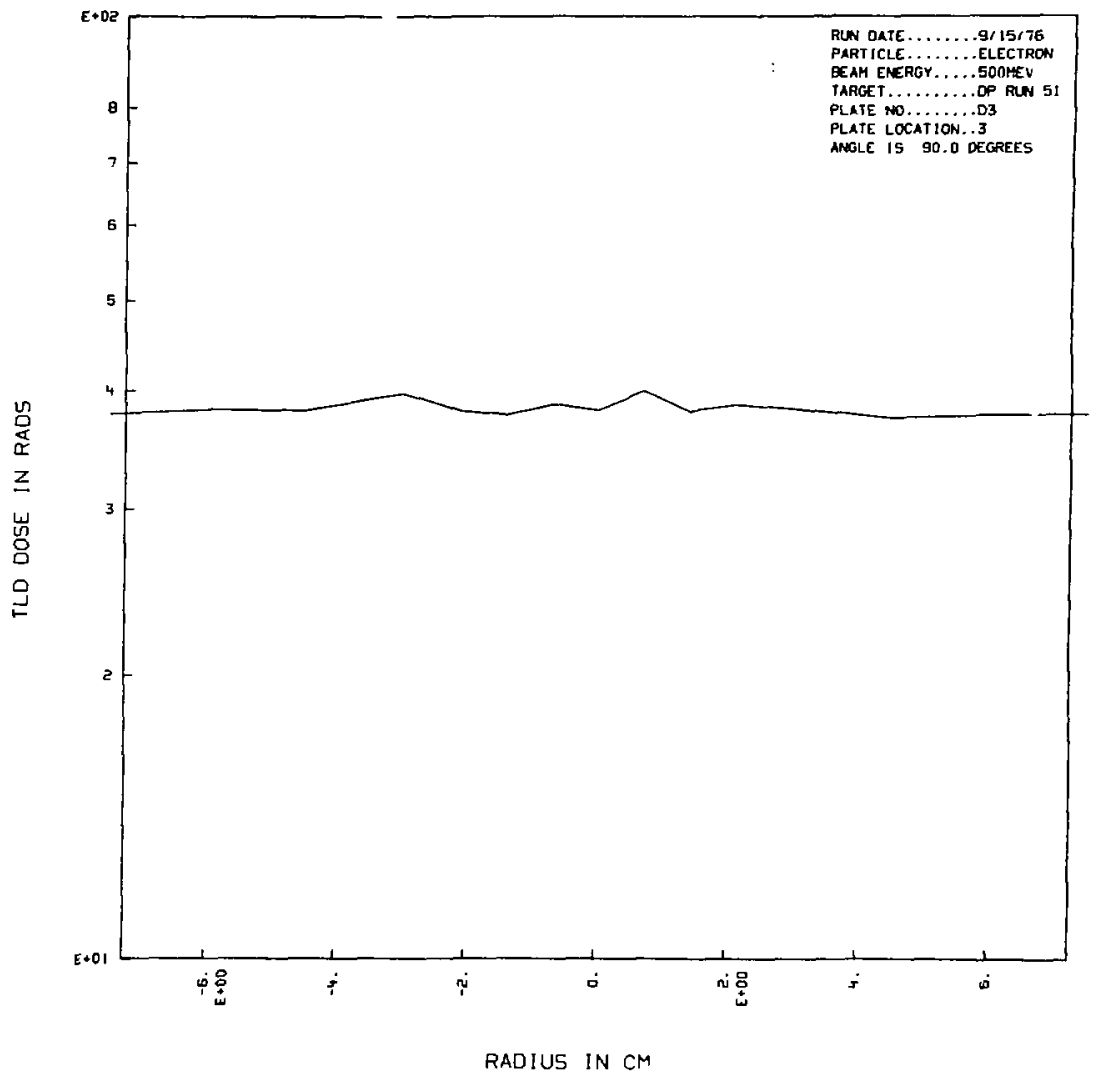

Fin. C.3. 


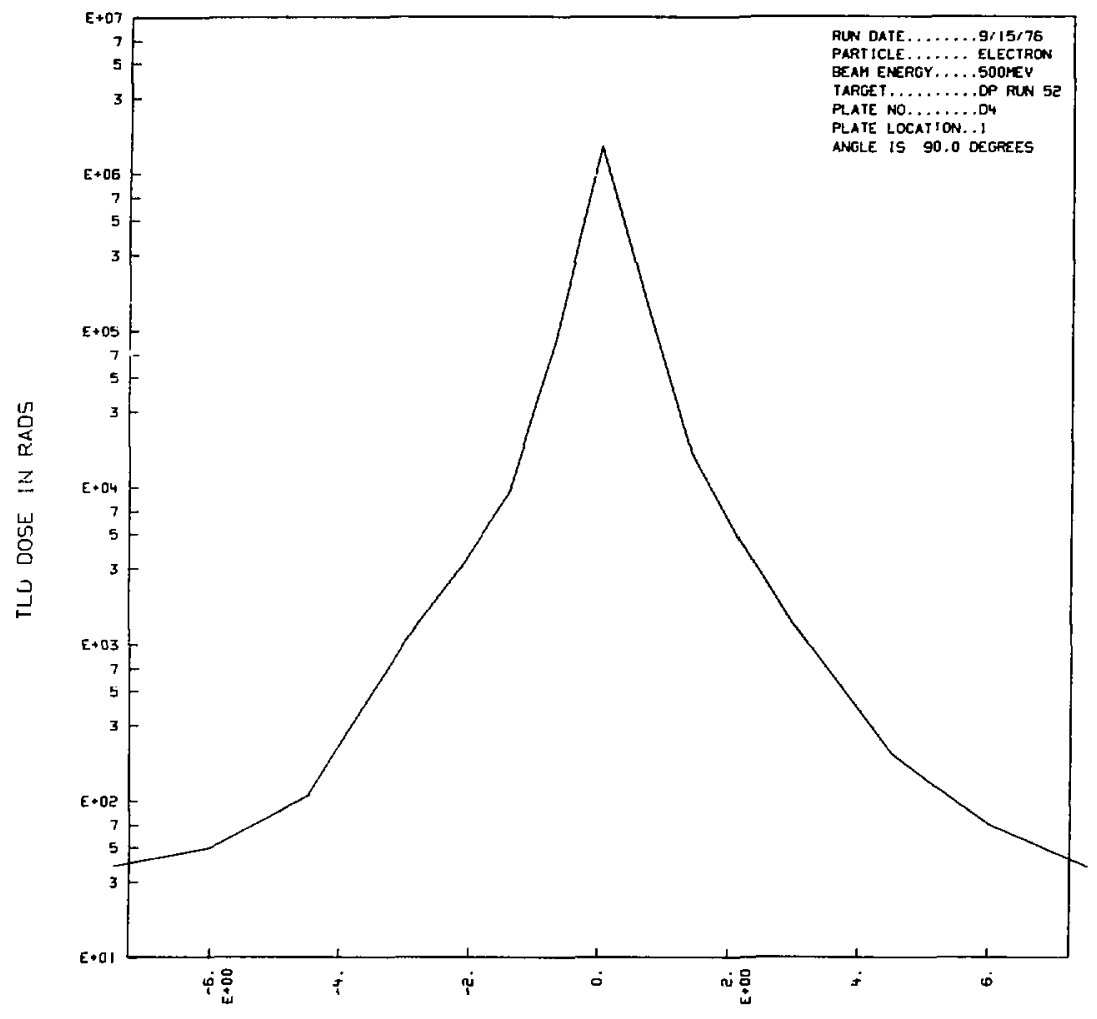

RADIUS IN CM

Fig. C-4, 


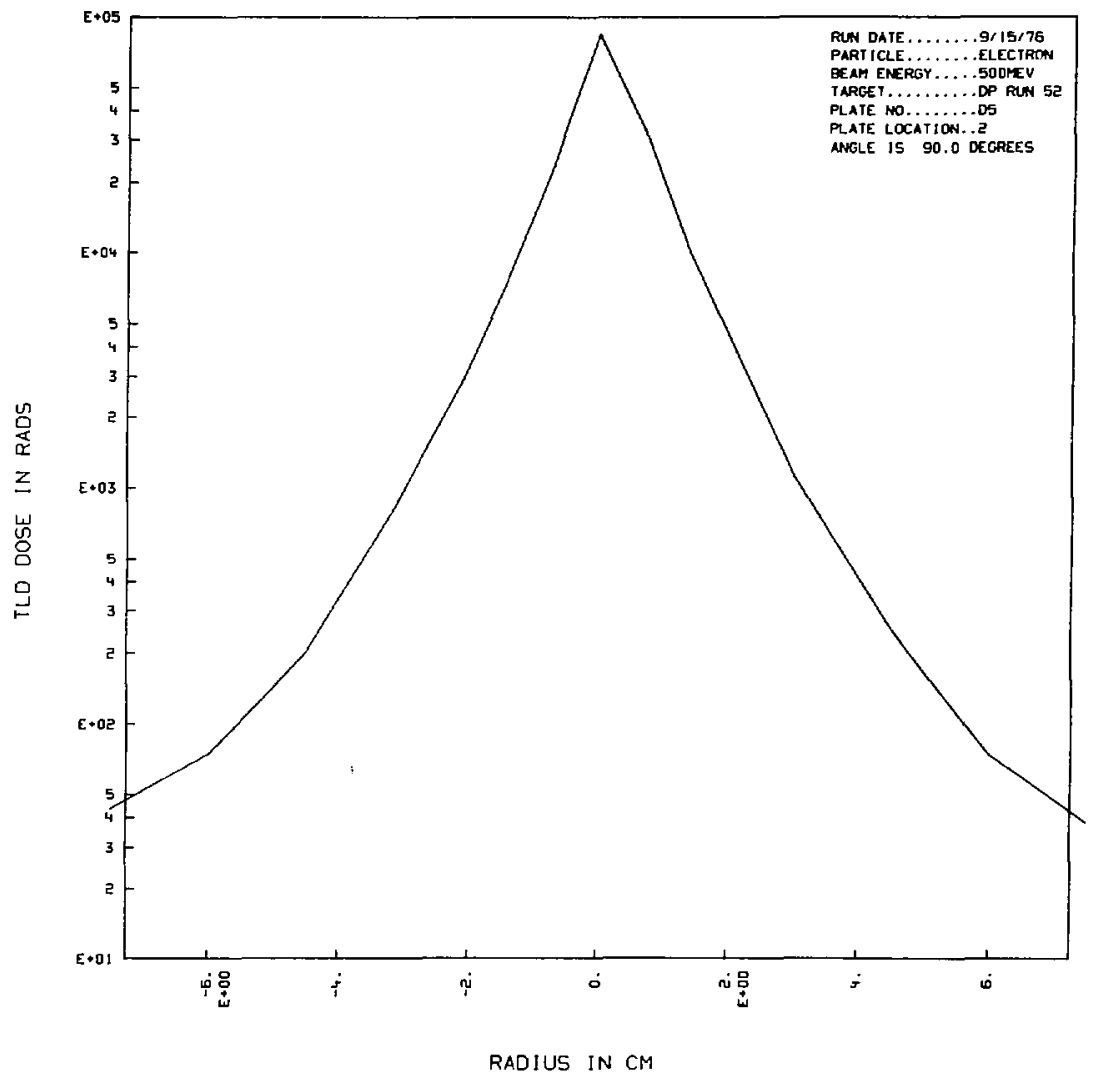

Fig. C.5. 


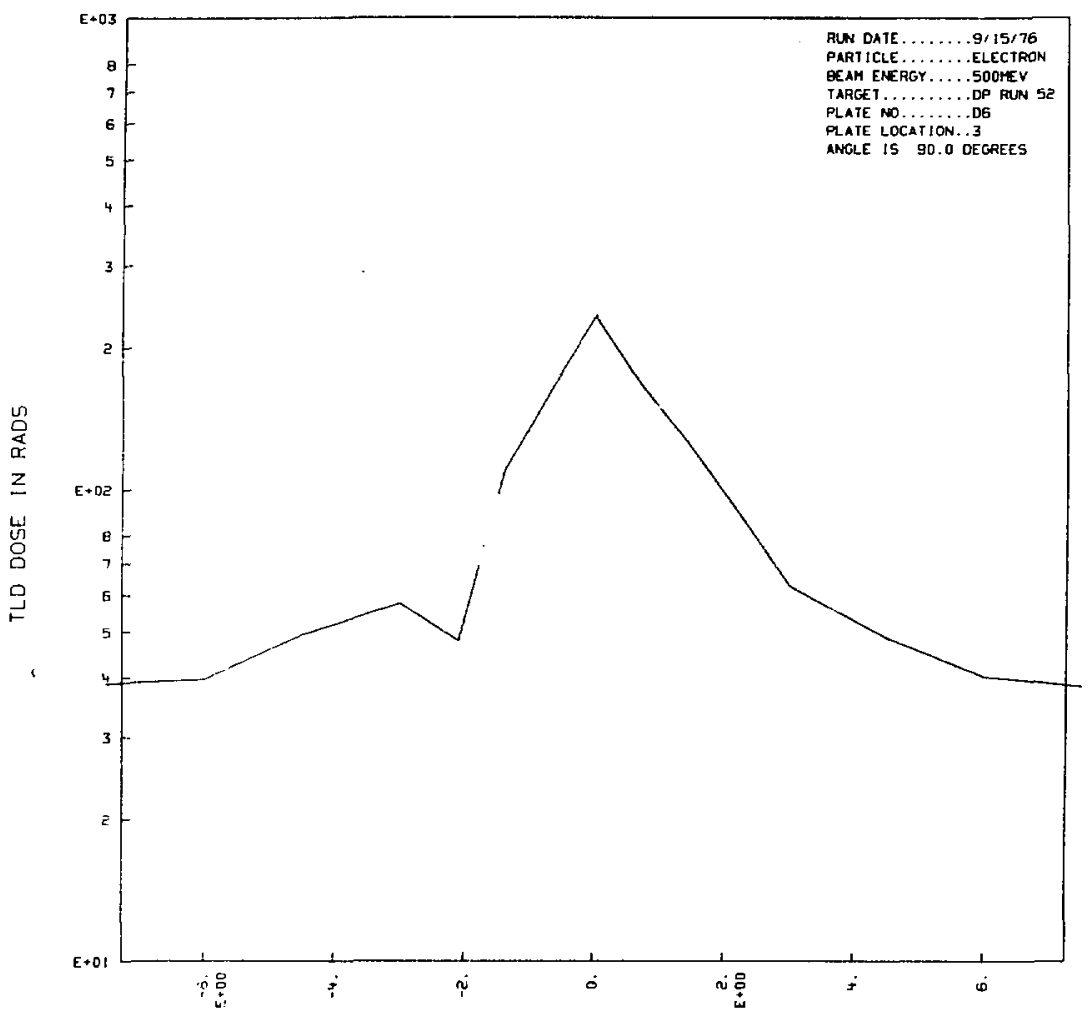

RADIUS IN CM

Fig. C-6. 


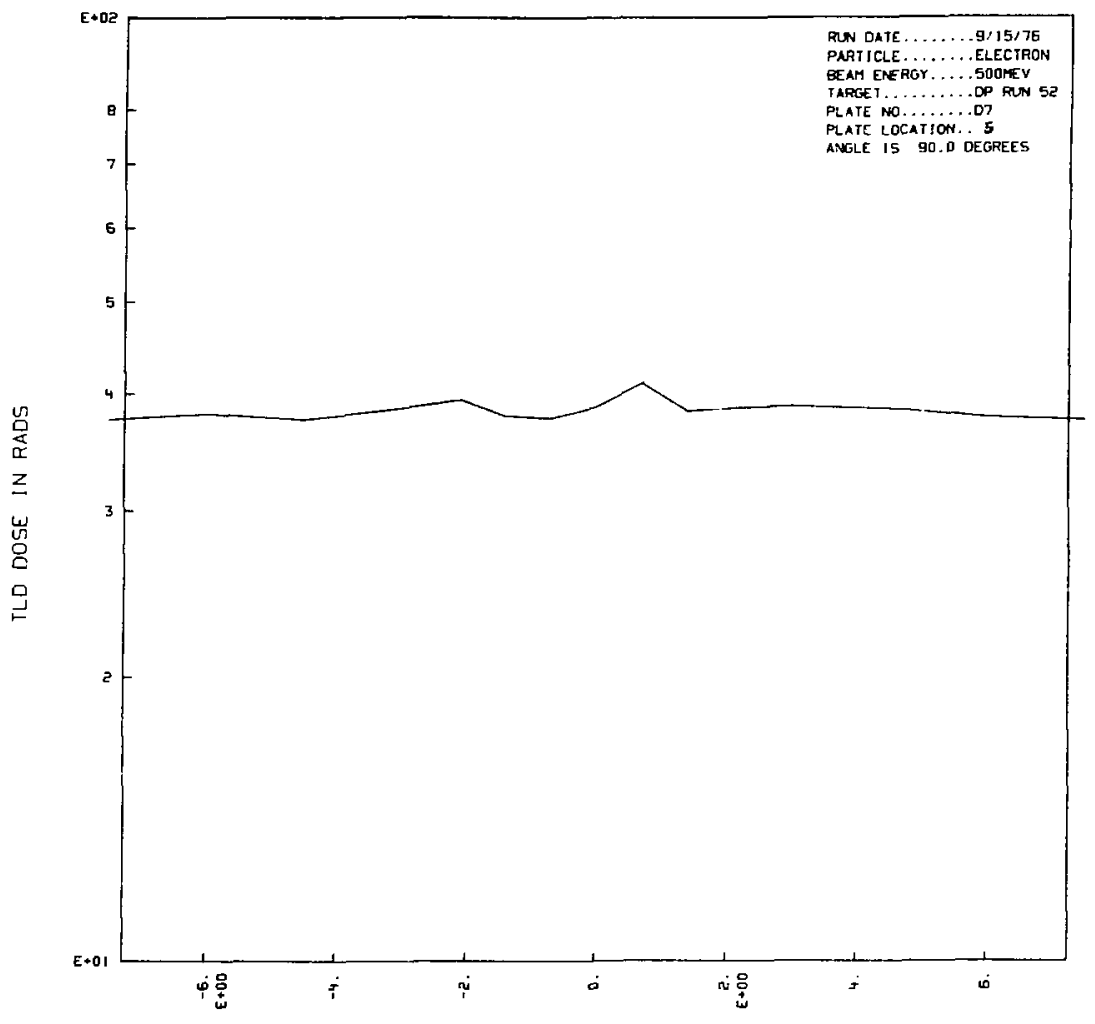

RADIUS IN CM

Fig. C-7. 


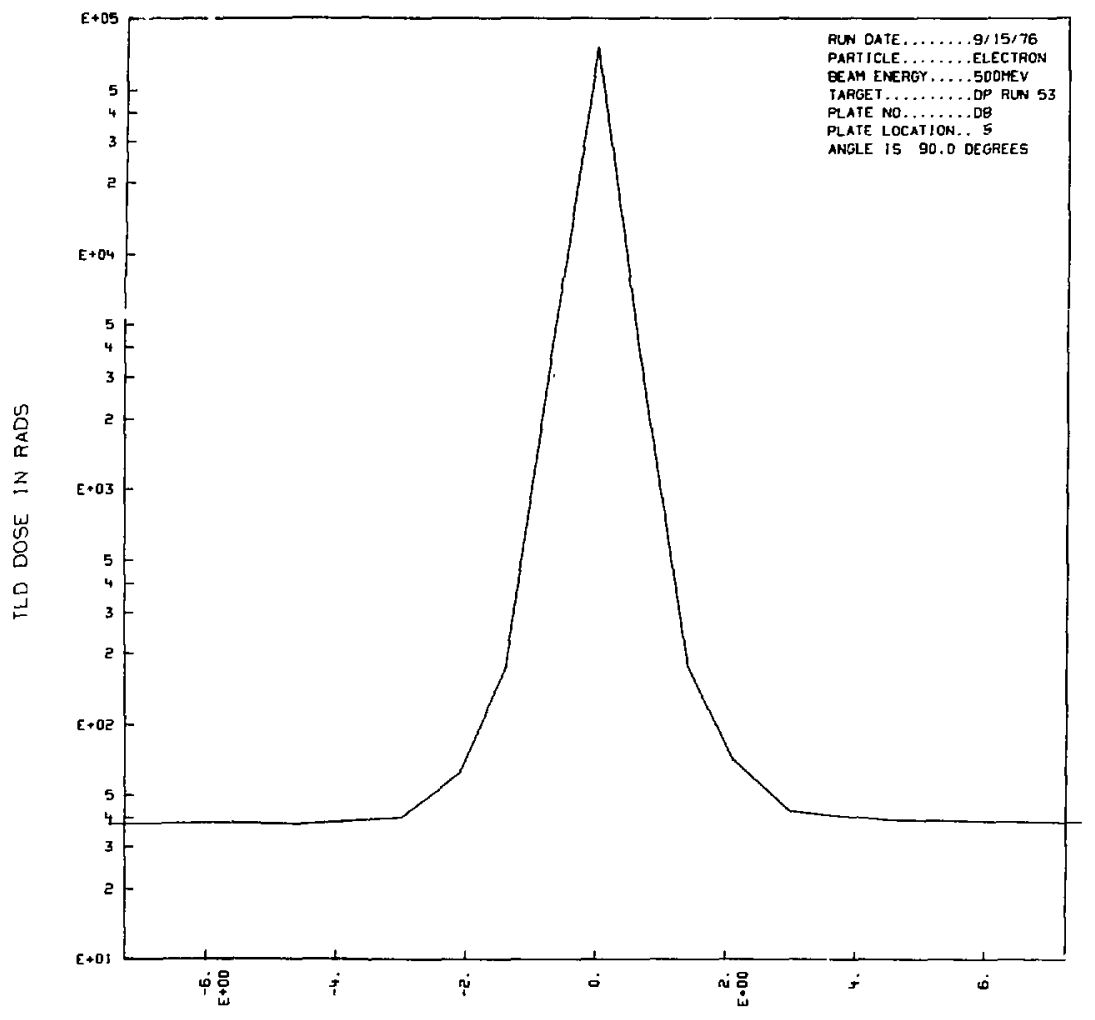

RADIUS IN CM

Fig. C-8, 


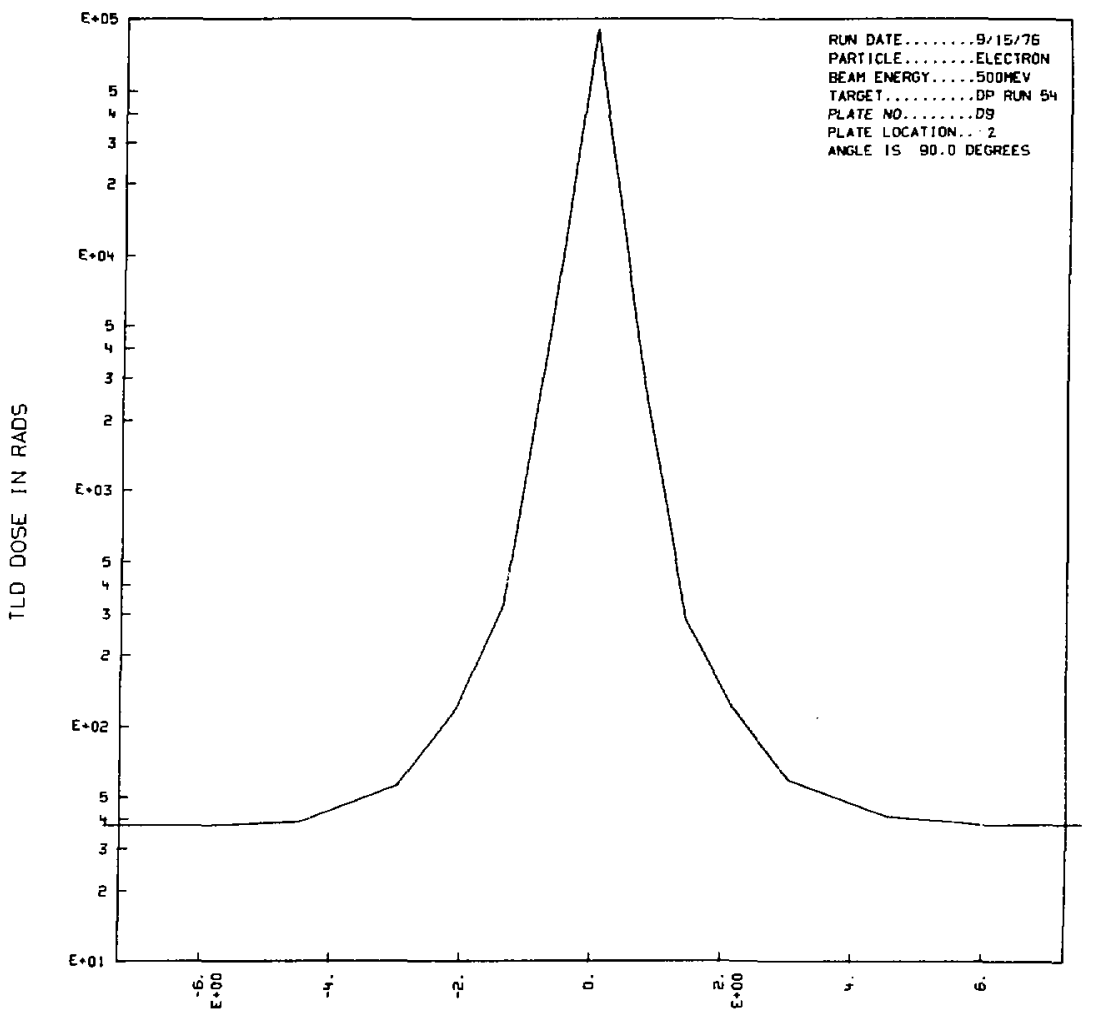

RADIUS IN CM

Fig. C.4. 


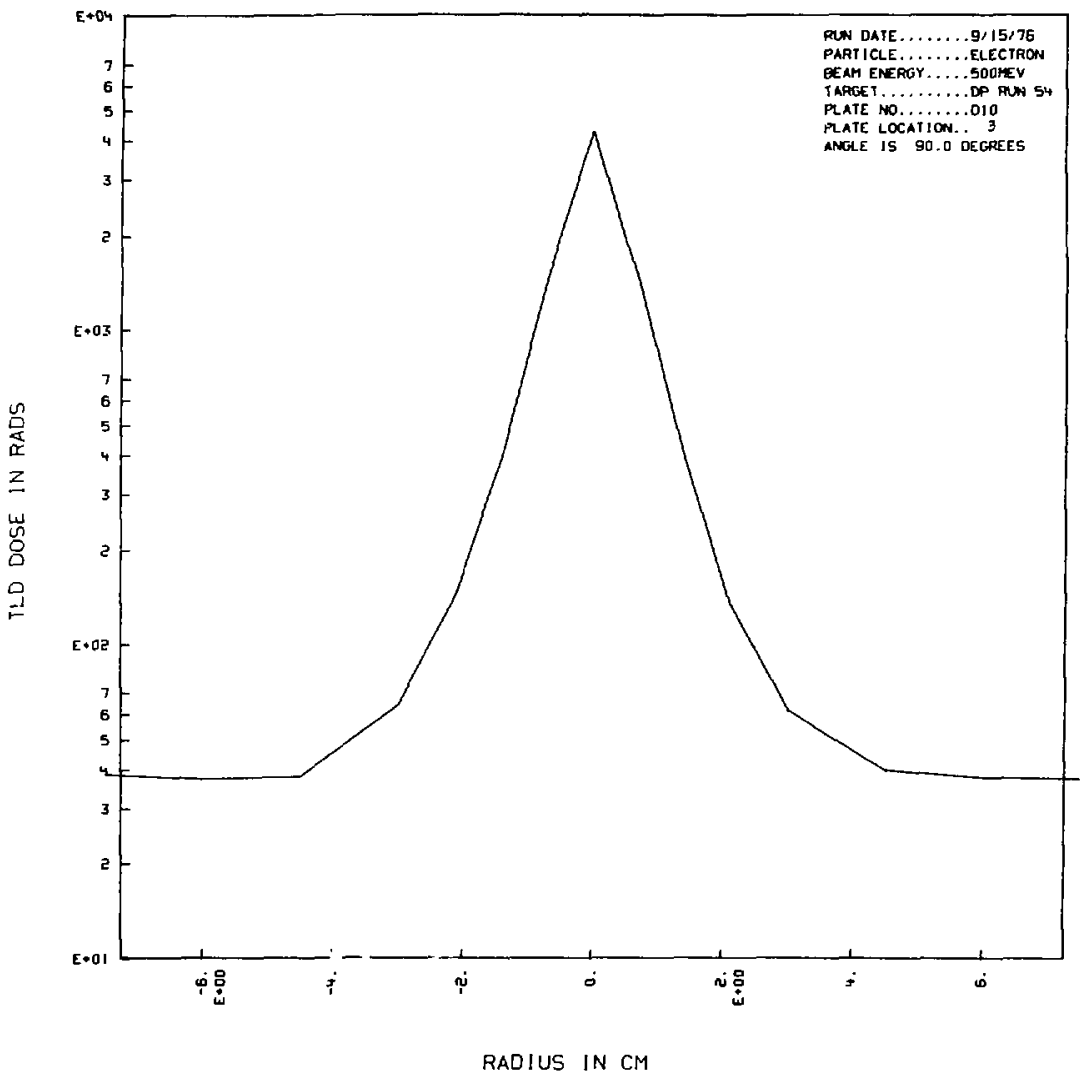

Fis. C-10. 


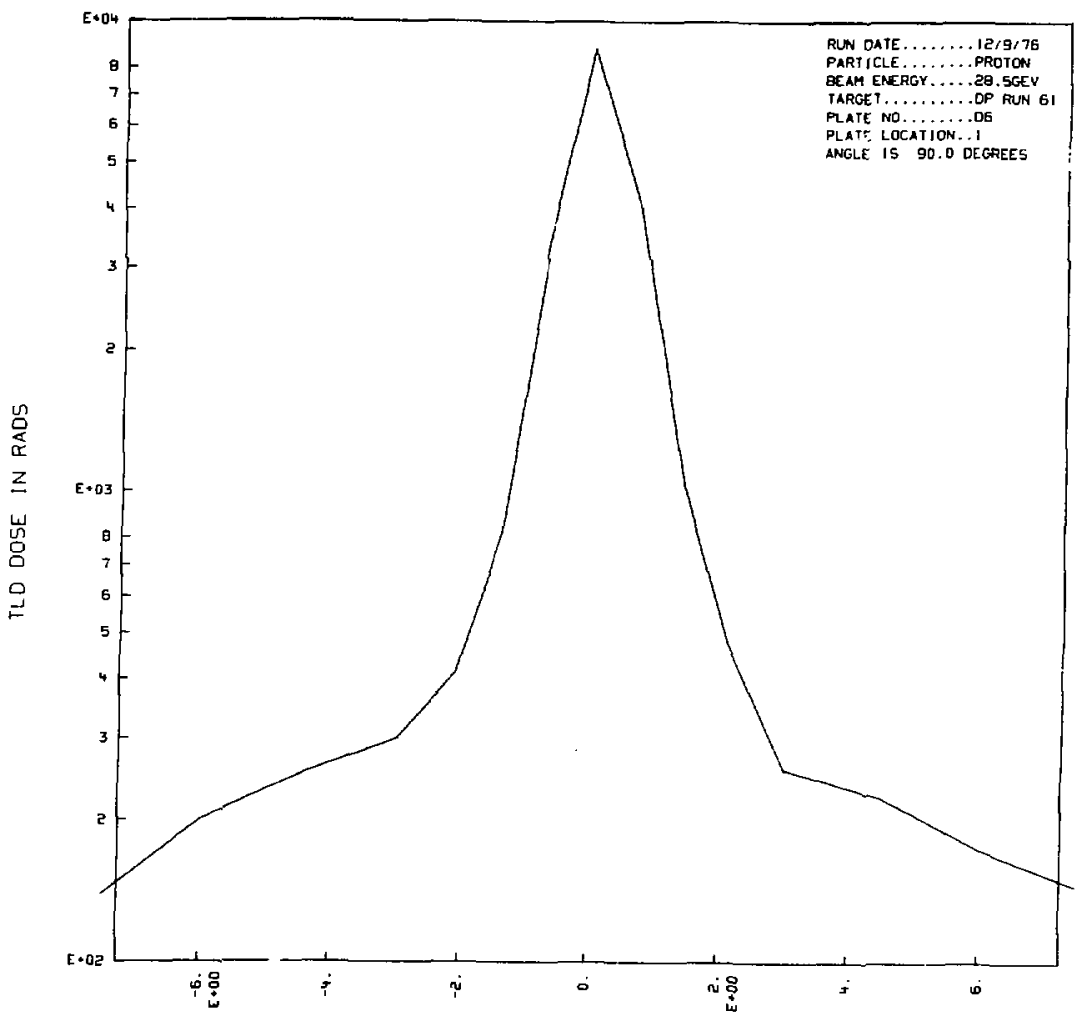

RADIUS IN CM

Fig. C.11. 


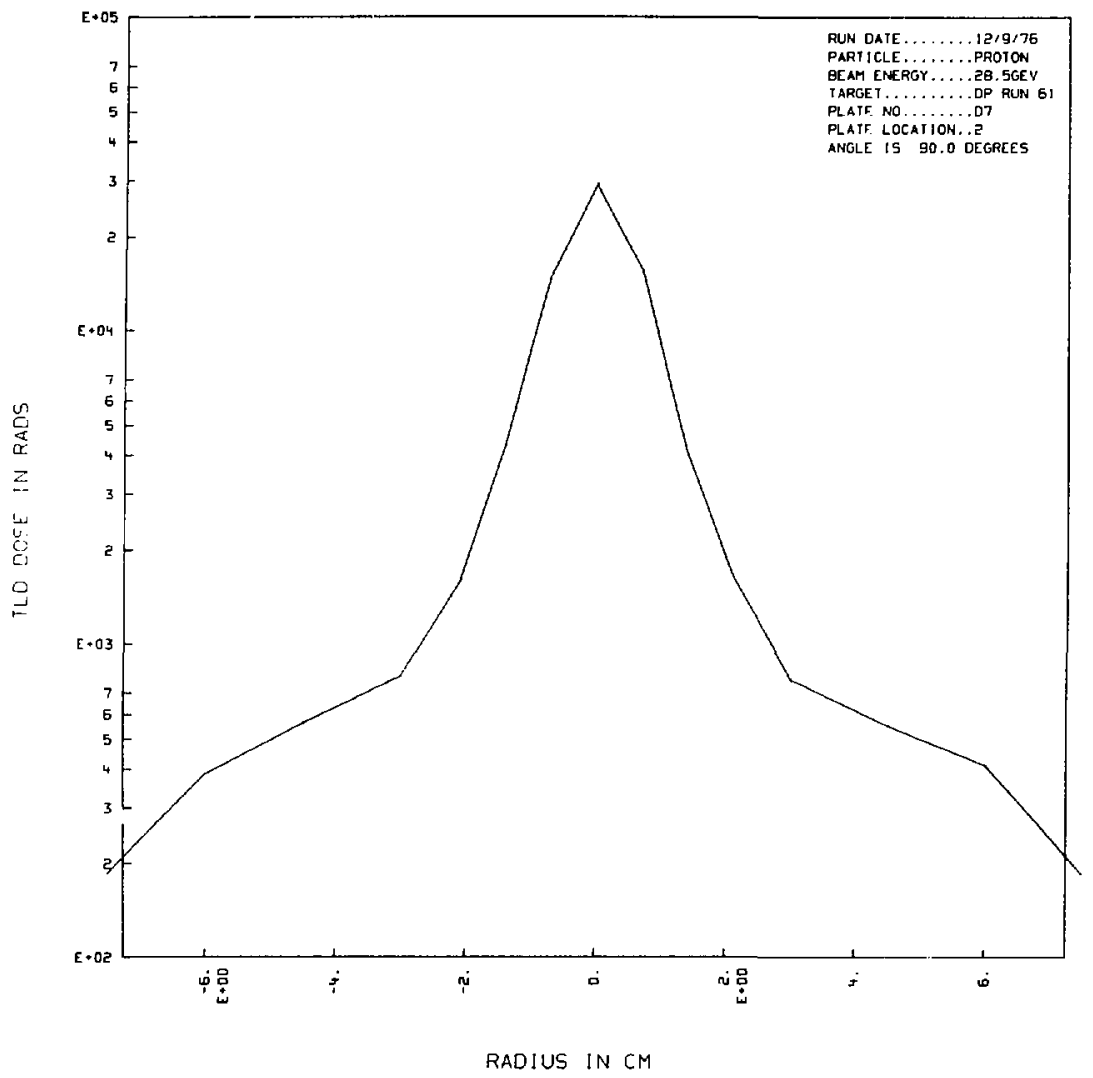

Fig. C.12.

166 


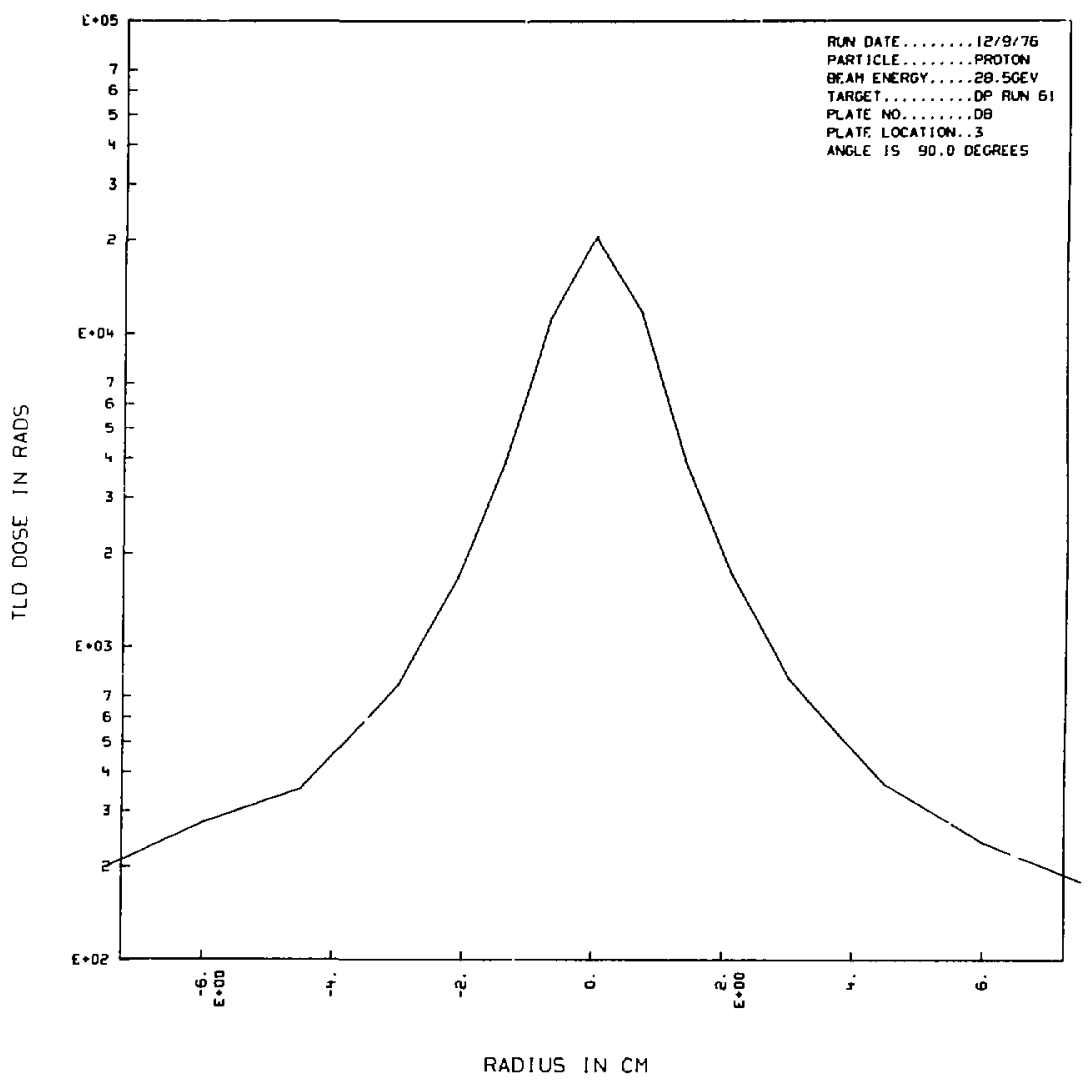

Fìg. C.13. 


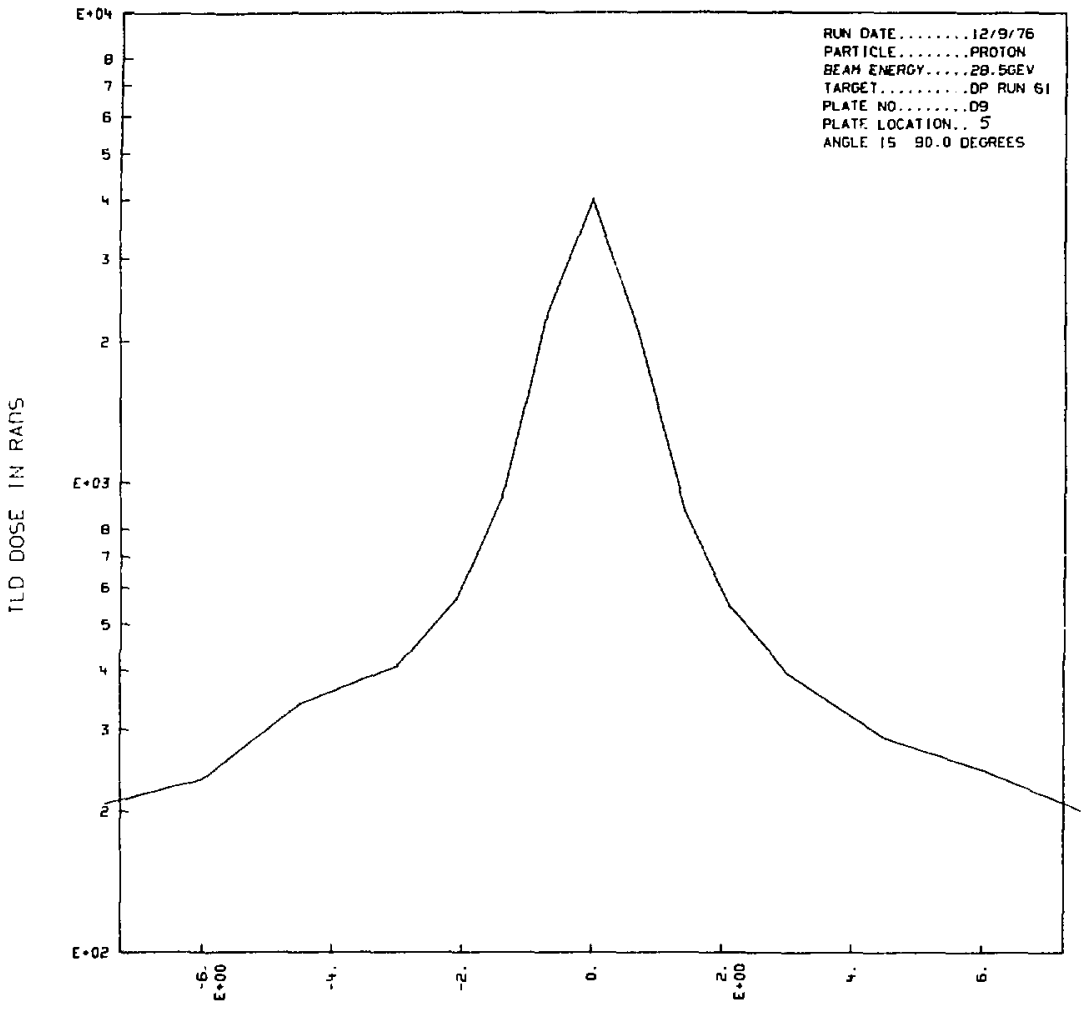

RADIUS IN CM

Fig. C.14. 


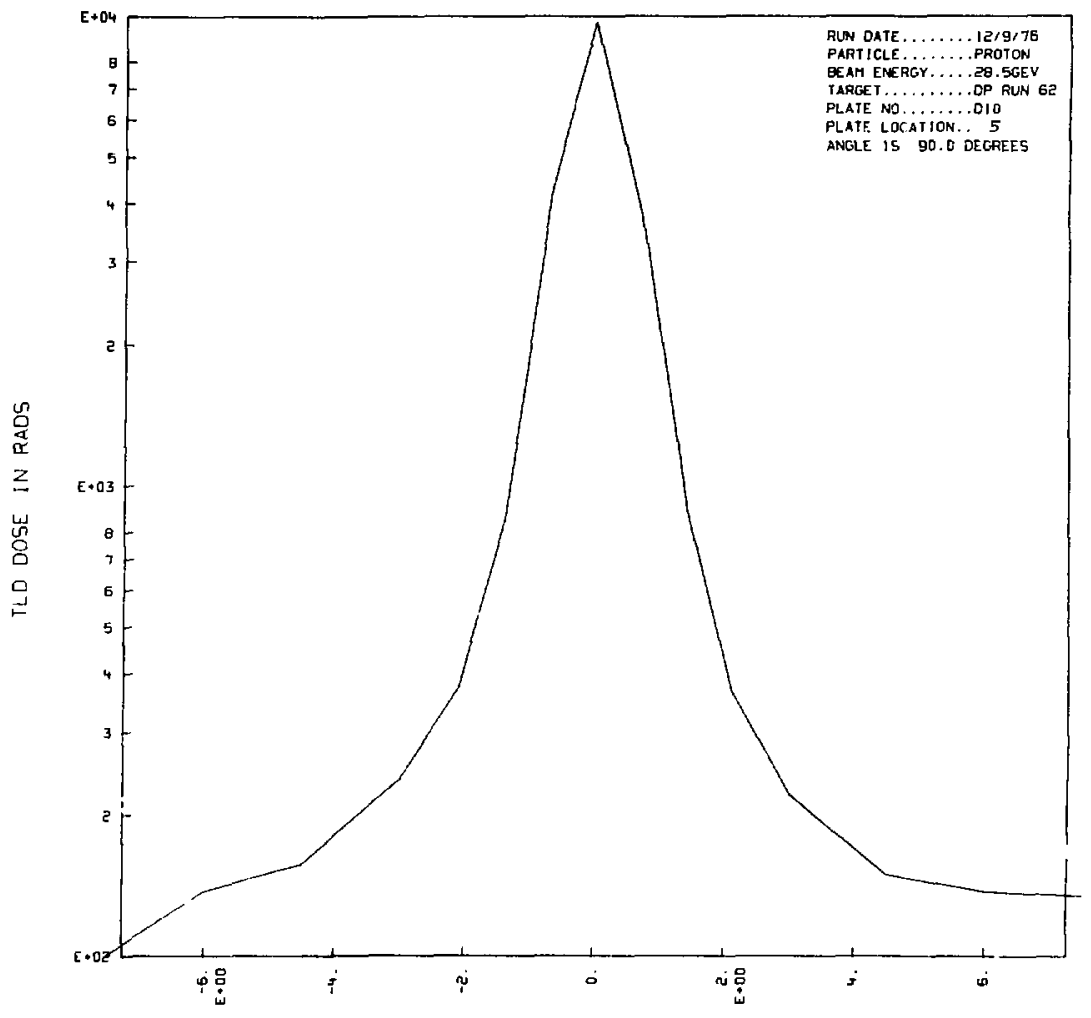

RADIUS IN CM

Fig, (-15. 


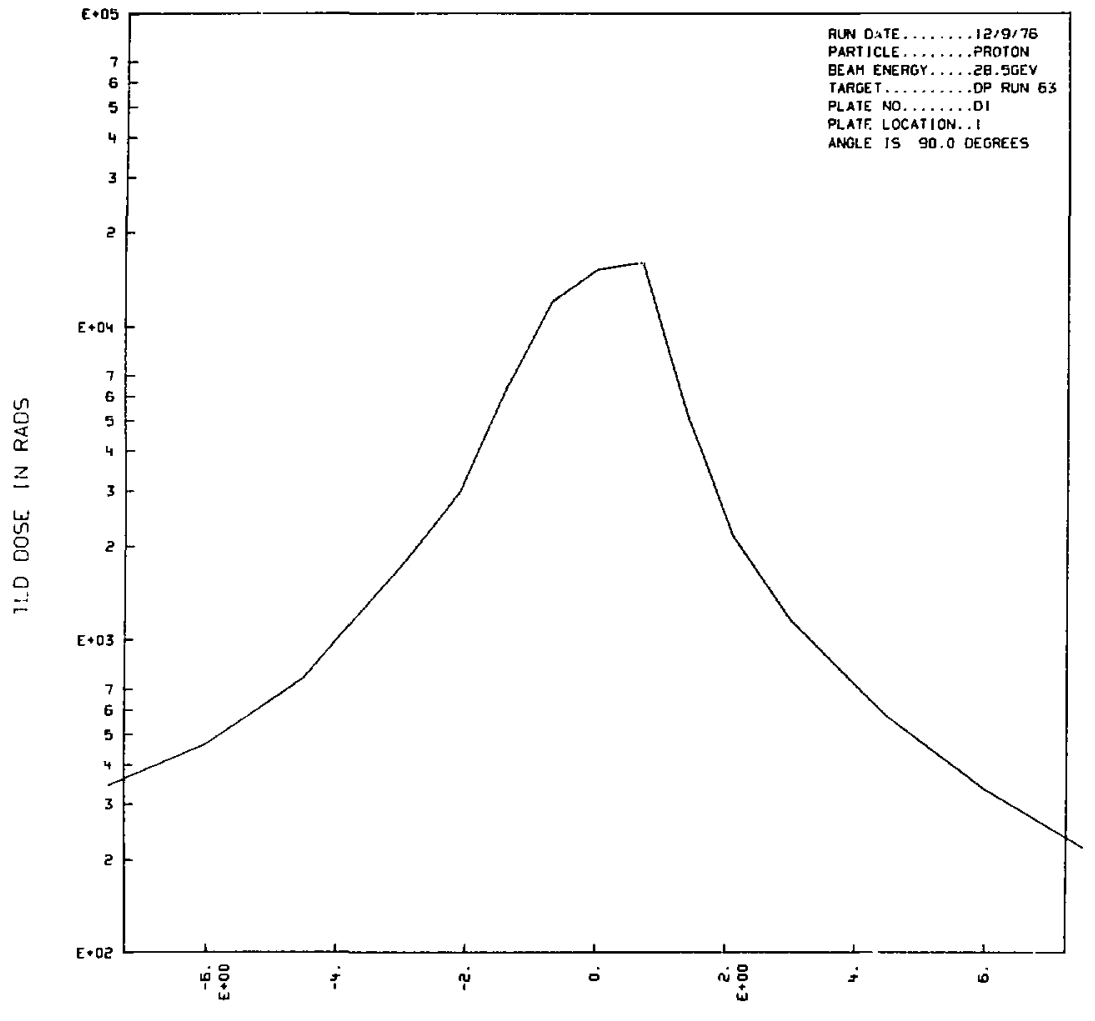

RADIUS IN CM

Fig. C.10. 


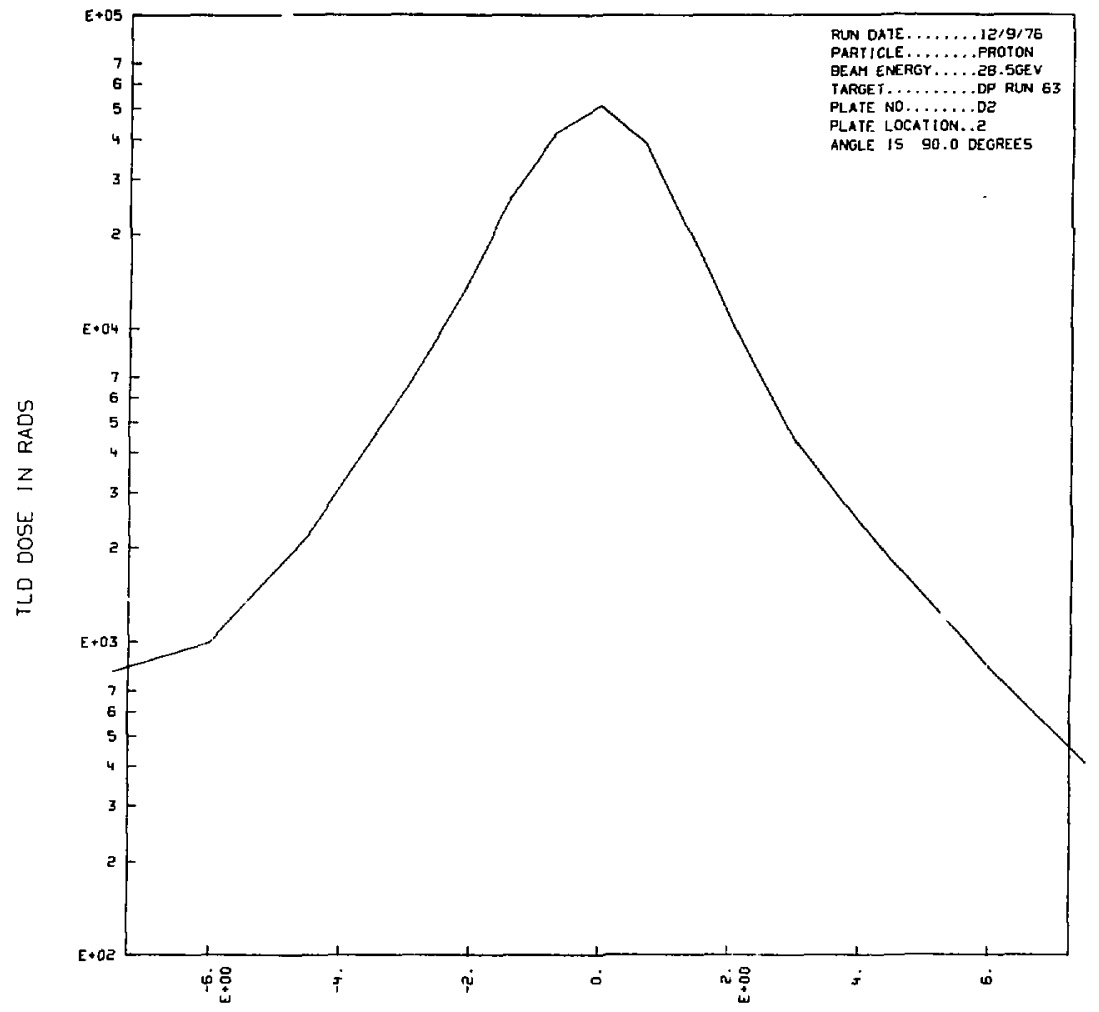

RADILS IN CM

Fig. C-17. 


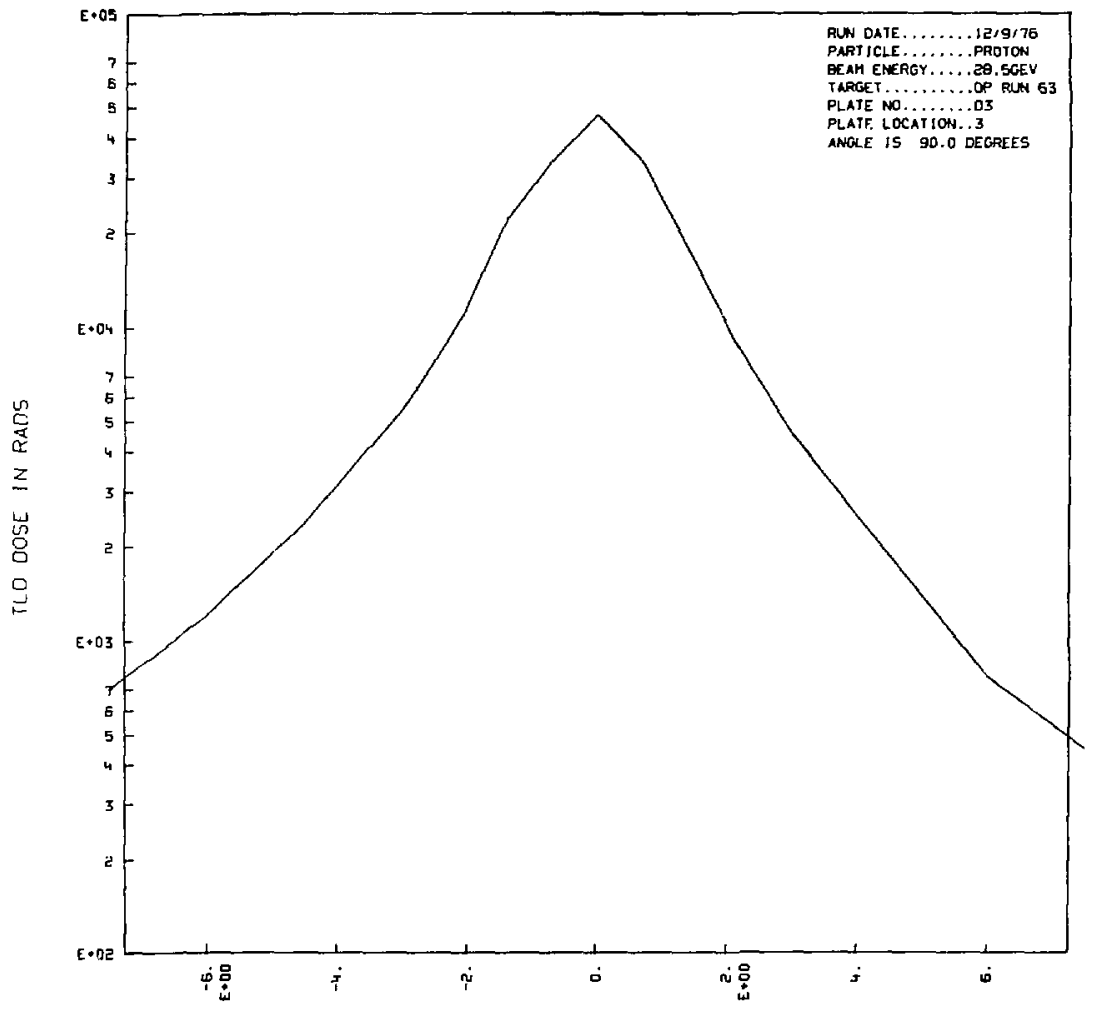

RADIUS IN CM

Fis. C-18. 


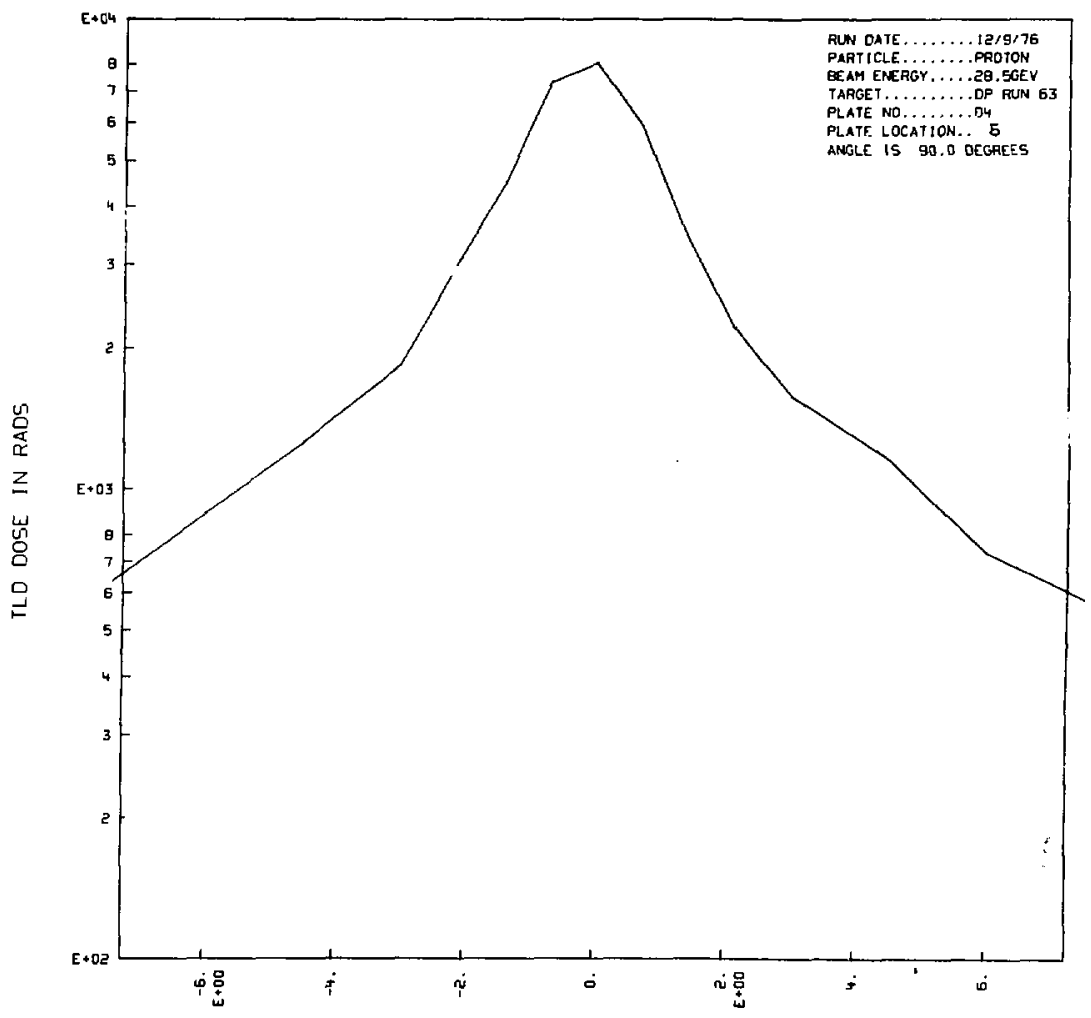

RADIUS IN CM

Fig. C-19. 


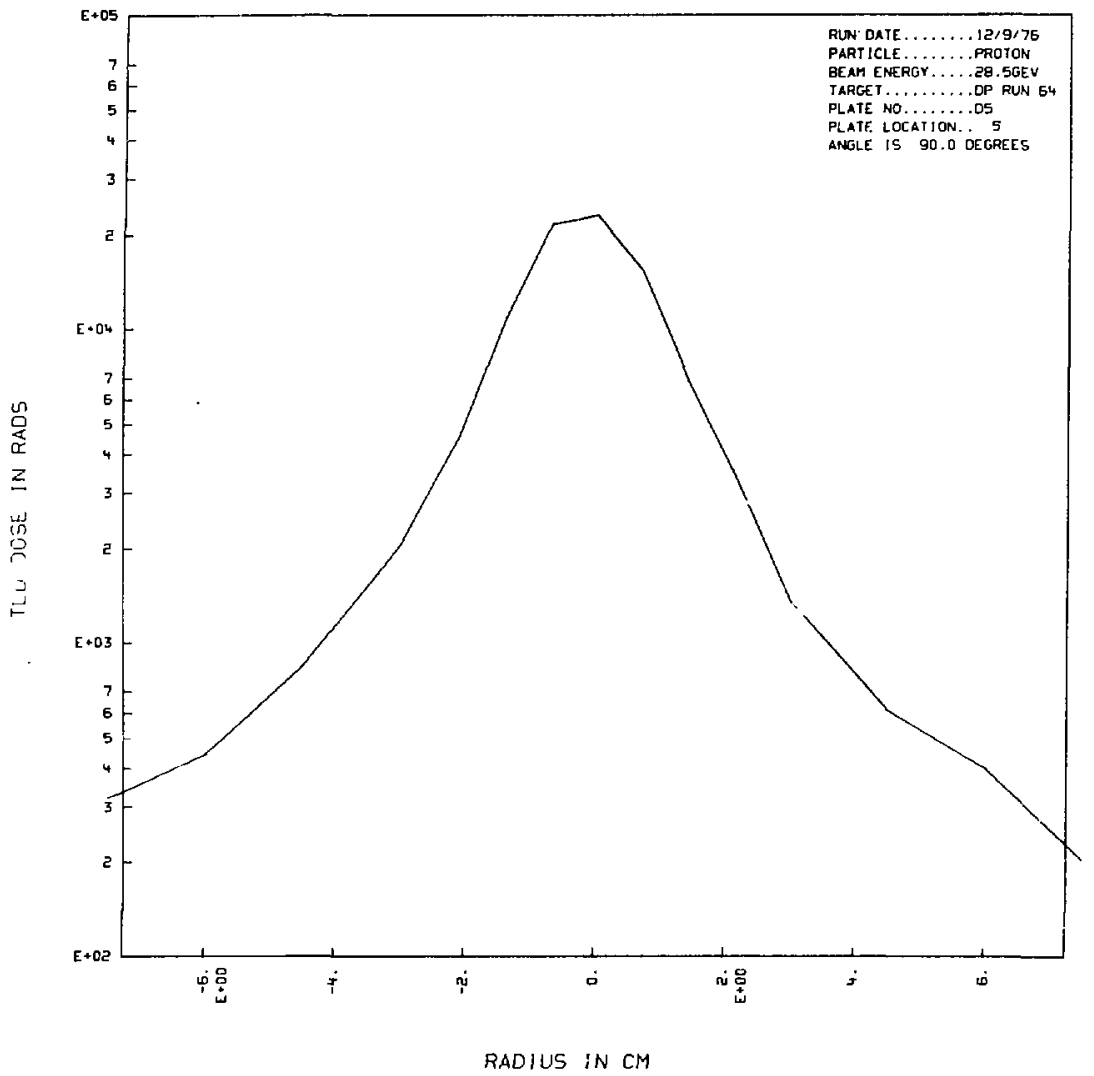

Fig. C-20.

174 


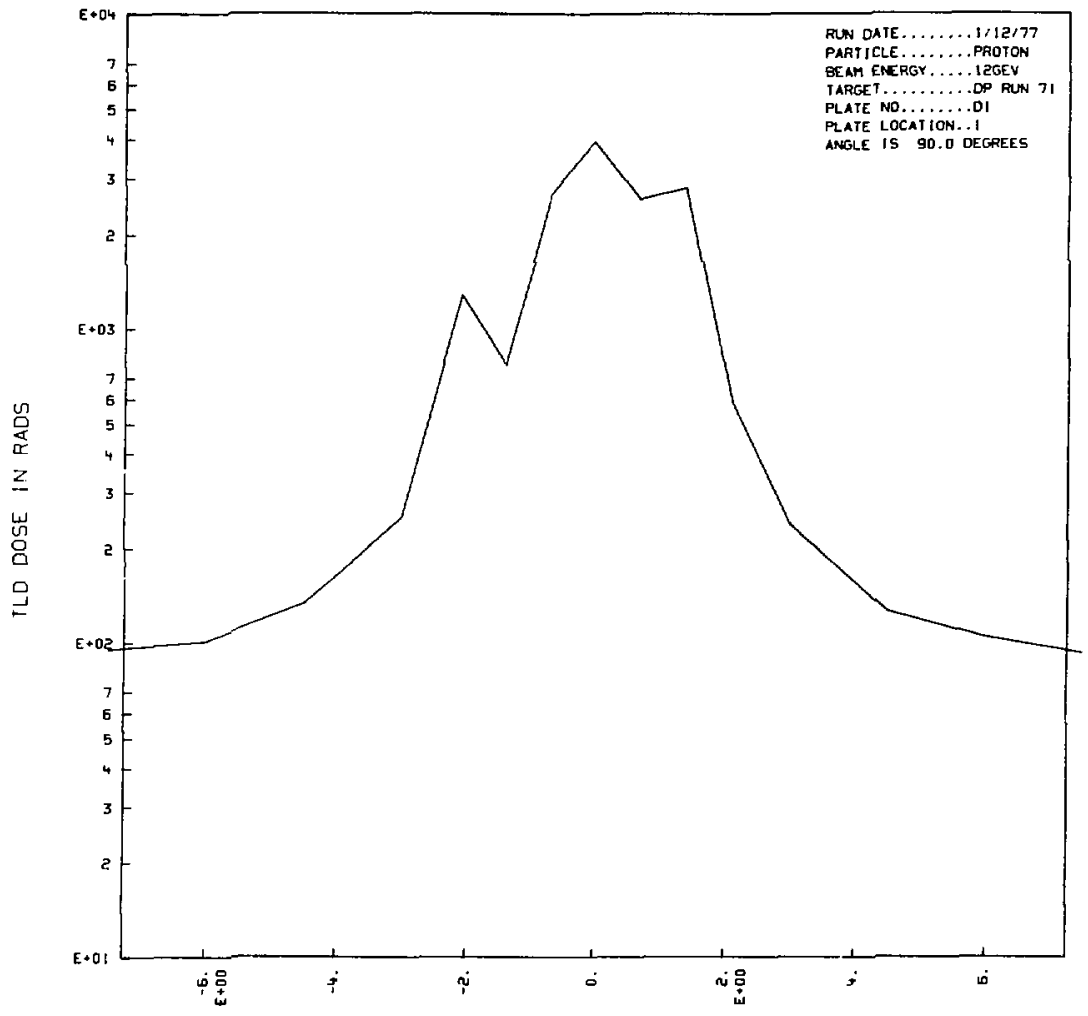

RADIUS IN CM

Fis. C-21. 


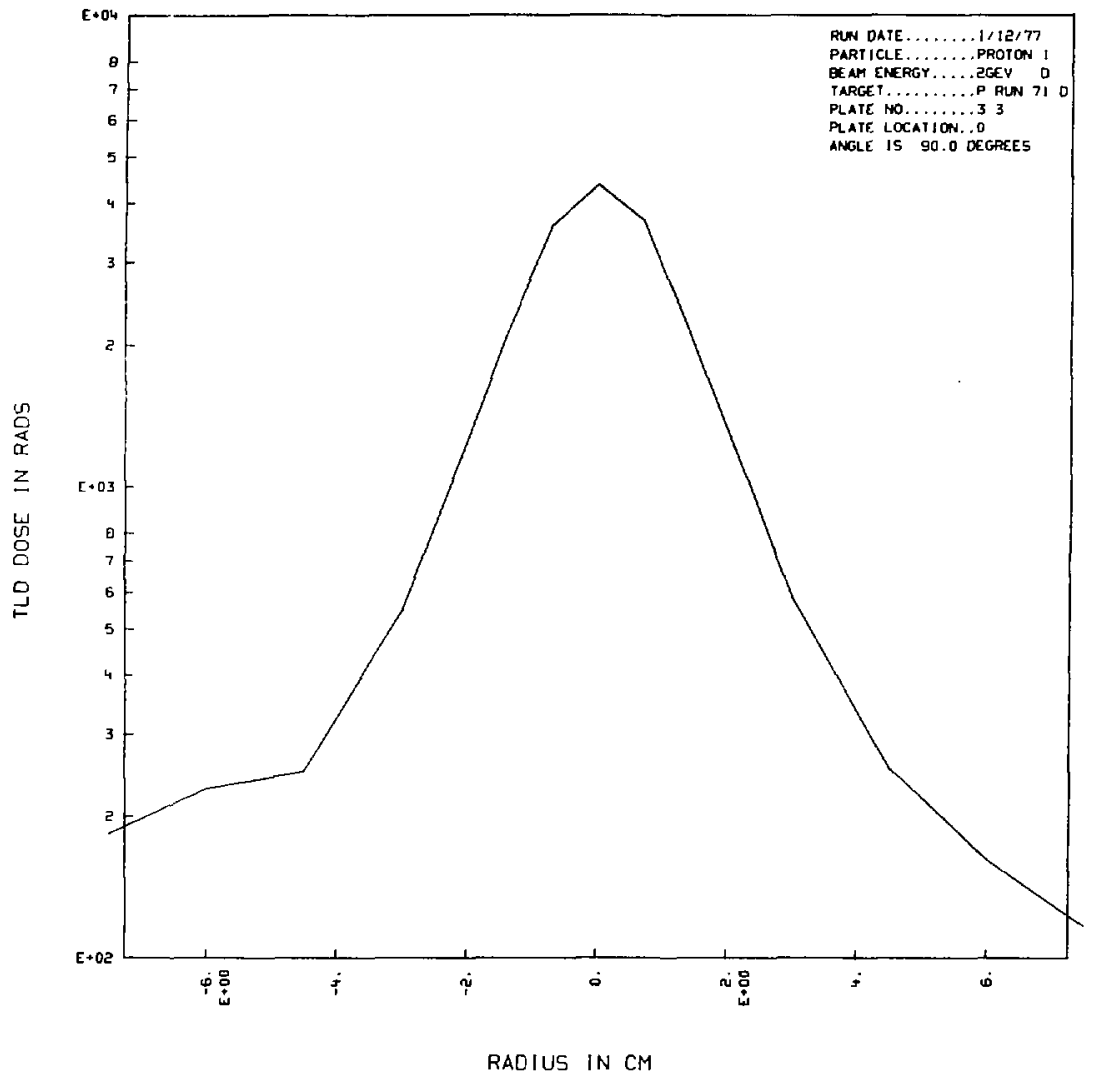

Fig. C-22.

176 


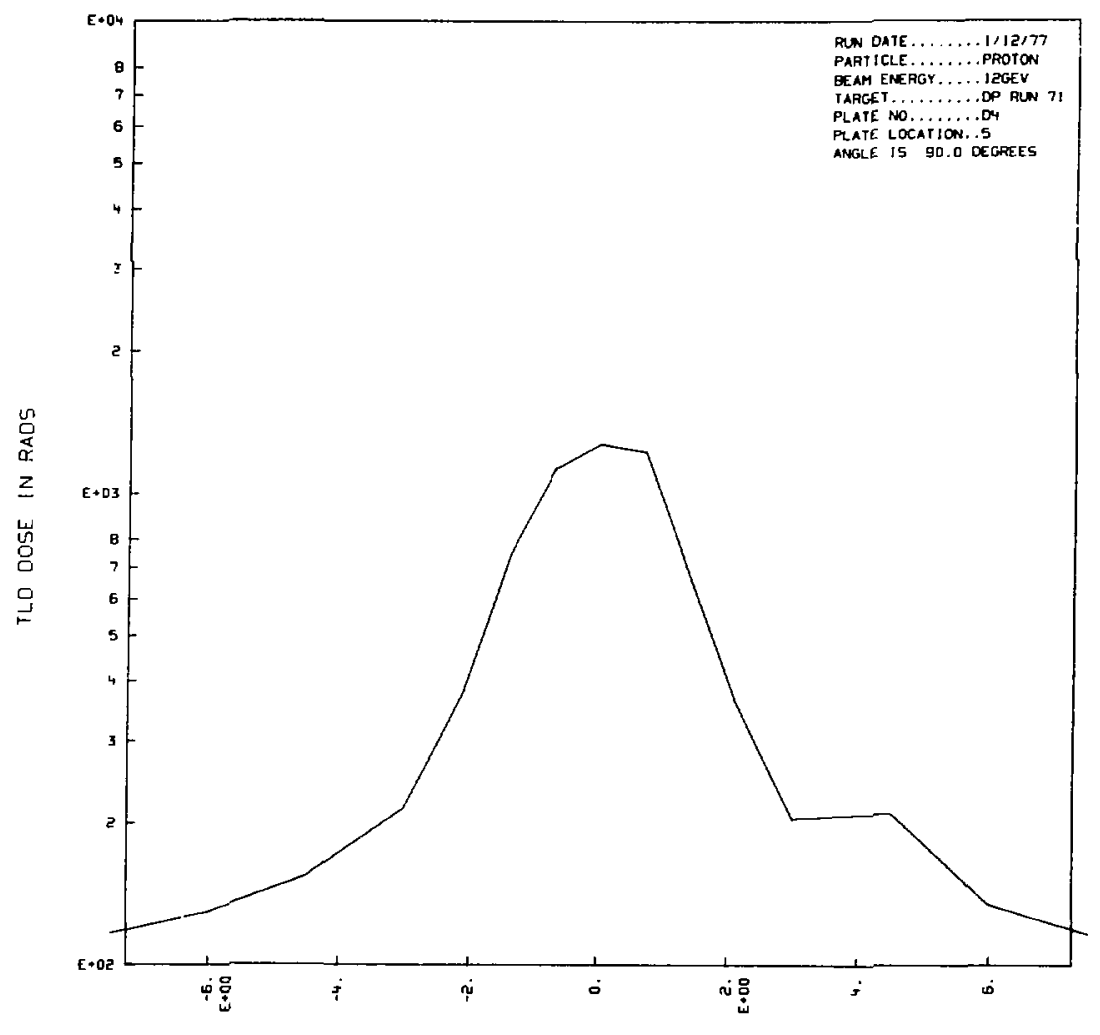

RADIUS IN CM

Fis. C.23. 


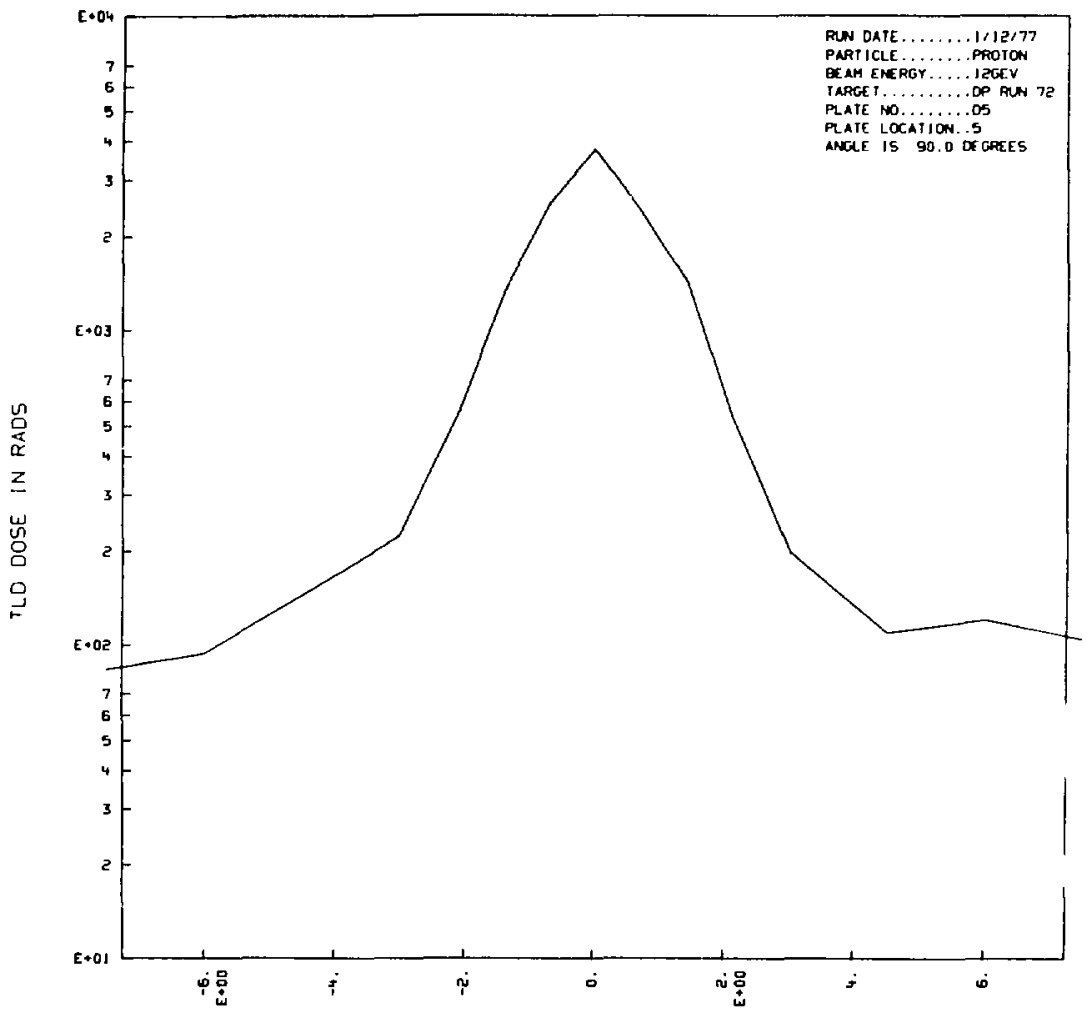

RADIUS IN CM

Fis. C-24, 


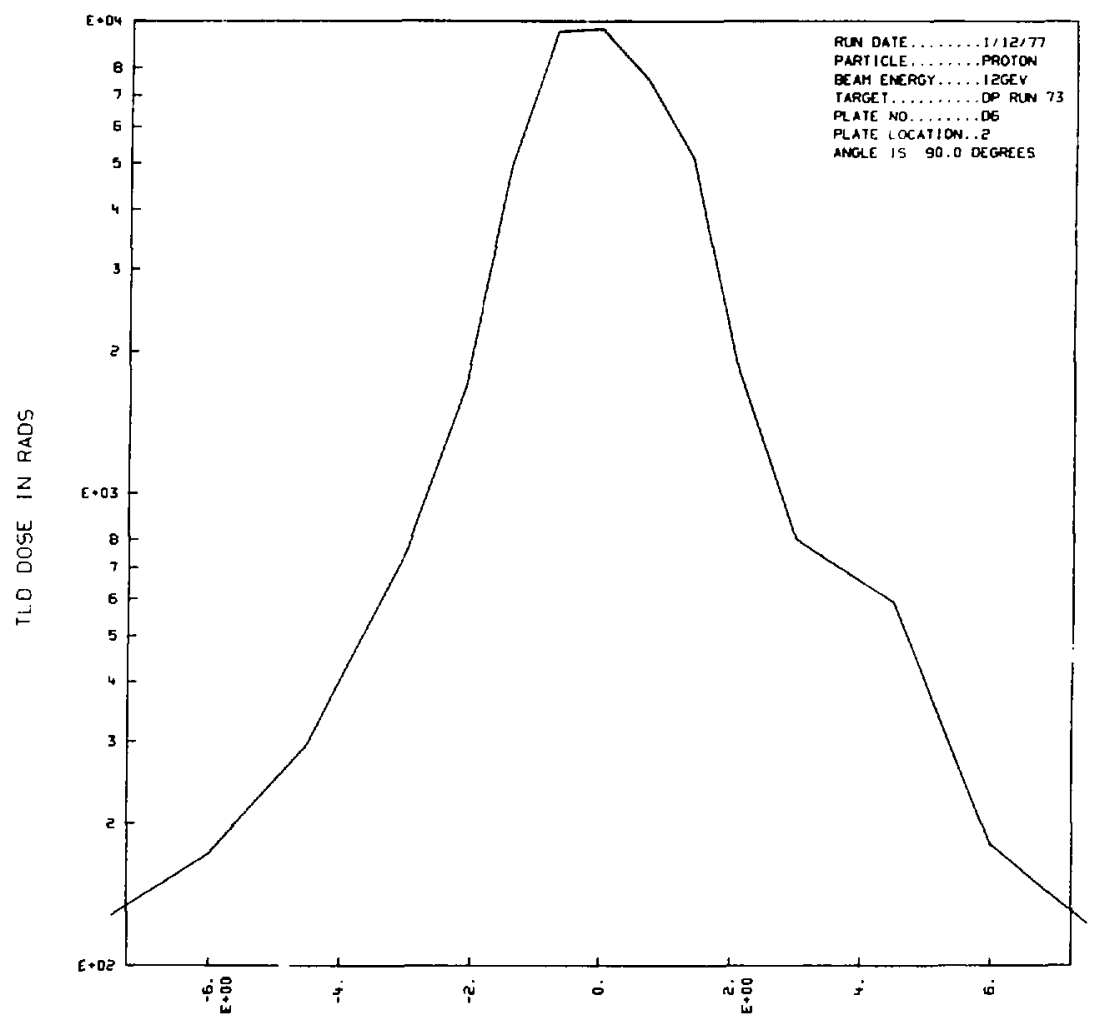

RADIUS IN CM

Fig. C-25. 


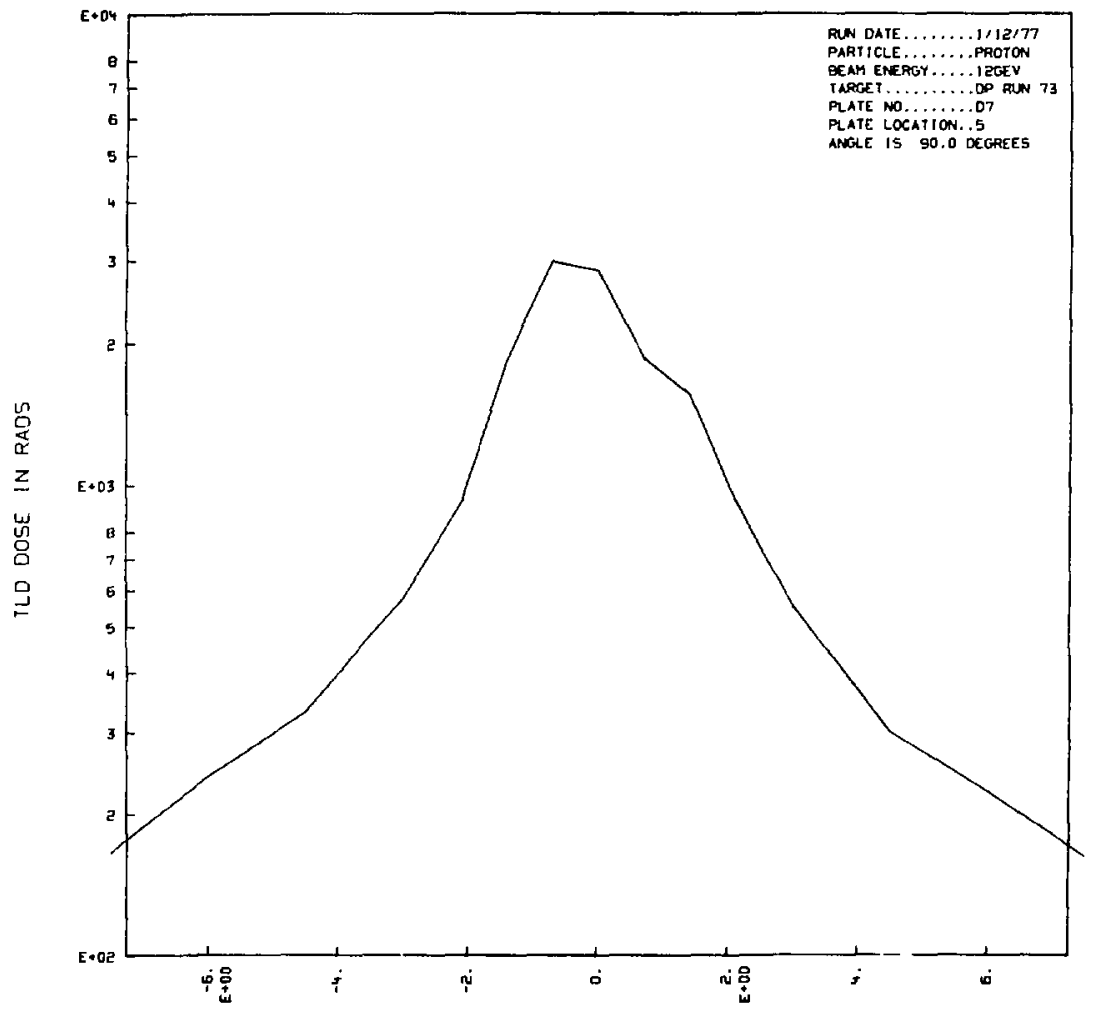

RADIUS IN CM

Fis. C-26. 


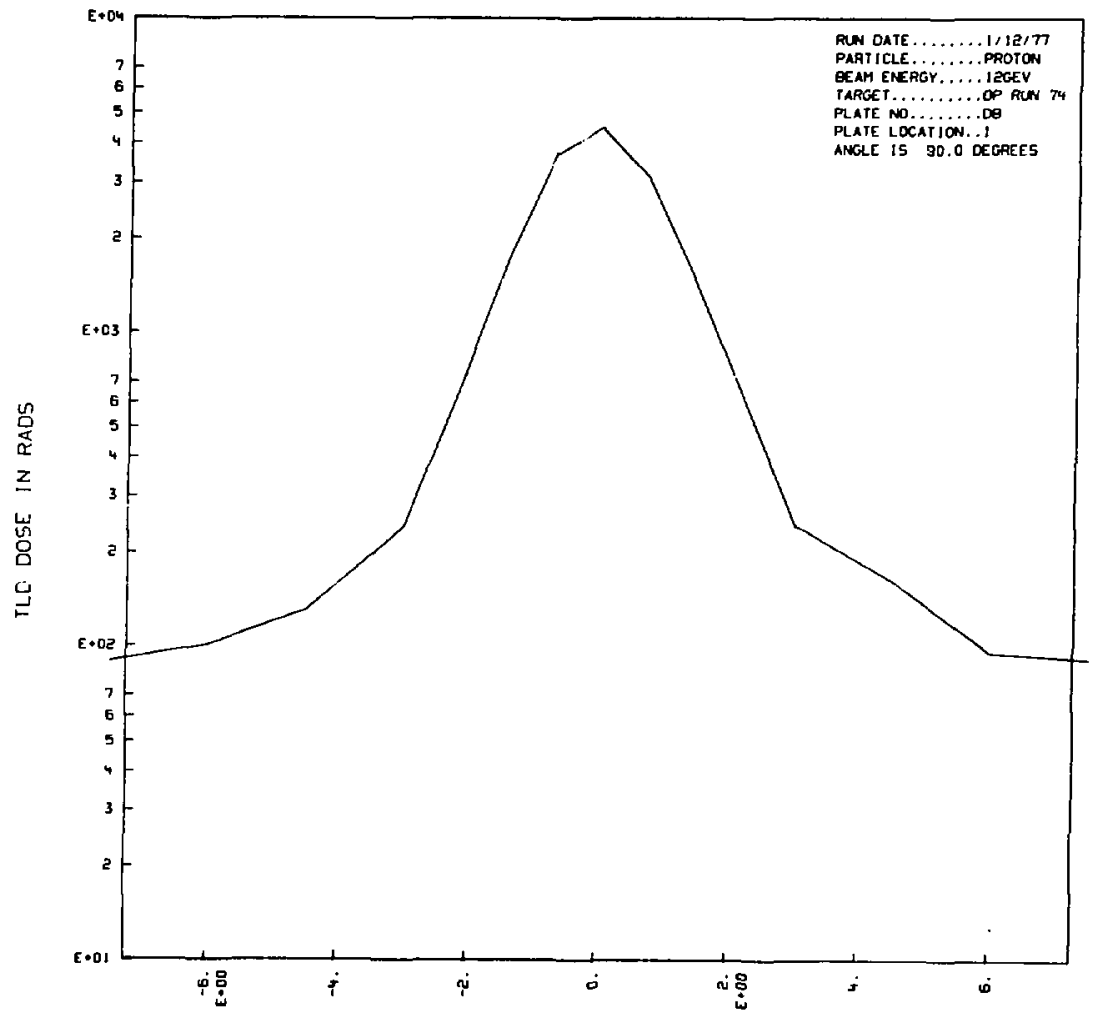

RADIUS IN CM

Fis. C.27. 


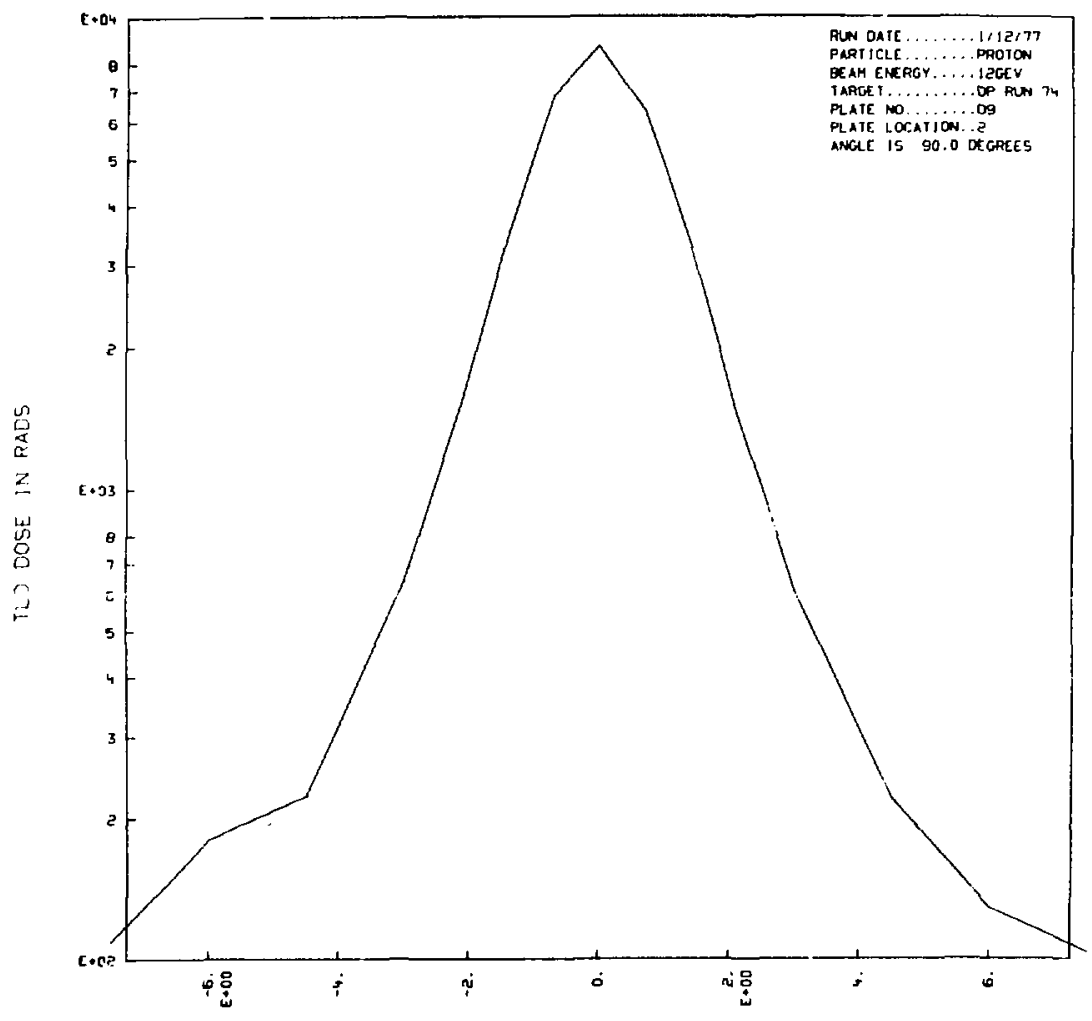

RADIUS IN CM

Fig. C.28. 


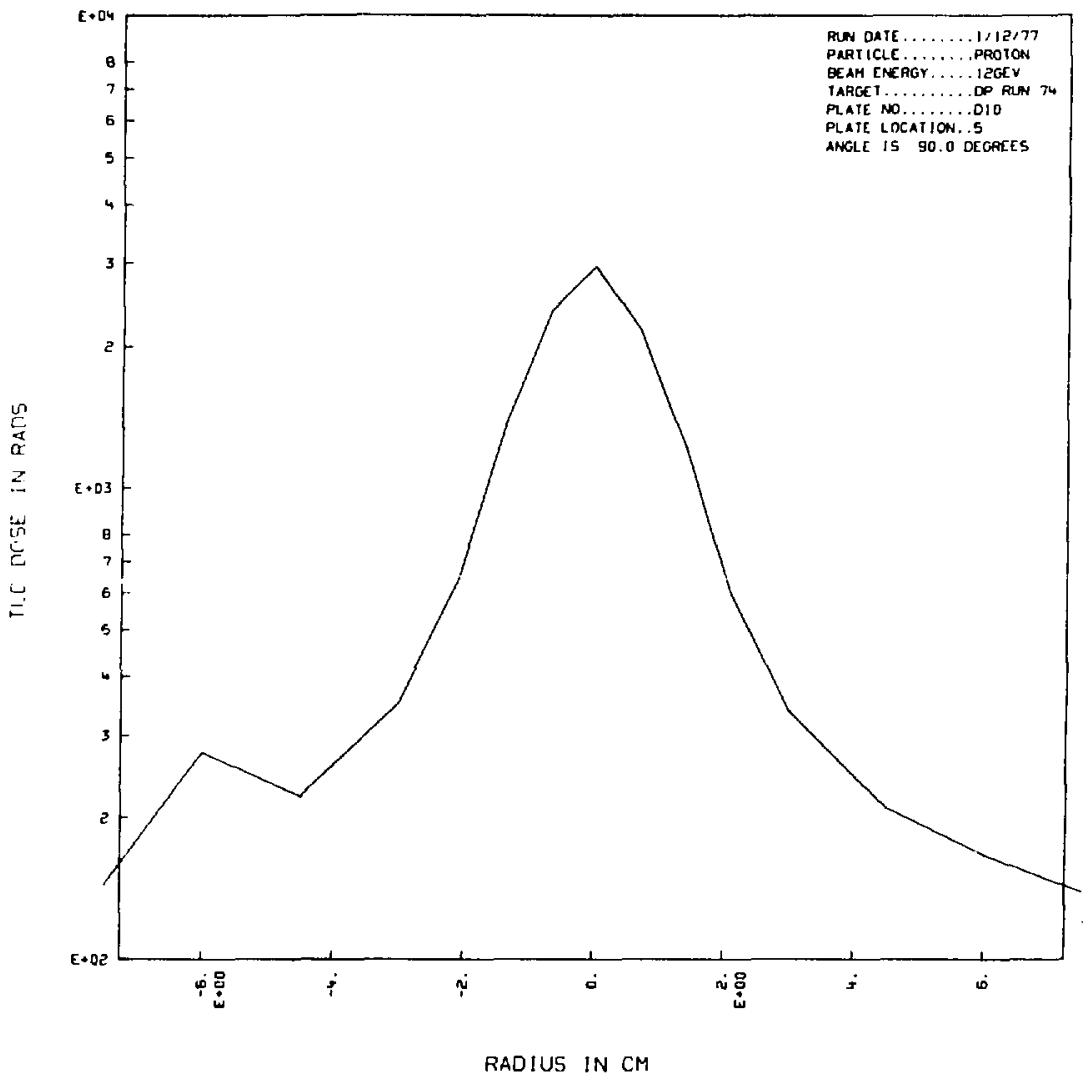

Fig. C.29. 

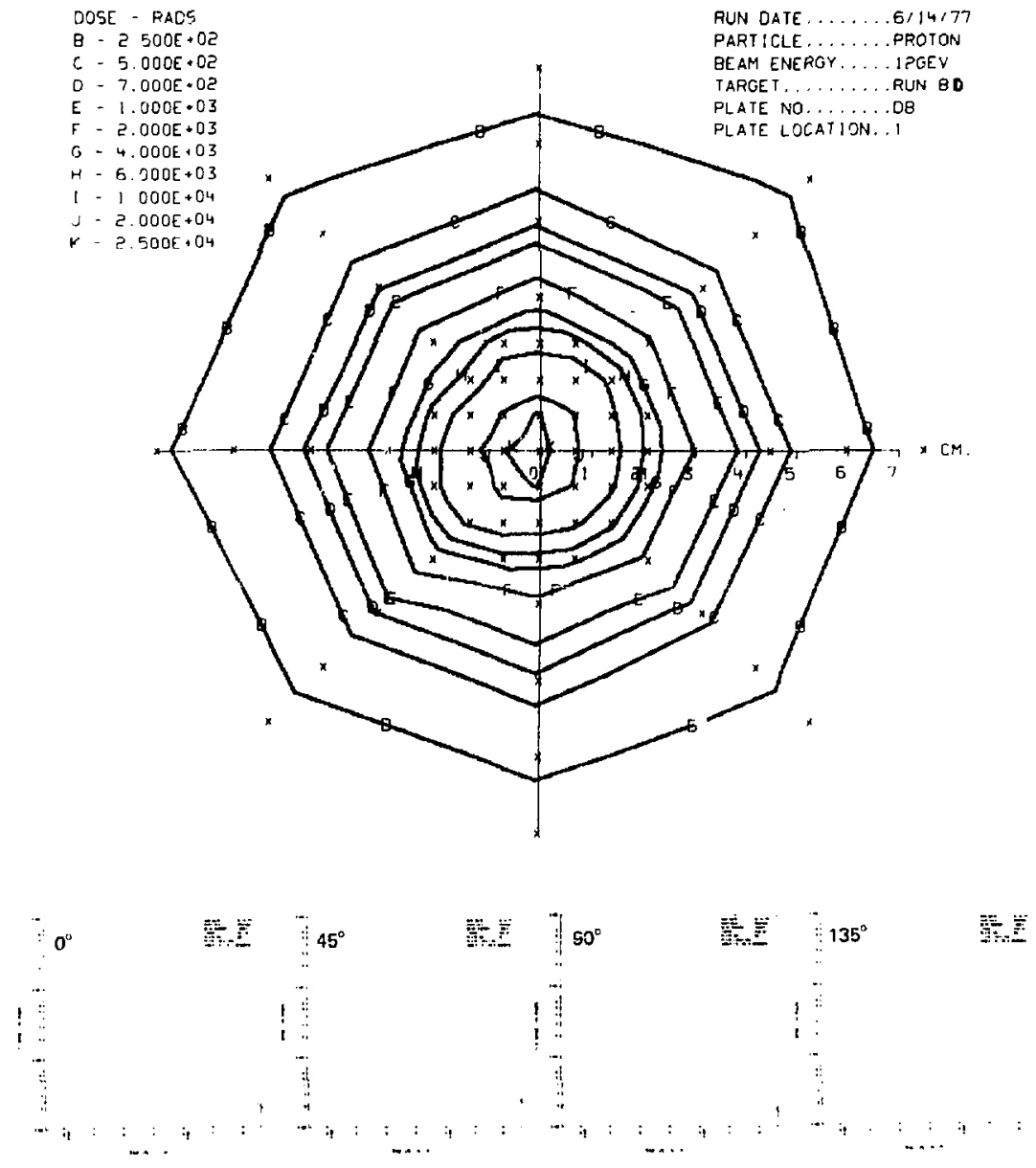

Fis. C-30. 


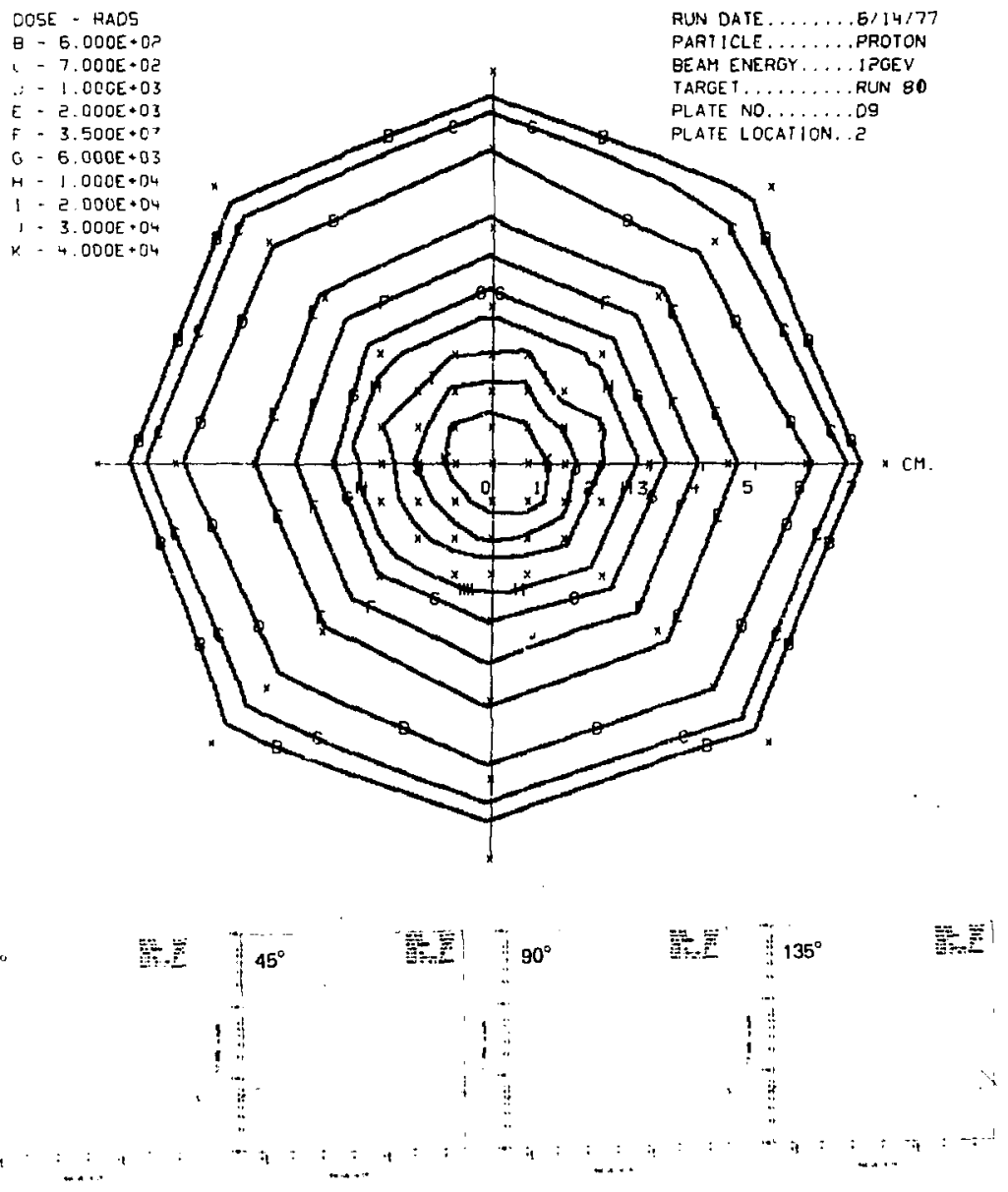

Fis. C.-31. 

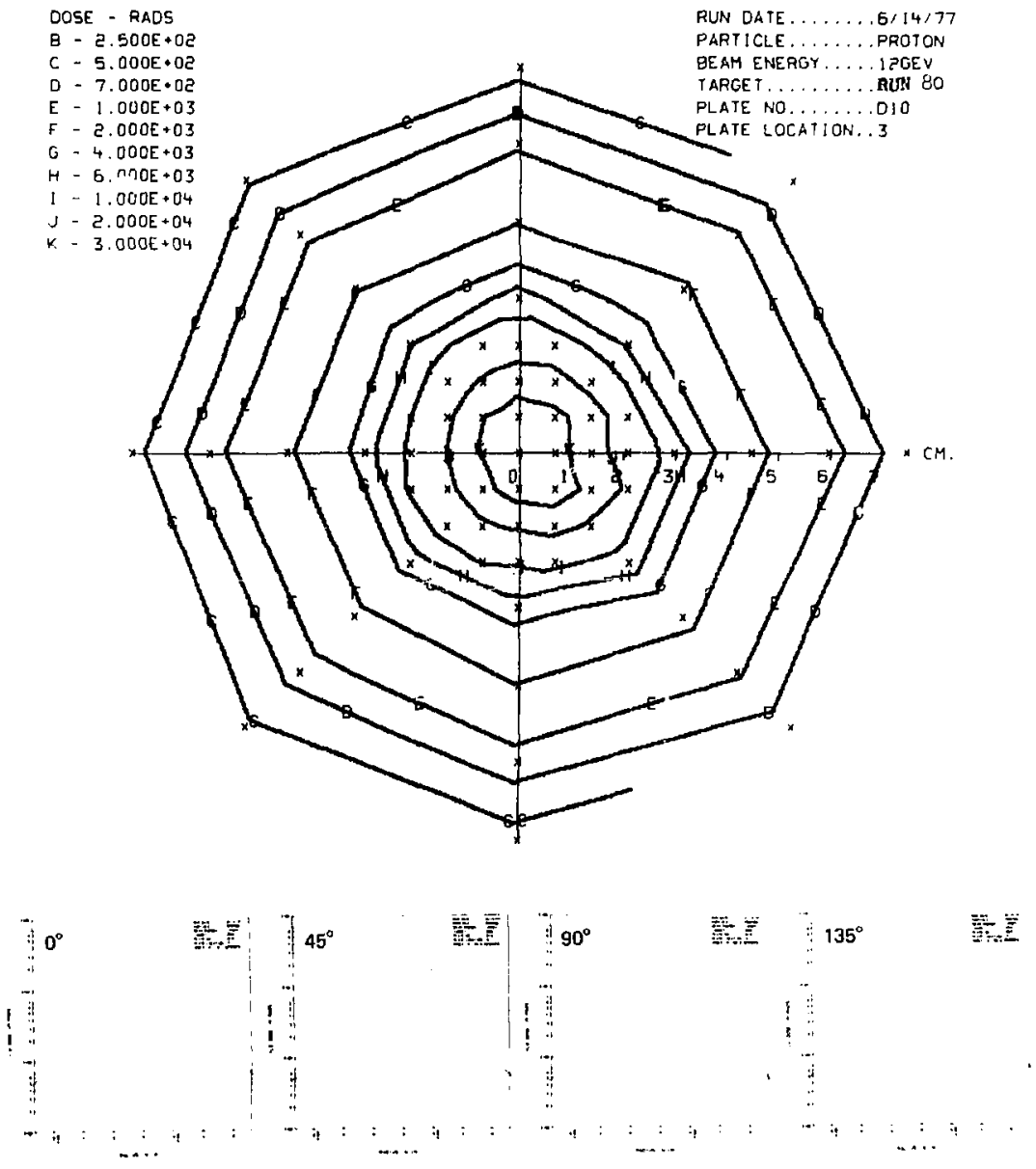

Kig, C-32. 


\section{APPENDIX D \\ TLD DETECTORS IN 238U PLATES FISSION DATA FROM INTEGRAL GAMMA COUNTING}

Figures D-1 through D-32 are the numerical dose data (in rad $\times 10^{-1}$ ) for TLD detectors in 23 U $U$ plates (top half of the circle). Fission data (in rad $\times 10^{-3}$ ) from integral gamma counting measurements are included in the bottom half of the circle for comparison (where available). 


\begin{tabular}{ll} 
Beam energy & $500 \mathrm{MeV}$ \\
\cline { 2 - 2 } & $\mathrm{9} / 15 / 76$ \\
Run date & 51 \\
Run No. & Electron \\
Particle & D1 (FB) \\
Plate Na. & 1 \\
\hline
\end{tabular}

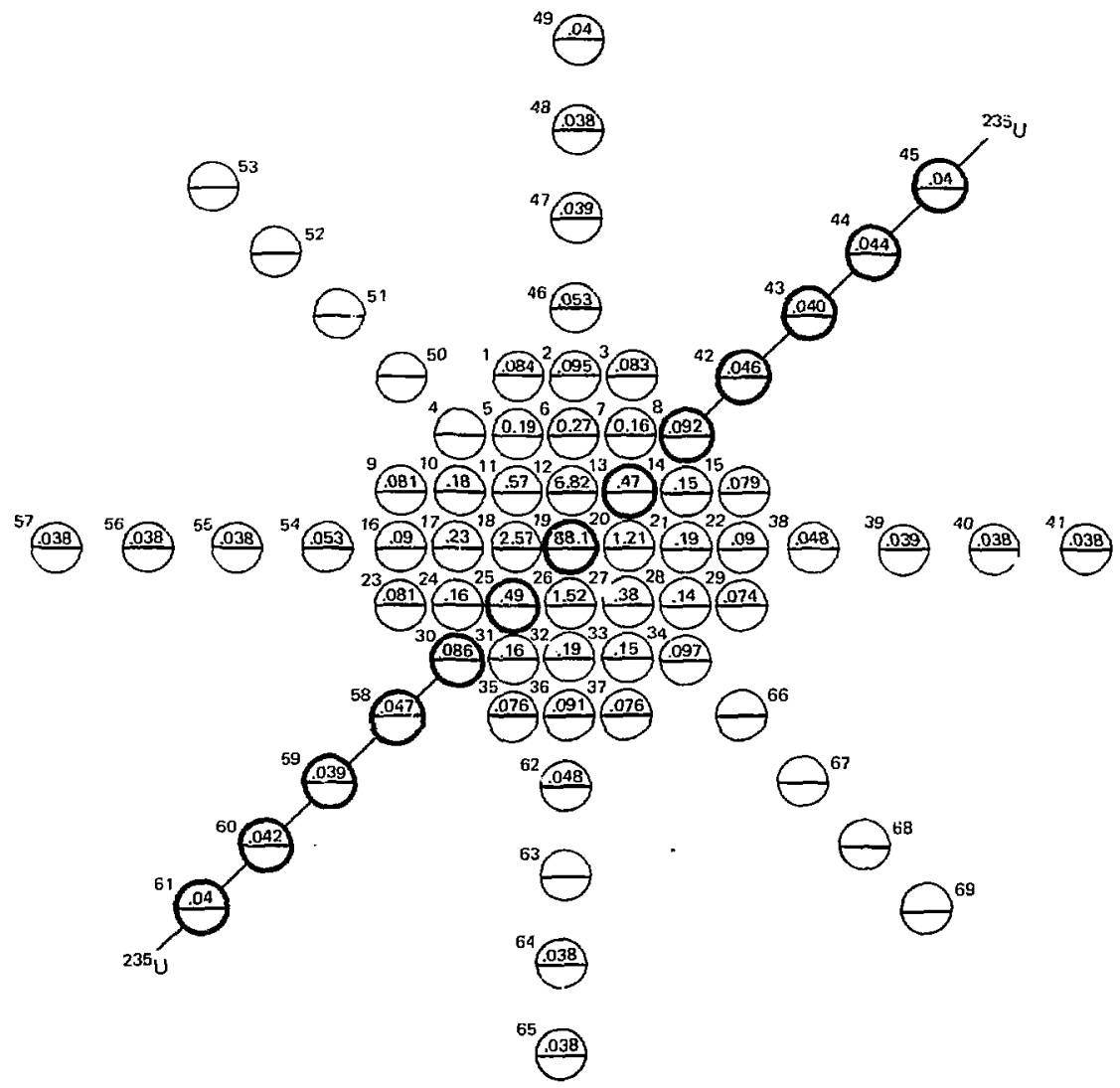

Fig. D-1. 


\begin{tabular}{ll} 
Beam energy & $500 \mathrm{MeV}$ \\
\cline { 2 - 2 } Run date & $9 / 15 / 76$ \\
Run No. & $\frac{51}{\text { Electron }}$ \\
Particle & $\frac{\mathrm{D} 2 \text { (AFB) }}{2}$ \\
Plate No. \\
Plate location
\end{tabular}

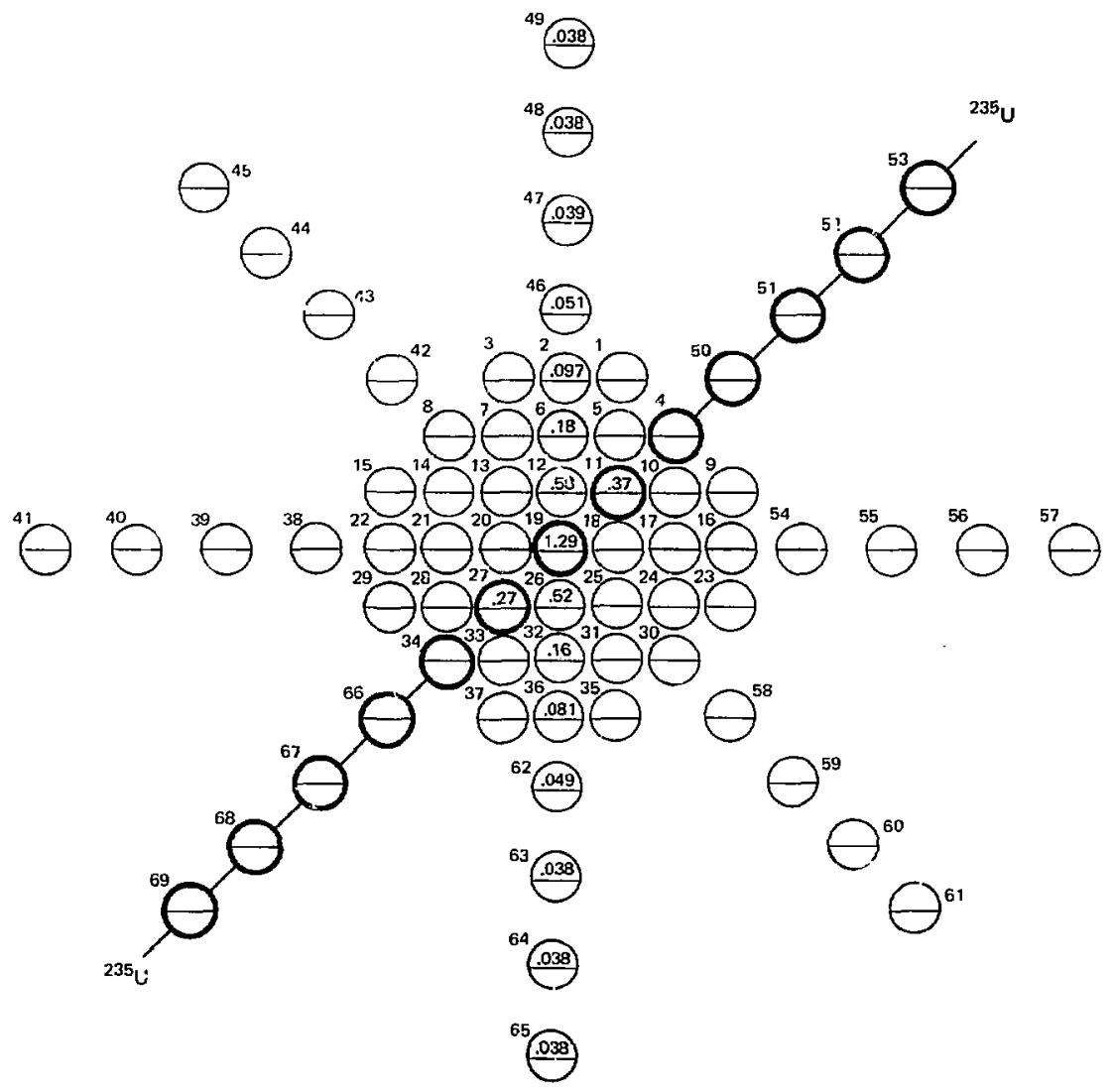

Fit. D-2. 


Beam energy
$\begin{aligned} & 500 \mathrm{MeV} \\ & \text { Run date }\end{aligned}$
Run No.
Particle
Plate No.
Plate location

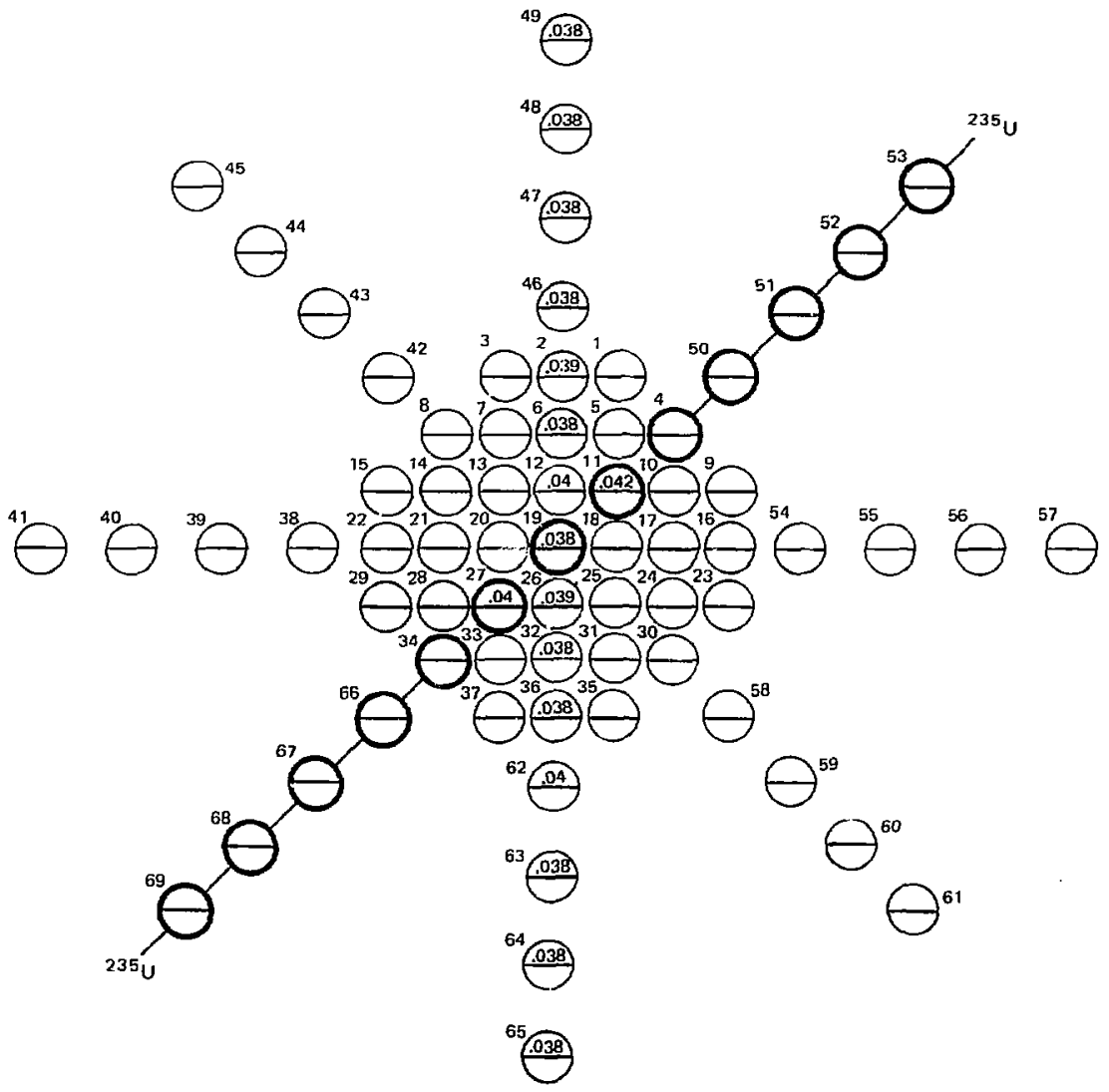

Fig. D-3. 


\begin{tabular}{ll} 
Beam energy & $500 \mathrm{MeV}$ \\
\hline Run date & $9 / 16 / 76$ \\
Run No. & 52 \\
Particle & Electron \\
Plate No. & D4 (FB) \\
Plate location & 1 \\
\hline
\end{tabular}

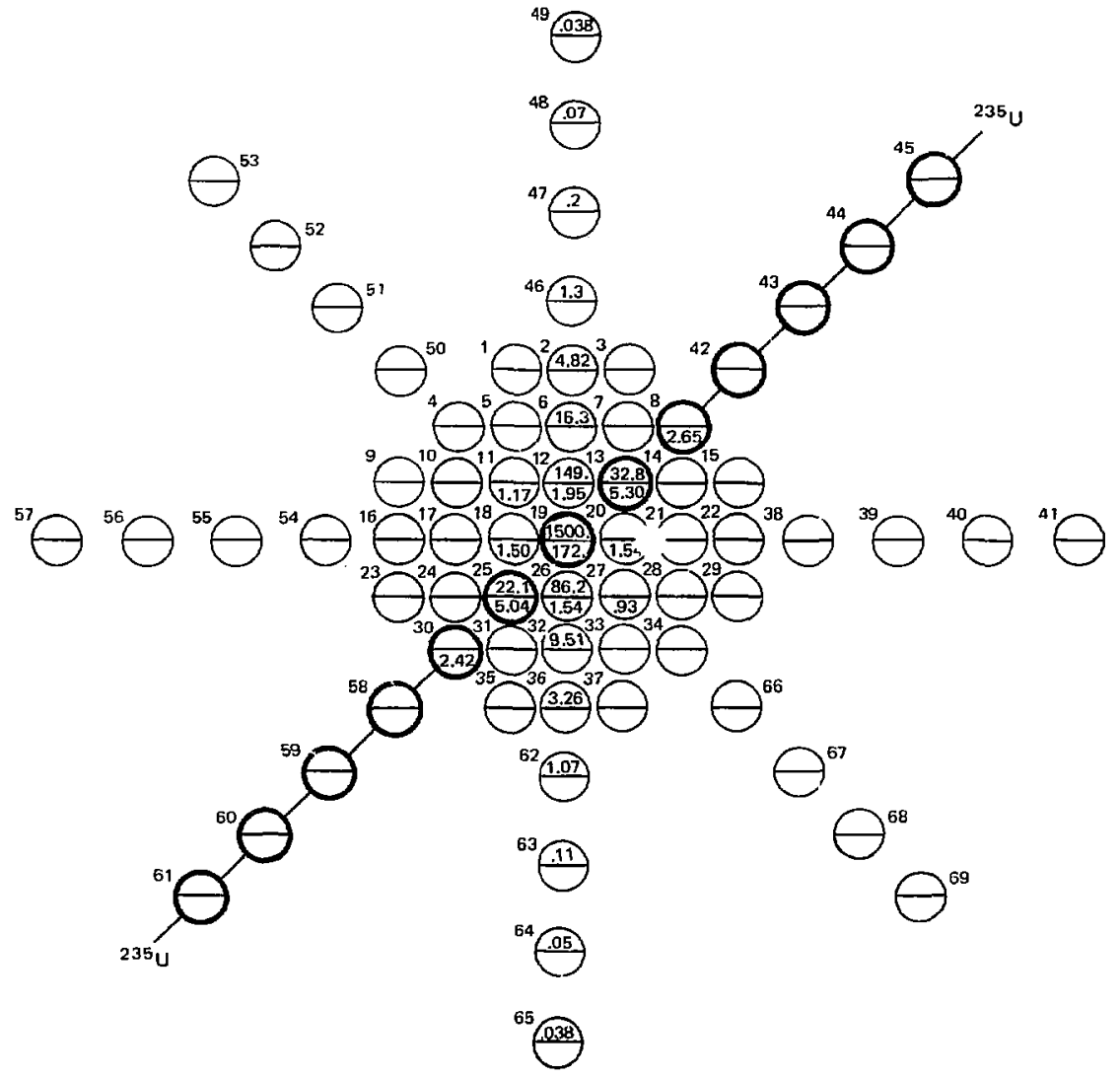

Fis. D-4. 


\begin{tabular}{ll} 
Beam energy & $500 \mathrm{MeV}$ \\
Run date & $9 / 16 / 76$ \\
Run No. & 52 \\
Particle & Electron \\
Plate No. & D5 (AFB) \\
Plate location & 2 \\
\hline
\end{tabular}

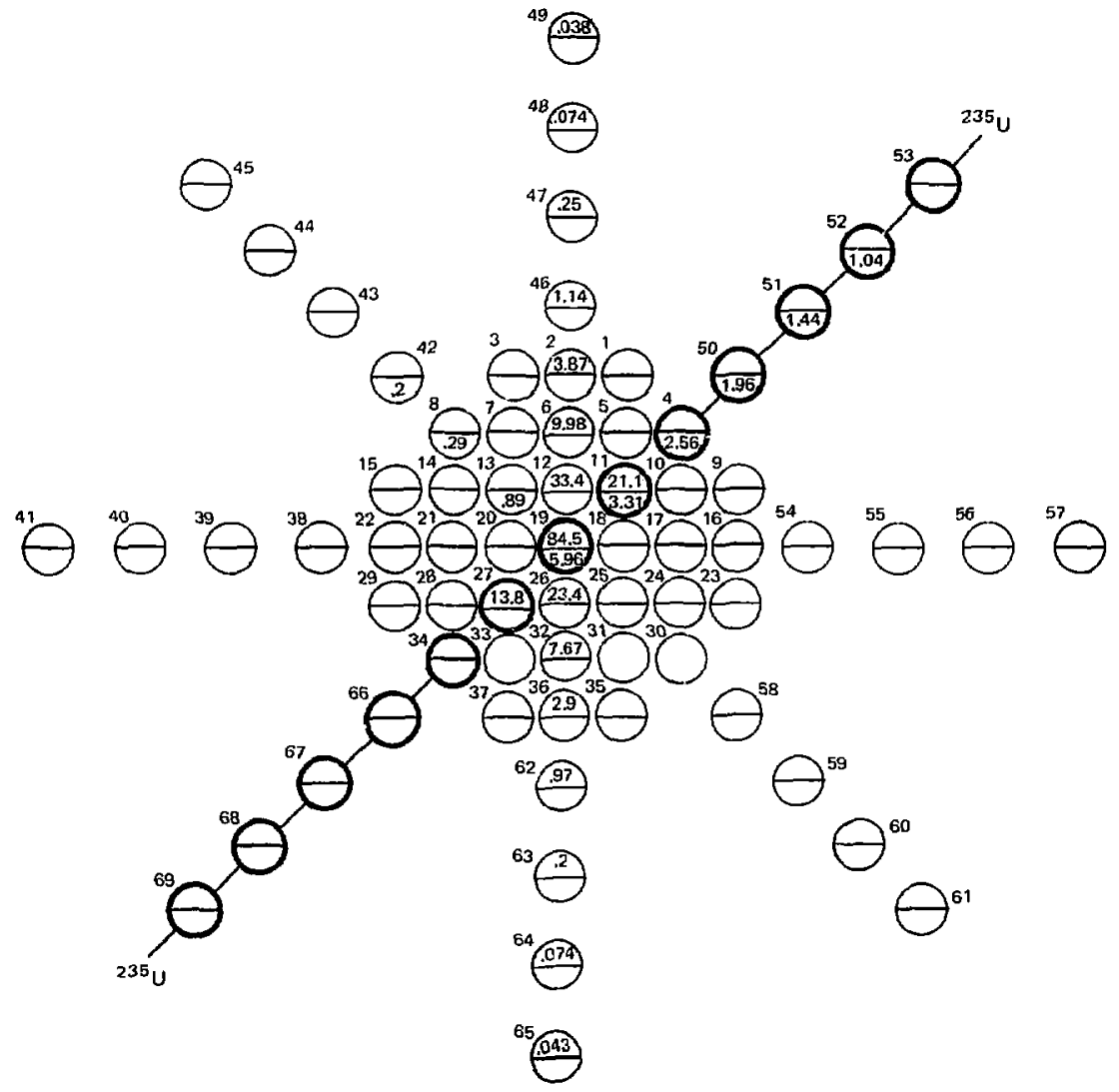

Fig. D-5. 


$\begin{array}{ll}\text { Beam energy } & 500 \mathrm{MeV} \\ \text { Run date } & 9 / 16 / 76 \\ \text { Run No. } & 52 \\ \text { Particle } & \text { Electron } \\ \text { Plate No. } & \text { D6 (AFB) } \\ \text { Plate location } & 3\end{array}$

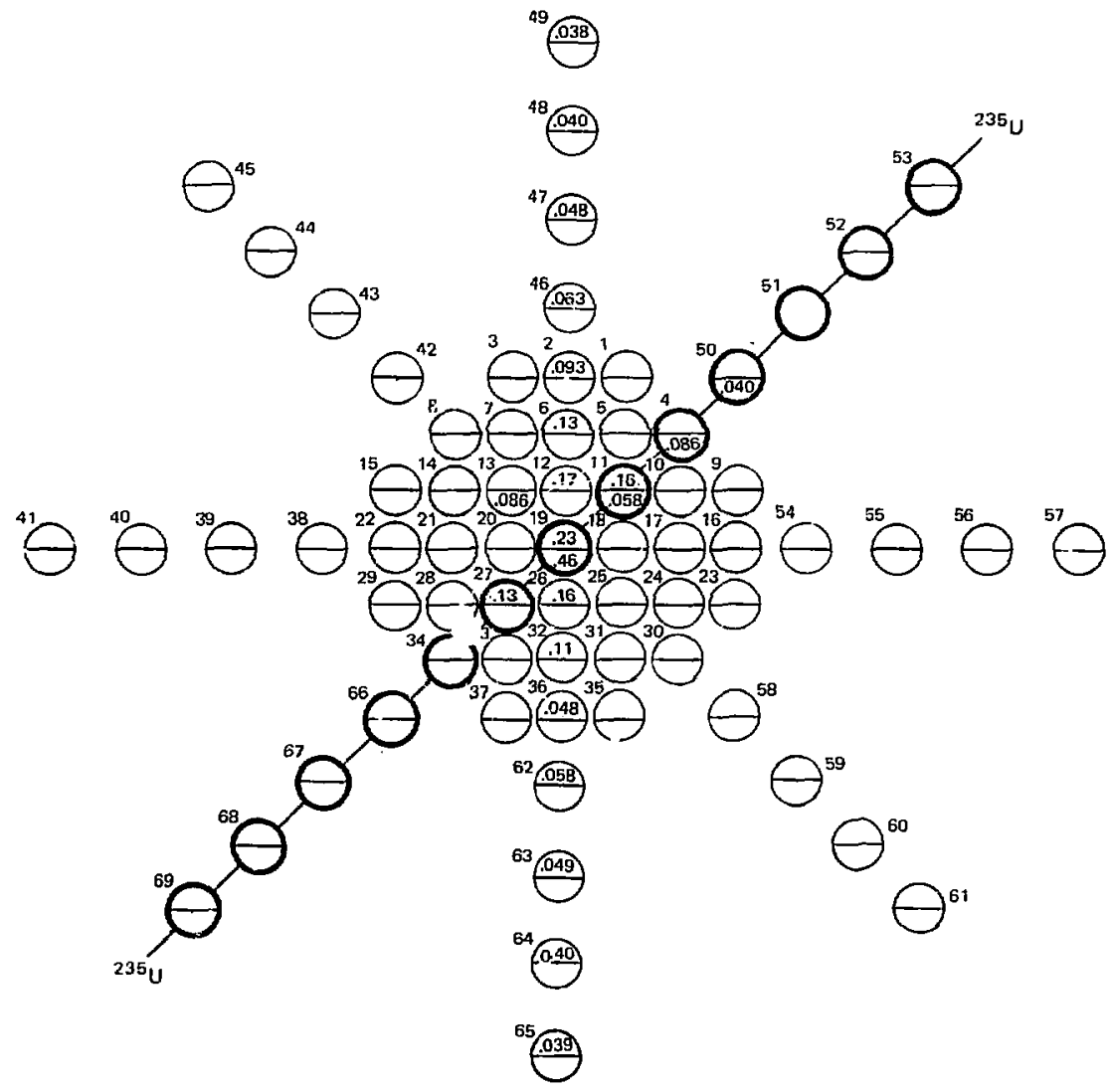

Fig. D-6. 


\begin{tabular}{|c|c|}
\hline Beam energy & $500 \mathrm{MeV}$ \\
\hline Run date. & $9 / 16 / 72$ \\
\hline Run No. & 52 \\
\hline Particle & Electron \\
\hline Plate No. & D7 (AFB) \\
\hline Plate location & 5 \\
\hline
\end{tabular}

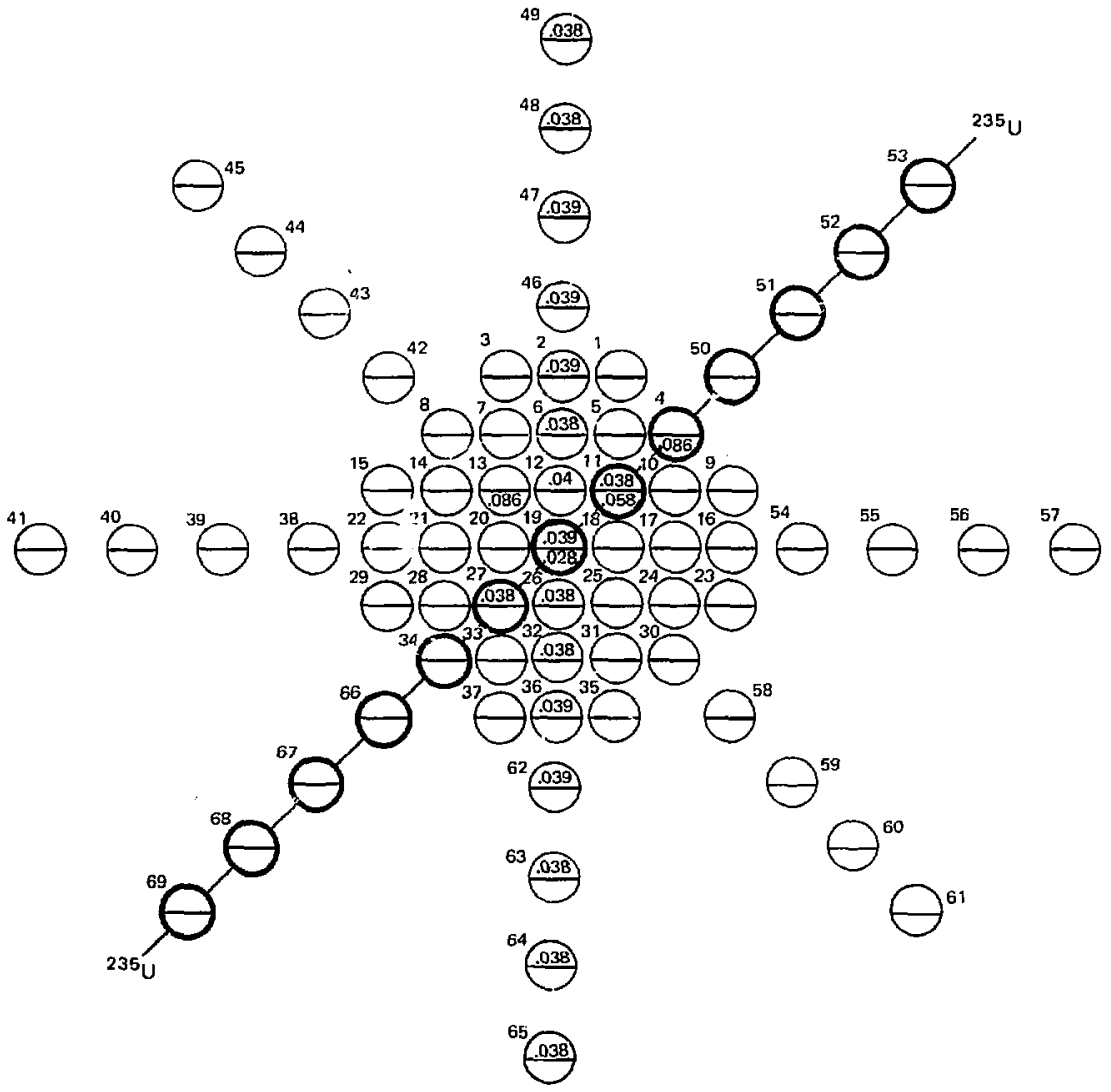

Fig. D-7. 


\begin{tabular}{ll} 
Beam energy & $500 \mathrm{MeV}$ \\
\cline { 2 - 2 } Run date & $\mathbf{9 / 1 6 / 7 6}$ \\
Run No. & $\mathbf{5 3}$ \\
\cline { 2 - 2 } Particle & Electron \\
Plate No. & $\mathrm{D} 8$ (AFB) \\
Plate location 5
\end{tabular}

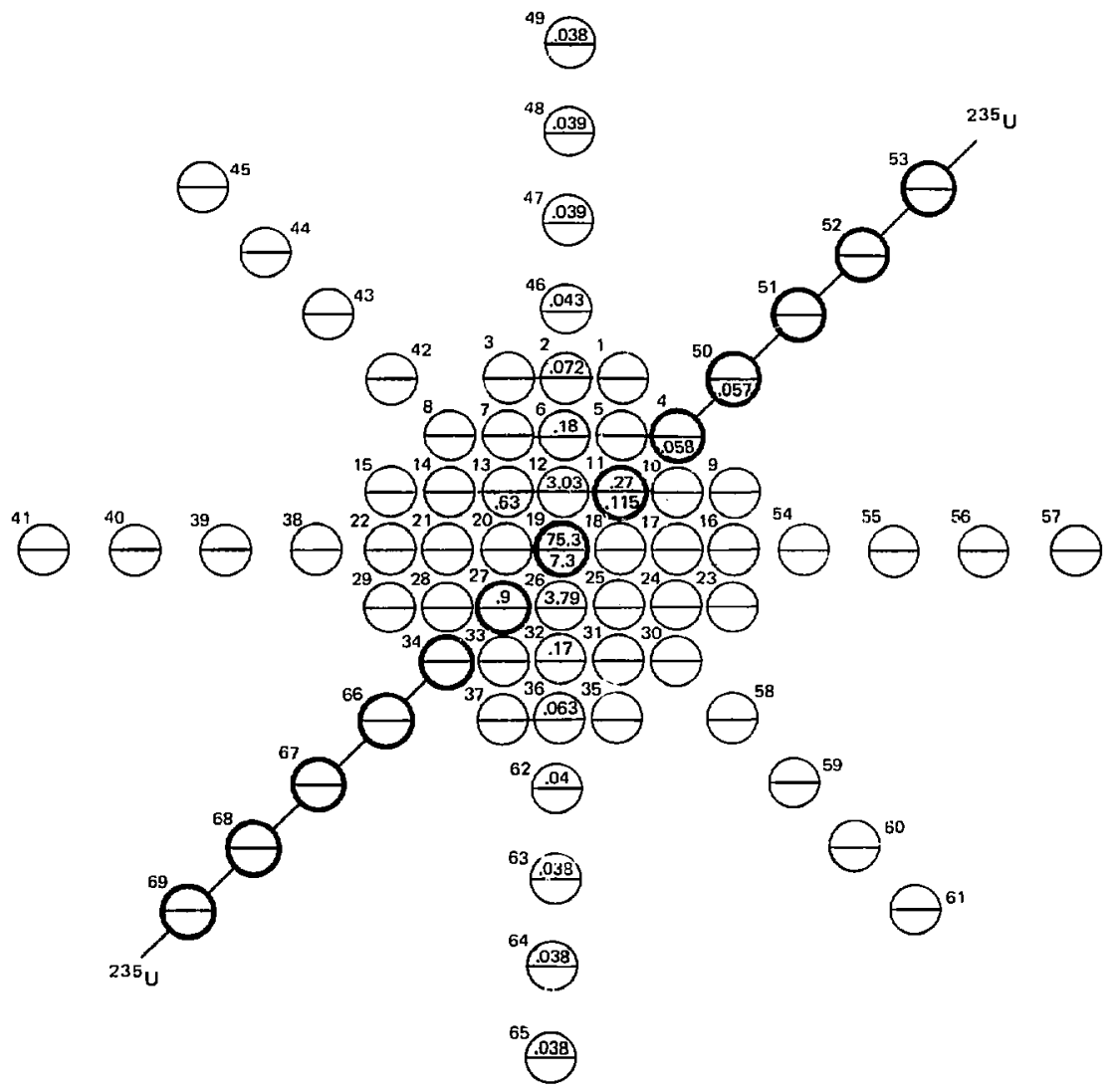

Fig. D-8. 


\begin{tabular}{ll} 
Beam energy & $500 \mathrm{MeV}$ \\
Run date & $9 / 16 / 76$ \\
Run No. & 54 \\
Particle & Electron \\
Plate Na. & $\mathrm{ng}$ (FB) \\
Plate location & 2 \\
\hline
\end{tabular}

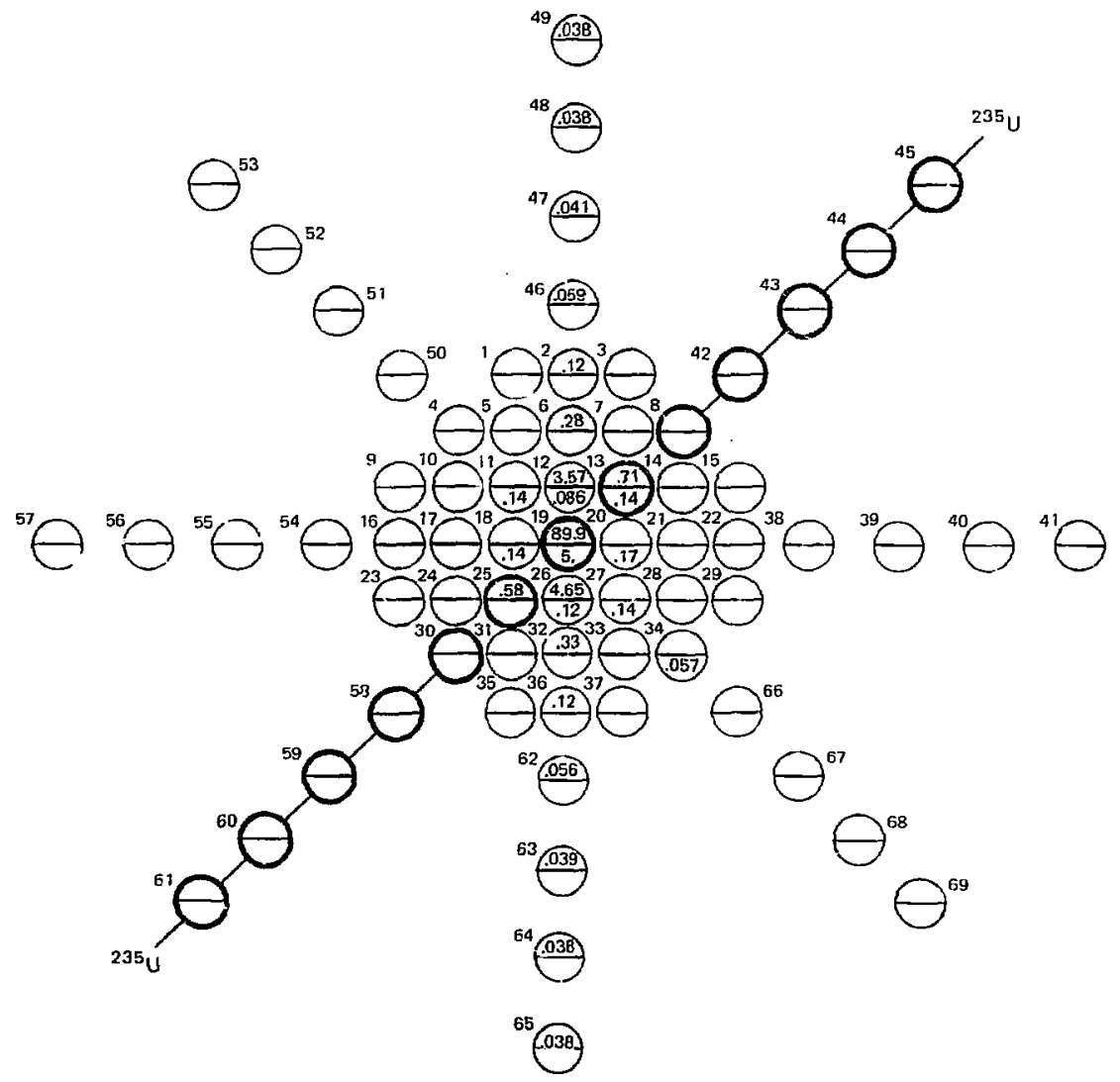

Fig. D-9. 


$\begin{array}{ll}\text { Beam energv } & 500 \mathrm{MeV} \\ \text { Run date } & 9 / 16 / 76 \\ \text { Run No. } & 54 \\ \text { Particle } & \text { Electron } \\ \text { Plate No. } & \text { D10 (AFB) } \\ \text { Plate location } & 3\end{array}$

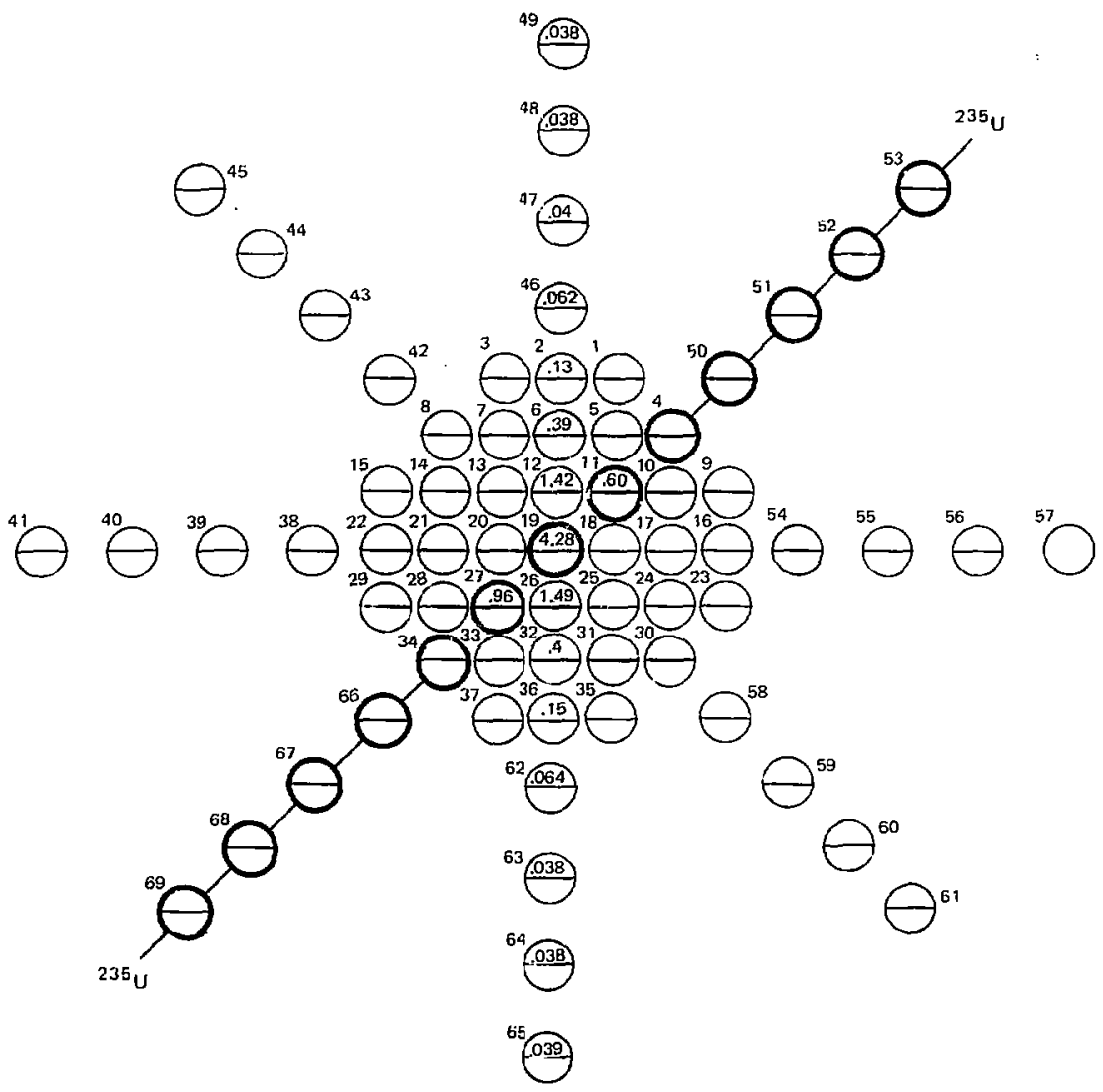

Flg. D-10. 
Beam energy $28.5 \mathrm{GeV}$

Run date

Run No.

Particle $12 / 10 / 76$

Plate No.

61

D6 (FB)

Plat? location 1

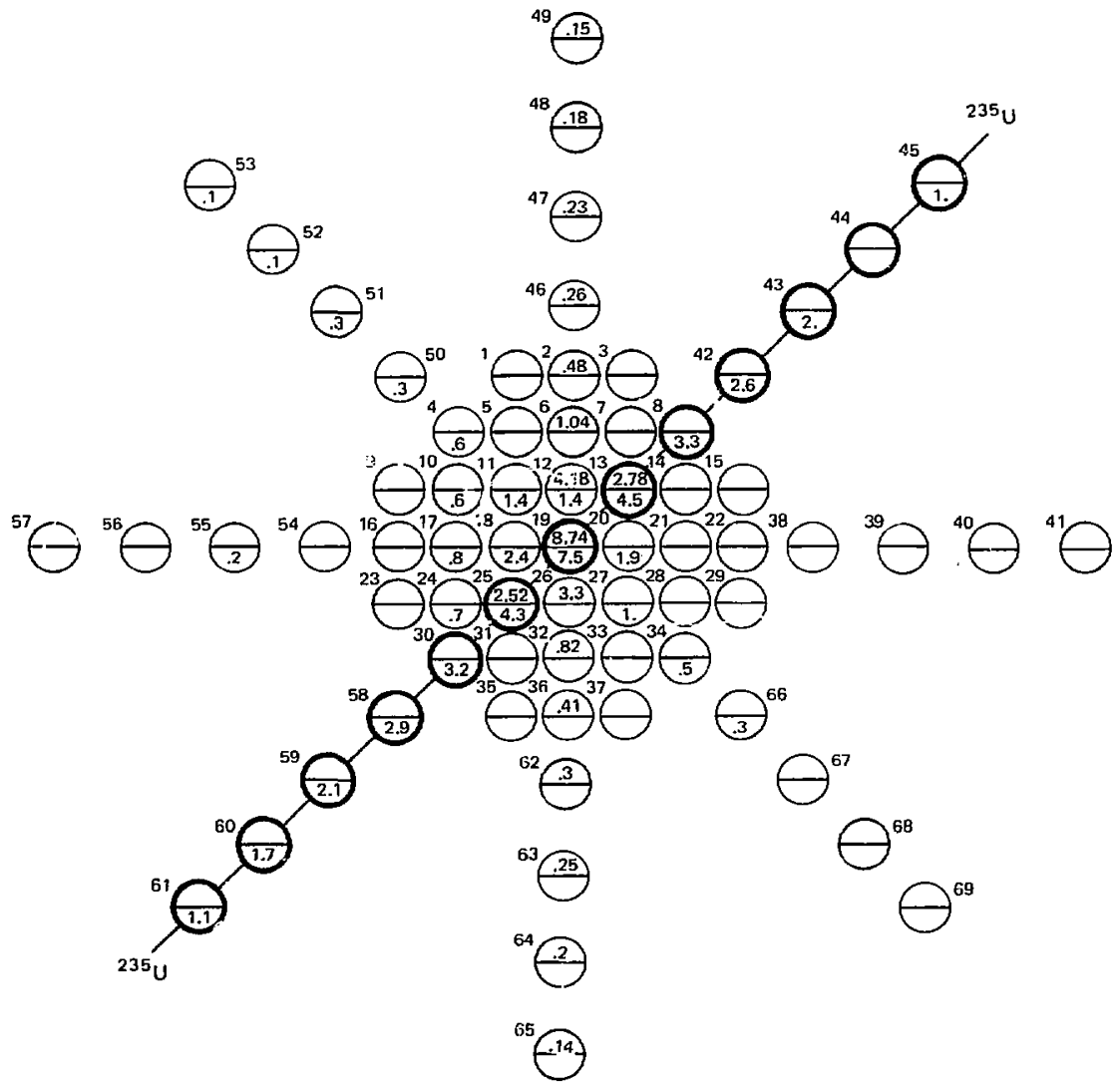

Fig. D-11. 


Beam energy $\frac{28.5 \mathrm{GeV}}{12 / 10 / 76}$
Run date $\frac{12 / 1}{6 !}$
Run No.
Particle $-\frac{\text { Proton }}{\text { C7(AFB) }}$
Plate No.
Plate location $\frac{2}{}$

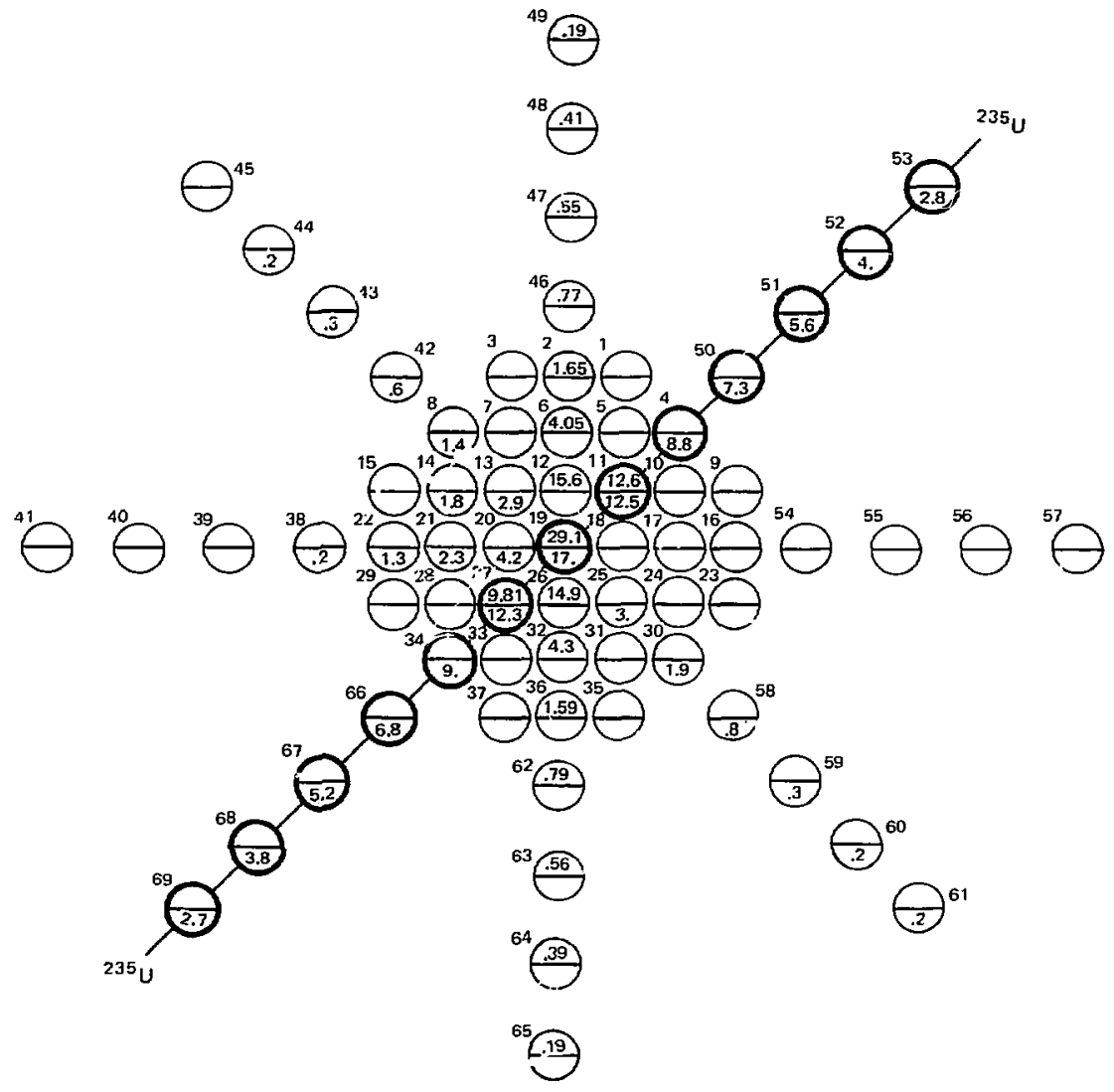

Fig. D-I2. 
Beam energs $28.5 \mathrm{GeV}$

Run date

Pun No.

Particle

$\frac{\frac{12 / 10 / 76}{61}}{\text { Proton }}$

Plate No. D8 (AFB)

Plate location 3

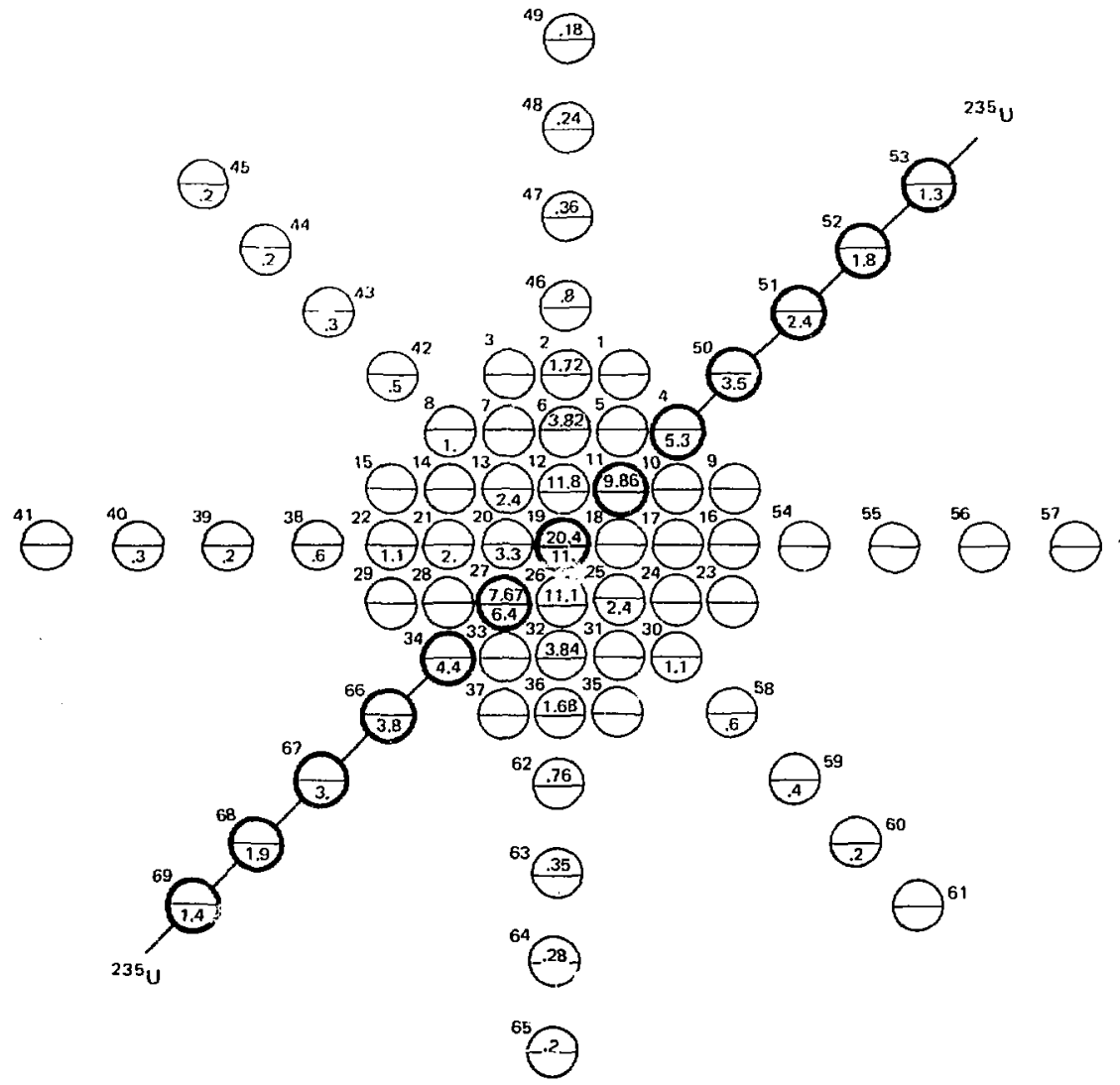

Fig, D-13. 
Beam energy 2B.5 GeV

Run date

Run No.

Particle $12110 / 76$

Plate No. 61

Plate location D9 (FB)

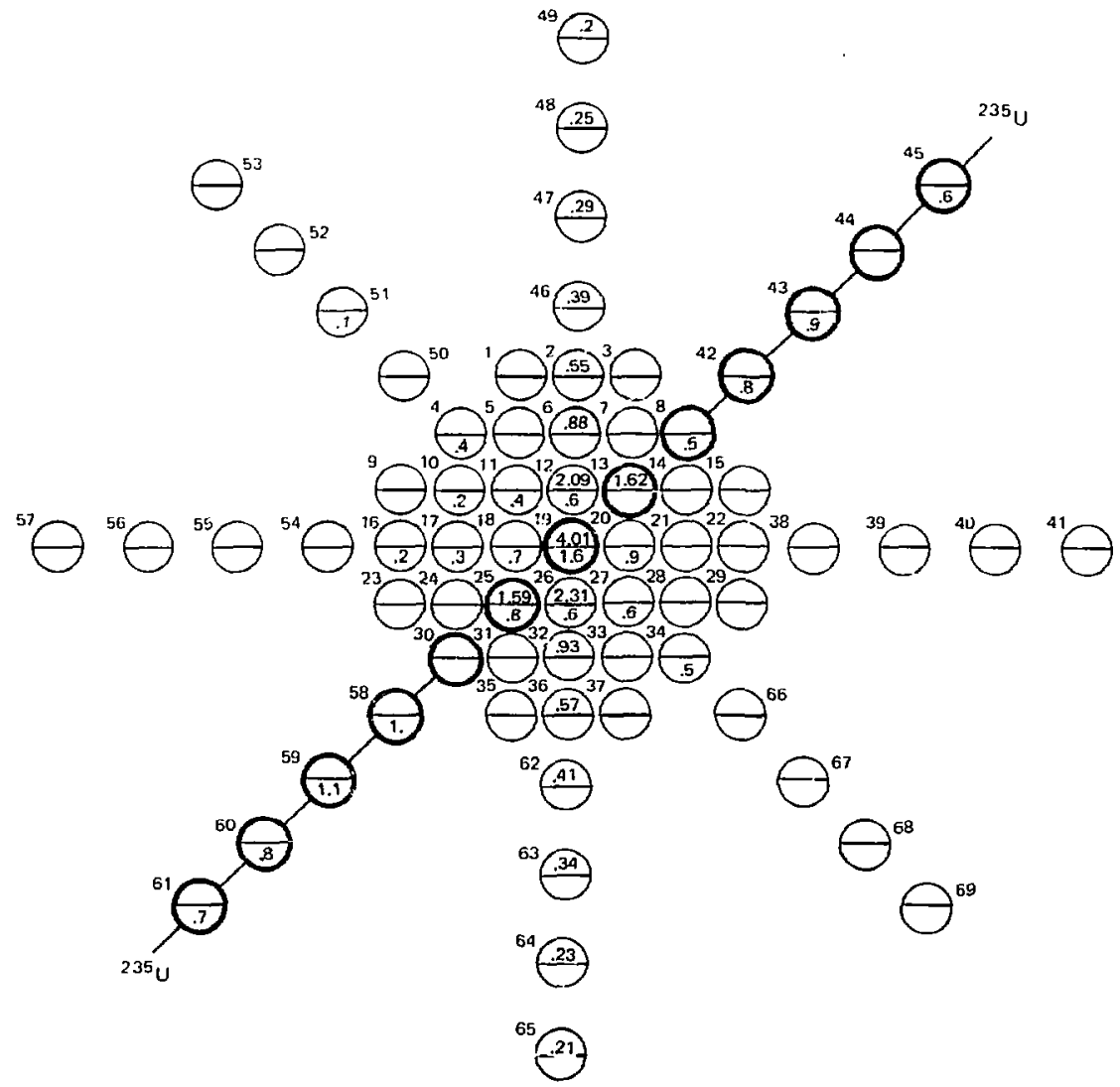

Fis. D-14. 


Beam energy $-\frac{28.5 \mathrm{GeV}}{12 / 10 / 76}$
Pun date $-\frac{62}{\text { Proton }}$
Run No. $-\frac{\mathrm{D} 10(\mathrm{FB})}{5}$
Particle
Plate Ni).
Plate location

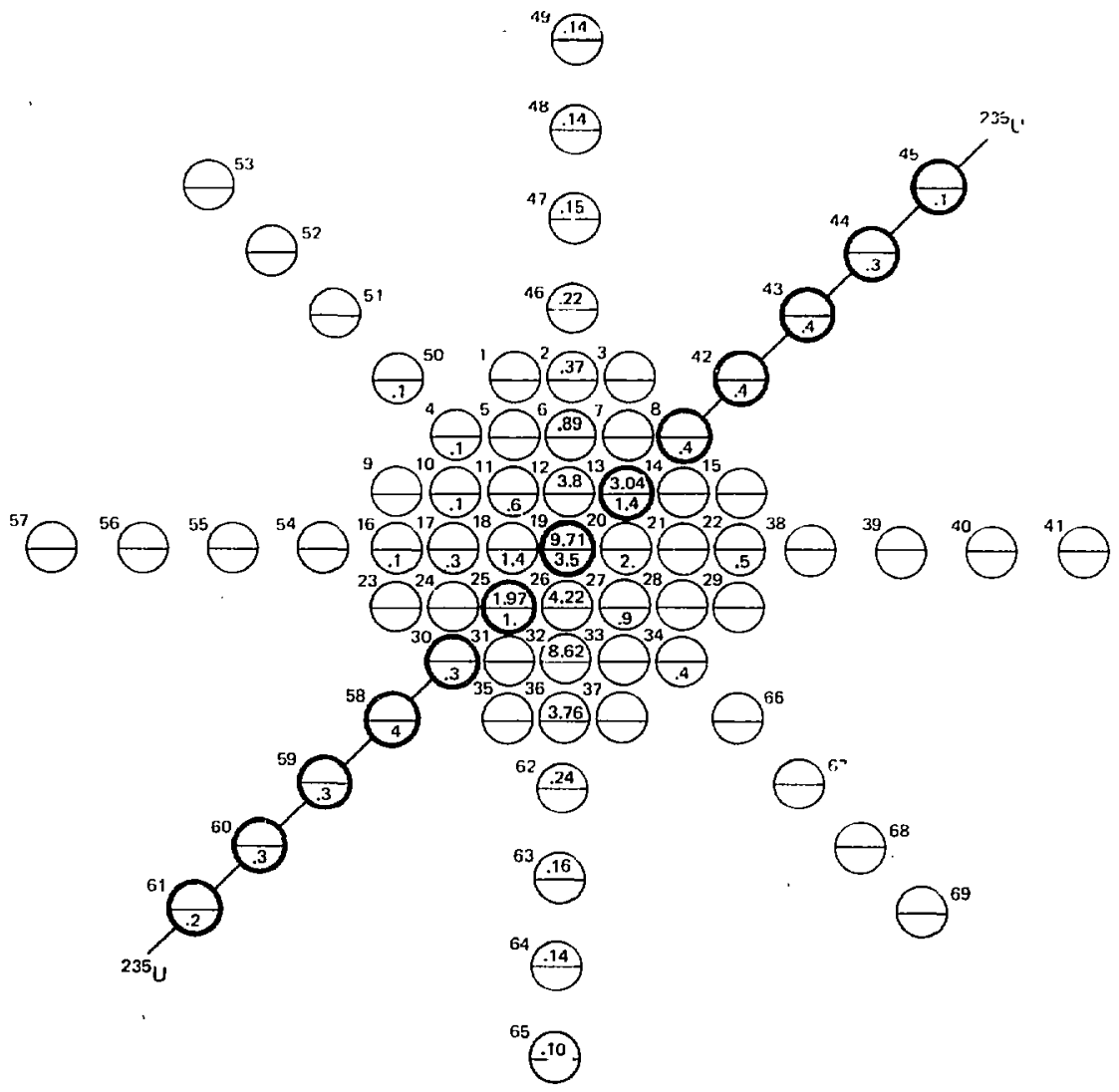

Fig. D-15. 


Beam energy $-\frac{28.5 \mathrm{GeV}}{12 / 9 / 76}$
Run date
Run No.
Particle
Plate No.
Plate 'xation

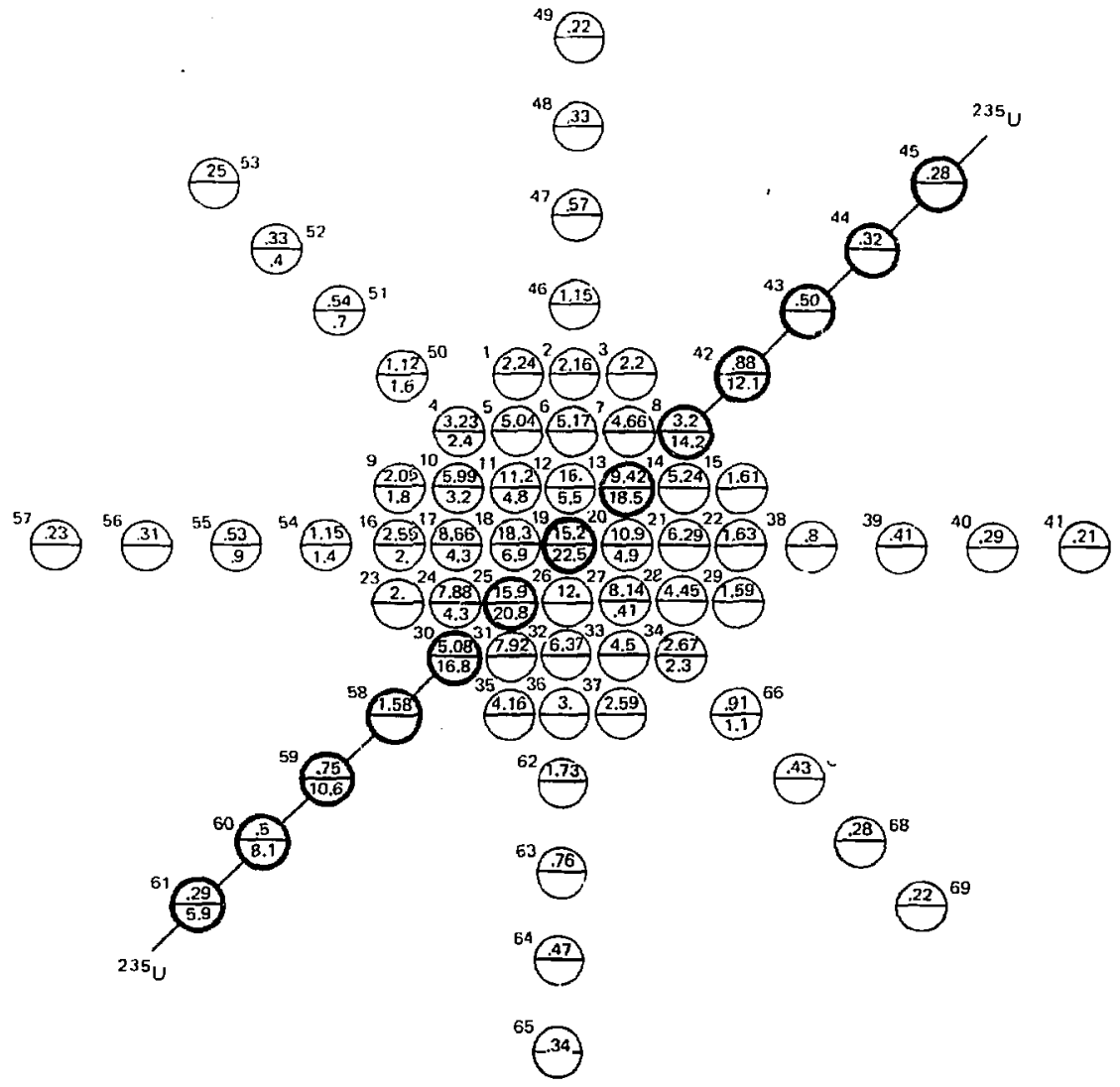

Fig. D-16. 


Beain energy $\frac{28.5 \mathrm{GeV}}{12 / 9 / 76}$
Run date
Run Nir.
Particie $-\frac{63}{\text { Pfoton }}$
Plate No. $-\frac{02 \text { (AFB) }}{2}$
Plate location -2

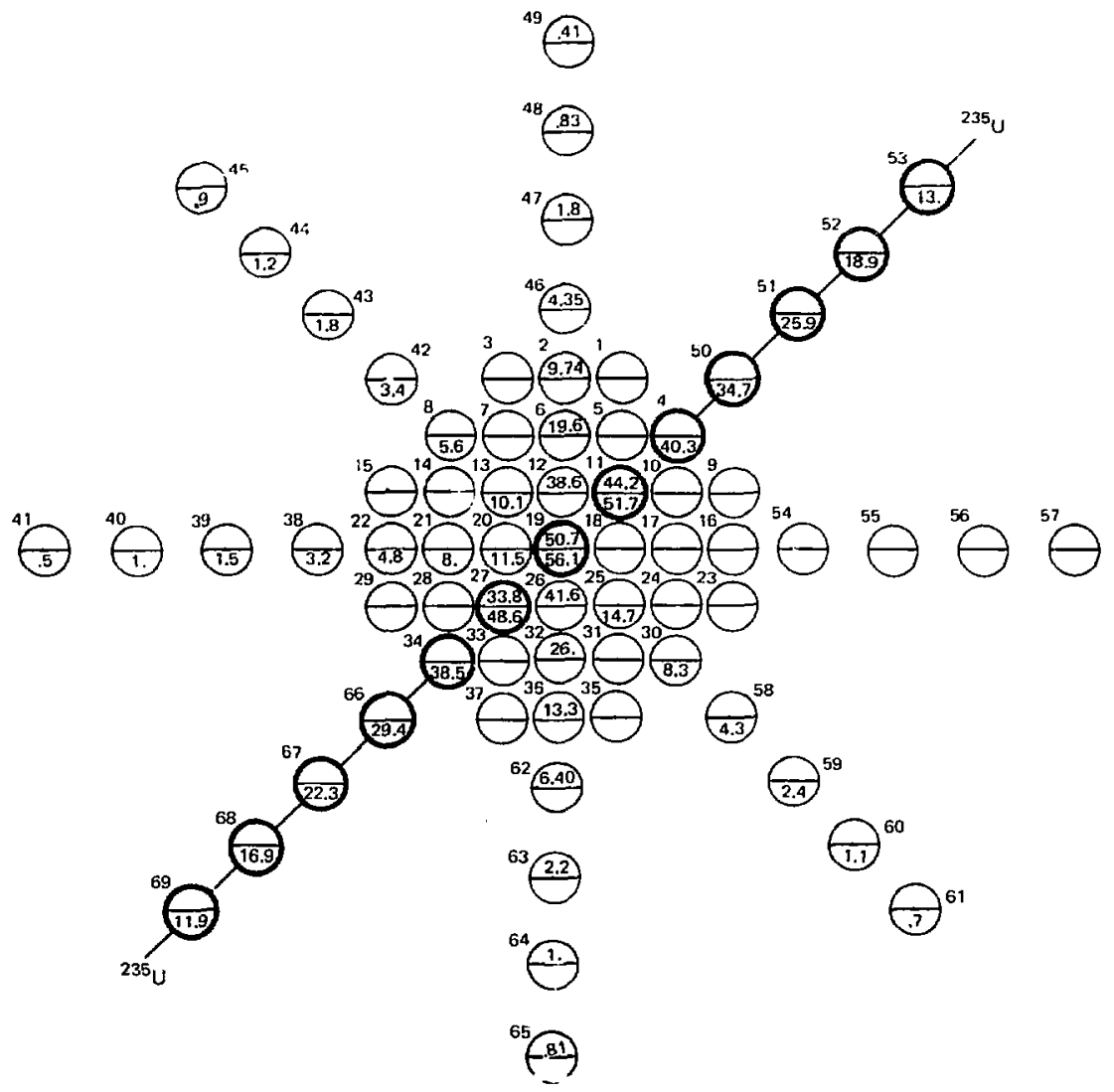

Fig, D-17. 


Beam energy $=\frac{28.5 \mathrm{GeV}}{12 / 9 / 76}$
Run date $-\frac{63}{\text { Proton }}$
Run No.
Particie $-\frac{\text { D3 (AFB) }}{3}$
Plate No.
Plate locdion

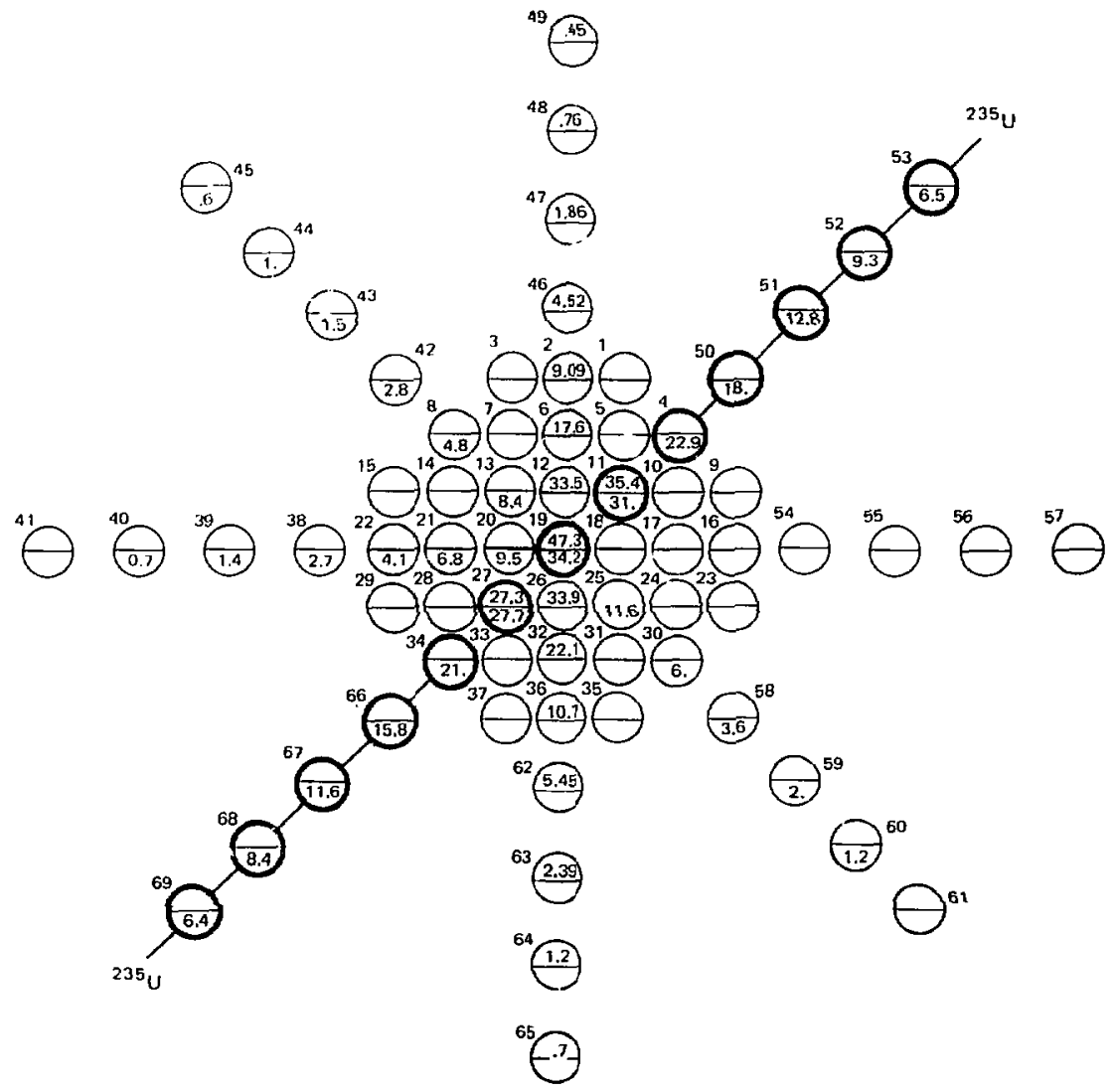


Beam cnergy $28.5 \mathrm{GeV}$

Rundare.

$12 / 9 / 76$

Run No.

Parlicle

Plale No.

Platelocisturn

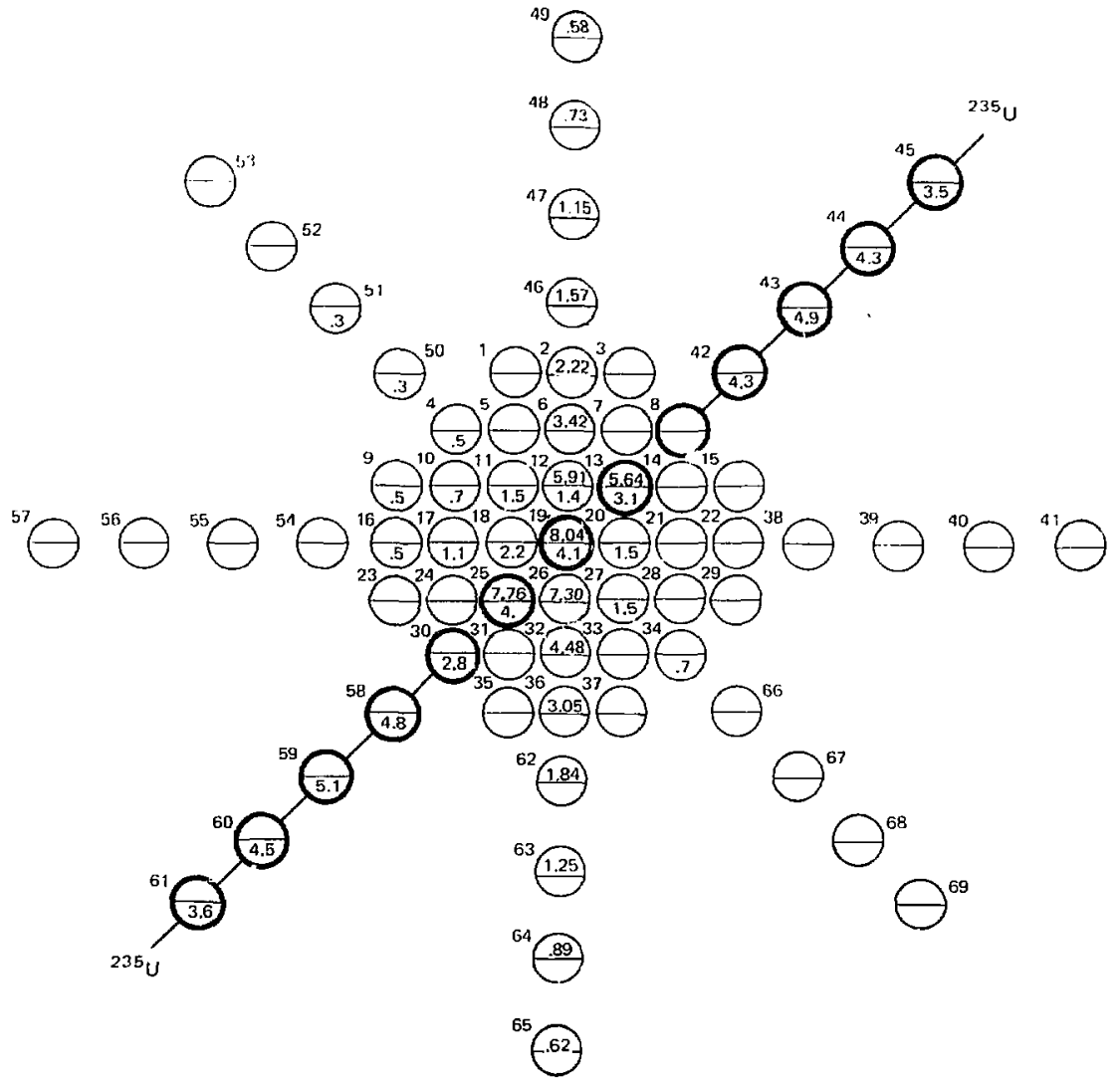

Fig. D-19. 


Beam energy $-\frac{28.5 \mathrm{GeV}}{12 / 9 / 76}$
Run date
Run No.
Particle $\frac{6^{4}}{\text { Proton }}$
Plate No.
Plate locution _....

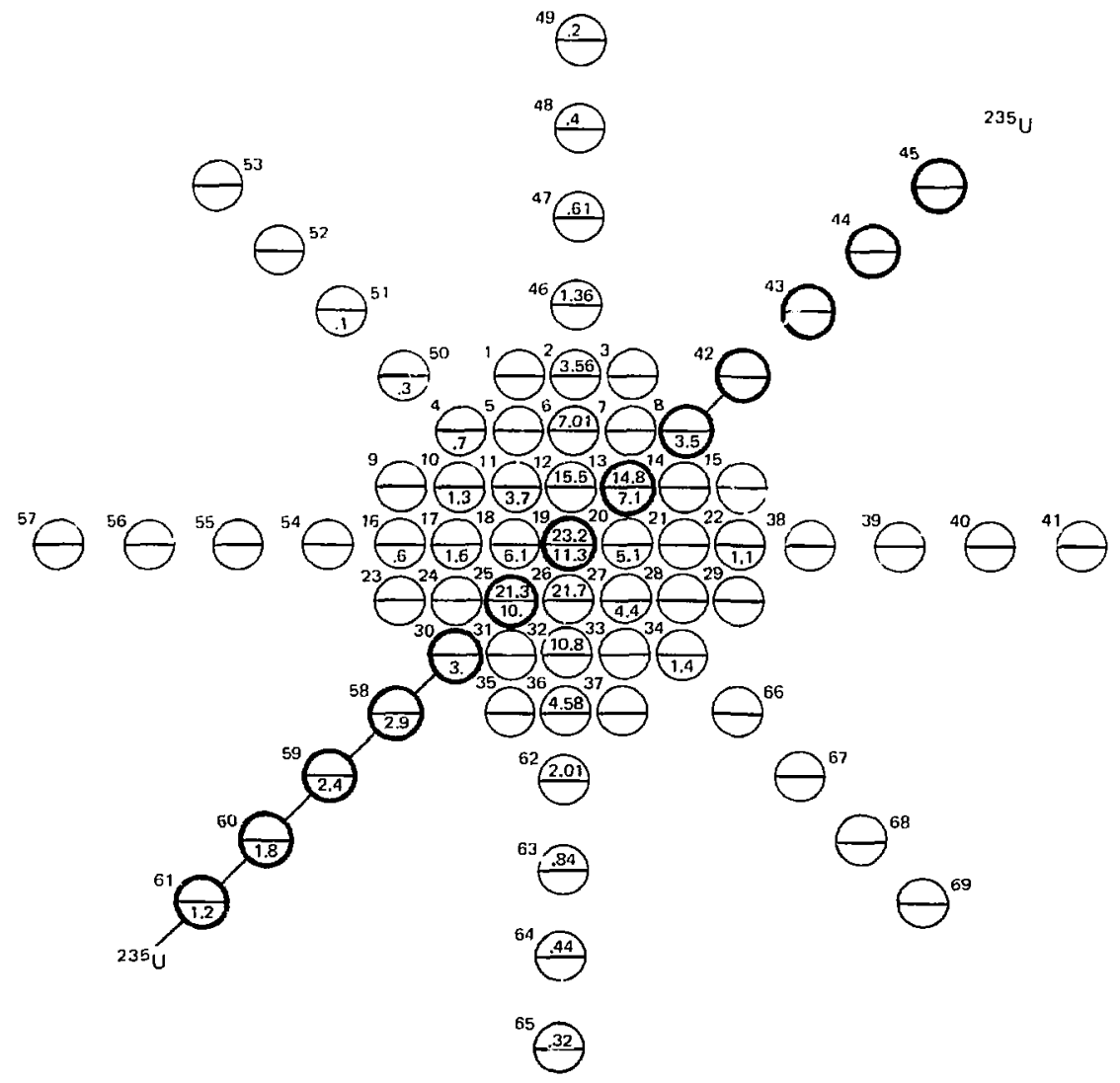

Fig. D-20. 


\begin{tabular}{l} 
Beam energy \\
Run date $\frac{11.4}{1 / 12 / 77}$ \\
Run No. $\frac{71}{\text { Proton }}$ \\
Particle \\
Plate No. D1 (FB) \\
Plate Iocution -1 \\
\hline
\end{tabular}

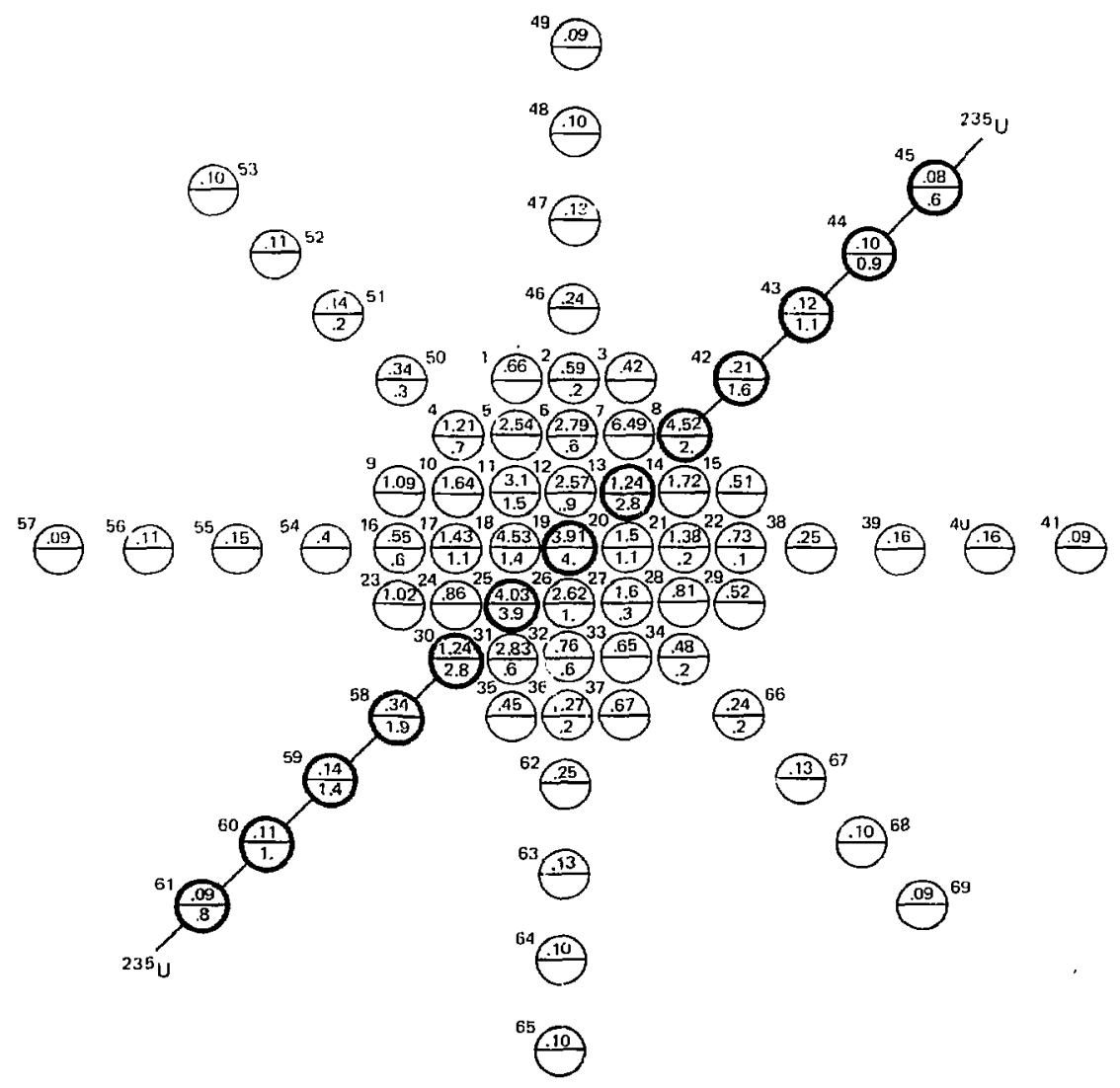

Fig. D-21, 

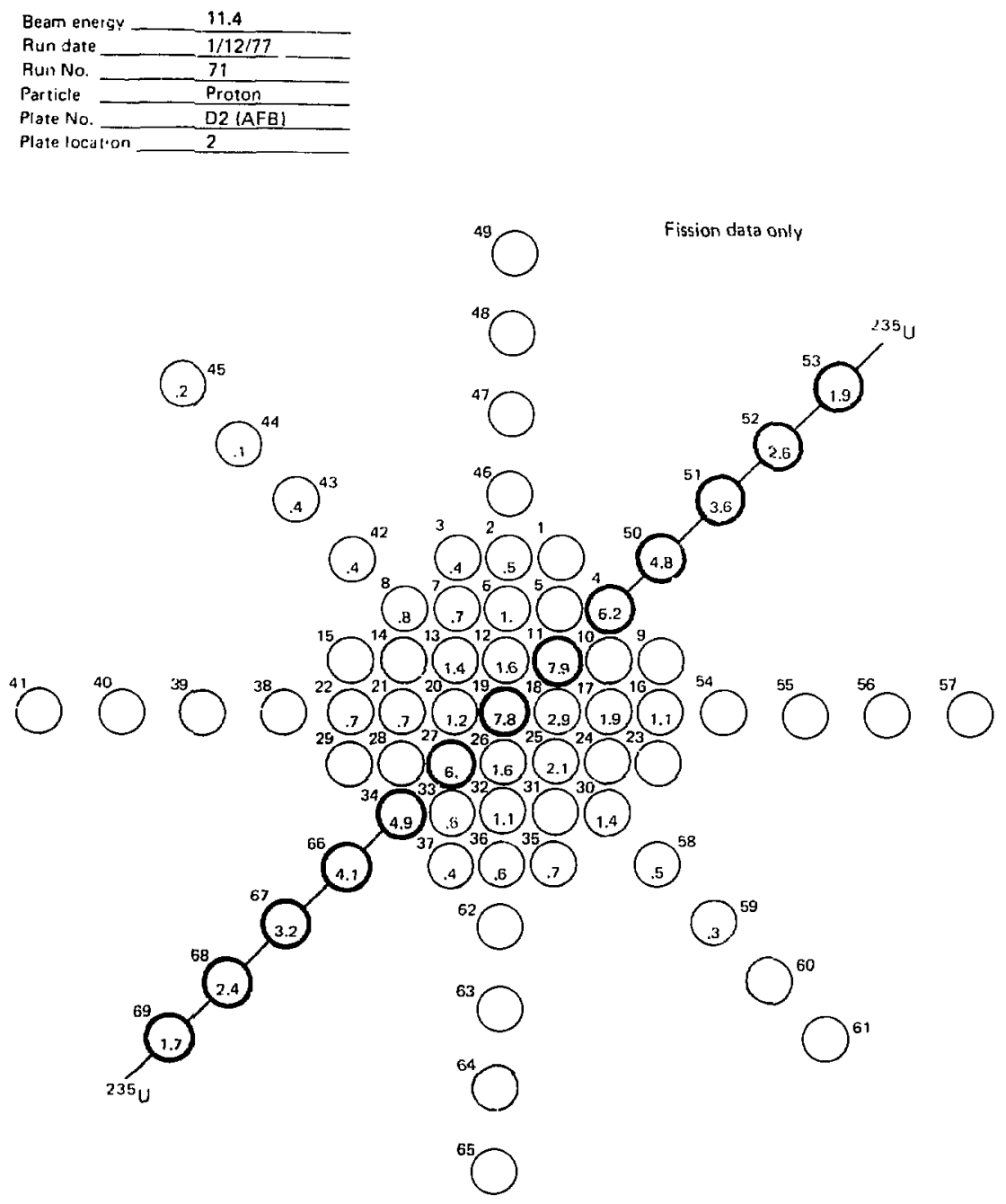

Fig. D-22. 


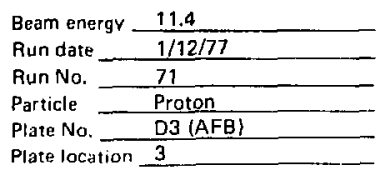

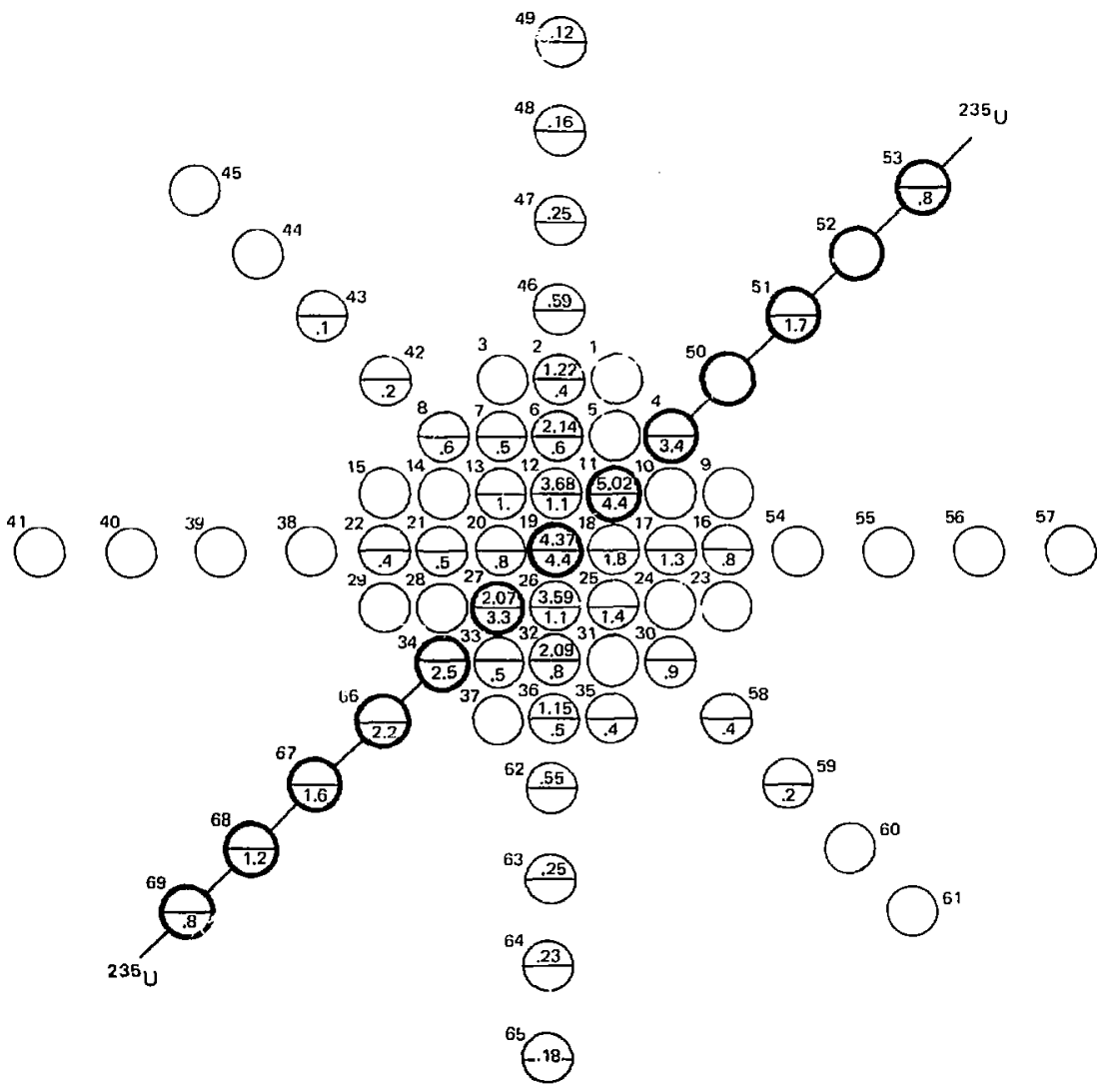

Fig. D-23. 


\begin{tabular}{|c|c|}
\hline Beam energy & 11.4 \\
\hline Run date & $1 / 12 / 77$ \\
\hline Run No. & 31 \\
\hline Particle & Proton \\
\hline Plate No. & D4 (FB) \\
\hline Plate location & 5 \\
\hline
\end{tabular}

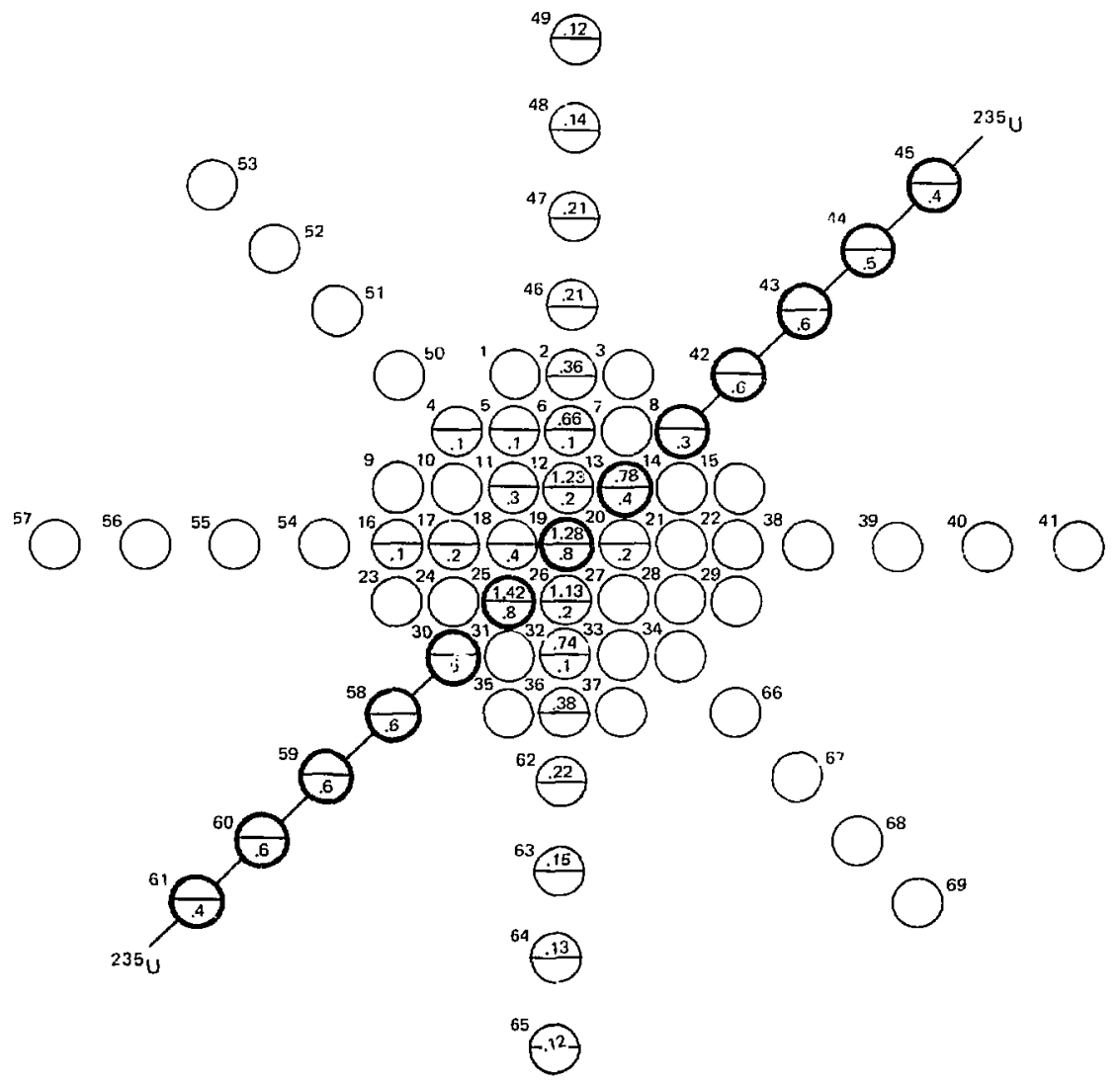

Flg. D-24. 
aeam energy $\quad 12.3 \mathrm{GeV}$

Run date $1 / 12 / 77$

Run No.

Particle 72

Plate No.

Plate location 5

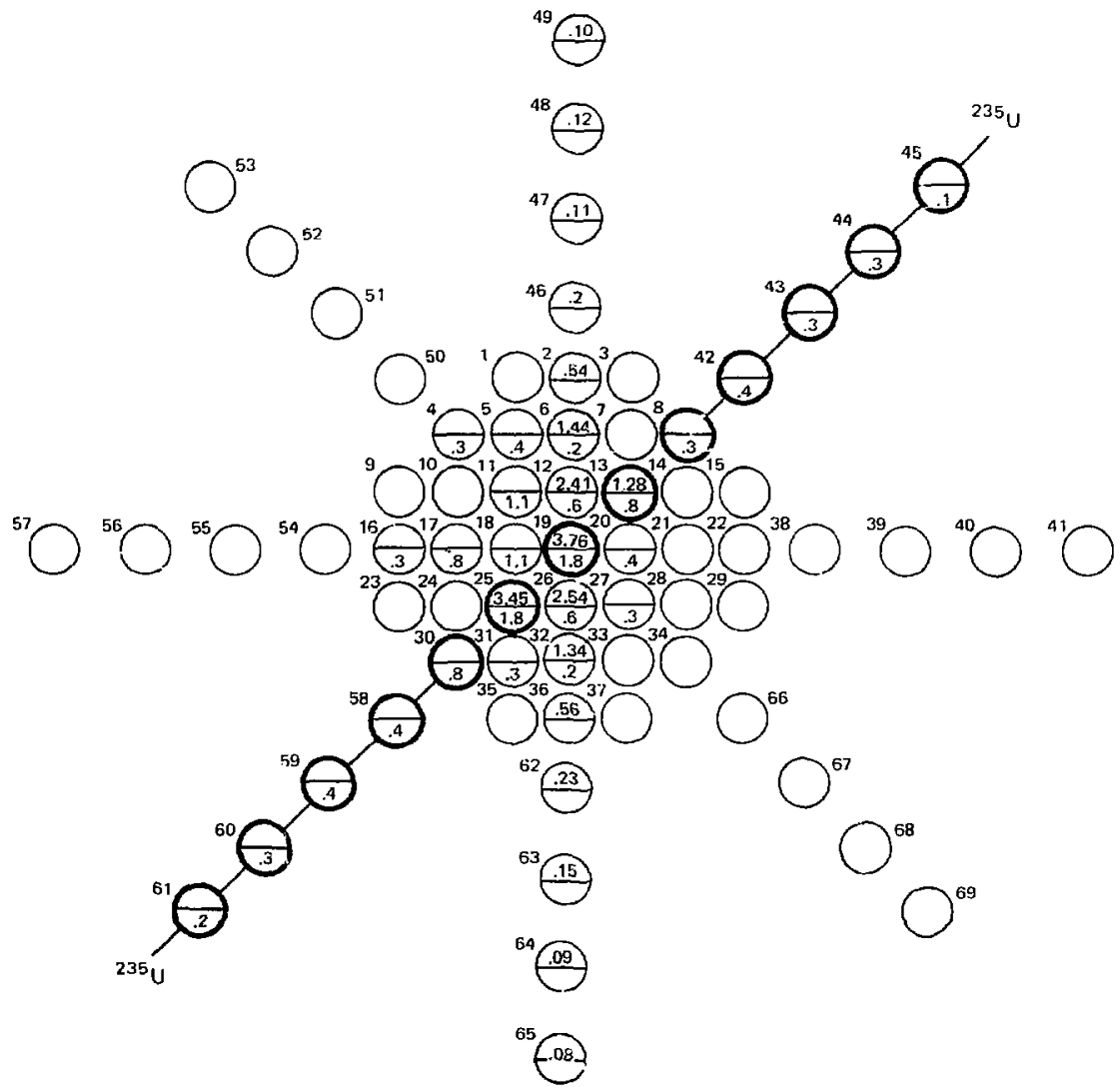

Fig- D-25. 


Beam energy $-\frac{11.4 \mathrm{GeV}}{1 / 12 / 77}$
Run date
Run No. $\frac{73}{\text { Proton }}$
Particle
Plate No.
Plate location $-\frac{\mathrm{D} 6(\mathrm{AFB})}{2}$

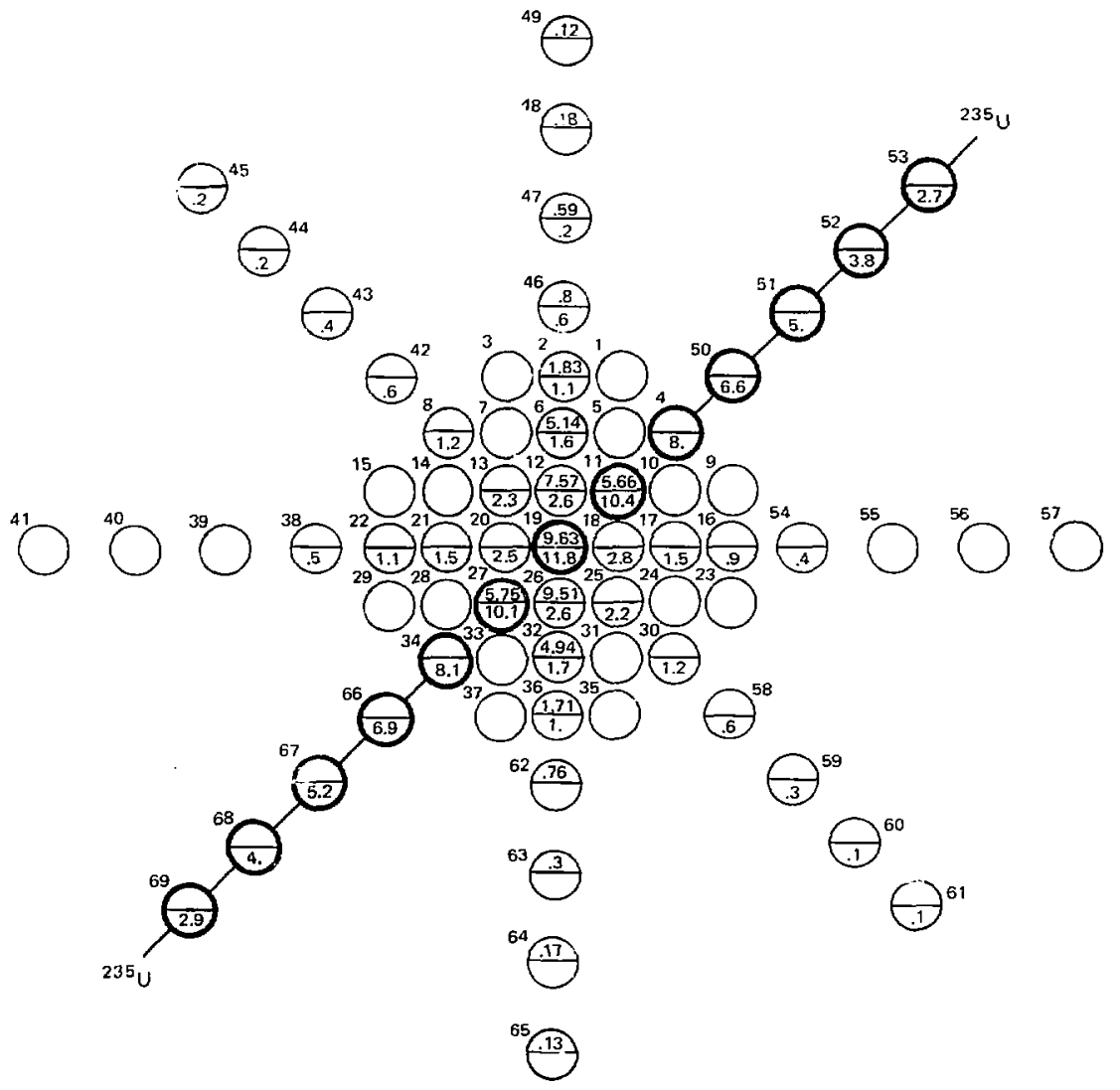

Fip. D-26. 


\begin{tabular}{ll} 
Beam energy & 11.4 \\
Run date & $1 / 12 / 77$ \\
Run No. & $\frac{73}{}$ \\
Particle & Proton \\
Plate No. & $\mathrm{D} 7(\mathrm{FB})$ \\
\hline Platc location & 5 \\
\hline
\end{tabular}

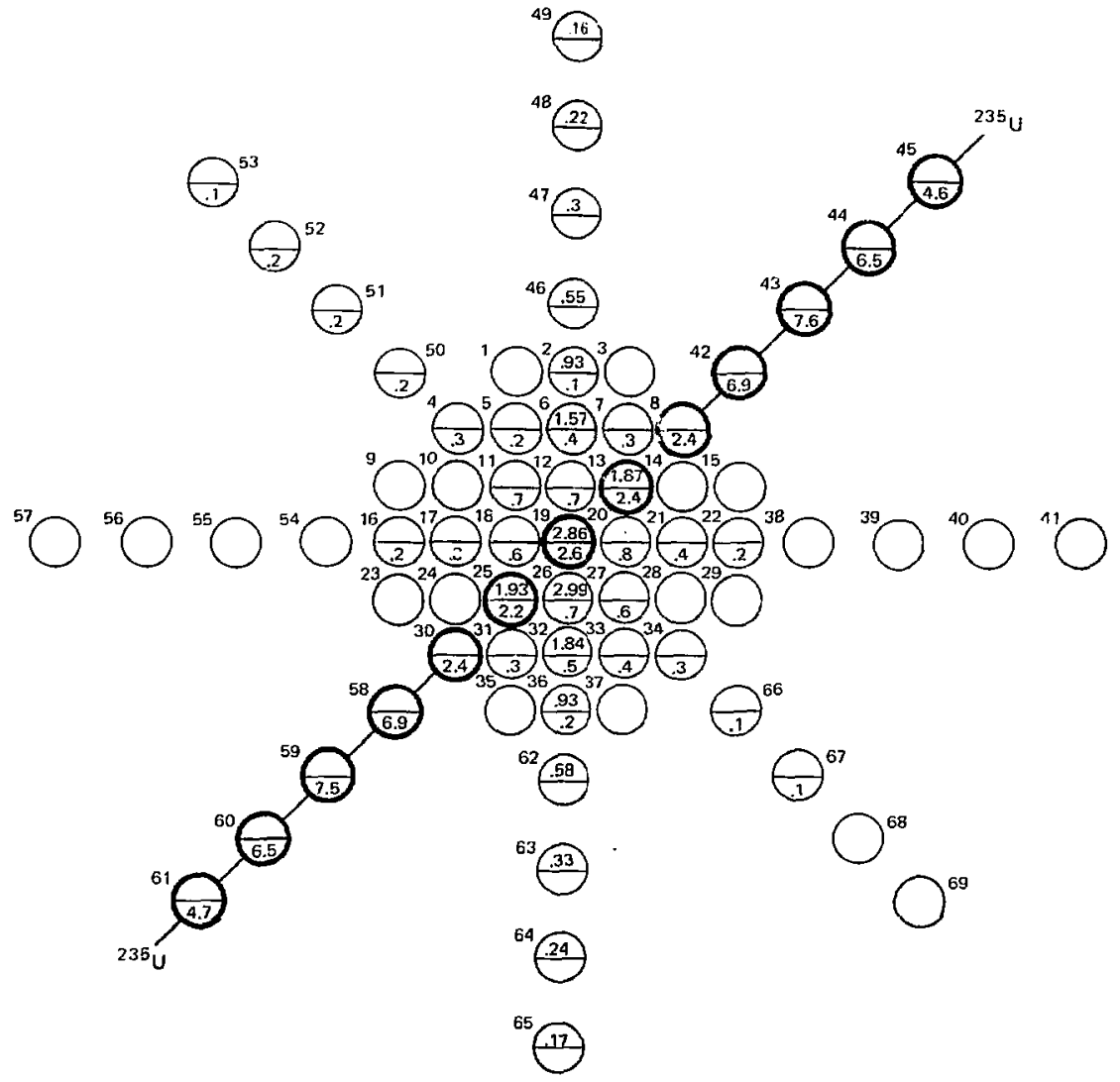

Fig. D-27. 


\begin{tabular}{l} 
Beam energy $-\frac{11.4}{1 / 12 / 37}$ \\
Run date \\
Run No. $\frac{74}{\text { Particle }}$ \\
Plate No. $\frac{\text { Proton }}{\mathrm{DB}(\mathrm{FB})}$ \\
Plate location -1 \\
\hline
\end{tabular}

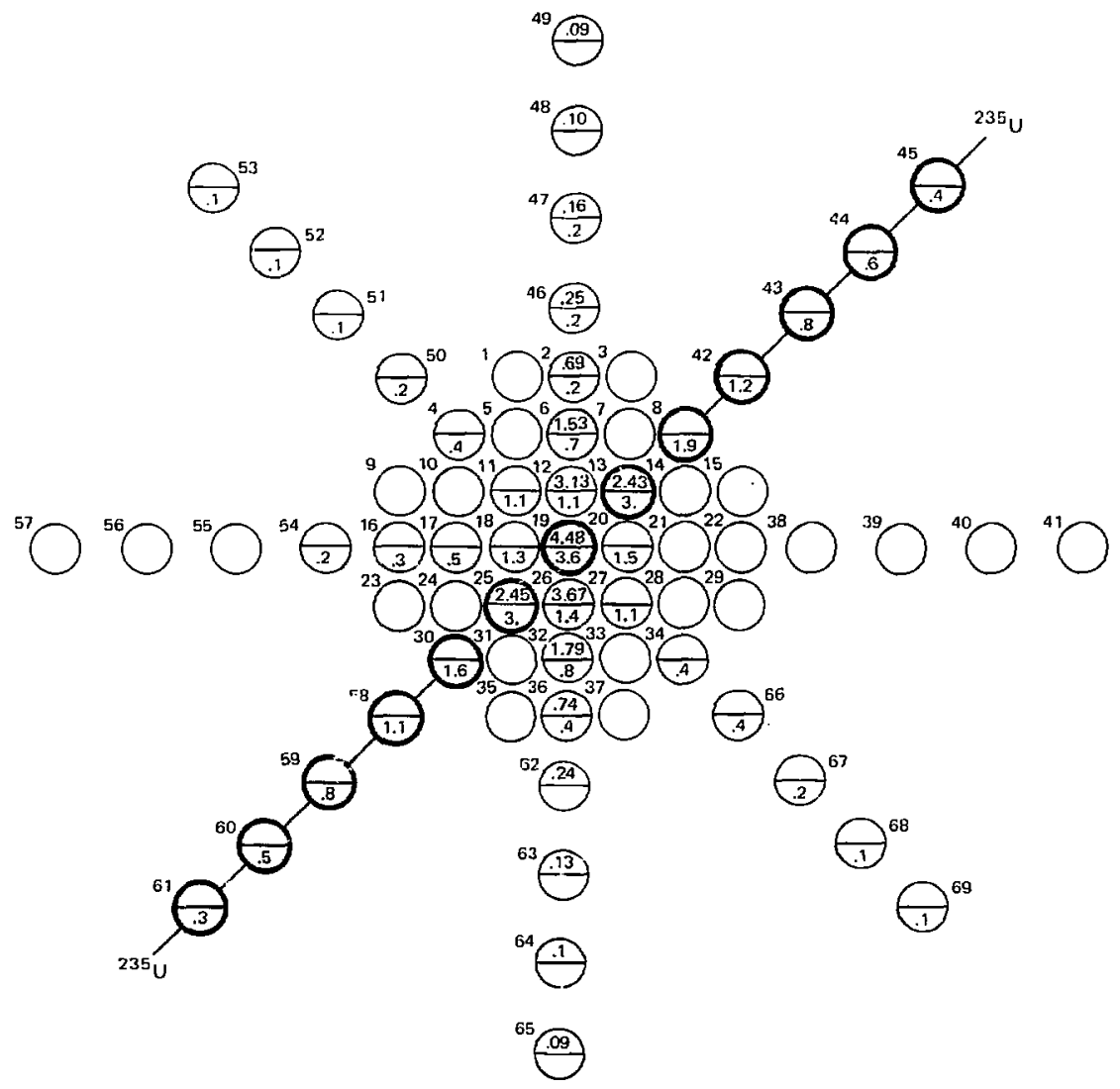

Fig. D-28. 


Beam energy
Run date
$\begin{aligned} & \text { Run No. } \\ & \text { Particle }\end{aligned} \frac{11 / 4}{74}$
Plate No.
Plate lociation

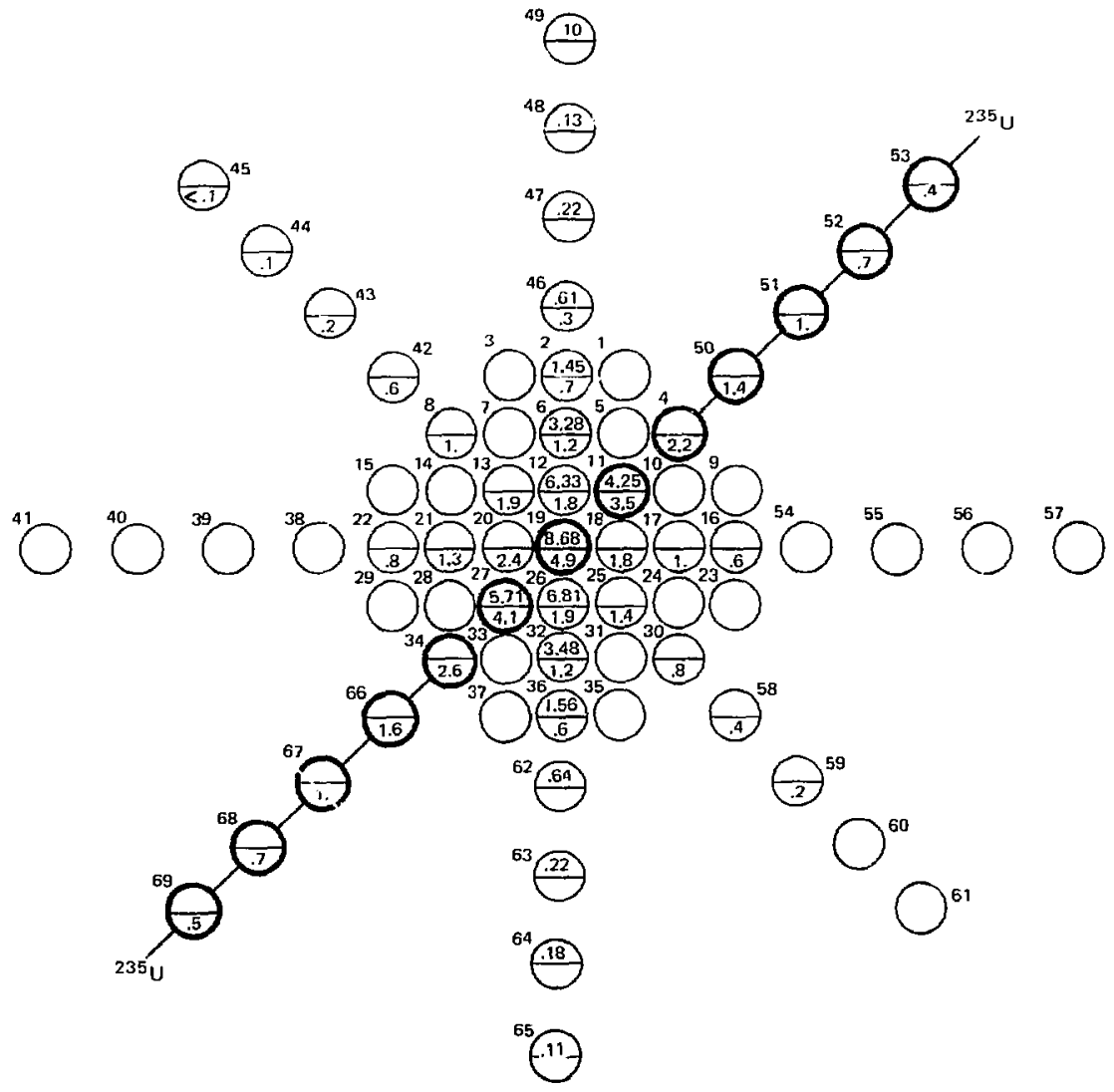

Fis. D-29. 


\begin{tabular}{ll} 
Beam energy & 11.4 \\
\cline { 2 - 2 } & $1 / 12 / 77$ \\
Run date & Proton \\
Particle & $\frac{74}{\mathrm{D} 10(\mathrm{FB})}$ \\
Plate No. & \\
Plate location & 5
\end{tabular}

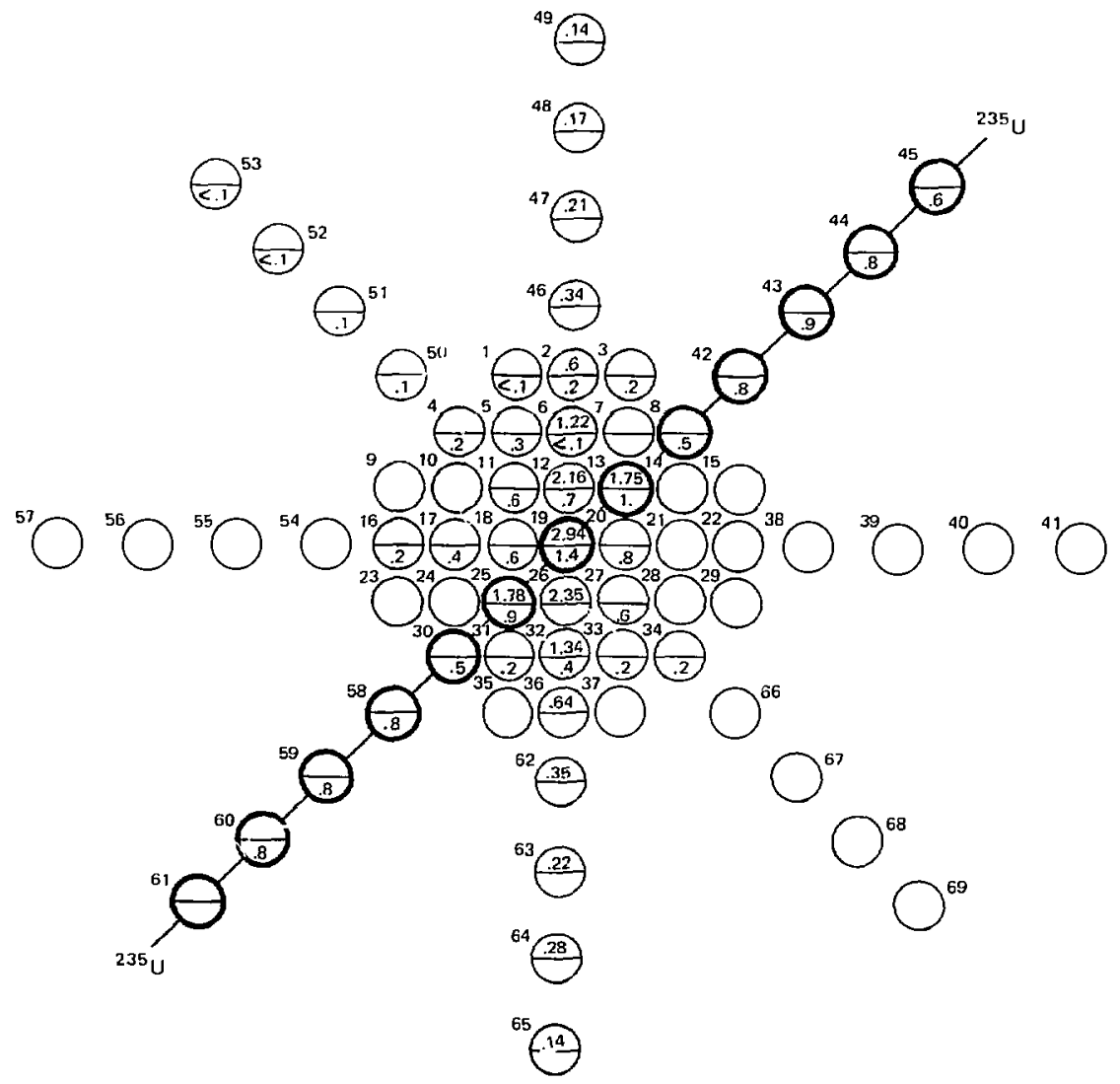

Fin. D-30. 


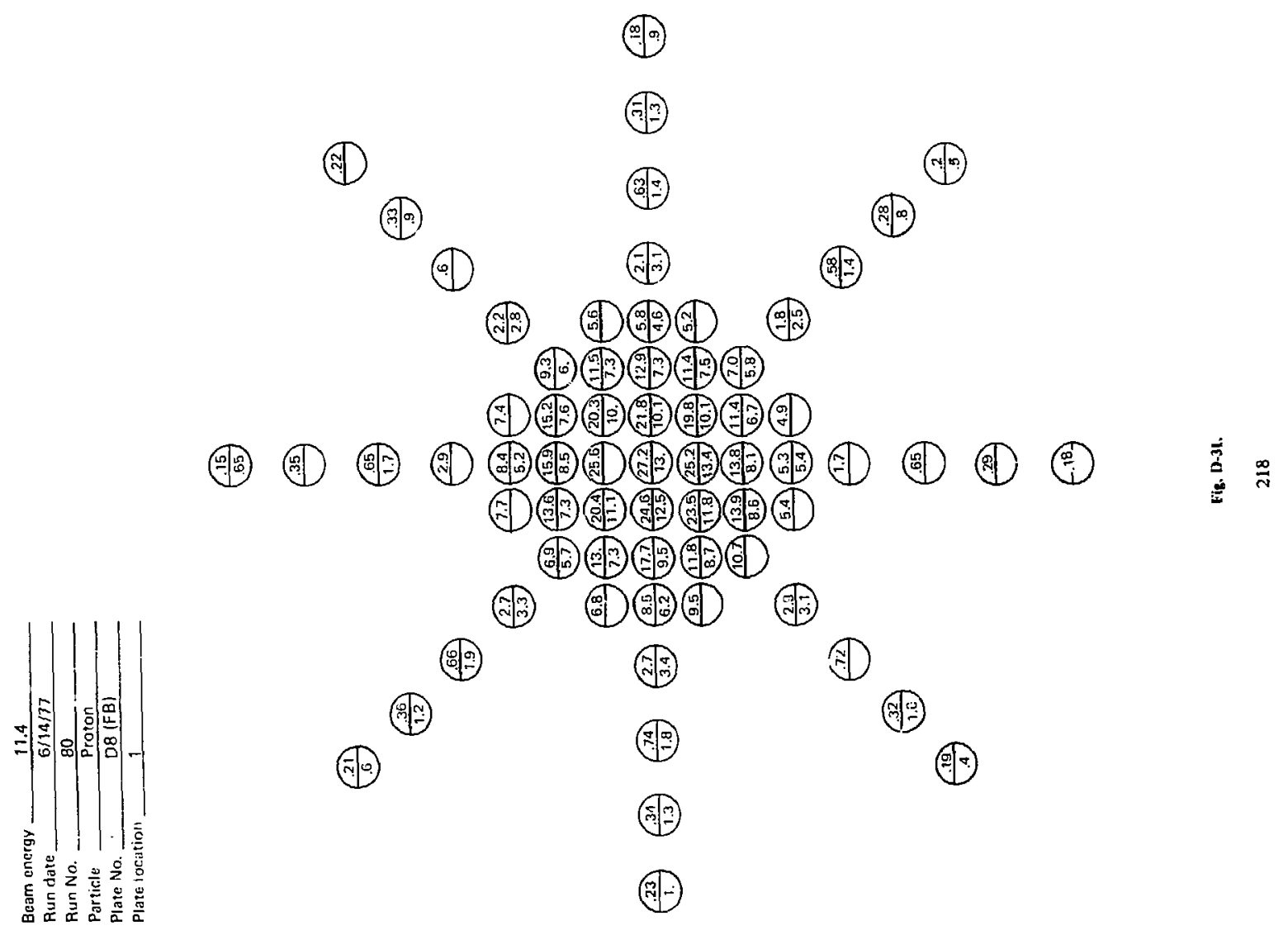




$\begin{array}{ll}\text { Bearn energy } & 11.4 \mathrm{GeV} \\ \text { Run date } & 6 / 14 / 77 \\ \text { Run No. } & \frac{80}{\text { Proton }} \\ \text { Particle } & \text { D9 (AFB) } \\ \text { Plate No. } \\ \text { Piate location }\end{array}$

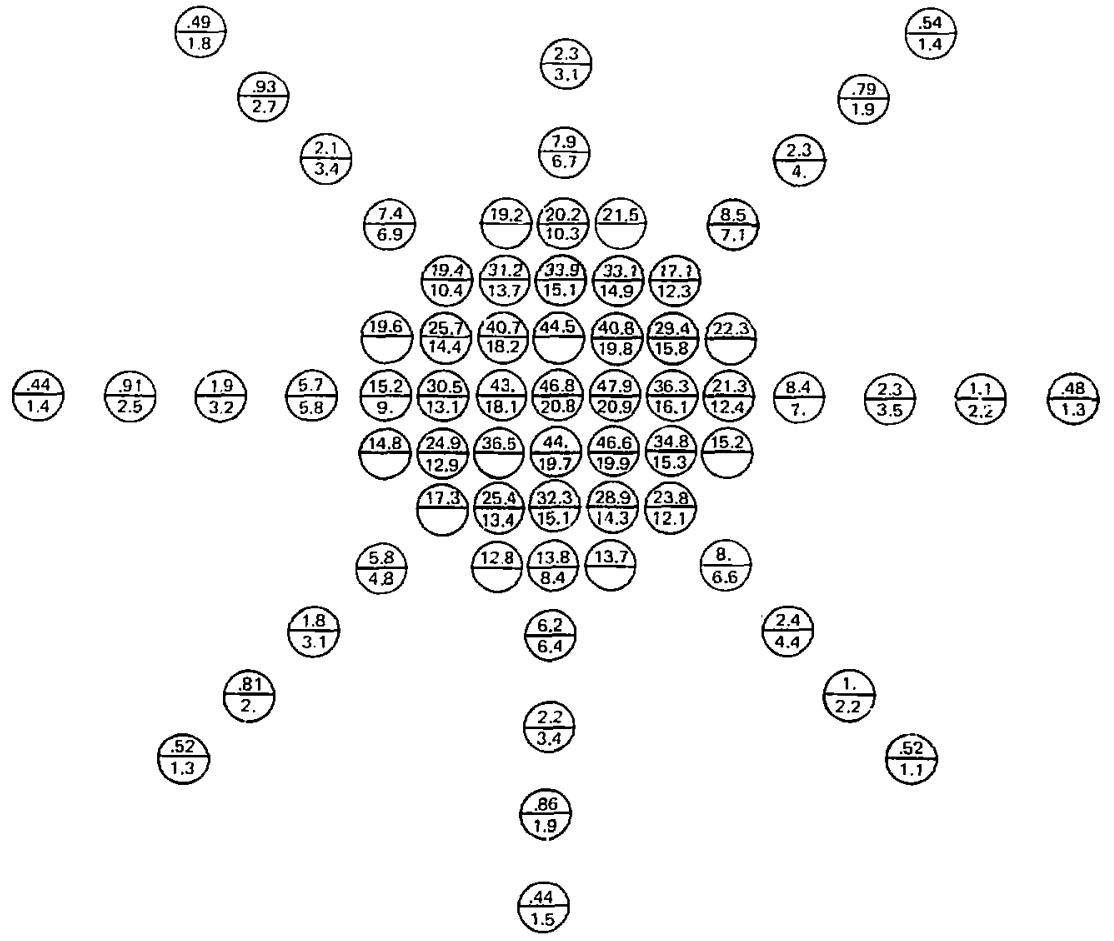

Fis, D-32. 
Beam energy $\quad 11.4$

Run date b/14/77

Run No.

Particle B0

Plate No.

Proton

Platil location

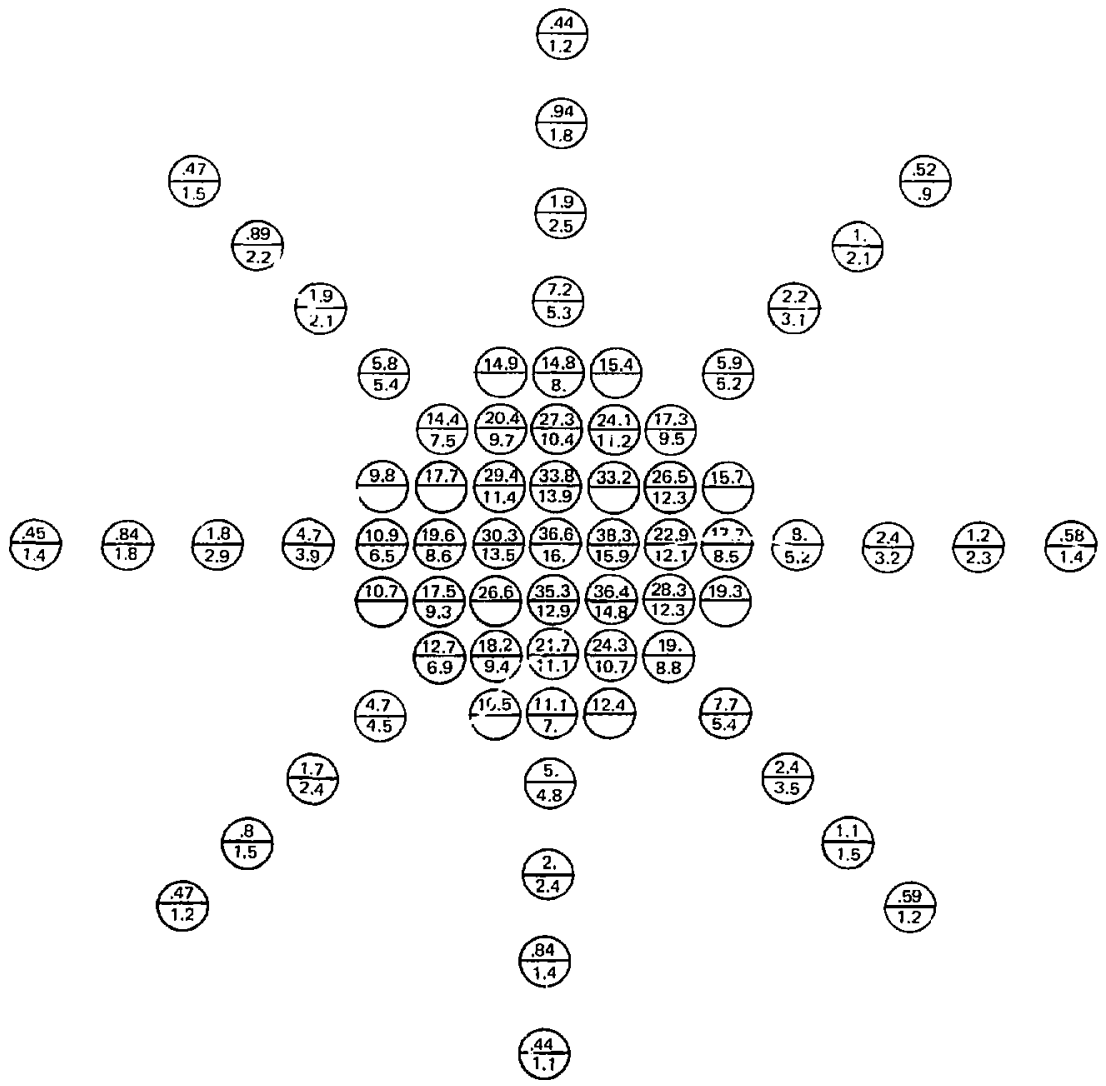

Fig, D-33. 


\section{APPENDIX E}

FISSION-DOSE DATA ALONG TWO AXIS OF PLATES VS DISTANCE FROM THE CENTER OF EACH PLATE
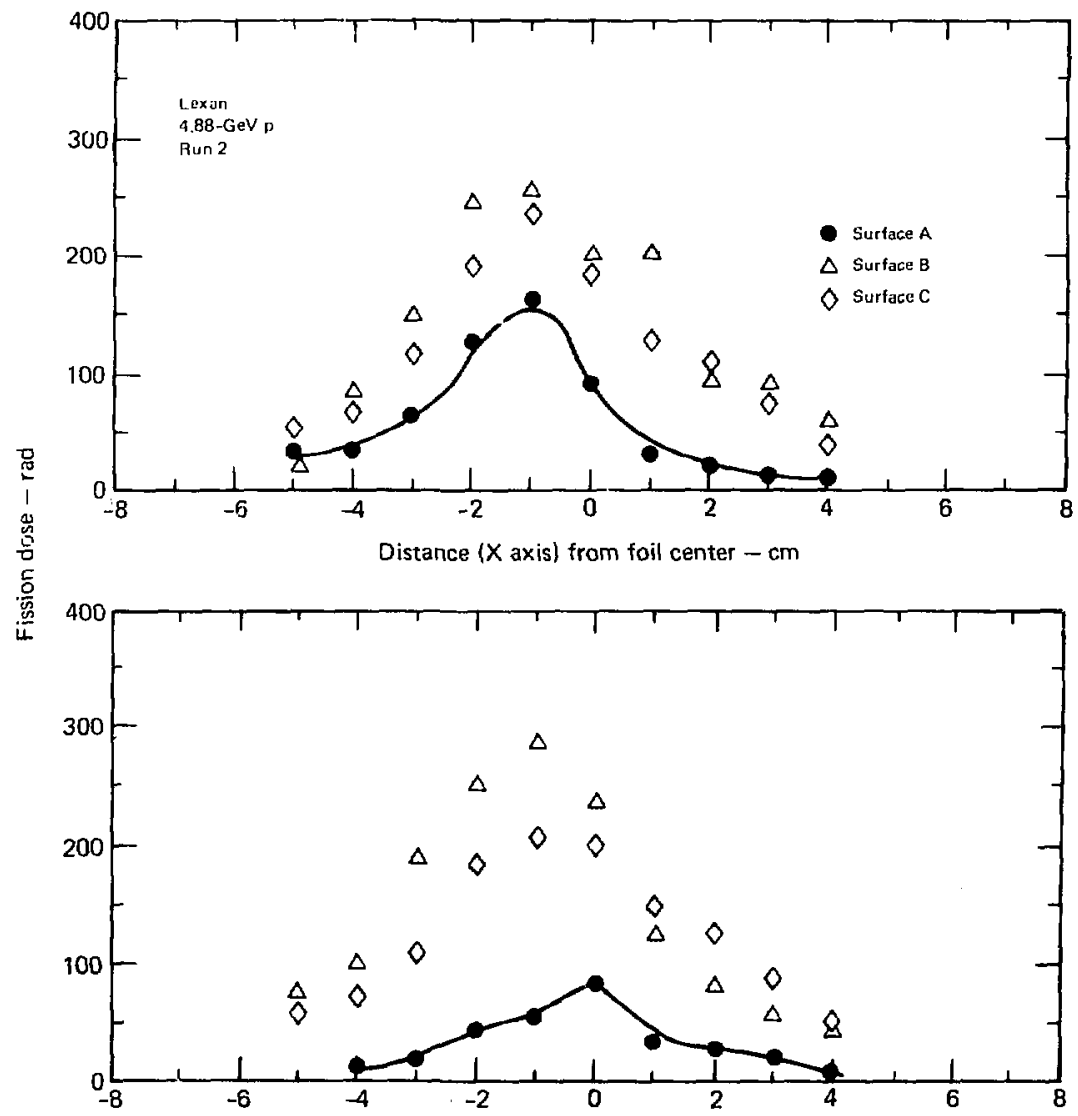

Distance ( $Y$ axis) from foil center $-\mathrm{cm}$

Flg. E.1. 

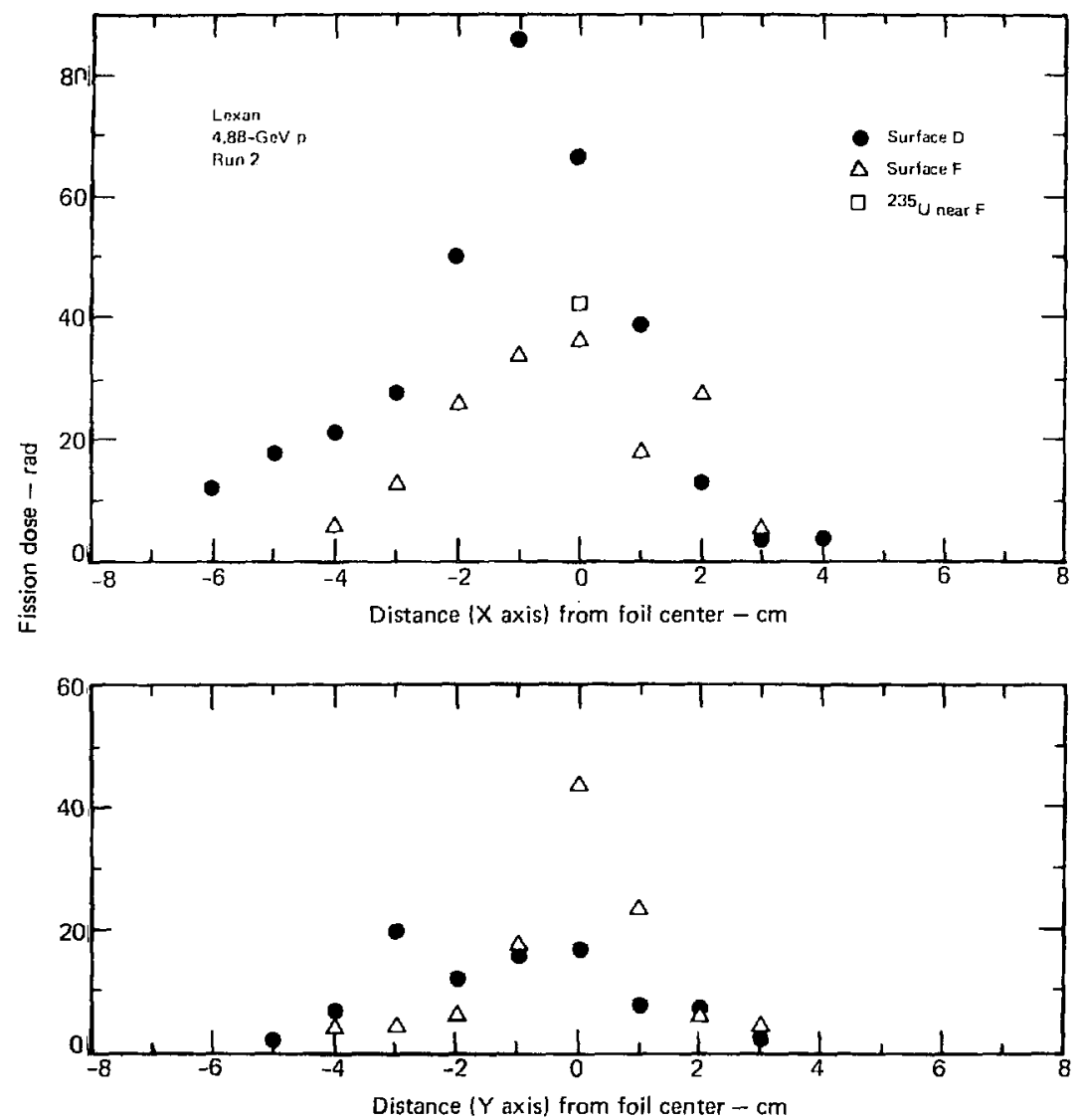

Fig, E-2. 


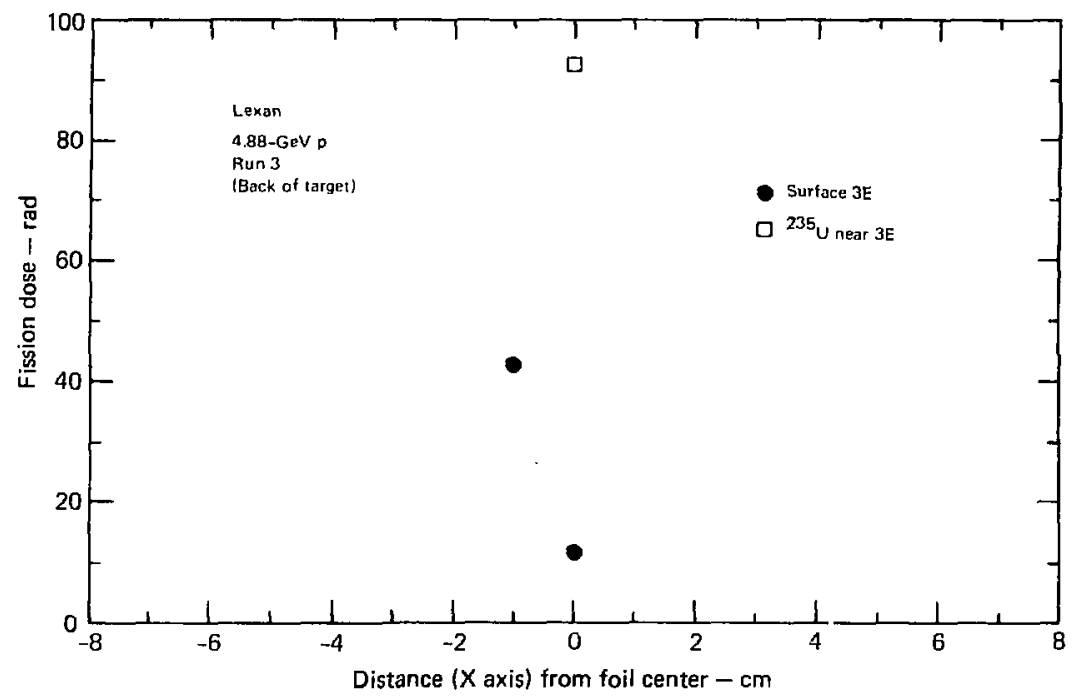

Fin, E-3,

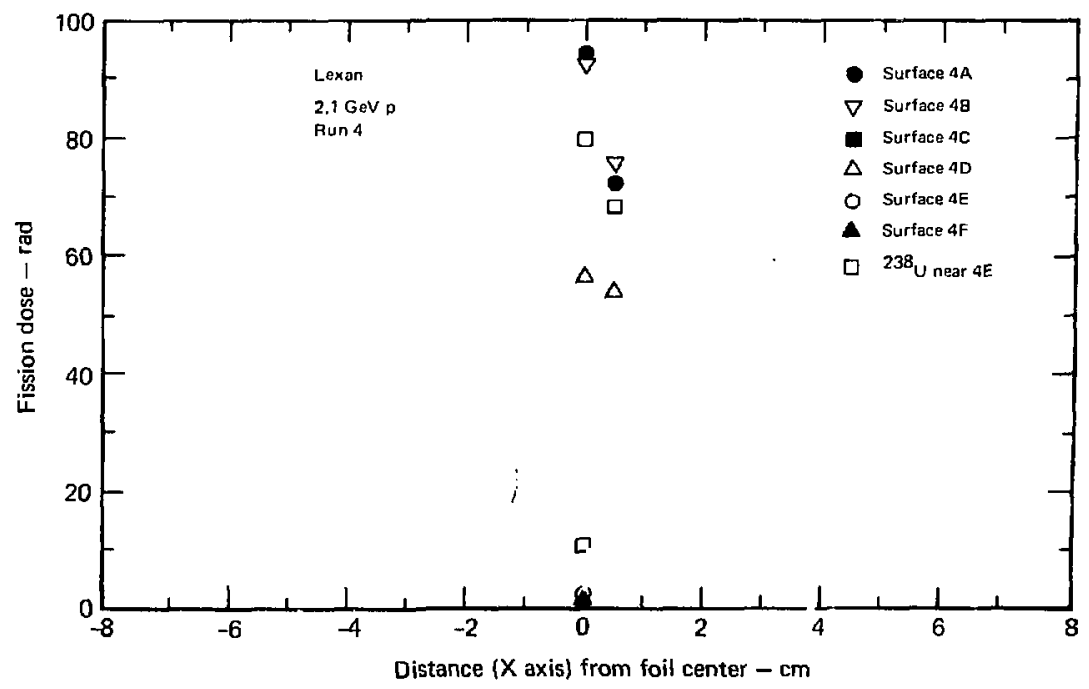

Fis. E-4. 


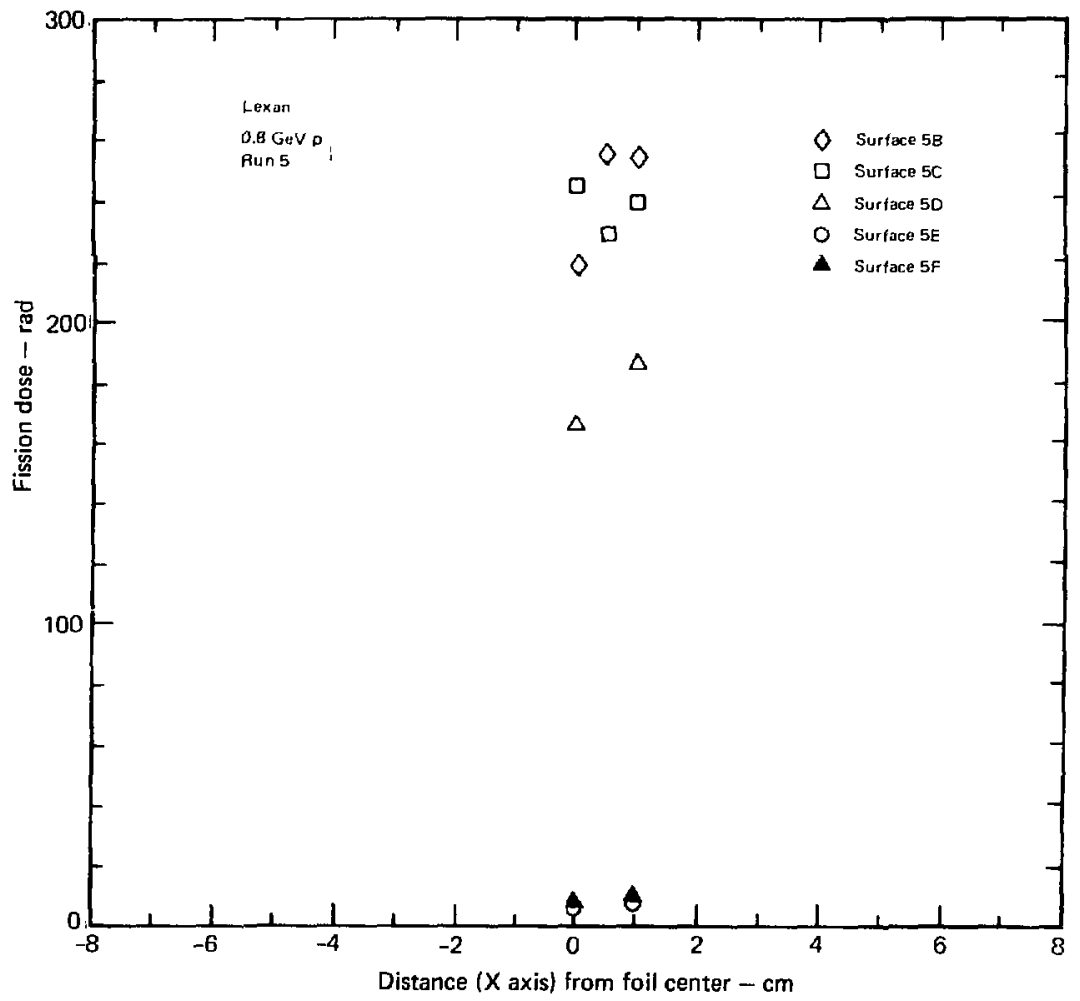

Fig. E-5. 


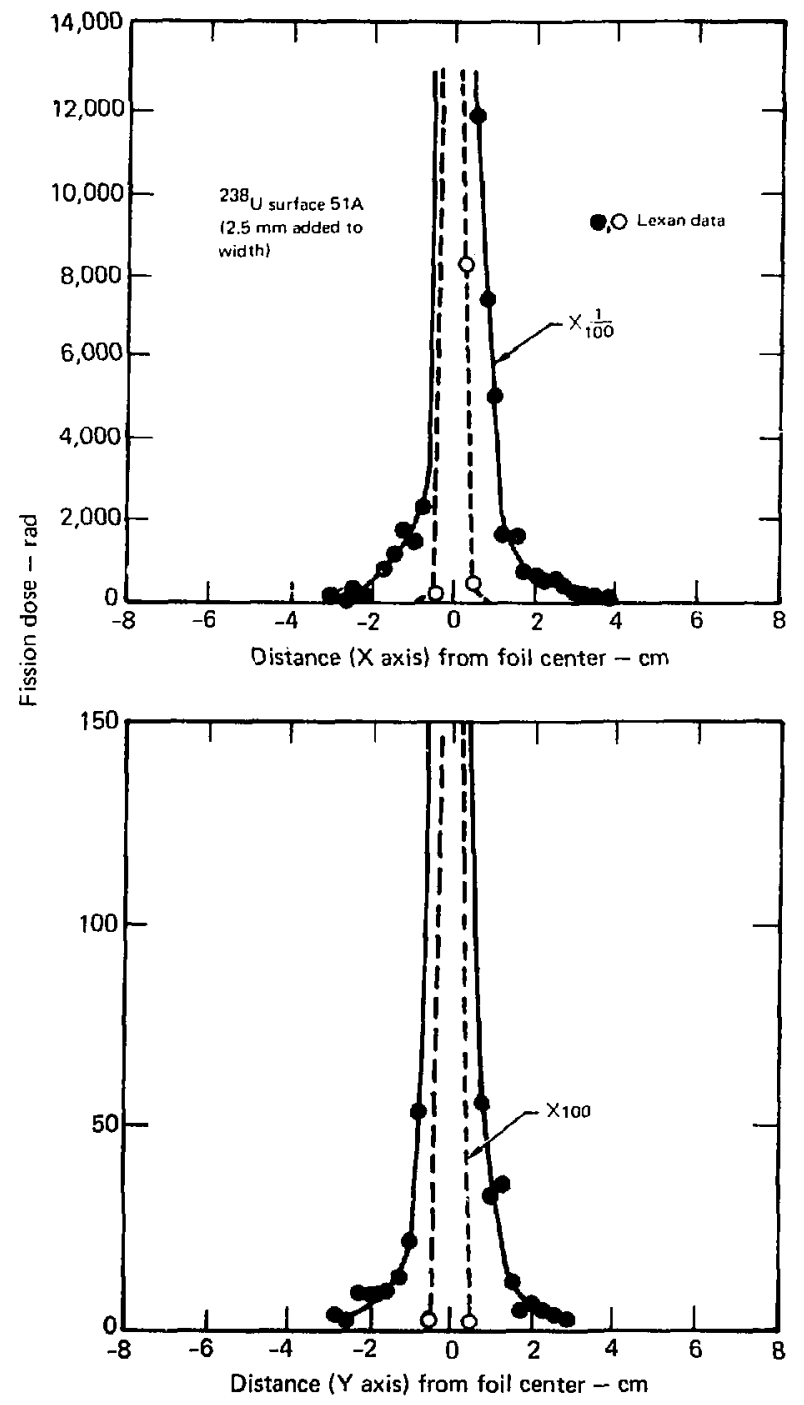

Fig. E-6. 


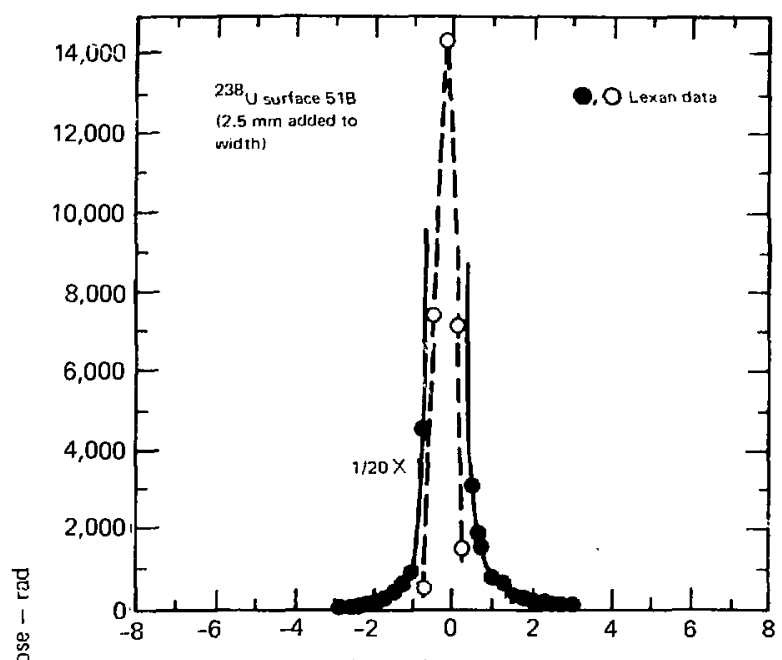

Distance ( $X$ axis) from foil center $-\mathrm{cm}$

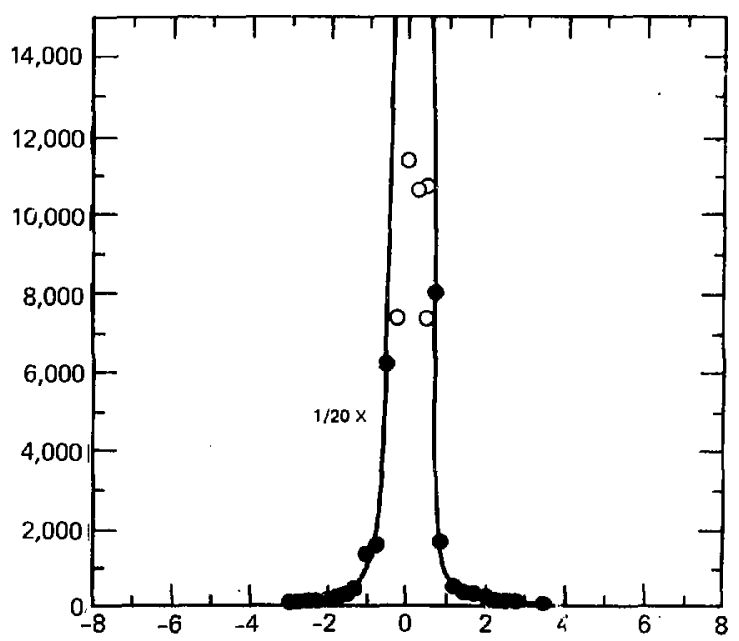

Distance ( $Y$ axis) from foil center $-\mathrm{cm}$

Fig, E-7. 

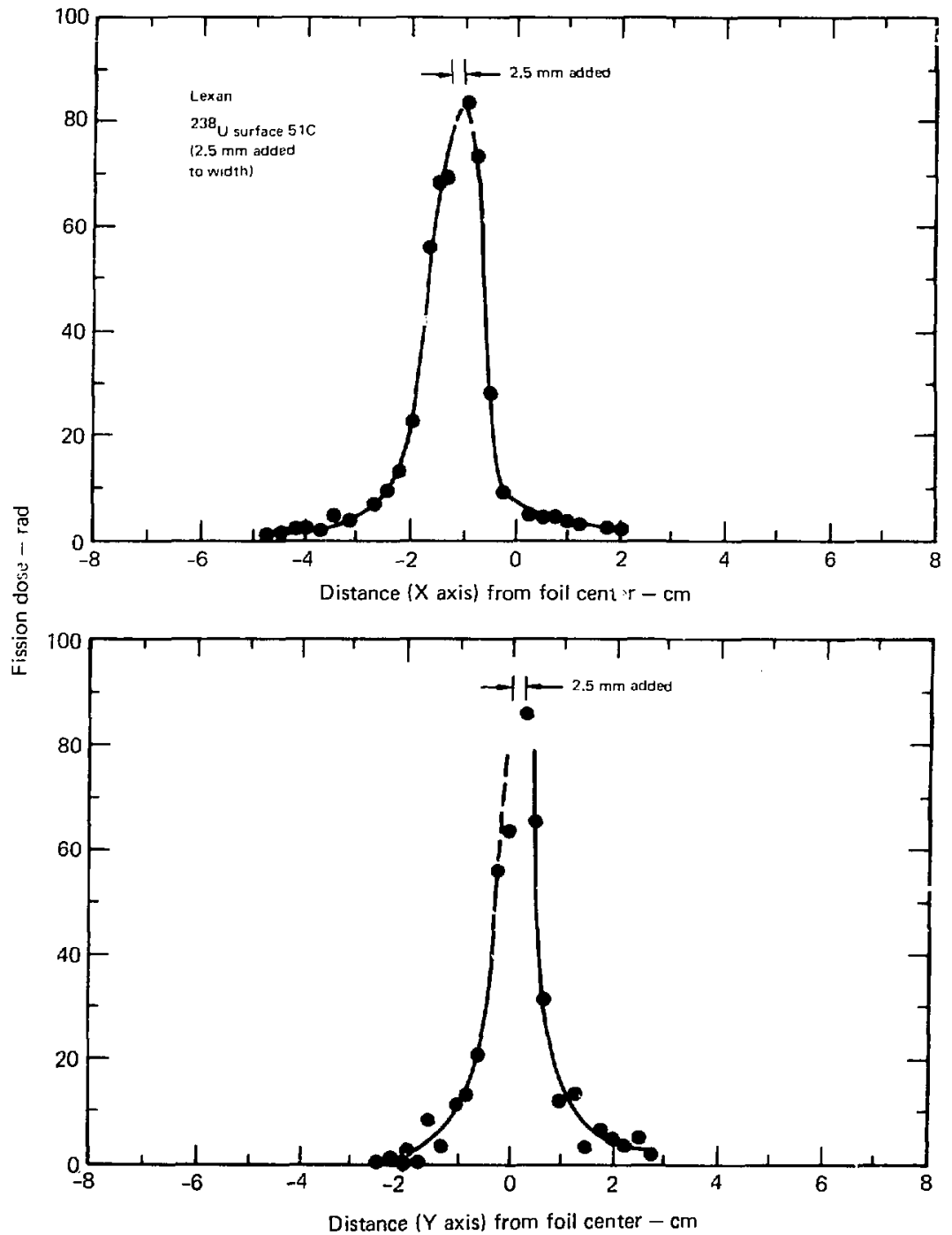

Fip. E-8. 

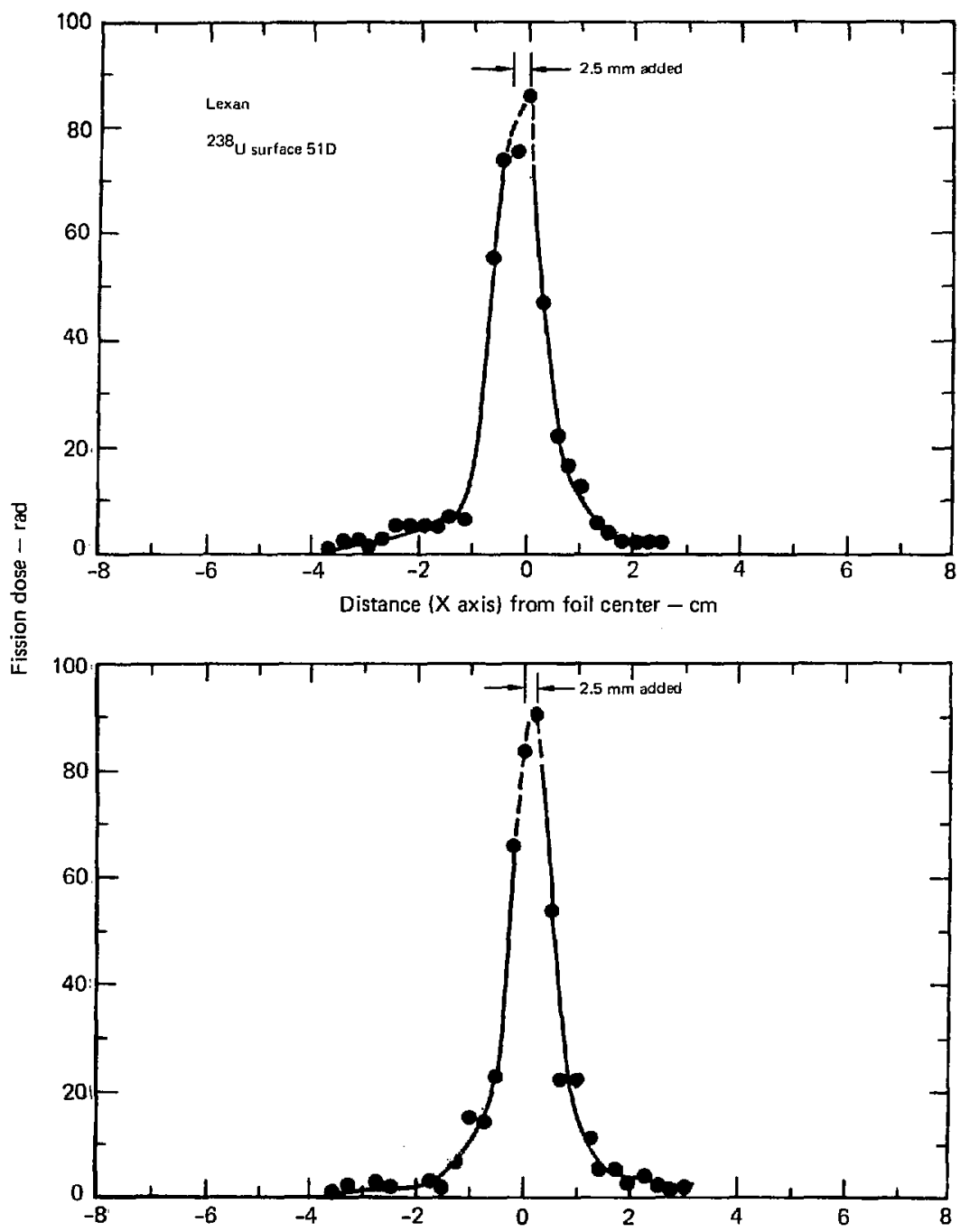

Distance ( $Y$ axis) from foil center $-\mathrm{cm}$

Fig. E-9. 

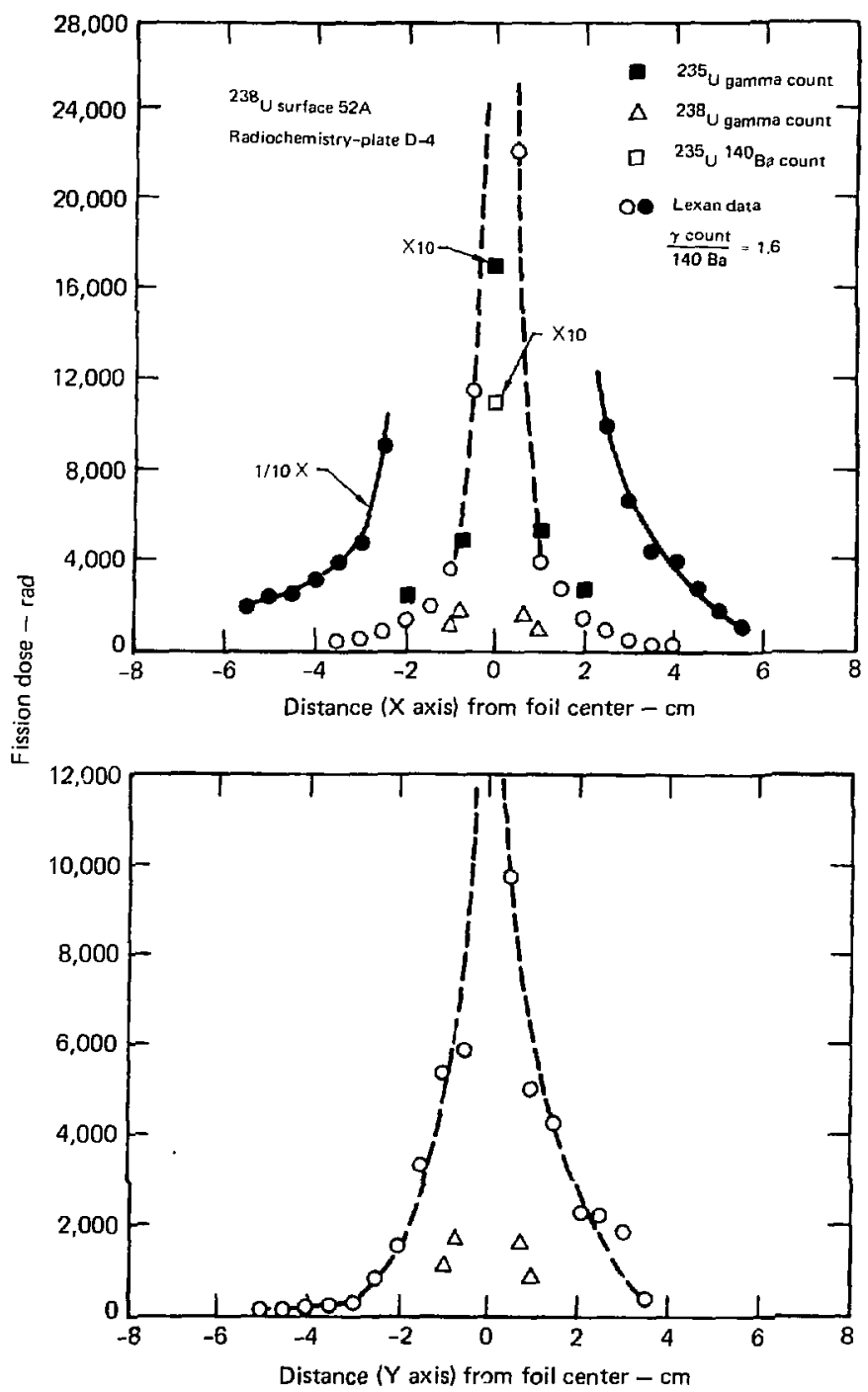

Fig. E-10. 


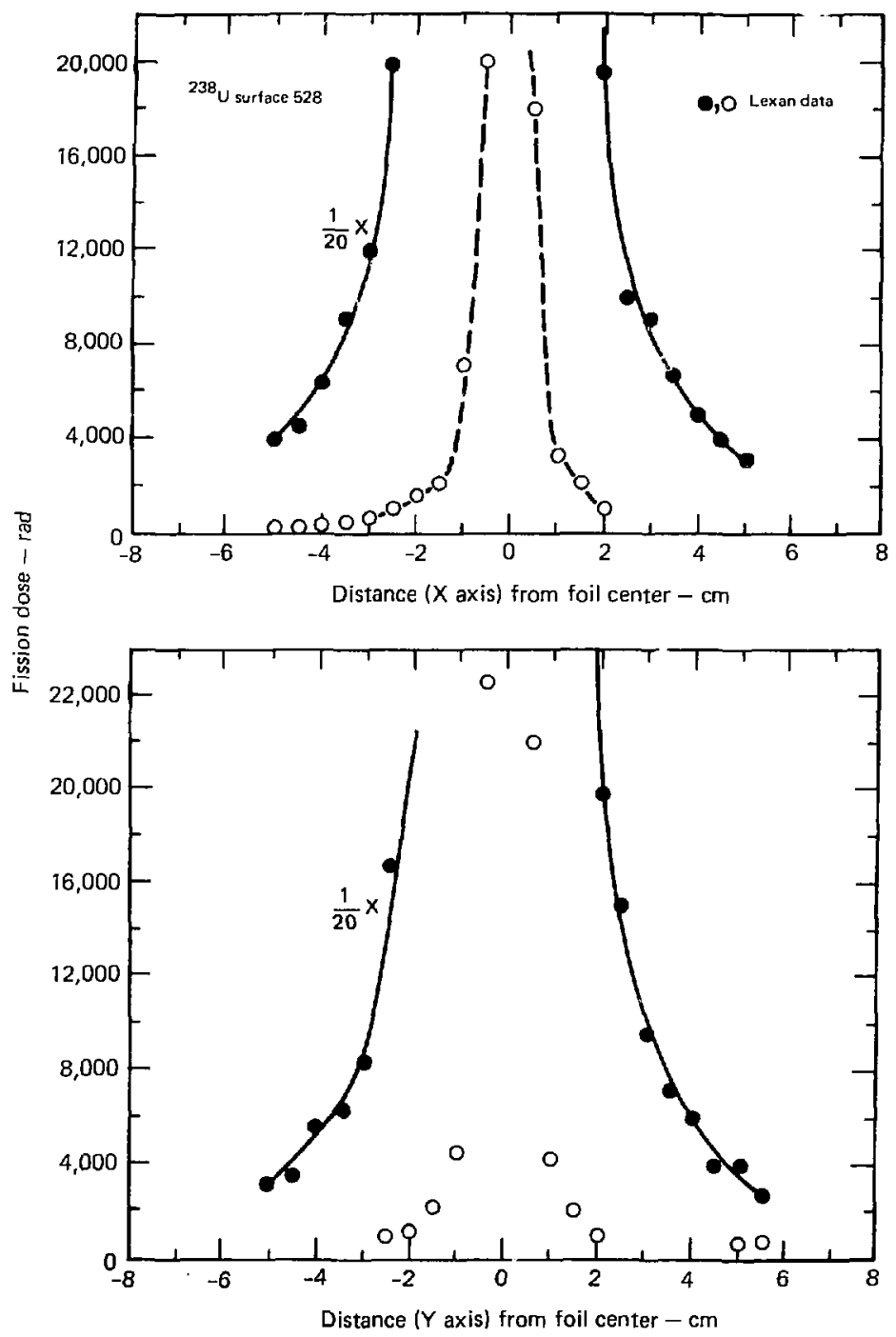

Fig. E-11. 


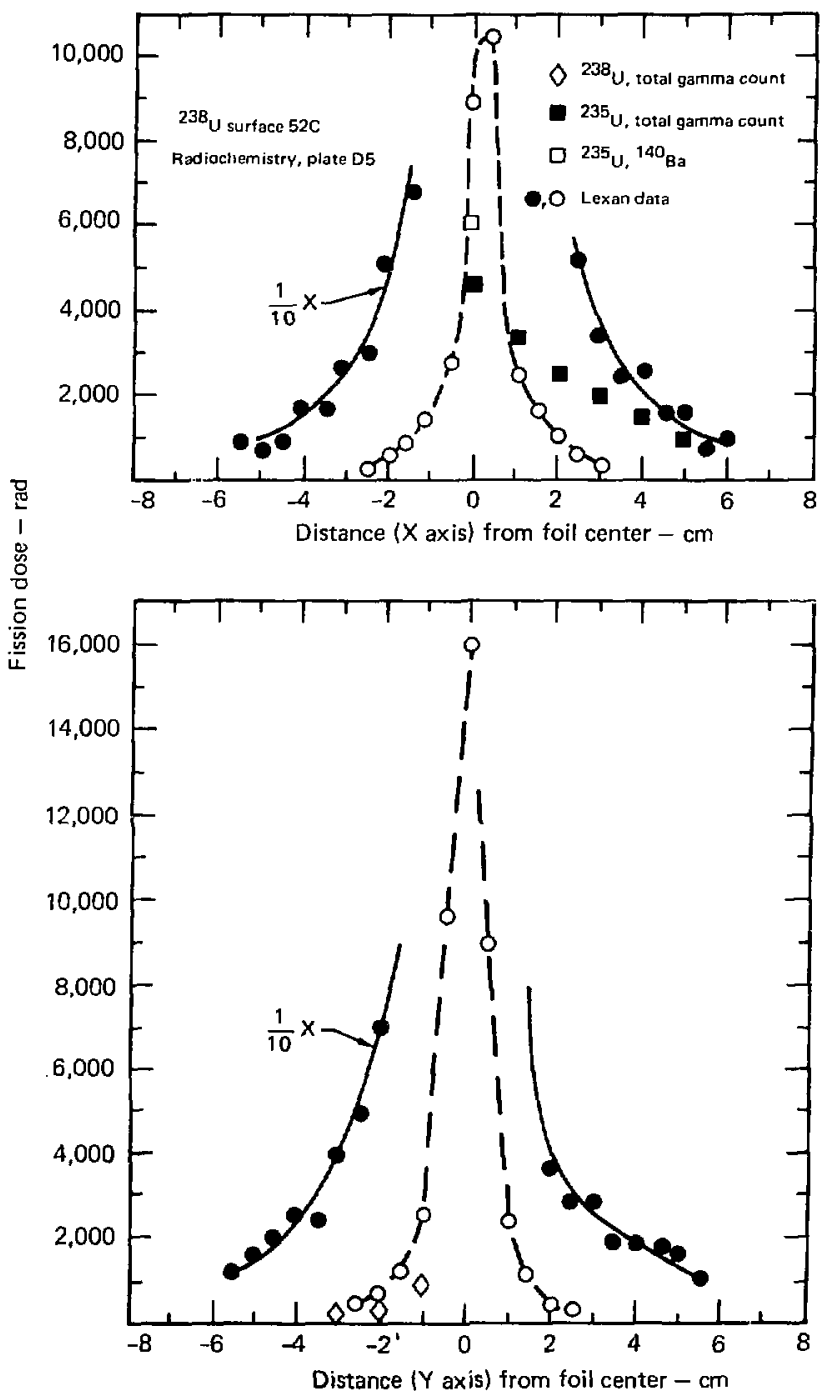

Fig. E-12. 


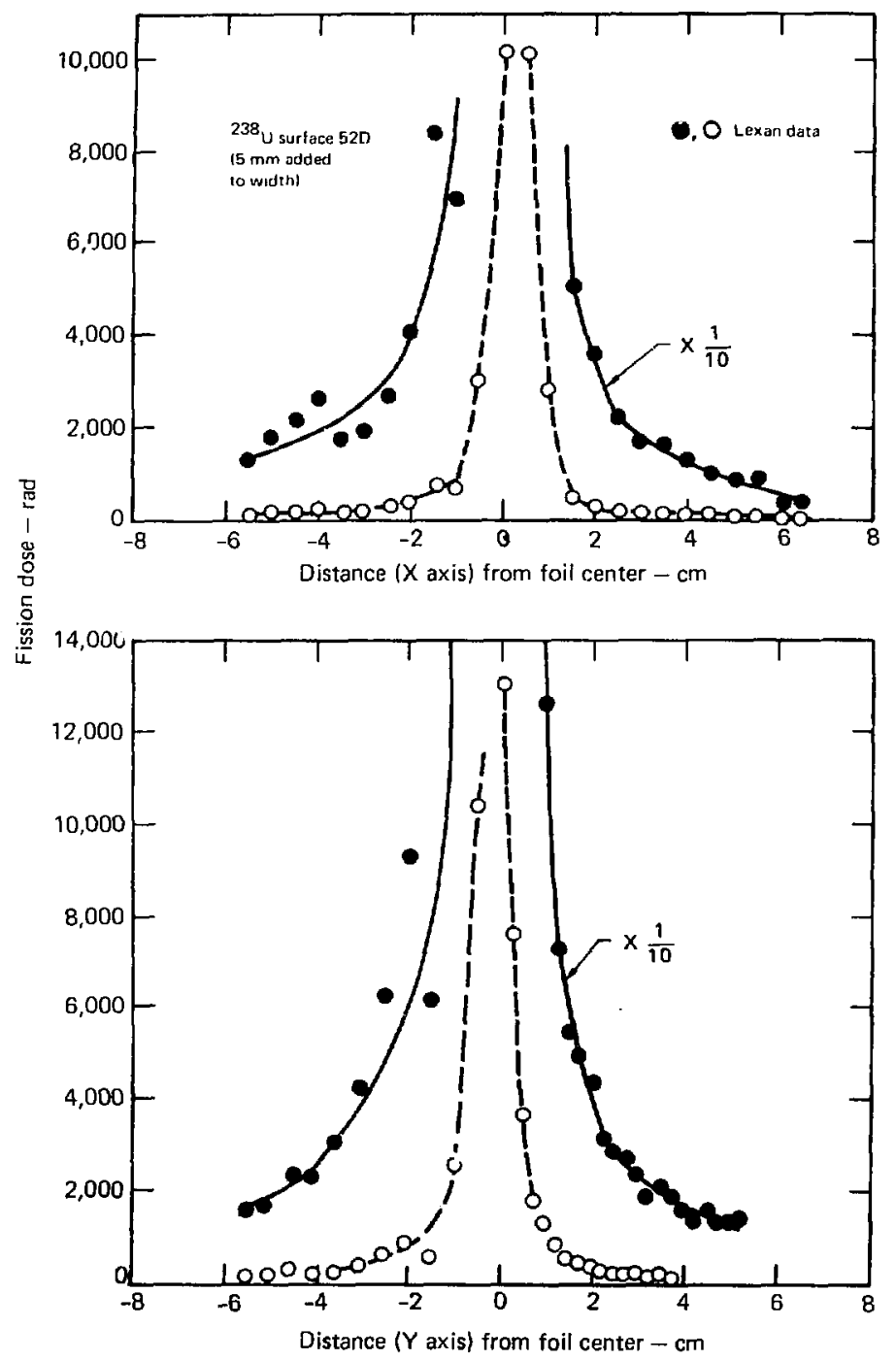

Fig. E-13, 

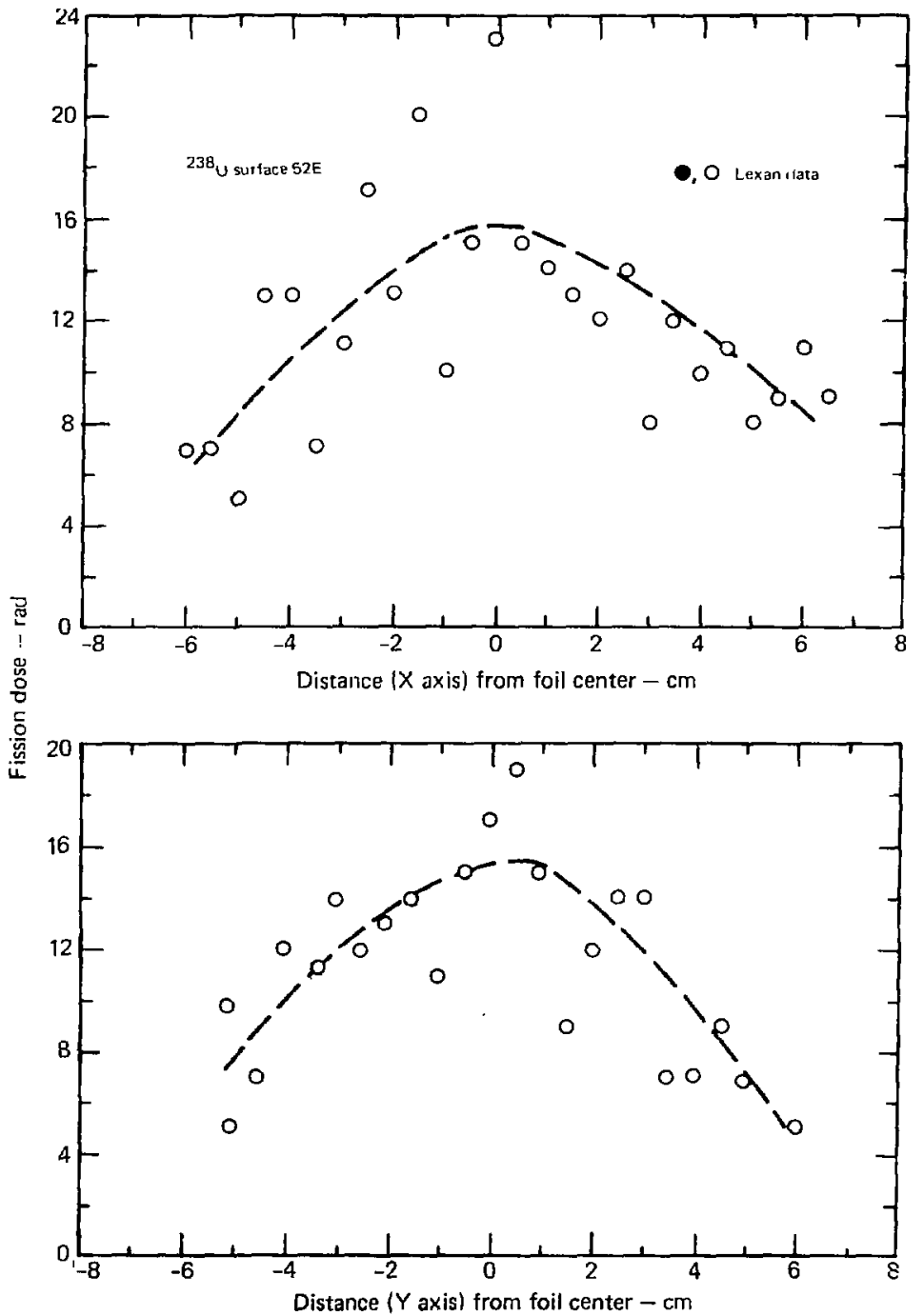

Note: Radiochemistry results are $\sim 30 \times$ higher than flision dose shown here.

Fig. E-14. 


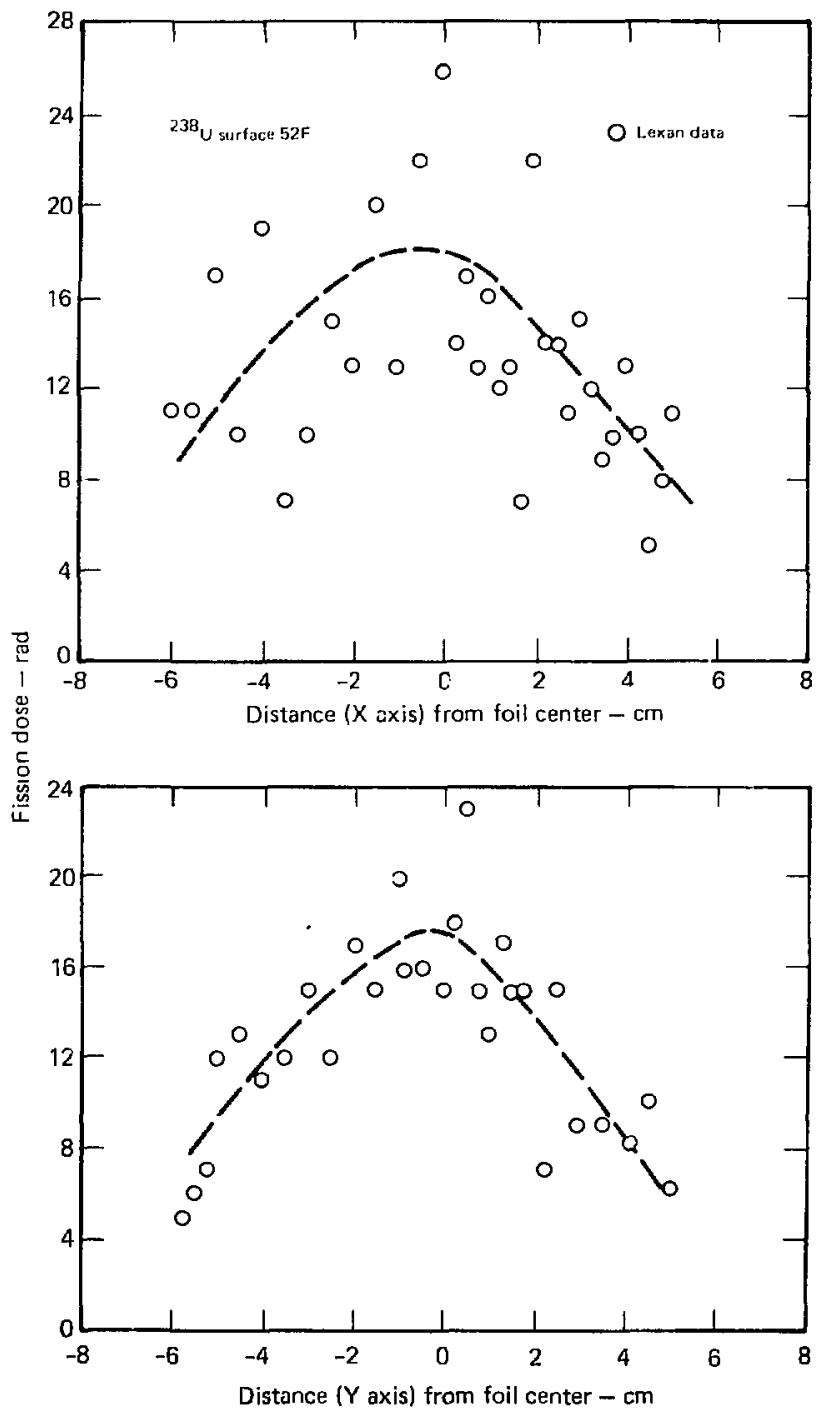

Note: Radiochemistry results are $\sim \mathbf{3 0} \times$ higher than fission dose shown here.

Fle, E-15. 

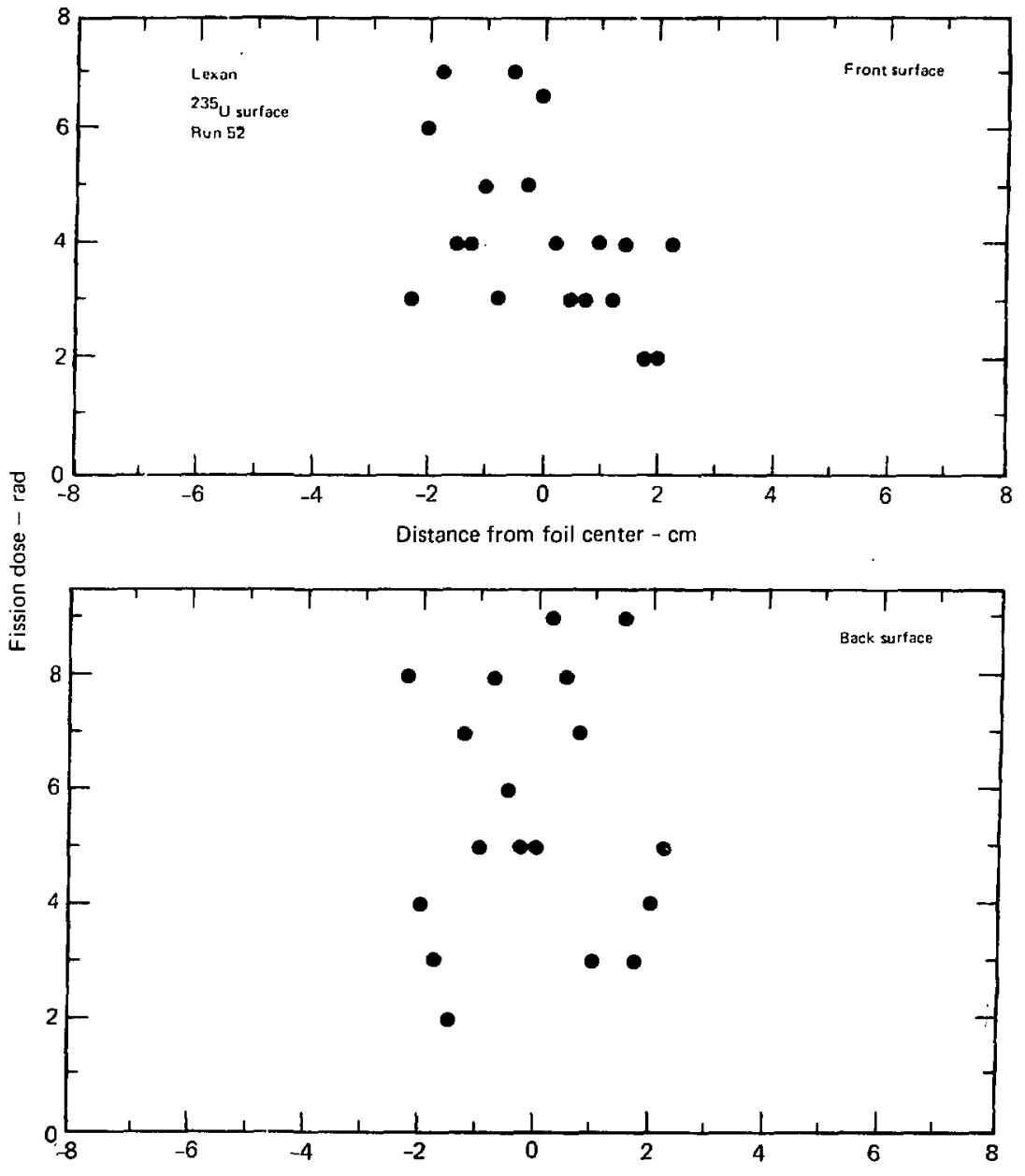

Distance from foil center - $\mathrm{cm}$

Note: Padiochemistry results of fission dose are one order of magnitude higher ( $\sim 30-80 \mathrm{rad})$. 


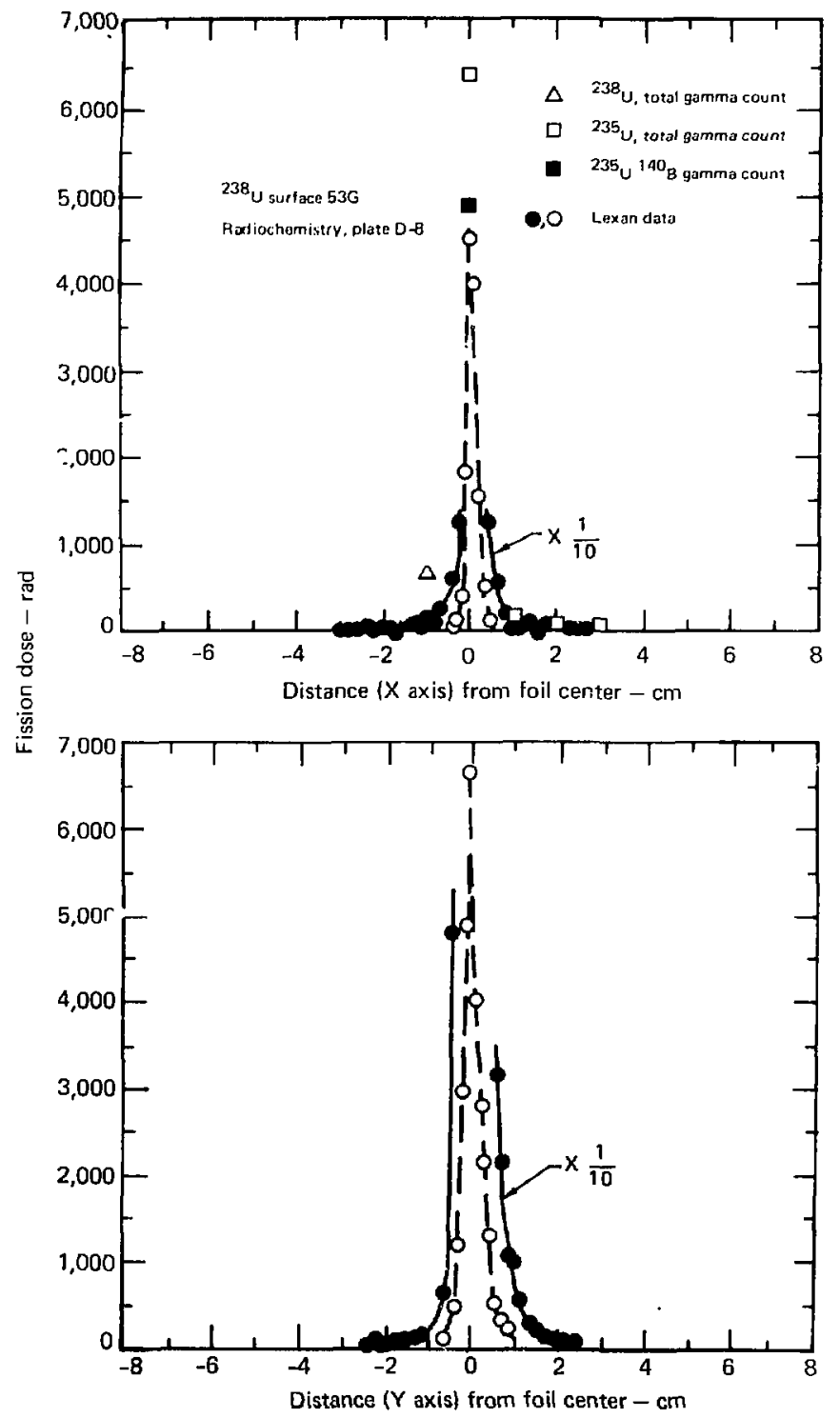

Fig. E-17. 


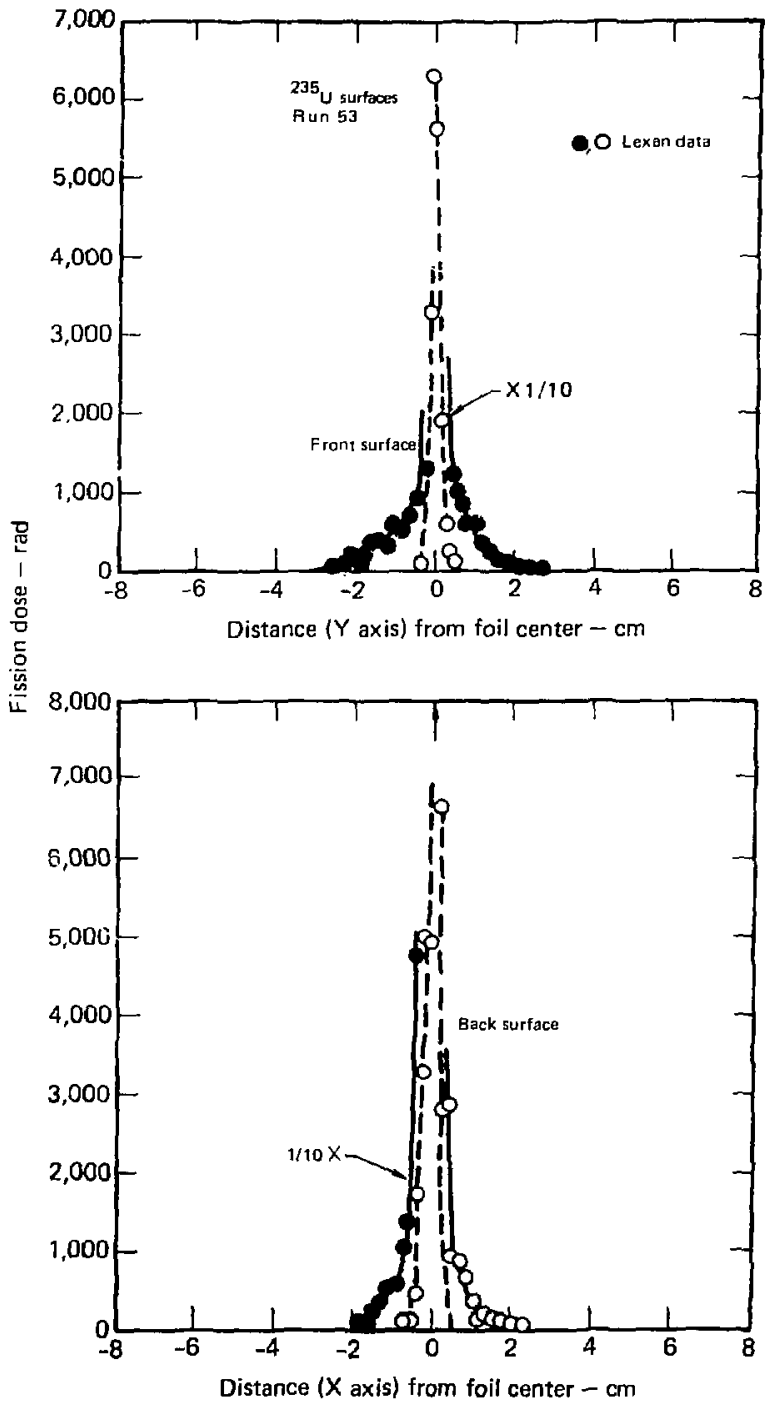

Fis. E-18. 


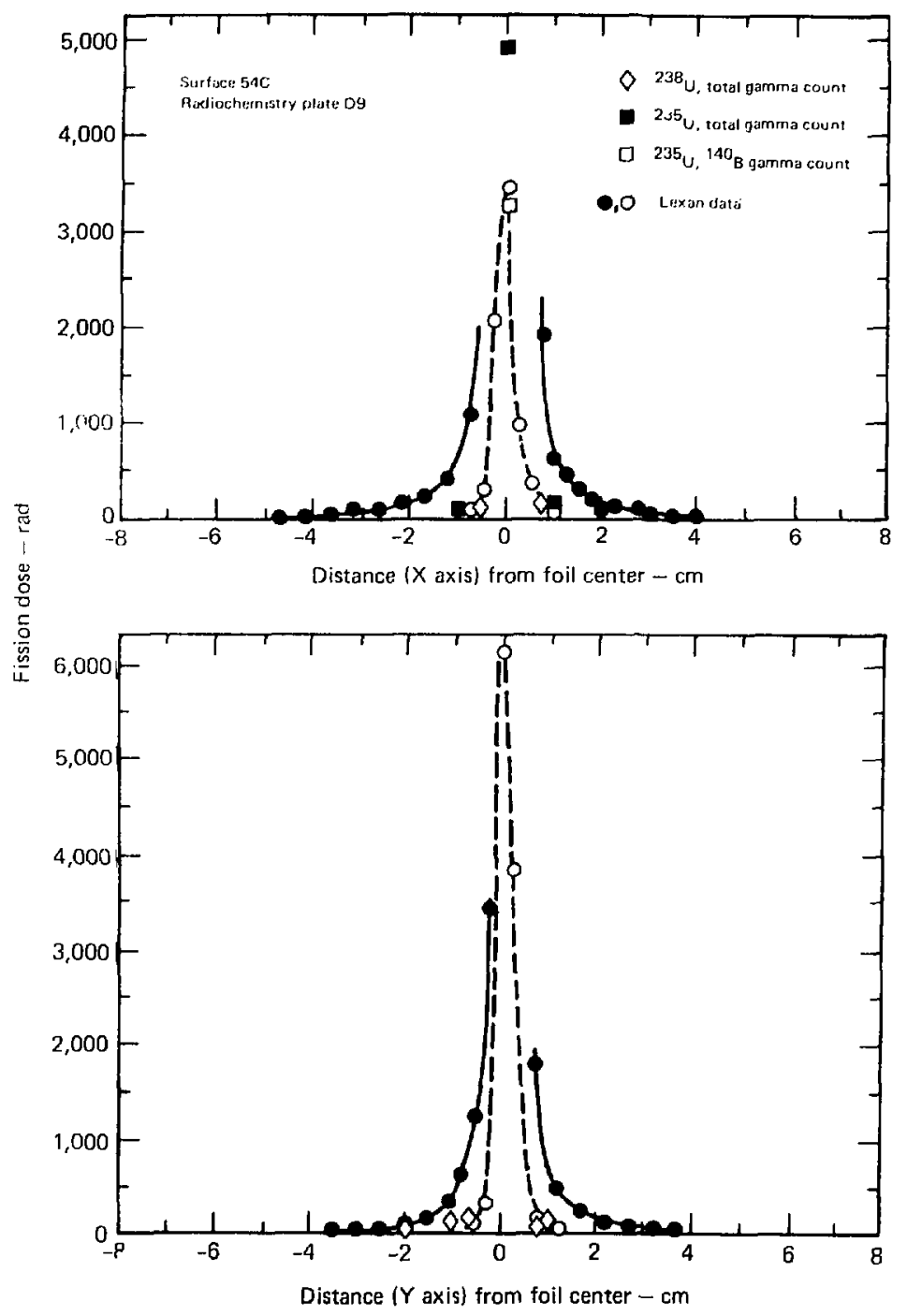

Fig. E. 19 . 


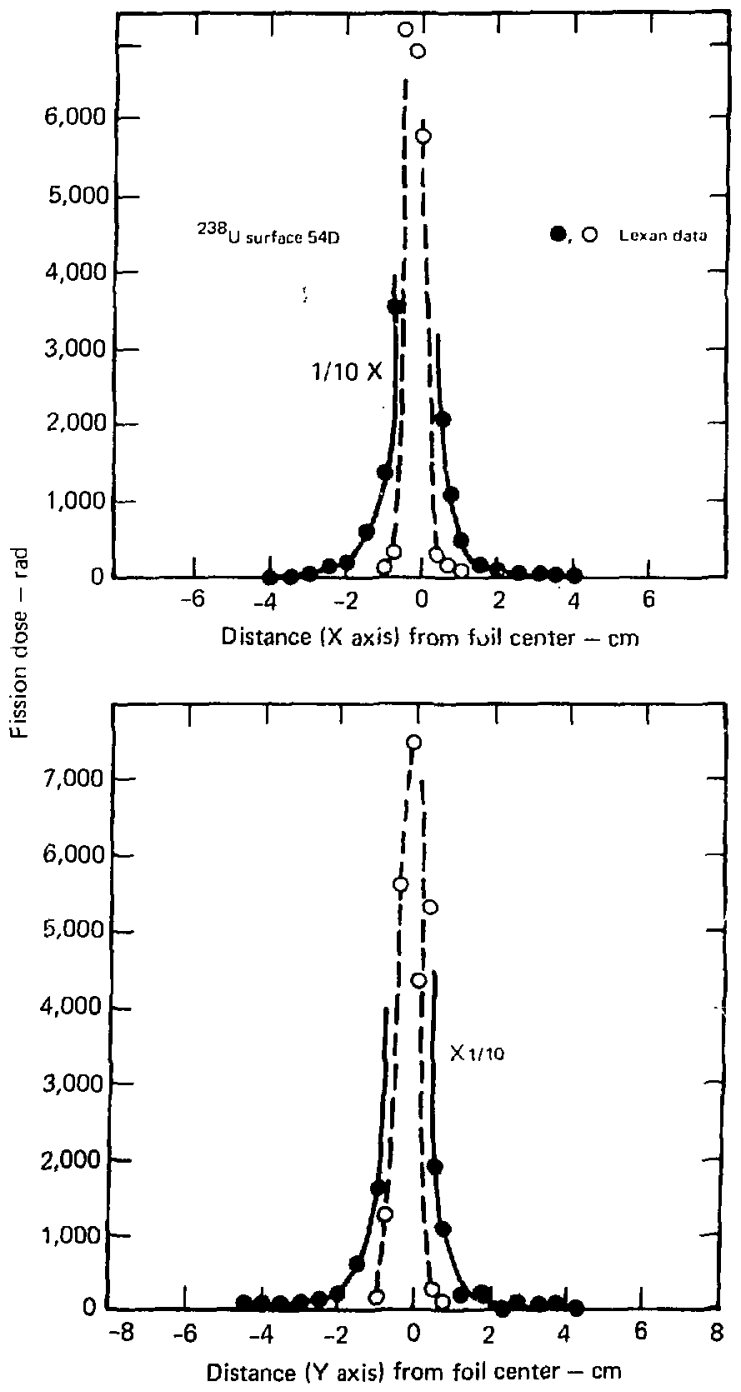

Fig. E-20. 


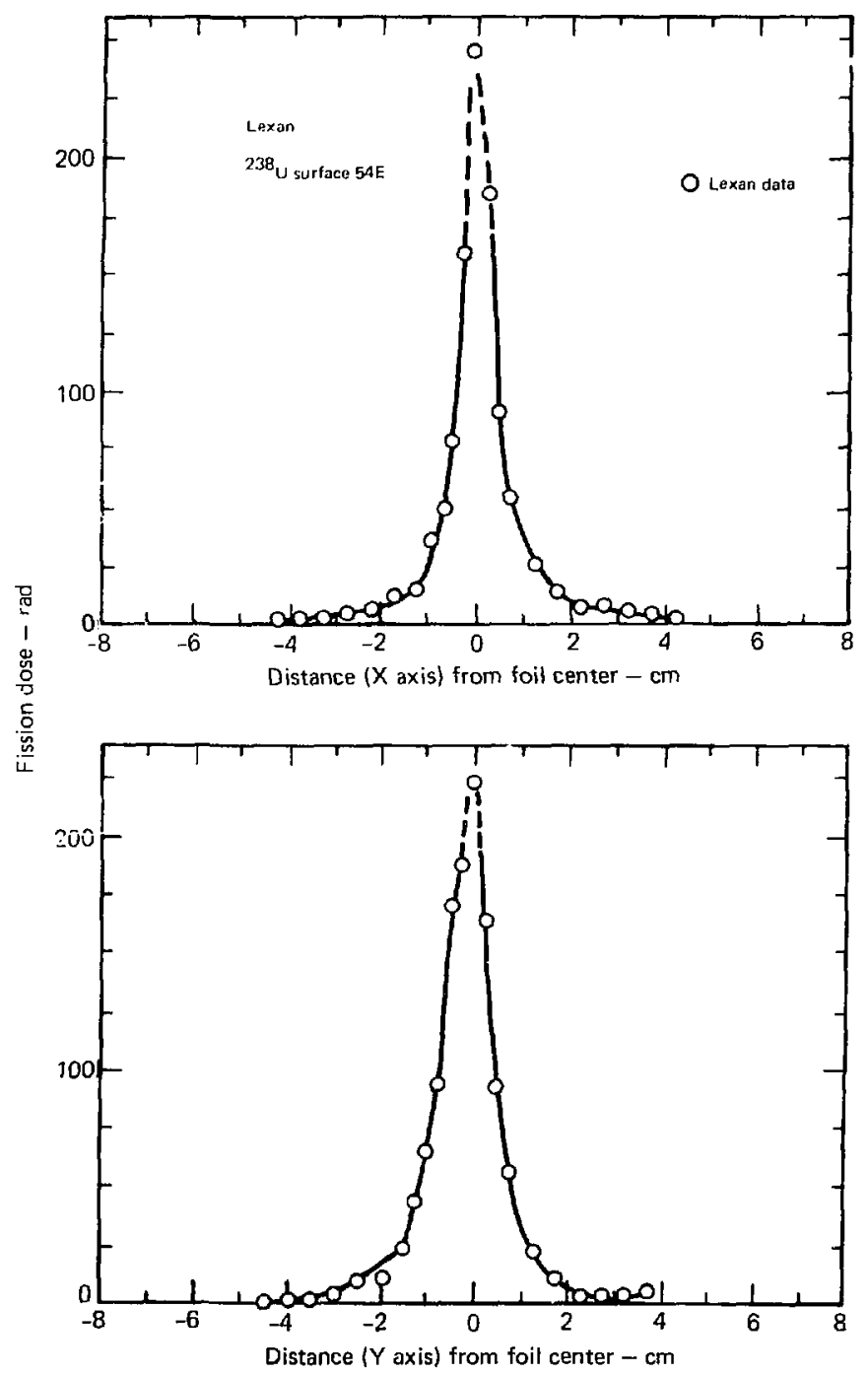

Fig. E-21. 


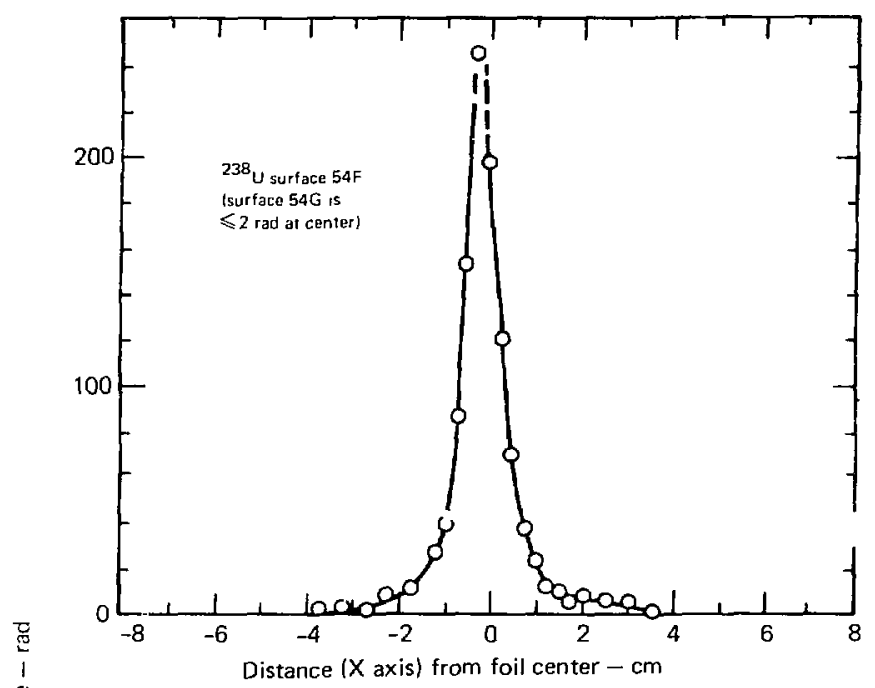

0
0
0
0
$\frac{0}{0}$
$\frac{5}{4}$
$\square$

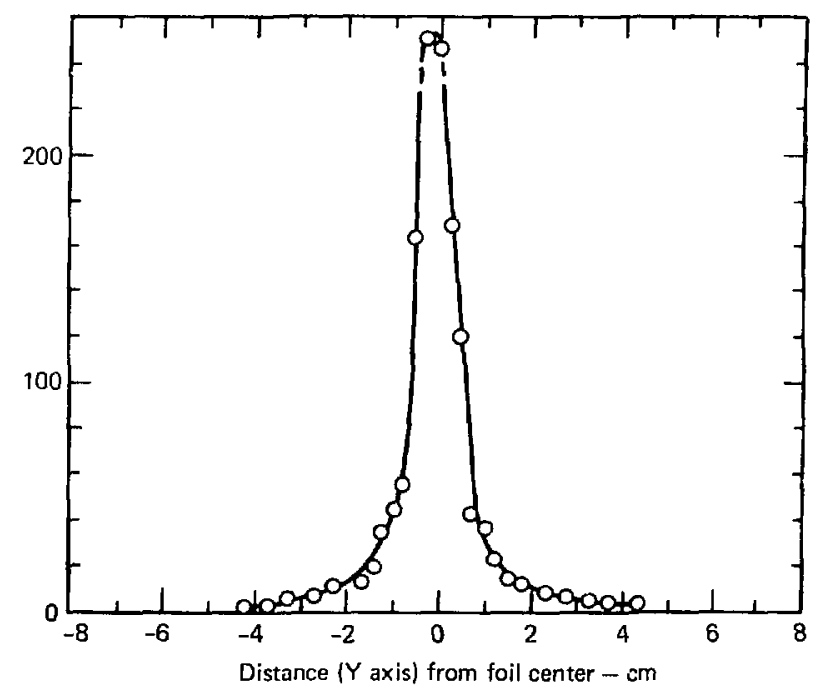

Fig. E-22. 


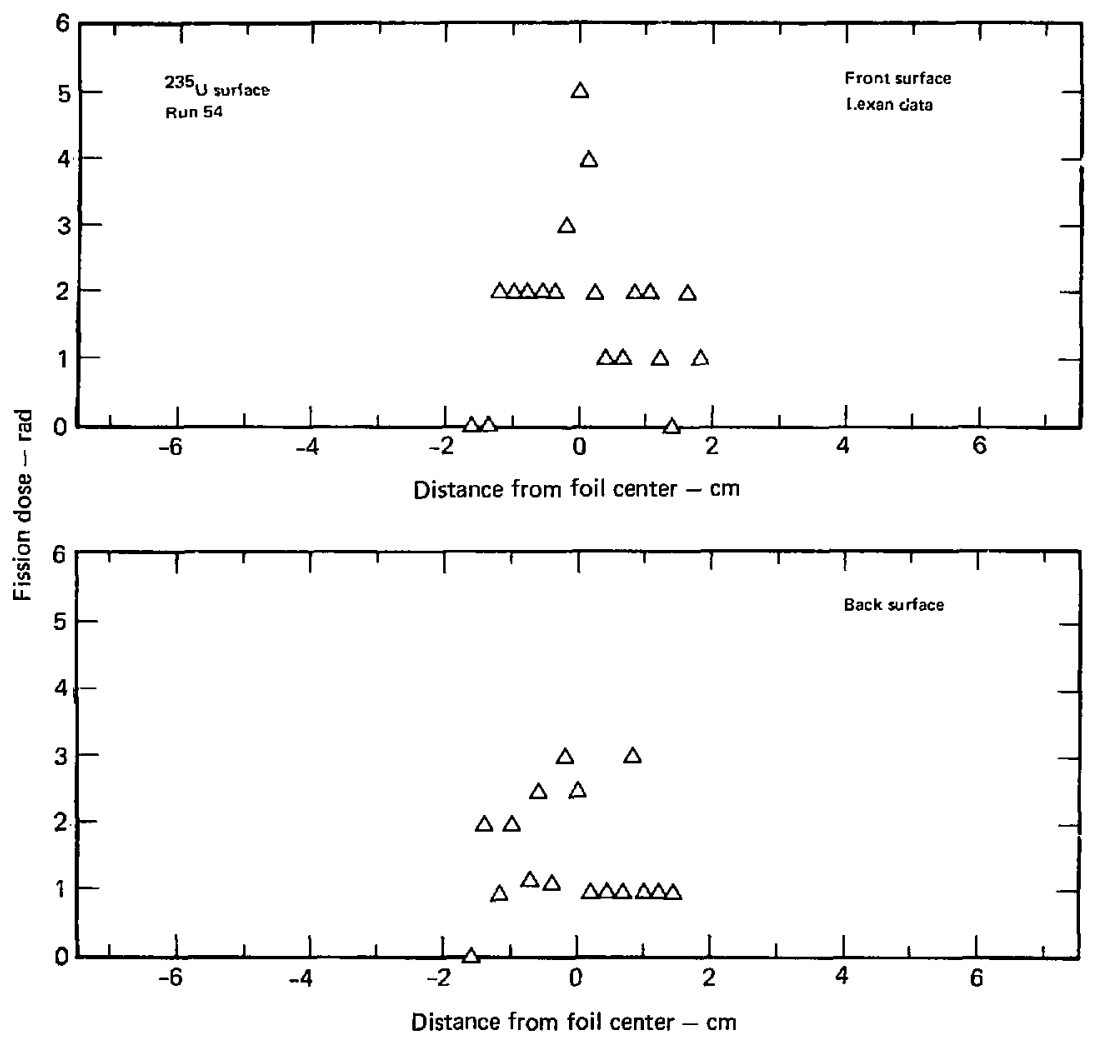

Fig. E-23. 


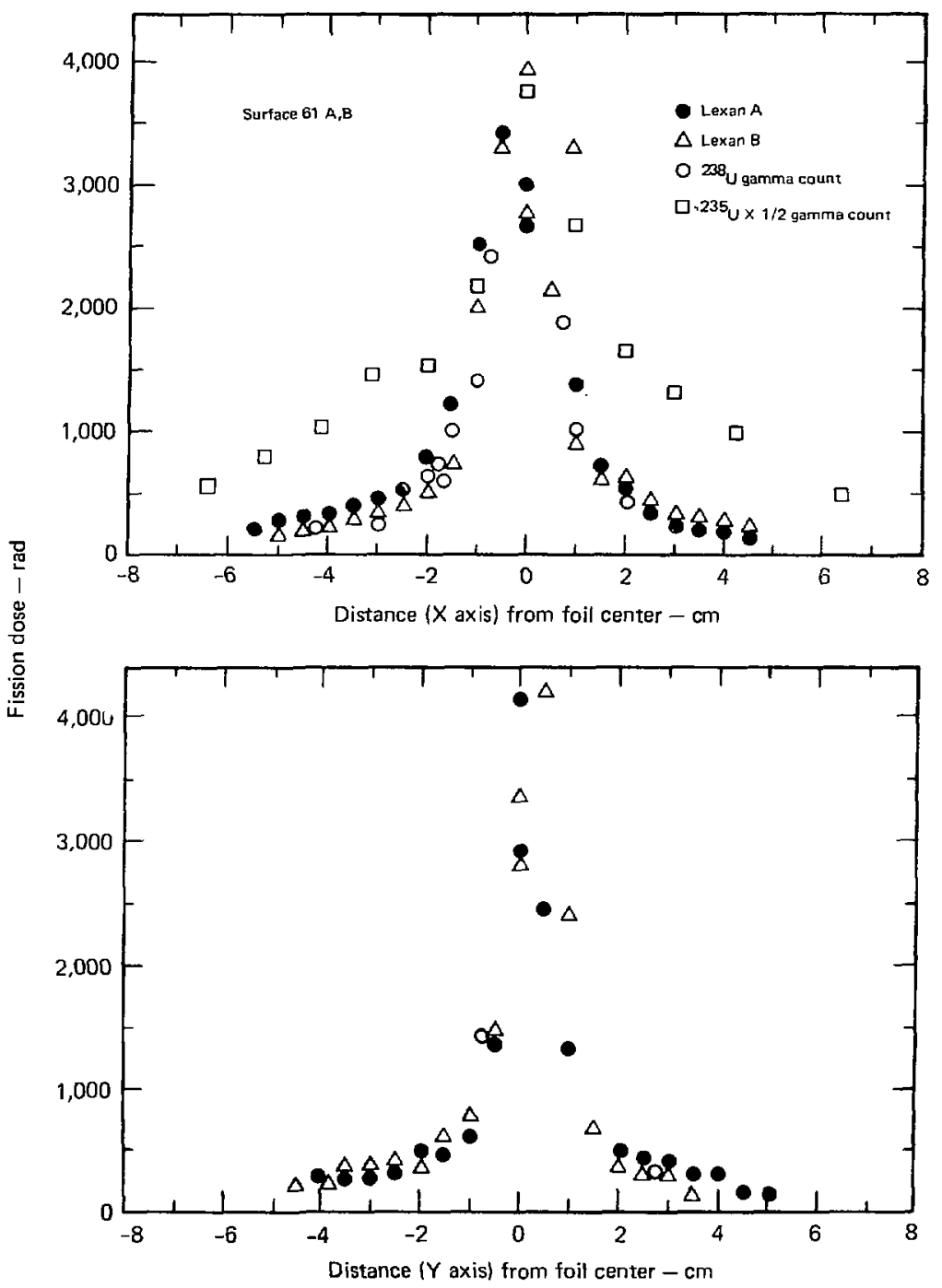

Fig. E-24. 


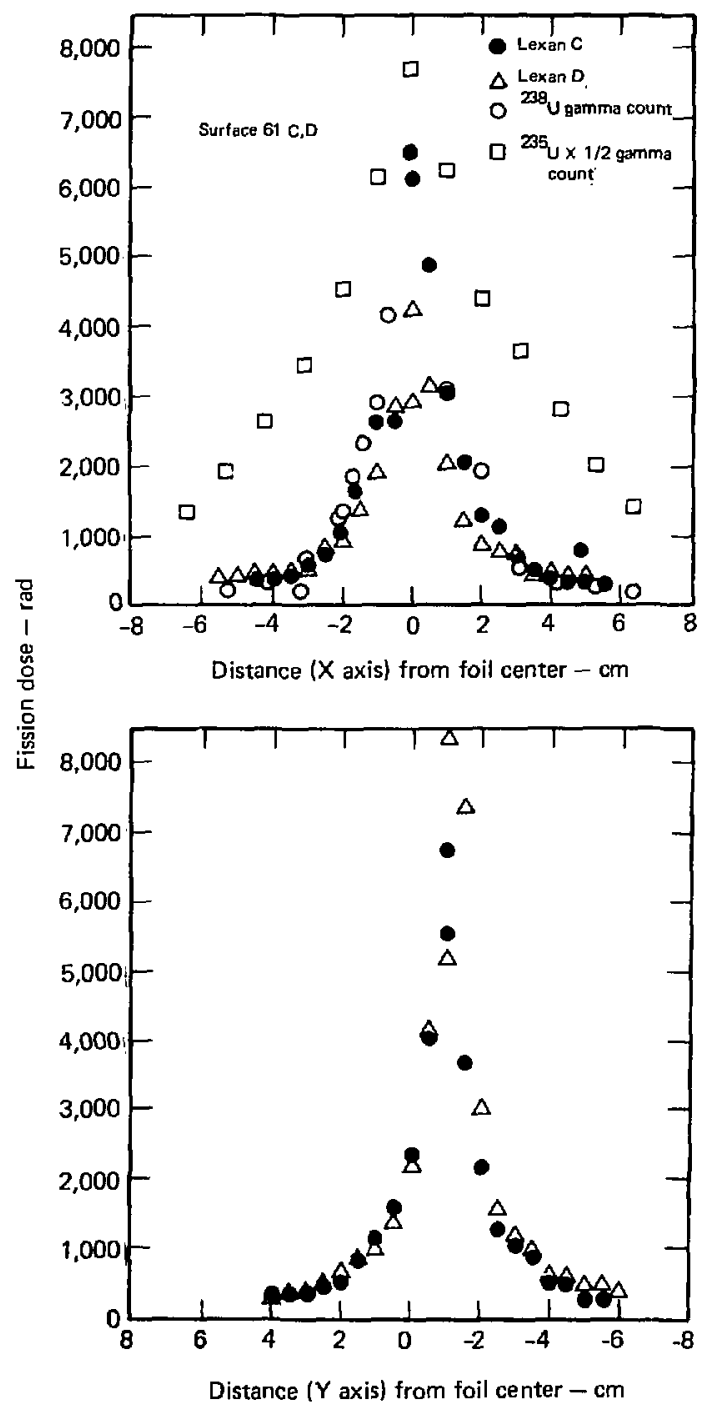

Fig. E-25. 


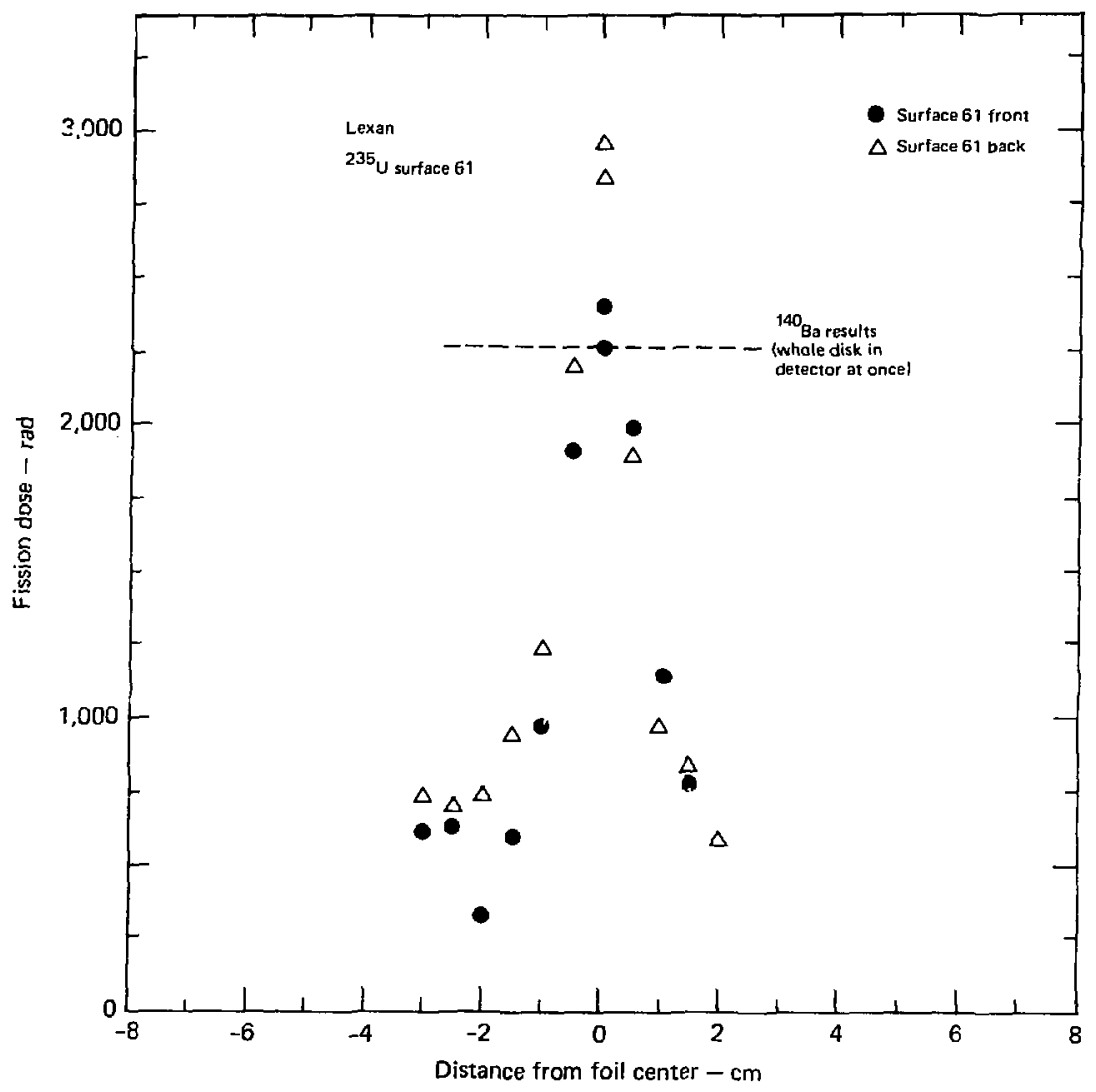

Fig. E-26. 

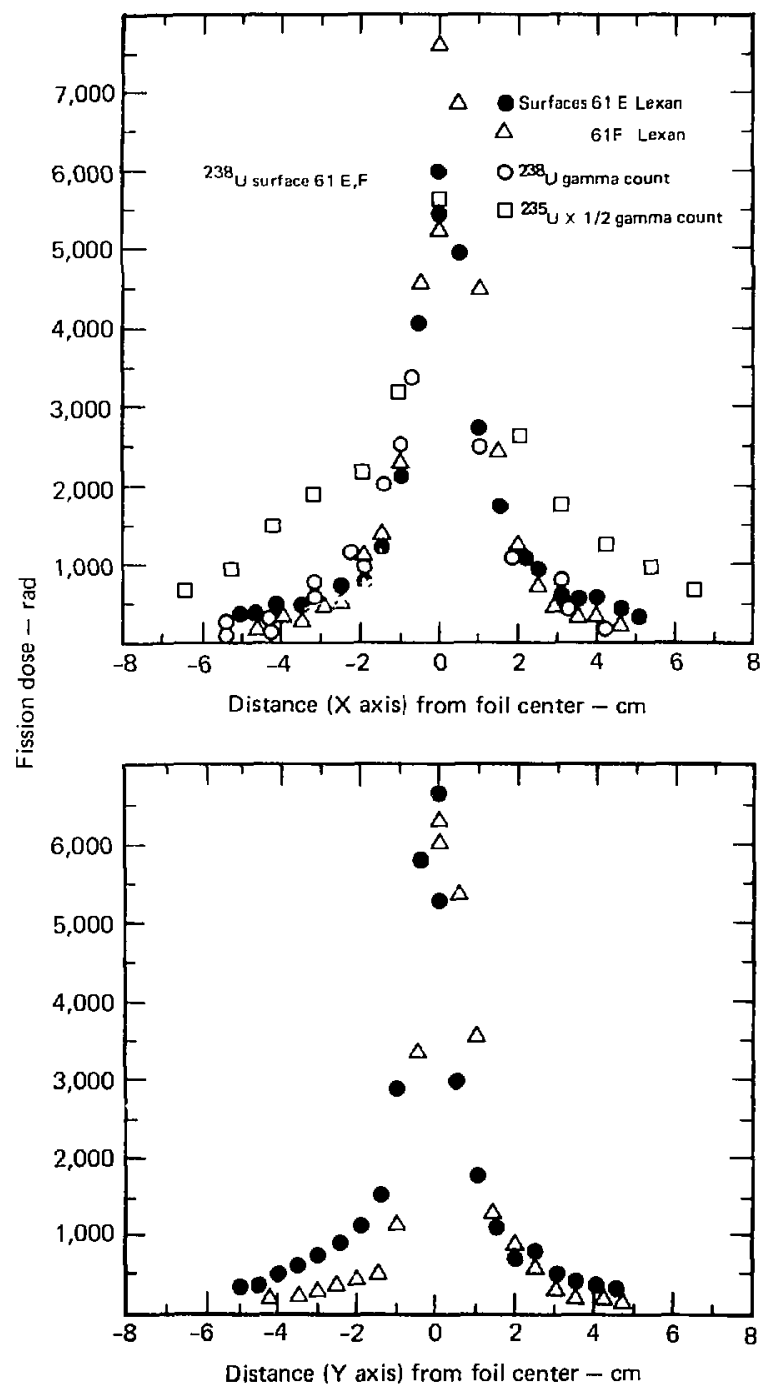

Fig. E-27. 


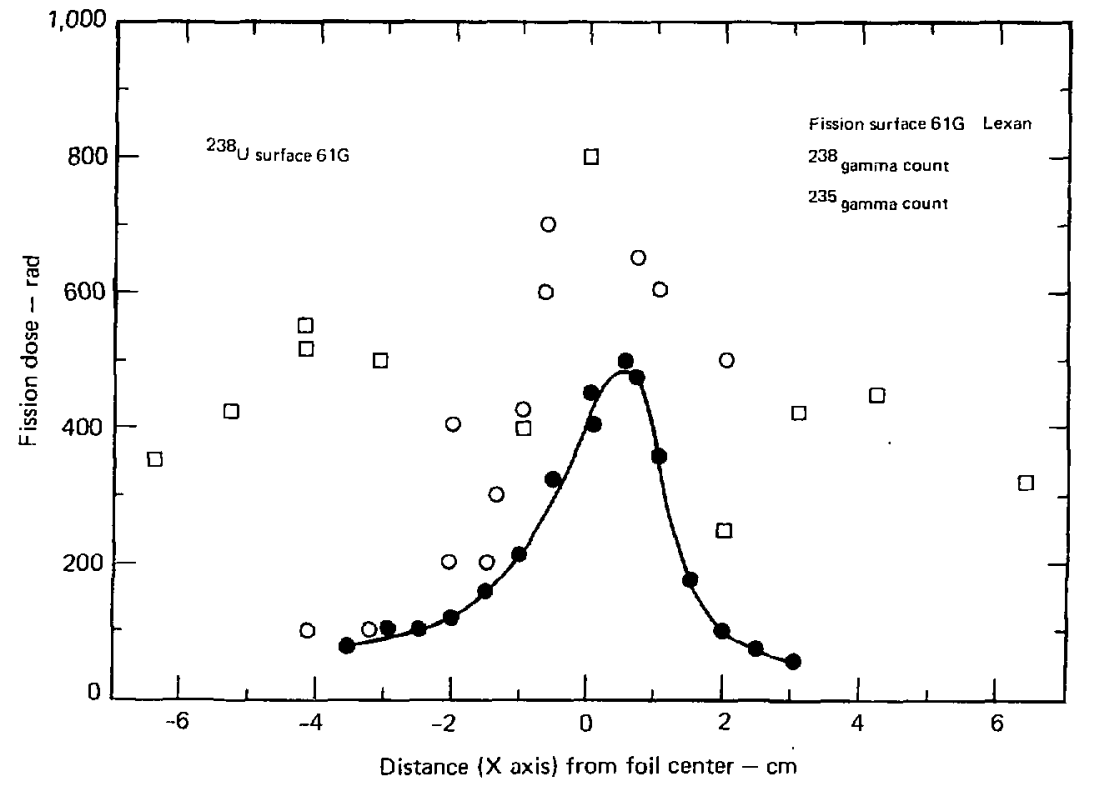

Fig. E-28. 


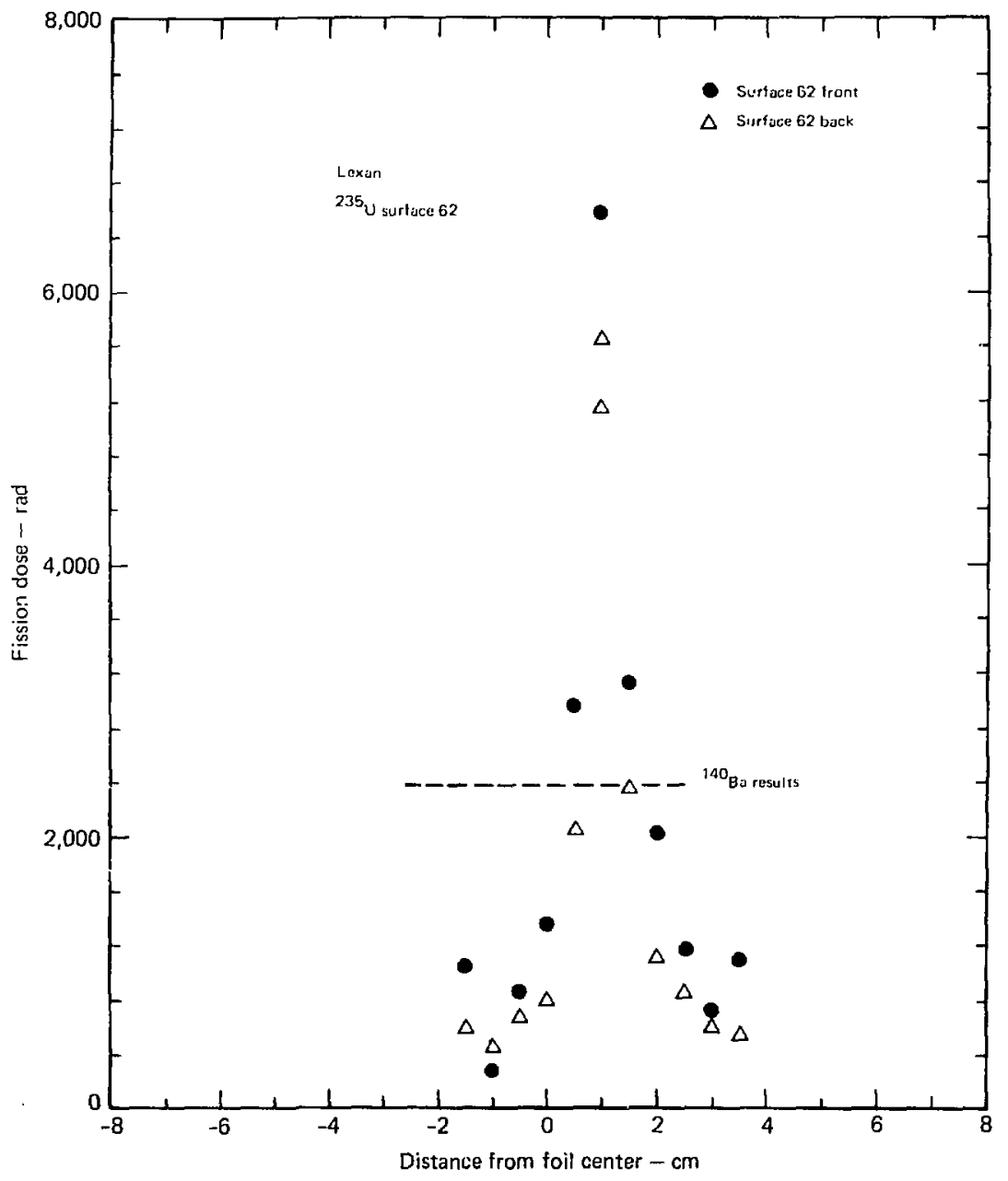

Fig. E-29. 

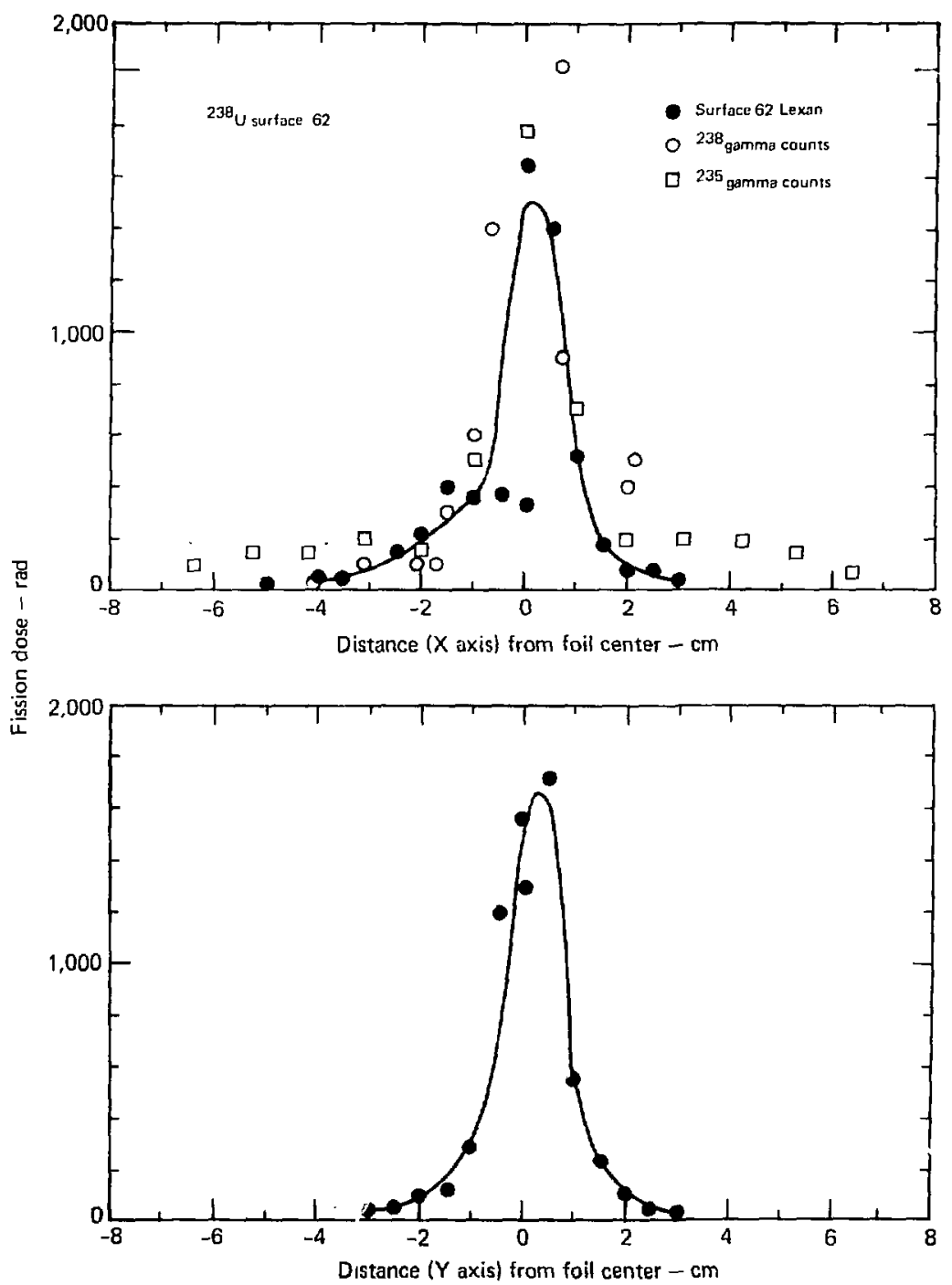

Fig, E-30. 

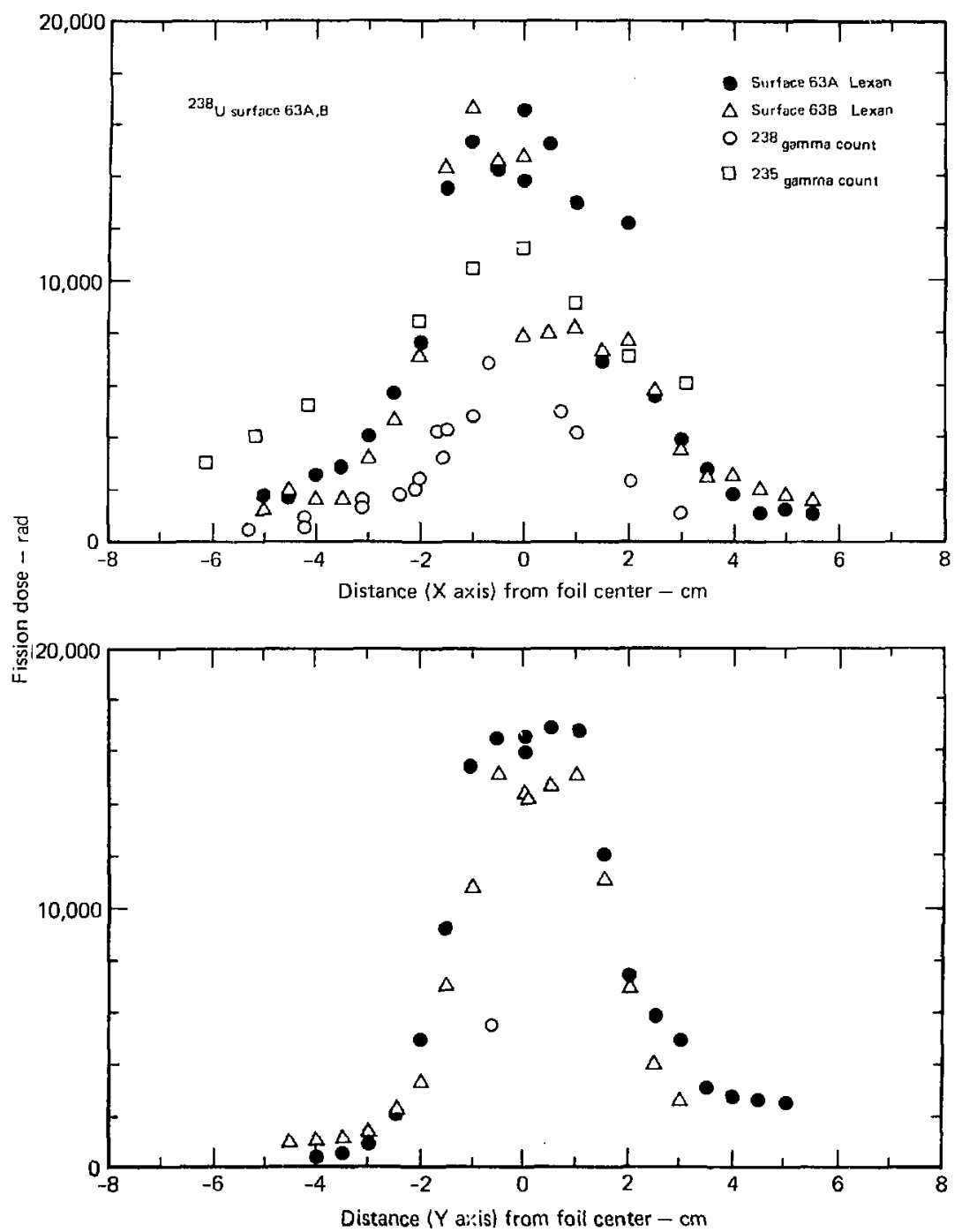

Fig, E-31. 


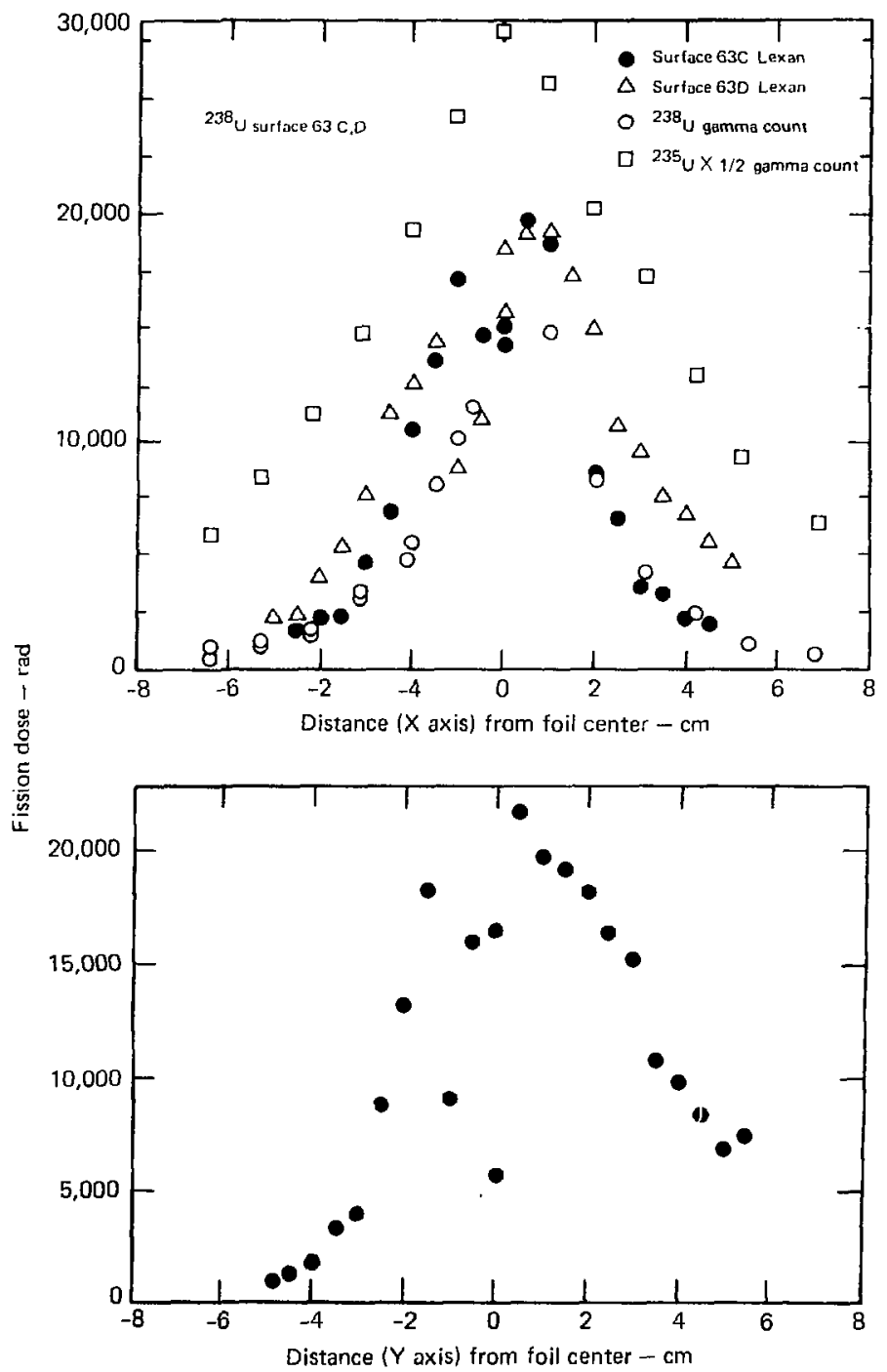

Fig. b.-.32. 


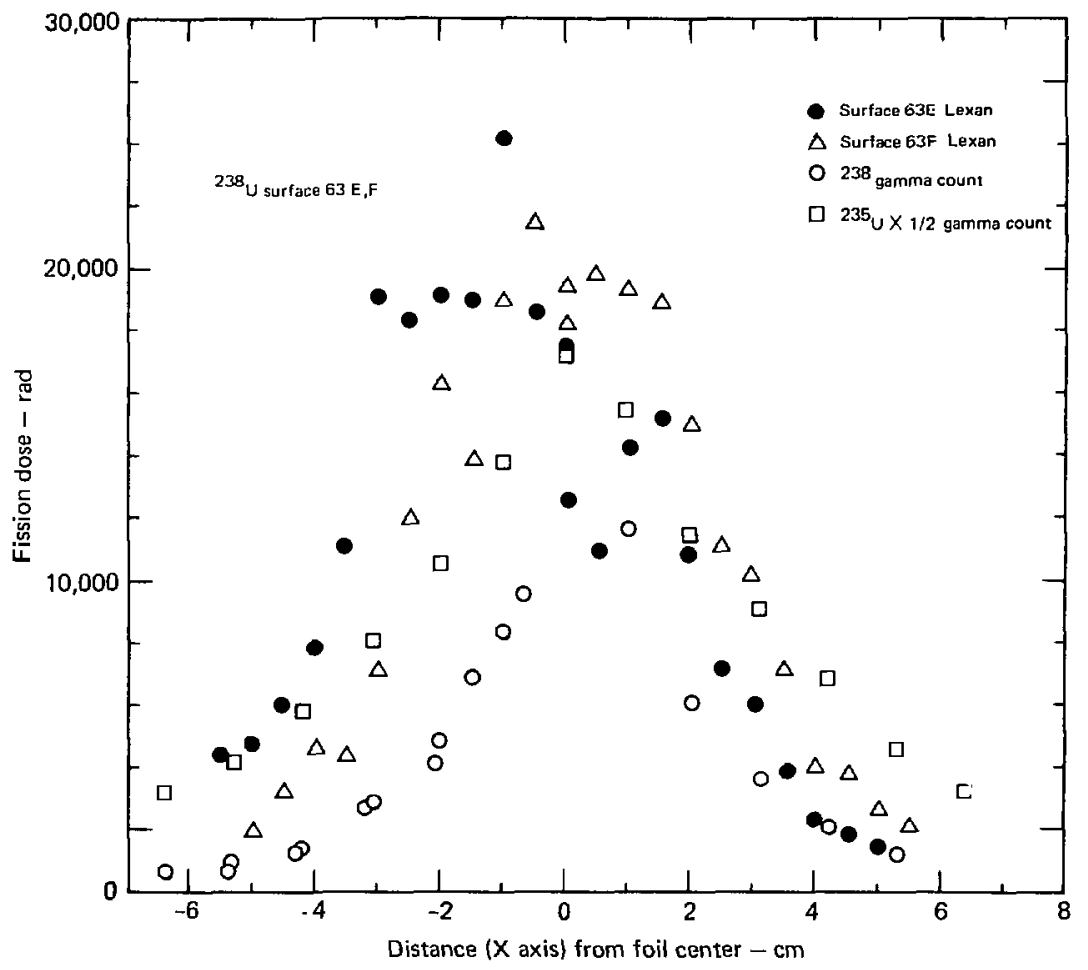

Fis. E-33. 


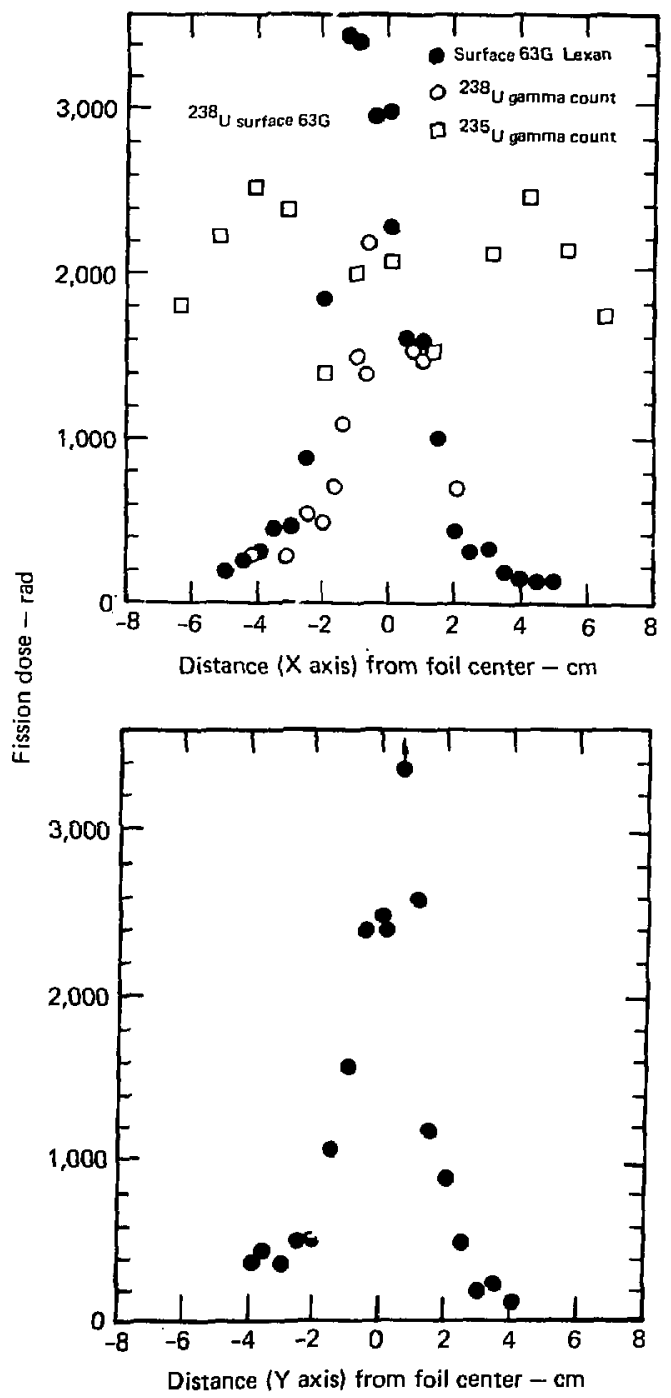

Fig. E.34. 


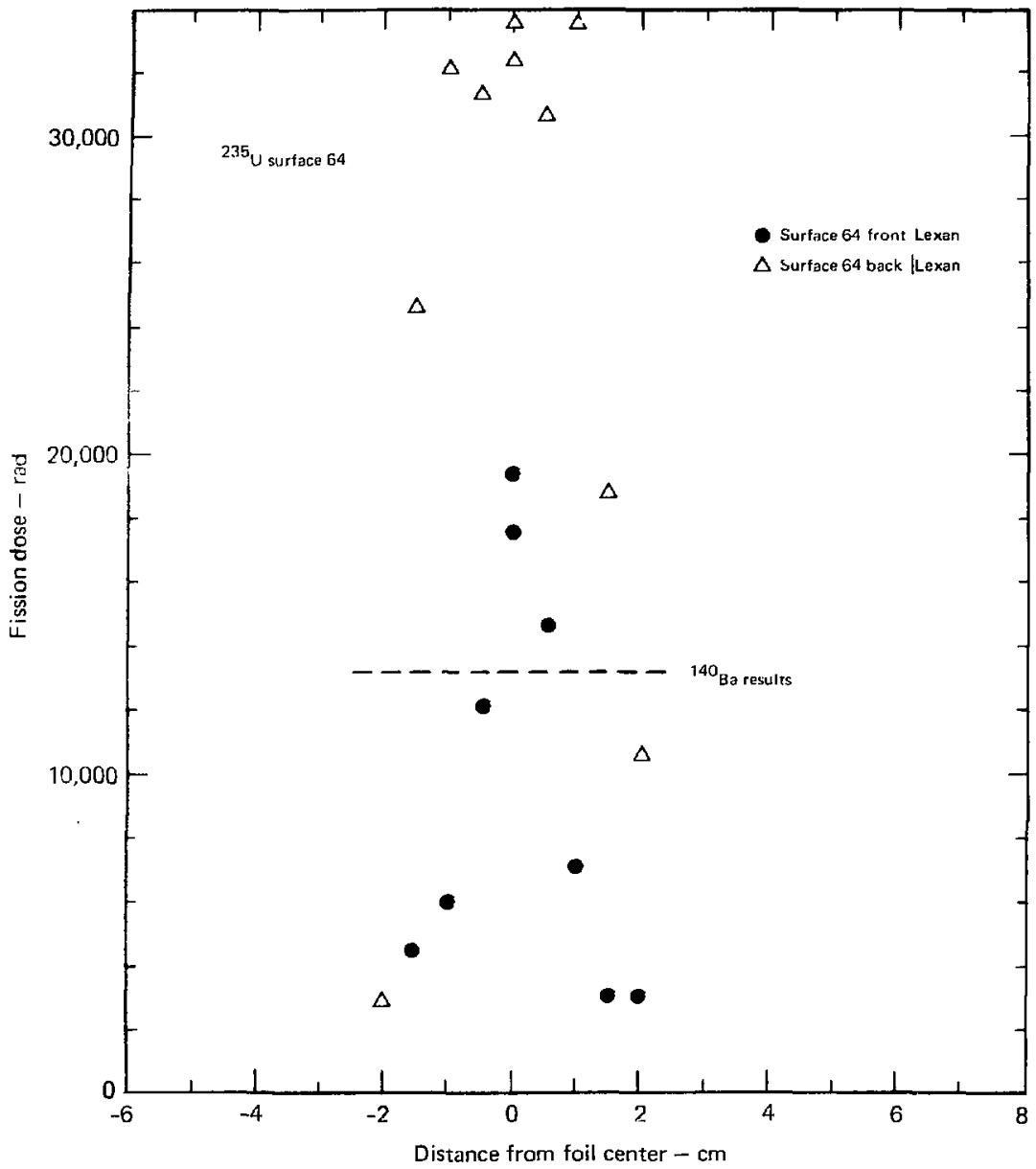

Fig. E-35. 


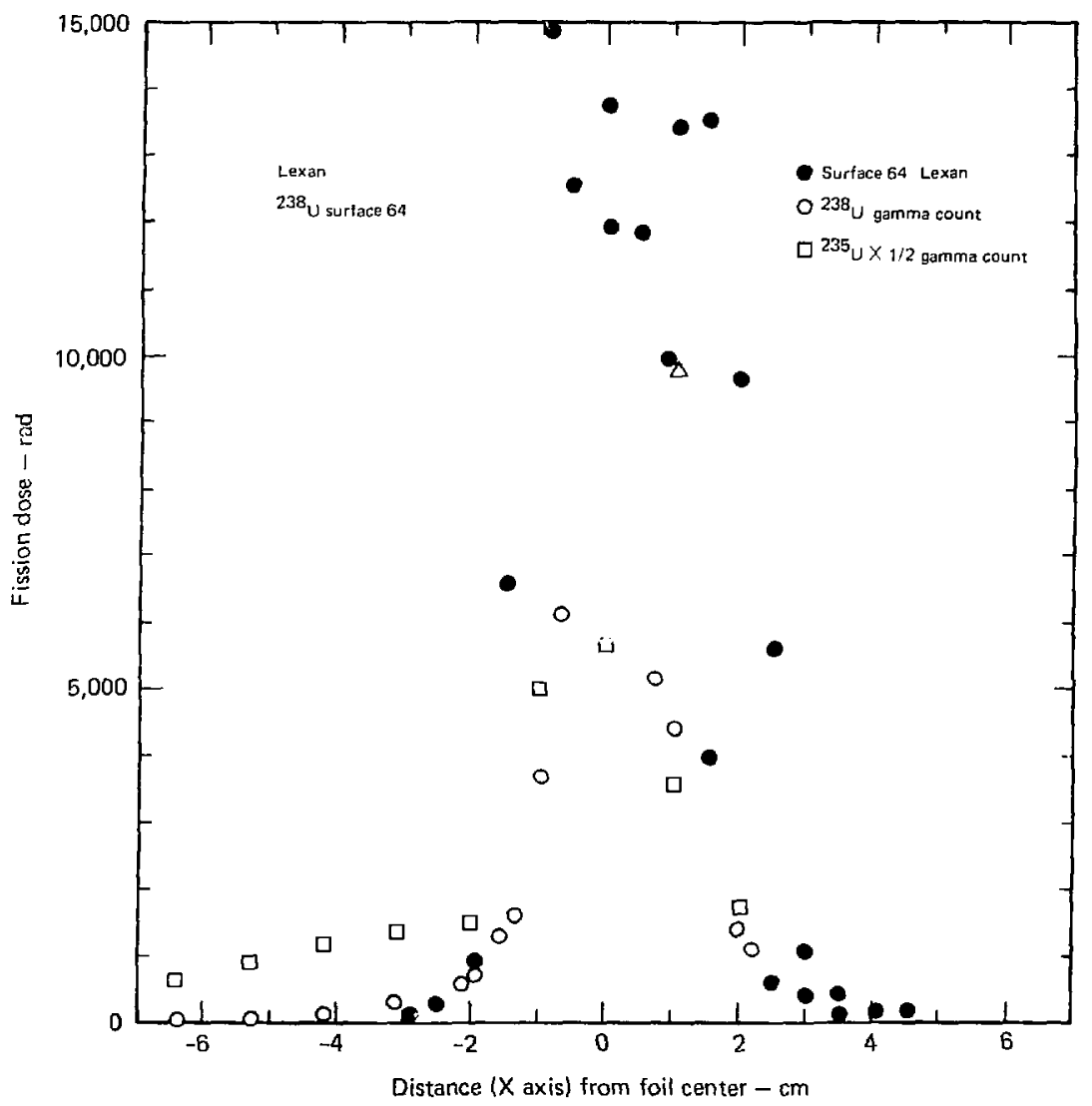

Fig. E-36. 


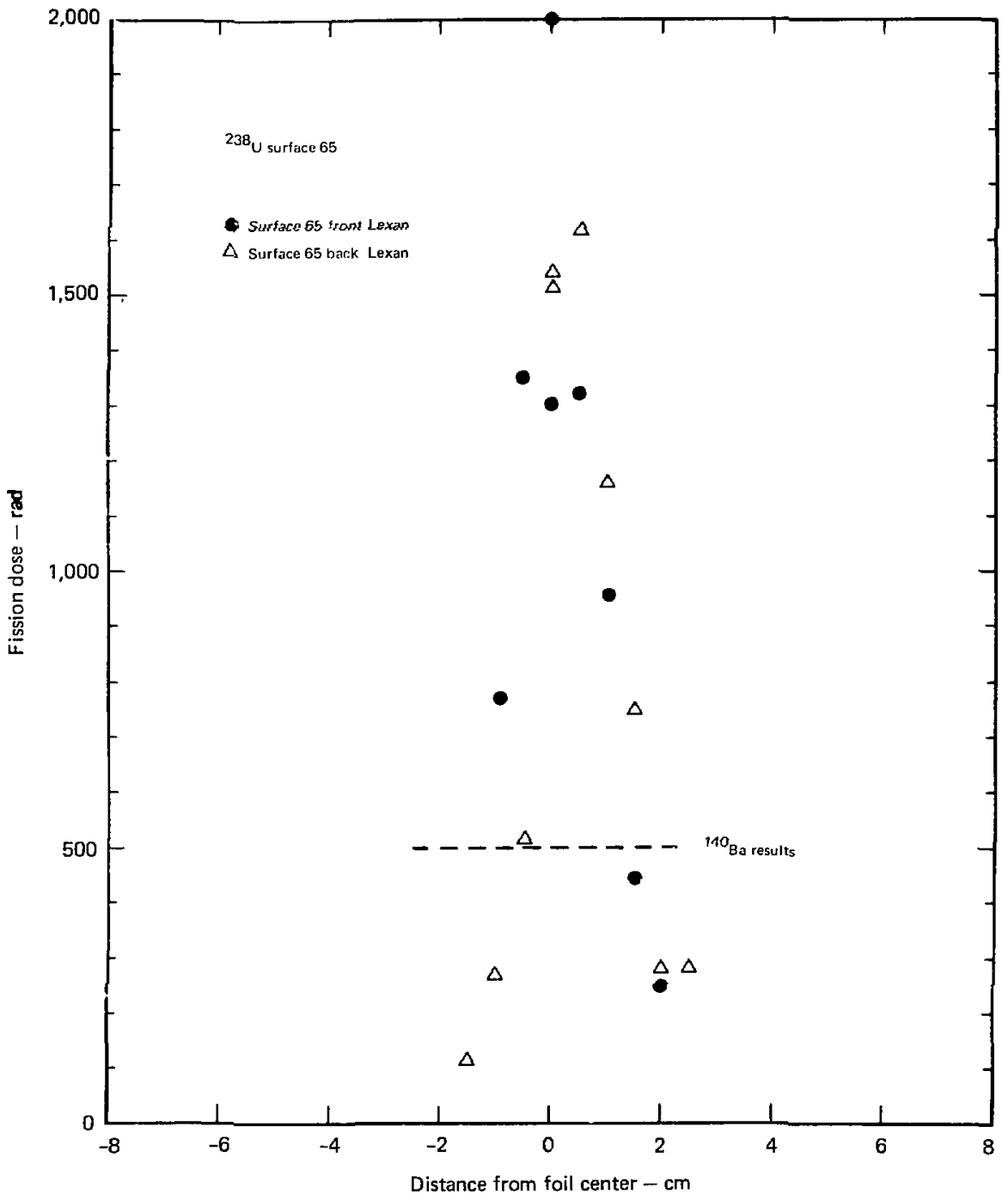

Fig. E-37. 


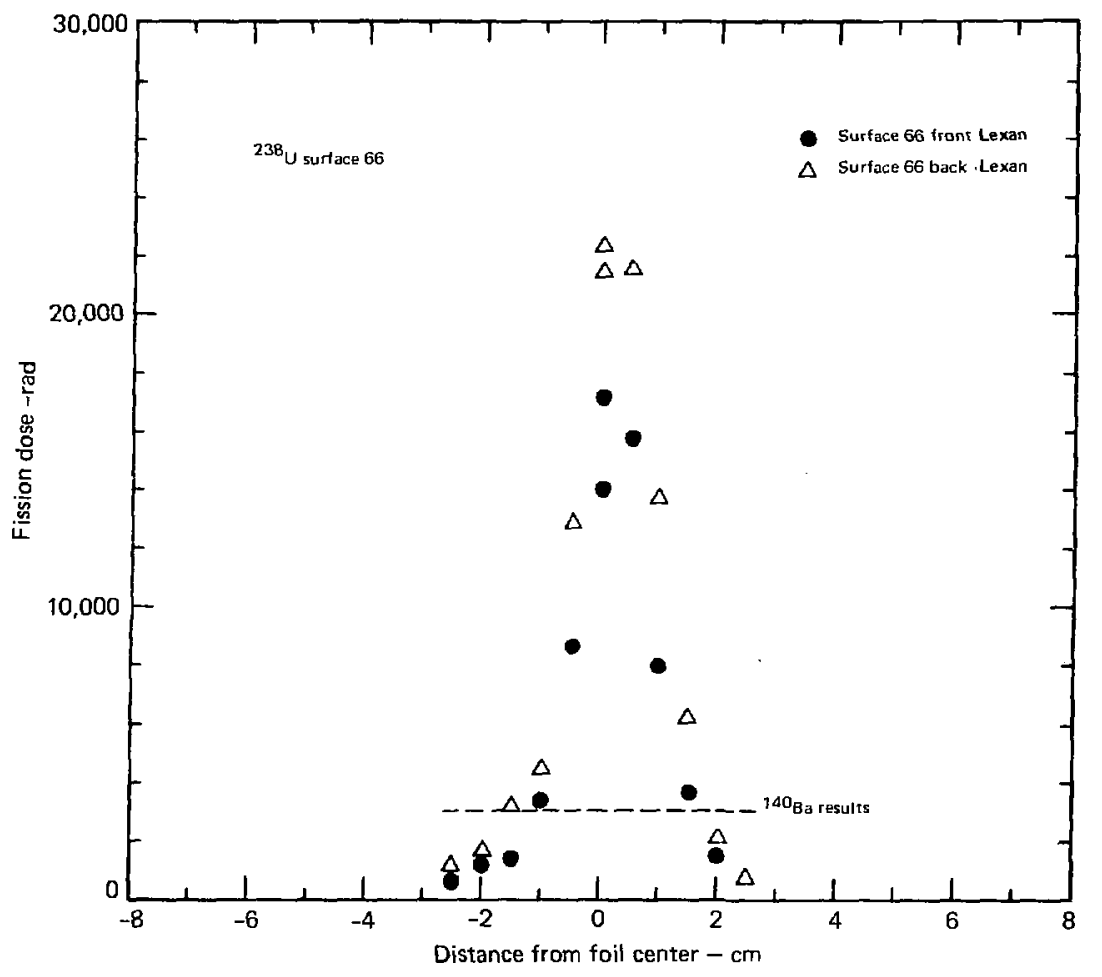

Fig. E-38, 


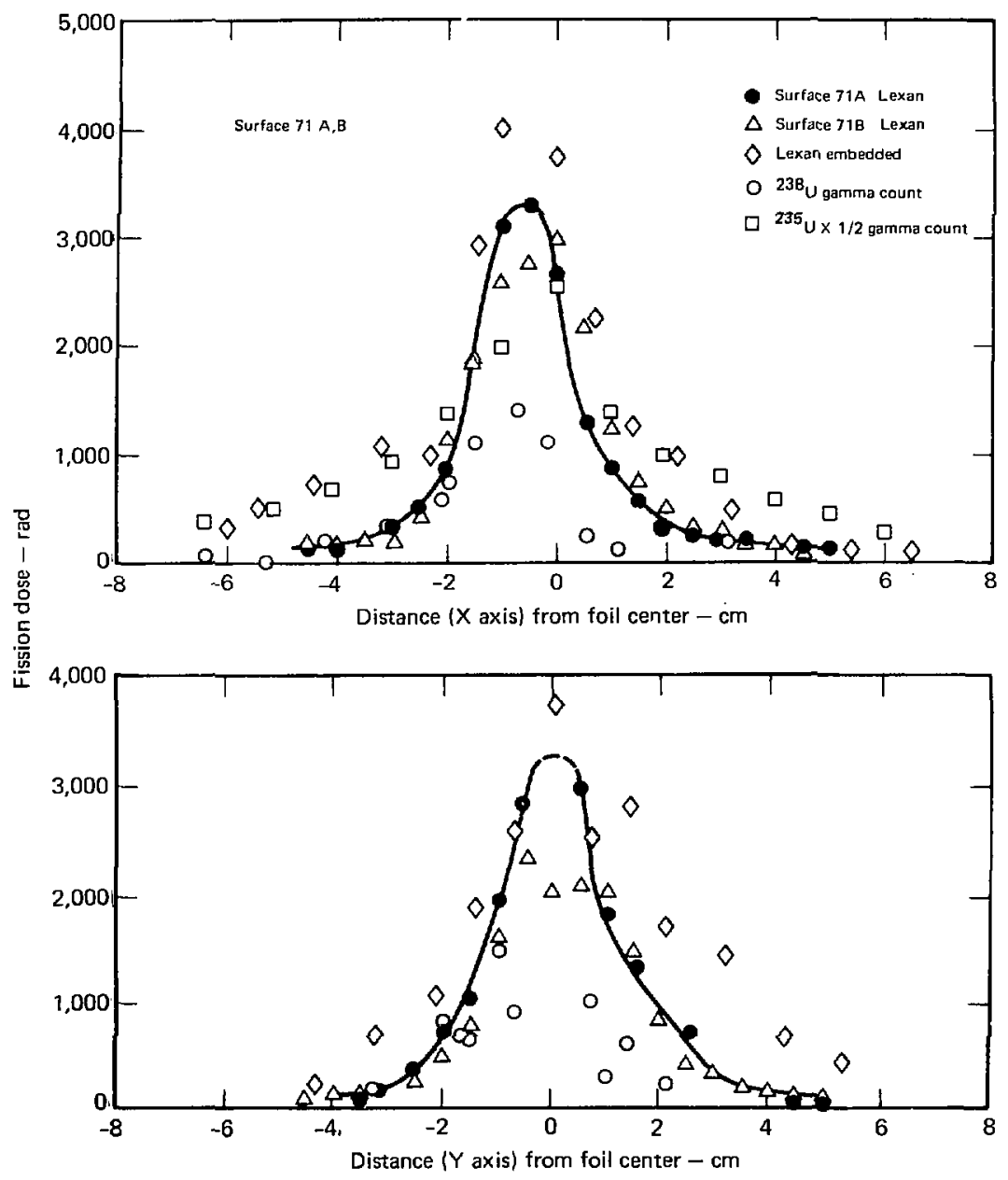

Fig. E-39. 


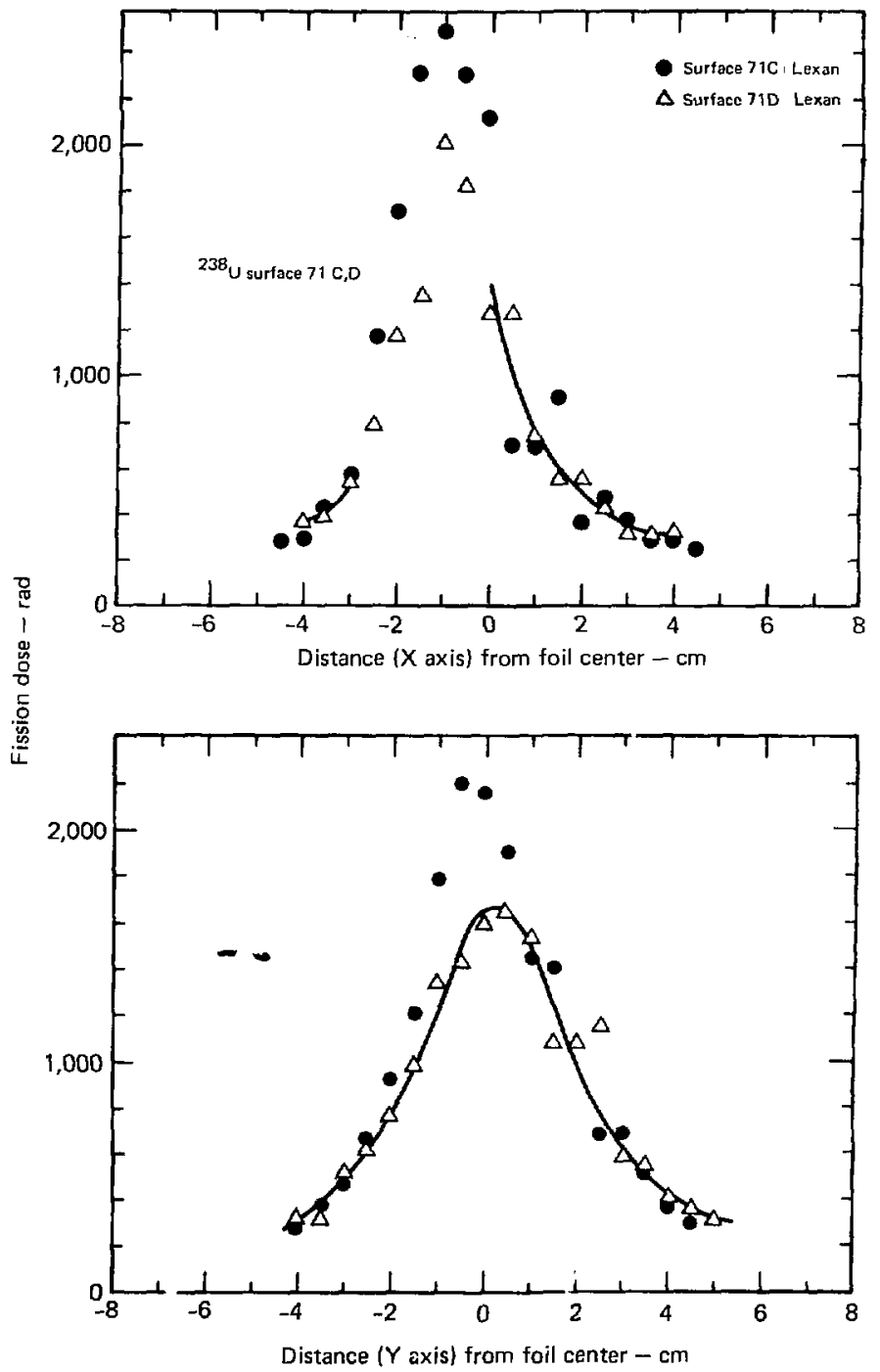

Fig. E-40, 

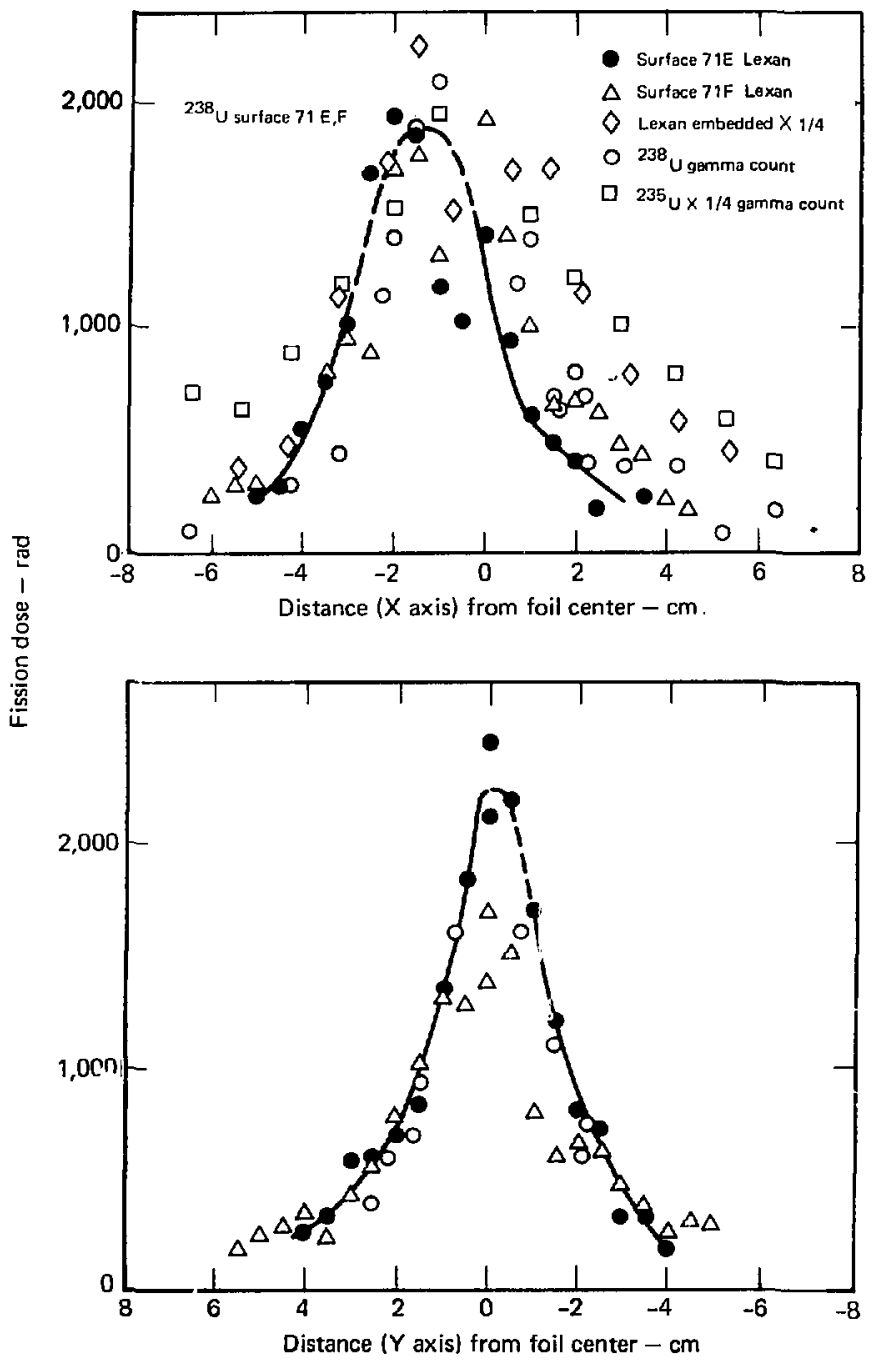

Fis. E-41. 


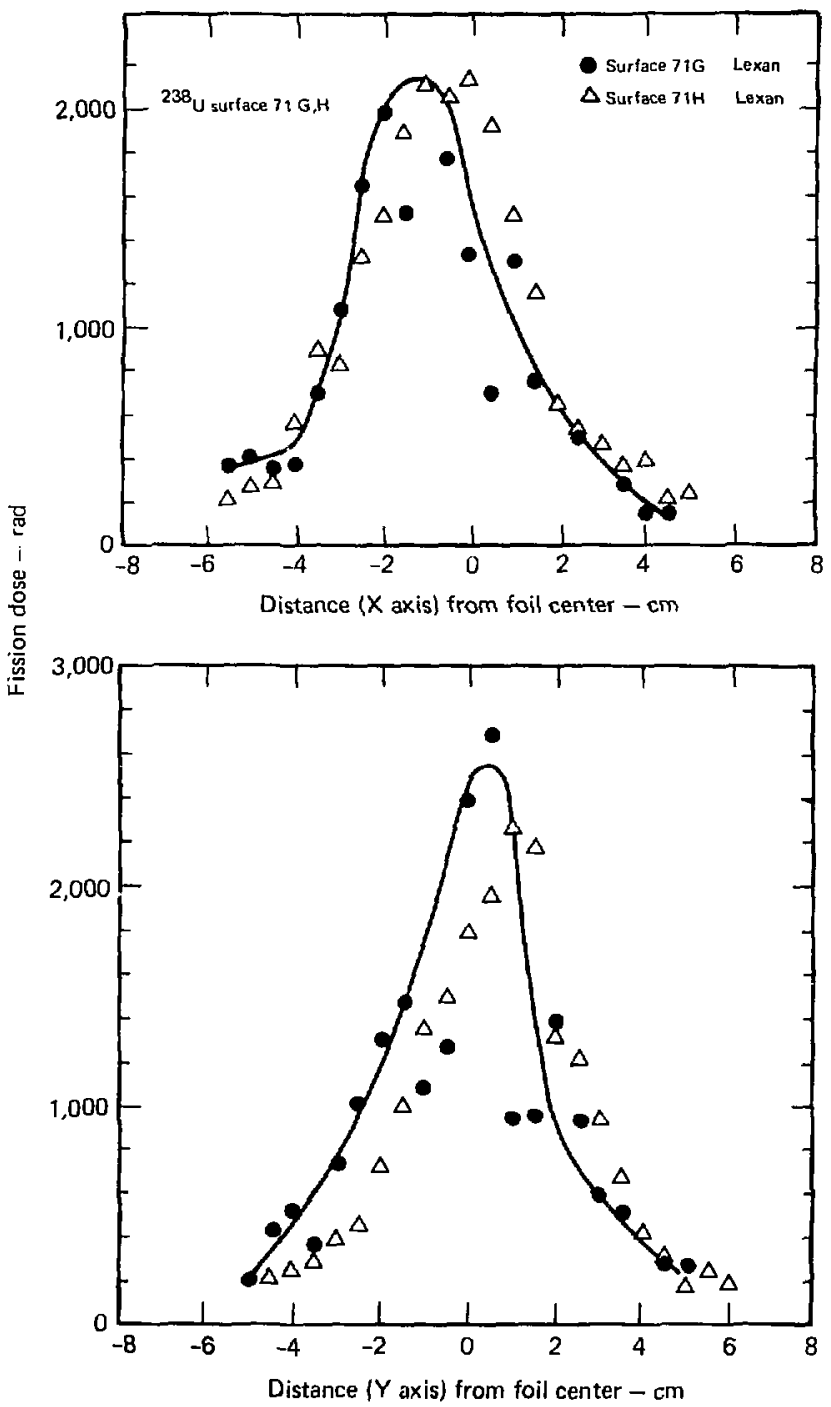

Fic. E-42. 


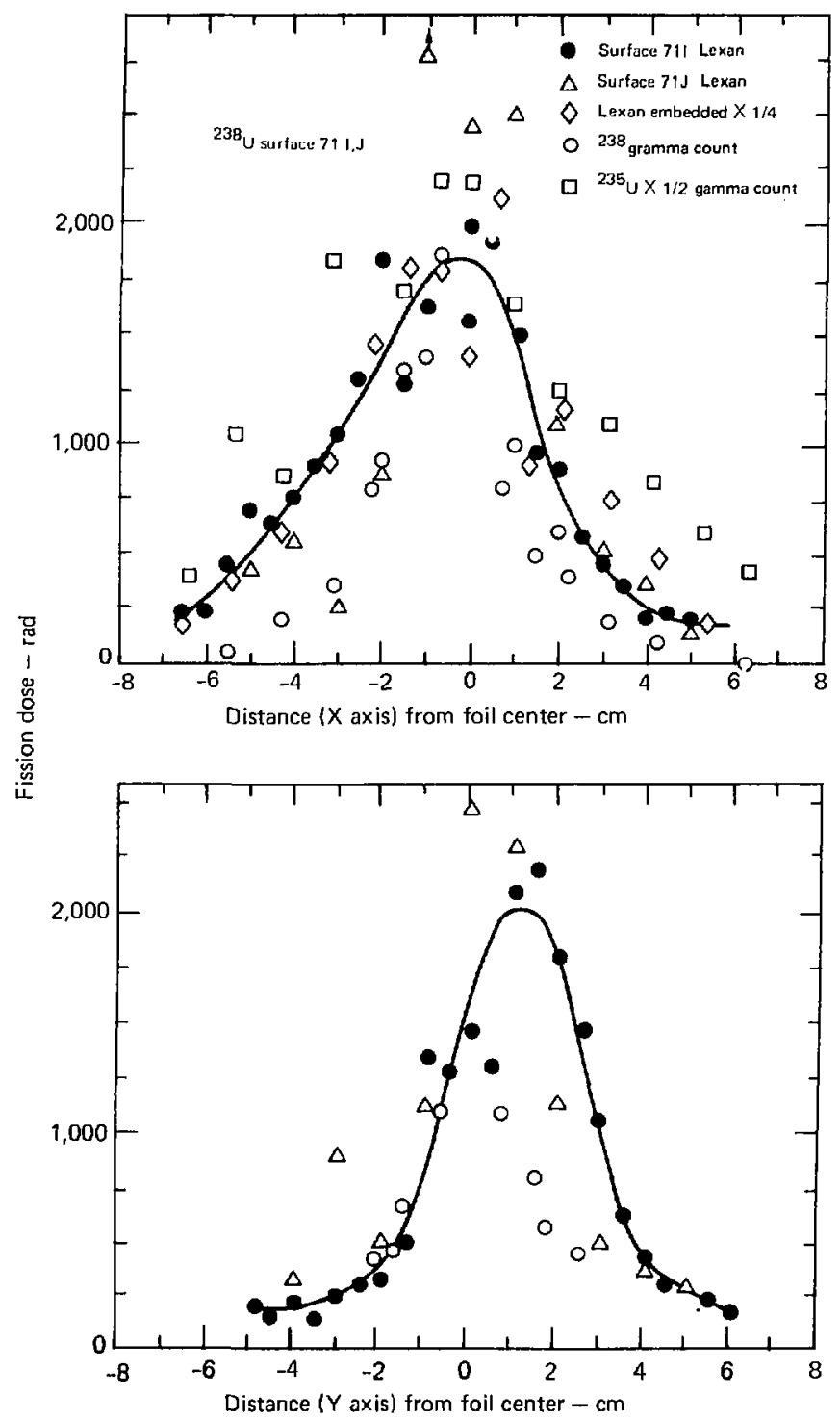

Fig, E-43. 


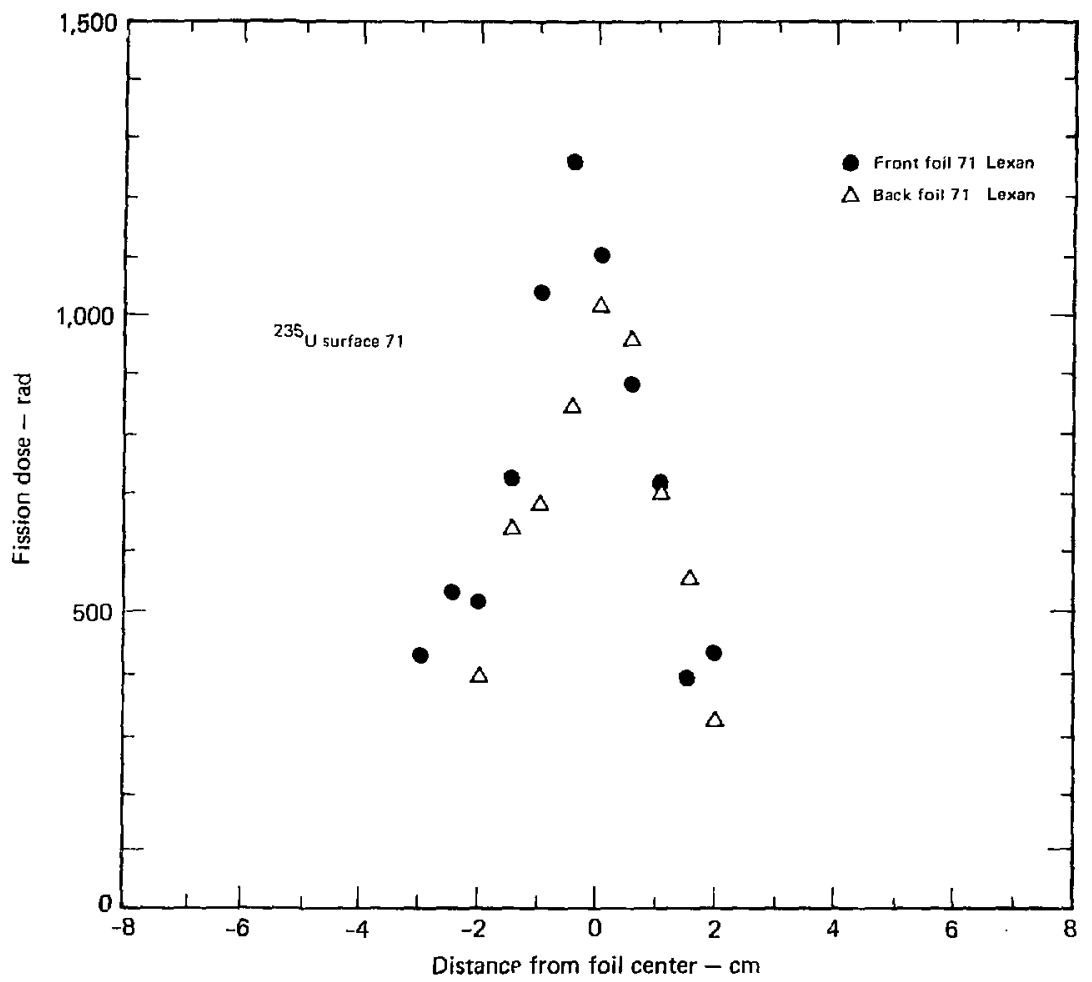

Note: Foil 712 was in contact with $1-\mathrm{cm}$ diam ${ }^{238} U$, and between foils $71 \mathrm{C}$ and D. The maximum fission dose was 4760 rad (Lexan) and 140 Ba count averaged $1.06 \times 10^{4}$ rad. $140 \mathrm{Ba}$ from $235 \mathrm{U}$ foil, whose Lexan data are plotted above, gave $2.1 \times 10^{3}$ rad.

Fig. E.-44. 

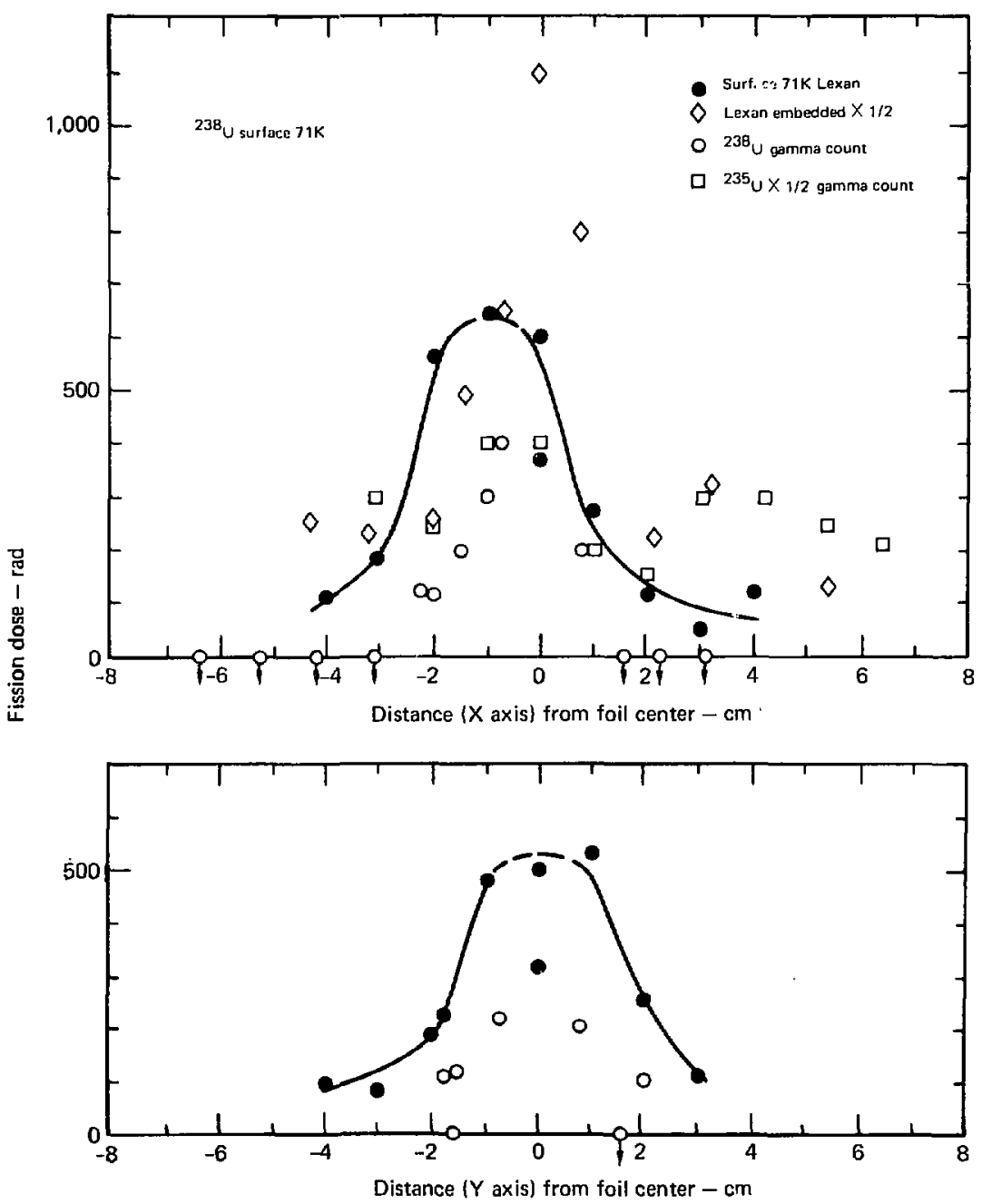

Fig. E-45, 


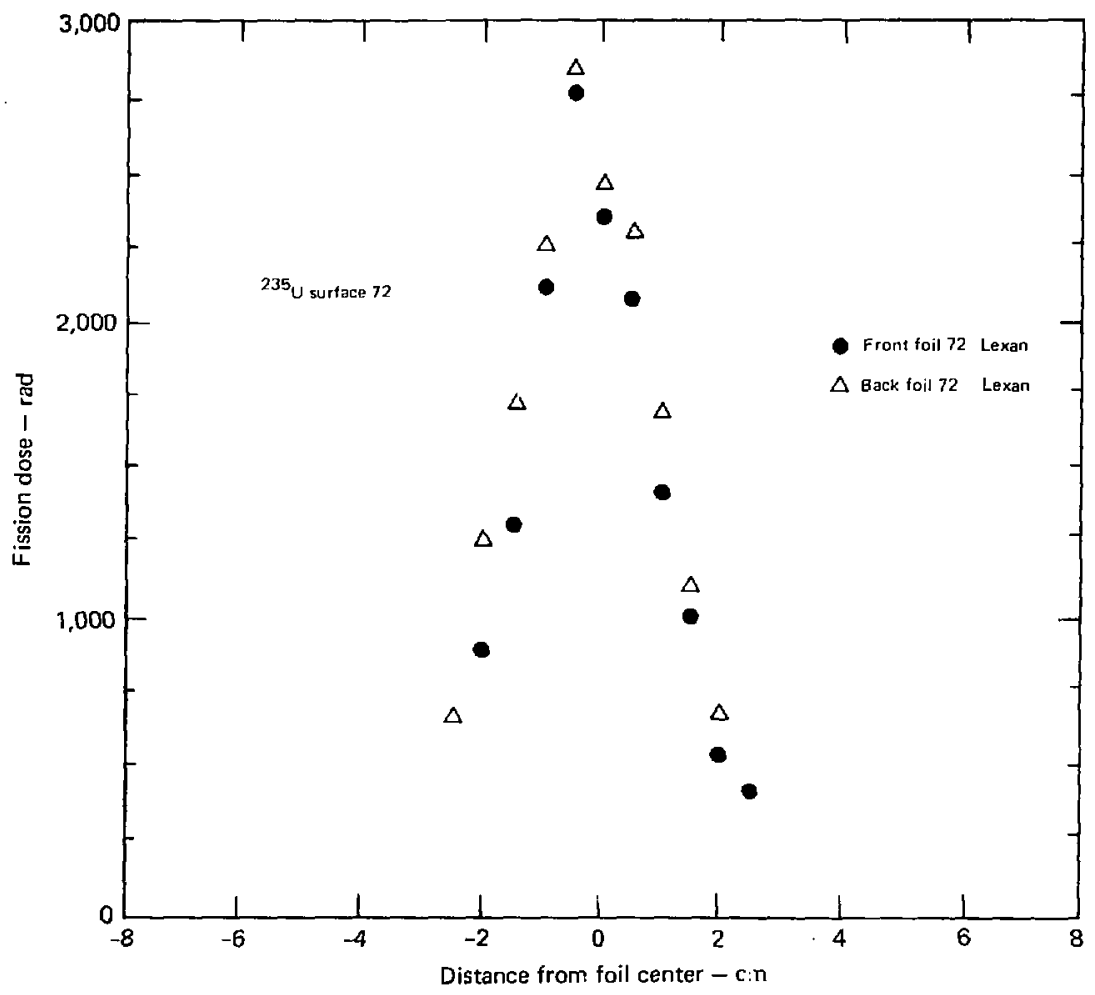

Fi⿱ 

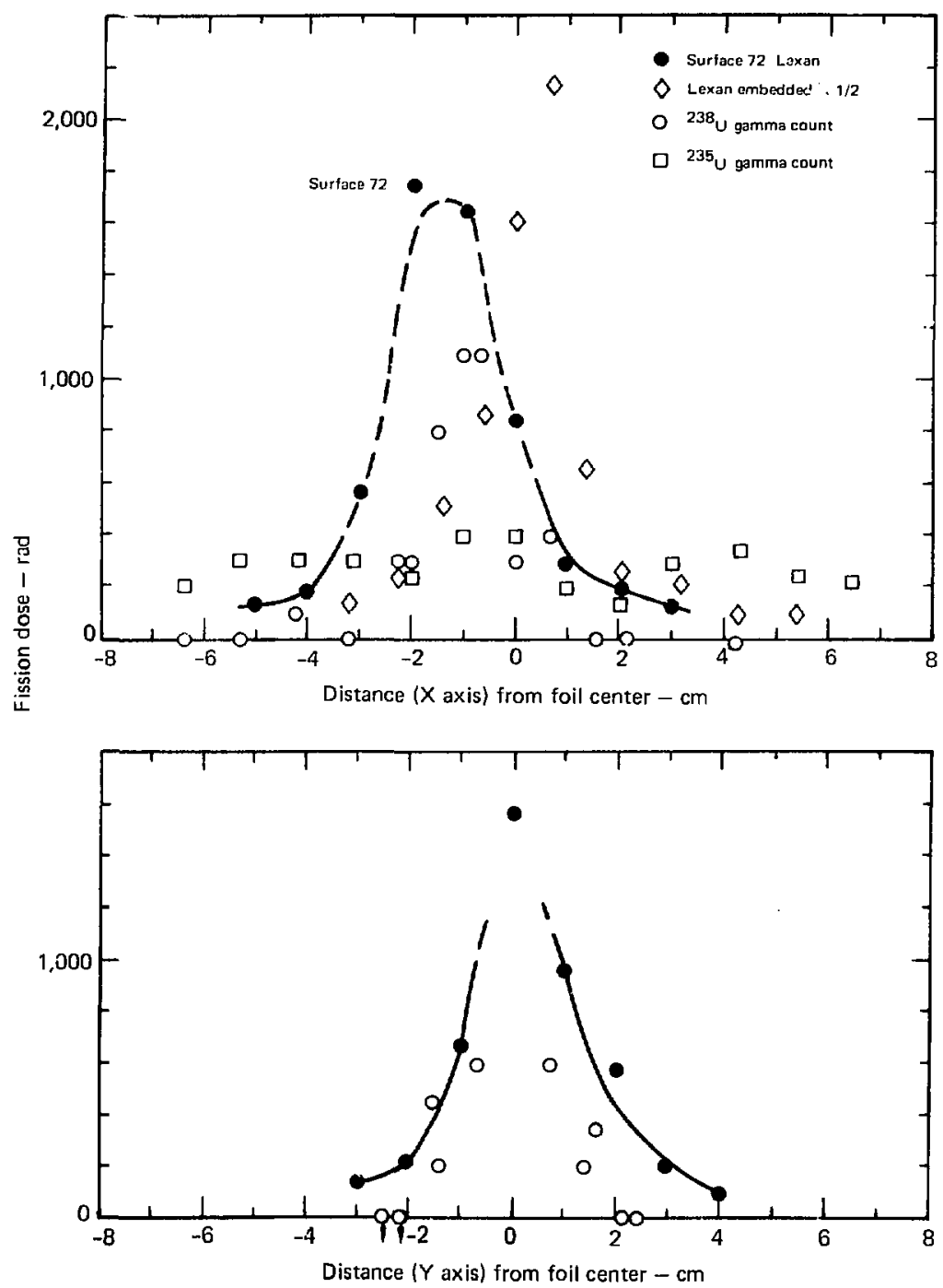

Fig, E-47. 

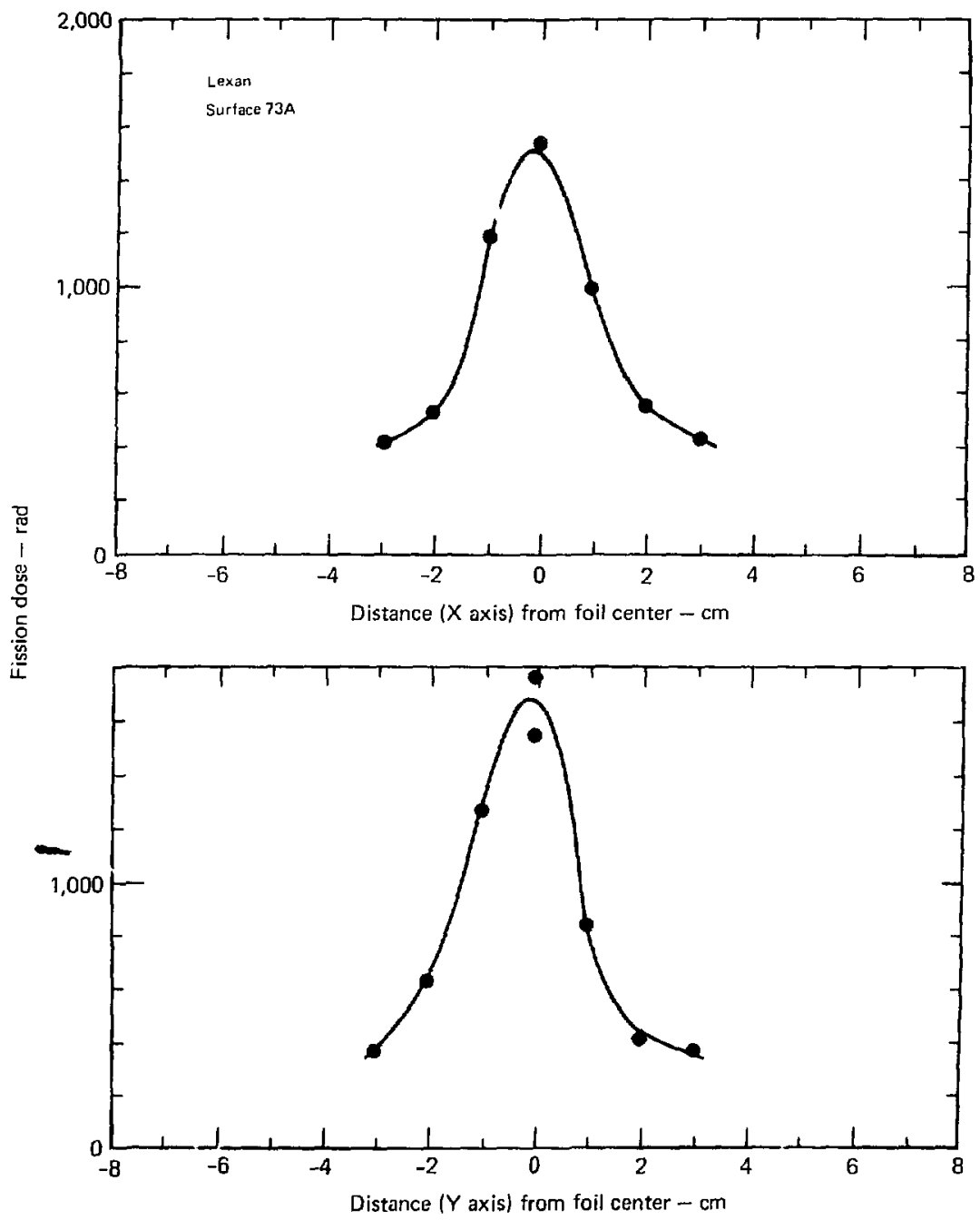

Fig, E-48, 

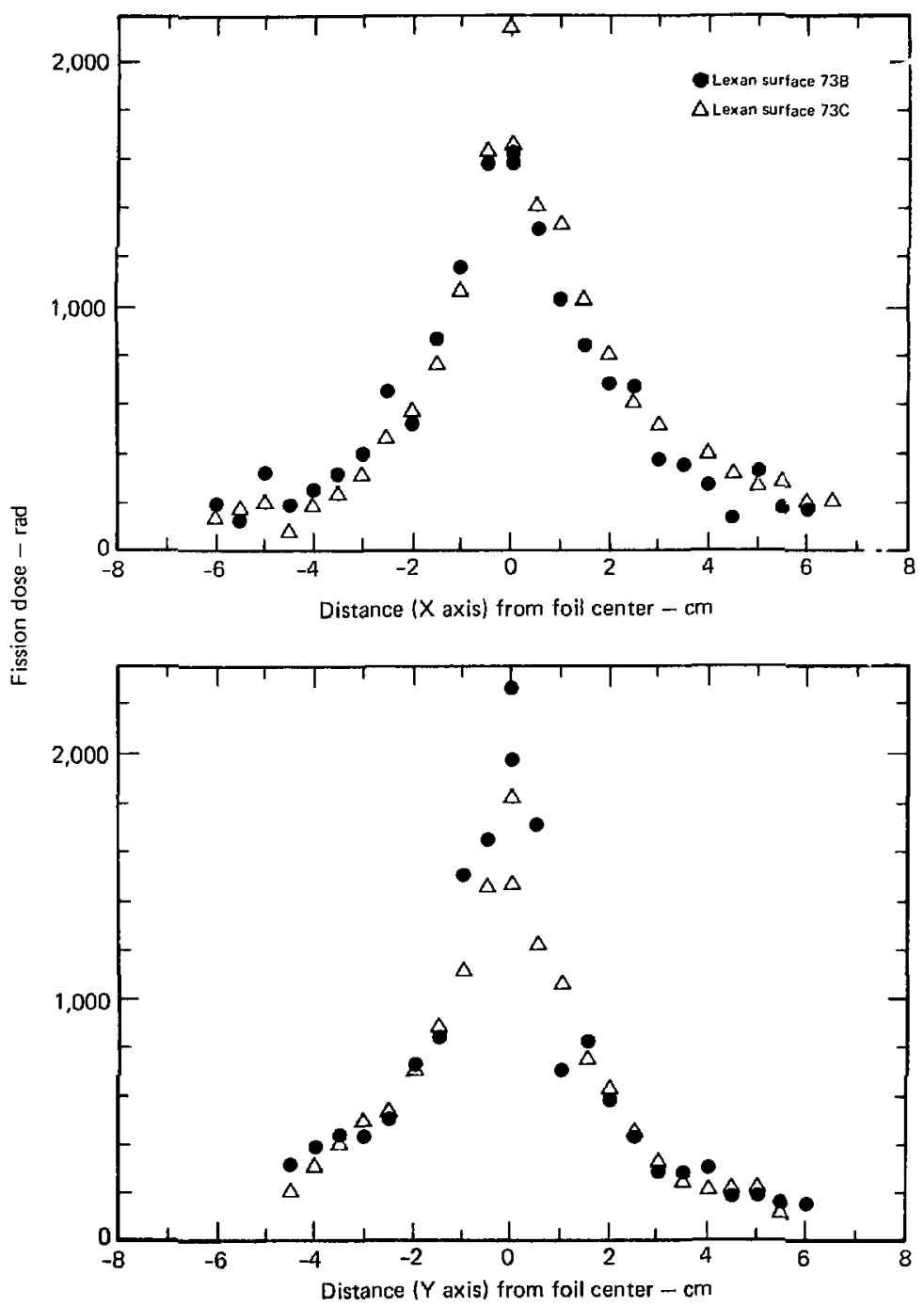

Fig. E-49. 

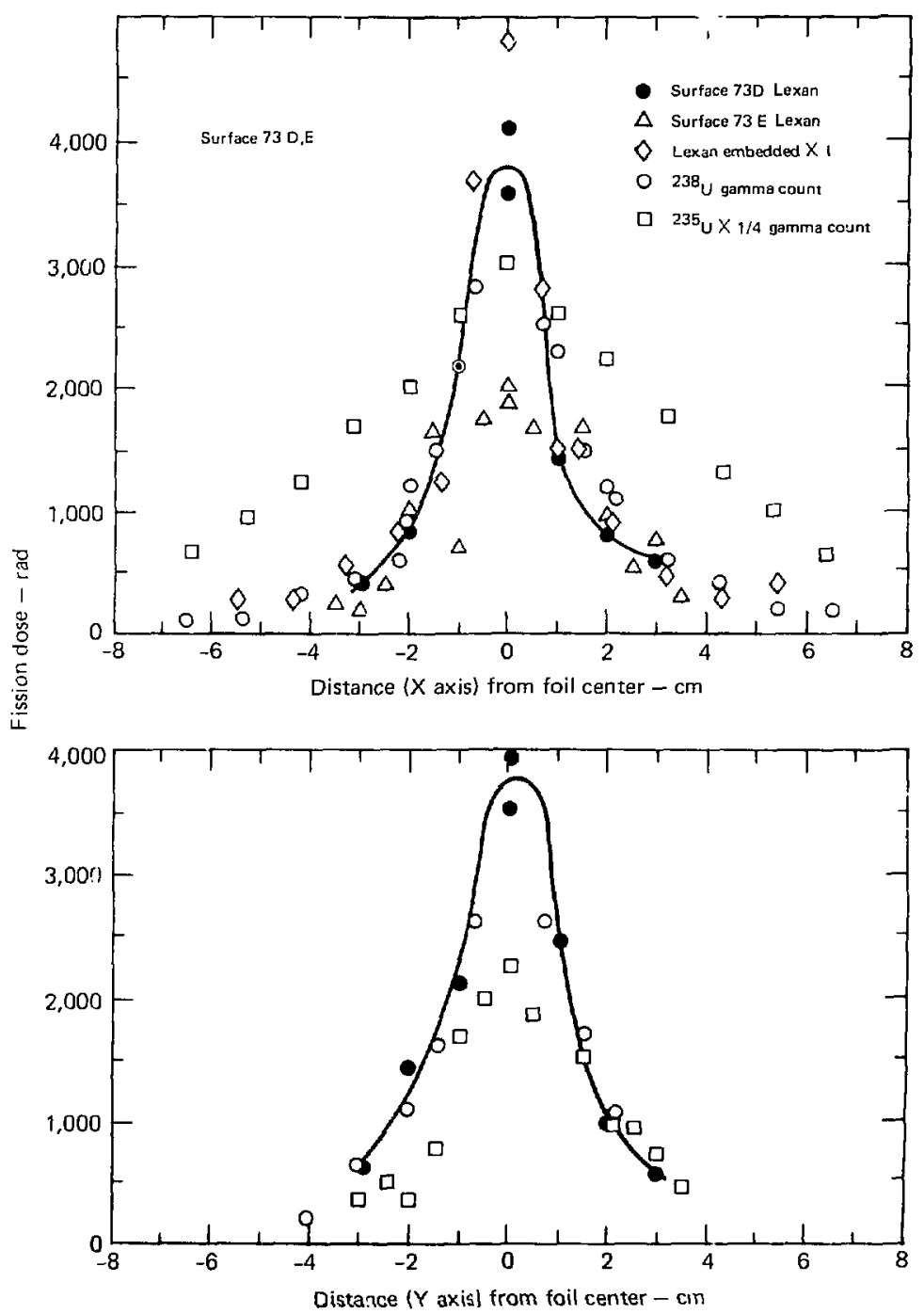

Fig. E-5n. 


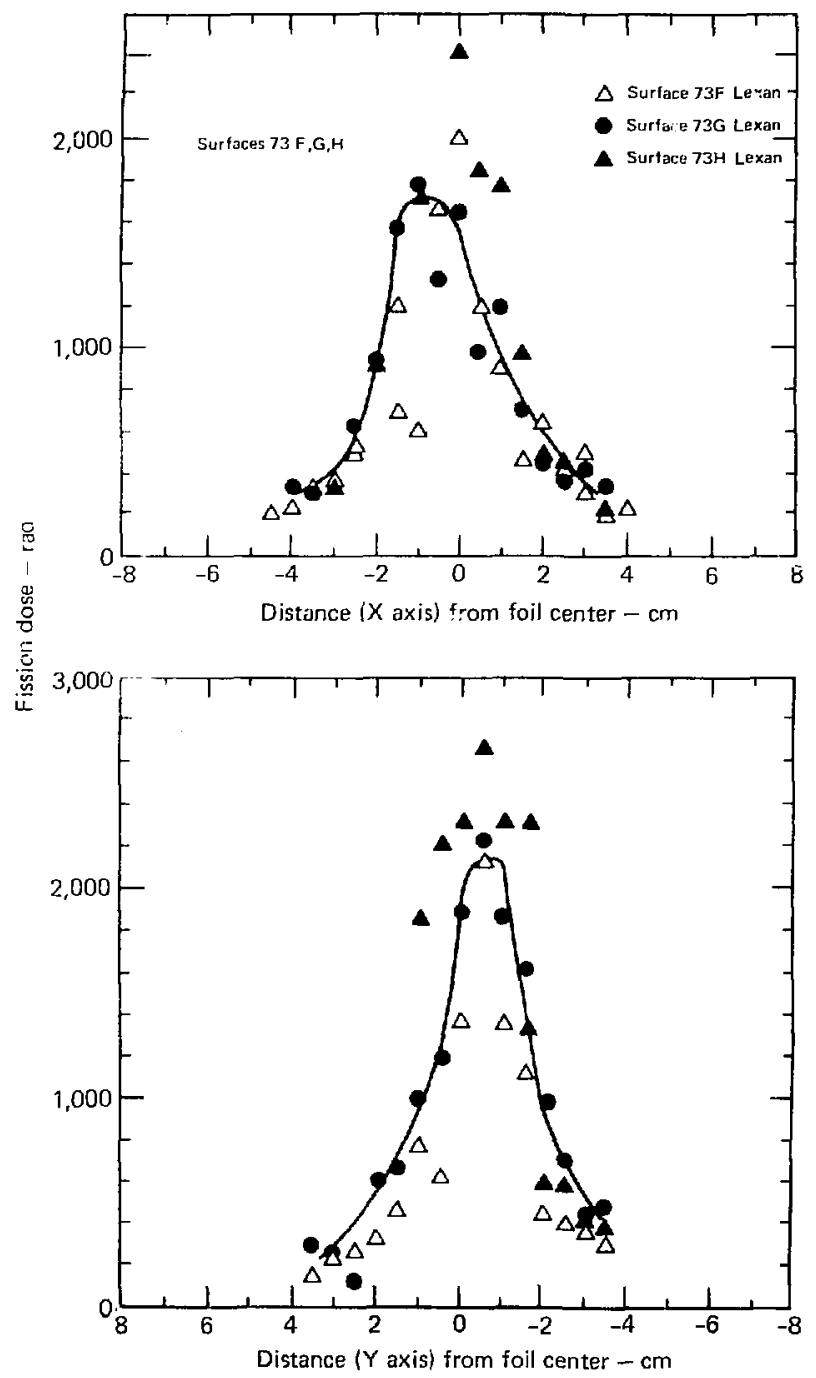

Eig. t.-s1. 


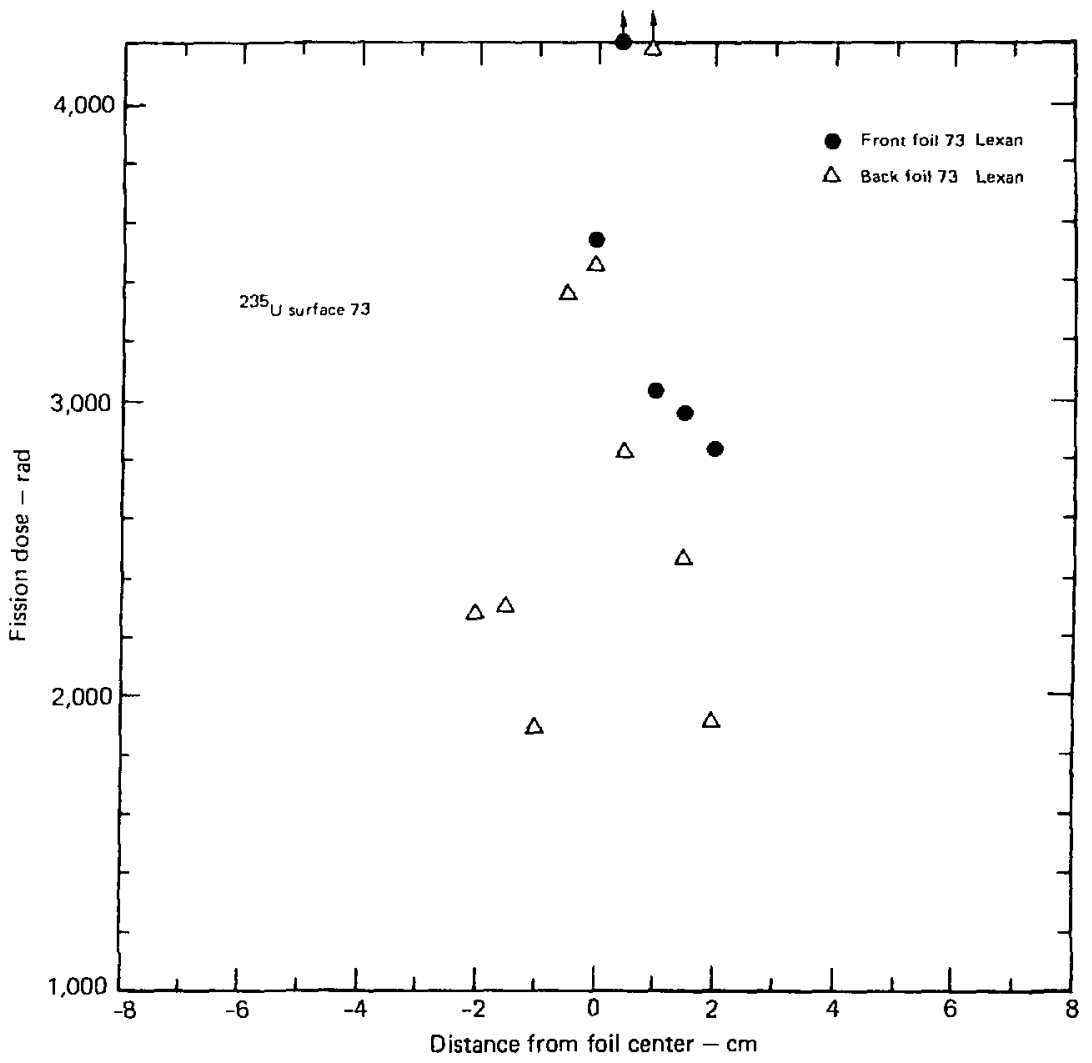

Note: Foil 732 indicat 202400 rad of fission in ${ }^{238} \mathrm{U}$, but ${ }^{140} \mathrm{Ba}$ count was $1.26 \times 10^{4}$ rad in ${ }^{238} \mathrm{U}$. ${ }^{14 C}$ Ba measured nothing in ${ }^{235} \mathrm{U}$.

Fig. E.s2. 

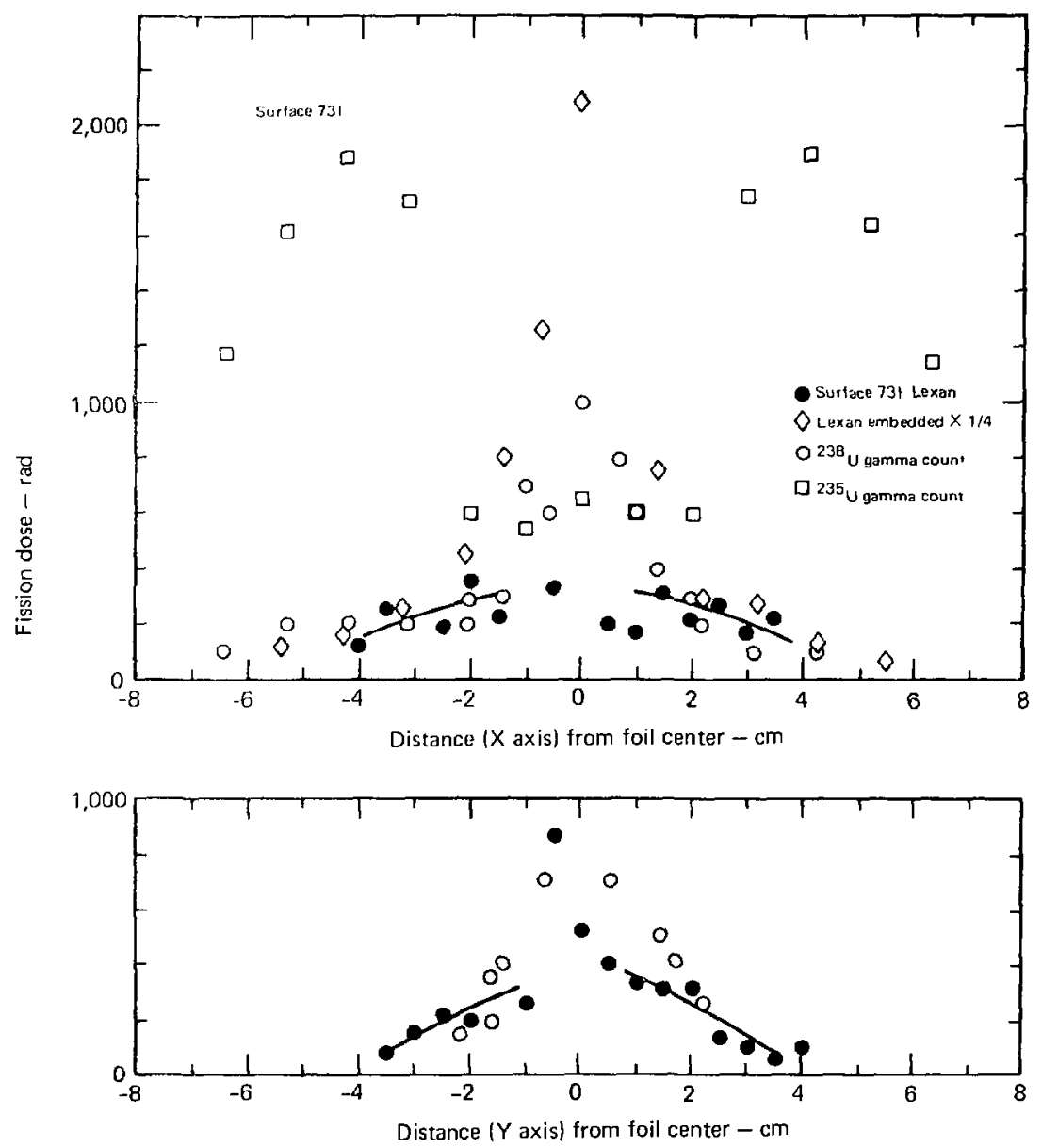

Fig. E-53. 

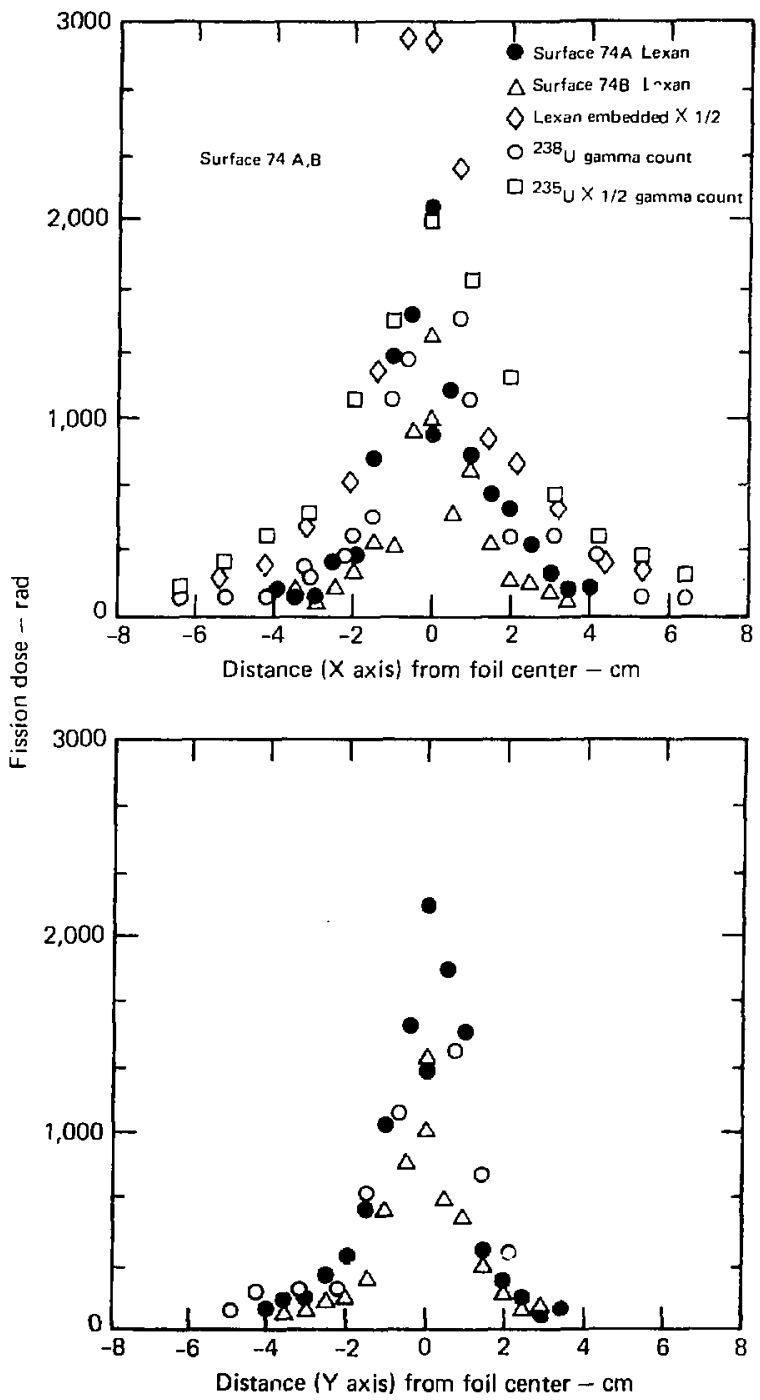

Fig. E-54 

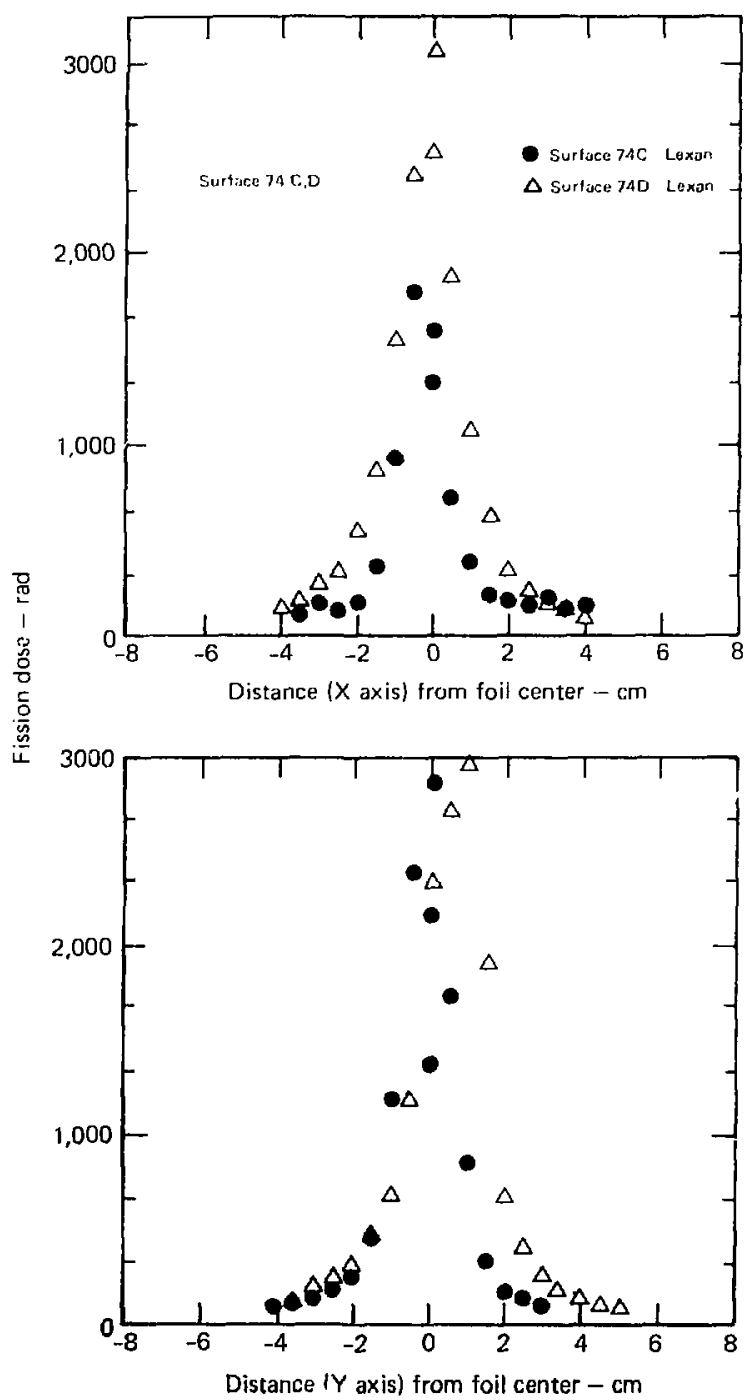

Fig. E-55. 

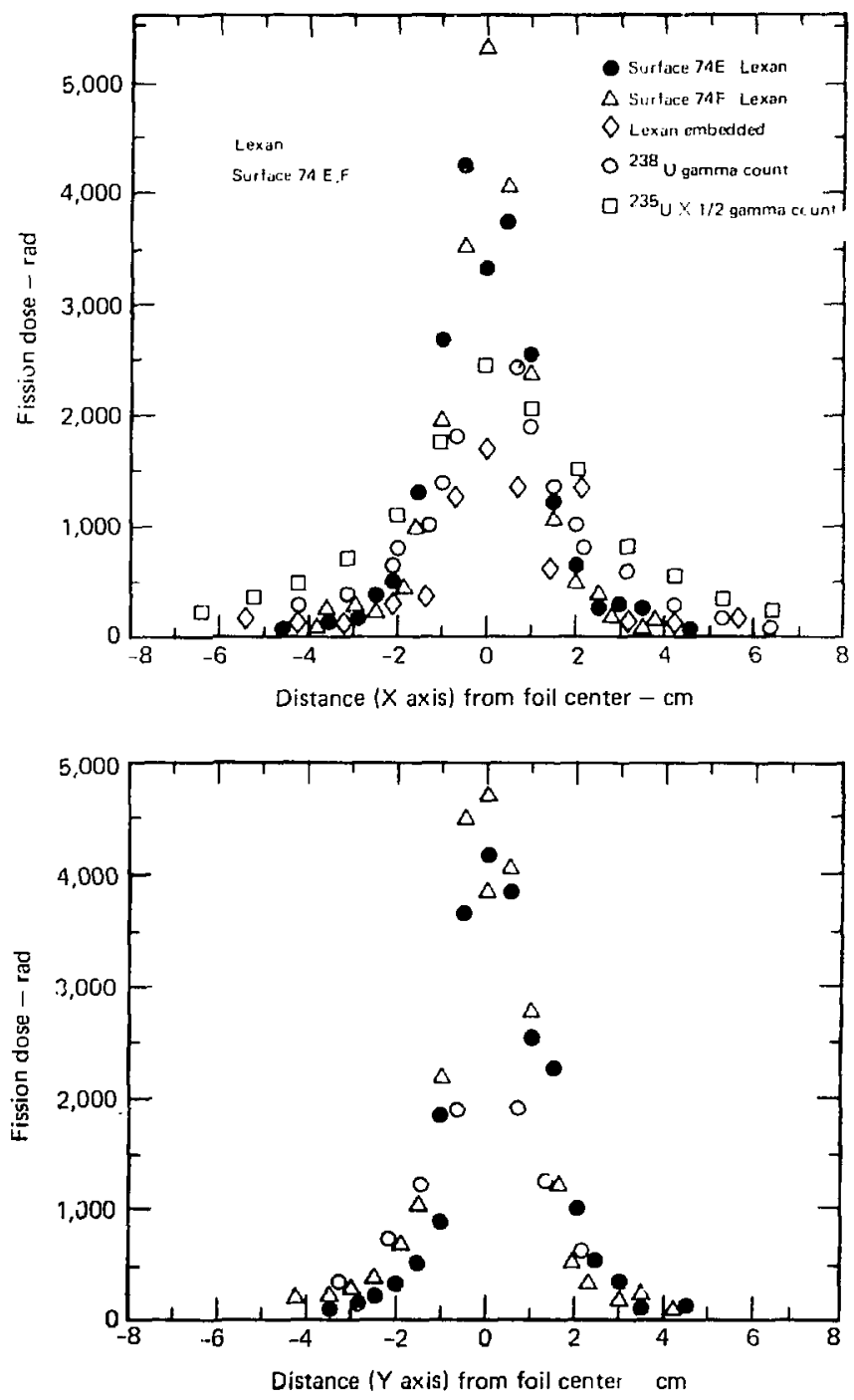

Fig, E-56. 


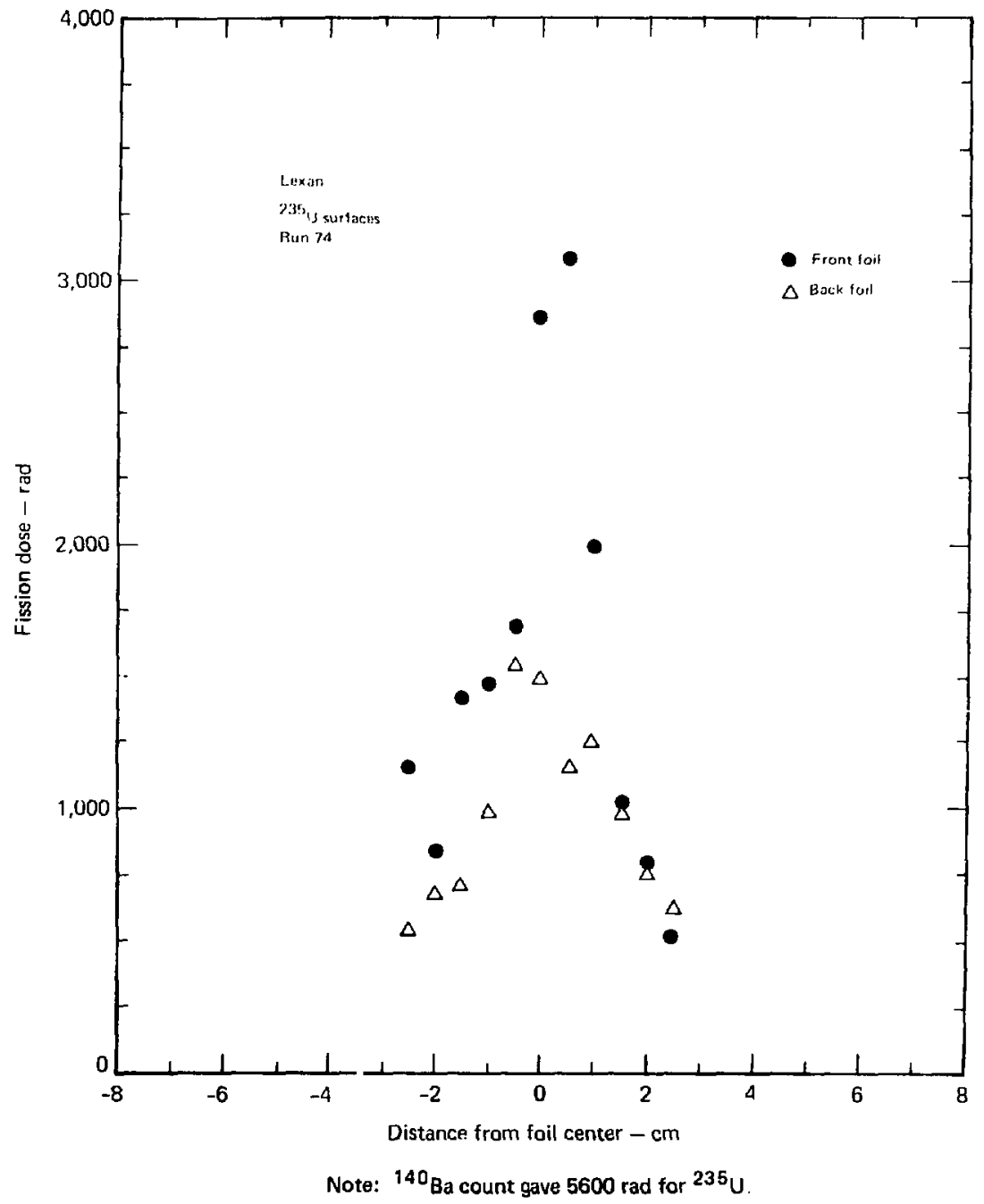

Fig. E-s?. 


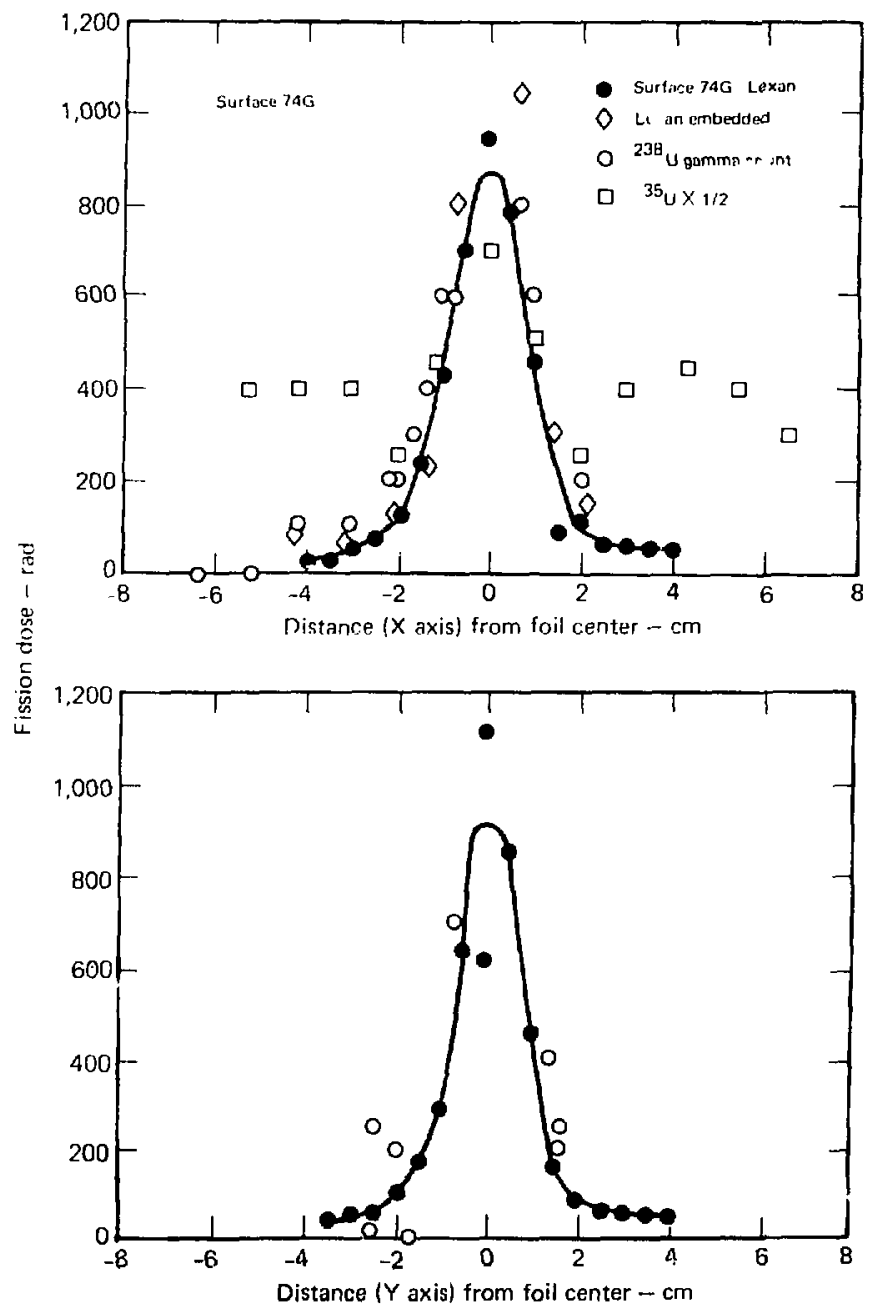

Fis. F. S8. 


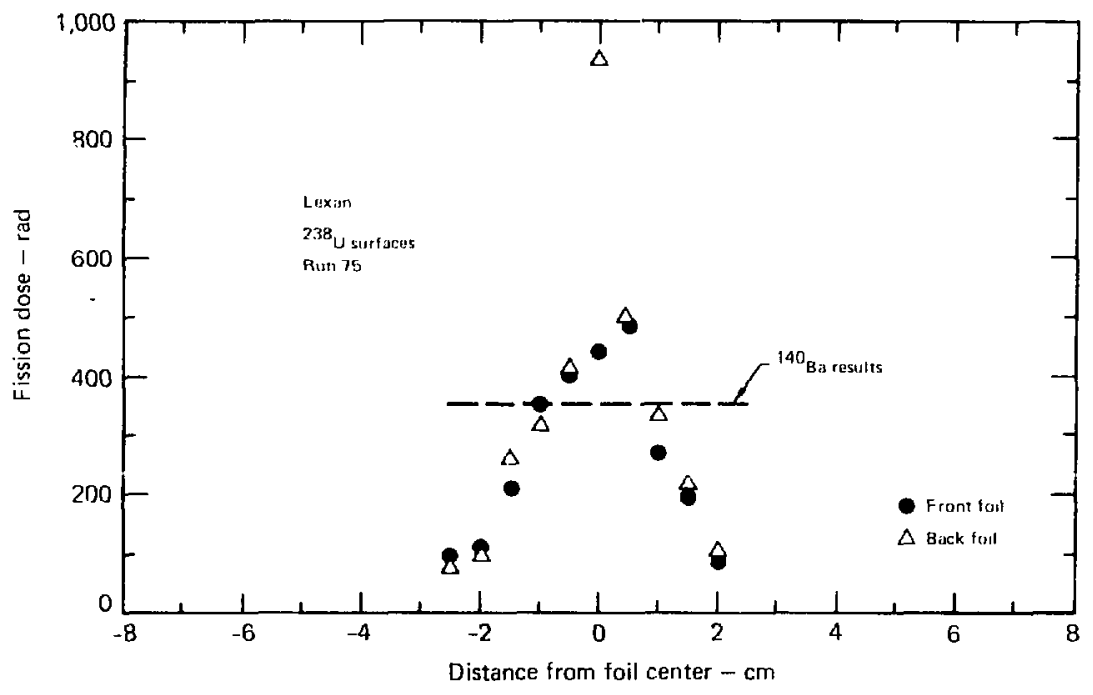

Fig. $\mathbf{E}+59$. 


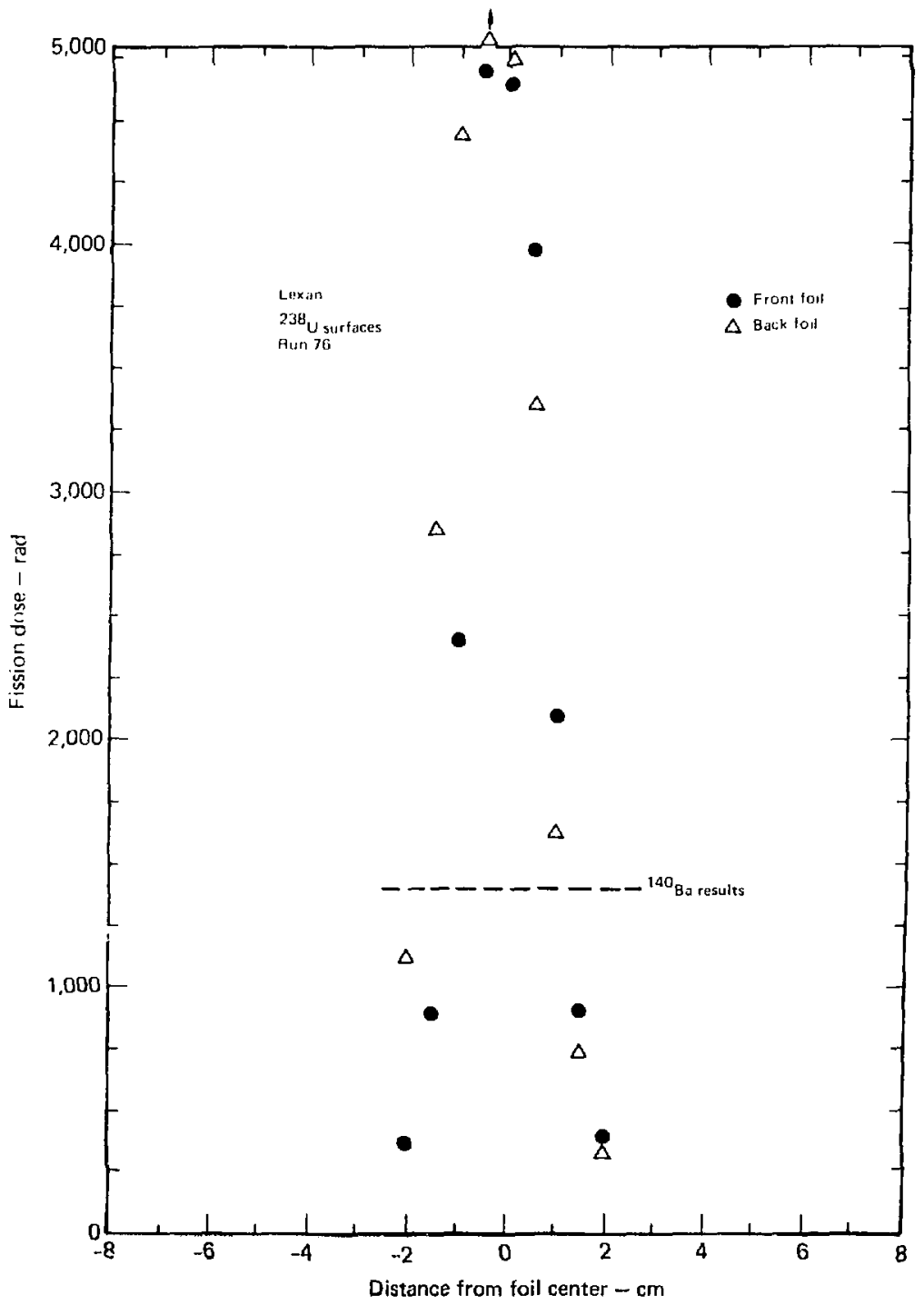

Fip. b.60. 


\section{APPENDIX F \\ SAMPLE DATA REDUCTION FOR THERMOCUUPLE INSTRUMENTED ANL STACK RUN 78}

In this appendix, we present sample calculations anc results for the thermocouple instrumented stack run performed at ANL (run 78). This experiment con: isted of six alternating disks of $\mathrm{Ta}$ and ${ }^{23 k} \mathrm{U}$ scparated by small air gaps on the same axis. All the disks were the same radius and thickness. Thermal contact with the environment and each other was minimized by suspending each disk from strings of low thermal conductivity. A thermocouple was attached to the outer edge of the first five disks. As the beum passed through them, they were exposed in line in the following order: $\mathrm{Ta}_{1}{ }^{7 \mathrm{k}} \mathrm{U}, \mathrm{Ta},{ }^{238} \mathrm{U}$, and $\mathrm{Ta}$. An uninstrumented $\mathrm{T}_{\mathrm{a}}$ disk llowed the last instrumented disk 10 provide with a similar temperature environment as the inner samples. The temperature isolation achievcd was adequate because the emperature decrease between beam pulses was small as was shown in Fig. 4.

In 1 able $1-1$, we present physical data on the disks, while in Table F-2 we give the experimental data.

Table F-1. Physical data for disks in ANL stack run.

\begin{tabular}{|c|c|c|}
\hline \multirow[b]{2}{*}{ Mlyscial paranicters } & \multicolumn{2}{|c|}{ Disk material } \\
\hline & $\mathbf{T}_{\mathbf{3}}$ & $23 n \mathrm{U}$ \\
\hline Radius, cm & 0.5 & 0.5 \\
\hline Thickutess cm & (1.0848t) & 0.0889 \\
\hline Mats. сח1 & 1.16 & 1.35 \\
\hline Ueat capacity, calig $\mathrm{C}$ at $25^{\circ} \mathrm{C}^{1}$ & 0.033 & 0.028 \\
\hline Density, $\mathrm{g}^{\prime} \mathrm{cm}^{31}$ & 16.6 & 18.9 \\
\hline Pistion tross section (mb) $)^{2 \cdot 1}$ & $\sim 0$ & $870 \leq 141\rangle$ \\
\hline $\begin{array}{l}\text { 140 Ba production cross } \\
\text { section imhi }\end{array}$ & $\sim$ & $7.7 \pm 0.3$ \\
\hline
\end{tabular}

Table F-2. Experimental data ANL stack run (20 beam pulses).

\begin{tabular}{|c|c|c|}
\hline \multirow[b]{2}{*}{ Disk } & \multicolumn{2}{|c|}{ Quantity moasured } \\
\hline & $\Delta T_{1}{ }^{\circ} \mathrm{C}$ & ${ }^{110} \mathrm{Ba}$ produced, atoms \\
\hline Tsi Ta & $9.8\left(: .1^{\circ}()\right.$ & 0 \\
\hline $1 \mathrm{st}+3 \mathrm{U}$ & $16,3\left(+.1^{\circ} \mathrm{C}\right)$ & $3.46 \times 10( \pm 3.2 \%)$ \\
\hline 2 nd 7 a & $11.6\left( \pm .1{ }^{\circ} \mathrm{C}\right)$ & 0 \\
\hline $2 n d x+U$ & $17.41 \div .140)$ & $3.0 \times 10( \pm 3.17)$ \\
\hline Jrd Ta & $12,2(1.1 \cdot C)$ & 0 \\
\hline
\end{tabular}

In this simplified analysis, we have neglected such matters as secondary production and their influence on the data even though the data are clearly influenced by them (compare the Ta data as the beam passes through successive disks).

The purpose of this experiment was to demonstrate a technique by which one could estimate the energy deposited per fission induced by high-energy protons. One therefore needs to know the energy deposited by fission and the number of fission events. The energy deposited by fission can be estimated from this experiment by comparing the tumperature rise in the $\mathrm{Ta}$ with that found in the ${ }^{213} \mathrm{U}$. For example, if we average the temperatures of the second and third Ta disks, we would find a temperature rise of $\sim 11.9^{\prime \prime} \mathrm{C}$ for a TA disk that would occupy the same position as the second ${ }^{218} \mathrm{U}$ c'isk; this approximately compensates for secondary nroduct deposition for everything but fission. The excess of energy (presumably from fission) deposited in the uranium is then:

$$
\begin{gathered}
\Delta H=(17.4)(0.028)-(11.9)(0.033)=0.095 \mathrm{cal} / \mathrm{g} \\
\text { or } \\
\Delta H=2.5 \times 10^{12} \mathrm{MeV}: \mathrm{g}
\end{gathered}
$$

The number or energy of fissions can be estimated from the available data $\because$ four methods.

I. Estimatc proton flux using gold-activation data and ratio of sample area to total beam area. The fission cross section is then used to ealculate the number of fissions.

2. The method is the same as the first except that the incident proton flux is calculated from the temperature rise of the first Ta disk by dividing it by the energy deposited per incident proton.

3. Estimate the number of fissions from the number of ${ }^{1+16} \mathrm{Ba}$ atoms produced in the sample.

4. The ratio of energy deposited in the ${ }^{336} \mathrm{U}$ to $\mathrm{Ta}$ is:

$$
\frac{\mathrm{E}_{\mathrm{U}}}{\mathrm{E}_{\mathrm{T}}}=\frac{\mathrm{I}_{\mathrm{U}}+\mathrm{F}_{\mathrm{u}} \rho_{\mathrm{f}}}{\mathrm{I}_{\mathrm{T}}}
$$

where $I_{U}$ and $I_{I_{2}}$ are the energies deposited in the ${ }^{238} \mathrm{U}$ and $\mathrm{Ta}_{\mathrm{a}}$ by all processes other than fission, $F_{\mathrm{V}}$ is the 
cnergy deposited per fission, and $\rho$ is the probability of fission. (The proton flux cancels out when the ratio is taken.) If the samples were thin, $I_{t}$ and $I_{i}$, would he the ionization lasses. One would then solve for $1 \%$.

We shall use the third method as an cxample. This depends on the ${ }^{14 h} B$ a production to estimatc the number of fissions. The ${ }^{1+1} \mathrm{Ba}$ production cross sections are nearly independent of proton energy frem 2 to ! 1.5 GeV. "The number of fissions per gram can then be calculated.

$$
\text { lasikus }=\begin{array}{r}
x 70 \\
7.7
\end{array} 1.3 \times 10^{x} \mathrm{~J}=3.4 \times 10^{10} \text { lissions } / g
$$

tIf

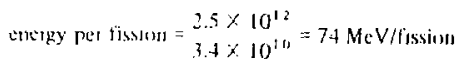

The value of $74 \mathrm{MeV}$; fission is much lower than expected. This is not a thin sample (relative to those used in typical cross-stction measurements) and therefore other processes nust be producing ${ }^{14 h} \mathrm{Ba}$. In comparing "Ha calculated fission levels with those measured by the lexan and total gamma-riby countong methods. we lind that the "th Ba is consistently high. In one such comparison between "Has and integral gamma-ray counting, we found the ratio to have a mean of 3.14 with o equal to 0.30 . The geometry of this experiment was considerably
Jifferent, so this ratio cannot be applied directly. However, it docs confirm our suspicions that ${ }^{1.30} \mathrm{Ba}$ is being produced by other processes than mercly fission.

Although there is a discrepancy between our results and the expected energy released per fission from the residual nuclei after a high-energy proton interaction, the method is promising and capable of greater accuracy with more cffort. The measurement of temperature is reliable. Our errot is apparently in the "Ba measurement. Our two ather methods of measuring fission density, i.e., with l.exan fols and the total residual fission gamma counts have shcwn results which are reasonably consistent with each other. With some exceptions, these results gave lower

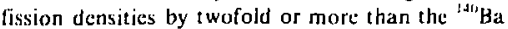
method. Considering this correction, we would interpret the energy released per lission to he 150-220 MeV, and not $74 \mathrm{MeV}$, fission. Unfortunately, we lost the opportunity to make the total residual gamma measurement on these disks lollowing the run, and Jission densities were too high for l.exin use.

In conclusion, this method of obtaining energy rclcased per fission gave results consistent with our expectations. The accuracy of our results is not good enough to be reliable, but if the experiment were to be repeated, we would achieve more accurate results.

\section{REFERENCES}

I. Handbook of Chemistry and Physics (The Chemical Rubber (o., Cleveland, Ohio, 1969). S0th ed., p. DI26.

2. J. Hudis and S, Kalcof, High-Energy-Proton Fission Cross Sections of U. Bi. Al, and $\mathrm{Ag}$ Measured with Mica Track Dezewors, Phys. Rev. $180(4), 1122$ (1969),
3. J. Hudis and S. Kalcoff, Inseraction of 0.6300 GeV Protons with U, Bi, Au, and Ag: Mica Track Detector Studj, Phys, Rev. C 13(5), 1961 (1976).

4. N. Beg and N. T. Porile. Energy Dependence of the Recoil Properites of Products from the Interaction of $U^{218}$ with $0.45-11.5$ - (jel Protons, Phys. Rev, C.3, 3(4), 1631 (1971).

\section{ACKNOWLEDGMENTS}

This work was sponsored by Larsy Havard of U.S. AImy BMDATC, Huntsville, Alabama, under contract M1PR 1 W3! RPD-73-2628I. The staff at the acculerator laboratories where the measurements wers inade deserve our gratitude for providing accelerator line and technical support. For special efforts, we would like to thank E. Lofgren, A. Smith and F. Lothrop of LAL, Berkeley: M. Yearian, $D$. Lee and $R$. Zdarko of Stanford; Hugh Brown and the AGS personsel at Brookhwen; and D. R.
Moffett and R. Klem of the Argonne National Laboratory. Thanks are also due to $\mathrm{H}$. Hicks and R. Nagle for proviting the gamma counting facilities, to $C$. Slettevold and C. Weaver for fission track counting. C. Sundbeck of dosimetry for measurements of TLD outputs, $C$. Dittnore and W. Trimble of the technical photography group, and to the members of the technical staff of LLL for efforts in support of the experiments. 